\title{
DIE MATERIELLE KULTUR IN DEN LÜNEBURGER TESTAMENTEN 1323 BIS 1500
}

Dissertation zur Erlangung des philosophischen Doktorgrades am Fachbereich Historisch - Philologische Wissenschaften der Georg-August-Universität zu Göttingen

\author{
vorgelegt von \\ Susanne Mosler - Christoph \\ aus Einbeck
}

Göttingen 1998 


\section{INHALTSVERZEICHNIS}

Vorwort

S. 7

I. Einleitung

S. 8

1. Der Forschungsgegenstand

S. 8

2. Das wissenschaftliche Umfeld

S. 9

3. Die Rahmenbedingungen der Stadtgeschichte

S. 13

a. Die Stadt Lüneburg

S. 14

b. Die Saline

S. 14

c. Stadtpolitische Konsequenzen

S. 17

4. Das Testament in der Stadt Lüneburg
a. Die stadtrechtliche Einbettung
S. 17
b. Formale Eigenschaften
S. 19
c. Die Quellenlage
S. 19

5. Anlage der Arbeit und Literatur

S. 22

II. Die Testatoren

S. 27 
a. smyde - Pauschal vererbte Schmuckstücke

S. 56

b. Einzeln bestimmbare Schmuckstücke

S. 58 handtruwe-Ringe-Armreife-Brosche-Kette-Kopfzier-

Bisamapfel-Rosenkranz·Agnus Dei·

c. Schlußbemerkung

S. 73

3. Liturgisches Gerät

S. 75

Kelche-Schrein·Kreuz·Pacificale.

Tragaltar

4. Das private Andachtsbild

5. Tuch

S. 85

a. Die Ware „Tuch“ in der Stadt Lüneburg

S. 85

b. Häufigkeit der testamentarischen Erwähnung, Donatoren und Empfänger

c. Verwendung der Tuchlegate

S. 88

Tuchlegate zur Bekleidung Armer.Tuchlegate für Verwandte und Bekannte-Tuchlegate für kirchliche Personen und Institutionen-Testament als Erinnerung an Schulden fürTuch.Verfügungen über Sargtuch 

a. Einleitung
S. 96

b. Kleid

S. 98

Ein Paar Kleider.Ein Kleid.Summarisch vergabte

Kleider-Kleidung, der erst anzuschaffen ist.

Kleiderhandel

C. Rock

S. 105

Die Farbe der Röcke.Herkunft und Art der verwendeten

Stoffe.Aussehen und Verwendung

d. Wams

S. 115

e. Jacke

S. 116

f. Hoike

S. 117

Farben-Aussehen und Verwendung W Wert

g. Schaube

Aussehen und Verwendung

S. 122

h. Pelz

S. 124

i. Futter

Futter ohne Kleidungsstück·Verbindung von Futter und

S. 127

Kleidungsstück.Futtermaterialien: Tuch und Pelz-Farbigkeit der gefütterten Kleidungsstücke.Futter im Spiegel der Lüneburger Luxusgesetzgebung.Verfügungen über Futter in den Testamenten anderer Städte

j. Kleidungszubehör

S. 132

Kopfbedeckungen.Kragen·hovedgad.Ärmel-Knöpfe.

smyde.Gürtel: Fertigungsmaterial und Aussehen der Gürtel, Nutzung der Gürtel für die Herstellung von

Kelchen, Gürtel in den Testamenten anderer Städte

7. Liturgische Gewänder

Terminologisch bezeichnete liturgische Gewänder.

Als Meßgewand oder Priesterkleidung bezeichnete liturgische Gewänder

8. Mobiliar und textiles Zubehör

S. 148

a. Betten und ihr textiles Zubehör

S. 148

Bett - Das Möbel-Textiles Zubehör: Laken, Polster, Kissen und Decken.Schlußfolgerungen

b.Truhen

S. 164

Herstellung und Aussehen der Truhen.Häufigkeit 
der testamentarischen Vererbung, Donatoren und

Empfänger. Truhen und das in innen Verwahrte.

Standort-Truhen in den Testamenten anderer

Städte

c. Schränke

Nutzungsgeschichte.Herstellungsmaterial.Häufigkeit

der testamentarischen Vererbung, Donatoren und Empfänger-Verwendung der Schränke-Standort

d. Kontor

e. Tische und ihr textiles Zubehör

S. 182

Häufigkeit der testamentarischen Vererbung,

Donatoren und Empfänger.Verwendung und

Aussehen der Tische-Tischtuch: Herstellung und Aussehen.Servietten

f. Sitzgelegenheiten und textiles Zubehör

S. 188

Häufigkeit der testamentarischen Vererbung,

Donatoren und Empfänger.Aussehen.

Verwendung.Sitzkissen

9. Küchen- und Tischgerätschaften

S. 194

a. Einleitung

S. 194

b. Küchengerätschaften

S. 195

$\alpha$. Grapen

S. 195

Donatoren und Empfänger.Herstellungsmaterial der Grapen, Größe und Qualität-Nutzung der Grapen und verschiedene Formen

$\beta$. Kessel

S.200

Donatoren und Empfänger-Material-Nutzung · Anzahl und Größe der Kessel

$\gamma$. Pfannen

S. 203

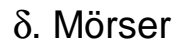

S. 205

ع. Geräte für das Kochen am Herdfeuer

S. 206

c. Tischzubehör

S. 207

$\alpha$. Kanne

S. 207

Donatoren und Empfänger-Materialien. Unterschiedliche Kannenformen.Hohlmaßkannen. Kannen als Transportmittel für Flüssigkeiten 
$\beta$. Flaschen

S. 212

$\gamma$. Trinkgefäße

S. 213

Die Empfänger von Trinkgefäßlegaten

Schalentrinkgefäße: Schale, Kopf und Schauer

Schale: Material-Aussehen der Schalen-Schalen mit und ohne Fuß-Gewicht der Schalen-Die Schale als Pfandobjekt-Weiterverarbeitung der Schale.Kopf. walsche noit-Schauer-Becher-Gläser-Die Empfänger von Trinkgefäßlegaten

$\delta$. Besteck: Löffel, Messer und Gabel

S. 227 Löffel: Material-Anzahl und Aussehen der

Löffel-Messer-Gabel-Donatoren und Empfänger der Bestecklegate

d. Handwaschgeräte und textiles Zubehör

S. 232

Handfaß: Material und Aussehen-Donatoren und Empfänger-Größe und Anzahl-Becken: HandbeckenRasierbecken-"Toilettenbecken"-stovenbecken.Handtuch

IV. Schlußbemerkung

S. 239

Anhang

Tabelle I:Tabellarischer Überblick über die Sachgutverfügungen

Tabelle II:Empfänger der Sachgüter

S. 260

Die Testamente

S. 273

Lüneburger Bildmaterial

S. 392

Zum Thema: Schmuckstücke

S. 392

Zum Thema: (Privates) Andachtsbild

S. 393

Zum Thema: Bettzubehör und goldenes Sargtuch

S. 394

Zum Thema: Truhen

S. 395

Zum Thema: Schrankmobiliar und Beutelbuch

S. 396

Zum Thema: Tisch

S. 397

Quellen und Literatur

S. 398 


\section{Vorwort}

Die vorliegende Untersuchung wurde im Sommersemester 1997 von der Philosophischen Fakultät der Georg-August-Universität Göttingen als Dissertation angenommen. Für die Veröffentlichung wurde sie geringfügig überarbeitet.

An erster Stelle bin ich meinem Doktorvater Herrn Prof. Dr. Hartmut Boockmann zu Dank verpflichtet, der nicht nur die Anregung für die Arbeit gab, sondern ihre Entstehung mit wohlwollendem Rat begleitete. Sein Tod im Frühsommer diesen Jahres kam völlig unerwartet und ist für mich unfaßbar. Prof. Dr. Ernst Schubert danke ich für die Übernahme des Korreferats.

Frau Dr. Uta Reinhardt unterstützte die vorliegende Arbeit durch das Bereitstellen der notwendigen Quellen im Lüneburger Stadtarchiv in großzügiger Weise. Bedanken möchte ich mich ferner bei den stets freundlichen Mitarbeitern des Lüneburger Stadtarchivs, namentlich bei Herrn Joachim Brauss. Herrn Dr. Eckhard Michael verdanke ich den Zugang zu dem Museum für das Fürstentum Lüneburg.

Ein Dankeschön für die erwiesene Gastfreundschaft in Lüneburg schulde ich meinen Freunden in Lüneburg: Kirsten, Martina und Doris, Theo, Thomas und Andreas, vor allem aber meiner Gastgeberin Karen.

Für die Korrektur des Manuskriptes danke ich meinen Eltern und Kadri-Rutt Allik. Dank gebührt Herrn Dr. Thomas Gade, der bei dem Layout der Arbeit hilfreich zur Seite stand.

Ein besonderer Dank gilt meinem Mann, der stets für mich da war.

Die Arbeit soll an meine verstorbene Großmutter Frau Charlotte Böker erinnern; die Fertigstellung dieser Arbeit ist das erste wichtige Ereignis, an dem sie nicht mehr teilnehmen kann. 


\section{Einleitung}

\section{Der Forschungsgegenstand}

Seit langem befaßt sich die Forschung mit der Auswertung der in großer Zahl überlieferten Testamente, die von im Spätmittelalter lebenden Stadtbewohnern aufgesetzt wurden. Testamente sind die Verschmelzung von maßvoll gesetzlich definierter Gußform und oft ausführlich angelegter, letztwilliger Verfügungen der spätmittelalterlichen Städter. Somit gehören Testamente zu den wenigen Quellengattungen, die einen Zugang zu den Menschen des Spätmittelalters bieten, der kaum durch einen den Blick verstellenden Formelapparat eingeengt ist. Der geschätzte und immer wieder hervorgehobene Vorzug der Quellengattung „Testament“ liegt neben dieser Unmittelbarkeit in der quantitativ-seriellen Komponente, die es ermöglicht, Einblicke in Dauer und Wandel mehr der Prozesse des religiös-ideellen oder materiellen Lebens in der spätmittelalterlichen Stadt, weniger in die emotionale Befindlichkeit der Bürger, die demographische Entwicklung oder die Preisentwicklung zu gewinnen.

Erst in jüngerer Zeit intensivierten sich die Bemühungen, mittels der Testamente Aussagen über die materiellen Güter zu gewinnen, mit denen sich Menschen im Spätmittelalter in Alltag und Festtag umgaben ${ }^{1}$. Etliche Arbeiten stellten nicht die Realien per se in den

\footnotetext{
${ }^{1}$ P. BAUR, Testament und Bürgerschaft. Alltagsleben und Sachkultur im spätmittelalterlichen Konstanz (=Konstanzer Geschichts- und Rechtsquellen XXXI), Sigmaringen 1989; J. SCHILDHAUER, Hansestädtischer Alltag auf der Grundlage der Stralsunder Bürgertestamente des 14. bis zum Ausgang des 16. Jahrhunderts (=Abhandlungen zur Handels- und Sozialgeschichte 28), Weimar 1992; H. D. LOOSE, Leben und Kultur der Bürger mittelalterlicher Hansestädte (= Magdeburger Gesellschaft von 1990 zur Förderung der Künste, Wissenschaft und Gewerbe. Magdeburger Geprächsreihe, Heft 3), Magdeburg 1992; M. RIETHMÜLLER, to troste miner sele. Aspekte spätmittelalterlicher Frömmigkeit im Spiegel Hamburger Testamente (1310-1400) (=Beiträge zur Geschichte Hamburgs, Bd.47), Hamburg 1994; K.-R. ALLIK, Die Revaler Testamente aus dem 15. Jahrhundert (=unveröffentlichte Hausarbeit zur Erlangung des Magistergrades am Fachbereich Historisch-
} 
Mittelpunkt, sondern ordneten sie ein in den Kontext von Alltagswelt, Seelgerätsstiftungen oder in den Fragekontext nach den Lebensbedingungen der Frauen. Insofern erscheint es gerechtfertigt, die materiellen Kulturgüter einmal selbst zum Thema einer Abhandlung zu machen, gilt doch Braudel zufolge das „Studium der Dinge“ als ein Zugangsweg zu dem Ganzen des materiellen Lebens, das aus Menschen und Dingen, Dingen und Menschen bestehe ${ }^{2}$.

Als Quelle werden hier die Lüneburger Testamente genutzt. Die Testamentssammlung der Stadt Lüneburg umfaßt für den Zeitraum von 1323 bis 1500, in dessen Rahmen sich die Auswertung bewegt, 297 Testamente. Die Lüneburger Testamente sind bisher von der Forschung in Ansätzen genutzt worden, so daß mit der Konzentration auf das gesamte Testamentskorpus der Stadt Lüneburg ein erster Schritt auf ein neu zu beschreibendes Feld der Forschung gewagt wird.

\section{Das wissenschaftliche Umfeld}

Die Testamentsauswertungen des ausgehenden 19. Jahrhunderts und die der ersten Hälfte des 20. Jahrhunderts hatten ganz im Zeichen einer rechtshistorischen Perspektive gestanden ${ }^{3}$. Ungefähr seit den 50 ger Jahren des 20. Jahrhunderts rückten allmählich sozial - und kulturgeschichtliche Fragestellungen in den Mittelpunkt des Forschungsinteresses, doch erst ab ca. 1970 erschienen themenrelevante Publikationen in engerer Folge ${ }^{4}$. Grund

Philologische Wissenschaften der Universität Göttingen), Göttingen 1995; B. KLOSTERBERG, Zur Ehre Gottes und zum Wohl der Familie: Kölner Testamente von Laien und Klerikern im Spätmittelalter (=Kölner Schriften zu Geschichte und Kultur, Bd.22), Köln 1995; J. GLADEN, Testamente - Spiegel spätmittelalterlichen Lebens und Wirkens, in: Kat. „Hanse•Städte•Bünde“, Bd. 1, Magedburg 1996, S. 518524.

${ }^{2}$ F. BRAUDEL, Der Alltag (= Sozialgeschichte des 15. - 18. Jahrhunderts, Bd. 1), München 1990, S. 21.

${ }^{3}$ C. W. PAULI, Abhandlungen aus dem lübischen Rechte. III Teil.: Das Erbrecht der Blutsfreunde und die Testamente, Lübeck 1841; L. H. EULER, Geschichte der Testamente in Frankfurt, in: AFGK, Heft 5/1853, S. 1 - 48; L. KALKMANN, Zur Geschichte der hamburgischen Testamente, in: ZVhG 7/1883, S. 193 - 202; O. LOENING, Das Testament im Gebiet des Magdeburger Stadtrechts (= Untersuchungen zur deutschen Staats und Rechtsgeschichte, Heft 82), Breslau 1906; G. ADERS, Das Testamentsrecht der Stadt Köln im Mittelalter ( Veröffentlichungen des Kölnischen Geschichtsvereins 8), Köln 1932; H. LENTZE, Das Wiener Testamentsrecht des Mittelalters, in: ZRG/GA (1952), S. 98 - 154 und ZRG/GA 70 (1953), S. 158 - 229; H. PIPER, Testament und Vergabung von Todes wegen im braunschweigischen Stadtrecht des 13. bis 17. Jahrhunderts (= Braunschweiger Werkstïcke 24), Braunschweig 1960 Verwiesen sei an dieser Stelle auf die umfassenden Forschungsüberblicke bei BAUR und KLOSTERBERG. P. BAUR, Testament und Bürgerschaft, S. 14-35; B. KLOSTERBERG, Zur Ehre Gottes, S. 13-19.

${ }^{4}$ Die Chronologie der Publikationen zeigt, daß das in den 70ger Jahren noch beklagte mangelnde Interesse an der Quellengattung „Testament“ längst einer intensiven Beschäftigung mit den Testamenten gewichen ist, die unterschiedlichste Fragestellung auszuloten sich zur Aufgabe machte und macht: A. v. BRANDT, Mittelalterliche Bürgertestamente. Neuerschlossene Quellen zur Geschichte der materiellen und geistigen Kultur ( = Sitzungsberichte der Heidelberger Akademie der Wissenschaften, Phil. - Hist. Kl.), Heidelberg 1973, 3, S. 5 - 32; erneuter Druck in: FRIEDLÄNDER, Klaus / SPRANDEL, ROLF, Lübeck, Hanse, Nordeuropa. Gedächtnisschrift für Ahasver von Brandt, Köln / Wien 1979, S. 336 - 358; G. JARITZ, Die realienkundliche Aussage der sogenannten „Wiener Testamentsbücher“, in: Das Leben in der Stadt des Spätmittelalters (=Österreichische Akademie der Wissenschaften. Philosophisch-Historische Klasse, Sitzungsberichte 325; Veröffentlichungen des Instituts für mittelalterliche Realienkunde Österreichs, Bd.2), Wien 1977, S. 171-190; H. - D. LOOSE, Erwerbstätigkeit der Frau im Spiegel Lübecker und Hamburger Testamente des 14. 
für diese wiederauflebende Beschäftigung mit Testamenten war nicht zuletzt der von Brandt formulierte Arbeitsimpuls, man solle die Testamente nach der „Denkweise, den religiösen und gesellschaftlichen Bindungen, den wirtschaftlichen Grundlagen, der materiellen Umwelt und Lebenshaltung, den Modeerscheinungen und Verhaltensweisen in Krisen und Katastrophen" befragen ${ }^{5}$. Mit der Übernahme dieses Arbeitsansatzes reihten sich die Historiker des deutschsprachigen Raumes ein in den entsprechenden europäischen Arbeitskontext, der vor allem durch die Arbeiten französischer und polnischer Historiker geprägt war ${ }^{6}$.

Die zwar auf älteren Traditionen beruhende, in mancher Hinsicht aber doch neue Sachkulturforschung ${ }^{7}$ wird besonders in den Arbeiten des Instituts für mittelalterliche

Jahrhunderts, in: Zeitschrift des Vereins für Lübeckische Geschichte und Altertumskunde 60/1980, S. 9 - 20; M. HASSE, Kleinbildwerke in deutschen und skandinavischen Testamenten des 13., 14. und frühen 15. Jahrhunderts ( = Niederdeutsche Beiträge zur Kunstgeschichte Bd. 20 ), 1981, S. 60 - 72; H. BOOCKMANN, Leben und Sterben in einer mittelalterlichen Stadt. Über ein Göttinger Testament des 15. Jahrhunderts, Göttingen 1984; G. JARITZ, Österreichische Bürgertestamente als Quelle zur Erforschung städtischer Lebensformen des Spätmittelalters, in: Jahrbuch für Geschichte des Feudalismus Bd. 8, 1984, S. 249 - 264 ; U. M. ZAHND, Spätmittelalterliche Bürgertestamente als Quellen zu Realienkunde und Sozialgeschichte, in: Mitteilungen des Instituts für österreichische Geschichtsforschung, Bd. 96/1 - 2, 1988, S. 55 - 78; S. MOSLER, Das Sülzgut in den frühen Lüneburger Testamenten ( = unveröffentlichte Staatsexamensarbeit am Fachbereich Hist. Phil. Wiss. der Universität Göttingen ), Göttingen 1989; U. REINHARDT, Stiftersorgen - Das Testament der Elisabeth Stöterogge (1385), in: Recht und Alltag im Hanseraum. Festschrift für Gerhard Theuerkauf (=,, De Sulte“, Nr. 4), hg. v. S. URBANSKI, Chr. LAMSCHUS, J. ELLERMEYER, Lüneburg 1993, S. 359 384.

${ }^{5}$ BRANDT, Ahasver von, Mittelalterliche Bürgertestamente. Neuerschlossene Quellen zur Geschichte der materiellen und geistigen Kultur (=Sitzungsberichte der Heidelberger Akademie der Wissenschaften, Phil.Hist. Klasse), Heidelberg 1973, 3, S. 5-32; erneuter Druck in: Lübeck, Hanse, Nordeuropa. Gedächtnisschrift für Ahasver von Brandt, hg. im Auftrag des Hansischen Geschichtsvereins von Klaus FRIEDLAND und Rolf Sprandel, Köln 1979, S.338.

${ }^{6}$ Einen umfassenden Überblick über die französischen Forschungsergebnisse gibt P. BAUR, Testament und Bürgerschaft, S. 21 - 24. Über den polnischen Ansatz und gelieferte Ergebnisse berichtet A. KLONDER, Geschichte der materiellen Kultur. Theorie und Praxis der Forschungen (1), in: , Die Erforschung von Alltag und Sachkultur des Mittelalters. Methode - Ziel - Verwirklichung ( = Österreichische Akademie der Wissenschaften, Philosophisch-Historische Klasse, Sitzungsberichte, Bd. 433, Veröffentlichungen des Instituts für mittelalterliche Realienkunde Österreichs, Nr. 6 ), Wien 1984, S. 14 - 16; dann wieder A. KLONDER, Geschichte der materiellen Kultur des Mittelalters und der Frühneuzeit. Theorie - Methoden -

Forschungsbilanz, in: Mensch und Objekt im Mittelalter und in der Frühen Neuzeit. Leben - Alltag - Kultur ( = Österreichische Akademie der Wissenschaften, Philosophisch-Historische Klasse, Sitzungsberichte, Bd. 568, Veröffentlichungen des Instituts für Realienkunde des Mittelalters und der Frühen Neuzeit, Nr. 13), Wien 1990, S. 23 - 36.

${ }^{7}$ Im 19. Jahrhundert wurde nicht nur das Mittelalter ,wiederentdeckt“, sondern auch das Interesse an den Lebenszeugnissen vergangener Generationen geweckt. Diese zunächst als Altertumskunde, dann Kulturgeschichte genannte Strömung der Geschichtsschreibung befaßte sich - pointiert formuliert - mit einer um die politische Geschichte dezimierten allgemeinen Geschichte. Wenn es auch - vor allem in den 20ger und 30ger Jahren des 20. Jahrhunderts - um die Erfassung des Zeitgeistes vergangener Epochen ging, so zeigen doch einige Arbeiten das Bemühen um die „Hausaltertümer“, also die Gegenstände, die das materielle Umfeld z.B. eines spätmittelalterlichen Menschen bildeten. M. HEYNE, Fünf Bücher deutscher Hausaltertümer von ältesten geschichtlichen Zeiten bis zum 16. Jahrhundert: 1. Das deutsche Wohnungswesen von den ältesten geschichtlichen Zeiten bis zum 16. Jahrhundert, Leipzig 1889; 2. Das deutsche Nahrungswesen von den ältesten geschichtlichen Zeiten bis zum 16. Jahrhundert, Leipzig 1901; 3. Körperpflege und Kleidung bei den Deutschen von den ältesten geschichtlichen Zeiten bis zum 16. Jahrhundert, Leipzig 1902. 
Realienkunde der Österreichischen Akademie der Wissenschaften sichtbar, deren erklärtes Ziel es ist, mittels „einer interdisziplinären Forschungsmethode, die unter Heranziehung der noch vorhandenen Originalgegenstände, der bildlichen und der schriftlichen Quellen ermöglichen soll, systematisch den Altag des Spätmittelalters zur erforschen und zu interpretieren" ${ }^{\circ 8}$. Diese Realienkunde ist angewiesen auf die Ergebnisse, die die Archäologie, die Sozialgeschichte und die Kunstgeschichte, aber auch die Rechtsgeschichte, die Wirtschaftsgeschichte und die Literaturwissenschaft bereitstellen ${ }^{9}$. Der von etlichen Vertretern der genannten Disziplinen unterstützte Arbeitsansatz hat in den letzten Jahren zu Abhandlungen geführt, deren Erkenntnisse den eingeschlagenen Weg auf das Beste bestätigen ${ }^{10}$. Die Objekte werden als Realien, Sachgüter oder materielle (Kultur-) Güter bezeichnet. Wenn es auch noch Forschungslücken zu schließen gilt, so liegen doch für etliche Sachkulturgruppen - z.B. auf dem Gebiet des Kleidungswesens, der Hausgerätschaften und der Möbel - wegweisende Erkenntnisse vor.

Eng verbunden mit der Realienkunde ist die Altagsgeschichte ${ }^{11}$. Trotz aller Bemühungen, den Alltag als Gegenstand der Geschichtsschreibung verbindlich zu beschreiben, gibt es bislang keine feststehende Definition ${ }^{12}$. Es ist fraglich, ob angesichts der Vielschichtigkeit des Alltagsbegriffs eine überzeugende Definition überhaupt gefunden werden kann.

\footnotetext{
${ }^{8}$ H. KÜHNEL, Zum Geleit,in: Die Erforschung von Alltag und Sachkultur des Mittelalters. Methode - Ziel Verwirklichung, S. 5. Der eingeschlichene Fehler bei der Infintivformulierung wurde im Sinne des korrekten Zitierens übernommen, gleichwohl sei hier auf die Fehlerhaftigkeit hingewiesen.

${ }^{9}$ Der von H. APPELT herausgegebene Band : Die Erforschung von Alltag und Sachkultur des Mittelalters. Methode - Ziel - Verwirklichung bietet folgende relevante Aufsätze: W. RÖSENER, Sozialgeschichte und mittelalterliche Realienkunde, S. 53 - 59; W. MEYER, Der Beitag der Archäologie zur mittelalterlichen Realienkunde,S. 88 - 98; G. KOCHER, Rechtsgeschichte und mittelalterliche Realienkunde, S. 99 - 121; U. DIRLMEIER, Realienkunde und mittelalterliche Wirtschaftsgeschichte Deutschlands, S. 122 - 128; H. SCHÜPPERT, Der Beitrag der Literaturwissenschaft für die mittelalterliche Realienkunde, S. 158 - 167; E. VAVRA, Kunstgeschichte und Realienkunde, S. 174 - 192; H. APPUHN, Realienkunde und Kunstgewerbe des späten Mittelalters, S. 193 - 199.

${ }^{10}$ Eines der früheren und immer noch überzeugenden Werke ist D. W. H. SCHWARZ, Sachgüter und Lebensformen. Einführung in die materielle Kulturgeschichte des Mittelalters und der Neuzeit (= Grundlagen der Germanistik, Bd.11), Berlin 1970. Als weitere Beispiele aus der Menge der relevanten Arbeiten seien herausgegriffen: R. - E. MOHRMANN, Wohnen und Wohnkultur in nordwestdeutschen Städten, in: Kat. „Stadt im Wandel“, Bd. 3, Stuttgart-Bad Cannstadt 1985, S. 513 - 523; S. SCHÜTTE, Bürgerliches Hausgerät des Hoch - und Spätmittelalters in Nordwestdeutschland, in: Kat. „Stadt im Wandel“, Bd.3, Stuttgart-Bad Cannstadt 1985, S. 545 - 568.

${ }^{11}$ Über die Problematik des Alltagsbegriffs in Verbindung mit der Realienkunde siehe W. RÖSENER, Sozialgeschichte und mittelalterliche Realienkunde, S. 96 Die sich mehr in der Praxis stellenden Probleme zeigt S. SCHÜTTE auf. ders., Bürgerliches Hausgerät, S. 547f.

${ }^{12}$ SCHILDHAUER macht den hansestädtischen Alltag zum Gegenstand seiner Auswertung der Stralsunder Testamente des 14 bis 16. Jahrhunderts. Eine seiner Arbeit zugrundeliegende Definition des Alltags gibt er nicht, immerhin stehe die allgemeine Verständigung über diese Fragen ( u.a. die Definition des Alltags - S. M. - C.), die Abgrenzung der einzelnen Gebiete durch interdisziplinäre Kooperation und schließlich die Gewinnung gültiger Definitionen noch aus. J. SCHILDHAUER, Hansestädtischer Alltag auf der Grundlage der Stralsunder Bürgertestamente des 14. bis zum Ausgang des 16. Jahrhunderts (=Abhandlungen zur Handelsund Sozialgeschichte 28), Weimar 1992, S.7.
} 
Der in der zweiten Hälfte der 80er Jahre formulierte Ansatz definiert Altag als eine Trias, bestehend aus Sprache, Sitten und den von Menschen hergestellten Gegenständen sowie Produkten $^{13}$. In besonderem Maße rekurriert dieser Alltag auf die sogenannte „kleine Welt“, die mit den gesamtgesellschaftlichen Strukturen zu verknüpfen sich die Alltagsgeschichte zum Ziel mache. Im Bewußtsein um das notwendige Differenzieren des Alltags der unterschiedlichen Sozialgruppen formulierte man, daß sich die Alltagsgeschichte für die „Lebenswelten“ (Alfred Schütz) interessiere, „für das Repetitive des menschlichen Handelns und Denkens, so wie es vor allem im Wohnen, Kleiden und Essen, im Privatleben und in der Berufsausübung, in Vergnügen und Geselligkeit sowie in der „Kultur“ im weiten Sinne zum Ausdruck kommt“"14. Fand der Begriff der "Lebenswelt" - übrigens gerade bei Testamentsauswertungen - bereits gelegentlich Verwendung ${ }^{15}$, so wurde er in jüngster Zeit zum stehenden Begriff in der „neuen Kulturgeschichte“"16. Definiert wird der Begriff als „die mehr oder weniger deutlich - wahrgenommene Wirklichkeit ..., in der soziale Gruppen und Individuen sich verhalten und durch ihr Denken und Handeln wiederum Wirklichkeit produzieren. Dazu gehört alles, was Sinnzusammenhänge herstellt und Kontinuität stiftet: die Objektivationen des Geistes in Sprache und Symbolen, in Werken und Institutionen, aber auch die Weisen und Formen des Schaffens, die Verhaltensweisen und Lebensstile, die Weltdeutungen und Leitvorstellungen“"17. Die Rolle, die der materiellen Kultur in diesem Theoriekonzept zugedacht wird, wird mit der Hervorhebung der Tatsache beschrieben, daß sich dem Historiker die Betrachtung der „Formen des materiellen ... Lebens“"18 auf dem Weg zur zusammenhängenden Darstellung biete.

Klar muß sein, daß sich die Ergebnisse zunächst auf die Lüneburger Situation beziehen, auf die Lebenswelten, die sich die Bürger dieser Stadt im späten Mittelalter geschaffen haben konnten. Und auch der Einblick durch die „Brille“ der Testamente ist ein beengter; Testamente bieten wie Inventare keinen absolut zu setzenden Blick auf die mobilen Habseligkeiten. Wenn auch (Nachlaß-) Inventare kraft ihrer Aufgabe mobilen Besitz relativ umfassend auflisten sollten, so trifft das auf die Testamente keineswegs zu. Die

\footnotetext{
${ }^{13}$ P. BORSCHEID, Alltagsgeschichte - Modetorheit oder neues Tor zur Vergangenheit, in: Soziales Verhalten und soziale Aktionsformen in der Geschichte ( = Sozialgeschichte in Deutschland, Bd. III ), hg. v. W. SCHIEDER, V. SELLIN, Göttingen 1987, S. 95.

${ }^{14}$ P. BORSCHEID, Alltagsgeschichte, S. 78.

${ }^{15}$ Ähnlich formuliert bei H. BOOCKMANN, Die Lebenswelt eines spätmittelalterlichen Juristen. Das Testament des doctor legum Johannes Seeburg, in: Philologie als Kulturwissenschaft. Festschrift für Karl Stackmann, hg. v. L. GRENZMANN, Göttingen 1987, S. 287 - 305 und bei H. D. LOOSE, Leben und Kultur der Bürger mittelalterlicher Hansestädte, S. 3 - 19.

${ }^{16}$ R. VIERHAUS, Die Rekonstruktion historischer Lebenswelten. Probleme moderner Kulturgeschichtsschreibung, in: H. LEHMANN (Hg.), Wege zu einer neuen Kulturgeschichte (= Göttinger Gespräche zur Geschichtswissenschaft, Bd. 1), Göttingen 1995, S. 5 - 28.

${ }^{17}$ R. VIERHAUS, Die Rekonstruktion historischer Lebenswelten, S. $13 \mathrm{f}$.

${ }^{18}$ R. VIERHAUS, Die Rekonstruktion historischer Lebenswelten, S. 15.
} 
Testamente sind als zusätzliches Rechtsinstitut neben einer gesetzlichen, also im Normalfall greifenden Erbrechtsregelung zu verstehen. Ererbte Besitztümer unterlagen der gesetzlichen Erbfolge, so daß sie an die eigenen Kinder oder - zumeist bei Kinderlosigkeit an die Nachkommen des eigenen Geschlechts fielen. Allein über das selbsterarbeitete, das sogenannte wohlgewonnene Gut konnte in Lüneburg frei verfügt werden ${ }^{19}$. Im Einzelfall kann das ein Nebeneinander von letztwilliger, freier Verfügung und gesetzlicher Erbfolge bedeuten. Güter, die dem Familienerbe zuzurechnen sind, müssen im Testament nicht aufgelistet sein. Es gibt auch keinen Verfügungszwang über das selbsterarbeitete Gut. Das heißt, daß ein Testament nicht unbedingt einen Überblick über den gesamten Besitz an Sachgütern eines Testators oder einer Familie gewährt.

\section{Die Rahmenbedingungen der Stadtgeschichte}

Mit den annähernd 300 Testamenten, die in dem durch die Jahre 1323 und 1500 begrenzten Untersuchungszeitraum nachgewiesen sind, bietet Lüneburg eine nicht zuletzt in quantitativer Hinsicht aussagekräftige Quellengrundlage. Die erwartete Aussagekraft der Testamente hinsichtlich der Quantität und Qualität materieller Kulturgüter gründet sich auf dem Reichtum etlicher Lüneburger Bürger, einem Reichtum, der - anders als es bei primär von kaufmännischem Warenhandel geprägten Städten der Fall war - in den relevanten 200 Jahren krisenfrei war, weil er von der Lüneburger Sole abhing ${ }^{20}$. Trotz der seit dem 14. Jahrhundert aufkommenden Konkurrenz des Baiensalzes vermochte das Lüneburger Salz seine Marktposition im relevanten Untersuchungszeitraum nicht nur zu halten, sondern sogar auszubauen ${ }^{21}$. Daß auch der spätmittelalterliche Lüneburger der Saline die Bedeutung des Lebensnervs der Stadt beimaß, zeigt sich in dem Heinrich Lange 1461 zugeschriebenen Spruch: de sulte dat is Luneborch ${ }^{22}$.

\section{a. Die Stadt Lüneburg}

Die Anfänge der Stadt wie ihre jahrhundertealte Prägung lassen sich stichwortartig umreißen mit den Begriffen „mons - fons - pons““23: Siedlungsbegünstigend waren die Nähe

\footnotetext{
${ }^{19}$ In Braunschweig und Köln konnte testamentarisch über das Gesamtvermögen verfügt werden. B. KLOSTERBERG, Zur Ehre Gottes, S. 47.

${ }^{20}$ Natürlich war das Lüneburger Salz auf eine ,,Vermarktung“ angewiesen, vor allem, als gegen Ende des 14. Jahrhunderts in den Baiensalzen eine Konkurrenz erwuchs. Die sinkende Bedeutung des für Lüneburg wichtigen Handelspartners Lübecks als Umschlagplatz der Waren verursachte eine Krisensituation ab ca. 1560. H. WITTHÖFT, Struktur und Kapazität der Lüneburger Saline seit dem 12. Jahrhundert, in: Vierteljahresschrift für Sozial- und Wirtschaftsgeschichte, Bd. 63, 1. Heft, 1976, S. 107f.

${ }^{21}$ Erst seit Mitte des 16. Jahrhunderts bricht die positive Exportbilanz ein. H. WITTHÖFT, Struktur und Kapazität der Lüneburger Saline seit dem 12. Jahrhundert, S. 108ff.

${ }^{22}$ W. REINECKE, Geschichte der Stadt Lüneburg, 1. Bd. (=Nachdruck der Ausgabe Lüneburg 1933 durch die Heinrich-Heine-Buchhandlung Lüneburg), Lüneburg 1977, S. 354.

${ }^{23}$ Nach W. REINECKE, Geschichte der Stadt Lüneburg, Bd. I, S. 3ff (=Überschrift des ersten Kapitels) Eine knapp umrissene, auf das Wesentliche konzentrierte Einführung in die Stadtgeschichte legte K. TERLAU -
} 
des Kalkberges, der einzigen Erhebung in einer weithin flachen Landschaft, die salzhaltigen Quellen sowie die Wasserstraße des Flusses IImenau, der die Verbindung zu Elbe und Nordsee garantierte. Zur für die Entstehung der Stadt entscheidenden Ansiedlung auf dem Kalkberg kam es durch die dort seit 955 feste Residenz der Billungerherzöge und die Gründung des Benediktinerklosters St. Michaelis. Ebenfalls seit dem 10. Jahrhundert urkundlich belegt, wenn wohl auch früher existierend, ist die Salzgewinnung in Kalkbergnähe ${ }^{24}$. Der zunächst über das regionale und überregionale Handelszentrum Bardowick laufende Salzvertrieb konnte nach der Zerstörung durch Heinrich den Löwen 1189 von Lüneburg aufgrund des Vertriebsnetzes der Wasserstraße problemlos übernommen und zunehmend ausgebaut werden. In der Folge kam es zu einem Zusammenwachsen der Siedlungskerne am Kalkberg, der Saline und der IImenau. Der entscheidende Schritt für die Stadt Lüneburg ist die Verleihung des Marktprivilegs durch Herzog Otto das Kind im Jahr $1247^{25}$. Katalysator für eine zunehmend eigene Politik der Stadt war die Zerstörung der herzöglichen Burg auf dem Kalkberg, zu der es $1371 \mathrm{im}$ Rahmen des Erbfolgekrieges nach dem Tod des Welfenherzogs Wilhelm 1369 kam.

\section{b. Die Saline}

Die Produktionsmethoden blieben während des gesamten Mittelalters gleich: Die Sole wurde bergmännisch erschlossen und mit Eimern, seit 1569 durch eine Pumpe an die Erdoberfläche befördert. Hier wurde sie durch Leitungen, die sogenannten Wege, auf die Siedehütten verteilt, in denen sie dann in Bleipfannen, die in einer der Saline zugehörigen Pfannenschmiede, der Bare, gegossen wurden, zu Salz gesiedet. Der Betrieb der Saline wurde seit Ende des 12. Jahrhunderts durch gezielte Maßnahmen wie Vergrößerung und Vermehrung der jährlichen Fluten optimiert. Die Vermehrung der Fluten pro Jahr bedingte die Zunahme der jährlichen Siedetage und täglichen Söde. Die für das Mittelalter endgültige, bis in das 18. Jahrhundert reichende Betriebsform der Saline mit 54 Siedehütten und 216 Pfannen (also 4 Pfannen pro Siedehütte) war ca. 1262 erreicht. Von diesem Zeitpunkt an wurde eine Ertragsverbesserung nur über eine Verfahrensoptimierung möglich. Seit spätestens 1388 wurde die Saline mit 13 Fluten pro Jahr optimal genutzt; man darf von einer täglichen Ausbeute von 32 - 34 1⁄2 Scheffel Salz je Siedehütte ausgehen, das

\footnotetext{
FRIEMANN in ihrer kürzlich publizierten Dissertation vor. K. TERLAU - FRIEMANN, Lüneburger Patrizierarchitektur des 14. bis 16. Jahrhunderts. Ein Beitrag zur Bautradition einer städtischen Oberschicht, Lüneburg 1994, S. 17f.

${ }^{24}$ Ein exakt datierbarer Beginn des Siedebetriebes ist nicht überliefert. Eine Urkunde König Ottos I. aus dem Jahr 956 ist der erste quellenmäßig gesicherte Beleg für die Existenz einer Saline, die in jener Zeit bereits voll funktionsfähig und gut funktionierend war. U. REINHARDT, Saline Lüneburg 956 - 1980, in: Der Anschnitt, Zeitschrift für Kunst und Kultur im Bergbau 2, 1981, S. 46.

${ }^{25}$ Genauere Ausführungen bei E. THURICH, Die Geschichte des Lüneburger Stadtrechts im Mittelalter, Lüneburg 1960, S. 19ff.
} 
entspricht einer Jahresproduktion von 14147 - 15329 t Salz. Diese hohe Ertragsmenge zeigt deutlich, daß der Salinenbetrieb auf den Export ausgerichtet war $^{26}$.

Einblick in die genauere Struktur der Saline ist erst seit dem 13. Jahrhundert möglich. Zu dieser Zeit präsentierte sich die Saline als Betrieb mit geistlichen und adligen Anteilseignern $^{27}$. In den Jahren zwischen 1250 und 1320 erfolgte der zunehmende Anstieg bürgerlicher Besitzanteile, der parallel verlief zur Abnahme des adligen Pfannengutes ${ }^{28}$. Hielten sich 1370 bürgerlicher und geistlicher Pfannenbesitz annähernd die Waage, so waren ca. 100 Jahre später fast drei Viertel der Pfannen in den Händen des Klerus. Auf dem Gebiet der Sülzrenten waren die geistlichen Institutionen mit $80 \%$ und mehr die Mehrheitseigner. Diese Besitzverteilung gewährt bereits einen Überblick über die verschiedenen Formen von Sülzbesitz: Mit der Pfannenherrschaft war das Anrecht auf Sole verbunden, mit Anteilen an Chor - oder Wispelgut verbunden war das Anrecht auf Salz, das bereits im 13. Jahrhundert in Form von Geldbeträgen vergütet wurde, und es gab den Besitz an Geldrenten. Unter den Sülzbegüterten gab es etliche, die nicht selbst in Lüneburg ansässig waren und die die Besiedung ihrer Pfannen durch die ausschließlich in Lüneburg ansässigen Siedeberechtigten vornehmen ließen. Aus der Schnittmenge von Salinenbesitz und Salinenverwaltung entfaltete sich die Bedeutung der Saline für Wirtschaft, Politik und Gesellschaft der Stadt.

Verwaltet wurde die Saline vom Barmeister und vom Sodmeister. Der Barmeister als Vorsteher der Pfannenschmiede, der sogenannten Bare, des Hauses, in dem die Bleipfannen aufgrund der durch ständigen Gebrauch hervorgerufenen Abnutzung annähernd monatlich um- oder neugegossen wurden, wurde vom Kollegium der Sülfmeister und dem Rat der Stadt gewählt ${ }^{29}$. Der Sodmeister sorgte für die Verteilung der Sole auf die einzelnen Siedehäuser und die Besoldung der für diese Arbeiten Zuständigen. Seit 1350 wurde er von einem Kollegium der Sülzbegüterten und dem Rat der Stadt gewählt. Pointiert

\footnotetext{
${ }^{26}$ S. MOSLER, Das Sülzgut in den frühen Lüneburger Testamenten, S. 12f.

${ }^{27}$ Hat es jemals königliche Rechte an der Saline gegeben, dann sind sie zu diesem Zeitpunkt nicht mehr existent. U. REINHARDT, Saline Lüneburg, S. 48.

${ }^{28}$ In der überkommenen Vorstellung der Ritterfamilien galt der Grundbesitz als wirtschaftliche Grundlage, den es der Familie zu erhalten galt. So wurde in Zeiten finanzieller Not eher der Sülzbesitz veräußert, obwohl gerade Sülzrenten im Verhältnis zu Landrenten wesentlich höhere Renditen einbrachten. K. BACHMANN, Die Rentner der Lüneburger Saline 1200 - 1370 (= Veröffentlichungen des Instituts für Historische Landesforschung der Universität Göttingen, Bd. 21), Göttingen 1983, S. 111. Der in Relation zum bürgerlichen Besitz geringere Pfannenbesitz der Adligen schlägt sich in den Testamenten des 14. Jahrhunderts nieder, in denen Verfügungen über Sülzgut in den Testamenten der Burgmannenfamilien nur ausnahmsweise vorkommen. Der 1352 über Sülzbesitz verfügende Segeband von Wittorf gehörte einer Familie an, die als einzige aller Ritterfamilien in der ersten Hälfte des 14. Jahrhunderts beachtliche Sülzrenten aufkaufte! ${ }^{29}$ Blei und auch Holz sind wichtige Materialien für die Besiedung, so daß sie in Sülfmeisterkreisen testamentarisch vererbt werden konnten. Beispiel dafür ist das Testament des Hermann Kruse von 1441 November 20. Der Testator, seinerseits Sülfmeister, Ratsherr, Bürgermeister und Vorsteher von St. Johannis, hinterläßt seinem Sohn Eggherd, der sogar zum Sodmeister aufsteigt, diese Basismaterialien.
} 
ließe sich formulieren, der Sodmeister ist der Beamte der Eigentümer, wie der Barmeister der Repräsentant der Besitzer ist ${ }^{30}$. Die Sülfmeister nun entstammten - wie oft ihren Familiennamen zu entnehmen ist - ehemaligen Handwerkerfamilien, denen die Siedeberechtigung zugesprochen wurde. Dazu mußten sie im Besitz von mindestens vier Pfannen sein, für deren Nutzung sie selbst zu sorgen hatten; dies war wegen des aus der intensiven Nutzung resultierenden Verschleißes an Pfannen und wegen des Kaufs von Brennholz ein durchaus kostspieliges Unterfangen, das eine nicht unbeträchtliche Finanzkraft der Familien voraussetzte. Der Sülfmeister erhielt für seine Arbeit die Hälfte des Ertrages, das sind drei Chor pro Flut ${ }^{31}$. Das Pachtverhältnis zwischen den Pfannenbesitzern und den Siedeberechtigten entwickelte sich fast bis zur Erblichkeit ${ }^{32}$. Trotz hoher Pachtzahlungen war das Pachten von Sülzpfannen für die Siedeberechtigten ein lohnendes Geschäft, weil die Pachtzahlungen nicht an die beständig steigende Salzproduktion angeglichen wurden. Wenn ein Sülfmeister auch nicht mehr als zwei Häuser besieden durfte, so war es beileibe keine Seltenheit, daß eine Familie mehrere Sülfmeister stellte. So führt ein Vertrag des Jahres 1488 bei den Familien Schomaker, Tzerstede und Töbing drei, fünf bzw. acht Sülfmeister auf ${ }^{33}$. Das sich in den Händen einiger Familien konzentrierende Kapital begründete die führende Stellung der Sülfmeisterfamilien in Lüneburg.

\section{Stadtpolitische Konsequenzen ${ }^{34}$}

Mit der steigenden Produktion, dem Blühen des Handels und der nach der Zerstörung der herzöglichen Burg abnehmenden Bedeutung der Burgmannenfamilien wuchs der der wirtschaftlichen Macht entspringende politische und gesellschaftliche Einfluß der Sülfmeister. Dieser Entwicklungsprozeß ist als genuin evolutionärer weder zeitlich noch urkundlich zu bestimmen; an seinem Ende hatten sich die Sülfmeister als neue Oberschicht etabliert. Das bedeutete freilich keineswegs, daß ein jeder Sülfmeister automatisch in den Rat aufgenommen wurde. Schon allein das Zahlenverhältnis von 24 Ratsherren in der Höchstzahl und maximal 56 Sülfmeistern ${ }^{35}$ zeigt, daß ein Sülfmeister nicht automatisch ein Ratsherr war. Aber je mehr Sülzbesitz die Familie eines Sülfmeisters hatte, desto größer war die Wahrscheinlichkeit, daß er Ratsmitglied war $^{36}$. Die ratsfähigen Sülfmeister waren

\footnotetext{
${ }^{30}$ Formuliert in Anlehung an VOLGERs Satz: ,So wie der Sodmeister der Beamte der Begüterten war, so ward der Barmeister der Repräsentant der Pächter, ...“. W. Fr. VOLGER, Die Lüneburger Sülze ( = Lüneburger Blätter / Osterblatt 1861; Nachdruck im Verlag der Heinrich - Heine - Buchhandlung, Lüneburg 1986), S. 225. ${ }^{31}$ H. WITTHÖFT, Struktur und Kapazität, S. 36.

${ }^{32}$ U. REINHARDT, Saline, S. 52. WITTHÖFT geht von einer Erblichkeit der Pacht aus, weil der Einfluß der Sülzbegüterten durch die Zersplitterung des Sülzbesitzes gesunken sei und die „Initiative“ bei den auf mindests vier zu besiedenden Pfannen angewiesenen Sülfmeistern lag. H. WITTHÖFT, Struktur und Kapazität, S. 36.

${ }^{33}$ W. REINECKE, Geschichte der Stadt Lüneburg, Bd. I, S. 361.

${ }^{34}$ S. MOSLER, Das Sülzgut, S. 14f.

${ }^{35}$ Besieder der 54 Siedehütten, der Bar - und der Sodmeister.

${ }^{36}$ K. BACHMANN, Die Rentner der Lüneburger Saline 1200 - 1370, S. 152, Tab. 22.
} 
eine durch verwandtschaftliche Beziehungen und gezielte Heiratspolitik relativ geschlossene Gruppe ${ }^{37}$. Sie konnten über Generationen ihre Position im Rat zum einen durch die stabile wirtschaftliche Grundlage ihres Vermögens behaupten, zum anderen durch die Möglichkeit einer gleichzeitigen Ratsmitgliedschaft naher Verwandter ${ }^{38}$. In Lübeck, wo der Handel als ungleich krisenanfälligerer Wirtschaftszweig die Vermögensgrundlage der ratsfähigen Geschlechter war, waren maximal zwei Generationen im Rat vertreten.

\section{Das Testament in der Stadt Lüneburg}

\section{a. Die stadtrechtliche Einbettung}

Erste Kunde über städtische Erbrechtsbestimmungen enthält das Privileg von 1247, das Herzog Otto das Kind der Stadt Lüneburg verlieh ${ }^{39}$. Zwar enthält es keine Äußerungen über das Rechtsinsitut Testament, aber es spiegelt doch eine bestimmte auf das subsidiäre Landrecht des Sachsenspiegels zurückgreifende Gewohnheit wider, wenn gesagt wird, daß nur jener kranke Bürger über sein wohlgewonnenes Gut verfügen darf, der aus eigener Kraft in der Lage ist, eine Mark Silber zu wägen. Die weiteren erbrechtlichen Bestimmungen betreffen Heergewät und Frauengerade: Ein Mann behält die Gerade seiner Frau, wenn sie nicht aus Lüneburg stammt und keine gemeinsamen Kinder hinterläßt, gemäß dem Satz: Frauengerade und Heergewät gehen nicht über die Brücke. Die außerhalb Lüneburgs wohnende Verwandtschaft der Frau hat damit keinen Anspruch auf die Gerade. Ferner wird festgelegt, daß Töchter das Heergewät ihres Vaters erben, wenn keine Söhne vorhanden sind und im umgekehrten Fall die Söhne die Frauengerade der Mutter erhalten. Eine erste Konkretisierung erfährt das Testament aufgrund kirchlichen Bestrebens, was angesichts der führenden Rolle der Kirche bei der Entstehung des deutschrechtlichen Testaments so verwunderlich nicht ist. Die vom Bischof beklagte angebliche Veruntreuung von Legaten ad pias causas durch Lüneburger Testamentsvollstrecker führt 1297 zu der Regelung, daß Testamente nur mit Wissen der Ratsherren aufgesetzt werden dürfen und die Ratsherren der Wahl der Testamentsvollstrecker zustimmen sollten ${ }^{40} .1333$ wird diese Verordnung von

\footnotetext{
${ }^{37}$ Ein gutes Beispiel bietet der Stammbaum der Familie von der Mölen bei K. BACHMANN, Die Rentner der Lüneburger Saline 1200 - 1370, S. 159.

${ }^{38}$ In Lübeck durften nahe Verwandte nicht zur gleichen Zeit dem Rat angehören. W. REINECKE, Geschichte der Stadt Lüneburg, Bd. I, S. 82.

${ }^{39}$ Druck bei W. Th. KRAUT, Das alte Stadtrecht von Lüneburg, Göttingen 1846, S. 3ff. De jure handelt es sich hier um ein Privileg, de facto um ein Rechtsgeschäft zwischen Herzog und Bürgern, die, die Finanznot des Herzogs nutzend, die Eigenleute von den Ansprüchen des Herzogs loskauften. Vgl. C. HAASE, Das

Lüneburger Stadtrecht, in: U. Wendland (Hg.), Aus Lüneburgs tausendjähriger Vergangenheit, Lüneburg 1956, S. 69; E. THURICH, Die Geschichte des Lüneburger Stadtrechts, Lüneburg 1960, S. 19.

${ }^{40}$ 1297, Mai 5 Druck im Urkundenbuch der Stadt Lüneburg, hg. v. W. F. VOLGER, Bd.I, Hannover 1872, Nr.222, S.123. Bischof Konrad von Verden beklagt, daß "plerique executores testamentorum civitatis
} 
Bischof Konrad von Verden erneuert. Die endgültige Festlegung der das Testament betreffenden Vorschriften erfolgt seitens der Stadt in den 1401 kodifizierten Eddagsartikel ${ }^{41}$. Es handelt sich hierbei um eine Zusammenstellung von bereits geltenden Rechtsnormen, die zwar von älteren Aufzeichnungen übernommen werden, hier aber zum ersten $\mathrm{Mal}$ in einer städtischen Rechtssammlung vereint und veröffentlicht werden ${ }^{42}$. Vorgeschrieben wird das Aufsetzen des Testamentes vor zwei Ratsherren, geregelt werden in Hinblick auf die gesetzliche Erbfolge die Vererbung von Heergewät und Frauengerade sowie verschiedene Möglichkeiten eines Erbfalls.

Damit gelten in Lüneburg die das Testament konstituierenden Elemente wie allgemeine Testierfreiheit, Öffentlichkeit des Rechtsaktes, Zeugnis mindestens zweier Ratsherren, Berufung von Testamentsvollstreckern; all dies sind Gepflogenheiten, die denen anderer (Hanse-)Städte durchaus vergleichbar sind.

\section{b. Formale Eigenschaften}

Die Testamente werden normalerweise als Siegelurkunden ausgestellt, wobei das Stadtsiegel, alternativ oder zusätzlich das Siegel des Testators der Beglaubigung dient. Im Lauf des 14. Jahrhunderts kommt die Doppelausfertigung der Siegelurkunden auf; zur Sicherung der Beweiskraft bleibt die Zweitausfertigung in den Händen des Rates. Kurz nach 1400 wird die beim Rat verbleibende Zweitausfertigung durch eine besiegelte Ausfertigung auf Papier ersetzt. Eine Eintragung in das Stadtbuch ist ebenfalls möglich. Geistliche setzen ihr Testament gewöhnlich in Form eines Notariatsinstruments auf. Kerbschnitturkunden kommen seltener vor. Bis 1365 sind die Testamente fast ausschließlich lateinisch verfaßt worden ${ }^{43}$. Nach einer Übergangszeit, in der Latein und Mittelniederdeutsch in den Testamenten als Schriftsprache in gleicher Stärke vertreten waren, werden Bürgertestamente seit 1370 eigentlich nur noch mittelniederdeutsch verfaßt. Lateinisch abgefaßte Testamente - in Form von Notariatsinstrumenten - stammen bis auf eine Ausnahme ausschließlich von Geistlichen ${ }^{44}$.

\section{c. Quellenlage}

Luneborg" Veruntreuende sind! Diese hier vorgelegte Verordung gilt übrigens für "civis Luneborgensis utriusque sexus". In dieser Urkunde wird den Lüneburgern ferner zugestanden, innerhalb der Stadt Kapellen und Altäre zu stiften und das Patronatsrecht darüber auszuüben.

${ }^{41}$ Eine Kurzübersicht über den Inhalt verschiedener Artikel gibt W. REINECKE, Geschichte der Stadt

Lüneburg, im Kapitel über die Entwicklung des Stadtrechts, bes. S. 331,ff.

${ }^{42}$ Die Veröffentlichung erfolgt in Form des Verlesens, vgl. W. REINECKE, Geschichte der Stadt Lüneburg, Bd.1, S. 331.

${ }^{43}$ Ausnahmen: Bode van Brokelde 1330, Ludeke van Putensen 1340, Heinrich Schermbeke 1354. Das Testament Ludekes van Putensen ist die erste überlieferte mittelniederdeutsche Urkunde im Lüneburger Archiv.

${ }^{44}$ Klerikertestamente erlangen ihre Gültigkeit erst durch die zustimmende Bestätigung des Diözesanbischofs. 
Die Überlieferung der Lüneburger Testamente setzt 1323 ein und umfaßt bis zum Jahr 1500297 Testamente. Auf das 14. Jahrhundert entfallen 60 Testamente, auf das 15. Jahrhundert 237.

Im Lüneburger Urkundenbuch sind Testamente fast gar nicht vertreten. Wenn sie aufgenommen wurden, dann erscheinen sie als Regest oder im Teilabdruck ${ }^{45}$. In vollem Wortlaut gedruckt sind die im Stadtbuch verzeichneten Testamente ${ }^{46}$. Seit kurzem liegt eine Edition der Lüneburger Testamente vor, die den Vollabdruck der Testamentstexte enthält ${ }^{47}$.

Tabelle: Anzahl der in Lüneburg überlieferten Testamente und Anzahl der Testatoren

\begin{tabular}{|l|c|c|}
\hline Jahreszahlen & Anzahl der Testamente & Anzahl der Testatoren \\
\hline $1300-1325$ & 1 & 1 \\
\hline $1326-1350$ & 10 & 10 \\
\hline $1351-1375$ & 29 & 24 \\
\hline $1376-1400$ & 20 & 19 \\
\hline $1401-1425$ & 100 & 97 \\
\hline $1426-1450$ & 59 & 59 \\
\hline $1451-1475$ & 35 & 34 \\
\hline $1476-1500$ & 43 & 43 \\
\hline
\end{tabular}

Unter den 297 Testamenten befinden sich in fünf Fällen Mehrausfertigungen des letzten Willens ein und desselben Testators ${ }^{48}$, wobei rechtskräftig allein die je letzte Ausfertigung ist. Aufgrund der Mehrfachausfertigung einiger Testamente entsteht ein Zahlenverhältnis von 297 Testamenten und 287 Testatoren. In sieben Fällen entschließen sich die Testatoren zur Ausstellung eines Gemeinschaftstestaments ${ }^{49}$.

\footnotetext{
${ }^{45}$ Fr. W. VOLGER, UB LG, Bd. I, Hannover 1872, S. 283ff, Nr. 469, S. 292f, Nr. 475, S. 298, Nr. 482; Fr. W. VOLGER, UB LG, Bd. II; Hannover 1875, S. 370, Nr. 1010, S. 370, Nr. 1011.

${ }^{46} \mathrm{~W}$. REINECKE, Lüneburgs Ältestes Stadtbuch und Verfestungsregister (=Quellen und Darstellungen zur Geschichte Niedersachsens, Bd. 8), Hannover 1903, S. 144f, S. 155f, S. 176f, S. 191, S. 210f, S. 211f, S. 217 , S. 231f, S. 246f.

${ }^{47}$ U. REINHARDT (Bearb.), Lüneburger Testamente des Mittelalters 1323 bis 1500 (= Veröffentlichungen der Historischen Kommission für Niedersachsen und Bremen, Bd. 37/Quellen und Untersuchungen zur Geschichte Niedersachsens im Mittelalter, Bd. 22), Hannover 1996.

${ }^{48} 1352$ März 27 Segeband von Wittorf mit vier weiteren überlieferten Ausfertigungen (1352 März 21, 1352 Juli 8, 1353 April 12 und 1382 Juli 9), 1355 Sept. 9 Dietrich Holle mit zwei weiteren Ausfertigungen (1357 März 26 und 1358 Sept. 1), 1414 Feb. 4 Johannes von Lippinghausen mit einer weiteren Ausfertigung (1424 Nov. 23), 1420 Nov. 14 Hermann Zierenberg mit zwei weiteren Ausfertigungen (1420 Nov. 29 und 1423 Nov. 19) , 1474 Aug. 31 Geseke Schwertfeger mit einer weiteren Ausfertigung (1475 Juli 26). Zusammen ergibt dies einen „Überhang“"von 10 Testamenten.

${ }^{49} 1323$ März 10 Bernhard und Heinrich von Erpensen, 1354 Dez. 10 Heinrich und Lucie Schermbeke, 1360 Jan. 13 Bernhard und Kunigunde Nyebur, 1370 Nov. 10 Jacob und Hermann Houth, 1382 Mai 1 Hille und Gesche Brockhöft, 1444 Dez. 13 Klaus und Grete von Wening, 1451 Juli 7 Ludeke und Geseke Wienebüttel. Wenn es sich hier vorwiegend um Gemeinschaftstestamente von Ehepaaren handelt, so sind auch Mutter Tochter- und Bruder - Bruderkombinationen vertreten.
} 
Die Lüneburger Testamentsüberlieferung ist für das 14. Jahrhundert relativ kontinuierlich: In einem Jahr werden ein bis zwei Testamente errichtet, wobei bis 1360 vorwiegend nur ein Testament errichtet wird, von 1360 an werden überwiegend zwei aufgesetzt ${ }^{50}$. Die durchschnittliche Ausfertigungsrate des 14. Jahrhunderts liegt bei 0,6 Ausfertigungen pro Jahr. Eine Ausnahme sind die Jahre 1375 mit fünf Testamenten und 1382 mit drei Testamenten. Beide Jahre - 1375 wie 1382 - sind wohl die Pestjahre des 14. Jahrhunderts in Lüneburg; 1375, weil für Lüneburger Verhältnisse außerordentlich viele Testamente errichtet werden, und dies sicherlich veranlaßt durch die Furcht vor der Pest, eine in diesem Jahr begründete Furcht, denn mindestens ein Testator des Jahres 1375 stirbt an der Pest ${ }^{51}$. Das Jahr 1382 ist in den Urkunden als Pestjahr in Lüneburg belegt ${ }^{52}$.

Die durchschnittliche Ausfertigungsrate im 15. Jahrhundert beträgt 2,37 Testamente pro Jahr. Eine Zweiteilung des Jahrhunderts zeigt, daß in der ersten Jahrhunderthälfte bis 1450 die Ausfertigungsrate bei überdurchschnittlichen 3,1 Ausfertigungen pro Jahr liegt, während in der zweiten Jahrhunderthälfte jährlich 1,56 Testamente ausgestellt werden. Die Spannbreite im 15. Jahrhundert erstreckt sich von mindestens einer Ausfertigung pro Jahr bis zu maximal elf Ausfertigungen pro Jahr, wobei diese Extrema jedoch selten sind. Ein Hinweis auf das Pestjahr dieses Jahrhunderts $1451^{53}$ könnte die in diesem Jahr - im Vergleich zu den vorhergehenden und nachfolgenden Jahren - hochschnellende Ausfertigungsrate von 7 Testamenten sein. Ein Testator des Jahres 1495 nennt die Pest als Testiergrund $^{54}$.

In Lüneburg sind für das 14. Jahrhundert weitaus weniger Testamente überliefert als in Hamburg (205 Testamente) ${ }^{55}$ und weniger für den gesamten vergleichbaren Zeitraum als in Lübeck (6368 Testamente) $)^{56}$, Köln (ca.1775 Testamente - bis 1525) ${ }^{57}$, Stralsund (825 Testamente) ${ }^{58}$ und Konstanz (446 Testamente - allerdings bis zum Jahr 1542) ${ }^{59}$. Wesentlich ist jedoch die Tendenz, die sich in Lüneburg trotz der Ausfertigungsschwankungen genauso

\footnotetext{
${ }^{50}$ Auf das angebliche Pestjahr 1350 könnte die Häufung von jeweils zwei Ausfertigungen pro Jahr im Zeitraum um 1350 hinweisen. Da aber für 1350 kein Testament überliefert ist, und die Argumentation sich auf die Schwankung zwischen einer oder zwei Ausfertigungen pro Jahr stützten müßte, erscheint der Unsicherheitsfaktor zu groß, um eine definitive Aussage machen zu können. Hinweis auf dieses Pestjahr bei MANECKE, zit. nach Hans FRESSEL, Do was tho Luneborch grote Pestilente. Medizin und Seuchenbekämpfung im Mittelalter (= Beilage der Landeszeitung 19./20. Aug. 1989, 44. Jahrgang, Nr.192), S.10.

${ }^{51}$ Johann von Bücken, der Archidiakon von Modestorpe, starb an der Pest. Vgl. Jörn-Wolfgang UHDE, Die Lüneburger Stadtschreiber von den Anfängen bis zum Jahr 1378, Phil.Diss. Hamburg 1977, S.191.

${ }^{52}$ W. REINECKE, Geschichte der Stadt Lüneburg, Bd.II, S.29. REINECKE berichtet, daß der Propst der Prämonstratenser Herzog Albrecht vor einem Einzug in Lüneburg warnt, da in der Stadt die Pest herrsche.

${ }^{53}$ H. FRESSEL, Pestilente, S. 10.

${ }^{54} 1495$ Sept. 24 Hans Duderstad.

${ }^{55} \mathrm{M}$. RIETHMÜLLER, to troste miner sele, S. 13.

${ }^{56}$ A. v. BRANDT, Mittelalterliche Bürgertestamente, Bd. I, S. 6.

${ }^{57}$ B. KLOSTERBERG, Zur Ehre Gottes, S. 24.

${ }^{58}$ J. SCHILDHAUER, Hansestädtischer Alltag, S. 14.

${ }^{59}$ P. BAUR, Testament und Bürgerschaft, S. 57.
} 
wie in den anderen Städten abzeichnet: Im Lauf der Jahre nimmt die Zahl der Testamentsausfertigungen zu. Das liegt zum einen daran, daß etliche Bürger mit zunehmender Wirtschaftskraft der Städte mehr selbsterarbeitetes Geld und Gut haben, über das sie (testamentarisch) verfügungsberechtigt sind, zum anderen liegt es an der zunehmenden Akzeptanz des Testaments als Institut im bürgerlichen Rechtswesen.

\section{Anlage der Arbeit und Literatur}

Zunächst wird der Frage nach den Testatoren gestellt. Zu überprüfen ist, ob sich im Rahmen der städtischen Bevölkerung bestimmte soziale Gruppen als Errichter von Testamenten benennen lassen ${ }^{60}$. Mit hoher Wahrscheinlichkeit werden die Testatoren vorrangig aus den führenden Gruppen der Stadt stammmen. Trifft es zu, daß viele Donatoren der Sachgüter aus den führenden städtischen Kreisen stammen, dann würde in geringerem Maße ein Einblick in das Sachvermögen der mittleren oder gar niederen sozialen Gruppen gegeben.

Angesichts dieser Fragestellung gilt es, möglichst viel von den Lebensumständen der Testatoren in Erfahrung zu bringen, und hier gibt es Quellen und Vorarbeiten, auf die zurückgegriffen werden kann: Hans - Jürgen von WITZENDORFFs Arbeit sind die „Stammtafeln Lüneburger Patriziergeschlechter“ ${ }^{61} \mathrm{zu}$ verdanken, die in weiten Teilen auf dem Register des 1745 verstorbenen Lüneburger Stadtsekretärs Johann Heinrich BÜTTNER ${ }^{62}$ beruhen. 1987 legte Irene STAHL eine Auflistung der Namen Lüneburger Ratsherrn vor $^{63}$, in der im wesentlichen Lebensdaten, die Abstammung väterlicherseits sowie die Jahre als regierende Ratsherrn oder/und Bürgermeister angegeben werden. Von Bedeutung zumindest für das 15. Jahrhundert ist Urs Justus DIEDERICHS Untersuchung

\footnotetext{
${ }^{60}$ E. MASCHKE, Soziale Gruppen in der deutschen Stadt des späten Mittelalters, in: Über Bürger, Stadt und städtische Literatur im Spätmittelalter. Bericht über Kolloquien der Kommission zur Erforschung der Kultur des Spätmittelalters 1975-1977 ( = Abhandlungen der Akademie der Wissenschaften in Göttingen, hist.-phil. Klasse, 3. Folge, Nr. 121), hg. v. J. Fleckenstein und K. Stackmann, Göttingen 1980, S. 127-145; M. MITTERAUER, Probleme der Stratifikation in mittelalterlichen Gesellschaftssystemen, in: Geschichte und Gesellschaft, Sonderheft 3/1977, S. 13-43; H. WUNDER, Probleme der Stratifikation in mittelalterlichen Gesellschaftssystemen. Ein Diskussionsbeitrag zu Thesen von M. Mitterauer, in: Geschichte und Gesellschaft, 4/1978, S. 542-550; J. ELLERMEYER, „Schichtung“ und „Sozialstruktur“ in spätmittelalterlichen Städten. Zur Verwendbarkeit sozialwissenschaftlicher Kategorien in historischer Forschung, in: Geschichte und Gesellschaft, 6/1980, S. 125-149. Eine kurze Zusammenfassung der Ansätze bei E. Isenmann, Die deutsche Stadt im Spätmittelalter, Stuttgart 1988, S. 250-254.

${ }^{61}$ H. - J. v. WITZENDORFF, Stammtafeln Lüneburger Patriziergeschlechter (=Veröffentlichung der Familienkundlichen Kommission für Niedersachsen und Bremen sowie angrenzende ostfälische Gebiete), Göttingen 1952.

${ }^{62}$ J. H. BÜTTNER, Genealogie - oder Stamm - und Geschlecht - Register der vornehmsten adligen Patriciergeschlechter, Lüneburg 1704.

${ }^{63}$ I. STAHL, Lüneburger Ratslinie, in: Niedersächsisches Jahrbuch für Landesgeschichte, 59/1987, S. 139 183.
} 
des Aufruhrs von 1454 - $1456^{64}$, denn hier werden - nach Bereichen gestaffelt Informationen gegeben über persönliche Daten, politische und berufliche Aktivitäten, soziales und kirchliches Engagement und Verwandtschaftsverhältnisse. Natürlich geben auch die Testamente Auskunft über die Person des Verfassers; oftmals liefert die Intitulatio Informationen über das Bürgerrecht, Beruf und Ratsmitgliedschaft, gelegentlich lassen sich die Lebensumstände dem Testamentsformular entnehmen. Die Intitulatio der Lüneburger Testamente enthält keine Angaben über die Eltern und die Verwandten des Testators, wie es z.B. in den Konstanzer Testamenten der Fall ist ${ }^{65}$. Die Anhaltspunkte über die Lebensdaten und Lebensumstände der einzelnen Testatoren sind in einem Schema vermerkt, das der vorliegenden Arbeit als Anhang beigefügt ist.

In einem weiteren Schritt wird das Zahlenverhältnis zwischen Testamenten mit Sachgutverfügungen und den Testamenten ohne Sachgutverfügungen verglichen. $\mathrm{Zu}$ erwarten ist hier der Beleg einer deutlichen Zunahme an testamentarisch verzeichneten Sachgütern im Lauf der Jahre. Wenn sich diese Erwartung bestätigt, kann nach den Gründen gefragt werden, die zu dieser Entwicklung führten.

Die Analyse der Testamente mit Sachguterwähnung beginnt mit der Frage, in welcher Weise die Testatoren die zu vererbenden Sachgüter erwähnen. Sprechen sie häufig pauschal von ihrer gesamten mobilen Habe oder überwiegt die deutliche Kennzeichnung einzelner Objekte? Gibt es erkennbare Gründe, die erklären, warum ein Testator eine zu vererbende Sachgutmenge nicht näher bezeichnet? Wann erscheint es dem Testator ratsam, die Realien einzeln zu vermerken?

Anschließend wird der Überlegung nachgegangen, in welchem Maß Objekte der Sachkultur als Legate ad pias causas, also für Seelgerätstiftungen, oder als Schenkungen für Familienmitglieder und/oder Freunde verwendet werden. Diese Einteilung ist ein Hilfskonstrukt für die Auswertung; das Verständnis des mittelalterlichen Testators kennt diese Zweiteilung nicht, für inn sind die Werke der Frömmigkeit nicht zu trennen von den Zuwendungen für arme Bekannte.

Von besonderer Bedeutung sind für die vorliegende Arbeit die einzeln bezeichneten Sachgüter wie Betten, Tische und Stühle mit ihrem textilen Zubehör, Schränke, Truhen, Tuche und Kleider, Hausgerätschaften für die Küche sowie Schmuckstücke und Bücher. Diese Sachgüter sind in dem bereits erwähnten, der Arbeit als Anhang beigefügten Schema aufgelistet. Neben den Angaben zu der Person und Familie des Testators sind hier unter dem Namen des Testators und neben der Datumsangabe des Testaments die Verfügungen über die testamentarisch erwähnten Sachgüter zusammengetragen. Die Sachgüter werden

\footnotetext{
${ }^{64}$ U. J. DIEDERICHS, Der Aufruhr von 1454 - 1456 in der Stadt Lüneburg. Eine prosopographische Untersuchung, Kiel 1981.

${ }^{65}$ P. BAUR, Testament und Bürgerschaft, S. 75.
} 
dabei in ihrem jeweiligen Vererbungskontext belassen. So bleibt ggf. im Einzelfall erkennbar, woher das jeweilige Objekt stammt, wie es aussieht, wo es sich im Wohnbereich des Testators befindet, an welche Person/Institution es unter Einbeziehung aller Vererbungseventualitäten fällt. In entsprechenden Kapiteln werden die Sachgüter einem Frageschema folgend behandelt, das komprimiert formuliert lautet: Welches Sachgut wird unter welchen Bezeichnungen, welcher Beschreibung und welcher Anzahl von welcher Person an welche Person/Institution vererbt?

Um sich ein Bild der jeweiligen Sachgüter machen zu können, wird - wenn möglich - in erster Linie auf die Lüneburger gegenständliche und bildliche Überlieferung Bezug genommen. Aufschlußreich sind hier die Lüneburger Quellen: Im Rahmen der Luxusgesetzgebung sind zwei Kleiderordnungen und eine Polizeiverordnung überliefert, die ungefähr um 1480 niedergeschrieben wurden, während die dritte überlieferte Kleiderordnung des 15. Jahrhunderts erst im 16. Jahrhundert niedergelegt wurde ${ }^{66}$. Überliefert sind die Bestimmungen über Heergewät und Frauengerade ${ }^{67}$. Bei Fragen in den Bereichen Kleidungswesen, Mobiliar und metallenes Hausgerät konnten die älteren Zunfturkunden Lüneburgs zu Rate gezogen werden ${ }^{68}$.

Neben Standardwerken über die verschiedenen Sachkultursparten wird die Literatur zu Rate gezogen, die Zugriff auf die Sachgüter des Lüneburgers Raums ermöglicht. Gut dokumentiert ist die gegenständliche Überlieferung in den Führern durch das Museum für das Fürstentum Lüneburg. Zu nennen ist hier als erstes das dreibändige Werk, welches ungefähr im ersten Drittel des 20. Jahrhunderts entstanden ist und sich als Führer durch unterschiedliche Abteilungen der Sammlungen des Museums versteht: F. KRÜGER legte den ersten Band über „Skulpturen und Formsteine“ vor, der für die vorliegende Auswertung nur ansatzweise von Bedeutung ist, den zweiten Band verfaßte W. REINECKE über die kirchliche Abteilung und sein Sohn H. REINECKE erläuterte die Holzarbeiten des Museums im dritten Band der Reihe ${ }^{69}$. G. KÖRNER gab in den 50ger Jahren einen „Leitfaden durch das Museum in Lüneburg“ heraus, in dem - nach Sachgruppen geordnet - die noch

\footnotetext{
${ }^{66}$ Fr. W. VOLGER, UB Lüneburg; Bd. III, Lüneburg 1877, 1478 (Hochzeitsordnung aus dem vierzehnten Jahrhundert), S. 420 - 427; 1479 ( Hochzeitsordnung Ende des vierzehnten Jahrhunderts), S. 427 - 430; 1480 (Polizeiverordnungen Ende des vierzehnten Jahrhunderts), S. 431 - 433; 1528 (Kleiderordnung vom Beginn des vierzehnten Jahrhunderts), S. 481f.

${ }^{67}$ Fr. W. VOLGER, UB Stadt Lüneburg, Bd. III, 1481, S. $435 f$.

${ }^{68}$ E. BODEMANN, Die älteren Zunfturkunden der Stadt Lüneburg (= Quellen und Darstellungen zur Geschichte Niedersachsens, Bd. 1), Hannover 1883.

${ }^{69}$ F. KRÜGER, Skulpturen und Formsteine (= Führer durch die Sammlungen des Museumsvereins für das Fürstentum Lüneburg, Bd. V, 1), Lüneburg 1908; W. REINECKE, Die kirchliche Abteilung (= Führer durch die Sammlungen des Museumsvereins für das Fürstentum Lüneburg, Bd. II ), Lüneburg 1911; H. REINECKE, Holz - Arbeiten (Bauschreiner - Möbel), (= Führer durch die Sammlungen des Museumsvereins für das Fürstentum Lüneburg, Bd. III, 2), Lüneburg 1937.
} 
vorhandenen Exponate beschrieben wurden $^{70} .1991$ erschien eine Neubearbeitung dieses Leitfadens von E. MICHAEL. 1991 wurde ein Lüneburger Museumsführer von der Reihe „museum" herausgegeben, in dem die Verfasser D. GEHRKE und E. MICHAEL die Exponate unter Stichwörtern wie „Patriziat“, „Goldschmiedearbeiten“ oder „Möbel“ zusammengefaßt in fortlaufendem, auch Hintergrundwissen präsentierendem Text vorstellten $^{71}$. Neben diesen die unterschiedlichen Sachgütergruppen präsentierenden Werken gibt es einige wenige Darstellungen, in denen Lüneburger Kulturgüter ausschließlich einer Art aufgelistet sind. Zu nennen sind hier H. SCHRÖDERs Abhandlung über Lüneburger Truhen, W. REINECKEs Untersuchung über das Lüneburger Zinn, H. APPUHNs Arbeiten über die Möbel auch des Spätmittelalters in den Lüneburg umgebenden Heideklöstern sowie über die mittelalterlichen Bildstickereien in Kloster Lüne und der in den 80gern erschienene Austellungsband S. BURSCHEs über das Lüneburger Ratssilber ${ }^{72}$. Gute Informationen für die Frage nach dem Fundort/Standort etlicher Sachgüter innerhalb des spätmittelalterlichen Hauses oder Haushalts vermag die Dissertation K. TERLAU FRIEMANNs über Lüneburger Patrizierarchitektur des 14. bis 16. Jahrhunderts zu liefern ${ }^{73}$. Als kritische Einführung zur Nutzung der Bildquellen der Goldenen Tafel und der Retabel Hans Bornemanns dienen die Aufsätze R. BLASCHKEs über die Meister der Flügelmalereien der Goldenen Tafel und S. KEMPERDICKs Überlegungen zum Werk Johannes Bornemanns ${ }^{74}$.

Die Lüneburger Quellen und die relevante Literatur über das spätmittelalterliche Lüneburg bieten ein gesichertes Forschungsfundament für die Untersuchung der materiellen Kulturgüter, wie sie dem heutigen Betrachter auf der Grundlage der Lüneburger Testamente begegnen. Von Vorteil ist es für die vorliegende Arbeit, daß sie Beziehungen herstellen kann zu den Testamentsauswertungen anderer Städte, Städten, die wie

\footnotetext{
${ }^{70}$ G. KÖRNER, Leitfaden durch das Museum in Lüneburg, 1975/3 Als vierte, veränderte und erweiterte Auflage des Leitfadens des inwischen verstorbenen Gerhard Körner erschien 1991 der Führer durch die Sammlungen, bearbeitet von E. MICHAEL.

${ }^{71}$ D. GEHRKE, E. MICHAEL, Museum für das Fürstentum Lüneburg ( = museum, Ausgabe 9/1991), Braunschweig 1991.

${ }^{72}$ H. SCHRÖDER, Gotische Truhen, in: Festblätter des Museumsvereins für das Fürstentum Lüneburg, Nr. 4, Lüneburg 1932; W. REINECKE, Lüneburger Zinn. Das Amt der Lüneburger Zinngießer, 1947; H. APPUHN, Möbel des hohen und späten Mittelalters in den ehemaligen Frauenklöstern um Lüneburg, in: Klösterliche Sachkultur des Spätmittelalters (= Österreichische Akademie der Wissenschaften, Philosophisch-Historische Klasse, Sitzungsberichte, Bd. 367, Veröffentlichungen des Instituts für mittelalterliche Realienkunde Österreichs, Nr. 3 ), Wien 1980, S. 343 - 352; H. APPUHN, Bildstickereien des Mittelalters in Kloster Lüne, Dortmund 1990/3; S. BURSCHE, Das Lüneburger Ratssilber (= Kunstgewerbemuseum Berlin, Bestandskatalog XVI), Berlin 1990.

${ }^{73}$ K. TERLAU - FRIEMANN, Lüneburger Patrizierarchitektur des 14. bis 16. Jahrhunderts. Ein Beitrag zur Bautradition einer städtischen Oberschicht, Lüneburg 1994.

${ }^{74}$ R. BLASCHKE, Die Meister der Flügelmalereien der Lüneburger Goldenen Tafel, In: Niederdeutsche Beiträge zur Kunstgeschichte, Band 17, 1978, S. 61 - 86; S. KEMPERDICK, Zum Werk des Johannes Bornemann. Überlegungen zu Chronologie und Vorbildern, in: Niederdeutsche Beiträge zur Kunstgeschichte, Bd. 33, 1994, S. 57 - 86.
} 
Hamburg, Lübeck, Stralsund und Reval im hansischen Bereich liegen, Städten wie Köln im rheinischen Gebiet und Konstanz im süddeutschen Raum, Städten der österreichischen und Schweizer Region. Der Vergleichbarkeit sind z.T. Grenzen gesetzt oder Hindernisse in den Weg gelegt, nämlich dann, wenn Sachgüter in gänzlich anderem Forschungskontext erwähnt werden, eine Realie z.B. aus dem Vererbungskontext herausgelöst erwähnt wird; auch eine vereinfachende Übersetzung kann eine genaue Identifizierung verhindern, wenn z.B. aus lantkiste, schyppkiste und votkiste in der Übersetzung jeweils eine Truhe würde ${ }^{75}$.

\section{Die Testatoren}

\section{Testierungsrate und soziale Stellung}

Aus der Zeit zwischen 1323 und 1500 sind in Lüneburg 293 Testamente überliefert. Daß es zu einer so hohen Anzahl an Testamenten im Lüneburg des Spätmittelalters kommt, liegt

\footnotetext{
${ }^{75}$ Schwerpunkt der Kölner Testamentsauswertungen KLOSTERBERGs ist z.B. das Aufzeigen der „persönlichen Bindungen und Verpflichtungen der Kölner Testatoren im späten Mittelalter“. Angesichts dieser Zielsetzung ist klar, daß für sie das Aussehen eines Bahrtuchs lediglich eine Fußnote sein kann. B. KLOSTERBERG, Zur Ehre Gottes, S. 19.;S. 66, Fußnote 301. Die Veröffentlichung der unter geneaologischer Fragestellung bearbeiteten Braunschweiger Testamente bietet Regesten, deren summarische Form und Übersetzung eine eingehendere Verwendung für andere wissenschaftliche Fragestellungen wie z.B. die vorliegende erschweren (Entsprechende Beispiele werden im auswertenden Teil gegeben). Auch die Abkehr von der chronologischen Folge und die Hinwendung zur alphabetischen Reihung erweisen sich als nicht förderlich. D. MACK, Testamente der Stadt Braunschweig. Teil I: Altstadt 1314 - 1411 Adenstede bis Holtnicker, Göttingen 1988 ( = Beiträge zu Genealogien Braunschweiger Familien. Forschungsberichte zur Personen - und Sozialgeschichte der Stadt Braunschweig 3/I ), Teil II: Altstadt 1314 - 1411 Dungelbeck bis Rike, Göttingen 1989 ( = Beiträge zu Genealogien Braunschweiger Familien. Forschungsberichte zur Personen - und Sozialgeschichte der Stadt Braunschweig 3/II ). Ähnliche Kritik übte bereits M. RIETHMÜLLER, to troste miner sele., S.9.
} 
neben dem Wohlstand der Stadt und ihrer Bürger sowie der Akzeptanz des Rechtsinstituts „Testament“ nicht zuletzt an der hohen Bevölkerungszahl der Stadt Lüneburg. Im nordöstlichen Teil des deutschsprachigen Raumes, in dem Lüneburg liegt, leben im Spätmittelalter 10-20\% der Bevölkerung in Städten, während im westlichen und oberdeutschen Raum 20 - 30 \% der Bevölkerung als stadtsässig gelten ${ }^{76}$. Diese Differenz der städtischen Bevölkerungsdichte darf jedoch nicht darüber hinwegtäuschen, daß der Städteraum Lüneburg - Hamburg - Lübeck der zentrale Wirtschaftsraum im Nordosten ist. Die drei Städte zählen zu dem kleinen Kreis spätmittelalterlicher Großstädte mit mehr als 10000 Bewohnern, deren Anteil am gesamten Städtewesen mit 0, 5\% bemessen wird ${ }^{77}$. Schätzungen gehen davon aus, daß im Lüneburg des 15. Jahrhunderts 14000 Menschen gelebt haben ${ }^{78}$. Die Bevölkerung setzt sich zusammen aus Bürgern, Einwohnern, Ausoder/und Pfahlbürgern, Klerikern, Juden und Gästen der Stadt ${ }^{79}$, wobei die Bürger wohl ungefähr ein Drittel der Stadtbevölkerung ausmachen. Das Recht, Testamente aufzusetzen, ist nicht mit dem Besitz des Bürgerrechts gekoppelt, so daß ein jeder in Lüneburg Weilende hier ein Testament errichten konnte ${ }^{80}$.

Das 14. Jahrhundert ist das Jahrhundert des Bevölkerungsrückganges, der veranlaßt wird durch klimatische Veränderungen, die dann folgenden Ernährungsengpässe und Hungersnöte und schließlich beschleunigt wird durch die Pestkatastrophen. Die erfolgte Bevölkerungsdezimierung ist auch in Lüneburg nachweisbar, ebenso wie die nach dem Erreichen des Tiefpunktes einsetzende, langsame Zunahme der städtischen Bevölkerung im 15. Jahrhundert ${ }^{81}$. Die Erwartung, daß sich diese Zunahme an Bewohnern der Stadt Lüneburg in der Zunahme der Testamentserrichtungen deutlich niederschlägt, bestätigt sich nicht. Das erste und das zweite Viertel des 15. Jahrhunderts bieten mit 4 bzw. 2,36 Ausfertigungen pro Jahr eine - bezogen auf das Jahrhundert - überdurchschnittliche Ausfertigungsrate an Testamenten, die aber im dritten Viertel auf 1,4 jährliche

\footnotetext{
${ }^{76}$ E. ISENMANN, Die deutsche Stadt im Spätmittelalter, Stuttgart 1988, S. 19.

${ }^{77}$ E. ISENMANN, Die deutsche Stadt im Spätmittelalter, S. 31, Tab. I, entwickelt nach den Angaben H. AMMANNs, Wie groß war die mittelalterliche Stadt, in: C. HAASE (Hg.), Die Stadt des Mittelalters, Bd. 1, S. $415-422$

${ }^{78}$ Th. PENNERS gibt für das 15. Jahrhundert 10000 bis 14000 Bewohner an. TH. PENNERS, Der Umfang der altdeutschen Nachwanderung des 14. Jahrhunderts in die Städte des Ostseegebiets, in: Lüneburger Blätter, Heft 2, 1951, S. 56, Fußnote 45; E. ISENMANN gibt für das Jahr 1493 eine Bevölkerungsgröße von 18500 für Lüneburg an. E. ISENMANN, Die deutsche Stadt im Spätmittelalter, S. 31, Fußnote 12 Nach der Einschätzung Frau Dr. Reinhardts ist dem Wert von ca. 14000 Bewohnern der Vorzug zu geben. ${ }^{79}$ Erläuterung der Termini bei E. ISENMANN, Die europäische Stadt im Spätmittelalter, S. 93-102.

${ }^{80}$ Überliefert sind fünf Testamente auswärtiger Personen: 1332 Dez. 10 Dedeko Widenvelt, Ratsherr zu Braunschweig; Kleriker Thideke Buhof aus Stockholm errichtet sein Testament um 1340; 1421 Juli 25 Tyle Schutte, Bürger zu Nordhausen; 1472 Aug. 27 Testament des Hamburger Bürgers Hans Jagow; 1420 Nov. 14, Nov. 29 Hermann Zierenberg, (verbannter) Bürger zu Lübeck. Alle anderen Testamente werden von Personen weltlichen und geistlichen Standes errichtet, die ausschließlich oder vorwiegend in Lüneburg leben.

${ }^{81}$ Th. SCHULER, Lüneburger Bürger (1426-1700), in: Kat. „Stadt im Wandel“, Bd. 1, S.145, Nr. 87 zugehörige Tabelle S.1330.
} 
Testamentsausstellungen zurückfällt, und im letzten Viertel des Jahrhunderts ohne wesentliche Veränderung bei 1,72 Testamenten pro Jahr liegt. Als möglicher Grund für den Rückgang an Testamenten muß die Pest um das Jahr 1451 in Betracht gezogen werden. Im Bereich des Denkbaren ist ein Akzeptanzverlust, den die Institution „Rat“ im Rahmen der Wirren des Prälatenkrieges in den 50ger und 60ger Jahren des 15. Jahrhunderts erlitten haben könnte, als alte und neue Ratsherren sich bekämpften ${ }^{82}$.

Ob der Rückgang an Testamentsausfertigungen in der zweiten Hälfte des 15. Jahrhunderts ein regionales Problem oder eine im Hanseraum greifende Erscheinung war, das sollte die Forschung auf der Suche nach weiteren, vielleicht prägenderen Gründen im Auge behalten $^{83}$.

Von den 287 Testatoren sind 249 Personen hinsichtlich ihrer Zugehörigkeit zur Bürgerschaft, zum Rat, zum Kreis der Sülfmeister, hinsichtlich ihres Berufs, ihrer Zugehörigkeit zum geistlichen Stand und ihres Witwentums bestimmbar. Wenn diese Kriterien sich auch in ihrer Aussagefähigkeit unterscheiden, so bleibt doch festzuhalten, daß sich mit ihrer Hilfe persönliche Anhaltspunkte für 86,7 \% der Testatoren ergeben.

Von den 287 Testatoren sind 26 geistliche Personen; das entspricht einem Anteil von 9,05\%. 130 Testatoren, also ca. 45,29\%, geben sich im Testamentsformular als Bürger zu erkennen. Da im Lüneburger Testamentsformular die rechtliche Stellung, die ein Testator innerhalb der Stadt hatte, nicht genannt werden mußte - auch der Familienstand oder die bekleidete Position in der Stadtverwaltung oder der Saline wurde wohl nur auf Betreiben des Testators vermerkt -, liegt auf der Hand, daß auch Testatoren, die im Testament nicht eigens auf ihr Bürgerrecht hinwiesen, durchaus mit dem Bürgerrecht ausgestattet sein konnten. Als Ratsherr oder Bürgermeister bezeichnen sich 8,01\% der Testatoren und 11 Testatoren (3,83\%) nennen sich Sülfmeister, also Pächter der Siedepfannen. Da in Lüneburg die Ratsherren ausschließlich von den Sülfmeisterfamilien gestellt wurden, ist es evident, daß diese Testatoren Mitglieder der politischen und ökonomischen Elite sind. So sind z.B. zwei Testamente von Sodmeistern erhalten, die auch einen Ratssitz innehatten, und vier Testamente von Barmeistern mit Ratsmitgliedschaft ${ }^{84}$. Diesem Kreis der

\footnotetext{
${ }^{82}$ In der „heißen Phase“ 1454-1456 verlief die Lüneburger Stadtverwaltung nicht reibungslos; z. B. ist in beiden Jahren in der Liste der Kämmerer aufgrund des Aufruhrs kein Name verzeichnet. A. RANFT, Der Basishaushalt der Stadt Lüneburg in der Mitte des 15. Jahrhunderts - Zur Struktur der städtischen Finanzen im Spätmittelalter (=Veröffentlichungen des Max-Planck-Instituts für Geschichte 84), Göttingen 1987, S.285.

${ }^{83}$ Einen vergleichbaren Verlauf der Testamentsausfertigungen bietet Stralsund, während in Konstanz und Köln in der zweiten Hälfte des 15. Jahrhunderts die Testamentsausfertigungen zunehmen. J. SCHILDHAUER, Hansestädtischer Alltag, S.13; P. BAUR, Testament und Bürgerschaft, S.50f; B. KLOSTERBERG, Zur Ehre Gottes, S.27.

${ }^{84} 1409$ März 7 Johann Semmelbecker, Ratsherr und Sodmeister; 1451 Sept. 26 Heinrich Hoyer, Ratsherr und Barmeister; 1464 Juli 28 Johann vame Lo; Ratsherr und Sodmeister; 1473 Sept. 29 Johann vame Lo d.
} 
ratsfähigen Sülfmeisterelite gehören auch die 14 testierenden Ratsherren- und Sülfmeisterwitwen an.

Frauen sind in Lüneburg relativ oft als Testatorinnen in Erscheinung getreten; die 61 Testatorinnen stellen einen Anteil von $21,25 \%{ }^{85}$. Dieser Prozentsatz zeigt, daß in Lüneburg vergleichbar viele Frauen testieren wie in Hamburg oder Lübeck, wobei sich die vergleichbaren Untersuchungsergebnisse auf das 14. Jahrhundert beschränken ${ }^{86}$. Weit mehr als die Hälfte der Lüneburger Testatorinnen vermerkt im Testament ihr Witwentum, und auch dies haben sie mit den Testatorinnen der genannten Hansestädte gemeinsam. Viele weisen darauf hin, die Witwe eines Bürgers zu sein, und einige erwähnen die Ratsmitgliedschaft ihres verstorbenen Mannes. Diese „Witwenformel“ könnte der Hinweis auf das Bürgerrecht sein, das nach dem Tod des Ehemannes vollgültig auf die verwitwete Ehefrau übertragen wurde- ${ }^{87}$. Geseke Rosemberg und Greteke Melbeck (1472 Aug. 4 und 1474 Sept. 10) sind die einzigen Testatorinnen, die sich direkt als Bürgerin bezeichnen. Da Geseke Rosemberg in ihrem Testament weder Ehemann noch Kinder bedenkt, muß offen bleiben, ob sie Inhaberin eines eigenen und nicht über den Ehemann definierten Bürgerrechts war oder als verwitwete Frau das nun auf sie übertragene Bürgerrecht herausstellen wollte.

Als Einwohner bezeichnen sich zwei Testatorinnen und ein Testator ${ }^{88}$.

Von 23 Testatoren $(8,01 \%)$ läßt sich der Berufsstand bestimmen. Testatorinnen geben im Regelfall den Beruf des Mannes $a^{89}$. Die größte Gruppe der durch ihren Beruf gekennzeichneten Testatoren gehört mit elf Personen dem Handwerk $a n^{90}$. Sechs Testatoren stehen in den Diensten des Rates oder zumindest in Beziehung zu einem Ratsbediensteten $^{91}$. Drei Testatoren arbeiten als Mühlenknechte ${ }^{92}$; Testamente des

\footnotetext{
Jüngere, Ratsherr und Barmeister; 1482 Juni 30 Heinrich Erpensen, Ratsherr und Barmeister; 1482 Nov. 18 Dietrich Döring, Ratsherr und Barmeister.

${ }^{85}$ Mitgezählt sind die in Gemeinschaftstestamenten verfügenden Frauen.

${ }^{86}$ H.-D. LOOSE, Erwerbstätigkeit der Frau im Spiegel Lübecker und Hamburger Testamente des 14.

Jahrhunderts, in: Zeitschrift des Vereins für Lübeckische Geschichte und Altertumskunde, 60/1980, S.11; A. v. BRANDT, Mittelalterliche Bürgertestamente, S.10.

${ }^{87}$ E. ISENMANN, Die europäische Stadt im Spätmittelalter, S.94.

${ }^{88} 1433$ Juli 9 Grete Kortüm - sie bezeichnet sich als Tochter eines Bürgers und Einwohnerin; 1452 März 22 Geseke Zimmermann; 1480 Aug. 13 Lutke Hilmers.

${ }^{89}$ Einzige Ausnahme ist Tibbeke von Netze (Testament 1406 Sept. 23); sie bezeichnet sich als Vorsteherin des ewigen Lichts am Marienaltar in St. Johannis.

${ }^{90} 1412$ März 27 Alheit, Witwe eines Malers; 1412 Juni 29 Hans Trebbow, Kannengießer; 1419 Juni 11 Wibke Saffan, wahrscheinlich die Mutter eines Bäckers; 1420 Dez. 32 Aldich von Schneverding, Schmied; 1425 Okt. 1 Dietrich Rosenhop, Glaser; 1432 Jan. 17 Johann Molne, Bäcker; 1473 Juli 23 Metteke von Dassel, Witwe eines Gewandschneiders und Sülfmeisters; 1474 Sept. 10 Greteke Melbeck, Brauerswitwe; 1475 April 16 Hans Konvelitz, Schneider; 1475 Juni 3 Jacob Döring, Barbier; 1491 Aug. 13 Gerd Lowe, Goldschmied.

${ }^{91} 1409$ Juli 10 Ludeke Burmester, Sohn eines Ratsbediensteten; 1419 April 3 Borchard Trumper, Ratsdiener; 1430 Feb. 24 Hans Junge, Ratsbediensteter, Spielmann; 1441 April 22 Meister Heinrich, Werkmeister des Rates; 1458 April 6 Adelheid Kale, Witwe des Ratszimmermeisters; 1481 April 19 Bethmann von Drubke, Ratsdiener. Allein die Ratsherren arbeiteten ehrenamtlich. Lohnempfänger waren der Stadtschreiber, der
} 
häuslichen Dienstpersonals sind in Lüneburg nicht überliefert. Unter den Testatoren befinden sich ein Apotheker und ein $\mathrm{Arzt}^{93}$.

Festzuhalten bleibt als Ergebnis folgendes: Die Mehrzahl der Testatoren ist im Besitz eines eigenen oder durch den Tod des Ehemannes übertragenen Bürgerrechts. Einigen wenigen Testatoren aus der Unterschicht/unteren Mittelschicht steht eine Vielzahl von Testatoren gegenüber, die Angehörige der ratsfähigen Sülfmeisterfamilien, der wirtschaftlichen, politischen und gesellschaftlichen Elite Lüneburgs, sind. Kein Zufall ist es, daß gerade diese Familien über die zwei Jahrhunderte des 14. und 15. Jahrhunderts immer wieder Testatoren hervorbringen und sich zahlreiche Verwandtschaftsverhältnisse zwischen den Testatoren nachweisen lassen ${ }^{94}$. Die Testierungskontinuität der führenden Familien über die Jahrhunderte hinweg ist Zeugnis „eines im Spätmittelalter außergewöhnlich festen inneren Zusammenhalts der politischen Elite und einer ... von Stadtunruhen weitgehend verschont gebliebenen Entwicklung der innerstädtischen Politik“"95, deren integratives Element die Saline ist. Selbst der „Prälatenkrieg“ (1454-1456/62), der wegen eines Streits mit den vorwiegend geistlichen Anteilseignern der Saline ausgebrochen war, führt an seinem Ende zur Wiederherstellung der alten Verhältnisse, wenn auch einigen zwar vermögenden, bislang aber nicht einflußreichen Personen der Aufstieg in die politische Elite gelingt ${ }^{96}$.

\section{Die Häufigkeit der Sachguterwähnung}

Nicht alle Testatoren haben Verfügungen über Sachgüter in ihr Testament aufgenommen.

Baumeister, Ratszimmermann, Wächter, Torhüter, Schützen und der Stadthauptmann. Sie bekamen wohl Stoff für die Kleidung, Stiefel sowie besondere Gaben. W. REINECKE, Geschichte der Stadt Lüneburg, Bd.I, S.183. ${ }^{92} 1434$ April 12 Hans Stute; 1475 Aug. 17 Albert Schulte; 1475 Nov. 17 Hans Gansebom.

${ }^{93} 1474$ Sept. 22 Matthias von der Most, Apotheker; 1482 Mai 7 Helmold von Lyderen.

${ }^{94}$ um 1348 Nikolaus Alardi (Vater) und 1472 Okt.31 Luder Brömse (Sohn); 1378 Sept. 7 Ludeke Stöterogge (Ehemann) und 1385 Juli 11 Elisabeth Stöterogge ( 2. Ehefrau Stöterogges); 1403 März 26 Dietrich Burmester (Schwager) und 1419 März 17 Immeke Burmester (Schwägerin) - weitläufig mit ihnen verwandt: Ludeke Burmester 1409 Juli 10; 1398 Nov.11 Johann Pattensen und 1411 Juni 6 Alard von Pattensen (Brüder?); 1410 Juli 14 Ludeke von Hagen (Vater) und 1439 Sept. 25 Heinrich Hagen (Sohn); 1419 Juni 11 Wibke Saffan (Großmutter/Mutter?) und 1437 Juli 11 Hans Saffan (Sohn/Enkel?); 1421 Okt. 13 Albert Koch und 1422 Jan.22 Berta Koch (Ehepaar); 1425 Juli 23 Albert von der Mölen und 1431 Juni 15 Margareta von der Mölen (Ehepaar); 1439 Sept. 24 Christian von Bergen (angeheirateter Onkel) und 1441 Nov. 20 Hermann Kruse ( Ehemann der Nichte); 1440 April 25 Gese von Gandersen (Schwiegermutter) und 1474 Sept. 22 Matthias von der Most (Schwiegersohn); 1447 Dez. 14 Hans Kruse (Vater) und 1473 Juli 23 Metteke von Dassel; 1451 März 12 Beke Groning (Tante/Großtante) und 1464 Juli 28 Johann van dem Lo (Neffe/Vater) sowie 1473 Sept. 29 Johann van dem Lo (Großneffe/Sohn); 1451 Juli 1 Metteke Schermbeck (Tante?) und 1460 Mai 30 Hilleke von Erpensen (Nichte?); 1491 Juni 25 Matheus Tetendorp (Vater) und 1493 Okt. 26 Hans Tetendorp (Sohn).

${ }^{95}$ O. MÖRKE, Der gewollte Weg in Richtung <Untertan>. Ökonomische und politische Eliten in Braunschweig, Lüneburg und Göttingen vom 15. bis ins 17. Jahrhundert, in: Bürgerliche Eliten in den Niederlanden und in Nordwestdeutschland, hg. v. H. SCHILLING und H. DIEDERICHS, Köln/Wien 1985, S.119.

${ }^{96}$ W. REINECKE, Geschichte der Stadt Lüneburg, Bd.I, S.203-242; U.J. DIEDERICHS, Aufruhr, passim. 
Über das Verhältnis von Testatoren mit Sachgutverfügungen und ohne Sachgutverfügungen soll die folgende Tabelle Auskunft geben:

Tabelle: Die Häufigkeit der Sachguterwähnung in Lüneburger Testamenten

\begin{tabular}{|l|c|l|c|}
\hline Jahreszahlen & $\begin{array}{l}\text { Testatoren, die über } \\
\text { Sachgut verfügen }\end{array}$ & $\begin{array}{l}\text { Testatoren, die über } \\
\text { kein Sachgut } \\
\text { verfügen }\end{array}$ & $\begin{array}{l}\text { Anzahl der } \\
\text { Testatoren } \\
\text { insgesamt }\end{array}$ \\
\hline $1300-1325$ & - & 1 & 1 \\
\hline $1326-1350$ & $5(50 \%)$ & $5(50 \%)$ & 10 \\
\hline $1351-1375$ & $15(62,5 \%)$ & $9(37,5 \%)$ & 24 \\
\hline $1376-1400$ & $14(73,7 \%)$ & $5(26,3 \%)$ & 19 \\
\hline $1401-1425$ & $88(90,7 \%)$ & $9(9,3 \%)$ & 97 \\
\hline $1426-1450$ & $56(94,9 \%)$ & $3(5,1 \%)$ & 59 \\
\hline $1451-1475$ & $28(82,4 \%)$ & $6(17,6 \%)$ & 34 \\
\hline $1476-1500$ & $40(93,0 \%)$ & $3(7 \%)$ & 43 \\
\hline
\end{tabular}

Die Tabelle zeigt deutlich, daß Sachgüter in den Lüneburger Testamenten stets eine wichtige Rolle einnehmen. Im gesamten Untersuchungszeitraum nehmen nur 41 Testatoren keine Sachgüter in ihr Testament auf, während 246 Testatoren Sachgüter testamentarisch erwähnen (85,71\%). Haben im 14. Jahrhundert 34 Testatoren über Sachgutwerte testamentarisch verfügt, so sind es im 15 Jahrhundert bereits 212 Testatoren. Das 14. Jahrhundert erweist sich als ein Jahrhundert, in dem Sachgüter in den Testamenten zunehmend eine Rolle zu spielen beginnen. Die Prozentsätze zeigen, daß die Anzahl an Testatoren stetig zurückgeht, die in ihren Testamenten keine Sachgüter verzeichnen.

Testamente ohne Verfügungen über Sachgüter werden bestimmt von Klauseln über Hausbesitz, Grundrenten, Sülzgutrenten und Legaten ad pias causas. Daß gerade im 14. Jahrhundert derartige Testamente weitaus häufiger ausgefertigt werden als im 15 . Jahrhundert hat verschiedene, zum Großteil kaum verfolgbare Gründe. Eine mögliche, vor allem für den wohlhabenden Testator zutreffende Erklärung liegt in der besonderen Wirtschaftssituation Lüneburgs begründet:

Als Geldanlage bietet sich in Lüneburg mit dem dominierenden, weitgehend krisenunabhängigen Wirtschaftsfaktor der Saline der Sülzrentenmarkt, der sich für Kapitalanleger aufgrund der gegenüber dem Grundrentenmarkt höheren und sicheren Renditen als äußerst attraktiv erweist. Bedingt durch die Struktur der Saline ist der Umfang an auszugebenden Renten vorgegeben. Die im Vergleich zum 14. Jahrhundert geringere 
Kauftätigkeit des 15. Jahrhunderts kündet von der weitgehenden Aufteilung der Sülzgutrenten, die von ihren Käufern in der Regel nicht wieder veräußert werden. Das 15. Jahrhundert bietet also dem reichen und reich gewordenen Lüneburger nur in geringem Umfang die bislang attraktivste Geldanlagemöglichkeit. Für den zunehmenden Ankauf von Sachgütern spricht zum einen die Suche nach neuen Geldanlagemöglichkeiten, zum anderen die Tatsache, daß es jetzt erst einen ansprechenden Markt an Sachgütern gibt. Im 14. Jahrhundert gab es ein derartiges Angebot an Sachgüter nicht, denn erst in der zweiten Hälfte des 14. Jahrhunderts kann man wieder von einem dem Leben der Antike vergleichbaren Lebensstandard ausgehen ${ }^{97}$. Bestimmt wird dieser Lebensstandard von Gegenständen für Haus, Hausrat und Kleidung, die aus z.T. wertvollen Materialien von gut ausgebildeten Handwerkern mittels z.T. neuartiger, z.T. wiederentdeckter Techniken hergestellt wurden. Jetzt erst stellt der Markt materielle Kulturgüter zur Verfügung, deren Wert eine testamentarische Vererbung nahelegt.

3. Die Art und Weise der Sachguterwähnung

Wenn Testatoren über Sachgüter verfügen, so tun sie dies in unterschiedlichen Nuancen.

Es kann unterschieden werden zwischen pauschal getroffenen Verfügungen über Sachgüter, in denen es z.B. „alle mobilen Güter“ heißt, und den Verfügungen, die die Sachgutart und teilweise auch die Qualität und Quantität erkennen lassen.

Tabelle: Art und Weise der testamentarischen Sachguterwähnung

\begin{tabular}{|l|l|l|l|c|}
\hline Jahreszahlen & $\begin{array}{l}\text { Sachgut } \\
\text { pauschal } \\
\text { erwähnt }\end{array}$ & $\begin{array}{l}\text { Sachgut } \\
\text { begrifflich und } \\
\text { quantitativ } \\
\text { bestimmt }\end{array}$ & $\begin{array}{l}\text { beiderlei Arten } \\
\text { der Sachgut- } \\
\text { erwähnung }\end{array}$ & $\begin{array}{l}\text { Anzahl der } \\
\text { Testatoren }\end{array}$ \\
\hline $1300-1325$ & - & - & - & - \\
\hline $1326-1350$ & $3(60,0 \%)$ & $2(40,0 \%)$ & - & 15 \\
\hline $1351-1375$ & $8(53,3 \%)$ & $6(40,0 \%)$ & $1(6,6 \%)$ & 14 \\
\hline $1376-1400$ & $7(50,0 \%)$ & $4(28,5 \%)$ & $3(21,4 \%)$ & 88 \\
\hline $1401-1425$ & $44(50,0 \%)$ & $25(28,4 \%)$ & $19(21,5 \%)$ & 56 \\
\hline $1426-1450$ & $17(30,3 \%)$ & $29(51,7 \%)$ & $10(17,8 \%)$ & \\
\hline
\end{tabular}

${ }^{97}$ M. HASSE, Neues Hausgerät, neue Häuser, neue Kleider, S.59. 


\begin{tabular}{|l|r|r|l|l|}
\hline $1451-1475$ & $6(21,4 \%)$ & $16(57,1 \%)$ & $6(21,4 \%)$ & 28 \\
\hline $1476-1500$ & $19(47,5 \%)$ & $15(37,5 \%)$ & $6(15,0 \%)$ & 40 \\
\hline
\end{tabular}

Eine stets wichtige Rolle spielen die Verfügungen, in denen Sachgüter in recht allgemeiner Form beschrieben werden. Mit Ausnahme der Zeit von ca. 1426 bis 1475 nimmt gut die Hälfte der Testatoren Sachgüter ausschließlich oder partiell auf diese Weise in ihr Testament auf. Die von den Testatoren kenntlich gemachten Gründe sind unterschiedlicher Natur:

1.) Um die Vererbung eines - nicht bestimmbaren - Anteils (wertvoller) Sachgüter handelt es sich, wenn Testatoren pauschal über ihr selbsterworbenes Gut verfügen ${ }^{98}$. Die von den Testatoren oft ausgesprochene Einsetzung der Frau als Gesamterbin erfolgt in der Regel unter dem Zusatz, dies Erbgut sei das von beiden Ehepartnern selbst erarbeitete Gut. Die Gemeinschaftsarbeit der Eheleute ist auch in Hamburger und Lübecker Testamenten oft erwähnt ${ }^{99}$. Daß der Erwerb dieses Besitzes mitunter recht mühevoll war, zeigt sich in dem Topos von der suren arbeyde, der in die Schriftsprache der Testatoren eingeflossen war. Hatte sich ein Familienmitglied dieser harten Arbeit verweigert, konnte der Testator dieses Verhalten im Nachhinein durch knappe Erbgutszuteilung vergelten oder bestrafen ${ }^{100}$; derartige Unmutsäußerungen enthalten Testamente anderer Städte ebenfalls ${ }^{101}$. Nicht zuletzt verbirgt sich hinter der Beteuerung des Eigenerwerbs der Güter die Bestätigung, daß die testamentarisch vererbten Besitztümer keine Familienerbgüter sind, deren Erbfolge ja gesetzlich geregelt war.

2.) Über eine gesetzlich definierte und damit in klaren Konturen erkennbare Summe an Sachgütern verfügen Testatoren bei der Vergabe von „Heergewät“ und „Frauengerade“. Beide Begriffe bezeichnen je eine Menge von Sachgütern, die als private Grundausstattung eines Mannes oder einer Frau gelten. Die Frauengerade umfaßt Kleider, Schmuck und Gefäße, das Heergewät die Kampfausrüstung, Kleider und Gefäße. Diesen „Basishaushalt“ rechtlich zu definieren, inn zu schützen und der männlichen oder weiblichen Rechtsperson zuzuweisen, machten sich bereits die frühen Rechtskodifikationen zur Aufgabe ${ }^{102}$. Dieser

\footnotetext{
${ }^{98}$ vgl. Tabelle I im Anhang.

${ }^{99}$ H.-D. LOOSE, Erwerbstätigkeit, S. 12; K. ARNOLD, Frauen in den mittelalterlichen Hansestädten, S.23.

${ }^{100} 1480$ Aug. 13 Luteke Hilmers. In seinem Testament findet der Einwohner Lüneburgs seine dritte Tochter mit wesentlich weniger Gut ab als ihre beiden Schwestern. Beke - so ist ihr Name - habe sich nicht nur als faul, sondern als ungehorsame Tochter erwiesen.

${ }^{101}$ U. M. ZAHND, Spätmittelalterliche Bürgertestamente, S.75.

${ }^{102}$ Ssp. I, Art.24, in: MGH, Sachenspiegel Landrecht, hg. v. Eckhardt, Göttingen 1955, S.91.
} 
rechtlichen Absicherung folgten die Stadtrechte, so auch in Lüneburg ${ }^{103}$. In erbrechtlichem Sinn werden Heergewät und Frauengerade als Sondervermögen angesehen, das geschlechtsspezifisch an Mann oder Frau fällt und im Regelfall vom Vater an den Sohn, von der Mutter an die Tochter weitergegeben wird $^{104}$. Die Tatsache, daß trotz dieser Verfügungsbegrenzung Testatoren immer wieder Heergewät und Frauengerade in ihr Testament aufnehmen, liegt vor allem in den möglichen Problemen, wie sie in der beerbten Ehe auftreten können ${ }^{105}$. Normalerweise haben der überlebende Ehepartner und die Kinder das vorhandene Vermögen gemeinsam genutzt. Wollte nun der Witwer/die Witwe oder ein Kind (erneut) eine Ehe eingehen, konnte - um die Verhältnisse zu klären - eine Aufteilung des Vermögens erfolgen ${ }^{106}$. Etliche Testatoren ergreifen die Möglichkeit, in ihrem Testament eine (eventuelle) Abteilung rechtlich zu sichern. Sie sorgen in Erfüllung ihrer rechtlichen Pflicht, der Ehefrau die Frauengerade und die Aussteuer zurückzugeben, über ihren Tod hinaus für die Unterhaltssicherung ihrer Frau. In einigen wenigen Fällen geht es um die Besitzstandsicherung für ein ungeborenes Kind. Johann Hintbergens Söhne z.B. erhalten nach des Vaters Tod normalerweise sein Heergewät; der Testator ist sich aber beim Aufsetzen des Testaments (1406 Mai 26) nicht sicher, ob seine (zweite?) Ehefrau von inm ein Kind erwartet. Als sorgender Vater konstatiert er, daß seine Söhne aus erster Ehe nun hinsichtlich des Heergewäts mit leeren Händen ausgehen würden, und so hinterläßt er innen in diesem Fall eine andere Grundausstattung für das tägliche Leben. Die Testamente Hans Niterds (1414 Mai 6) und Vicke Bottermanns (1476 März 4) sichern den Mägden Grete bzw. Barbara eine großzügige Ausstattung mit Utensilien zu, weil beide Frauen ein Kind erwarten. Das generöse Versorgen von Mägden, die mit ihrem Arbeitgeber ein Verhältnis und deswegen auch oft ein Kind hatten, belegen Testamente anderer Städte ebenfalls $^{107}$.

Das Zahlenverhältnis von pauschaler Sachgutvergabung und den Verfügungen über einzeln aufgelistete Realien belegt die Zunahme von konkret in ihrer Art und Anzahl beschriebenen Sachgütern. Die Verfügungen deuten darauf hin, daß es sich bei den einzeln aufgelisteten Sachgütern vorrangig um Objekte handelt, die im Gegensatz zur

\footnotetext{
${ }^{103}$ Zunächst im Stadtrechtsprivileg von 1247, dann ein Ratsbeschluß von 1329 mit herzöglicher Bestätigung, und in ausführlicher Form in der Stadtrechtskodifikation von 1401. E. THURICH, Die Geschichte des Lüneburger Stadtrechts und seiner Verbreitung im Mittelalter, S. 17-59.

${ }^{104}$ Über die einzelnen Bestandteile der Frauengerade und des Heergewäts informieren die Kapitel über Kleidung, Mobiliar und Bücher. Hier kommen auch erbrechtliche Aspekt zur Sprache.

${ }^{105}$ Die unterschiedlichen Vererbungsmodi sind in den Statuten von den Erbschichtungen verankert. Vgl. W. Th. KRAUT, Das alte Stadtrecht von Lüneburg, S. 35ff.

${ }^{106}$ Der Testator Heinrich Uplegger benennt in seinem Testament die seiner Frau im Falle der Abteilung zustehenden Güter. Er geht von einer Vermögensteilung zwischen Mutter und Sohn aber erst in dem Moment aus, in dem es zu Zwistigkeiten zwischen Mutter und Sohn oder zwischen Mutter und Schwiegertochter kommt. Testament 1414 Juni 29.
} 
Frauengerade, dem Heergewät und dem ererbten Familiengut nicht der gesetzlichen Erbfolge unterlagen. Einige Testatoren lassen erkennen, daß sie sich bei der Wahl des Empfängers allein ihrer persönlichen Zuneigung folgend bewegt haben. Die Intensität der Beziehung zwischen Donator und Beschenktem beeinflußt in diesen Fällen maßgeblich den Wert der testamentarisch vergabten Realie.

\section{Die Empfänger der Sachgüter}

Als Empfängergruppen lassen sich zwei Gruppen unterscheiden: Die Empfänger der Seelgerätstiftungen und der Kreis der Privatpersonen, die mit dem Testator verwandt oder bekannt sind. Diese Zweiteilung in einen gemeinten Profan- und einen Sakralbereich ist bezogen auf die Vorstellung (spät-) mittelalterlicher Testatoren anachronistisch. Für den spätmittelalterlichen Testator ist es durchaus normal, sowohl „professionelle Beter“'108 als auch seine persönlichen Freunde mittels einer testamentarischen Schenkung zur Fürbitte $\mathrm{zu}$ bewegen. Die hier vorgenommene Einteilung dient allein der besseren Übersichtlichkeit $^{109}$, sie spiegelt keine mittelalterliche Vorstellungswelt wider.

Untersucht wird hier, ob ein Testator Sachgüter testamentarisch im Rahmen eines Legats ad pias causas ${ }^{110}$ oder als Zuwendung an Privatpersonen vererbt. Die nach dem „Ja-NeinPrinzip“ angelegte Tabelle trifft keine Aussagen über die jeweilige Häufigkeit der Verfügungen.

Der mit der Sparte „Sachgüter für Verwandte und Bekannte“ angesprochene Empfängerkreis besteht aus Personen, die nicht kirchliche Funktionsträger, sondern Familienmitglieder und persönliche Freunde oder Bekannte des Testators sind. Wenn die Zuwendungen an Töchter von Bekannten, Nichten und Enkelinnen auch den Charakter frommer Gaben haben, so werden sie hier als Zuwendung an Privatpersonen gewertet, weil der Testator eine inm bekannte Person als Erbnehmer einsetzt.

Tabelle: Empfänger von Sachgutlegaten

\footnotetext{
${ }^{107}$ U. M. ZAHND, Spätmittelalterliche Bürgertestamente, S.74; B. KLOSTERBERG, Zur Ehre Gottes, S.238.

${ }^{108}$ H. BOOCKMANN, Leben und Sterben, S.10.

${ }^{109}$ Auch bei der Auswertung Hamburger Testamente unter dem Aspekt der spätmittelalterlichen Frömmigkeit wurde diese Zweiteilung vorgenommen. M. RIETHMÜLLER, to troste miner sele, S.42ff.

${ }^{110}$ Legate ad pias causas sind Schenkungen von Vermögenswerten, die in frommer Absicht Kirchen, Klöstern und Stiftungen entweder zum Eigengebrauch oder zur Almosenvergabe gestiftet wurden. Die hinter dieser Praxis stehende - von Johannes Chrysostomos (407 gest.) formulierte - Grundidee ist die Einsetzung Christi als Miterben. Die mit sühnender und verdienender Funktion ausgezeichnete mildtätige Gabe werde dem Stifter im Jenseits vergolten.
} 


\begin{tabular}{|l|l|l|l|c|}
\hline Jahreszahlen & $\begin{array}{l}\text { Sachgüter für } \\
\text { Legate ad pias } \\
\text { causas }\end{array}$ & $\begin{array}{l}\text { Sachgüter für } \\
\text { Verwandte und } \\
\text { Bekannte }\end{array}$ & $\begin{array}{l}\text { beiderlei } \\
\text { Verfügungen } \\
\text { über } \\
\text { Sachgüter }\end{array}$ & $\begin{array}{l}\text { Testatoren } \\
\text { insgesamt }\end{array}$ \\
\hline $1300-1325$ & - & - & - & - \\
\hline $1326-1350$ & $1(20,0 \%)$ & $2(40,0 \%)$ & $2(40,0 \%)$ & 5 \\
\hline $1351-1375$ & $2(13,3 \%)$ & $9(60,0 \%)$ & $4(26,7 \%)$ & 15 \\
\hline $1376-1400$ & $3(21,4 \%)$ & $6(42,9 \%)$ & $5(35,7 \%)$ & 14 \\
\hline $1401-1425$ & $12(13,6 \%)$ & $61(69,3 \%)$ & $15(17,0 \%)$ & 88 \\
\hline $1426-1450$ & $5(8,9 \%)$ & $31(55,4 \%)$ & $20(35,7 \%)$ & 56 \\
\hline $1451-1475$ & $4(14,3 \%)$ & $11(39,3 \%)$ & $13(46,4 \%)$ & 28 \\
\hline $1476-1500$ & $11(27,5 \%)$ & $26(65,0 \%)$ & $3(7,5 \%)$ & 40 \\
\hline
\end{tabular}

Das Ergebnis zeigt, daß Sachgüter stets in stärkerem Maße an Privatpersonen vererbt werden. Seit 1375 sind es pro Zeitraum von 25 Jahren immer mehr als drei Viertel der Testatoren, die Realien an Freunde oder Verwandte vererben.

Die vorrangige Vergabe von Sachgütern an Familienmitglieder und bekannte Personen ist auch in den Testamenten des hansischen, des süddeutschen und des österreichischen Raums zu finden ${ }^{111}$.

Das bevorzugte Einsetzen von Verwandten und Bekannten als Empfänger der Sachgutlegate bedeutet, daß Sachgutlegate in den Stiftungen zum Heil der Seele eine untergeordnete Rolle einnehmen. In Lüneburg verfügt im Schnitt ca. ein Drittel der Testatoren über Sachgut, das als Legat ad pias causas vererbt wird. Die relativ geringe Rolle, die mobile Güter bei der Seelenheilstiftung spielen, liegt im Wesen der Stiftungen. Geht es um die Einrichtung einer Vikarie oder um Meßstiftungen wie Memorienfeiern und Anniversarien, birgt der von den Testatoren immer wieder hervorgehobene Ewigkeitscharakter der Legate ad pias causas Finanzierungsprobleme besonderer Art in sich. Zu überlegen gilt es, welches Finanzierungsmittel auf unabsehbare Zeit krisenfest und wertbeständig ist. Diese auf die Ewigkeit hin angelegten Stiftungen, die einen ständig fließenden Geldstrom benötigten, werden mit Sülzgut- und mit Hausrenten finanziert. Anders sieht es bei Stiftungen aus, die ausschließlich oder teilweise mit einer einmaligen Geldzahlung eingerichtet werden können; sie können mit dem Verkauf von Sachgut

${ }^{111}$ J. SCHILDHAUER, Hansestädtischer Alltag, S.25; M. RIETHMÜLLER, to troste miner sele, S.44; P. BAUR, Testament und Bürgerschaft, Kap. V. „Inhaltliche Analyse der Gemächte“, S.127-250; G. JARITZ, Religiöse Stiftungen als Indikator der Entwicklung materieller Kultur im Mittelalter, in: Materielle Kultur und religiöse Stiftung im Spätmittelalter (=Österreichische Akademie der Wissenschaften, Philosophisch- 
finanziert werden. Einen Verkauf ihres gestifteten Objekts ordnen jedoch die wenigsten Lüneburger Testatoren an. Das Gros will seine in der Regel wertvollen Edelmetallgeräte oder Textilien zum Schmuck der Kirche verwendet sehen. Derartige vorwiegend aus dem 15. Jahrhundert datierende Willensäußerungen der Lüneburger Donatoren lassen sich einordnen als letzte Phase einer Entwicklung, die wohl im 12. Jahrhundert mit Stiftungen zur Befriedigung der Grundbedürfnisse kirchlicher Einrichtungen ihren Beginn nahm ${ }^{112}$. Das 13. und 14. Jahrhundert zeichnet sich vor allem durch die Stiftung von mit Geld bezahlten Meßfeiern aus, während im 15. Jahrhundert vorrangig die "Gotteszierde“ vermehrt wurde ${ }^{113}$. Die entweder vorhandenen oder gekauften, möglicherweise auch eigens angefertigten Stiftungsobjekte sind - den Testamenten zufolge - nicht alltägliche Wertgüter, die von der bedachten Einrichtung oder Person verwendet und tradiert wurden ${ }^{114}$.

Historische Klasse, Bd. 554, Veröffentlichungen des Instituts für Mittelalterliche Realienkunde Österreichs, Nr. 12), Wien 1990, S.15.

${ }^{112}$ G. JARITZ, Religiöse Stiftungen als Indikator der Entwicklung materieller Kultur im Mittelalter, S.22.

${ }^{113}$ G. JARITZ, Religiöse Stiftungen als Indikator der Entwicklung materieller Kultur im Mittelalter, a.a.O.

${ }^{114} \mathrm{Da}$ Geistliche angesichts des Wertes und/oder der Schönheit eines gestifteten Geschenks „,schwach“ wurden, belegen die Testamente. Erläuterungen folgen bei der Auswertung des „Diebesgutes“. 



\section{Die Sachgüter}

\section{Bücher}

Etliche Testatoren haben die Kunst des Lesens beherrscht. Es kann nicht mit Sicherheit gesagt werden, wieviel Prozent der Stadtbevölkerung des Lesens mächtig waren, doch wird der Anteil lesefähiger Stadtbürger relativ hoch gewesen sein. In größeren Städten wie Augsburg, Nürnberg und Straßburg konnte um 1500 wohl jeder vierte oder dritte Stadtbürger lesen ${ }^{1}$. Das 14. und vor allem das 15. Jahrhundert bedeuten durch die Zunahme an Lese- und Schreibkundigen eine Veränderung in der Einstellung dem Buch gegenüber: Es wird nicht mehr vorwiegend als Wertgegenstand betrachtet, sondern wird zunehmend Gebrauchsgegenstand eines verbreiterten Benutzerkreises. So verwundert es nicht, daß in den Lüneburger Testamenten Bücher vererbt wurden.

Bücher stellten nach wie vor einen nicht unerheblichen Wert dar, wenngleich sie je nach Ausführung und Verkaufsort unterschiedlich wertvoll waren. Indiz für die Wertschätzung der Bücher war die Tatsache, daß sie als Pfand akzeptiert wurden: Zwei Testamente berichten von drei verpfändeten Büchern - einem für fünfzehn Mark verpfändeten Stundenbuch, einem für sechs Mark Denare verpfändeten Viaticum sowie Dekretalen, die zusammen mit silbernen und vergoldeten Wertgegenständen für zwanzig Mark Denare einstehen ${ }^{2}$. Ein weiterer Beweis für den Wert der Bücher ist der Entschluß Volrad Lassans, durch den Verkauf seiner besseren Bücher eine Rente von fünf oder sechs Mark zu kaufen (Testament 1401 Aug. 16).

Die im Rahmen eines Legats ad pias causas getroffenen Formulierungen, ein Buch solle z.B. ewig bei einer Vikarie bleiben oder dürfe nicht veräußert werden, zeugen von der Furcht vor Diebstahl. Von dieser Schattenseite kündet ein Eintrag aus dem 15. Jahrhundert in dem Winterteil eines Breviers ${ }^{3}$ : Der Propst des Klosters Lüne, Hinricus Bodenstede, stiftete das zweibändige Brevier 1433 für seine Vikarie in St. Johannis. Der nachfolgende Vikar war Kanoniker in Bardowick und nahm das Brevier mit. Hier in Bardowick wurde es gestohlen, konnte jedoch nach seinem Tod wiederbeschafft werden.

Die Zeit vor 1500 war die Zeit der Handschriften und Inkunabeln, also der um 1500 entstandenen Wiegendrucke ${ }^{4}$.

\footnotetext{
${ }^{1}$ T. CRAMER, Geschichte der deutschen Literatur im späten Mittelalter, S.240; H. BOOCKMANN, Die Stadt im späten Mittelalter, S.333.

${ }^{2} 1385$ Mai 18 Segeband von Thune, 1444 Nov. 27 Johannes Weidenknepel.

${ }^{3}$ M. STÄHLI, Handschriften der Ratsbücherei Lüneburg, Bd.III (=Die theologischen Handschriften. Quartreihe. Die juristischen Handschriften), Wiesbaden 1981, S.16, 29.

${ }^{4}$ Wiegendruck ist zunächst die Übersetzung des lateinischen Worts incunabula $=$ Windeln oder Wickelbänder, die zum Wickeln der Kinder dienten. In übertragenem Sinn meint es Kindheit, hier sozusagen die Kindheit der Drucke. GELDNER definiert Inkunabel als ,ein vor dem 1. Januar 1501 vollendetes, mit Metallettern
} 
Vervielfältigt wurden die handschriftlichen Texte in Schreiberwerkstätten, in denen Texte in großer Zahl in Hinblick auf einen möglichen Absatzmarkt oder als Auftragsarbeit in den klösterlichen Skriptorien abgeschrieben wurden. In der unmittelbaren Nähe der Stadt Lüneburg und in Lüneburg befanden sich solche Skriptorien in reicher Anzahl. Zu nennen sind die Heideklöster Lüne, Medingen, Ebstorf, Isenhagen, Walsrode und Wienhausen sowie in Lüneburg das Franziskanerkloster St. Marien ${ }^{5}$. Die Testamente selbst verweisen auf zwei Franziskaner, die sich als Schreiber des Marienklosters verdient gemacht haben. Johann von Minden, Provinzial der sächsischen Ordensprovinz und Magister regens der Erfurter Barfüßerschule, sicherte für seinen Heimatkonvent Lüneburg den Unterhalt einer Schultätigkeit, die vor allem in der regen Schreibtätigkeit der ersten Jahrzehnte des 15. Jahrhunderts ihren Ausdruck fand ${ }^{6}$. Johann (von) Hagen, der um 1448 in England studierte, trat als Schreiber hervor und hinterließ dem Lüneburger Konvent eine theologische Sammelhandschrift".

Zwei Testatoren weisen auf die Anfertigungsart ihrer Schriften hin: 1440 vermerkt der Vikar Eckhard Stein, er habe sein Meßbuch von seinem Geld schreiben lassen, und sieben Jahre später vererbt Hans Tespe ein Gebetbuch, das die Mutter einer Bekannten/Verwandten schreiben ließ. Daß auch Druckerzeugnisse den Testatoren nicht fremd gewesen sein dürften, dafür sprechen die in Lüneburg überlieferten Drucke aus der Zeit bis 1500, die aus Städten wie Rom, Mantua, Mailand, Venedig, Paris, Lyon, Löwen, Nymwegen, Antwerpen, Köln, Speyer, Augsburg, Nürnberg, Tübingen, Leipzig, Reutlingen, Rostock, Hamburg, Merseburg, Lübeck und Basel stammten ${ }^{8}$.

hergestelltes Druckwerk“ (S.1). Gleichzeitig betont er die Problematik dieser aufgrund des Zeitkriteriums zwar sehr praktischen Definition, die angesichts der Unmöglichkeit einer strikten Trennung von Inkunabel und Druck aber willkürlich ist. F. GELDNER, Inkunabelkunde, Wiesbaden 1978 ( = Elemente des Buch- und Bibliothekswesens, hg. v. F. DRESSLER und G. LIEBERS, Bd.5 ), S.1ff.

${ }^{5}$ Informationen über die Tätigkeit in den Skriptorien der Heideklöster bei B. UHDE-STAHL, Figürliche Buchmalereien in den spätmittelalterlichen Handschriften der Lüneburger Frauenklöster, in: Niederdeutsche Beiträge zur Kunstgeschichte, Bd.17/1978, S. 25-60. Über das Franziskanerkloster berichtet I. FISCHER, Die theologischen Handschriften (=Handschriften der Ratsbücherei Lüneburg. Bd.II), Wiesbaden 1972, S.VIIff. ${ }^{6}$ I. FISCHER, Die theologischen Handschriften (=Handschriften der Ratsbücherei Lüneburg, Bd.II), S.VIII. Aus dem Jahr 1464 April 11 stammt das Testament des Johannes von Minden, der sich zu erkennen gibt. Die Amtsdauer des Provinzials Johannes von Minden wird mit den Jahren 1396-1405 angegeben. Im Testament des Friedrich Hogeherte 1434 fungiert ein Johann von Minden - hier unter der Bezeichnung „Ratsschreiber“- als Testamentsvollstrecker. Im Lüneburger Testament eines Johann von Minden, Lübecker Domherr, einstiger Propst in St. Johannis und Stadtschreiber, aus dem Jahr 1464 geht es im wesentlichen um die Beglaubigung eines Rentenkaufs von 1452/54. Die große Zeitspanne, innerhalb derer sich der Name nachweisen läßt, kann Indiz für ein außergewöhnlich langes Leben, aber auch Indiz für die Existenz zweier Personen gleichen Namens sein.

${ }^{7}$ I. FISCHER, Die theologischen Handschriften, S.VIII; Katalogteil - Bildungswesen und Bibliotheken der Bettelorden, Exponat 21, in: 700 Jahre Paulinerkirche, hg. v. Elmar Mittler, Göttingen 1994, S.55.

Wahrscheinlich ist er jener Johann Hagen, der im Testament des Johannes Weidenknepel 1444 Nov. 27 mit einem Stundenbuch bedacht wird.

${ }^{8}$ W. REINECKE, Geschichte der Stadt Lüneburg, Bd.II, S.192. 
Die Testatoren erwähnen gelegentlich das äußere Erscheinungsbild, also den Einband des Buches. Neben der Nennung des Titels diente der optische Eindruck des Einbandes den Testamentsvollstreckern als Erkennungszeichen für ein bestimmtes Buch, das aus dem Buchbestand des Erblassers herauszunehmen war. Die Holzdeckel, zwischen denen die Blättersammlung eingebunden war, konnten teilweise oder ganz mit Pergament oder Leder überzogen sein. Hartwig Hannover vermerkt in seinem Testament 1484: Item diurnale unum legatum in asseribus choreo subductis lego domino lohanni Mynden, presbitero. ${ }^{9}$. Im frühen Mittelalter verwendete man als Überzug oft rotgefärbtes Schafsleder, seit dem 14. Jahrhundert dann glattes Kalbsleder und das durable Rindsleder. Aussagen über einen rotgefärbten Einband enthalten zwei Testamente: Die Heiligenpredigten des Heinrich Wangelo sind in rubeo comperculo eingebunden (Testament 1367), und 1474 beschreibt der Apotheker Mathias von der Most sein Exemplar des Alexanderromans als dat rode bock $^{10}$.

Bücher befanden sich überwiegend in Bibliotheken. Die Testatoren weisen z.T. auf die in Lüneburg liegenden Bibliotheken hin: Die Ratsbücherei, die 1401 zum ersten Mal erwähnt wird und 1488 in neue Räumlichkeiten innerhalb des Rathauses umzog, enthielt Geschichtswerke, theologische und medizinische Literatur und juristische Bücher. Eine weitere Bibliothek befand sich in der Johanniskirche. Von den Bibliotheken der Klöster ist die des Klosters Lüne und des Marienklosters belegt, aus der später unter Einbeziehung der Bibliothek der Johanniskirche die heute noch bestehende Ratsbibliothek hervorging. Auch die Prämonstratenser des Klosters Heiligenthal haben über eine Bibliothek verfügt, auf die das Testament des Heinrich Wangelo aus dem Jahr 1367 hinweist. Werden die Bücher einer Bibliothek vererbt, wie z.B. im Fall des Ludolf Mangard 1478 der Bibliothek von St. Johannis, dann sind die Testamentsvollstrecker für die Bewahrung des Buchbestandes zuständig.

Abgesehen von den Kloster- und Kirchenbibliotheken gab es Büchersammlungen in den Häusern der akademisch Gebildeten und denen der Wohlhabenden. Vorwiegend besaßen Geistliche private Bücher, während Laien in geringerem Maße Eigentümer von Büchern waren. Diese Verteilung widerspiegelt sich in den Testamenten: Sechzehn Testatoren bezeichnen sich entweder selbst als Kleriker oder lassen sich dem Klerikerstand eindeutig zuordnen, in zwei weiteren Fällen darf man eine derartige Zugehörigkeit annehmen. Acht Testatoren entstammen dem Laienstand: Vier Testatoren nennen sich entweder selbst Ratsherr oder tragen zumindest den Namen ratsfähiger Familien, Most ist Apotheker und

\footnotetext{
${ }^{9}$ U. REINHARDT, Testamente, Nr. 269, S.424.

${ }^{10}$ U. Reinhardt, Testamente, Nr. 27, S. 36; Nr. 244, S. 375.
} 
Lyderen Arzt. Die einzigen Bücher testamentarisch vererbenden Frauen sind die Begine Hilleke von Erpensen und die Witwe Geseke Rosemberg.

Es werden also in relativ wenigen Testamenten Verfügungen über Bücher niedergeschrieben. 26 von insgesamt 287 Testatoren verfügen über Buchbesitz (9,05\%). Wird über Buchbesitz verfügt, dann werden in zwei Dritteln der Testamente mindestens zwei, maximal ca. zwölf Bücher vergabt. Von wenigen Ausnahmen abgesehen sind die Bücher geistlichen Inhalts.

Problematisch ist die in etlichen Testamenten auftretende Klausel über das nicht näher spezifizierte restliche Gut, das pauschal an einen Erbnehmer vergabt wird, der, da er in der Regel Familienmitglied ist, offenbar genau weiß, welche Güter unter den Begriffen Mobilia und Immobilia subsumiert wurden. Daß der Begriff Mobilia auch Bücher umfaßt, darf man mit einiger Wahrscheinlichkeit annehmen; als Beispiel mag hier das Testament des Johannes von Lippinghausen aus dem Jahr 1424 dienen, in dem es heißt: Residuum vero omnium et singulorum derelictorum meorum tam in pecuniis et clenodiis quam in libris, vestibus et utensilibus remanens ... ${ }^{11}$. Eine zweite Schwierigkeit bereitet die Tatsache, daß sieben der sechsundzwanzig Testatoren teilweise oder ausschließlich summarisch über ihre Bücher verfügen. In einigen Testamenten wird diese Schwierigkeit erweitert durch das Problem, die Bücher nicht näher bestimmen zu können. Als Beispiel dafür mag das Testament des Arztes Helmold von Lyderen dienen, der seinen gesamten Buchbesitz mit der Formulierung erfaßt, er gebe alle seine Bücher der Universitätsbibliothek zu Rostock (1482 Mai 7); hier sind weder Angaben zur Quantität noch die Titelbestimmung möglich. Vier Testatoren sprechen von anzuschaffenden Büchern, verankern in ihrem Testament jedoch weder die Buchbestimmung noch die Angabe der Anzahl der zu kaufenden Bücher (1375 Johann von Bücken, 1409 Ludolf bi dem Sode, 1439 Christian von Bergen und 1473 Johann vame Lo). Zwar ist es möglich, wie z.B. im Fall des Christian von Bergen, Vikar in St. Johannis und St. Lamberti, zu vermuten, er stifte seinen beiden in den genannten Kirchen zu errichtenden Vikarien zwei Meßbücher; beweisbar ist diese Vermutung nicht. Aus dem Dargelegten ist der Schluß zu ziehen, daß eine summarische Zahlenangabe der testamentarisch erwähnten oder vergabten Bücher im Höchstfall eine Grobeinschätzung sein kann. Sinnvoll ist aus diesem Grund allein die Beschäftigung mit allen genauer bezeichneten Büchern.

\footnotetext{
${ }^{11}$ U. REINHARDT, Testamente, Nr. 150, S. 204.
} 
1414 stiftet Johannes von Lippinghausen ein Brevier mit der Formulierung unum librum breviarum pro horis dicendis ${ }^{12}$. Breviere sind Gebetsbücher des kirchlichen Stundengebets $^{13}$. Sie entstanden, weil das monastische Stundengebet immer umfangreicher wurde, Heiligenlegenden, Hymnen und Predigttexte von Kirchenvätern integriert wurden, so daß aus Gründen der Praktikabilität eine kürzere Sammlung der wesentlichen Texte, das Brevier, entstand. Es besteht in der Regel aus zwei Teilen, der „pars hiemalis“ und der „pars aestiva“. Zusätzlich wird es eingeteilt in die beiden Kalender des Kirchenjahres, die die hohen Feste wie Ostern und Weihnachten („de tempore“) von den Festen der Heiligen („de sanctis“) unterscheiden. Im Spätmittelalter wurden Breviere auch als Stundenbücher bezeichnet. Die Namensgleichheit birgt die Gefahr von Verwechslungen, denn vom Ansatz her sind die Breviere der Geistlichen nicht identisch mit den meist kleinformatigeren, kostbarer ausgeschmückten Stundenbüchern der Laien. Die neuere Forschung hält eine strikte Trennung zumindest im Spätmittelalter nicht mehr aufrecht $^{14}$. In den Lüneburger Testamenten wird das Brevier selten erwähnt. 1474 heißt es im Testament des Apothekers Matthias von der Most: Item dat groteste bock negest dem verdenbuke geve ik to Lubeke in Unser Leven Vrouwen kerken uppe de liberyen ${ }^{15}$. Das als Vergleichswerk herangezogene verdenbuke ist ein (zweibändiges) Brevier ${ }^{16}$. Wenn von der Most das von inm vergabte Buch mit einem Brevier, so bedeutet das, daß auch dieses Buch ein Brevier sein könnte.

Drei Kleriker vererben in ihren Testamenten je ein Viaticum, also ein Reisebrevier ${ }^{17}$. Zur Verrichtung ihrer täglichen Gebete waren Geistliche unterwegs auf ihr Brevier angewiesen. Segeband von Thune erwähnt in seinem Testament aus dem Jahr 1385 mehrere Aufenthaltsorte, zwischen denen er hätte pendeln können - Minden, Verden und Lüneburg $^{18}$. So ist es bezeichnend, daß auch Segeband von Thune unter den ein Reisebrevier besitzenden Testatoren ist. 1386 errichtete Dietrich von Lembeke, Vikar in St.

\footnotetext{
${ }^{12}$ U. REINHARDT, Testamente, Nr. 103, S. 142.

13“"Breviarium“, in: E. J. THIEL, Die liturgischen Bücher des Mittelalters. Ein kleines Lexikon zur Handschriftenkunde, In: Börsenblatt für den Deutschen Buchhandel, 23/1967, S.2380f.

${ }^{14}$ Beispiel für diese Zuordnung des Stundenbuchs zur laikalen Gebetsliteratur im Jenseitsglossar des Ausstellungskatalogs Himmel - Hölle - Fegefeuer unter dem Stichwort „Stundenbuch“. Eine modifiziertere Auffassung vertritt B. BRINKMANN im gleichen Band; er weißt zumindest in einer Fußnote auf den im Spätmittelalter möglichen Stundenbuchbesitz von Klerikern hin. B. BRINKMANN, Zur Rolle der Stundenbücher in der Jenseitsfürsorge, in: Kat. „Himmel - Hölle - Fegefeuer. Das Jenseits im Mittelalter“, hg. v. Peter Jelzer, Zürich 1994, S. 91ff; bes. S.100, Fußnote 24.

${ }^{15}$ U. REINHARDT, Testamente, Nr. 244, S. 375.

${ }^{16}$ SCHILLER- LÜBBEN, Mittelniederdeutsches Handwörterbuch; nach dem Tode des Verfassers vollendet von Christoph Walther, reprograph. Nachdruck, Darmstadt 1989, S. 475; F. KRÜGER, W. REINECKE, Kunstdenkmale der Stadt Lüneburg, S. 74.

${ }^{17}$ Das Glossarium Latino - Germanicum von L. DIEFENBACH übersetzt „,viaticum“ als „,Wandelbuch“, Frankfurt Main 1857, S.617. H.-D. LOOSE übersetzt „libri viatici“ als „,eigens für die Reise geschriebene handliche Bücher“, die Geistlichen gehörten. ders., Leben und Kultur,S.18.
} 
Johannis und letzter Pfarrer von St. Cyriacus, sein Testament, in dem er ein Reisebrevier seinem Neffen Johannis Lembeke vererbt. Der Priester Leo hinterläßt sein Reisebrevier 1339 einem gewissen Meyner, der zudem ein Superpellicum erhält, ein von Klerikern getragenes Kleidungsstück, so daß man in dem Bedachten mit einiger Wahrscheinlichkeit einen Kleriker vermuten kann. Anhaltspunkte über das mögliche Aussehen der Reisebreviere können den Bildquellen entnommen werden: Sie zeigen als Utensil Reisender die sogenannten Beutelbücher ${ }^{19}$. Ihren Namen verdanken die Beutelbücher ihrem äußeren Erscheinungsbild: Über den Ledereinband legte man einen zweiten Bezug, der über die Buchkante hinausragte. Auf diese Weise konnte das Buch an diesem überstehenden Bezugstück getragen oder am Gürtel befestigt werden. Auch Buchtaschen, in die die Bücher hineingeschoben wurden, erlaubten dieses Befestigungsprinzip.

Ein Diurnale vergaben 1444 Johann Weidenknepel und Hartwig Hannover. Das aus Zisterzienserkreisen stammende Diurnale ist ein „partielles Brevier“, das das gesamte Kirchenjahr in einem Buch vereinigt ${ }^{20}$. Die Einteilung des Diurnale entspricht der des Breviers; aufgeführt sind die Horae, es gibt die Einteilung in einen Sommer- und Winterteil sowie die Unterscheidung nach Hoch- und Heiligenfesten (,proprium de tempore et de sanctis“).

Die Lüneburger Testatoren verfügen vorrangig über Stundenbücher. Das Stundenbuch, ein privates Andachtsbuch, ist eine besondere Form des Gebetbuchs, das seinen Namen der sich nach der altrömischen Tageseinteilung ausrichtenden Gebetsordnung der Klöster verdankt. Das Verlangen der Laien, über ein ähnliches Gebetskompendium zu verfügen, führte zur Entstehung des Stundenbuchs, das sich somit an das monastische Stundengebet anlehnt, aber ein geringeres Pensum enthält.

In sieben Testamenten werden mindestens acht Stundenbücher vererbt. Verfügt der Testator über ein Stundenbuch, heißt das nicht zwangsweise, daß der jeweilige Erblasser auch nur ein Stundenbuch besessen habe, wie das Testament des Dietrich Junge aus dem Jahr 1476 zeigt: Der Vikar an St. Johannis verfügt über librum suum horarum canonicarum maximum $^{21}$. Die Wahl des Superlativs läßt darauf schließen, daß Junge mindestens zwei Stundenbücher besessen haben muß. Auf jeden Fall hat Junge zu diesem zu vererbenden

\footnotetext{
${ }^{18}$ Thune hatte zwei größere Höfe, deren Ausstattung Wohnqualität garantieren. Sie lagen in Minden und in Verden, wo Thune noch einen kleineren Hof besaß.

${ }^{19}$ Eine Lüneburger Bilderchronik von 1595 zeigt ein Beutelbuch in den Händen eines Prämonstratensers. Die Figur befindet sich inmitten einer Szene, die den Einzug des Ordens im August 1382 in die Stadt Lüneburg zeigt. Die Chronik befindet sich im Museum für das Fürstentum Lüneburg und ist hier unter den Signaturen A1 und E20 ausgestellt. Ebenfalls im Museum befindet sich ein Hostienschrank aus dem Lüneburger Umkreis, ca. 1510 gefertigt (H53). Das untere der zwei Geschosse zeigt Maria und Johannes unter dem Kreuz. Johannes hält ein Beutelbuch in den Händen. H. G. GMELIN, Spätgotische Tafelmalerei in Niedersachsen und Bremen, Hannover 1974, S. 174f, Nr. 26.

${ }^{20}$ E.J. THIEL, Die liturgischen Bücher des Mittelalters, S.2383.

${ }^{21}$ U. REINHARDT, Testamente, Nr. 253, S.390.
} 
Buch eine besondere Beziehung, da er eigens betont, in diesem Buch täglich die Stundengebete zu lesen. Die persönliche Bindung macht das Stundenbuch zu einem besonderen Geschenk für den bedachten Bernhard Stake, der ebenfalls Vikar der Johanniskirche ist. Die Unterteilung in Sommer- und Winterbuch beruht auf dem mit dem Wechsel der Jahreszeiten verknüpften Wechsel der Gebete, die zudem der Verehrung des oder der jeweiligen Tagesheiligen Rechnung trugen. So stand am Anfang vieler Stundenbücher ein Kalender, wobei jeder Monat eine Seite einnahm, auf der oft in recht summarischer Weise die für den Monat bezeichnenden menschlichen Tätigkeiten dargestellt waren. Die Ausschmückungsmöglichkeiten der Stundenbücher erklären die Beschreibung Heinrich Geismars, seine Stundenbücher seinen zu lesende und zu betrachende (Testament 1461).

Nicht nur die drei eben genannten Donatoren, sondern auch alle anderen über Stundenbücher verfügenden sind Kleriker gewesen: Vikare an Lüneburger Kirchen waren von Dannenberg, von Lippinghausen, Tetendorp und Junge, Geismar war neben seiner Tätigkeit als Vikar in der Ratskapelle Pfarrer in Böken, das im heutigen Kreis Schwerin liegt, und Weidenknepel war Lübecker Kanoniker.

Der Kreis der Erbnehmer besteht ebenfalls vorwiegend aus Personen geistlichen Standes, wie im Fall des Dideric Broun, Johannes Hagen und Bernhard Stake. Der Lübecker Kanoniker Johannes Weidenknepel knüpft an seine Schenkung die Bedingung, der Bedachte solle das Buch erst dann erhalten, wenn er die ordines sacros erhalte ${ }^{22}$. Da das Testament den bedachten Dideric Bruon als Benefiziaten eines vom Testator in der St. Georgskapelle vor den Toren Lübecks gegründeten Benefiziums ausweist, scheint hier ein unübersehbarer Zusammenhang zwischen dem Buchlegat und dem Innehaben einer Vikarie zu bestehen. Weidenknepels Verwandter, der Franziskaner Johannes von Hagen, ist der Empfänger des zweiten Stundenbuches, aus dem sie, wie der Testator schreibt, gemeinsam die Stundengebete zu lesen pflegen. An dieser Schenkung unter Klerikern zeigt sich, daß die zunächst vermutete, ausschließliche Zugehörigkeit des Stundenbuchs zur Laienkultur zumindest im Spätmittelalter nicht aufrechtzuerhalten ist.

Empfänger von (Stundenbuch-) Legaten können auch Vikarien sein, wie im Fall des Marquard von Dannenberg zu sehen ist: Hier heißt es : .. una cum omnibus libris suis in horis canonicis neccesariis.. cum calice et preparamentis sacerdotialibus ad missam pertinentibus manebunt indivisa ... ad altare beate et gloriose virginis Maria in capella beati Lamberti in Luneborg pro una vicaria ${ }^{23}$. Auch Johannes von Lippinghausen hinterläßt 1414 sein Stundenbuch einer in der Kapelle St. Gertrud liegenden Vikarie, die er selbst gegründet hatte. Am Ende seines zehn Jahre später errichteten Testaments nimmt

\footnotetext{
${ }^{22}$ U. REINHARDT, Testamente, Nr.206, S.295.
} 
Lippinghausen bezug auf die Dannenbergsche Buchschenkung. Zunächst teilt er mit, daß er während seines Lebens die im Testament Dannenbergs verzeichneten Bücher benutzt habe, und er fährt fort, daß nach seinem Tode die Bücher möglichst schnell wieder zugänglich gemacht werden sollen.

Bedacht werden in zwei Fällen Laien. Heinrich Tetendorp hinterläßt sein Stundenbuch Heinrich von Lyderen. Heinrich Geismar bedenkt seine famula Greteke.

In zwei Testamenten ist von Gebetbüchern die Rede. 1447 heißt es im Testament des Hans Tespe: Item gheve ik Wybeken, syner (Heinrich Oldenstadts - Anmerkung S. M.-C.) sustere, Hinrikes Ryben husfrowen, myne twe bedeboke, de er moder heft scriven laten ${ }^{24}$. Die Testatorin Geseke Rosemberg formuliert 1472: Item der Thomeschen myn bedebok, dar soventich namen innestat ${ }^{25}$. Beide Formulierungen lassen eine persönliche Beziehung des Erblassers dem Buch gegenüber erkennen, die sich nicht nur in der Verwendung des Possessivpronomens äußert, sondern auch durch die Tatsache, daß hier das Buch im Auftrag einer (nahen?) Bekannten/Verwandten angefertigt wurde, dort mit persönlichen Gedenkzusätzen versehen ist. Es war keinesfalls ungewöhnlich, Stundenbücher - also Gebetsliteratur - mit handschriftlichen Vermerken über das jeweilige Todesdatum naher und auch entfernterer Bekannter oder Verwandter zu versehen, damit innen zu den Totengedenkfeiern gedacht werden konnte. Die Eintragung siebzig verschiedener Namen deutet auf eine bereits mehrere Generationen dauernde Benutzung hin. Man darf mit einiger Sicherheit vermuten, daß die von Geseke Rosemberg bedachte Thomesche dem näheren Be- oder Verwandtenkreis der Testatorin zugerechnet werden kann.

Ein Passional vererbt 1367 Heinrich Wangelo, Pfarrer der Kirche in Bergedorf. Das Passional ist der Legendendichtung zuzuordnen, einer Literaturgattung, deren Verbreitung im Spätmittelalter annähernd unübertroffen ist. Klosterbibliotheken, Weltgeistliche und Laien besaßen Legendentexte und -sammlungen. Die Legendensammlungen entsprechen der zeitgenössischen Vorliebe für umfangreiche Sammelwerke, den sogenannten Summen. Nicht eindeutig geklärt ist die Textrezeption. Denkbar ist die private Lektüre, vielleicht zu bestimmten Anlässen wie Heiligenfesten, denn der Textaufbau etlicher Summen entspricht dem kalendarischen Jahresablauf, wie im Fall des von Lippinghausen 1424 genannten Sommer- und Winterteils des Buches. Das umfangreichste Werk war mit rund 110000 Versen das sogenannte Vers - Passional, das um 1300 vollendet war. Es ist in drei Bücher gegliedert, die entweder als Buch I und II zusammen oder als Buch III überliefert sind. Das dritte Buch lehnt sich eng an die „Legenda aurea“ des Jacobus a Voragine (1228/29-1298) an, eines Dominikaners und Erzbischofs von Genua, der mit der Sammlung von 170

\footnotetext{
${ }^{23}$ U. REINHARDT, Testamente, Nr. 41, S.54f.

${ }^{24}$ U. REINHARDT, Testamente, Nr.210, S.303.

${ }^{25}$ U. REINHARDT, Testamente, Nr.237, S.354.
} 
Legenden die grundlegende Legendensammlung des Spätmittelalters geschaffen hatte ${ }^{26}$. An Beliebtheit übertroffen wurde die Legenda aura im deutschen Sprachgebiet von „Der Heiligen Leben“, dem sogenannten Prosapassional, das wahrscheinlich zwischen 1350 und 1400 in Nürnberg entstanden ist ${ }^{27}$. Merkmal der Passionalliteratur ist die kalendarische Ausrichtung, die in die Zweiteilung des Jahres mündet, und die immer wieder auf den gleichen Stoffundus rekurrierenden Kompilationen. Die Wertschätzung der Passionalliteratur schlägt sich in der geringen testamentarischen Erwähnung nicht nieder. Die Leidensgeschichten Christi und der Märtyrer scheinen vornehmlich im engen Familienkreis vererbt worden zu sein, so daß die testamentarische Verankerung dieses Erbgang im Regelfall überflüssig erschien. Heinrich Wangelos Passional bleibt nicht in den Händen von Familienmitgliedern, und so wird es testamentarisch greifbar.

Insgesamt vier Psalter werden per Testament vererbt. Ein Psalter enthält die 150 Psalmen in der Reihenfolge des Alten Testaments. Psalmen sind in dichterische Form gegossene Gesänge, vereinigen gemäß der Mehrdeutigkeit des griechischen Wortes „psalmós“ die Elemente Musik und Dichtung. Bereits in einem der frühesten Lüneburger Testamente vermacht der Priester Leo 1339 zwei Psalter, die er als größeren und kleineren Psalter voneinander abhebt. Beide Psalter gelangen in das Kloster Ebstorf, hier allerdings in unterschiedliche Hände. Der größere Psalter ist für die Armen im Kloster bestimmt, der kleinere für seine Nichte und einen Herrn Wedekin. Die Zuwendung des größeren Psalters für die ärmeren Klosterinsassen bedeutet mit einiger Sicherheit die Aufnahme in die Klosterbibliothek, wo der Psalter denjenigen, die aus finanziellen und sozialen Gründen keinen eigenen besitzen, zugänglich sein soll. Die Begine Hilleke von Erpensen hinläßt dem Lüneburger Beginenhaus, das in Anlehnung an die blauen Kleider der Beginen Blauer Konvent genannt wurde, ihren großen Psalter zum ewigen Verbleib. Zunächst soll er in Verwahrung derer bleiben, die mit der Testatorin zusammen im Konvent leben. Erst nach ihrer aller Tod darf er dem Obersten des Konventes übergeben werden, der den Psalter keiner Mitschwester verweigern darf, die um ihn bittet. Es hat den Anschein, als wolle die Testatorin mit dieser Regelung eine ihr nicht unbekannte Praxis im Vorhinein verhindern. Der Lübecker Kanoniker Johannes Weidenknepel vererbt seinen Psalter wahrscheinlich seinem Verwandten Johann von Hagen. Die von Johannes von Lippinghausen 1424 in seinem Testament vorgelegte Auflistung der Bücher, die Marquard von Dannenberg 1380

\footnotetext{
${ }^{26}$ Im Jenseitsglossar des Kataloges Himmel-Hölle-Fegefeuer ist von 243 Legenden die Rede, die nach fünf Abschnitten des Kirchenjahres zusammengestellt seien. U.Amcher, P.Jelzer, S. Marti, Jenseitsglossar, Stichwort „Legenda aurea“, in: Kat. „Himmel-Hölle-Fegefeuer“, S. 403.

${ }^{27}$ Weiterführende Informationen in W. WILLIAMS - KRAPP, Studien zu „Der Heiligen Leben“, in: Zeitschrift für das deutsche Altertum, hg. v. Kurt RUH, Nr.105, 1976, S.274ff.
} 
gestiftet hatte, nennt die Schrift des Franziskaners Nikolaus von Lyra ${ }^{28}$ über den Psalter. In seiner „Postilla litteralis super Biblia“ hatte Nikolaus von Lyra beinahe die gesamte Heilige Schrift gedeutet, wobei der Literalsinn jeder Stelle erläutert wurde. Dieses Werk war das Handbuch des 14. - 16. Jahrhunderts schlechthin.

Der Psalter ist eines der wenigen Bücher, von deren Gebrauch in den Testamenten die Rede ist. Zwei Testatoren und eine Testatorin treffen Aussagen über Psalterverwendung im Rahmen ihrer Begräbnisfeierlichkeiten (1401 Volrad Lassan, 1419 Immeke Burmester und 1473 Johann vame Lo). Alle drei Testatoren wünschen, daß an ihrem aufgebahrten Leichnam Psalmen gelesen werden; es handelt sich wohl um einen bestimmten Text, da Volrad Lassan und Immeke Burmester den zu lesenden Psalter als goldenen Psalter präzisieren. Offensichtlich war mit dem Lesen dieses goldenen Psalters ein gewisses Ritual verbunden, da Johann vame Lo für den Vortrag vier Priester bezahlt, die jedoch nacheinander in Zweiergruppen zu lesen haben. Volrad Lassan beauftragt die Nonnen in Medingen und Lüne mit dem Psalmenvortrag, bei dem jedes Kloster zwei goldene Psalter zu lesen hat; denkbar ist auch hier die Zweiteilung im Sinne zweier hintereinander zu lesender Gebetsteile. Der goldene Psalter ist ein Gebet, das in Zusammenhang mit dem Tod steht. Dieser Sachverhalt verweist auf den ambrosianischen Ritus, der das Beten des Psalters in der Totenvigilie, und zwar „praesente cadavere“, kennt ${ }^{29}$. Gebetet wird der sog. Dekadenpsalter, bei dem der Psalter aufgeteilt ist in fünfzehn, je zehn Psalmen umfassende Abschnitte. In den Testamenten der Hansestädte Hamburg, Lübeck und Stralsund ist ebenfalls vom Lesen des Psalters die Rede. Stralsunder Testatoren geben wie die Lüneburger als Zeitpunkt des Lesens die Zeitspanne zwischen Tod und Beerdigung $\mathrm{an}^{30}$. In Hamburg unterschieden die Testatoren den einfachen vom goldenen Psalter; diese Unterscheidung deutet RIETHMÜLLER als Unterscheidung zwischen dem einzelnen Psalm und der Gesamtheit der 150 Psalmen ${ }^{31}$. Daß sich der Wunsch des Lüneburger Testators Volrad Lassan, die Psalmen nicht nur an einem Ort lesen zu lassen, durchaus im Rahmen des Üblichen bewegte, wird durch das Testament der Lübeckerin Margarete Thodinghusen unterstrichen; sie bedenkt zehn Frauenklöster mit je 10 Mark pro aureis Psalteriis legendis ${ }^{32}$.

In vier Testamenten wird je ein Missale vererbt. Das Missale ist das für die Meßfeier maßgebliche Buch, das alle im Kirchenjahr erforderlichen Texte und Gesänge in sich vereinigt. Seiner Verwendung entsprechend sind die Donatoren Kleriker wie der Lübecker

\footnotetext{
${ }^{28}$ K. RUH, „, Nikolaus von Lyra“, in: Verfasserlexikon, hg. v. K. Ruh, Bd.6, 1987, Sp.1117-1122; A. KLEINHANS, „Nikolaus von Lyra“, in: LThK, Bd.7, Sp. 992f.

${ }^{29}$ zit. nach E. J. THIEL, „Psalterium“, in: ders., Die liturgischen Bücher des Mittelalters, S. 2391.

${ }^{30}$ J. SCHILDHAUER, Hansestädtischer Alltag, S.28.

${ }^{31}$ M. RIETHMÜLLER, to troste miner sele, S.85.

${ }^{32}$ zit. nach M. HASSE, Kleinbildwerke, S.69.
} 
Volrad Lassan, der Benefiziat in der Ratskapelle zu Lüneburg war. Johannes von Lippinghausen war wie Eckhard Stein Vikar in der Johanniskirche, und Heinrich Geismar war Pfarrer in Böken. Die Testatoren wenden ihre Meßbücher Vikarien zu, so daß die Bücher an die Vikarien gebunden sind. Lediglich Heinrich Geismar vererbt sein Meßbuch personenbezogen seinem Kaplan Theoderic Intwesten.

Predigtbücher werden im Testament Heinrich Wangelos 1367 erwähnt. Seine neuen Predigten hinterläßt er Ludolf Hufnagel. Wangelos Nachfolger im Amt erhält die Heiligenpredigten in dem roten Ledereinband sowie die "Sermones de tempore et de sanctis“ des Dominikaners Peregrinus ${ }^{33}$, die aufgrund ihrer Anschaulichkeit und Volksnähe einen großen Bekanntheitsgrad erreichten. An die Übergabe der Bücher ist die Auflage gebunden, diese Werke weder zu verpfänden noch zu verkaufen, damit sie auf alle künftigen Nachfolger übergehen können und so der ewigen Memorienfeier in Bergedorf dienen.

Neben anderen Büchern verfügt 1376 Heinrich Wangelo über ein „Compendium theologicae veritatis" des Straßburgers Hugo Ripelin ${ }^{34}$. Wangelo vererbt sein Exemplar dieses wohl verbreitetsten Werkes über Moraltheologie und Glaubenslehre seinem Onkel Hermann Dusecop, der Vikar in Bergedorf war.

Heinrich Wangelo ist es, der dem Propst und Konvent in Heiligenthal seine „Historia Scholastica“ hinterläßt. Die „Historica Scholastica“, verfaßt von Petrus Comestor, verband die in der Bibel enthaltenen philosophischen Wahrheiten mit historischen Fakten, trug maßgeblich zu der Entstehung der Historienbibeln bei und entwickelte sich zu einem der wichtigen und weit verbreitetsten Schulbücher ${ }^{35}$. Das Beispiel dieser Buchschenkung zeigt die vom Donator intendierte Absicht, die durch das Medium Buch gewährleistete Bildungsmöglichkeit zu maximieren.

1413 vererbt Johann von der Mölen testamentarisch seine Bibel. Bibellektüre im Spätmittelalter hieß mehr bibelkommentierende Schriften als die Bibel selbst zu lesen, von der es die Vulgataausführung gab. Mögliche Irrlehren aufgrund eines „falschen“ Bibelverständnisses drohten bei Bibellektüre ohne Kommentierung, denn für die Schriftauslegung bedurfte es intensiver Studien sowie Lateinkenntnisse. Auch aus diesem Grund hatten sich die deutschsprachigen Historienbibeln zu einem beliebten Literaturzweig entwickelt. Aus der Sphäre laikaler Kultur in Lüneburg ist eine siebenbändige „Bibelpostille“ bekannt, die Cord Lange und seine Ehefrau Ghebeke Schomaker Heinrich Lange

\footnotetext{
${ }^{33}$ G. GIERATHS, "Peregrinus“, in: LThK, Bd.8, S.270.

${ }^{34}$ T. CRAMER, Geschichte der deutschen Literatur im späten Mittelalter, S. 188.

${ }^{35}$ T. CRAMER, Geschichte der deutschen Literatur im späten Mittelalter, S. 204.
} 
geschenkt hatten ${ }^{36}$. Mölens Bibel soll Johann Malsdorp erhalten, ein Vikar in St. Johannis. Nach Malsdorps Tod ist sie zu ewigem Verbleib an St. Lamberti zu geben.

Dekretalen werden in zwei Testamenten erwähnt. Der Archidiakon von Bevensen, Segeband von Thune, vermerkt, inm schulde Heinrich von Rameslo zwanzig Mark Denare, für die Thune u.a. Dekretalen als Pfand hat. Der Pfarrer der Kirche von Böken, Heinrich Geismar, schenkt in seinem 1461 errichteten Testament seinen „Liber Sextus“ ${ }^{37}$ Bruno Malstorp.

Heinrich Geismar zeigt sich in seinem Testament als Eigentümer etlicher Bücher, über die er pauschal als omnibus libris verfügt. Aus dieser Menge der seinem Kaplan zugedachten Bücher sollen jedoch die oben genannten Dekretalen sowie die „Summa casuum“ des Dominikaners Bartholomäus Pisanus ${ }^{38}$ herausgenommen werden, um in die Hände Bruno Malstorps überzugehen.

Hartwig Hannover erwähnt 1484 eine Schrift über spera materialis, die für seinen Scholaren bestimmt ist ${ }^{39}$. Eine Bestimmung des genauen Titels und/oder des Autors ist nicht möglich, aber es gibt doch öfter Titel dieser Art. So befindet sich z.B. unter den Handschriften der Ratsbücherei Lüneburg eine Handschrift des 14 . Jahrhunderts aus dem Franziskanerkloster, der „Liber de astronomia“40. In inm ist die Schrift des Johannes De Sacrobosco vel Johannes De Holywood „De sphera“ enthalten, die Schrift „De sphera“ des Johannes Peckham, „Sphera“ des Robertus Grosseteste, ein Kommentar zur Schrift des Johannes De Sacrobosco sowie vierzehn weitere Schriften mit astronomischem Inhalt.

Über das bedeutendste Rechtsbuch des Spätmittelalters verfügt Johannes Hoyemann 1401: Er vererbt seine zwei Bücher des Sachsenspiegels an Albert von der Mölen. Rechtsbücher wie der Sachsenspiegel waren Privatarbeiten, erhielten aber kraft der Praxis weitestgehend Gesetzesrang. In weiten Teilen des Rechtslebens fehlten gesamtrechtrechtliche Kodifikationen, so daß den privaten Rechtsaufzeichnungen eine tragende Bedeutung zukam, zumal in innen das Gewohnheitsrecht weiter Landteile anschaulich wiedergegeben wurde. Verfasser war der Sachse Eike von Repgow, der zwischen 1220 und 1235 in niederdeutscher Sprache das Gewohnheitsrecht des sächsischen Stammes in zwei Teilen, dem Land- und dem Lehnsrecht, niederschrieb. Das Werk wurde weit verbreitet und ist in verschiedenen Handschriftengruppen überliefert. Der Lüneburger Ratsherr Brand von Tzerstede trat als Bearbeiter des Sachsenspiegels hervor:

\footnotetext{
${ }^{36}$ W. REINECKE, Geschichte der Stadt Lüneburg, Bd.1, S.259.

${ }^{37}$ A.M. STICKLER, „Corpus Iuris Canonici, III. Liber Sextus Bonifatius’ VIII, in: LThK, Bd.3, Sp. 66f..

${ }^{38}$ J.F. von SCHULTE, Die Geschichte der Quellen und Literatur des canonischen Rechts, Bd.2, 1877, S. 428f.

${ }^{39}$ U. REINHARDT, Testamente, Nr.269, S.424.

${ }^{40}$ M. WIERSCHIN (Bearb.), Handschriften der Ratsbücherei Lüneburg. Miscellanea und Historica, Wiesbaden 1969, Ms. Miscell. D44G, S.76ff.. Den Hinweis auf diese Schrift verdanke ich Herrn Jörg Mollenhauer.
} 
Tzerstede stellte 1442 dem Sachsenspiegel eine ergänzende Glossensammlung an die Seite; damit bediente er sich der im ersten Drittel des 14. Jahrhunderts von oberitalienischen Rechtsgelehrten eingeführten Arbeitsmethode der flankierenden Glossierung. Sowohl Hoyemann als auch Mölen zählten wie Tzerstede zu den führenden Ratsgeschlechtern, die juristisch gebildet waren. Von dieser Bildung zeugen die überlieferten Rechtshandschriften aus dem 15. Jahrhundert, die zum Teil im Privatbesitz Lüneburger Ratsfamilien gewesen sind ${ }^{41}$. Bei der Vererbung seines Sachsenspiegels scheint der Testator Johannes Hoyemann von der Überlegung ausgegangen zu sein, in den Händen welchen Familienmitglieds die Schrift am besten aufgehoben sei. Seine Wahl fiel nicht auf seine Tochter oder seinen Schwiegersohn Lübberstedt, sondern auf den Sohn seiner Cousine Margarete von der Mölen, geborene Hoyemann, den Bürgermeister Albert von der Mölen. In von der Mölens Testament aus dem Jahr 1425 wird der Sachsenspiegel nicht erwähnt ${ }^{42}$. Des Testators Kinderlosigkeit veranlaßte Reinecke, zu vermuten, die Bücher seien nach von Mölens Ableben dem Rat anheim gefallen ${ }^{43}$.

Der Apotheker Matthias von der Most schenkt in seinem 1474 errichteten Testament dat rode bock, dar vita Alexandri ynnesteyt der Bibliothek von St. Johannis ${ }^{44}$. Von der Person des Alexander ging aufgrund seiner ungeheuren Eroberungszüge, die inn in entfernte und damit für den zeitgenössischen Leser in faszinierende Gegenden geführt hatten, und aufgrund seines frühen Todes eine große (literarische) Anziehungskraft aus. Das kirchliche Alexanderbild war durch die Bibel (Daniel 7/8) geprägt: Der Makedonenkönig galt als Begründer und Beherrscher des dritten der vier Weltreiche und damit als Werkzeug Gottes für die heilsgeschichtliche Gestaltung des weltgeschichtlichen Ablaufs. Indem der Apotheker von der Most den Alexanderroman der Bibliothek zu St. Johannis vererbt, macht er inn einem weiten Kreis von Interessenten und Studierwilligen zugänglich.

\section{Empfänger der Legate}

Von den vierzig Schriften werden einundzwanzig Priestern, Vikaren, Klöstern oder kirchliche Einrichtungen zugewendet. Sie können als Legate ad pias causas betrachtet werden, wenn sie auch verschiedenen Funktionen zugewiesen werden. Der Testator hinterläßt seine Bücher, in der Regel liturgische Literatur, entweder der Vikarie, die er als Vikar versorgt, oder der von ihm gestifteten Vikarie. Vikarien scheinen mit etlichen gestifteten Büchern ausgestattet gewesen zu sein. Buchstiftungen für (neuerrichtete) Vikarien oder Altäre

\footnotetext{
${ }^{41}$ W. REINECKE, Geschichte der Stadt Lüneburg, Bd.1, S. 341ff.

${ }^{42}$ U. REINHARDT, Testamente, Nr.155, S.212ff.

${ }^{43}$ W. REINECKE, Geschichte der Stadt Lüneburg, Bd.1,S.452.

${ }^{44}$ U. REINHARDT, Testamente, Nr.244, S.375.
} 
wurden in kürzester Zeit vollzogen. So betonen die Testatoren oft, man solle die (Buch-) Bestimmungen möglichst schnell ausführen, und die 1320 erbaute Allerheiligenkapelle der Johanniskirche verfügte bereits 1325 u.a. über zwei Missale, einen Psalter, ein Evangelienbuch und ein Verdebuk ${ }^{45}$. Hier tragen die Bücher nicht allein zur grundlegenden Versorgung mit Texten und Liedern bei, sie gereichen dem Stifter durch die Schenkung zur Ehre und sorgten für die Präsenz seines Namens in den Gebeten nachfolgender Generationen.

Bücher dienten aber nicht nur als Gebetsvorlage, sondern auch für die (Aus-) Bildung Anderer: In fünf Fällen haben Lüneburger Testatoren eine Bibliothek als Bestimmungsort ihrer Bücher gewählt ${ }^{46}$. Zwei Bibliotheken liegen nicht in Lüneburg. Die vom Arzt Helmold van Lyderen auserkorene Universitätsbibliothek zu Rostock wird inm nicht unbekannt gewesen sein; mit einiger Wahrscheinlichkeit handelt es sich um die Bibliothek, die er einst während seines Studiums nutzte. Der Apotheker Matthias von der Most schenkt sein Brevier der Bücherei Unser Lieben Frau in Lübeck; seine Beziehung dorthin bleibt im Dunkeln. Seine Alexandervita bleibt hingegen in der Bibliothek von St. Johannis. Ludolf Mangard, Priester in St. Johannis, wendet seinen gesamten Buchbesitz 1478 derselben Bibliothek zu, damit er dort den Studien armer Scholaren und Studenten diene. Diese Bevorzugung der Johannisbibliothek vor den anderen Lüneburger Bibliotheken wird zum einen aus der Bedeutung der Johanniskirche als Sitz des Archidiakonats und als Pfarrkirche resultieren, sie mag aber auch ihren Grund in der unmittelbaren Nachbarschaft der 1406 gegründeten, unter dem Patronat des Rates stehenden Lateinschule des Johanneums ${ }^{47}$ haben, deren Scholaren die Bibliothek nutzten. Das Arrangement von Rat und Kirche verlieh der Johannisbibliothek ansatzweise den Charakter einer öffentlichen Einrichtung ${ }^{48}$. Ludolf Mangard beschreibt den von ihm gewünschten Benutzerkreis nicht nur sehr genau mit der Nennung sowohl der Lernenden wie eben der Scholaren und Studenten als auch mit der Aufführung verschiedener Klerikerränge wie Prediger, Priester, Vikare,

\footnotetext{
${ }^{45}$ W. REINECKE, Geschichte der Stadt Lüneburg, Bd.1, S.109.

${ }^{46}$ Es fällt auf, daß das Wort „liberie“ nur in Testamenten des letzten Viertels des 15. Jahrhunderts fällt, und nur von dem Apotheker und dem Arzt benutzt wird. In Klerikertestamenten werden die Bücher der Kirche oder „dem Propst und Konvent“" zugewendet.

${ }^{47}$ Johann von der Mölen erwähnt in seinem Testament 1413 ein offenbar ihm gehörendes Haus, das zur Zeit die Schule von St. Johannis ist; demzufolge hatte die dem Rat unterstehende Schule zumindest im achten Jahr nach ihrer Gründung ihren Sitz im Haus eines Ratsherrn, der dieses Haus wiederum an einen Ratsherrn, nämlich Hinrik Viskule, vererbt. Zur Geschichte des Johanneums siehe G. MATTHAEI, Lüneburgs Kirchen und Schulen. in: Aus Lüneburgs tausendjähriger Vergangenheit. Festschrift, hg. im Auftrag der Stadt Lüneburg von Ulrich Wendland, Lüneburg 1956, S.48ff; E. ENNEN, Stadt und Schule in ihrem wechselseitigen Verhältnis vornehmlich im Mittelalter, in: Die Stadt des Mittelalters, Bd. 3, Darmstadt 1976, S.455ff; bes. S.466.

${ }^{48}$ Hinweis bei H. BOOCKMANN, Die Stadt im späten Mittelalter, München 1986, S. 334. Über die Öffentlichkeit spätmittelalterlicher Bibliotheken schreibt K. SCHREINER, Bücher, Bibliotheken und „Gemeiner Nutzen“, in: Bibliothek und Wissenschaft, hg. v. U. HÖGY und H. VOGELER, Band 9, Wiesbaden 1975, S. 244ff.
} 
Kommendisten und Offizianten, er bezieht auch in den Benutzerkreis ausdrücklich die vor den Toren der Stadt lebenden Benefiziaten mit ein ${ }^{49}$. Vikaren, Kommendisten und Offizianten stehen die Bücher zu bestimmten Zeiten zur Verfügung, während die Buchbenutzung der Scholaren und Priester augenscheinlich keiner Zeitgebundenheit unterliegt. Wichtig ist, daß all diese Bücher ewig erhalten bleiben, und so wird in einigen Fällen vom Testator ausdrücklich ein Verbot der Verpfändung oder des Verkaufs ausgesprochen; darüberhinaus wird gelegentlich eine (als Ewigkeitsrente erkennbare) Geldsumme zur „Verbesserung“ der Bücher ausgesetzt.

Fast alle von Klerikern vergabten Bücher fallen letztlich an die tote Hand, auch wenn sie vielleicht zunächst einer bekannten Person für ihre Lebensdauer überlassen werden. Die von Laien vergabten Bücher fallen vorrangig an innen bekannte, ja wahrscheinlich geschätzte oder liebgewonnene Personen, wobei besonders bei den Gebetsbüchern diese persönliche Bindung ausschlaggebend erscheint.

Die Frage ist angebracht, warum die Laien das Testament in geringem Maße für die Vergabe von Buchbesitz nutzten. Denn daß Laien Bücher besaßen, steht außer Zweifel. Ein Gebetbuch für die kanonischen Stunden gehörte zusammen mit einem Buchbeutel zur Frauengerade ${ }^{50}$, die in der beerbten Ehe das nicht frei verfügbare Erbgut darstellt, mithin auch nicht zwingend in den Testamenten erwähnt werden muß. Aller Wahrscheinlichkeit nach werden laikale Buchbesitzer weitere literarische Wertgegenstände nach Möglichkeit an ihre Nachkommen weitergegeben haben, so daß sie entweder nicht im Testament erwähnt zu werden brauchten oder in der Mobilia subsumierenden Formulierung enthalten waren. Offensichtlich werden Bücher testamentarisch von Laien nur in besonderen Fällen erwähnt, wie von Albert von der Mölen und Matthias von der Most, die kinderlos starben. Ludolf bi dem Sode und Johann von der Mölen wenden ihre Bücher einem Vikar bzw. einer Vikarie zu, entziehen sie insofern einem zwar nicht gesetzlich verankerten, aber vielleicht doch ideell vorhandenen Anspruchsdenken ihrer Nachkommen. Die durch den Öffentlichkeitscharakter des Testaments zu erreichende Fixierung und Beweiskraft ihres letzten Willens ist gleichsam die Prävention eines potentiellen Erbstreits.

Auch in den Testamenten anderer Städte werden Bücher selten erwähnt. Die Auswertungen Lübecker und Hamburger Testamente erwähnen Bücher gar nicht. Die Untersuchung Stralsunder Testamente kommt zu dem Ergebnis: "Bücher kommen in den Stralsunder Testamenten sehr selten vor, sie gehörten jedoch zu den wertvollen

\footnotetext{
${ }^{49} \mathrm{Ob}$ die Bücher ausgeliehen wurden, läßt sich aus den Formulierungen nicht entnehmen. In der Regel waren die Bibliotheken Präsenzbibliotheken, doch verliehen z.B. die Franziskanerbibliotheken gegen Leihscheine ihre Bücher auch an Außenstehende. E. SCHLOTHEUBER, Bibliothekswesen und Bibliotheken der Bettelorden, in: 700 Jahre Paulinerkirche, hg. v. E. MITTLER, Göttingen 1994, bes. S. 23.

${ }_{50}^{50}$,ere beste tidebuk mit dem bokesbudele“ W.F. VOLGER, Urkundenbuch der Stadt Lüneburg; Hannover 1875, BD.III, S. 436.
} 
Nachlaßgegenständen. So wurden Mitte des 15. Jahrhunderts ein breviarium im Werte von 15 Mark und ein Missale von 40 Mark vererbt“ ${ }^{51}$. In den Wiener Testamenten werden Bücher „regelmäßig“ erwähnt ${ }^{52}$. Auch hier sind es wie in Lüneburg überwiegend Geistliche, die über Bücher testamentarisch verfügen. Empfänger der Schenkung sind oft religiöse Einrichtungen; dies ist ebenfalls eine Parallele zu den Ergebnissen der Auswertung Lüneburger Testamente. So scheint sich das Testierverhalten Lüneburger Testatoren in Hinblick auf die Vergabung von Büchern nicht wesentlich von den Testiergewohnheiten anderer Testatoren spätmittelalterlicher Städte unterschieden zu haben.

\footnotetext{
${ }^{51}$ J. SCHILDHAUER, Hansestädtischer Alltag, S.99.

${ }^{52}$ G. JARITZ, Die Realienkundliche Aussage der sogenannten „Wiener Testamentsbücher“, in: Das Leben in der Stadt des Spätmittelalters. Veröffentlichungen des Instituts für mittelalterliche Realienkunde Österreichs, Wien 1977, S.182f.
} 


\section{Schmuckstücke}

a. smyde - Pauschal vererbte Schmuckstücke

Das Wort smyde bedeutet geschmiedetes, also bearbeitetes Edelmetall ${ }^{1}$ und steht für Schmuckstücke unterschiedlicher Lebensbereiche. Bekannt ist Kleiderschmuck, Körperschmuck und Tafelschmuck. Schmuckgegenstände dieser Verwendungsbereiche werden, wenn sie aus Edelmetall sind, von Goldschmieden angefertigt, deren Zunfturkunden in Lüneburg überliefert sind ${ }^{2}$. Lüneburger Testatoren verfügen seltener über einer Sparte zuzuordnendes smyde wie Kleiderschmuck ${ }^{3}$ und tafelsmyde, also silbernes Tafelgeschirr ${ }^{4}$, sondern verwenden eher die weiter gefaßten Formulierungen smyde ${ }^{5}$ oder sulvern smyde ${ }^{6}$. Silber- oder Goldgegenstände, die terminologisch oder aufgrund des Testamentskontextes einem der genannten Verwendungsbereiche zugeordnet werden können, werden in entsprechenden Kapiteln über Kleider-, Körper- und Tafelschmuck ausgewertet. Von Interesse sind zunächst die Verfügungen, in denen pauschal von smyde oder sulvern smyde die Rede ist. Unter dem Begriff sulversmyde werden in den Testamenten auch clenode subsumiert ${ }^{7}$.

Tabelle: Testamentarische Verfügungen über smyde

\begin{tabular}{|l|l|}
\hline Jahre & Anzahl der Testamente \\
\hline $1300-1325$ & \\
\hline $1326-1350$ & - \\
\hline $1351-1375$ & 1 Testament \\
\hline $1376-1400$ & 2 Testamente \\
\hline
\end{tabular}

${ }^{1}$ SCHILLER-LÜBBEN, Mittelniederdeutsches Handwörterbuch, S.358.

${ }^{2}$ E. BODEMANN, Die älteren Zunfturkunden der Stadt Lüneburg, S.94-102.

${ }^{3} 1490$ Mai 11 Heinrich Winthe.

${ }^{4} 1413$ Aug. 15 Johann von der Mölen, 1414 Juni 29 Heinrich Uplegger, 1436 Nov. 19 Ludolf Kirchhof, 1441 Nov. 20 Hermann Kruse Die das Tafelgeschirr betreffenden Legate werden in dem Kapitel über Geschirr und Besteck behandelt.

${ }^{5} 1388$ Aug. 6 Arnd Neuenburg, 1402 Mai 25 Curd von Botzen, 1409 März 7 Johann Semmelbecker, 1440 Dez. 17 Curd Dalhusen, 1493 Okt. 26 Hans Tetendorp.

${ }^{6} 1378$ Sept. 7 Ludeke Stöterogge, 1415 Juni 28 Gese Lübberstedt, 1425 Juli 23 Albert von der Mölen, 1431 Jan. 15 Johann Rese, 1447 Dez. 14 Hans Kruse, 1458 April 6 Adelheid Kale, 1473 Sept. 29 Johann van dem Lo, 1474Aug. 23 Beke von Esche, 1474 Sept. 22 Matthias von der Most, 1494 Lorenz König, 1495 März 12 Ludeke Brodermann, 1500 Feb. 1 Hans Holstenland).

${ }^{7} 1474$ Sept. 22 Matthias von der Most: twe edder dre clenodia van mynem sulversmyde. 


\begin{tabular}{|l|l|}
\hline Jahre & Anzahl der Testamente \\
\hline $1401-1425$ & 5 Testamente \\
\hline $1426-1450$ & 3 Testamente \\
\hline $1451-1475$ & 4 Testamente \\
\hline $1476-1500$ & 6 Testamente \\
\hline
\end{tabular}

Unter den 21 Donatoren befinden sich drei Frauen. Kein Kleriker schreibt in seinem Testament Verfügungen über smyde nieder.

Dreizehn Testatoren beschreiben ihre Objekte als sulvern smyde. Eine Mengenangabe entfällt zugunsten der Subsumation unter dem Oberbegriff; deutlich ist hingegen, daß es sich um eine Mehrzahl von Objekten handelt. Matthias von der Most konkretisiert als einziger Testator die Legate als twe edder dre clenodia van mynem sulversmyde ${ }^{8}$.

Alle Testatoren vererben ihre silbernen Kostbarkeiten fast ausschließlich personenbezogen. Die Mehrzahl bedenkt Frau und Kinder zu gleichen Teilen (in zehn Fällen) und Verwandte oder Bekannte (in sechs Fällen). Zwei Testatoren setzen ein Geldgeschenk für die Finanzierung eines Schmuckstückes aus, und ein Testator läßt vom smyde seiner verstorbenen Frau drei Kelche anfertigen. Die Lüneburger Testatoren nehmen smyde und sulvern smyde oftmals dann in ihr Testament auf, wenn es um Fragen der Abteilung, also der Besitzverteilung zwischen der (verwitweten und ggf. erneut heiratenden) Mutter und den Kindern geht ${ }^{9}$. Da diese Formulierungen weitestgehend das gängige Erbrecht widerspiegeln, erfolgt durch die Aufnahme in das Testament sozusagen eine doppelte Sicherung in rechtlichem Sinn. Dies kann als Indiz für die besondere Wertschätzung gewertet werden, die silberne Gerätschaften bei den Bürgern genießen. Nur wohlhabende Bürger sind im Besitz derartig wertvoller Objekte, und so finden sich unter den Testatoren Angehörige der reichsten Familien Lüneburgs wie die von der Mölen, Semmelbecker und vame Lo.

Die Frauen zeigen einen anderen testamentarischen Umgang mit smyde als die Männer: Testatorinnen vererben Schmuckstücke sachbezogen als Legate ad pias causas. Gese Lübberstedt wendet das Silbergeschmeide, das zuvor ihrer

\footnotetext{
${ }^{8}$ U. REINHARDT, Testamente, Nr.244, S.376.

${ }^{9}$ Im Testament des Heinrich Uplegger 1414 Juni 29 heißt es z.B., daß die Heirat des gemeinsamen Sohnes möglicherweise zu Spannung zwischen Sohn und Mutter oder Mutter und Schwiegertochter führen könnte; im Fall einer auf diese Weise herbeigeführten Abteilung soll die
} 
Schwester Alheid gehört hatte, der von ihr in St. Nikolai errichteten Vikarie zu. Adelheid Kale wünscht von ihren Silbergerätschaften den Kauf eines Kelchs, einer Pathene, eines Priestergewandes, eines Amikts und einer Albe, wobei die je beste Ausführung anzuschaffen sei. Empfänger all dieser Dinge sind die Franziskaner in St. Marien. Beke von Esche will ihr Silber für einen Kelch geben, der für eine bestimmte Kommende anzufertigen ist.

Die silbernen und goldenen, z.T. sicherlich auch edelsteinverzierten Wertgegenstände werden eingeschmolzen oder verkauft, wenn sie dem liturgischen Dienst zugute kommen sollen. Unberührt bleiben sie, wenn sie an Familienmitglieder und Bekannte fallen.

\section{b. Einzeln bestimmbare Schmuckstücke}

In diesem Kapitel werden die Schmuckstücke zusammengefaßt, die in den Testamenten als einzelne greifbar sind. Zählt man sie zunächst zusammen, so ergibt sich folgende Verteilung:

Tabelle: Testamentarische Verfügungen über Schmuckstücke

\begin{tabular}{|l|l|}
\hline Jahre & Anzahl der Testamente und Schmuckstücke \\
\hline $1400-1425$ & 6 Testamente mit mindestens ${ }^{10} 13$ Schmuckstücken \\
\hline $1426-1450$ & 5 Testamente mit mindestens 14 Schmuckstücken \\
\hline $1451-1475$ & 3 Testamente mit 9 Schmuckstücken \\
\hline $1476-1500$ & 3 Testamente mit mindestens 10 Schmuckstücken \\
\hline
\end{tabular}

Schmuckstücke finden in den Testamenten des 14. Jahrhunderts keine Erwähnung, treten dann aber in den Testamenten des 15. Jahrhunderts mit zunehmender Häufigkeit auf. Insgesamt sind aus dem 15. Jahrhundert 17 Testamente mit mindestens 46 Schmuckstücken überliefert. Unklar bleibt,

Ehefrau des Testators das Tafelsilber behalten. Die Mehrzahl der Testatoren legt die zu gleichen Teilen ausfallende Aufteilung fest.

${ }^{10}$ Pro Zeitraum von 25 Jahren gibt es je eine Verfügung über Schmuckstücke, die im Plural aufgeführt werden. Hier wird die Minimalanzahl von zwei Objekten angenommen. 
wieviele Schmuckstücke möglicherweise unter den Titeln clenode oder smyde vergeben werden.

handtruwe

Die handtruwe ist ein das Gefühl der Liebe und der Zugehörigkeit symbolisierendes Schmuckstück, das mit zwei ineinanderverschlungenen Händen versehen ist. Dieses Symbol steht für ein Versprechen, eine Abmachung zweier Menschen und meint im besonderen ein Eheversprechen. Die handtruwe kann als Ring oder Brosche ${ }^{11}$ ausgearbeitet sein, so daß eine Formbestimmung der testamentarisch vererbten Objekte nicht möglich ist.

Erwähnt werden fünf dieser Schmuckstücke, wobei allein drei im Testament des Heinrich Winthe 1490 aufgelistet werden, während die Testamente Wobbeke Boltzens 1428 und Soffeke Springintguts 1439 je über eine handtruwe verfügen. Die Beschreibung der handtruwe in Soffeke Springintguts Testament als myn beste hanttruwe, dat myn sone, her Werner, my kofte ${ }^{12}$ verweist auf die mögliche Verwendung nicht nur als Symbol der Liebe zwischen Eheleuten, sondern auch zwischen Eltern und Kindern oder - neutraler formuliert - als Zeichen persönlicher Zuneigung. Diese Symbolik läßt an vorrangige Schenkungen innerhalb der vertikalen Familienlinie denken, und die Tochter bzw. Sohn bedenkenden Testatorinnen bestätigen dies. Heinrich Winthe, der in seinem Testament weder Sohn noch Tochter erwähnt, stiftet eine handtruwe dem Bau von St. Johannis, die zweite fällt einer Bekannten zu und die dritte wohl einem Verwandten.

Ringe

Das testamentarisch am häufigsten vererbte Schmuckstuck ist der Ring. Die zehn über Ringe verfügenden Testamente sind annähernd kontinuierlich über das 15. Jahrhundert verteilt. Vier dieser Testamente sind von Frauen angefertigt worden, eines stammt von einem Kleriker.

\footnotetext{
${ }^{11}$ Abbildung einer handtruwe als Brosche in Katalog „Stadt im Wandel“, Bd.1, Nr. 246, S.309

${ }^{12}$ U. REINHARDT, Testamente, Nr.183, S.257.
} 
Die Testatoren bezeichnen ihre mindestens $21^{13}$ Schmuckstücke als ringh, vingeren oder annullum. Getragen werden die Ringe auf allen Fingern außer dem Mittelfinger; offenbar ist es durchaus üblich, mehrere Ringe auf einem Finger zu tragen, bekannt ist auch das Tragen von auf Ketten aufgezogenen Ringen ${ }^{14}$.

In den Testamenten werden ausschließlich Goldringe erwähnt. Auch die beiden einzigen in Lüneburg gegenständlich überlieferten Ringe bestehen aus Gold, wobei einer der Ringe mit einem Herz versehen und somit Beispiel der beliebten Liebessymbolik ist ${ }^{15}$. Drei der testamentarisch erwähnten Goldringe sind mit Edelsteinen verziert. Edelsteine stammten aus dem asiatisch - indischen Bereich und gelangten über zu See oder Lande verlaufende Transportwege zunächst nach Venedig, dann auf die Messen Europas ${ }^{16}$. Innerhalb der Rangordnung der Edelsteine ist an erster Stelle der Diamant zu nennen, gefolgt vom Korund, in roter Ausformung als Rubin und in blauer Ausformung als Saphir bekannt, sowie vom Beryll, der grüngefärbt als Smaragd bezeichnet wird $^{17}$. Drei mit einem Saphir geschmückte Ringe werden in den Lüneburger Testamenten erwähnt, wobei Wobbeke Boltzen ihren Ring mittels der blauen Farbe charakterisiert, während Beke Groning die Bezeichnung des Steines nennt. Dem äußeren durch die Farbigkeit geprägten Erscheinungsbild des Steines schreibt „der noch vom Wunderglauben stark gefesselte spätmittelalterliche Stadtmensch" magische Kräfte $\mathrm{zu}^{18}$; das im Blau des Saphirs eingefangene Blau des Himmels strahlt die himmlische Liebe aus und steht in diesem Sinne für Treue und Beständigkeit ${ }^{19}$. Vor dem Hintergrund dieser möglichen Konnotation wird die Form der beiden Saphirringe Beke Gronings zu

\footnotetext{
${ }^{13}$ Da die Testamente Curd von Boltzens 1402 Mai 25 und Luteke Nyeburs 1481 Mai 25 keine direkte Zahlenangabe enthalten, aber auf die Schenkung eben nicht nur eines Ringes hinweisen, wird die Zahl von zwei Ringen pro Testament geschätzt.

${ }^{14}$ Die Darstellung eines von Rogier van der Weyden in der ersten Hälfte des 15. Jahrhunderts geschaffenen weiblichen Bildnisses zeigt einen mit drei Ringen geschmückten Ringfinger, wobei die Ringe aber nicht aufeinandergeschoben auf dem dem Handrücken nahen, sondern entfernten Fingerglied sind. H. HOFSTÄTTER, Spätes Mittelalter (=Kunst im Bild, Bd. 18), München o.J., S.175; E. VAVRA, „SCHMUCK“, in: Lexikon des Mittelalters, Bd.7, Sp. 1508 - 1510, hier 1509.

${ }^{15}$ Beide Ringen stammen aus dem 16. Jahrhundert. Der mit Herz versehene Ring wird auf den Jahrhundertanfang datiert, während der schwerere, durchbrochene Goldring wohl vom Ende des Jahrhunderts stammt. Leider verschollen ist ein im Michaeliskloster gefundener Goldring, der mit einer Pilgermuschel verziert war. E. MICHAEL, Leitfaden durch das Museum in Lüneburg, F.71, S.102.

${ }^{16}$ E. WURMBACH, Das Wohnungs- und Bekleidungswesen des Kölner Bürgertums, S.69; P. BAUR, Testament und Bürgerschaft, S.242.

${ }^{17}$ H. BETHE, ,Edelsteine“, in: RDK, Bd.2, Sp. 714 - 742, hier Sp.715f.

${ }^{18}$ P. BAUR, Testament und Bürgerschaft, S.242; Ch. DAXELMÜLLER, Heil- und Volksglaube, in: Kat. „, Aus dem Altag der mittelalterlichen Stadt“, S.181 - 192.
} 
einer sprechenden: In einem der Ringe steht auf beiden Seiten der Name „Malde Wolken“, während aus dem Ring erwachsene Hände den Saphir des zweiten Ringes halten. Die gleichen Testatorinnen vererben je einen Smaragdring, dessen Grün für die Hoffnung steht, ganz praktisch aber auch vor Augenkrankheiten schützt ${ }^{20}$. Einen weiteren goldenen Ring vererbte Beke Groning, allerdings nun mit einem braunen Stein, bei dem es sich um einen Hyazinth handeln könnte.

Bis in die zweite Hälfte des 15. Jahrhunderts wird der Edelsteinschliff mittels der Technik des Mugelns durchgeführt, wie die aus dem Orient übernommene Abrundung der Ecken, das leichte Wölben und das Polieren des Steins bezeichnet wird. Bei dieser bereits in der Antike praktizierten Methode geht es im Prinzip um die verfeinernde Ausarbeitung der natürlichen Steinform. Der ausgeformte geschliffene Stein gleicht jedoch recht oft „einer Truhe mit gewölbtem Deckel“21. Im späten Mittelalter wird zunehmend der Facettenschliff bevorzugt. Ungefähr im 14. Jahrhundert kommen Schleifmühlen auf, wobei sich besondere Zentren des Edelsteinschliffs in Brügge, Paris, Sraßburg, Freiburg i. Br., Nürnberg, Wien, Prag und in Idar - Oberstein ausbilden, Zentren, die z.T. bis auf den heutigen Tag Bestand haben. Als Lieferanten für den nordeuropäischen Markt sind besonders im 15. und 16. Jahrhundert flämische Schleifereien nachgewiesen. Auffällig ist, daß diese Großregion in Lüneburg als Tuchlieferantin frequentiert wird und sich die mögliche Perspektive eines hier verlaufenden Edelsteinhandels eröffnet.

Im deutschsprachigen Raum sind zwei Arten der Fassung bekannt: die Kastenfassung, bei der der Stein in einen Kasten eingepaßt und auf einen senkrecht stehenden Stift aufgesetzt wird, sowie die freie Fassung ohne Bodenplatte, bei der der Edelstein durch Krappen gehalten wird. Die in Ringe gefaßten, in Lüneburg testamentarisch erwähnten Edelsteine, gerade Saphir und Smaragd, sind alle von hohem Wert. Angesichts des nicht unbeträchtlichen Reichtums etlicher Lüneburger Bürger scheint es in gewissem Sinne eher ein Zufall zu sein, daß ein Diamant nicht in den Testamenten verzeichnet ist. Ein Diamantenbesitz zumindest einiger Lüneburger Bürger ist anzunehmen, wenn er sich auch nicht wie in Lübeck oder Konstanz in den Testamenten

\footnotetext{
${ }^{19}$ C. ERSKINE CLEMENT, Legendary and Mythological Art, S.7.

${ }^{20}$ Abbildung eines - allerdings aus dem 16. Jahrhundert stammenden - Goldringes, der mit einem Smaragd verziert ist, in: Kat. „Stadt im Wandel“, Bd.1, Abb. 247a mit Erklärung.

${ }^{21}$ vgl. auch die Ringfunde aus Münster und Göttingen, dargestellt in: Kat. „Stadt im Wandel“,

Bd.1, Nr. 246, 247 a-c.
} 
niederschlägt ${ }^{22}$. Die mehrheitliche Nennung des Saphirs als Schmuckstein korrespondiert mit der bevorzugten Verwendung dieses Steins durch spätmittelalterliche Goldschmiede.

Einen goldenen Ring mit einer feinen Perle besitzt Hans Junge, der vermutlich der Sohn des Lübecker Goldschmieds Stefan Junge ist. So wird es sich bei dieser Perle um eine echte Perle handeln, die der Europäische Markt aus dem Indischen Ozean bezog ${ }^{23}$.

Eine mögliche Form der ohne Stein verfertigten Goldringe kann das Verflechten dreier Stränge sein ${ }^{24}$; einen derartigen Ring vererbt der in den Diensten der Stadt Lüneburg stehende Hans Junge dem Rat der Stadt und fügt - wie ein Goldschmiedsohn es täte ${ }^{25}$ - hinzu, der Ring wiege zwei licht gulden ${ }^{26}$. Beke Groning, die in ihrem Testament nicht nur über viele Schmuckstücke, sondern im besonderen auch über einige Ringe verfügt, empfindet ihren unverzierten Goldring als enen slichten gulden ringk ${ }^{27}$. Ebenfalls einen goldenen Ring, in vielleicht nicht ganz so schlichter Ausführung, hinterläßt der Lübecker Kanoniker Johannes Weidenknepel seinem Bischof Nikolaus.

Geseke Rosemberg beschreibt ihren goldenen Ring als Ring, da lasper, Melchior unde Baltasar ingegraven $i^{28}$. Die Lüneburger Zunftrollen der Goldschmiede von ca. 1400 zeigen, daß diese Technik der eingelassenen Buchstaben eine gerngenutze war, deren Beherrschung jeder zunftzugehörige Goldschmied nachweisen mußte ${ }^{29}$. Es ist nicht unüblich, Schmuckstücke mit

\footnotetext{
${ }^{22}$ In Lübeck AHL, Test. 1473 Juli 10, Testament des Jürgen Geverdes, Sohn des Lübecker Ratsherrn Andreas Geverdes, in dem ein goldener Ring mit Rubin und Diamant vererbt wird. Hinweis auf Lübeck freundlicher Hinweis R. Feismann; für Konstanz siehe P. BAUR, Testament und Bürgerschaft, S.242.

${ }^{23}$ Über den Fundort der Perlen siehe E. WURMBACH, Das Wohnungs- und Kleidungswesen des Kölner Bürgertums, S.70. Aufschlußreich über ,unechte“ Perlen W. ERDMANN und H.

NITSCH, Spätmittelalterliche und frühneuzeitliche Perlen aus einer Kloake der Fronerei auf dem Schrangen zu Lübeck, in: Lübecker Schriften zur Archäologie und Kulturgeschichte, Bd.12, Bonn 1986, S.137 - 165.

${ }^{24}$ Einen vielleicht dreisträngigen, vielleicht aber auch aus drei Einzelsträngen bestehenden Ring zeigt das Portrait des Nürnberger Kaufmanns Jörg Ketzler aus dem Jahr 1471. H. BOOCKMANN, Die Stadt im späten Mittelalter, Abb.474, S.324. Drei Ringstränge nebeneinander, die den Eindruck eines einzigen Ringes hervorrufen, auf dem Bildnis des Hans Tucher, gemalt von Albrecht Dürer, 1499, abgebildet in: Kat. „Kunst der Reformationszeit“, Berlin 1983, Nr. C. 39. 1.

${ }^{25}$ Der heilige Eligius in seiner Goldschmiedswerkstatt, Petrus Christus (1410/20-1472/73), Abb. in: Kulturgeschichte Europas, hg. v. F. Winzer, Braunschweig o.J., S.335.

${ }^{26}$ U. REINHARDT, Testamente, Nr.163, S.224.

${ }^{27}$ U. REINHARDT, Testamente, Nr.217, S.313.

${ }^{28}$ U. REINHARDT, Testamente, Nr.237, S.354.

${ }^{29}$ Das dritte vorzuweisende Meisterstück is eyn handtruwebratze gegraven myt bo(e)kstaven und amlegeret. E. BODEMANN, Die älteren Zunfturkunden der Stadt Lüneburg, S.96.
} 
Anrufungen an Heilige zu versehen; so vererbt Beke Groning 1451 einen Armreif mit der Inschrift „Sankt Katherina“. Zwei in Münster gefundene Fibeln, die wohl aus der Jahrhundertwende vom 13. zum 14. Jahrhundert stammen, weisen eine emaillierte Inschrift mit einem Muttergottesanruf auf, eine im Vergleich zu den Lüneburger Schmuckstücken von der Intention her gleiche, jedoch anders ausgeführte Machart ${ }^{30}$.

Zwölf Ringe fallen an Familienmitglieder, wobei neun Ringe für Frauen, drei Ringe für Männer bestimmt sind, und zehn Ringe bleiben den Testatoren bekannten Personen vorbehalten, unter denen sich fünf Frauen und vier Männer befinden, und einmal - im Fall Hans Junges - soll der Rat als Dienstgeber des Testatoren Empfänger des Legats sein. Eine definitive Bevorzugung der Frauen als Legatsempfängerin kann nicht geschlußfolgert werden, weil die Anzahl an Ringen im Testament der Beke Groning mit fünf Exemplaren derart hoch ist, daß es das Gesamtergebnis maßgeblich beeinflußt. Fünf Ringe werden als Legate ad pias causas vergabt. Neben der gewollten Verwendung für den Bau von St. Lamberti sowie der Johanniskirche und für eine neue Monstranz in St. Nikolai bestimmt Meyne von der Moyde in seinem 1417 errichteten Testament, den zwei nach Aachen und Wilsnack auszusendenden Pilgern solle man rechtzeitig je einen Ring geben, damit sie unterwegs nicht betteln müßten ${ }^{31}$. Diese Verfügung zeigt exemplarisch einige Komponenten des Pilgerwesens: Ein Pilger soll möglichst schnell nach dem Tod des Testators auf die Pilgerreise gehen und er soll seine Reise finanziert bekommen, um unterwegs nicht betteln zu müssen. Der Hintergedanke dieser Überlegungen war wohl die Idee, das Ablenkungsrisiko des Pilgers von seiner „Arbeit“ möglichst minimal zu halten. Im Vorhinein mußte also der Testator oder einer seiner Vollstrecker die Kosten einer Pilgerreise abschätzen. Lübecker Testamente geben für die Pilgerschaft nach Aachen Kosten in der Höhe von

\footnotetext{
${ }^{30}$ Kat. „Stadt im Wandel“, Bd.1, Nr.246, S.308ff.

${ }^{31}$ Mit der Wahl des Zielortes Wilsnack befand sich der Testator gewissermaßen „im Trend“, denn das Wilsnacker Pilgerzeichen ist das in Norddeutschland am häufigsten aufgefundene, ein Indiz für die regional übermäßige Beliebtheit dieses Wallfahrtsortes. J. WITTSTOCK,

Pilgerzeichen und andere Wallfahrtsdevotionalien in Norddeutschland, in: Kat „Aus dem Alltag der mittelalterlichen Stadt“, S.196 Der Wallfahrtsort Aachen mit der alle sieben Jahre stattfindenenden Aussetzung der Reliquien ist für die Lüneburger insofern präsent, als eben alle sieben Jahre vor der Hasenburg an der Landwehr eine Proviantstation für die aus dem Norden bzw. bei der Heimkehr aus dem Süden strömenden Pilger eingerichtet wurde. Etliche Testatoren steuern in ihren letztwilligen Verfügungen Essenslegate zur Versorgung der Pilger bei. Kurzinformation und weiterführende Literatur zur Aachenfahrt J. RAMACKERS, „Aachenfahrt“, in: LThK, Bd.1, Sp.2.
} 
zwei bis zehn Mark $a^{32}$. Eine Wallfahrt nach Wilsnack müßte aufgrund der größeren geographischen Nähe entsprechend günstiger gewesen sein.

Armreife

Drei Frauen sind es, die in ihren Testamenten über Armreife, den boech, verfügen. Neben die bereits über Ringe verfügenden Wobbeke Boltzen und Beke Groning tritt Geseke Leyferd mit ihrem 1485 errichteten Testament, in dem über drei Armreife verfügt wird. Wobbeke Boltzen verschenkt zwei Armreife und Beke Groning einen Armreif. Beide Testatorinnen bedenken ihre Kinder, während Geseke Leyferd, deren Testament keine Kinder verzeichnet, Bekannte als Erbnehmer einsetzt. Insgesamt befindet sich unter den sechs Bedachten nur ein Mann.

Die beiden Armreife, deren Herstellungsmaterial angegeben ist, bestehen aus Silber, wobei der eine jedoch vergoldet ist. Auch Armreife können mit Edelsteinen besetzt sein: Geseke Leyferd besitzt einen mit einem Saphir versehenen Reif. Armreife dienen auch als Träger religiöser Motivik, wie der mit der heiligen Katherina versehene Armreif und Geseke Leyferds ewangelium bœck ${ }^{33}$.

Brosche

Vier Testatoren verfügen in der ersten Hälfte des 15. Jahrhunderts über insgesamt sieben Broschen (Vikar Johannes von Lippinghausen 1414 und 1424, Hans Junge 1430, Soffeke Springintgut 1439 und Nickel Lesnis 1447).

Genannt werden die Schmuckstücke tassia, bratze, span und spange. Ihr praktischer Nutzen lag in der gewandraffenden Funktion. Die Bildwerke zeigen Broschen vorwiegend als zusammenhaltendes Element der Überbekleidung wie z.B. der Hoiken ${ }^{34}$.

Offenbar werden Broschen gerne aus Silber angefertigt, denn allein sechs der testamentarisch erwähnten Broschen sind aus diesem Metall hergestellt. Über das eigentliche Aussehen der Broschen gibt keines der Testamente Auskunft, wenngleich die Broschen nach Größe unterschieden oder durch Wertangaben in Lüneburger Währung charakterisiert werden.

\footnotetext{
${ }^{32}$ N. OHLER, Zur Seligkeit und zum Troste meiner Seele. Lübecker unterwegs zu mittelalterlichen Wallfahrtsstätten, in: Zeitschrift des Vereins für lübische Geschichte und Altertumskunde 63, 1983, S.89.

${ }^{33}$ U. REINHARDT, Testamente, Nr.270, S.426.
} 
Johannes von Lippinghausen schenkt seine drei Broschen inm bekannten Personen, darunter eine dem Archidiakon von Modestorpe, während Soffeke Springintgut ihren Sohn bedenkt. Vier Broschen fallen also an Verwandte des Testators oder inm bekannte Personen, während drei Broschen einer Kirche und einem Kloster zugewendet werden. Nickel Lesnis Schmuckbroschen sollen zur Herstellung eines Kelches dienen, wobei man noch drei ungarische Gulden hinzunehmen soll, altes Geld und Knöpfe, eben alles, was in seinem Nachlaß aus Silber besteht. Hans Junge hinterläßt den Barfüßern nicht nur seine silberne Brosche, sondern auch eine silberne Kette und ein silbernes Marienbild oder Marienfigur. Die Brosche - so formuliert der Testator - sei für eine Chorkappe; zu denken ist weniger an den Verkauf des Schmuckstücks für die Anschaffung einer Chorkappe, sondern eher an eine gewollte Benutzung der Brosche zum Zusammenhalten des Chormantels. Das Bildprogramm der Broschen war überwiegend religiös geprägt, so daß allein bei der gegenständliche Überlieferung des deutschsprachigen Raums nicht immer feststeht, ob ein Schmuckstück von einem laikalen oder klerikalen Träger verwendet wurde. Der Wert des Legats nun läßt sich anhand der Gegenleistung bemessen, die die Barfüßer Hans Junge zugestehen: Hans Junge bekommt eine Grabstelle in ihrem Kreuzgang zugewiesen ${ }^{35}$; die Kette und das Marienbild bzw. die Marienfigur werden zur Finanzierung des Begräbnisses und der Seelenmessen herangezogen.

Kette

Außer der testamentarischen Erwähnung der Silberkette Hans Junges findet sich in Lüneburg nur noch das 1473 errichtete Testament des Sülfmeisters, Barmeisters und Ratsherrn Johann vame Lo, in dem keden und halszbant Erwähnung finden ${ }^{36}$. Die überwiegend wohl goldenen (Hals-) Ketten können von

\footnotetext{
${ }^{34}$ z.B. Mantelbrosche auf der Darstellung „,Der heilige Martin teilt seinen Mantel mit einem Bettler“, Sierenz/Elsaß, Mitte 15. Jahrhundert, in: H. BOOCKMANN, Die Stadt im späten Mittelalter, Abb. 23, S.22.

${ }^{35}$ Ein Begräbnis im Klosterbereich war bei den Bürgern Lüneburgs recht beliebt. Dem Interesse der Bürger an einem Begräbnis im Kloster St. Marien stand eine eindeutig lebensbetonende Haltung der Klosterbrüder gegenüber, wie KRÜGER/REINECKE berichten: „Da ist vom Bruch der Klausur, von Trinkgelagen innerhalb und außerhalb des Klosters, von Errichtung einer Klosterschenke,von sonntäglichen Geldverteilungen, von privatem Hausgerät, goldenen und silbernen Kleinodien der einzelnen Klosterinsassen, von Vergehen gegen die Sittlichkeit die Rede.“ Alle Angaben bei F. KRÜGER/W. REINECKE, Kunstdenkmale, S.160f.

${ }^{36}$ Ein Halsband wird wohl eine eng am Hals anliegende Kette sein, so wie sie auf der Danziger Festtafel aus dem Jahr 1518 dargestellt ist. H. BOOCKMANN, Die Stadt im späten Mittelalter, Abb. 109, S.74.
} 
beachtlicher Breite und damit Schwere sein $^{37}$. Gerade Ketten unterschiedlicher Länge werden gemeinsam getragen ${ }^{38}$. Zwei Ketten - möglicherweise unterschiedlicher Länge - hinterläßt Johann vame Lo in seinem Testament 1473. Sie müssen sehr wertvoll gewesen sein, denn aus ihnen soll ein vom Testator genau beschriebenes, prachtvolles Kreuz gefertigt werden.

Während in den Lüneburger Testamenten die drei Ketten für das Seelenheil verwendet werden, so werden in Konstanzer Testamenten Ketten ausschließlich an Frauen vererbt, obschon Männer durchaus Ketten tragen ${ }^{39}$.

Ein sulverne henghe, das sich beim Goldschmied Hans Schele befindet, besitzt Geseke Springintgut, wie sie in ihrem 1425 errichteten Testament vermerkt. Spätmittelalterlichen Darstellungen zufolge werden die Anhänger an Ketten getragen ${ }^{40}$. Sie scheinen von einer durchaus auffallenden Größe gewesen zu sein. Bekannt sind Anfertigungen in Blumen und Tierform ${ }^{41}$. Der Anhänger Geseke Springintguts, dessen Aussehen unbekannt bleibt, soll zum Anlegen einer Rente von vier Mark dienen, die zunächst der Klosterfrau Ilsebe Gildehausen im Kloster Lüne zugute kommen soll, nach deren Tod dann an deren Schwester Gheseke Schonewerder in Lübeck fallen soll.

\section{Kopfzier}

Eine einzigartige Verfügung trifft 1441 Hermann Kruse in seinem Testament: Er hinterläßt seinen drei Töchtern die parleden kronen, die seine verstorbene Frau für die Töchter anfertigen lie $\beta^{42}$. Auch die Frauen seiner Söhne dürfen diese Krone tragen, aber die Töchter bleiben die Eigentümerinnen dieser Kostbarkeit. Eine derartige reifartige, mit Perlen besetzte Kopfzierde ist für die reiche Oberschicht keine Alltäglichkeit, denn die „kleinen Kränze aus Gold, Silber und Perlen waren die kostbarsten “43. Insofern ist es nicht weiter verwunderlich, daß

\footnotetext{
${ }^{37}$ E. WURMBACH, Das Wohnungs- und Bekleidungswesen des Kölner Bürgertums, S.92f; Abbildung einer schwere Goldkette, die ihren Träger als besitzgierigen Menschen darstellen soll auf dem wohl 1503 entstanden Gemälde „St. Fridolin mit Urso vor Gericht“, in: Kat. „Himmel Hölle Fegefeuer“, Abb.63, S.249.

${ }^{38}$ Ein Beispiel aus den ersten Jahren des 16. Jahrhunderts ist das Stifterbildnis der Margarete, Frau des Frankfurter Ratsbürgers Klaus Stalburg. H. BOOCKMANN, Die Stadt im späten Mittelalter, Abb.467b, S.318.

${ }^{39}$ P. BAUR, Testament und Bürgerschaft, S.243.

${ }^{40}$ Kat. ,, Aus dem Alltag der mittelalterlichen Stadt, Abb. 50, S.46; H. BOOCKMANN, Die Stadt im späten Mittelalter, Abb.8, S.15.

${ }^{41}$ E. WURMBACH, Das Wohnungs- und Kleidungswesen des Kölner Bürgertums, S.93.

${ }^{42}$ U. REINHARDT, Testamente, Nr.200, S.282. In der Drucklegung ist das Wort parleden fälschlicherweise getrennt.

${ }^{43}$ L. C. EISENBART, Kleiderordnungen, S.155.
} 
das Tragen dieser wertvollen Zierstücke in etlichen Städten verboten ist. Die Lüneburger Kleiderordnung enthält keine diesbezügliche Klausel.

\section{Bisamapfel}

Vicke Bottermann ist der einzige Testator, der testamentarisch über eynen sulveren dezemes knop verfügt ${ }^{44}$. Das an den Vikar und Testamentsvollstrecker Borchard Springk fallende Legat ist unter dem Namen „Bisamapfel“ bekannt. Diese mit Geruchsstoffen gefüllte Schmuckkugel ${ }^{45}$ gilt als Ausdruck besonderen Reichtums und wird gern als Synonym des Wohlstandes vorwiegend auf Portraitzeichnungen abgebildet, auf denen der Auftraggeber oder seine Angehörigen einen Bisamapfel in den Händen halten. So zeigen Bilder Lüneburger Bürgermeister die beiden aus der Familie Töbing stammenden Bürgermeister des 16. Jahrhunderts mit einem Bisamapfel in der Hand ${ }^{46}$. Der einzige in Lüneburg überlieferte Bisamapfel ist wie der des Testators Bottermann aus Silber gefertigt; er stammt aus dem 16. Jahrhundert ${ }^{47}$. Am Schraubverschluß befinden sich an zwei Seiten Ösen, an denen der Bisamapfel befestigt werden kann. Die Kugelhälften sind mit Rosetten verziert, deren zwei nicht durchbrochen sind und Wappen tragen. Eines der Wappen ist das der Familie Töbing.

Der Bisamapfel kam durch Vermittlung der Kreuzzüge aus dem Orient nach Europa, und noch die von Vicke Bottermann verwendete Bezeichnung dezemes - andernorts manchmal auch als a la façon de Damaz genannt - verweist auf die Herkunft. Durchaus üblich ist es, das Schmuckstück aufgrund seiner runden Form als Knopf zu titulieren; natürlich legt die Form auch die Assoziation mit Apfel nahe, die sprechender ist, weil 1174 Gesandte Balduins von Jerusalem Kaiser Friedrich Barbarossa mit Moschus gefüllte, goldene Äpfel überreichten, die bislang den Vertretern des Abendlands unbekannt waren. Moschus, auch Bisam oder Pisam genannt, gilt als wertvollster aller Riechstoffe des Mittelalters, durch dessen Besitz ein Jeder, der es sich leisten konnte, neben dem Wert der Ausfertigung des zugehörigen Gefäßes seinen Wohlstand aufs Trefflichste

\footnotetext{
${ }^{44}$ U. REINHARDT, Testamente, Nr.252, S.387.

${ }^{45}$ Grundlegende Informationen bei H. WENZEL, „Bisamapfel“, in: RDK, Bd. II, Sp.770ff; E. VAVRA, „Bisamapfel“, in: Lexikon des Mittelalters, Bd.II, Sp.227.

${ }^{46}$ Kat. „,Das Lüneburger Ratssilber“, bearb. v. H. Appuhn, Lüneburg 1954, Nr.51, 52 Aus Konstanz stammt das Portrait des Heinrich Blarer, der einen an einer langen Kette befestigten Bisamapfel von beträchtlicher Größe in der rechten Hand hält. Abgebildet bei $\mathrm{H}$. BOOCKMANN, Die Stadt im späten Mittelalter, Abb. 473, S.323 BAUR sieht in der Kette aus nicht einsichtigem Grund eine Rosenkranzkette. P. BAUR, Testament und Bürgerschaft,S.241
} 
hervorheben konnte. Bisamäpfel können an Ketten befestigt oder auch Teil des Rosenkranzes $\operatorname{sein}^{48}$. Aufgrund seines starken Geruchs ist der Bisamapfel während Pestzeiten sehr beliebt, wobei inm ohnehin medizinische Eigenschaften zugeschrieben wurden ${ }^{49}$.

Wenn auch Bildwerke und Sachüberlieferung in Lüneburg aus dem 16. Jahrhundert stammen, so mag doch der testamentarisch erwähnte, aus dem 15. Jahrhundert stammende Bisamapfel nicht so anders ausgesehen haben; darüberhinaus ist er Beleg für die aufgrund des Reichtums etlicher Lüneburger Bürger auch nicht anders zu erwartende Existenz von Bisamäpfeln im Lüneburg des Spätmittelalters. Das Testament des Vicke Bottermann als alleiniges Zeugnis der testamentarischen Vererbung von Bisamäpfeln zeigt, daß diese hochgeschätzen Wertgüter im Regelfall innerhalb der Familie vererbt wurden. Das Legat des Vicke Bottermann wird vor dem Hintergrund des sich um sein gehbehindertes Kind sorgenden Vaters verständlich, der wünscht, daß man seinem Kind zu gegebener Zeit eine Pfründe besorgen soll; und wer könnte diese Versorgung besser organisieren als der Vikar Borchard Springk zusammen mit den Brüdern des Testators?!

\section{Rosenkranz}

Ein aus dem religiösen Bereich stammendes Schmuckstück ist der Rosenkranz, der auch der rein profanen Schmuckzier dient. Gebetsschnüre sind verschiedensten Religionen als zur Andacht gedachtes Zählmittel von Gebetsformeln bekannt, wobei mehr oder minder unterschwellig die Erzielung einer magischen Wirkung unterstellt wird ${ }^{50}$. So verschmelzen im Rosenkranz die Bereiche Religion, Schmuck und Magie.

\footnotetext{
${ }^{47}$ E. MICHAEL, Leitfaden durch das Museum in Lüneburg, Nr. F 8, S.118; zuletzt in Kat. „Hanse•Städte•Bünde“, Bd.2,Nr.2.49, S.97ff (o. Abb.).

${ }_{48}$ siehe Portrait des Frankfurter Bürger Klaus Stalburg. H. BOOCKMANN, Die Stadt im späten Mittelalter, Abb. 467a, S.318 JARITZ berichtet von zwei, 1464 in Tulln testamentarisch vererbten Korallenrosenkränzen, bei denen die Korallenperlen durch Bisamäpfel gegliedert sind. G. JARITZ., Zur Lebenshaltung in niederösterreichischen Kleinstädten während des späten Mittelalters, In: Festschrift für F. Hausmann, Graz 1977, S.258.

${ }^{49}$ vgl. Spruch des Nürnberger Meistersingers Hans Folz von 1482. Zitierte bei P. BAUR, Testament und Bürgerschaft, S.241.

${ }^{50}$ A. WALZ, „Rosenkranz“, in: LThK, Bd.9, Sp.45 - 49; instruktive Ausführungen auch bei P. BAUR, Testament und Bürgerschaft, S.243 - 246 mit Literaturhinweisen Die Gebetsschnur selbst gilt als Vorläufer der Rosenkränze; sie bestand aus auf eine Reihe gezogenen kleinen Ringen. Erklärung zu der unter Nr. 87 abgebildeten Gebetsschnur in: Kat. „Das ritterliche Basel. Zum 700. Todestag Konrads von Würzburg“, S.137.
} 
Anders als in Konstanzer Testamenten ist in Lüneburg der Rosenkranz kein ständig in den Testamenten auftretendes Legat ${ }^{51}$, sondern wird in sieben Testamenten des 15. Jahrhunderts verzeichnet. Männer und Frauen treten in fast gleicher Anzahl als Erblasser auf (den vier Testatorinnen Wobbeke Boltzen 1428, Soffeke Springintgut 1439, Beke von dem Berge 1466 und Geseke Rosemberg 1472 stehen drei Testatoren Hans Junge 1430, Luteke Nyebur 1481 und Hans Tetendorp 1493 gegenüber).

Im Lauf der Zeit verschmelzen die bei Klerikern und Laien von jeher weit verbreiteten Marienanrufungen, genauer der Marianische Psalter mit den $150 \mathrm{zu}$ betenden Ave Maria, mit dem Beten des Rosenkranzes. Als Gebetshilfe umfaßt die Gebetskette fünfmal je zehn Kugeln/Perlen für die Ave Mariagebete, das Vaterunser und die Betrachtungen ${ }^{52}$. Zeichen der besonderen Beliebtheit des Rosenkranzes im Spätmittelalter ist der große Bedarf und die umfangreiche Produktion von Rosenkränzen sowie die Gründung der Rosenkranzbruderschaft 1475 durch den Kölner Dominikaner Jakob Sprenger, dessen Idee der Gebetsbruderschaften bis auf den heutigen Tag - wenn auch in abgeschwächter Form - Bestand hat.

Der überwiegend von der Literatur verwendete, den Quellen entnommene lateinische Terminus paternoster wird von den Lüneburger Testatoren nicht verwendet. Sie bezeichnen ihren Rosenkranz entweder als corallensnor bzw. crallensnor oder als vefftich (aus 50 Kügelchen gefertigt). Wenn auch die Andersartigkeit der verwendeten Schriftsprache, nämlich des Mittelniederdeutschen, als vorrangige Erklärung angeführt werden muß, so zeigt sich gerade in dem Zurückdrängen der lateinischen Sprache der Wandel, bei dem als Ersatzbegriff ein nicht mehr auf das Gebet verweisendes Wort dient, sondern eines, das definiert ist durch Beschaffenheit und Stückzahl des verwendeten Materials ${ }^{53}$. Natürlich steht die Stückzahl der Perlen für die Anzahl der Gebete und auch die Korallen stehen wie das Gebet in nahezu synkretistischer Weise für die Abwehr von Unheil jeder Art $^{54}$, aber unübersehbar ist doch der Akzent, der der Namensgebung immanent ist. Die von jedem der Lüneburger Testatoren sowie auch von etlichen Konstanzer Testatoren angeführte Bezeichnung des Materials verweist auf die zunehmende Beliebtheit

\footnotetext{
${ }^{51}$ P. BAUR, Testament und Bürgerschaft, S.243.

${ }^{52}$ Die verschiedenen Gebetsarten des Rosenkranzes sind bei A.WALZ, „Rosenkranz“, in: LThK, Bd.9, Sp.46f, dargestellt.

${ }^{53}$ ERDMANN/NITSCH sprechen von ,Paternostern, welche im späten Mittelalter auch als Rosenkränze bezeichnet wurden“. W. ERDMANN und H. NITSCH, Spätmittelalterliche und frühneuzeitliche Perlen aus einer Kloake der Fronerei auf dem Schrangen zu Lübeck, S. 143.
} 
des Rosenkranzes auch als Schmuckelement, bei dem der Wert des Materials die soziale Wertigkeit der Trägerin oder des Trägers ausdrückt. Insofern ist es gar nicht weiter verwunderlich, daß die Ende des 14. Jahrhunderts kodifizierte Lüneburger Polizeiverordnung das Tragen des Korallenrosenkranzes reglementiert: Die Mägde der Bürgerinnen und Bürger dürfen als Hoikenschmuck Zierat bis zu einer halben lötigen schweren ferding tragen, darüberhinaus ist es unter Strafandrohung untersagt, weiteres Geschmeide oder Korallenrosenkränze zu tragen ${ }^{55}$. Gänzlich verboten ist das Tragen von Rosenkränzen Frauen mit schlechtem Ruf. Über die Nutzung des Rosenkranzes als Schmuckstück von Bürgerinnen und Bürgern gibt das Luxusgesetz keine expliziten Angaben, weil die Angabe der zu Tragen erlaubten, nach dem zu versteuernden Vermögen bemessenen Schmuckmenge allein in finanzieller Wertigkeit ausgedrückt wird.

Der Wert der aus dem Mittelmeerraum stammenden, zu Perlen verarbeiteten Korallen bedingt das Aufnehmen des Korallenrosenkranzes in die Luxusgesetze etlicher Städte ${ }^{56}$. Am Beispiel Göttingens konnte gezeigt werden, daß nur ein Bruchteil der Bürger sich das Tragen der Korallenrosenkränze leisten konnte ${ }^{57}$. Offen bleibt die Frage, inwieweit die Luxusgesetze tatsächlich gegriffen haben. Die Herkunft, die Lebensumstände und der Inhalt der Testamente der Lüneburger Testatoren sprechen für die Zugehörigkeit der Testatoren zu jenem Bruchteil der Stadtbürger, denen das Tragen eines solchen Wertobjektes nicht versagt ist ${ }^{58}$.

Nicht jeder Rosenkranz besteht aus derart kostbarem Material. Schon allein die Verankerung des Rosenkranzes als Teil der Frauengerade weist auf sein Vorkommen in nahezu jedem Haushalt hin ${ }^{59}$. Die Perlen können hergestellt sein aus Bernstein, Gagat, Korallen, Holz und Bein, wobei Gagat, Bernstein und Korallen aufgrund der innen zugeschriebenen magischen Wirkung gerne zu Rosenkränzen verarbeitet werden. Wie die echten Korallen ${ }^{60}$ als entsprechend günstigeres Gegenstück unechte Korallen (z.B. aus Holz) haben, so ist der

\footnotetext{
${ }^{54}$ Bedeutung, die der Koralle beigemessen wurde in: Kat. „Stadt im Wandel“, Bd.1, S.248.

${ }^{55}$ W. F. VOLGER, UB Lüneburg, Bd. III, S. 434.

${ }^{56}$ H. BOOCKMANN, Leben und Sterben, S.11ff. Über die Verarbeitung der Korallen bei W. ERDMANN und H. NITSCH, Spätmittelalterliche und frühneuzeitliche Perlen aus einer Kloake der Fronerei auf dem Schrangen zu Lübeck, S.144.

${ }^{57}$ H. BOOCKMANN, Die Stadt im späten Mittelalter, S.12.

${ }^{58}$ Über welches Gesamtvermögen Hans Junge, vermutlich Spielmann, Ratsbedienster und Sohn eines Goldschmieds, verfügen konnte, bleibt unklar, wenngleich sein vorwiegend über Schmuckstücke verfügendes Testament auf einen nicht unwohlhabenden Mann hinweist.

${ }^{59}$ W. F. VOLGER, UB Lüneburg, Bd.III, S.436.

${ }^{60}$ M. GRAMS - THIEME, ,Koralle“, In: Lexikon des Mittelalters, Bd.V, Sp.1441f.
} 
vorwiegend aus England oder Spanien stammende Gagat (=schwarze Braunoder Pechkohle) das günstige Pendant zum Bernstein. Die Perlen des Rosenkranzes können - wie offenbar sieben der acht testamentarisch erwähnten Rosenkränze - aus ein und demselben Material bestehen; immerhin zeigen etliche Bildwerke reine Korallenrosenkränze ${ }^{61}$. Aber auch eine Materialkombination war möglich, wie das Beispiel des Rosenkranzes des Hans Junge zeigt; beschrieben wird er als en veftich van aghaten stene, dar sint corallen mede $y n n e^{62}$. Ein von der Machart der Materialkombination her vergleichbarer Rosenkranz ist in Lüneburg überliefert ${ }^{63}$; das verwendete Material ist Gagat, Silber und Perlmutt. Vor der ersten Gagatperle befindet sich als Einhänger eine kleine Pilgermuschel aus Perlmutt und in die erste Perle eingeschnitzt sind vier Muscheln. Nach der je zehnten Perle befindet sich jeweils durchbrochen gearbeitetes Silber. Pilgermuschel und die vorrangige Verwendung von Gagat, das in großen Mengen in Spanien gewonnen wurde, sprechen für die Herkunft von einer Pilgerfahrt nach Santiago de Compostela.

An wen fallen die Rosenkränze? Vier der acht testamentarisch vererbten Rosenkränze bleiben in den Händen von Familienmitgliedern. Unklar ist, ob es sich bei den in Luteke Nyeburs Testament bedachten Mädchen/jungen Frauen um die Töchter eines Verwandten oder eines Bekannten handelt. Die Tatsache, daß es sich bei dem Erbstück um den Rosenkranz von Luteke Nyeburs Mutter handelt, deutet zumindest auf eine enge Verbundenheit zwischen Testator und Erbnehmerinnen hin. Die Frauen werden den Rosenkranz natürlich zum Beten genutzt haben, aber sie können ihn auch als Zierde - wie oben beschrieben verwendet haben. Die Bildquellen zeigen die Rosenkränze in den Händen ihrer (betenden) Besitzer, wobei oft an den Rosenkranz ein Kreuz oder auch Bisamapfel angehängt ist; er konnte aber auch an den Gürtel gehängt sein oder um den Hals getragen werden ${ }^{64}$.

\footnotetext{
${ }^{61}$ Als Beispiel: Ausschnitt aus dem Epitaph des Georg Keypers, Gemälde von M. Wolgemut, ca. letztes Viertel des 15. Jahrhunderts, Nürnberg, Lorenzkirche, in: Kat. „Aus dem Wirtshaus zum Wilden Mann“, Abb. 7, S. 24.

${ }^{62}$ U. REINHARDT, Testamente, Nr.163, S.224.

${ }^{63}$ Beschreibung bei E. MICHAEL, Leitfaden durch das Museum, Nr. E 69, S.100; mit Abbildung in: Kat. „Aus dem Alltag“, S.197f; zuletzt Kat. „Hanse•Städte•Bünde“, Bd.2, Nr.4.26, S.219 (o. Abb.).

${ }^{64}$ Am Gürtel der Elisabeth hängender Rosenkranz mit Einhängsel auf der Darstellung der Begnung mit Maria vom „Meister des Marienlebens“ aus der Kölner St. Ursulakirche, 15. Jahrhundert bei H. BOOCKMANN, Die Stadt im späten Mittelalter, Abb.462, S.312; Rosenkranz als Attribut einer Bürgerin auf der 1481 enstandenen Tafel des Eggelsberger Altars, Geburt Mariens, ebd., Abb.138, S.90; Stifterbildnisse des Klaus Stalburg und seiner Ehefrau Margarete; Klaus Stalburgs Rosenkranz ist mit einem Bisamapfel versehen, ebd., Abb. 467 a, b, S.318 Um
} 
Hans Junge bedenkt nicht seinen Stiefsohn mit dem Rosenkranz, sondern der Testator ordnet an, daß der Kranz Unser Leven Vrowen bilde, dar dat licht steyt um den Hals gehängt werde ${ }^{65}$. Offensichtlich meinte er die von inm dem Franziskanerkloster überlassene silberne Maria, die er nun mit dem Rosenkranz zu schmücken gedachte. Das Schmücken eines Bildes oder einer Statue mit Rosenkränzen, Ringen oder gar Kleidern war etwas durchaus Übliches ${ }^{66}$. Da Korallen als Förderer einer lebensfrohen Einstellung gerade eines Kindes galten und gerne dem Jesuskind umgehängt wurden, ist zu vermuten, daß das Marienbildnis Junges ebenfalls den Knaben Jesus darstellt. Ein vom Prinzip her vergleichbares Beispiel ist die silberne Marienstatue aus St. Johannis, die nach der Reformation dem Ratssilber zugeschlagen wurde ${ }^{67}$. Die um 1500 in Lüneburg hergestellte Maria hält das Kind auf dem Arm; ihrer Krone übergehängt - und damit auch das Kind umrahmend - ist ein Rosenkranz, dessen Material entweder als Bernstein oder als Koralle bezeichnet wird ${ }^{68}$. Ein zweites Mal wird, nun im Testament Bekes von dem Berges 1466, die Schenkung eines Rosenkranzes an das Franziskanerkloster St. Marien greifbar. Die Beliebtheit des Klosters als Empfängerin von Rosenkranzlegaten wird an dem Marienpatrozinium gelegen haben. Beke von dem Berges testamentarische Sicherung der bereits vor einem halben Jahr erfolgten Schenkung zeugt von der Sorge der Testatorin, den Rosenkranz auch wirklich dem von ihr präferierten Kloster zu erhalten. Geseke Rosemberg setzt als Empfängerin ihres Korallenrosenkranzes zunächst ihre Schwägerin ein, zieht aber deren Zurückweisen des Legats in Betracht; in diesem Fall soll der Rosenkranz zur Ehre Gottes verkauft werden.

\section{Agnus Dei}

Sowohl Nickel Wulfferam als auch Geseke Leyferd vererben ein Agnus Dei (Testamente von 1483 bzw. 1485). Das Agnus Dei stellt „eine der beliebtesten Amulettformen" dar, bei dem es sich um eine Wachsscheibe mit dem Bild des

den Hals gehängter Rosenkranz bei Ch. DAXELMÜLLER, Heil - und Volksglaube, in: Kat. „,Aus dem Alltag“, Abb.4, S.188.

${ }^{65}$ U. REINHARDT, Testamente, Nr.163, S.224.

${ }^{66}$ H. WENTZEL, „Bekleiden von Bildwerken“, in: RDK, Bd. 2, Sp. $219 \mathrm{ff}$.

${ }^{67}$ Sie wurde mit dem Ratssilber nach Berlin verkauft. Genaue Beschreibung bei S. BURSCHE, Das Lüneburger Ratssilber, Nr. 34, S.170ff.

${ }^{68}$ Abbildung der Figur nebst übergehängtem Rosenkranz in Kat. „,Das Lüneburger Ratssilber. Austellung im Oberen Gewandhaus des Rathauses zu Lüneburg (= Sonderdruck des Kestner Museums Hannover), 1956, Abb. 2 sowie Nr.2. Hier wird als Material Bernstein genannt, während BURSCHEL Korallen angibt. 
Lamm Gottes handelt ${ }^{69}$. Ursprünglich stammen die Wachsscheiben von der in der Lateranbasilika vom Papst geweihten Osterkerze, die am Weißen Sonntag in Scheiben geschnitten und an die Gläubigen verteilt wurde ${ }^{70}$. Das früheste Zeugnis stammt aus der Mitte des 8. Jahrhunderts. Die vom Papst zu vollziehende Weihe reduzierte die Weihhäufigkeit von der alljährlichen zu einer im ersten, dann in jedem siebten Pontifikaljahr zu leistenden Weihe. Weil die aus der Osterkerze zu gewinnenden Scheiben von nur geringer Anzahl waren, wurden aus einer mit Öl vermischten Wachsmasse Lämmer hergestellt, die nach der Weihe zerbrochen und an die Gläubigen verteilt wurden. Im späten Mittelalter sind die Wachsscheiben und - stücke so beliebt, daß sie trotz Verbots auch außerhalb von Rom angefertigt und vertrieben werden ${ }^{71}$. Nicht selten wird das Agnus Dei in ein Behältnis aus Silber oder Gold gefaßt, das ebenfalls als Agnus Dei bezeichnet wird ${ }^{72}$. Die zwei Erscheinungsformen dieses Agnus Dei Behälters waren zum einen eine runde, zu öffnende Kapsel, die an Ösen an Kette oder Schnur befestigt werden kann, zum anderen ein monstranzartiges Ostensorium. Ein Ostensorium verweist in erster Linie auf den kirchlichen Bereich, so daß ein Agnus Dei- Behältnis in bürgerlichem Besitz eher an eine verzierte Kapsel denken läßt, die als Ketten- oder Rosenkranzanhänger getragen werden kann ${ }^{73}$. In Lüneburg überliefert ist ein aus dem 16. Jahrhundert stammendes Kapsel - Agnus Dei, das mit einem silbernem Ring an einer silbernen Kette hängt ${ }^{74}$. Auf der Vorderseite befindet sich ein von einem vergoldeten Blütenstab eingerahmter Bergkristall, der den Blick auf einen vergoldeten Cruzifixus ermöglicht. In die als Deckel gearbeitete Rückseite ist das Lamm Gottes eingraviert. Aus dem Nachlaß des 1530 verstorbenen Propstes von St. Johannis, Johann Koller, stammt ein ebenfalls an einer Silberkette hängendes Agnus Dei, das umrahmt ist von 16 Korallen und 17 Perlen $^{75}$. Auf der Vorderseite befindet sich in Perlmuttschnitt das Lamm Gottes mit Fahne und Kelch mit dem Schriftzug „Ecce agnus dei“, auf der Rückseite ist eine Mondsichelmadonna im Strahlenkranz eingraviert. Neben den hier

\footnotetext{
${ }^{69}$ Ch. DAXELMÜLLER, Heil - und Volksglaube, S.187.

${ }^{70}$ S. BEISSEL, Die Verehrung der Heiligen und ihrer Reliquien in Deutschland im Mittelalter ( reprograph. Nachdruck der Originalausgabe 1890.1892), Darmstadt 1991, S.91; W. DÜRIG, „Agnus Dei“ - Absatz III A.D. als Sakramentale, in: LThK, Bd.I, Sp.303f . Bei Beissel ist der Hinweis auf ein Agnus Dei des Lüneburger Schatzes, das man um den Hals trug.

71 „Agnus Dei“", Wörterbuch der deutschen Volkskunde, S. 9.

72 J. BRAUN, , Agnus DEI“, in: RDK, Bd.I, Sp.212 - 216.

${ }^{73}$ Hiervon berichtet E. WURMBACH, Das Wohnungs- und Bekleidungswesen des Kölner Bürgertums, S.92.

${ }^{74}$ Beschreibung bei E. MICHAEL, Leitfaden durch das Museum in Lüneburg, Nr. H 35, S.167.

${ }^{75}$ Beschreibung bei E. MICHAEL, Leitfaden durch das Museum in Lüneburg, Nr. H 34, S.166.
} 
vorgelegten Möglichkeiten der Schmuckfunktion bietet das geweihte Agnus Dei Schutz vor vielerlei Gefahr: Ihm wird der Schutz vor dem Teufel zugeschrieben, vor Blitz, Donner, Feuer, Seuchen, Sünden und Tod im Kindbett ${ }^{76}$. Ein solches Schmuck und Schutz in sich vereinigende Agnus Dei schenkt Nickel Wulfferam seiner Enkelin, während Geseke Leyferds Agnus Dei den Mönchen in Winsen für ein auf den Altar zu stellendes Kußtäfelchen überlassen wird.

\section{c. Schlußbemerkung}

Das Einsetzen von Klerikern als Empfänger von Schmucklegaten, wie z. B. des Bischofs im Testament Johannes Weidenknepels (goldener Ring) oder des Lüneburger Vikars im Testament Vicke Bottermanns (Bisamapfel), zeigt im Wortsinn die Empfänglichkeit des Klerus für Kleinodien. Der z.T. recht ausufernden Vorliebe suchten Konzilien und Synoden mit Verbotserlassen zu begegnen, aber dieser parallel zu den städtischen Luxusverordnungen verlaufenden Gesetzgebung war - wie im Profanbereich auch -nicht der Erfolg beschieden, den die Verfasser beabsichtigt hatten ${ }^{77}$.

Die öfter zu verzeichnenden Schenkungen von Schmuckstücken als Legate ad pias causas sind keine Eigenart Lüneburger Testatoren; es ist eine allseits „beliebte Geste .. das auffälligste Abzeichnen weltlicher Eitelkeit ... im Tode (auf Kosten der Erben) Gott“ zu geben ${ }^{78}$.

Schmuck ist eine Sachgruppe mit relativ konstanter Wertimmanenz. Einen Überblick über den möglichen Bestand an Schmuckstücken und seine Aufbewahrung gibt das Inventar der Lüneburgerin Margarete Grönhagen aus dem Jahr 1544, das die Große Kammer, den eigentlichen „Privatraum der Familie Grönhagen“ als Aufbewahrungsort nennt ${ }^{79}$. Von praktischem Denken zeugt die Wahl dieses Raumes insofern, als hier auch Kleider aufbewahrt werden, so daß die Wahl der "Garderobe“ leichter vonstatten gehen kann, dann ist der Raum durch seine Heizbarkeit und damit wohl geringere Feuchtigkeit ideal zur Lagerung der Edelmetalle geeignet und bietet darüberhinaus aufgrund seiner steten Nutzung eine gute Diebstahlsprävention. Daß ein solcher Schutz

\footnotetext{
${ }^{76}$ Ch. DAXELMÜLLER, Heil - und Volksglaube, S.188; H. SCHAUERTE, Agnus Dei - IV A.D. volkskundlich, in: LThK, Bd.I, Sp.204.

${ }^{77}$ Verhältnis der Kleriker zum Schmuck kurz umrissen bei E. VAVRA, „Schmuck“, in: Lexikon des Mittelalters, Bd.7, Sp.1509.

${ }^{78}$ M. HASSE, Kleinbildwerke, S.64. Hasse nennt das Beispiel der Lübeckerin Margarete Todinghusen, die das Zerbrechen ihres kostbarsten Schmuckstücks und den Verkauf der Einzelteile zur Ehre Gottes anordnete.

${ }^{79}$ Die hier verwendeten Informationen sind entnommen K. TERLAU-FRIEMANN, Lüneburger Patrizierarchitektur, S.89f.
} 
nicht unwichtig ist, zeigt der Umfang des Schmucks, der beschrieben wird als eine Anzahl von „etlichen gefaßten und ungefaßten Perlen und Steinen“, neben denen es "verschiedenste Kleinode, Ketten, Spangen und 60 Ringe“ gibt, die z.T. mit Rubinen, Saphiren und Smaragden verziert $\operatorname{sind}^{80}$. Die Ringe werden z.T. auf Stöcke gesteckt aufbewahrt, so wie es auch in der Werkstatt des Goldschmiedes üblich ist - ein offensichtlich allgemein bekanntes Verfahren ${ }^{81}$. Die Aufsteckstöcke wiederum werden in Laden verschlossen, die zur Aufbewahrung aller Schmuckstücke dienen. Von dieser Aufbewahrungsmöglichkeit zeugt auch das Testament des Heinrich Winthe aus dem Jahr 1490, in dem es heißt: islikeme eyn sulveren handtruwe, de liggen in myner kusten.

Schmuck wird gern alltags getragen, wenn die bildlichen Darstellungen auch ein anderes Bild zeichnen: Sie zeigen Schmuck im Regelfall nicht in der alltäglichen Straßenszenerie oder bei der Hausarbeit, sondern vorwiegend zu repräsentativen Anlässen ${ }^{82}$. Geseke Leyferd kennzeichnet zwei ihrer Armreifen als Festtagsschmuck. Daß etliche der Lüneburger Testatoren als Angehörige der Oberschicht an etlichen opulenten Festen teilgenommen und hier Schmuck getragen haben werden, versteht sich von selbst. Aufgrund des Reichtums Lüneburger Bürger ist anzunehmen, daß sich nicht unbeträchtliche Mengen Schmuck in einigen Haushaltungen befinden. Die Testamente, in denen Schmuck allerdings nur aus besonderem Anlaß Eingang findet, erlauben den ausschnitthaften Einblick in den möglichen Bestand an Pretiosen.

\section{Liturgisches Gerät}

Kelche

\footnotetext{
${ }^{80}$ K. TERLAU-FRIEMANN, Lüneburger Patrizierarchitektur, a.a.O..

${ }^{81}$ Der heilige Eligius in seiner Goldschmiedswerkstatt, Petrus Christus (1410/20-1472/73), Abb. in: Kulturgeschichte Europas, hg. v. F. Winzer, Braunschweig o.J., S.335.

${ }^{82}$ In der Regel zeigen die Malereien mit Schmuck behängte Personen bei Portraits und bei geselligen Anlässen wie z.B. dem Geschlechtertanz in Augsburg oder der Festtafel in Danzig. H. BOOCKMANN, Die Stadt im späten Mittelalter, Abb.109, S.74; Abb.219, S.140 Portraitbeispiel, H. BOOCKMANN, Die Stadt im späten Mittelalter, Abb.470 a,b, S.321.
} 
In fünfzehn Lüneburger Testamenten wird über mindestens siebzehn Kelche verfügt ${ }^{83}$. Die Mehrzahl der Testatoren ist männlichen Geschlechts; unter den zwölf Testatoren befinden sich vier Kleriker. Die drei Testatorinnen sind verwitwet. Die von den Testatoren gewählte Bezeichnung ist kelk.

Einen silbernen Kelch zu spenden, konnte sich nicht Jeder leisten, auch nicht jeder Testator, und so ist es nicht verwunderlich, daß sich unter den Testatoren drei Ratsherren und ein Archidiakon von Modestorpe befinden ${ }^{84}$, und auch die anderen Testatoren wie z.B. Ludolf bei dem Sode aufgrund ihrer Testamente als durchaus wohlhabend erscheinen. Daß nicht alle Testatoren die Finanzkraft eines Heinrich Miles hatten, dessen Gürtel genug Silbergehalt aufwies, um einen Kelch daraus zu fertigen, beweist das Testament des Nickel Lesnis, das in einer Verfügung das restliche Geld und die restlichen Silberutensilien zusammenzieht, um die Anfertigung der Kelches zu ermöglichen. Silberne Gürtel sind beliebte Einschmelzobjekte, deren je eigener Wert an Silber über die Größe und Ausfertigung eines Kelchs entscheidet.

Insgesamt fünf Gürtel werden in den Testamenten als Materialgrundlage für einen Kelch genutzt. Auch auf Trinkgefäße wird zurückgegriffen, wie das Testament des Presbyters Leo aus dem Jahr 1339 zeigt. Das Umschmelzen von Wertstücken ist eine durchaus gängige Praxis, und älteres liturgisches Gerät dient als Materialreservoir für neues ${ }^{85}$. Nicht unüblich ist es, den Kelch ausschließlich oder je nach vorrätigem Material teilweise mit Geld zu finanzieren. Als Höhe des investierbaren Betrages nennen die Testamente Rentenkapital von 100 Mark Pfennigen (allerdings für mehrere Objekte im Testament des Archiakons Johann von Bücken 1375), und Geldbeträge von 20 Mark Pfennigen (Testament des Heinrich vom Hove 1451, in dem erkennbar wird, daß der Gesamtpreis höher liegt) und 30 Mark Pfennigen (Testament Hilleke Blickershusen 1499; hier wohl auch als Teilbetrag anzusehen, da noch drei Ornate mitzufinanzieren sind).

Kelche sind Güter einer materiellen Kultur, die in den Häusern der Lüneburger Bürger im Normalfall nicht verteten sind. So müssen die Testatoren die Anfertigung eines Kelches anordnen oder sie haben sich bereits zu Lebzeiten

\footnotetext{
${ }^{83}$ Das Testament Johann von Bückens 1375 nennt den pluraligen Begriff, bei dem die Anzahl von mindestens zwei Kelchen unterstellt wird.

${ }^{84}$ Heinrich Miles ist Ratsherr und Provisor der Cyriacus- und Johanniskirche, Johann von Bücken ist der Archidiakon von Modestorpe, Johann Semmelbecker ist Ratsherr und Sodmeister und Johann van dem Lo ist Ratsherr und Sülfmeister.
} 
darum gekümmert, so daß die Schenkung des Kelches nun im Testament noch einmal abgesichert wird - wie im Testament Gese Lübberstedts 1415.

Welche Beweggründe für dieses Testierverhalten lassen sich vermuten oder gar anhand der Testamente nachzeichnen? Der Kelch ist mit eines der wichtigen, wenn nicht das wichtigste Altargerät überhaupt. Er zählt zu den vasa sacra, den heiligen Gefäßen, wie Kelch, Pathene, Ziborium und Monstranz aufgrund ihrer Aufnahmefunktion für die zu konsekrierende bzw. konsekrierte Hostie genannt werden $^{86}$. Welche Bedeutung mußte es haben, wenn gerade das vornehmlichste Altargerät die Präsens eines Stifters über seinen Tod hinaus sichern konnte, ein Altargerät, das bereits die frühmittelalterliche lkonographie als Abbild des Lebensbrunnens deutete, für den Stifter sozusagen als symbolischer Garant für das jenseitige Leben stand! In besonderem Maße bedeutet das Umschmelzen eines silbernen Gürtels die Entsagung von weltlichem Schmuck, mit dem ein Testator möglicherweise zu Lebzeiten Gottes Mißfallen hatte erregen können. So formuliert der Ratsherr Johann vame Lo 1473 selbstkritisch: „Ifft ik unsen heren god myd gesmucke effte mid tziringhe vortornet hedde, dat he my dat barmhertigen vorgheve ${ }^{\star 87}$.

Nicht wenige Kelche werden im Rahmen einer Vikarieaustattung gestiftet. Von den sieben für die Kirchen St. Johannis, St. Lamberti und St. Nikolai bestimmten Kelchen sollten fünf Kelche an die vom Testator in der Kirche gestiftete Vikarie fallen: Heinrich Miles stiftet vermutlich eine Vikarie am Grablegungsaltar in der Johanniskirche, an dem er auch begraben werden will ${ }^{88}$, Johann von Bücken errichtet zwei Vikarien am Altar der Maria, ebenfalls in der Johanniskirche ${ }^{89}$, Gese Lübberstedt errichtet eine Vikarie am Martinusaltar der Johanniskirche ${ }^{90}$ und Johann vame Lo stiftet vier Vikarien in St. Nikolai am Altar der Maria in der

\footnotetext{
${ }^{85}$ B. BÄNSCH, Der Schatz der Goldenen Tafel zu Lüneburg bis 1235, in: Kat. Heinrich der Löwe und seine Zeit“", Bd. 2, S. 326.

${ }^{86}$ Die für den Altardienst notwendigen Gerätschaften werden hinsichtlich ihrer Eigenschaften unterschieden nach „heiligen Geräten“ (vasa sacra) und liturgischen Geräten. Der Kelch zählt zu den vasa sacra. Etliche Altargefäße entstammen dem profanen Bereich wie Kelch (Becher) und Patene (Teller), haben aufgrund ihres Verwendungszwecks einen Wandel in ihrer Ausstattung durchlaufen, der dazu führte, daß sie sich von gleichartigem Profangerät abhoben. Vor der Erstbenutzung mußte der Kelch mittels eines Weiheformulars gesegnet werden. J. BRAUN, „Altargerät“, in: RDK, Bd.I, Sp.489-492. Ausführliche Beschreibung des Formenwandels des Kelches bei A. REINLE, Austattung deutscher Kirchen, S.71ff . Neben umfangreichen Informationen wird eine Darstellung der unterschiedlichen Kelcharten wie calix maior, calix minor, calix viaticus etc. dargelegt bei V. H. ELBERN, „,Kelch“, in: LThK, Bd.6, Sp.104 - 106. ${ }^{87}$ U. REINHARDT, Testamente, Nr.240, S.363.

${ }^{88}$ G. MATTHAEI, Vikariestiftungen, S.171.

${ }^{89}$ G. MATTHAEI, Vikariestiftungen, S. 180 .
} 
Marienkapelle, die er selbst an der Südseite des Turmes erbauen lie ${ }^{91}$. Ein Drittel der relevanten Testamente verfügt nicht allein die Anschaffung eines Kelches, sondern bestimmte darüberhinaus die Anschaffung von Pathene, Missale und Meßgewändern, womit eine „Grundausstattung“ für die Meßfeiern vorhanden war.

Wie das Meßgewand ${ }^{92}$, so eignete sich auch der Kelch trefflich als Träger des Familienwappens oder zumindest doch als Träger des Namenszuges des Stifters. Etliche der in Lüneburg überlieferten Kelche tragen derartige Schriftzüge ${ }^{93}$. Auf diese Weise vermag ein Stifter bzw. Testator seine Finanzkraft, seinen sozialen Rang zu dokumentieren, sorgt für das Lebendigbleiben seines Namens, ermöglicht Meßfeiern und die Verehrung des Herrn.

Die testamentarische Erwähnung eines Kelches kann auch einen anderen Grund haben, nämlich dann, wenn der Kelch bereits vorhanden ist und sich in den Händen eines Priesters befindet. Als Beispiel mag hier das Testament des Vikars Ludolf Mangard aus dem Jahr 1478 dienen. Mangard notiert in seinem Testament, zu seiner Vikarie am Marienaltar der Lambertikirche gehörten nicht nur Kleinode, sondern auch ein Haus und Utensilien. Nach seinem Tod müsse alles seinem Nachfolger übergeben werden. Da die Gefahr des Entfremdens bestehe, habe er Kelch, Pathene und eine bessere Kasel nebst Zubehör mit in das Wohnhaus genommen, und so seinen auch diese Dinge seinem Nachfolger auszuhändigen. Im Testament des Klerikers Heinrich Geismars aus dem Jahr 1461 erscheint der dem Nachfolger zu übergebende Kelch nicht direkt gefährdet, eine testamentarische Erwähnung war die Übergabe Heinrich Geismar allemal wert.

In den Testamenten werden über das (mögliche) Aussehen der Kelche keine Angaben gemacht. Grundmaterialien der Kelchanfertigung sind Gold und Silber, Perlen und Edelsteine können als Zierat dienen. Die in Lüneburg überlieferten Kelche bestehen zumeist aus Silber und/oder vergoldetem Silber. Im Regelfall scheint der Testator auf den Geschmack und die Entscheidungen von Frau,

\footnotetext{
${ }^{90}$ G. MATTHAEI, Vikariestiftungen, S.182. Gleichzeitig errichtet Gese Lübberstedt eine Vikarie in St. Nikolai am Petrus- und Georgiusaltar, die sie zwar mit Silbergeräten bedenkt, aber nicht explizit deren Umarbeitung in einen Kelch anordnet. G. MATTHAEI, Vikariestiftungen, S.208.

${ }^{91}$ G. MATTHAEI, Vikariestiftungen, S.206f; auch bei KRÜGER/REINECKE, Kunstdenkmale, S.133.

${ }^{92}$ H. BOOCKMANN, Die Gegenwart des Mittelalters, S.26.

${ }^{93}$ H.W.H. MITTHOFF, Kunstdenkmale und Alterthümer, passim; KRÜGER/REINECKE, Kunstdenkmale, passim; KÖRNER, Leitfaden Museum, S.133 - 137; E. MICHAEL, Die
} 
Tochter und Testamentsvollstrecker gebaut $z u$ haben. $\mathrm{Zu}$ vermuten ist, daß besondere Wünsche mit dem Testator zu Lebzeiten abgesprochen sind. Diese Entscheidungsfreiheit der vom Testator zur Kelchanfertigung beauftragten Personen korrespondiert mit der Entscheidungsfreiheit, die innen in einigen Fällen bei der Wahl des Bestimmungsortes gelassen wird ${ }^{94}$.

Gemeinsam mit den Hamburger Testamenten ist den Lüneburger Testamenten die oft anzutreffende Kelchvererbung, aber auch die Auffälligkeit, daß außer den Kelchen kaum andere Geräte der vasa sacra in den letztwilligen Verfügungen erwähnt werden ${ }^{95}$.

\section{Schrein}

Der Testator Luteke Nyebur stiftet 1481 in seinem Testament 5 Mark Pfennige to deme nyen sulveren schryne to sunte Johanse ${ }^{96}$. Mit Hilfe des Testamentes läßt sich die Datierung dieses Schreins präzisieren, die von der Forschung aufgrund vergleichbarer Goldschmiedearbeiten schon recht genau mit der Zeit um 1480 angegeben wurde ${ }^{97}$. Das Geldlegat Luteke Nyeburs ist als Teilfinanzierung eines Hostienkastens zu verstehen, der für die Johanniskirche gedacht war. Der Hostienkasten steht noch heute in der Johanniskirche in einer Wandnische des Hochaltars. Seinem Aussehen verdankt er die Bezeichnung „Goldene Kirche“. Es handelt sich um einen auf einem Holzuntersatz stehenden rechteckigen Kasten, auf dem ein dachartiger Deckel sitzt. Gefertigt ist er aus auf Holz gezogene, stark vergoldete Silberplatten. Silberrosetten und Edelsteine verzieren den Fußbereich wie das Gesims, auf dem Dach selbst befindet sich durchbrochenes Blattwerk. In der Mitte des Daches ragt der Crucifixus empor, unter dem eine Marien- und eine Johannesfigur angebracht sind. Hostienkästen in dieser Form gibt es sehr selten; normalerweise haben sie die Form einer Pyxis oder eines Kelches.

In dem Schrein befinden sich neben mehreren Reliquien eine aus Silber gefertigte runde flache Weinflasche und eine Hostiendose.

\section{Kreuz}

Inschriften des Lüneburger St. Michaelisklosters und des Klosters Lüne, passim, mit Abbildungen.

941339 Presbyter Leo, 1413 Johann Tespe, 1447 Nickel Lesnis.

${ }^{95} \mathrm{M}$. RIETHMÜLLER, to troste miner sele, S.94ff.

${ }^{96}$ U. REINHARDT, Testamente, Nr.260, S.403.

${ }^{97}$ Kat. „Stadt im Wandel““, Bd.2, Nr. 1123, S.1300f (Beschreibung und Abbildung). Angaben über ein mögliches Anfertigungsjahr fehlen bei Mithoff und Krüger/Reinecke. H.W.H. MITHOFF, Kunstdenkmale und Alterthümer, S.145; F. KRÜGER/W. REINECKE, Kunstdenkmale, S.121. 
Kreuze werden äußerst selten in Lüneburger Testamenten vererbt. Drei Testatoren, Johann Semmelbecker 1409, Eckart Stein 1440 und Johann vame Lo 1473, wünschen die Anschaffung eines Kreuzes. Der Ratsherr und Sodmeister Johann Semmelbecker setzt eine lötige Mark für die Anfertigung des Kreuzes aus. Die Anfertigung eines Kreuzes wünscht auch der Sülfmeister, Barmeister und Ratsherr Johann vame Lo. Der Vikar Eckart Stein verfügt über ein bereits vorhandenes Kreuz. Die Testatoren, die die Herstellung eines Kreuzes wünschen, sind sehr reiche Bürger. Nur sie können es sich leisten, die Grundmaterialien Gold und Silber sowie die Arbeit des Goldschmieds zu finanzieren. Johann vame Lo, der in seinem Testament als Fertigungsmaterial seine beiden Ketten zur Verfügung stellt, hat eine genaue Vorstellung vom Aussehen des Kreuzes: eyn schone cruce mid deme lichame crucifixi und eynen schonen vote und under den armen des cruces dat bilde Unser Leven Frowen und sunte lohannis, dat de kercke to ewighen tiiden hebbe vor eyn clenode ${ }^{98}$. Das kurz vor der Reformation entstandene Inventar der Kunstwerke von St. Johannis verzeichnet "1 groß silbern Crucifix überguldet und mit Johannis und Marienbilde“, dessen Identität mit dem Legat des Johann vame Lo nicht unwahrscheinlich ist ${ }^{99}$.

Alle drei Kreuze werden der Johanniskirche zugewendet.

\section{Pacificale}

Im Jahr 1485 verfügt Geseke Leyferd: „Item geve ick to Wynsen den monniken myn Agnus dei to enem pacificale.."100. Der Begriff pacificale weist auf die Bedeutung und Verwendung des Kußtäfelchens hin. Es dient dem Friedenskuß, der „Ausdruck u. (jedenfalls in späterer Deutung) Sakramentale brüderl. Gemeinschaft $u$. so bes. in der Eucharistiefeier üblich" ist ${ }^{101}$. Die seit der Karolingischen Zeit bestehende Tradition der Weitergabe des Friedenskusses äußert sich in dem Küssen des Altars oder der Umarmung, wobei diese Symbolik allein auf den Klerus beschränkt ist. Seit dem 13. Jahrhundert wird auch der Laie einbezogen, der nun eine Kußtafel zur Verfügung hat. Auch den Klerikern können die Kußtäfelchen zur Übermittlung des Friedenskusses dienen, so daß größere Kirchen für die unterschiedlichen Feste verschiedene Kußtafeln

\footnotetext{
${ }^{98}$ U. REINHARDT, Testamente, Nr.240, S.363.

${ }^{99}$ F. KRÜGER/W. REINECKE, Kunstdenkmale, S.81, Fußnote *.

${ }^{100}$ U. REINHARDT, Testamente, Nr.270, S.426.

${ }^{101}$ E. LENGELING, Kuß - II Friedenskuß, in: LThK, Bd.6, Sp.696 Knapp gehaltene

Information auch bei A. REINLE, Die Ausstattung deutscher Kirchen im Mittelalter, S.179.
} 
besitzen ${ }^{102}$. Das von der Lüneburger Testatorin gewünschte Umarbeiten eines Wertgegenstandes in ein Kußtäfelchen ist ein übliches Vorkommen ${ }^{103}$, dem hier jedoch durch das geweihte Wachsstück ein besonderer Anstrich verliehen wird. Überliefert ist in Lüneburg ein Kußtäfelchen aus vergoldetem Bronzeguß, das 1471 Dietrich vom Berge, Neffe des Abtes Boldwin von Wenden des Lüneburger Michaelisklosters, dem Kloster Hittfeld gestiftet hat. Die Maße betragen 17, $5 \times 8,2 \times 5 \mathrm{~cm}$, und das Aussehen wird folgendermaßen beschrieben: „Das rechteckige Hauptfeld zeigt im Hochrelief bis zu $12 \mathrm{~mm}$ Stärke den Gekreuztigten mit Maria und Johannes, das Rundbogenfeld den HI. Gereon als stehenden Ritter mit Lanze und Schild, einen Federschmuck auf dem Haupte. Auf dem Fußrande ist folgende Unterschrift eingraviert „Reliqvie de ligno dni $\mathrm{m}^{\circ} \mathrm{CCCCLXXI“} \mathrm{....,} \mathrm{außen} \mathrm{am} \mathrm{linken} \mathrm{Seitenrande} \mathrm{„de} \mathrm{sancto}$ gereone“, am rechten: „de sancto ciriaco“. Auf der Rückseite ist unter dem Kreuzchen ein Wappenschild eingeschnitten mit dem Wappen der Lüneburger Burgmannenfamilie von dem Berge. Als Handhabe dient ein auf der Rückseite der Tafel aufgelöteter rechteckiger Griff mit flacher, massiver Längsseite und achteckigen Verbindungsstücken; diese letzteren, einst durch einen Schieber, bzw. ein abhanden gekommenes Deckelchen geschlossen, enthalten die Reliquien." ${ }^{104}$

Tragaltar

Der Vikar der Johanniskirche Johannes von Lippinghausen bedenkt 1414 in seinem Testament Johann Varendorp, der ebenfalls als Vikar an der Johanniskirche tätig ist, mit portativum meum cum duabus novis flasculis, quos ipse mihi dedit ${ }^{105}$.

Gedacht ist ein solcher Tragaltar für das Zelebrieren der Messe außerhalb der Kirche, z.B. auf einem Friedhof, bei einer Reise oder einer Pilgerfahrt ${ }^{106}$. Er vereinigt die beiden wesentlichen Elemente des Meßaltars in sich: die geweihte Steinplatte und die darunterliegenden Reliquien. Bekannt sind zwei Grundformen, nämlich der kassettenförmige Tragaltar auf Füßen und der

\footnotetext{
${ }^{102}$ S. BEISSEL, Verehrung der Heiligen, S.91.

${ }^{103}$ S. BEISSEL beschreibt Kußtäfelchen des Aachener Münsters, die aus Agraffen von Chorkappen hergestellt waren. S. BEISSEL, Verehrung der Heiligen, a.a.O.

${ }^{104}$ W. REINECKE, Die kirchliche Abteilung, (= Führer durch die Sammlungen des Museumsvereins für das Fürstentum Lüneburg, Bd. 2), Nr. 89, S. 78ff Siehe auch TH. MEYER, Ein Reliquiar vom Jahre 1471 aus der Kirche Sancti Mauritii zu Hittfeld (= 5. und 6.

Jahresbericht des Museumsvereins, 1884), S. 87f.

${ }^{105}$ U. REINHARDT, Testamente, Nr.103, S.143f.

${ }^{105}$ A. REINLE, Die Ausstattung deutscher Kirchen im Mittelalter, S.6.
} 
plattenförmige Tragaltar. Die offensichtlich dem Altar zugehörigen Fläschen nehmen Wein und Wasser für die Wandlung auf.

${ }^{106}$ A. REINLE, Die Ausstattung deutscher Kirchen im Mittelalter, S.6. 


\section{Das private Andachtsbild}

Aus der ersten Hälfte des 15. Jahrhunderts stammen die einzigen Testamente, in denen Gegenstände der privaten Andacht vererbt werden. Gerade im 15. Jahrhundert vermehrte sich die Zahl der Statuen und Bildtafeln im häuslichen Bereich, der mehr als der öffentliche Kirchenraum Platz für die private, in das Innere gekehrte Andacht bot ${ }^{107}$. Als Bezugspunkt für die innere Andacht konnten Sakralgegenstände unterschiedlichster Art und Ausführung dienen - ein Kreuz, ein Relief ${ }^{108}$ oder eine Skulptur aus Edelmetall oder eben kleine Andachtsbilder, wie sie die Wienhäuser Nonnen im Gebetbuch hatten ${ }^{109}$ und wie es sie noch heute - wenn auch mit anderen Produktionstechniken - in den Gebetsbüchern der Katholiken gibt. Die Sujets sind den gängigen Motiven der Kirchenkunst entlehnt wie z.B. Maria, die das Kind im Arm hält. Unabhängig von Form und Material werden all diese Gegenstände hinsichtlich ihrer Zweckbestimmung als private Andachtsbilder bezeichnet; dieser Begriff ist im mittelalterlichen Sprachgebrauch nicht nachgewiesen und ist heute trotz üblicher Verwendung nicht unumstritten ${ }^{110}$.

In den Testamenten werden Andachtsbilder trotz zunehmender Beliebtheit kaum verzeichnet. Die kostbarsten Gegenstände scheinen - wie so oft bei besonderen Wertgegenständen mit auch ideellem Wert-außertestamentarisch an die eigenen Kinder gefallen zu sein, und nur in Ausnahmefällen, also bei Kinderlosigkeit oder bewußt anders gewähltem Erbnehmer, Aufnahme in die Testamente gefunden zu haben. In Lüneburg gibt es lediglich die Testamente Wobbeke Boltzens 1428 und Hans Junges 1430 mit entsprechenden Formulierungen.

Die Ratsherrnwitwe Wobbeke Boltzen bedenkt ihre Tochter Beke, die Ehefrau des aus dem wohlhabenden Geschlecht der Viskules stammenden Heinrich, mit de tafelen, dar dat hilgedom inne $i^{111}$. In den Testamenten anderer Städte werden Reliefs oder kleinere

\footnotetext{
${ }^{107}$ A. LEGNER, Das Andachtsbild im späten Mittelalter. Eine Betrachtung vor dem Elendchristus im Braunschweiger Dom, in: Kat. „Stadt im Wandel“, Bd. IV, S.449-465; M. HASSE, Kleinbilderwerke, S.60 72.

${ }^{108}$ Das Lüneburger Museum verwahrt ein aus Ton gebrannte Andachtsbild der Maße $70 \times 54 \mathrm{~cm}$, das die Verkündigung der Maria darstellt. Das Gemach der Maria ist topisch ausgestaltet mit Kamin, Betpult, Sitzbank, Waschschränkchen, Kannen und Tellern. Farbreste verweisen auf eine ursprüngliche Bemalung, wohl in den Farben blau, rot und gold. Die Entstehungszeit wird vermutet in der Wende vom 15. zum 16. Jahrhundert, als Entstehungsort wird der westfälische Raum angenommen. W. REINECKE, Die kirchliche Abteilung (= Führer durch die Sammlungen des Museumsvereins für das Fürstentum Lüneburg, Bd. 2 ), Nr.12, S. $22 \mathrm{ff}$.

${ }^{109}$ H. APPUHN, Das private Andachtsbild im Mittelalter an Hand der Funde des Klosters Wienhausen, in: Das Leben in der Stadt des Spätmittelalters, S. 97-109.

${ }^{110}$ H. APPUHN, Einführung in die Ikonographie der mittelalterlichen Kunst in Deutschland, Darmstadt 1991/4, S.87.

${ }^{111}$ U. REINHARDT, Testamente, Nr.160, S.221.
} 
Gemälde als „tavola“ bezeichnet ${ }^{112}$. Da das hier vererbte Andachtsbild mit einer Reliquie versehen ist, darf eine entsprechend würdig-wertvolle Ausfertigung angenommen werden, wenn allerdings zu berücksichtigen ist, daß die Testatorin ihre Tafel nicht als silberne oder vergoldete bezeichnet, obschon die Testatoren allgemein und auch Wobbeke Boltzen ihre Wertgegenstände präzise mit der Angabe des Materials oder seines farblichen Eindrucks beschrieben.

Auf den ersten Blick mag es verwunderlich erscheinen, daß der Spielmann und Ratsangestellte Hans Junge neben der reichen Wobbeke Boltzen der einzige Testator ist, der ein Andachtsbild von beträchtlichem Wert testamentarisch vererbt. Erklärbarer wird dieses Legat vor dem Hintergrund der wohl zutreffenden Annahme, er sei der Sohn des Lübecker Goldschmieds Stefan Junge gewesen ${ }^{113}$. Nach Hans Junges Tod nun soll an das Franziskanerkloster eine Brosche im Wert von 4 Lüneburger Mark fallen, eine silberne Kette und en sulveren Marienbilde, also ein silbernes Marienbild oder eine silberne Marienfigur ${ }^{114}$. Diesen testamentarischen Verfügungen sind Absprachen zwischen dem Kloster und dem Testator vorausgegangen, denn laut Testament ist klar, daß für die für eine Chorkappe zu verwendende Brosche Junges Grabplatz innerhalb des Kreuzganges gesichert ist, und sein Begräbnis für Kette und Bild mit Vigilien und Seelenmessen würdig begangen werden würde ${ }^{115}$. Der Spielmann Junge will sein Marienbild/seine Marienfigur an dem Altar aufgestellt sehen, an dem ein Licht der Spielleute brennt ${ }^{116}$. Zusätzlichen Schmuck soll der mit Korallen versehene Gagatrosenkranz des Testators verleihen, den Junge der Maria um den Hals zu hängen wünschte. Wie bereits dargestellt, ist allgemein das Schmücken der Bildwerke etwas Selbstverständliches, und gerade für Lüneburg gibt es nicht allein relativ umfassendes Schriftmaterial ${ }^{117}$, sondern auch die gegenständliche Überlieferung einer ca.

\footnotetext{
${ }^{112}$ M. HASSE, Kleinbildwerke,S.62.

${ }^{113}$ M. HASSE, Kleinbildwerke, S.66. Für diese Annahme sprechen die vielen Kleinode, die Hans Junges Testament auflistet, seine Beziehungen zu Lübeck und die Namensgleichheit des Testators mit der des Goldschmiedsohnes.

${ }^{114}$ M. HASSE, Kleinbildwerke, S.62, übersetzt „ymagines“ als Skulptur. LEGNER legt diesen Begriff weiter aus: „, $<$ Imago > oder < Bild > ist die mittelalterliche Bezeichnung, und zwar für jede Darstellung, gleich ob gemalt oder skulpiert, zwei- oder dreidimensional und ungeachtet der materiellen Beschaffenheit oder gar der formalen Kategorie“. A. LEGNER, Das Andachtsbild im späten Mittelalter, S.450.

${ }^{115}$ Ein Begräbnis im Klosterbereich war bei den Bürgern Lüneburgs recht beliebt. Daß die Mönche diese Beliebtheit und die Klosterannehmlichkeiten zu nutzen wußten, beschreiben KRÜGER/REINECKE folgendermaßen: „Da ist vom Bruch der Klausur, von Trinkgelagen innerhalb und außerhalb des Klosters, von Errichtung einer Klosterschenke, von sonntäglichen Geldverteilungen, von privatem Hausgerät, goldenen und silbernen Kleinodien der einzelnen Klosterinsassen, von Vergehen gegen die Sittlichkeit die Rede.“ Alle Angaben bei F. KRÜGER/W. REINECKE, Kunstdenkmale, S.160f.

${ }_{116}$ Nicht unüblich war die Verehrung Mariens auch an den ihr nicht geweihten Altären.

${ }^{117}$ Aus St. Johannis wurden ins Rathaus überführt: Aus der „Bede ... - ist der Standt, darinne itzo die Diacen stehen“ stammen „... 11) 1 silbern Johannis mit dem Bocke, darauf das Lamb Gottes, weinig geguldet mit einen Corallenschnor und kleinen Creutz, .., 13) 1 silberne Maria mit dem Kinde und Cepter mit zween Ringen und einen Corallenschnür, 14) 1 silbern St. Ursula mit Stralen, einem Bocke, Coralenföftig und vier Ringen, 15) 1 silberne St. Anna, mit zween silb. Agnus Dei, einem kleinem Brustschmide, mit achte Knopfen klein und groß mit zween Ringen und einer silb. Ketten, 16) 1 silberne St. Cathrine mit dem Schwerte, Bocke,
} 
1510 in Lüneburg entstandenen silbernen Maria, die mit ihrem linken Arm das Jesuskind hält, während ihrem rechten Arm ein Korallenrosenkranz übergehängt ist ${ }^{118}$. Wie bei dem Bildrelief der Wobbeke Boltzen ist auch die Marienfigur mit Reliquien versehen; in die Vorderseite des achtseitigen Sockels eingearbeitet ist ein Reliquienkästchen, in dem ein mit Rot beschriebener Pergamentstreifen die Reliquien der heiligen Katharina anzeigt, die Reliquien des heiligen Veit, Vinzenz, Stephanus und Ansgar. So ist es nicht undenkbar, daß auch die von Hans Junge geschenkte Marienfigur mit Reliquien versehen sein konnte. Aus der Fülle der privaten Andachtsbilder sind in den Lüneburger Testamenten also lediglich zwei Objekte aufgeführt, bei denen es sich sicher im Fall Hans Junges, wahrscheinlich im Fall Wobbeke Boltzens um wertvolle Produkte handelt. In Köln werden offenbar überwiegend aus Holz gefertigte Bilder oder Figuren erwähnt, die in Wohnstube oder Schlafzimmer auf Truhen standen ${ }^{119}$. Die Kleinbildwerke zeugen von einer Frömmigkeit, die nicht alleine an die Kirchen, Kapellen und Klöster, an die Mittlergestalt des Priesters gebunden war, sondern in der der Einzelne sich durch die Gestaltung des Andachtsbild auf je individuelle Weise angesprochen fühlte.

Corallenschnor und einem kleinen Agnus Dei, 17) St. Ursula, ein silbern Brustbilde mit einer gulden Ketten daran ein klein Creutz mit 5 Steinen etwas überguldet ...“. Aus der Sakristei ,... 6) 1 silb. Johannis mit Edelgesteinen und Perlen auch etzlichen kleinen geopferten silbern Platen u. einem gulden Ringe 7) 1 silb. überguldet Marienbild mit etzlichen anhangenden silbern Kleynodien und 5 gülden Ringe u. einen Corallen Rosencrantz ...“ zit. nach F. KRÜGER/W. REINECKE, Kunstdenkmale, Fußnote S.81f.

${ }^{118}$ Die teilvergoldete, mit Perlen und Türkisen versehene Figur befand sich in der Johanniskirche und wurde 1573 vom Rat der Stadt zusammen mit anderen Wertgegenständen gekauft und dadurch vor dem Einschmelzen bewahrt. Im Rahmen des Verkaufs des Lüneburger Ratssilbers ging die Marienfigur nach Berlin. Ausführliche Beschreibung, Abbildungen und Literaturhinweise bei S. BURSCHE, Das Lüneburger Ratssilber, Nr.34, S.170 - 174.

${ }^{119}$ E. WURMBACH, Das Wohnungs- und Bekleidungswesen des Kölner Bürgertums, S.31. 
a. Die Ware „Tuch“ in der Stadt Lüneburg

Lüneburg war für Handelswaren, die auf dem Landweg ausgetauscht wurden, ein Knotenpunkt des Ost-West-Verkehrs zwischen dem baltischen und dem flandrischen Raum und des Nord-Süd- Verkehrs zwischen dem nördlichen Raum und den süddeutschen Zentren Nürnberg und Frankfurt ${ }^{1}$. Eines der hauptsächlich gehandelten Güter der Hanse, deren Mitglied Lüneburg seit Ende des 14. Jahrhunderts war, waren Tuche ${ }^{2}$.

Gehandelt wurden Tuche unterschiedlichen Preisniveaus und unterschiedlicher Qualität, die vor allem durch die Herkunft aus einer der europäischen Tuchlandschaften bestimmt wurde $^{3}$. Als wertvoll galten flämische Tuche, die als Luxusgut vor allem im 13. und dem beginnenden 14. Jahrhundert beinahe ausschließlich den Markt beherrschten. Sie waren Wolltuche, die hergestellt wurden aus der Wolle englischer Schafe und zum Großteil gefärbt wurden mit dem in Nordfrankreich angebauten Waid (Rohstoff für die Blaufärbung). Auf dem Sektor der Luxustuche kamen im 15. Jahrhundert englische, französische und holländische Tuche hinzu. Daneben gab es den Sektor der „,normalen“, billigeren Tuche, die vor allem in regionalen Zentren im deutschen Raum gefertigt wurden.

Daß Lüneburg ein bedeutender Markt für Tuch war, geht eindrucksvoll aus den Zollrollen der Bäckerstraße hervor, in denen alle durch die Stadt transportierten Waren verzeichnet waren ${ }^{4}$. Alle sieben Rollen bis 1500 listen mehrheitlich Leinen und Laken - sowie auch Leder - auf, wobei drei Rollen aus dem 15. Jahrhundert unter dem Punkt „Tuch“ verschiedene Sorten aufzählen ${ }^{5}$.

Der Tuchverkauf erfolgte über die Gewandschneider, die bereits 1302 im Gewandhaus ihrer Tätigkeit nachgingen und nur zum Michaelismarkt außerhalb ihre Stände aufschlugen. In den Nächten zur Zeit des Michaelismarktes durfte jeder Gewandschneider einen met eynem spete bewaffneten Nachtwächter an seinem Stand postieren, damit die kostbare

\footnotetext{
${ }^{1}$ Informativ - auch für den Tuchhandel R. HAMMEL-KIESOW-M. NORTH-S. JENKS, Außenbeziehungen der sächsischen Städte. Lübeck-Hamburg-Übersee, in: Kat. „Hanse•Städte•Bünde“, Bd.1, S.350-374.

${ }^{2}$ Beim Handel der Hanse stand Tuch ,wertmäßig an der Spitze des Handelsaustausches und warf Gewinne von $15 \%$ bis $30 \%$ ab“. E. ISENMANN, Die deutsche Stadt im Spätmittelalter, S.370.

${ }^{3}$ H. AMMANN, Deutschland und die Tuchindustrie Nordwesteuropas im Mittelalter, in: Hansische Geschichtsblätter 72, S. 1-63.

${ }^{4}$ H. WITTHÖFT, Das Kaufhaus in Lüneburg als Zentrum von Handel und Faktorei, Landfracht, Schiffahrt und Warenumschlag bis zum Jahr 1637, Lüneburg 1962 Über die den Zoll der Bäckerstraße passierenden Waren bes. S.54f.

${ }^{5}$ Die sieben Rollen stammen aus den Jahren 1278-1430/90-1471-1484-1495-1500 Sandträgerrolle-1500 Kaufhausträgerrolle. Die verschiedene Tucharten aufzählendenden Rollen sind aus den Jahren 1430/90-1471-1495. H. WITTHÖFT, Das Kaufhaus in Lüneburg, Anhang A = Die Warenlisten der Kaufhaus, Sandträger- und Zollrollen von 1278 bis 1566, S.242-248.
} 
Ware nicht gestohlen wurde $^{6}$. Den auswärtigen Tuchhändlern, die während des Michaelismarktes in Lüneburg ihre Ware selbst verkaufen durften, waren feste Standplätze zugewiesen ${ }^{7}$. Verkauft wurde Hamburger und Stader Tuch, Tuch aus England, aus Holland, den Rheinlanden und Hessen, Braunschweig, Hannover und Uelzen.

Etliche Sülfmeister betätigten sich auch als Gewandschneider ${ }^{8}$, und so befindet sich unter den Testatoren die Ehefrau Dietrichs von Dassel, der als Sülfmeister und Gewandschneider tätig war? ${ }^{9}$.

b. Häufigkeit der testamentarischen Erwähnung, Donatoren und Empfänger

Unverarbeiteten Tuchstoff vererben Lüneburger Testatoren zwar seltener als fertig gearbeitete Kleidung, aber immerhin 57 Testamente, aufgesetzt von 55 Testatoren $(19,16 \%)$, enthalten Aussagen über Tuche. Es handelt sich hierbei um noch zu kaufendes Tuch und um bereits sich im Besitz des Testators befindenden Stoff. Der gemeinsame Nenner dieser sich um Stoff drehenden Verfügungen sind die Formulierungen der Testatoren, die in diesen Verfügungen im Gegensatz zu anderen Verfügungen über Textilien hier von wand, pannum und laken ${ }^{10}$ sprechen bzw. schreiben.

Nur wenige Testatoren geben an, um welche Art Tuch es sich bei den von innen vererbten Stoffen handelt. Die Mehrzahl der Testamente mit genaueren Angaben erwähnt Leinentuch. Leinen wurde jedoch weniger für Bekleidung als für Haushaltszwecke verwendet $^{11}$, und offensichtlich erscheint die Verwendung von Leinen für Kleidung den Testatoren nicht zwangsläufig immer, aber in etlichen Fällen doch erwähnenswert. Demzufolge kann mit einiger Wahrscheinlichkeit davon ausgegangen werden, daß es sich bei Tuch in unbezeichneten Formulierungen um Wollstoffe handelt.

Tabelle: Testamentarische Verfügungen über Tuch

\begin{tabular}{|l|l|}
\hline Jahreszahlen & Anzahl der Testatoren, die über Tuch verfügen \\
\hline
\end{tabular}

\footnotetext{
${ }^{6}$ E. BODEMANN, Die ältesten Zunfturkunden der Stadt Lünebur (=Quellen und Darstellungen zur Geschichte Niedersachsens, Bd.1), Hannover 1883, S.85. Neue Hinweise zu den Märkten in und um Lüneburg: N.

BRÜBACH, Kauffschlag und Herrenmesse-Messen und Jahrmärkte und ihre Funktion für den Raum zwischen Weser und Elbe, in: Kat. „Hanse•Städte•Bünde“, Bd.1, S.375-395.

${ }^{7}$ E. BODEMANN, Die ältesten Zunfturkunden, IX. Gewandschneider, Nr.2 (um 1400), S.75f.

${ }^{8}$ W. Fr. VOLGER, Die Patrizier der Stadt Lüneburg, in: Lüneburger Blätter, bearb. v. W. Görges (=Nachdruck im Verlag der Heinrich-Heine-Buchhandlung), Lüneburg 1986, S.50.

${ }^{9}$ Metteke von Dassel, 1473 Juli 23.

${ }^{10}$ laken bedeutet Tuchstoff, während ein par laken ausschließlich Bettlaken meint.

${ }^{11}$ E.WURMBACH, Das Wohnungs- und Bekleidungswesen des Kölner Bürgertums um die Wende des

Mittelalters (=Veröffentlichungen des Historischen Museums der Stadt Köln, Nr.1), Bonn 1932, S.58, S.60f.
} 


\begin{tabular}{|c|c|}
\hline $1350-1375$ & 2 Testatoren \\
\hline $1376-1400$ & 5 Testatoren \\
\hline $1401-1425$ & 15 Testatoren $^{12}$ \\
\hline $1426-1450$ & 14 Testatoren \\
\hline $1451-1475$ & 6 Testatoren \\
\hline $1476-1500$ & 13 Testatoren \\
\hline
\end{tabular}

Vor 1350 nimmt kein Testator eine Verfügung über Tuch in sein Testament auf. Zwischen der zweiten Hälfte des 14. Jahrhunderts und der ersten Hälfte des 15. Jahrhunderts steigt die Zahl der über Tuche verfügenden Testatoren um ein Vierfaches an. Allerdings ist die Zeit zwischen 1400 und 1450 die Zeit mit der größten Anzahl an Tuchverfügungen. Pro Testament setzen die Testatoren ein bis zwei Verfügungen über Tuche auf, selten sind es drei oder mehr Verfügungen.

Bei den Donatoren fällt das Übergewicht männlicher Testatoren auf; 44 Männer, aber nur 11 Frauen treten als Testatoren in Erscheinung. Von den 44 Männern sind 7 Kleriker.

Derm Überblick über die Art der Verwendung von Tuchlegaten zeigt, daß Tuchlegate für Bekannte oder Verwandte ${ }^{13}$, für die Bekleidung Armer und für kirchliche Personen und Instituionen ausgesetzt werden oder für die Versorgung mit Sargtuch genutzt werden. Wenn sich je nach Art der Zuwendung eine andere Empfängergruppe präzisieren läßt, so kann doch angesichts der unterschiedlichen Häufigkeit der Vererbungsarten resumiert werden: Insgesamt gesehen wählen Testatoren Verfügungen über unverarbeitetes Tuch dann, wenn sie nicht nahe Familienmitglieder bedenken, sondern eine Seelgerätstiftung aussetzen wollen, in dem sie die Armen bekleiden ${ }^{14}$. Mit dieser Entscheidung für das kostengünstige Tuch reihen sich die Lüneburger (Testatoren) ein in das Spenderverhalten der spätmittelalterlichen Städter ${ }^{15}$.

\section{c. Verwendung der Tuchlegate}

\footnotetext{
${ }^{12}$ In diesem Zeitabschnitt setzen Johannes von Lippinghausen und Hermann Zierenberg je zwei Testamente auf. Lippinghausen 1414 Feb. 4 und 1424 Nov. 23; Hermann Zierenberg 1420 Nov. 14und 1423 Nov. 19.

${ }^{13}$ Im Testament der Gesche Henning von 1494 Sept. 10 ist deutlich, daß die Nichte der Testatorin Wobbeke Wichtenbeke ist, während die mit einem Tuchlegat bedachten Cylie und Metteke Wichtenbeke nicht genau zugeordnet werden können.

${ }^{14}$ Einen Schatz im Himmel - so die mittelalterliche Vorstellung - kann man sich durch die sechs Werke der Barmherzigkeit erwerben, von denen Matthäus berichtet (Mt. 25,35-40). Eines davon heißt: ,... ich war nackt, und ihr habt mich bekleidet; ..".

${ }^{15}$ Eine Untersuchung, bezogen auf die Städte Braunschweig, Göttingen, Hameln, Duderstadt und Hildesheim, präsentiert ein gleiches Ergebnis. I. TSCHIPKE, Lebensformen in der spätmittelalterlichen Stadt. Untersuchungen anhand von Quellen aus Braunschweig, Hildesheim, Göttingen, Hameln und Duderstadt (=Schriftenreihe des Landschaftsverbandes Südniedersachsen, Bd. 3), Hannover 1993, S.102.
} 


\section{Tuchlegate zur Bekleidung Armer}

Die mit ungefähr 30 Verfügungen zahlenmäßig größte Menge unter den Tuchlegaten sind die Bestimmungen zur Bekleidung armer Mitmenschen. Bei den hier Bedachten handelt es sich in der Regel im Gegensatz zu den Hausarmen um die Gruppe der für den Testator vielleicht gesichts -, und oft namenslosen Bedürftigen, die das (spät-) mittelalterliche Straßenbild mitbestimmten und deren Aufenthaltsort, wie nicht nur die Bildwerke zeigen, häufig der kirchliche Bereich war. Die Kirche, ihr Vorplatz oder Hospitäler waren oftmals Ausgabeort der mildtätigen Gaben, und so läßt Eckhard Stein 1439/40 die Provisoren von und vor St. Vitus in Uelzen Leinentuch an die Armen und Leprösen verteilen, während Johann vame Lo 1473 den Chor von St. Johannis in Lüneburg zum Ausgabeort des restlichen Tuchs an zwölf Arme erwählt, die offensichtlich während des Offiziums anwesend gewesen sein müssen. Angaben über den Termin der Kleidungsverteilung enthalten weit weniger als die Hälfte der relevanten Testamente. Sind Termine angegeben, dann handelt es sich in einem Fall um die Stunde nach dem Tode des Testators (1398 Johann Pattensen), an Allerheiligen (1441 Hermann Kruse), in vier Fällen um St. Michaelis (1352 Segeband von Wittorf, 1361 B. Degenardi, 1376 V. Kramer und Metteke von Dassel 1473), einmal um einen Termin zwischen St. Michaelis und St. Martin (1412 Johann Heyne), ein anderes Mal heißt es, die Verteilung solle gegen Winter erfolgen (1477 Hans von Rethem). In ähnlicher Weise formuliert Johannes Steinberg, das Tuch sei als Schutz gegen die Kälte gedacht (instante frigoris horrore, Testament 1438). Die Verteilungstermine stehen in Zusammenhang mit der Finanzierungsweise der Legate; in überwiegendem Maße wird Armenbekleidung mit Renten bezahlt, deren Ausschüttung zu den vier an kirchliche Feste gebundenen Zahltagen des Jahres zu Ostern, Michaelis, Johannis und Weihnachten erfolgte. „Hauptumschlagswoche“16 war in Lüneburg die Michaeliswoche, in der der Michaelismarkt stattfand, der in besonderem Maße ein Markt der Tuche war. So boten die acht Markttage zu St. Michaelis als Verteilungstermin alles, was für eine bestmögliche Ausführung der letztwilligen Verfügungen wichtig war: Aufgrund des Zinstermins stand das benötigte Geld zur Verfügung, gleichzeitig fanden die Käufer eine außergewöhnlich umfangreiche Auswahl an Tuchen vor, und für die Stadtarmen dürften Kleidungsgaben angesichts der kälter werdenden Jahreszeit ein hochwillkommenes Geschenk gewesen sein. So ist es gerade in Hinblick auf den nahenden Winter nicht verwunderlich, daß in mehr als der Hälfte der relevanten Testamente die zusätzliche Schenkung von Schuhen verordnet wurde ${ }^{17}$. Über die Beschaffenheit des zu kaufenden - selten des vorhandenen Tuchs enthält die Hälfte der Testament genauere Angaben: Viermal wird Leinentuch

\footnotetext{
${ }^{16}$ REINECKE, Geschichte der Stadt Lüneburg, Bd.I, S.181f.

${ }^{17}$ Schuhe werden in Lüneburger Testamenten ausschließlich in diesem Kontext ohne nähere Beschreibung erwähnt.
} 
genannt, dreizehnmal graues Tuch, wobei in drei Fällen (1361 Bernard Degenardi, 1420 Hermann Zierenberg und 1441 Meister Heinrich) der Kauf grauen Tuchs die Alternative zum Kauf anderen Tuchs ist, und sechsmal soll weißes Tuch angeschafft werden, auch hier in zwei Testamenten (1361 Bernard Degenardi und 1441 Meister Heinrich) als Alternativkauf. In der Mehrzahl wird das grobe, einfache graue Tuch gekauft. Allerdings lassen die Zahlen nicht die Ableitung einer Gesetzmäßigkeit zu. Fakt ist jedoch, daß alle Testatoren, die den Kauf von weißem Tuch wünschen, den gleichzeitigen Kauf von grauem Tuch anordnen. Möglicherweise ist dies ein Hinweis auf die unterschiedliche Verwendung von feinerem, gebleichten und gröberem, ungebleichten Tuch zur Unter- und Ober- bzw. Überbekleidung?!

Die gewünschte Provenienz des Tuches wird von den Testatoren in einigen Fällen angegeben: Die Verteilung Lüneburger Tuchs wünschen die Testatoren Johann von Hasle (1423), Hans Junge (1430), Klaus Schmied (1443), und gleich vier Lüneburger Laken vergabt Dietrich Döring 1482. Johann vame Lo ordnet in seinem Testatment 1473 den Kauf von veer Dreszmeschen laken an. Dietrich Döring verfügt 1482 auch über ein weißes Stendaler Laken.

Hans Junge und Klaus Schmied geben die Menge ihres Legats mit zwei Laken Tüchern an; Segeband von Wittorf nennt in seinem Testament 1352 fünf weiße zu vergabende Tücher. Das Testament Vicke Kramers aus dem Jahr 1376 ist ein Beispiel dafür, daß sich der Tuchkauf nach dem Rentenertrag des Jahres bemessen kann: Kramer wünscht, daß seine Testamentsvollstrecker eine ewige Rente von 4 Mark Geldes mit Zinstermin St. Michaelis anlegen, damit sie Tuch und Schuhe kaufen können. Hans Junges Testament aus dem Jahr 1430 nennt die Menge des an jeden einzelnen Empfänger zu gebenden Tuchs, nämlich je sechs Ellen.

Abgesehen von dem Testament des Dietrich Döring aus dem Jahr 1482 findet sich in keinem Testament eine Angabe über die aus dem Tuch zu fertigenden Kleidungsstücke. Döring verfügt, Männer sollten wand to eynem clede und hoszen und scho erhalten, während für Frauen wand und scho vorgesehen sind ${ }^{18}$. Döring ist einer der wenigen Testatoren, die in ihrem Testament gleich drei Legate über Tuchverteilung an die Armen aussetzen. Neben der eben beschriebenen jährlichen Gabe ordnete er den Ankauf und das Verteilen von Tuch durch die Kirchgeschworenen des Kleinen Heiligen Geistes an, seinem Sohn Johann sollte eine tägliche Armenbekleidung und Speisung zweier Bedürftiger obliegen. Bei den mit Tuchspenden gestifteten Legaten ad pias causas ist die große Diskrepanz von 19 : 1 auffällig, die zwischen Zuwendungen an Arme und an Kranke besteht. Heinrich Hoyer (1451) ist der einzige, der eine diesbezügliche Verfügung trifft: er

\footnotetext{
${ }^{18}$ U. REINHARDT, Testamente, Nr.265, S.417.
} 
stiftet eine Mark Geldes dem Benedictushof zum Kauf von Bett und Bettuch für die Kranken.

Tuchlegate für Verwandte und Bekannte

Mitglieder besonders wohlhabender Familien wie die der von Dassel und die der Kruse bedenken ihre Töchter mit qualtitiv gutem Tuch wie dem Flämischen (1441 Hermann Kruse). Ein auffallendes Legat hinsichtlich der Qualität, besonders aber der Quantität des Tuches findet sich in Metteke von Dassels Testament: Sie hinterläßt 1473 ihrer Tochter zehn Ellen weißen Englischen Tuchs. Die testamentarische Erwähnung größerer Mengen Tuches findet sich - abgesehen von Tyle Schuttes Testament - in keinem weiteren Testament. Tyle Schutte, Nordhäuser Bürger, schreibt in seinem Testament 1421: To dem ersten gheve ik to sunte Johanse bynnen Luneborg en blaw vervet laken van den eenundetwintich verweden lakenen, de ik an twen stucken to Luneborg stande hebbe ${ }^{19}$. Beide Testatoren stehen offenbar in direkter Verbindung zum Tuchhandel: Metteke von Dassels Mann ist Sülfmeister und Gewandschneider, und der Nordhäuser Bürger Tyle Schutte ist dem Inhalt seines Testaments zufolge Tuchhändler.

Gesche Henning bedenkt in ihrem Testament 1494 Cylie und Metteke Wichtenbeke, ihre Verwandten, die Jungfrauen in Diesdorf sind, mit soviel Tuch, wie sie es für je eine cappe benötigen. Nickel Wulfferam hinterläßt seinem Sohn Klaus Leinentuch, dessen Endverwendung vermutlich durch den Kontext angedeutet wird, in dem es vererbt wird: Es wird in Zusammenhang mit einem Bett und einem Deckbett vergabt. Hans Tetendorp bedenkt 1493 inm bekannte Frauen: Die Frau Cord Jordans soll das Leinentuch behalten, das sie ohnehin schon verwahrt; weiteres Leinentuch soll Hebele von der Mölen erhalten, und zwar erhält sie je zwei Paar Laken, Hemden, Hauben und Kragen; allerdings scheint es sich hier um bereits angefertigte Stücke zu handeln. Aus den Verfügungen wird ersichtlich, in welcher Weise Leinentuch im Bekleidungswesen Verwendung fand, nämlich als Grundstoff für Hoikenkragen, Hauben und Hemden.

Empfängerinnen von Tuchlegaten unter den Bediensteten sind in allen vorliegenden vier Fällen Mägde. Tuch in unverarbeitetem Zustand ohne Angabe eines möglichen Verwendungszwecks vererbt lediglich Johannes von Lippinghausen 1424. Gesche Henning bedenkt ihre Magd in ihrem 1494 errichteten Testament mit solchem Tuch, wie sie es für ihre Magd besorgt hat. Geseke Leyferd wollte ihre Magd mit Bettzeugtuch für einen Hoikenkragen bedenken, hinterläßt ihr aber in ihrem Testament 1485 anstelle dessen einen Pfühl. In einer weiteren Verfügung für eine andere Magd bekräftigt sie noch einmal das

\footnotetext{
${ }^{19}$ U. REINHARDT, Testamente, Nr.138, S.184.
} 
Fehlen des lennewandes bure; so hinterläßt sie dieser Magd Wobbeke ihren kleinsten Pfühl, der aus dem billigsten Tuch gefertigt ist ${ }^{20}$.

Tuchlegate für kirchliche Personen und Institutionen

Kirchen bzw. kirchliche Einrichtungen sind dreimal Empfänger von Tuchlegaten. Tyle Schutte bedenkt in seinem Testament aus dem Jahr 1421 St. Johannis. Hans Tedendorp schenkt 1493 den Kirchherrn zu St. Nikolai testamentarisch viff elen musterde filie ${ }^{21}$. Margarete von der Mölen trifft in ihrem Testament 1431 Vorsorge für die Bekleidung und das Schuhwerk der armen Schulkinder der Franziskaner; es sollen soviel Schuhe und Kleider gekauft werden, wie es die Sülzgutrente von 3 Mark Geldes erlaubt.

Priester, die nicht in ihrer Person, sondern in ihrer Funktion von den Testatoren als Empfänger beschrieben werden ${ }^{22}$, werden ebenfalls bedacht: Johannes von Lippinghausen stiftet 1414 ein besseres Leinentuch für eine Albe und ein Amikt unter der Kasel. Henning von Bulten weist 1439 in seinem Testament seine TV an, aus seinem Nachlaß ein gutes goldenes Stück zu kaufen, von dem priesterliche Kleidung mit Albe, Amikt und allem, was dazugehört, für die Kirche in Bülten angefertigt werden soll. Beide Testatoren beschreiben mit Albe und Amikt Gewänder, die zu den liturgischen Untergewändern gehören. Die Formulierungen der übrigen zwei über Tuchlegate verfügenden Testatoren lassen offen, welches liturgische Gewand mit ihrer Spende angefertigt werden soll: Die Frau des Cord Jordan verwahre - so berichtet Hans Tetendorp 1493 in seinem Testament - fünf Ellen gemusterten Tuchs, das sie den Kirchherrn von St. Nikolai für Gebete geben solle. In ihrem im darauffolgenden Jahr errichteten Testament wünscht Gesche Henning, daß den Observanten im Franziskanerkloster eyn laken wandes für ihre Kleidung gegeben werde ${ }^{23}$.

\section{Das Testament als Erinnerung an Schulden für Tuch}

Drei Testatoren fixieren in ihren Testamenten ausstehende Schulden für Tuch. Segeband von Thune nennt in seinem Testament 1385 nur die Summe des von inm noch zu erstattenden Betrages, nämlich zehn Mark, gibt aber nicht die Menge des dafür gegebenen Tuchs an. Anders ist es im Fall des Testators Titke Prilep 1483: Er gibt an, Heinrich Ketsche habe von inm sechs Ellen Tuch für vierzehn Schillinge erhalten; das heißt, eine Elle des betreffendenTuchs kostete zumindest im angegebenen Jahr ungefähr zwei Schillinge.

\footnotetext{
${ }^{20}$ U. REINHARDT, Testamente, Nr.270, S.427.

${ }^{21}$ U. REINHARDT, Testamente, Nr.282, S.451. filum kann auch Garn heißen

${ }^{22}$ Hier handelt es sich um Tuch, das vorher nicht als Sargtuch Verwendung fand, das also entweder im Besitz des Testators war oder das angekauft werden mußte. Auswertung der Sargtuch - /Tuchklauseln siehe weiter oben.

${ }^{23}$ U. REINHARDT, Testamente, Nr.283, S.454.
} 
Tibbeke Harendorp vermerkt 1498 in ihrem Testament, die Nyenborgesche sei ihr 6 Mark für Leinwand schuldig.

\section{Verfügungen über Sargtuch}

Legt man die Ausdrucksweise der Lüneburger Testatoren zugrunde, muß man von Sargtuch sprechen, denn sie formulieren mehrheitlich, das Tuch solle über ihren Sarg gelegt werden. Sargtuch ist der eigentlich angemesse Begriff, dem gegenüber dem heute noch verwendeten „Bahrtuch“ der Vorzug zu geben ist ${ }^{24}$. Vor dem 13. Jahrhundert wurden die Toten auf Bahren liegend und mit einem Bahrtuch verhüllt zu Grabe getragen. Särge und Sargtücher kommen im 13. Jahrhundert auf, bedingt durch das - wie Ariès formuliert „Phänomen der Verbergung des Toten“25. Das Sargtuch ist Ausdruck eines „bemerkenswert (en) Wandel (s) der Bestattungsbräuche“26, ist letztes und äußeres Glied der Kette des Verhüllens des Leichnams. So bietet es sich als Repräsentationsmöglichkeit an, bei der noch einmal durch die Kostbarkeit des Stoffes Finanzkraft und damit auch gesellschaftlicher Rang des verstorbenen Testators sichtbar gemacht werden kann.

Elf Testatoren haben im 15. Jahrhundert diesbezügliche Verfügungen in ihr Testament aufgenommen. Testamentarisch verankerte Sargtuchregelungen treten überwiegend in den ersten vierzig Jahren des 15 . Jahrhunderts auf, die zweite Jahrhunderthälfte weist nur drei derartige Verfügungen auf.

Vier Testatoren wünschen die Verwendung von fünf guldenen stucken (1409 Johann Semmelbecker / 2 Stück, 1410 Ludolf von Haghen, 1439 Henning von Bulten und 1472 Hans Jagow). Hierbei handelt es sich wohl um kostbaren goldurchwirkten Stoff, von dessen gelegentlicher Verwendung als Sargtuch Aries in seiner "Geschichte des Todes“ berichtetet $^{27}$. Riethmüller erwähnt in ihrer Auswertung Hamburger Testamente des 14. Jahrhunderts ebenfalls die Verwendung guldener stucke als Sargtuch; sie kommt zu dem Schluß, daß es sich bei diesem Tuch „wahrscheinlich um Goldbrokat“ handelt ${ }^{28}$. Brokat ist ein aus Seiden-, Silber- und Goldfäden gewebter Stoff, dessen Grundmaterialien für sich genommen bereits wertvoll sind. Dieser Wert potenzierte sich für den nordeuropäischen Menschen des Spätmittelalters dadurch, daß in seinen Heimatregionen die Herstellung

\footnotetext{
${ }^{24}$ Bereits M. RIETHMÜLLER schränkt diesen Begriff ein, indem sie „das sogenannte Bahrtuch“ schreibt. M. RIETHMÜLLER, to troste, S.119.

${ }^{25}$ PH. ARIÈS, Geschichtes des Todes, München 1987, S. 216.

${ }^{26} \mathrm{Ph}$. ARIÈS, ebd., S.221.

${ }^{27} \mathrm{Ph}$. ARIÈS, ebd., S.221. Leider bleiben die Quellen unerwähnt, so daß es hier nicht möglich ist, Stadt oder Region zu benennen, in der diese ,goldenen“ Sargtücher auftraten.

${ }^{28}$ M. RIETHMÜLLER, to troste, S.120. In Konstanz wird als Sargtuch überwiegend schwarzer Stoff verwendet. Zu überprüfen wäre, ob dieser Farbunterschied rein zufällig war oder ob sich dahinter regionale Unterschiede verbergen. P. BAUR, Bürgerschaft und Testament, S.239
} 
unbekannt war, so daß der nicht zuletzt durch den Import verursachte hohe Kaufpreis den Käufer als finanzstarken und damit gesellschaftlich etablierten Menschen auswies ${ }^{29}$. Den Preis für Brokat gibt Adelheid Kolse mit 10 Mark, Hans Jagow mit 20 Mark an. Johann Semmelbecker ist zum Zeitpunkt der Testamentserrichtung im Besitz zweier goldener Tuchstücke; ein möglicher Grund für diese Vorsorge mag in seiner offensichtlich bewußten Todesvorbereitung liegen, da er sich als crank in me lichame, doch van godes gnaden wolmechtich myner reddelicheit und sinne bezeichnet ${ }^{30}$.

Drei Testatoren, Adelheid Kolse 1430, Heinrich Steinhagen 1439 und Johann vame Lo 1464 verlangen die Anschaffung weißen Sargtuchs, wobei Johann vame Lo für seine Begräbnisfeiern Tuch aus England wünscht. Lüder Bardewiks Bahrtuch soll ein seidenes sein (1415), Werner Volkmer bestimmt den Kauf von Tuch aus Eeclo (1418), und Dietrich Junge wählt schwarzes Tuch aus Leiden (1476). Die Größe seines Sargtuchs bestimmt Werner Volkmer mit sechs Ellen und Dietrich Junge mit der Hälfte eines Tuchlakens. Zwei von innen, Heinrich Steinhagen und Johann vame Lo, wünschen, daß sich die Menge des zu beschaffenden weißen Tuches nach der Menge bemißt, die für die Anzahl der von innen gewünschten Anfertigung von Chorkappen benötigt wird.

Die Farben der Sargtücher Gold, Weiß und Schwarz sind dem Spätmittelalter als Trauerfarben bekannt. Das das Licht wie keine andere Farbe reflektierende Weiß bewirkt aufgrund dieser Eigenschaft einen großflächigen und spiegelnden Eindruck, der in der Johannesapokalypse in die Beschreibung der Verklärung und Himmelfahrt Christi Erwähnung fand ${ }^{31}$. Die Idee des die Auferstehung symbolisierenden Weiß fand Akzeptanz und Verbreitung. Bei Trauerfeierlichkeiten wurde die Trauergemeinde durch die Lichtfarbe Weiß auf die Unsterblichkeit in Christi und die kommende Auferstehung von den Toten erinnert und in ihrem Schmerz um den Verstorbenen getröstet. Die Überhöhungsfunktion der Farbe Weiß wurde in gesteigertem Maße der Farbe Gold beigemessen, die als Farbe des Metalls der Sonne galt. Während Gold und Weiß als Lichtfarben bei einer Trauerfeier die Auferstehung und das ewige Leben verhießen, so symbolisierten stumpfes Weiß und Schwarz die Trauer, die düstere Seite des Todes.

Welche Angaben machen die Testatoren über die Weiterverwendung des Sargtuchs? In zwei Fällen ist erkennbar, daß angesichts eines offenbar anders gelagerten Pietätsmaßstabs Sargtücher im täglichen Lebensbereich Verwendung fanden. Werner Volkmer übergibt den Stoff nach den Beerdigungsfeierlichkeiten einer dem Testator und seiner Frau offenbar treu dienenden Magd (1418 April 30). Geseke Leyferd (Testament

\footnotetext{
${ }^{29}$ R. JAQUES, „Brokat“, in: RDK, Bd.2, Sp. 1179-1181.

${ }^{30}$ U. REINHARDT, Testamente, Nr.75, S.106.

${ }^{31}$ H. NIXDORF, H. MÜLLER, Weiße Westen - Rote Roben. Von den Farbordnungen des Mittelalters zum individuellen Farbgeschmack (= Katalog zur Sonderausstellung der Staatlichen Museen Preußischer Kulturbesitz Berlin. Museum für Völkerkunde und Museum für Deutsche Volkskunde), Berlin 1983, S.90ff.
} 
1485 Jan. 31) ist bereits im Besitz eines kleinen Pfühls, der myt liikdoke betogen is. Es ist nicht unwahrscheinlich, daß dieser Pfühl mit edlem Stoff, vielleicht Goldbrokat, bezogen ist, denn eine Lüneburger Luxusverordnung des 14. Jahrhunderts versucht die Vorliebe für guldener stucke...guldener kolten...guldener pole...guldener kussene einzudämmen ${ }^{32}$.

Die übrigen Testatoren wünschen, daß aus dem Tuch Gewänder für Klosterjungfrauen oder für Priester gefertigt würden. Die bedachten Klosterjungfrauen sind stets Schwestern der Testatorin oder des Testators, denen beim Tragen eines aus dem Sargtuch ihres Bruders oder ihrer Schwester gefertigten Gewandes aufgrund der familiären Bindung eine besondere Aufgabe hinsichtlich des gedenkenden Gebets zukommt. In vier Fällen werden Jungfrauen oder weibliche Familienangehörige als Bewohnerinnen eines Klosters (hier entweder Medingen oder Diesdorf) ausgewiesen, und in drei dieser vier Fälle soll für jede Bedachte je eine chorkappe oder kappe angefertigt werden, im vierten Fall darf man eine solch gewünschte Anfertigung vermuten. Die Cappa ist ein klerikal - mönchisches Gewand, bei dem es sich um einen vorne geschlitzten, fußlangen Mantel handelt, der mit einer Kapuze versehen ist ${ }^{33}$. Getragen wurde er beim Chorgebet und bei Prozessionen. Die Testamente weisen aber nicht nur Frauen als Trägerinnen von Kappen aus, sondern in einem Fall auch einen Mann, den Dominikaner Johann Schirwater (1476 Dietrich Junge). Es wird also als liturgisches Gewand von Männern und Frauen getragen. An Festtagen werden auch seidene Kappen angelegt, und eine solche seidene Kappe stiftet Lüder Bardewik der Kirche in Rameslo, denn sein Sargtuch sollte ein seidenes sein. Johann Semmelbecker bedenkt die Johanniskirche. Hans Jagow, Hamburger Bürger, wünscht, daß der ebenfalls seinem Sarg überzulegende beste Rock dem Kirchbau St. Katherina in Hamburg zugutekommen sollte, während das goldene Tuch an die Kommende des Thomasaltars daselbst fallen solle.

Sargtücher werden den Lüneburger Testamenten zufolge in überwiegendem Maße zu liturgischen Gewändern umgearbeitet, können aber auch Kirchen, Kommenden oder Bediensteten zugewendet werden. Diese Art der Weiterverwendung ist nicht auf Lüneburg beschränkt, sondern ist auch in Hamburger Testamenten zu finden ${ }^{34}$ ebenso wie in Stralsunder ${ }^{35}$ und in Konstanzer Testamenten ${ }^{36}$. In dieser Weise verwendete Sargtücher sind zumindest in Lüneburger Testamenten und den angeführten Beispielen der Vergleichsstädte von wertvoller Qualität, oft auch von entsprechender Quantität, so daß die in den österreichischen Bürgertestamenten zu beobachtende konträre Vererbungstendenz,

\footnotetext{
${ }^{32}$ Fr. W. VOLGER, UB LG, Bd.III, S.431.

${ }^{33}$ J. WAGNER, „Cappa“, in: LThK, Bd. 2, Sp. 928.

${ }^{34}$ M. RIETHMÜLLER, to troste, S.97, S.119f.

35 J. SCHILDHAUER,Hansestädtischer Alltag (=Abhandlungen zur Handels- und Sozialgeschichte, Bd.28), Weimar 1992, S.28.

${ }^{36}$ P. BAUR, Testament und Bürgerschaft, S.178.
} 
Sargtücher im Rahmen der Kleiderlegate an Arme zu verteilen ${ }^{37}$, sich vermutlich auf Tücher einfacherer Qualität bezieht.

\section{Kleidung}

\section{a. Einleitung}

Der Anfangszeitraum der Untersuchung fällt zusammen mit dem Zeitpunkt der Bekleidungsgeschichte, der nach KÜHNEL als der Beginn jener Phase anzusehen ist, seit dem Kleidung nach zeitgenössisch - heutigem Maßstab mit dem Wort „Mode“ bezeichnet werden kann ${ }^{38}$. Gemeint ist damit folgendes: Vorüber ist die Zeit, in der Kleidung in ihren Schnittformen annähernd ohne Veränderung bleibt, weil das Primat des Witterungsschutzes vorherrscht und Kleidung durch den jeweiligen Stand des Trägers determiniert ist. Dieser sich im ersten Drittel des 14. Jahrhunderts vollziehende Wandel ist die Folge verschiedener miteinander verwobener Faktoren ${ }^{39}$ : Auf der Seite der Arbeitstechnik hatte die Tuchindustrie durch die Kreuzzüge einen wesentlichen Impuls bekommen, denn aus dem arabischen Bereich wurden Handspinnrad und Trittwebstuhl übernommen. Das Handspinnrad führte die Arbeitsgänge „Aufspulen“ und „Zwirnen“ fünfmal schneller durch, als es mit der Handspindel möglich gewesen wäre. Der Trittwebstuhl mechanisierte die Arbeitsgänge „Fadenbildung“ und „Ladenschlag“, was ein Mehr an qualitativ guten Tucherzeugnissen zur Folge hatte. Zusammen mit dem Einsatz der Walkmühle führte das in den Tuchzentren Flanderns, Italiens und den betreffenden Tuchregionen Deutschlands - vor allem in Köln - zur Ausbildung von Großwerkstätten. Der Schwerpunkt der europäischen Tuchproduktion lag in der flämischen Region, die die zu verarbeitende Wolle aus England bezog. Auf der wirtschaftlich-finanziellen Seite leistete der von den Städtern ausgehende Aufschwung in Produktion und Handel sowie der damit verbundene finanzielle Gewinn diesem Wandel Vorschub. Auf der mentalen Seite stand die durch verschiedenste Einflüsse wirtschaftlicher, historischer und philosophischer Art veränderte Lebenseinstellung, in der der Einzelne, und gerade der wohlhabende Stadtbürger, (selbst -) bewußter auftrat. Diese durch so unterschiedliche Faktoren möglich gewordene Mode bestand aus Kleidungsstücken, die zu tragen eben nicht mehr schützende oder verordnete Notwendigkeit war, sondern von den Trägern bewußt ausgewählt wurde und als allerorten sichtbares Zeichen den Erfolg zur Schau stellte, der durch die eigene Arbeitskraft in finanzieller und sozialer Hinsicht errungen war. Wenn es

\footnotetext{
${ }^{37}$ JARITZ, Österreichische Bürgertestamente, in: Jb für Geschichte des Feudalismus 8 (1984), S. 261.

${ }^{38}$ H. KÜHNEL, Bilderwörterbuch der Kleidung und Rüstung, S. XXXVIII.

${ }^{39}$ H. KÜHNEL, Bilderwörterbuch der Kleidung und Rüstung, S. XXXIX ff.
} 
auch Unterschiede zwischen Alltags- und Festtagsgewand, zwischen Kleidung der verschiedenen sozialen Gruppierungen gegeben hat, so kann doch festgehalten werden, daß in der Zeit von 1300 bis 1500 sich die städtische Kleidung durch ihre Träger von einer die höfische Mode rezipierenden zu einer eigenständig impulsgebenden und nun ihrerseits imitierten entwickelte.

Kleidungsstücke werden in den Testamenten nicht als Selbstzweck en detail beschrieben, sondern im Regelfall mit einer dem Testator als treffend erscheinenden Formulierung genannt, die es möglich macht, im Erbfall das betreffende Kleidungsstück aus der Menge der übrigen Kleider des Testators herauszugreifen. Für diese Konkretisierung wählen Testatoren ihrer qualitativ und quantitativ unterschiedlich zusammengesetzten Kleidermenge und ihrer nicht durchgängig einheitlichen Terminologie entsprechend unterschiedliche Formulierungsweisen, die sich in wesentlichen Zügen zusammenfassen lassen als:

Legate, in denen zählbare Kleidungsstücke bezeichnet werden

Legate, in denen Kleidung summarisch erfaßt wird

Legate, in denen Kleidungsstücke vom Testator terminologisch bezeichnet werden

Legate, in denen Kleidungsstücke vom Testator in „Oberbegriffen“ genannt werden

Legate über bereits vorhandene Kleidungsstücke

Legate über anzufertigende Kleidungsstücke

Für die Auswertung stehen somit das Kriterium der Zählbarkeit, das Kriterium der Terminologie und das Kriterium des Vorhandenseins zur Verfügung. Die herausgearbeiteten Kriterien sind wichtig für die Bewußtwerdung der unterschiedlichen Vergabungsweisen von Kleidungsstücken. Angesichts der weitverzweigten letztwilligen Verfügungen der Testatoren erscheint es nicht ratsam, eine Auswertung im Sinne des Abhakens dieser Kriterien vorzunehmen. Zu groß ist die Gefahr, durch die aus der Strukturierung erwachsenen, hier notwendigen Abgrenzung Folgeverfügungen abzuspalten. Die Auswertung entscheidet sich für das Zugrundelegen der von den Testatoren genannten Bekleidungsbegriffe. Um Übersichtlichkeit zu gewährleisten, werden die Bekleidungsbegriffe unter Überschriften zusammengefaßt. Die mittelalterlich zeitgenössischen Termini sollen kritisch reflektiert übernommen werden. Das bedeutet zunächst das Hinweisen auf mögliche Probleme, wie sie bereits von Jaritz subsumiert wurden als Problem von Ober- und Unterbegriff, Problem der terminologischen Varianz und 
dem Problem der Schnellebigkeit der Objekte und der sie bezeichnenden Begriffe ${ }^{40}$. Lediglich ein Aspekt, der im Rahmen der Auswertung in vielen Fällen zutage tritt, soll an dieser Stelle betont werden: Eine mögliche Fehlerquelle muß nicht, kann aber in der "Problematik der Verwendung und Verbindung von Ober- und Unterbegriff" liegen, die JARITZ sicherlich nicht zufällig gerade am Beispiel der Quellengattung Testament erläutert ${ }^{41}$. Abschließend sei hervorgehoben, daß die vorliegende, auf der Auswertung von Testamenten beruhende Arbeit Probleme terminologischer Natur nicht lösen kann. Ihr Ziel ist es, in dem folgenden Kapitel den testamentarischen Umgang mit Kleidungsstücken zu beleuchten.

b. Kleid

Die unter diesem Stichwort zusammengefaßten Verfügungen sind bestimmt von der Wortwahl der Substantive cleder und vestis. Das Problem von Ober- und Unterbegriff zeigt sich in der Verwendung dieser Wörter: Die Testatoren gebrauchen das Wort „Kleid“ sowohl als Gattungsbezeichnung als auch als Bezeichnung eines konkreten Kleidungsstücks. Möglich ist, daß im Sprachgebrauch der Testatoren ein konkret bezeichnetes Kleid sowohl ein Rock oder eine Hoike sein konnte, denn wenn en par cleder die Kombination Rock Hoike ist ${ }^{42}$, dann erscheint es nicht unlogisch, jeweils einen Bestandteil dieses Paares auch als Kleid zu bezeichnen, ein sprachlicher Mechanismus, der dem unsrigen bei „ein Paar Schuhe - ein Schuh" vergleichbar wäre. In diesem Sinne kann auch die Formulierung der Testatorin Greteke Melbek verstanden werden, die in ihrem 1474 errichteten Testatment schrieb: Ock schal men geven alle iar eneme armen mynschen eyn kleyt, en rok edder enen hoyken ${ }^{43}$.

Kleider, über die die Testatoren verfügen, sind mehrheitlich bereits vorhandene Kleider, die sich im Besitz des jeweiligen Testators befinden. In einigen Fällen müssen die einem bestimmten Empfänger zugedachten Kleidungsstücke - offensichtlich nach dem Tod des Testators -angeschafft werden.

Vererbt werden Kleider, deren genaue Anzahl vom Testator erwähnt wird, und Kleider, die in ihrer Summe ohne Bestimmung der Anzahl vom Testator aufgelistet werden. Zählbare Kleider sind im Regelfall im Besitz des Testators vorhandene.

\footnotetext{
${ }^{40}$ G. JARITZ, Mittelalterliche Realienkunde und Fragen von Terminologie und Typologie. Probleme, Bemerkungen und Vorschläge am Beispiel der Kleidung, (=Österreichische Akademie der Wissenschaften, Philosophisch-Historische Klasse, Bd. 511, Veröffentlichungen des Instituts für Mittelalterliche Realienkunde Österreichs, Nr.10), Wien 1988, S.7 - 19. In besonderem Maße relevant für die vorliegende Arbeit seine Ausführungen über die Auswertungen schriftlichen Quellenmaterials S.12 - 16.

${ }^{41}$ G. JARITZ, Mittelalterliche Realienkunde und Fragen von Terminologie und Typologie. Probleme, Bemerkungen und Vorschläge am Beispiel der Kleidung, S.13.

${ }^{42}$ Max HASSE; Neues Hausgerät, neue Häuser, neue Kleider - eine Betrachtung der städtischen Kultur im 13. und 14. Jahrhundert sowie ein Katalog der metallenen Hausgeräte, In: ZAM 7 (1979), S.56.
} 
Tabelle: Testamentarische Verfügungen über Kleider

\begin{tabular}{|c|c|}
\hline Jahre & Anzahl der Testatoren und Verfügungen \\
\hline $1300-1325$ & - \\
\hline $1326-1350$ & 1 Testatoren mit 1 Verfügung \\
\hline $1351-1375$ & 5 Testatoren mit 5 Verfügungen \\
\hline $1376-1400$ & 2 Testatoren mit 2 Verfügungen \\
\hline $1401-1425$ & 16 Testatoren mit 27 Verfügungen \\
\hline $1426-1450$ & 14 Testatoren mit 14 Verfügungen \\
\hline $1451-1475$ & 10 Testatoren mit 11 Verfügungen \\
\hline $1476-1500$ & 6 Testatoren mit 8 Verfügungen \\
\hline
\end{tabular}

Die Anzahlskurve der mit Klauseln über Kleider versehenen Testamente verläuft pro Quartal zwar in weit geringerer Anzahl, aber dennoch parallel zu der Kurve aller überhaupt in Lüneburg überlieferten Testamente. Aus dem 14. Jahrhundert stammen insgesamt 8 Testamente mit 8 Verfügungen, aus dem 15. Jahrhundert 46 Testamente mit 60 Verfügungen. Unter den 54 Kleider vererbenden Testatoren sind 7 Kleriker (12,96\%) und 17 Frauen (31,48\%). Als Empfänger werden in überwiegendem Maße Verwandte und Bekannte eingesetzt, wobei kein vorrangiges Bedenken weiblicher Erbnehmer zu beobachten ist.

Aus den Testamenten ist wenig über das Aussehen oder das Material der Kleider zu erfahren. Die Erklärung für die Zurückhaltung in der Beschreibung liegt im Kontext der Verfügungen. Beschrieben werden die Kleider, wenn sie angeschafft werden sollen. Da jedoch das Vorhandensein der Kleider herausragendes Merkmal der Kleiderverfügungen ist, erscheint hier den Testatoren im Normalfall jedes weitere Beschreiben überflüssig.

\section{Ein Paar Kleider}

Acht Testatoren vererben ein Paar Kleider. Mit diesem Begriff wird die Kombination Rock Hoike bezeichnet, bei der beide Kleidungsstücke aus gleichem Stoff gefertigt waren ${ }^{44}$. Johannes von Lippinghausens Legat ist mit neun Paar Kleidern das umfangreichste dieser Art; bedacht werden neun männliche Bekannte (Testament 1414).

\footnotetext{
${ }^{43}$ U. REINHARDT, Testamente, Nr.243, S.372.

${ }^{44}$ Max HASSE; Neues Hausgerät, neue Häuser, neue Kleider, S.56.
} 
In Heinrich von Gothings Testament 1413 heißt es : 1 par cleder alse er vor to dreghende isset, dat se erenvast blift ${ }^{45}$. Der Testator bedenkt also die Empfängerin Gheseke, die Tochter Drudens, (möglicherweise seine Enkelin) mit einer Kombination, deren Schnitt und Stoffqualität dem zu entsprechen hatten, was sich für ein junges Mädchen zu tragen geziemt. Die übrigen sechs Testamente sind von Frauen angefertigt worden (1414 Grete Masendorp, 1429 Tibbeke Poterow, 1423/31 Adelheid Seidentopf, um 1440 Alheid Weidelerche, 1460 Hilleke von Erpensen und 1469 Tibbeke Godenstedt). Zwei Testatorinnen vererben testamentarisch ihre zweitbeste Kombination, vier Testatorinnen inr bestes Paar Kleider. In drei Fällen sind kirchliche Einrichtungen Empfänger der Kleiderlegate; es handelt sich um St. Nikolai, das Kloster Ebstorf und den Bau der Johanniskirche. Tibbeke Poterow schenkt ihr zweitbestes Paar Kleider ihrer Magd Wulmeke, und sowohl Hilleke von Erpensen als auch Tibbeke Godenstedt bedenken bekannte/verwandte Frauen. Die von Tibbeke Godenstedt bedachte Soffeke Busse soll ihr Paar Kleider erst zum Zeitpunkt ihrer Ausstattung zur Ehe erhalten.

\section{Ein Kleid}

Von den insgesamt vier Testamenten (1474 Beke von Esche, 1474 Grete Melbek, 1482 Dietrich Döring und 1484 Hartwig Hannover), in denen der Legatsempfänger mit je einem Kleid bedacht wird, bezieht sich nur das Testament Hartwig Hannovers auf ein Kleid, das der Testator besitzt. Hannover wünscht, daß ein inm bekannter Priester sich eines aus seinen Kleidern für verschiedentlich geleistete Dienste aussuche. In den anderen Testamenten geht es um die Anschaffung eines Kleides. So heißt es z.B. im Testament der Beke von Esche, Henneke Rethmer aus Salzhausen solle jährlich ein neues graues Kleid erhalten.

Die Kombination von Rock und Hoike wird sowohl Frauen wie auch Männern zugewendet. Es handelt sich bei den zählbaren Kleiderlegaten oft um bereits vorhandene Kleider.

\section{Summarisch vergabte Kleider}

Nahezu ausschließlich handelt es sich bei den summarisch vergabten Kleidern um bereits vorhandene Kleider.

Ein möglicher Grund für diese Art der Kleidervergabe besteht in der Abteilung des Gutes der Ehefrau nach dem Tod ihres Ehemanns. Die Abteilung war nicht zwingend notwendig, wie aus dem Erbrecht und auch aus einigen Testamenten ersichtlich ist. Sie erscheint dann aber den Testatoren als erwähnenswert, wenn an eine mögliche Wiederverheiratung der

\footnotetext{
${ }^{45}$ U. REINHARDT, Testamente, Nr.101, S.140.
} 
Ehefrau zu denken ist ${ }^{46}$, auf die zwar einige, aber nicht alle Testatoren explizit hinweisen. Dreizehn verheiratete Testatoren haben eine dementsprechende Klausel in ihr Testament aufgenommen (1388 Arnd Neuenburg, 1409 Johann Semmelbecker, 1410 Ludolf von Hagen, 1411 Klaus Garlop ${ }^{47}, 1414$ Heinrich Uplegger, 1416 Ludolf Woye, 1419 Klaus Remstede, 1432 Hermen Snitker, 1434 Friedrich Hogeherte, 1436 Meinecke von Lübeck, 1451 Robke van dem Jettebrok, 1464 Johann van deme Lo, 1489 Christofel Rekel).

Der Frau steht nach dem Tod des Mannes die Frauengerade zu. In einer 1329 in einem Privileg der Herzöge Otto und Wilhelm bestätigten Ratssatzung wurde festgelegt, daß unter die Bezeichnung Frauengerade das falle, was die Frau von Eltern oder Verwandten erhalten habe. Die Lüneburger Stadtrechtsaufzeichnung von 1401 übernimmt diese Bestimmung. Kleidergeschenke und andere Gaben, die die Frau von ihrem Mann vor oder während der Ehe erhalten hatte, wurden nicht als der Frauengerade zugehörige Güter betrachtet. So formuliert z.B. Ludolf von Hagen 1410 in seinem Testament, nach Abzug aller Schulden hinterlasse er seiner Frau die restlichen mobilen und immobilen Güter; für den Fall ihrer Wiederverheiratung sei ihr die halbe Salzpfannenherrschaft, die sie in die Ehe einbrachte, zurückzugeben, ferner ihr Teil des Gutes mit ihren Kleidern und smyde. Überlegenswert ist, welche Kleidermenge von den Testatoren als der Ehefrau Kleidung bezeichnet wird: De jure sind es die von der Frau mit in die Ehe gebrachten oder während der Ehe geerbten oder gekauften Kleider, de facto mag es sich doch-zumindest bei glücklich geführter Ehe-auch um die vom Ehemann gekauften Kleidungsstücke handeln. Im Sinne der letztgenannten Möglichkeit formuliert Hermen Snitker 1432, seine Ehefrau möge u.a. ihre Kleider zurückerhalten, alles, was sie in die Ehe mitbrachte, aber auch das, was inr der Testator im Lauf dieser Ehe gab. Johann Semmelbecker ist der einzige Testator mit dem Wunsch, daß seine Frau in jedem Fall Jahr und Tag nach seinem Tod abgefunden werde. Sinn war in jedem Fall einerseits die Besitzstandswahrung des Gutes der Frau, andererseits der präventive Schutz der Erbmasse des Testators, die dieser für seine Nachkommen vor möglichen Ansprüchen des neuen Ehemannes seiner Frau zu sichern suchte.

In drei Testamenten werden Töchter mit Kleidern bedacht (1366 Heinrich Miles, 1440 Gese von Gandersen und 1482 Heinrich Erpensen). Ebenso wie in den Abteilungsklauseln für die Ehefrauen werden die den Töchtern zugedachten Kleider oftmals in Zusammenhang mit Geldlegaten und Fahrhabe bzw. ingedome genannt.

\footnotetext{
46 „Sterfft en vnser burgere in der stad vnd let he achter sik wiff vnd sone vnd dochtere, nympt de vrowe denne enen anderen man, so scal se touoren utgeuen den sonen eres vader herewede.

De vrowen rade schal se halff beholden vnd scal delen mit den dochteren, ere deghelikes cledere beholt se touoren. "Wilhelm Theodor KRAUT, Das alte Stadtrecht von Lüneburg, Göttingen 1846, S. 18, Nr. CXVIII; siehe auch S.35f (das erste Stück der Erbschichtungen ).
} 
Andere nahe Verwandtschaftsverhältnisse bei der Vergabe bereits existierender Kleidung liegen in den Testamenten Ludolf von Lafferts 1450 (Bruder als Legatsempfänger) und Albert Schultes 1475 (Neffe als Bedachter) vor. Schultes Testament ist wie Lafferts eines der wenigen Testamente, das die Kleider genau als des Testators grüne Kleider bezeichnet. Laffert will seinem Bruder all die Kleider hinterlassen, die inm, dem Testator, auf den Leib geschneidert sind. Auch Grete von dem Wede konkretisiert inr Kleiderlegat 1422 als Kleider, de to mynem live sneden $\operatorname{sind}^{48}$; unberührt von dieser ihrer Magd zugedachten Schenkung soll die Frauengerade und damit wohl die zur Frauengerade zählenden Kleidungsstücke bleiben. Dietrich von Bevensen verfügt 1421, man solle seine Kleider unter seinen armen vrunden verteilen ${ }^{49}$. Armen Menschen wollen Johann von Lippinghausen 1424, Johannes Weidenknepel 1444 und 1469 Tibbeke Godenstedt ihre Kleidungsstücke zugewendet wissen, wobei Tibbeke Godenstedt - offensichtlich das Schicksal etlicher nach dem Tod ihres Mannes verarmter Geschlechtsgenossinnen vor Augen - bedürftige Witwen als Empfängergruppe nennt.

Kleidung, die erst anzuschaffen ist

Aus den Legaten von vierzehn Testatoren wird erkennbar, daß die vergabte Kleidung noch angeschafft werden muß. Testatoren treffen derartige Verfügungen dann, wenn sie für Kleidung im Sinne des Lebensunterhalts zu sorgen haben, wenn sie eine Einkleidung bei einem Klostereintritt vornehmen müssen, wenn sie eine Beradung vornehmen oder wenn sie Vikarien mit Kleidung ausstatten:

Der Testator kann für die Versorgung eines Kindes oder seines Bruders nicht nur mit Nahrung, sondern explizit auch mit Kleidung sorgen. Die Testamente 1410 Ludolf von Hagens und Ludolf Ossendorfs 1451 zeigen, daß derartige Kleiderlegate bis zum 25. Lebensjahr, bis zur Volljährigkeit, limitiert waren. Um jeweils ihren Bruder sorgen sich Metteke Schwertfeger 1408 und Hans Rodenborg 1497. Metteke Schwertfeger hinterläßt ihr Gut ihrem Bruder und seiner Ehefrau für den Lebensunterhalt und eben auch für Bekleidung, und Hans Rodenborg wünscht, daß - falls sein Bruder inn überleben sollte sein Bruder mit allem, auch mit Kleidung, versorgt werde. Gertrud Semmelbecker weist in ihrem Testament 1370 darauf hin, einen in nicht klärbarer Verbindung zu ihr stehenden Mann nebst Frau und Kindern neun Jahre lang bekleidet und beköstigt zu haben.

\footnotetext{
${ }^{47}$ Hier ist nicht deutlich zu erkennen, ob Garlop seine Ehefrau abfindet. Es könnte sich auch um eine nichteheliche Beziehung handeln.

${ }^{48}$ U. REINHARDT, Testamente, Nr.145, S.192.

${ }^{49}$ U. REINHARDT, Testamente, Nr.139, S.186.
} 
Kleidung ist weiterhin zu beschaffen, wenn Kinder für den Klostereintritt einzukleiden sind. Diesbezügliche Legate enthalten die Testamente Degenard Bernardis 1353 und Geseke Wangelows 1487. Geseke Wangelow vermerkt in ihrem Testament, sie habe den Wunsch ihres Vaters erfüllt und zwei Kinder (ihre Schwestern ?) eingekleidet und jeweils eines in das Kloster Lüne bzw. in das Kloster Medingen gebracht; das alles habe mehr als 500 Mark gekostet. Natürlich wurde nicht ein so hoher Geldbetrag allein für Kleidung ausgegeben, denn Einkleiden für ein Kloster bedeutete eine komplette Ausstattung anzuschaffen. Allerdings werden die angeschafften Sachgüter angesichts einer derartigen Summe von gehobener Qualität gewesen sein. Daß großer Aufwand bei dem Eintritt in ein Kloster gemacht wurde, davon zeugt eine Lüneburger Polizeiverordnung, die im Jahr 1480 niedergeschrieben wurde. Hier heißt es : Welk man edder vrowe eyn kind to clostere gheven wolde, de scal dat kind men mit ses vrowen und mit ses megheden to clostere senden und nicht mer. Dar moten wol vere by riden. Wanne de vrowen wedder van dem clostere komen, de mach me wol to gaste hebben und sesse siner vrund darto unde nemende mer to der tyd. ${ }^{50}$. Klar wird, daß ein Klostereintritt eine teure Angelegenheit sein konnte, und auch der Kleidungskauf wird im Rahmen eines solchen Klostereintritts einen nicht geringen Geldbetrag gekostet haben.

Lüder Bardewik setzt in seinem 1415 errichteten Testament den zwei Töchtern seines Bruders einen Geldbetrag von 30 Mark für die Kleidung bei der Beradung aus.

Für die Bekleidung von Vikaren oder /und Priestern sorgen Johann von Bücken 1375 und Ludolf Bartholomäus 1427 in ihren Testamenten. Johann von Bücken möchte, daß die von inm gegründete Vikarie u.a. mit Kleidern versehen wird. Ludolf Bartholomäus setzt seinem Sohn für den Fall, daß dieser Priester wird, eine Rente von 40 Mark für Kost und Kleidung aus.

\section{Kleiderhandel}

Die Testamente legen von einem Lüneburger Kleiderhandel Zeugnis ab. Insgesamt sechs Testamente weisen auf Kleiderankauf und Kleiderverkauf hin. Das einzige Kleiderankauf beweisende Testament ist das zeitlich erste des Untersuchungszeitraums, nämlich das Testament des Priesters Leo aus dem Jahr 1339. Der Testator vermerkt, er hinterlasse seiner Schwester quinque marcas pro vestibus emendandis ${ }^{51}$.

In fünf Testamenten aus dem 15. Jahrhundert wird der Verkauf von Kleidung gewünscht (1424 Johannes von Lippinghausen, 1430 Adelheid Kolse, 1437 Metteke Bere, 1439 Heinrich Steinhagen und 1473 Metteke von Dassel).

\footnotetext{
${ }^{50}$ W.Fr. VOLGER, UB LG, Bd. III, S. 431.

${ }^{51}$ U. REINHARDT, Testamente, Nr.1, S.1.
} 
Metteke Bere ordnet den Verkauf ihrer Kleider und ihres Hausrates aus zunächst einmal praktischen Gründen zur Finanzierung ihres Begräbnisses an, das Übrigbleibende soll an Sohn und Tochter fallen. Ein Blick in das Testament Johanns vame Lo aus dem Jahr 1473 mit seinen expliziten Begräbnisanweisungen zeigt, wie extensiv und damit finanziell intensiv Begräbnisfeierlichkeiten unter Umständen sein konnten.

Heinrich Steinhagen und Johannes von Lippinghausen wollen den Erlös des Kleiderverkaufs dem Heil ihrer Seele zugewendet wissen, wobei Lippinghausen seinen Testamentsvollstreckern die Möglichkeit läßt, die Kleidungsstücke direkt an die Armen zu verteilen; immerhin ist dies auch eine mildtätige Gabe, die dem Seelenheil dient.

Metteke von Dassel konkretisiert die zu verkaufenden Kleidungsstücke als zwei Tuchhoiken und zwei Tuchröcke, deren finanzieller Erlös an ihre Bediensteten fallen soll; auch wenn man einkalkuliert, daß Bedienstete sicherlich keine Reichtümer vererbt bekamen, erwartet die Testatorin einen Erlös, der für mehrere Bedienstete je ein ausreichendes Legat ist.

Das Testament Adelheid Kolses zeichnet das Bild einer von ihrem Sohn enttäuschten, ihm aber dennoch zugeneigten Mutter, die trotz seiner Verschwendungssucht und seines Ungehorsams ihm eine für seinen Lebensunterhalt sorgende Rente hinterläßt. Sie klagt: ..wat ik em gaf van clederen des enen dages, des vorbrachte he und vorkofte des andern dages ... 52 .

Auf die Bedeutung des Altkleidergeschäfts im Mittelalter wies HEIMPEL mit der Bemerkung hin, für den einfachen Mann sei das Altkleidergeschäft und der Altschuhhandel das gewesen, was die Gegenwart als Konfektion bezeichne ${ }^{53}$. Die Testamente selbst geben keine Auskunft über die Kunden. Es ist durchaus denkbar, daß der sogenannte einfache Mann nicht der einzige Käufer war, denn wenn die Lüneburger Testatoren - wie die anderer Städte auch - wertvollere Kleidung Kirchen und Klöstern zuwandten, so heißt das unter Umständen, daß diese Institutionen die Kleidung in Geld umwandelten, und demzufolge wertvollere Kleidung durchaus Bestandteil des Kleidergeschäftes war.

\section{c. Der Rock}

Die Lüneburger Testatoren verwenden zur Bezeichnung dieses Kleidungsstücks das Wort rock, rok oder roke. Geistliche, die ihr Testament in Form des in lateinischer Sprache abgefaßten Notariatsinstruments niederlegten, verwendeten das Wort tunica ${ }^{54}$. Im folgenden wird die durch die Testatoren vorgegebene Wortwahl „Rock“ beibehalten.

\footnotetext{
${ }^{52}$ U. REINHARDT, Testamente, Nr.164, S.225.

${ }^{53}$ H. HEIMPEL, Auf neuen Wegen der Wirtschaftsgeschichte, in: Die Stadt des Mittelalters, Bd. 3 (= Wirtschaft und Gesellschaft), Darmstadt 1976, S. 24f Erstveröffentlichung: Vergangenheit und Gegenwart 23, 1933, S.495 - 515.

${ }^{54}$ Ausnahme ist der laycus opidanus in Medinge, Heinrich Müller, mit seinem in lateinischer Sprache abgefaßten Testament von 1425 März 31.
} 
Rock bezeichnet ein einteiliges Kleidungsstück in kurzer oder langer Form, gegürtet oder ungegürtet, mit oder ohne Ärmel. Diese Begriffsbeschreibung erlaubt die Zusammenfassung von Rock und Tunica unter den Stichwort Rock. Legt man eine durch das Kriterium Körpernähe definierte Rangfolge der Kleidung fest, so kann man den Rock von der Überbekleidung wie den verschiedenen Mantelformen oft, aber nicht zwangsläufig abgrenzen.

Auffallend ist, daß die Testatoren zwei Jahrhunderte lang konstant die Bezeichnung Rock beibehalten, während andere Kleidungsstücke wie Schecke oder Wams, die den Rock in der Mode ablösten oder zumindest doch eine Alternativbekleidung darstellten, kaum erwähnt werden. Auch die Testamentsauswertungen anderer Städte zeigen, daß im Regelfall klassifizierend von Rock gesprochen bzw. geschrieben wird und eben selten andere modische Kleidung kennzeichnende Begriffe fallen.

Tabelle: Testamentarische Verfügungen über Röcke

\begin{tabular}{|c|c|}
\hline Jahre & Anzahl der Testatoren und Verfügungen \\
\hline $1300-1325$ & 1 Testator mit 1 Verfügung \\
\hline $1326-1350$ & 1 Testator mit 1Verfügung \\
\hline $1351-1375$ & 1 Testator mit 1 Verfügung \\
\hline $1376-1400$ & 7 Testatoren mit 11 Verfügungen \\
\hline $1401-1425$ & 17 Testatoren mit 34 Verfügungen \\
\hline $1426-1450$ & 7 Testatoren mit 13 Verfügungen \\
\hline $1451-1475$ & 9 Testatoren mit 11 Verfügungen \\
\hline $1476-1500$ &
\end{tabular}

In den Testamenten von dreiundvierzig Testatoren, ein Drittel waren Frauen, finden sich zweiundsiebzig Verfügungen über Röcke. Aus dem 14. Jahrhundert sind drei Testamente mit drei Verfügungen überliefert, aus dem 15. Jahrhundert vierzig Testamente mit neunundsechzig Verfügungen.

Es handelt sich hier in erster Linie um Verfügungen über Röcke, die sich im Besitz des Testators befinden; selten geht es um anzufertigende Röcke und in nur einem Fall um Rockzubehör.

Empfänger der Rocklegate sind in erster Linie Familienmitglieder. Von den sechsundzwanzig als Familienmitglieder erkennbaren Beschenkten sind vierzehn weiblichen und zwölf männlichen Geschlechts. Als Bekannte einzuordnen sind achtzehn 
Bedachte. In fast gleichem Umfang wie Bekannte werden auch die Bediensteten von den Testatoren bedacht. Hinter diesen siebzehn Legaten scheint die oft von persönlicher Zuneigung geprägte Beziehung zwischen Dienstgeber und Dienstnehmer zu stehen, die wie die Testamente erkennen lassen - häufig in jahrelangem Miteinander entstanden ist. Zwar werden Röcke von Kleriker zu Kleriker vererbt, sie werden aber in begrenztem Maße Kirchen zugewendet. Von den insgesamt fünf Testatoren, die ihren Rock einem Kleriker zuwenden, ist Johann von der Mölen der einzige Laie. Alle anderen, der Priester Leo 1339, Johannes von Lippinghausen 1414, Heinrich Tetendorp 1441 und Heinrich Geismar 1461, sind Personen geistlichen Standes, die ihren (Chor -) Rock Kollegen zuwenden.

In drei Verfügungen werden Röcke für den Kirchbau bestimmt.

Die Unterschiedlichkeit der testamentarisch vergabten Röcke kommt nicht durch verschiedene Bezeichnungen zur Geltung, sondern durch die von den Testatoren erwähnte, unterschiedliche Farbigkeit des Rocks selbst oder der seines Futterstoffes. Weiter differenzierend sind die Angabe des Herkunftsorts des verwendeten Tuchs oder die Bezeichnung des Materials.

\section{Die Farbe der Röcke}

Die Testatoren haben von vierundvierzig Röcken die Farbigkeit angegeben, womit mehr als die Hälfe aller testamentarisch vergabten Röcke erfaßt ist, unterstellt man, daß in zweiundsiebzig Rockverfügungen über mindestens zweiundsiebzig Röcke verfügt wird. Im Vergleich zu den anderen in Testamenten erfaßten Kleidungsstücken ist das ein hoher Prozentsatz an Farbnennung. Eine mögliche Erklärung für die genaue Beschreibung der Farbigkeit mag in der Bedeutung dieses Kleidungsstücks liegen, das als grundlegendes Kleidungsstück in keiner Garderobe fehlte. Darüberhinaus haben gerade die Testatoren, die in ihrer Mehrzahl Repräsentaten der wohlhabenden Schicht waren, mehrere Röcke gehabt, die es zu unterscheiden gilt. Indiz dafür ist die Tatsache, daß etliche Testatoren über mehrere Röcke verfügen: 1367 Johann Beve und 1425 Heinrich Müller über je fünf Röcke; 1414 Johannes von Lippinghausen über vier Röcke ebenso wie Hans Jagow 1472, über je drei Röcke 1423 Adelheid Seidentopf, 1430 Hans Jagow, 1441 Heinrich Tetendorp, 1444 Cyeke Witting, 1472 Geseke Rosemberg; 1418 Tibbeke Remsnyder über zwei Röcke wie Wobbeke Boltzen 1428, Adelheid Kolse 1430, Dietrich Heket 1433, Heinrich Steinhagen 1439, Johannes Weidenknepel 1444 und Heinrich Winthe 1490. Weil die Farbe wesentliches Gestaltungselement der Mode war, erscheint es natürlich, daß gerade eines, wenn nicht das grundlegende (Ober-) Bekleidungsstück in wohlhabenden Haushalten in verschiedenen Farben vorhanden und damit vielfach kombinierbar war. 
Die Farbvorstellungen waren eingebettet in ein bestimmtes Wertesystem. Die mittelalterlichen Farbauffassungen fußen auf der Antike ${ }^{55}$. Antike Grundfarben sind Schwarz, Weiß, Gelb und Purpur, Farben, die sich im Regenbogen wiederfinden. Bemißt sich nach Plato die Schönheit einer Farbe nach ihrem eigenen Symbolgehalt, so sieht Aristoteles die Ebenmäßigkeit zwischen den Farbpolen Schwarz und Weiß als wesentliches Kriterium der Schönheit. Isidor von Sevilla vollzieht die Adaptation der Farbenlehre für das Christentum, in dem er die Farben als Symbole der Gottesherrschaft deutet. Die von Beda Venerabilis eingeführten Grundfarben Violett/Blau, Grün und Rot sind die dann in der mittelalterlichen Kleidung bevorzugten Farben. Das durch das Christentum evozierte Schönheitsideal bemißt sich nach der Nähe, die eine Farbe zum Licht und damit zur Herrlichkeit Gottes besitzt.

Von den achtunddreißig einfarbigen Röcken sind dreiundzwanzig in dunklen Farben gehalten. Insgesamt elf schwarze Röcke werden testamentarisch vergabt. Sie werden in Testamenten des fünfzehnten Jahrhunderts in einer über das Jahrhundert annähernd gleichbleibenden Verteilung erwähnt. Vier der Donatoren sind Frauen (Tibbeke Remsnyder, Adelheid Seidentopf, Geseke Rosemberg und Gesche Henning), und drei Donatoren, nämlich Johannes von Lippinghausen, Heinrich Tetendorp und Heinrich Geismar, sind Kleriker. Hans Junge, Dietrich Heket und Heinrich Winthe sind Lüneburger Bürger. Sechs der elf Verfügungen lassen erkennen, daß der jeweilig vergabte schwarze Rock von gehobener Ausführung war. Da schwarz gefärbte Kleidung teuer war ${ }^{56}$, erscheint eine entsprechend solide Verarbeitung angemessen. Sechs dieser schwarzen Röcke sind gefüttert: zwei mit Iltispelzen und drei mit Tuchstoff, beim sechsten Rock ist keine Angabe über das Futtermaterial formuliert worden. Die tuchgefütterten Röcke weisen die Farbkombinationen schwarz/grün, schwarz/blau, schwarz/rot und schwarz/weiß auf. Diese mehr auf Zurschaustellung als auf einen Wärmeeffekt hindeutenden Farbkombinationen lassen einen Schnitt der Röcke erahnen, der in irgendeiner Form die Andersfarbigkeit des Futters zur Geltung bringt. Im (Spät-)Mittelalter ist man sich durchaus bewußt, daß durch die dunkleren „Rahmenfarben“ der Farbkontrast zu leuchtenderen Farben erst recht zur Geltung kommt ${ }^{57}$.

Eindeutig modisch ist der enge Schnitt des schwarzen Rockes, den Tibbeke Remsnyder 1418 Hans Voghels ältester Tochter hinterläßt. Der enge Schnitt zeichnet zunächst die Mode des Adels aus, der durch die Arbeitsuntauglichkeit der Kleidung sein Privileg der Nicht-Werktätigkeit ausdrückt. In der zweiten Hälfte des 14. Jahrhunderts fallen dann die

\footnotetext{
${ }^{55}$ Darstellung orientiert sich an H. NIXDORF, H. MÜLLER, Weiße Westen - weiße Roben, S. 57 - 60.

${ }^{56}$ H. NIXDORF, H. MÜLLER, Weiße Westen - weiße Roben, S.86.

${ }^{57}$ H. NIXDORF, H. MÜLLER, Weiße Westen - weiße Roben, ebd.
} 
Schnitte der städtischen Mode körperbetont eng aus, wobei vor allem die Festtagsmode eng ist. So darf man in dem engen schwarzen Rock der Tibbeke Remsnyder den Festtagsrock der Testatorin vermuten.

Empfänger der Legate sind fast ausnahmslos Familienmitglieder oder Bekannte, lediglich Adelheid Seidentopf wendet ihren schwarzen Rock ihrer Magd Leneke zu.

Mit neun Verfügungen ist braun nach schwarz die in Testamenten am häufigsten erwähnte Rockfarbe. Braune Röcke werden ausschließlich im fünfzehnten Jahrhundert testamentarisch vererbt. Die Rocklegate sind nicht gleichmäßig über das Jahrhundert verteilt: Sie werden entweder in der Spanne von ca. 1420 bis 1440 oder in der Zeit von ca. 1470 bis 1500 erwähnt. Von den sieben braune Röcke vererbenden Testatoren sind sechs weiblichen Geschlechts. Die überwiegende Vererbung brauner Röcke durch Frauen gründet sich in erster Linie auf die Verwendung der Farbe Braun als Trauerfarbe. Im Spätmittelalter tragen gerade die Witwen Kleidung aus ungefärbter dunkler Wolle, die einen bräunlichen Eindruck vermittelt ${ }^{58}$. Ein Blick auf die Liste der Testatorinnen zeigt, daß Soffeke Sprintgud, Geseke Leyferd und Hilleke Blickershusen verwitwet sind wie wohl auch Cyeke Witting und Geseke Rosemberg; über den Familienstand Adelheid Seidentopfs ist keine Aussage möglich. Der einzige männliche Testator, der Vikar Heinrich Tetendorp, vererbt einen brauen Rock, der seinem Vater gehört hatte; allerdings soll er nun an eine Frau fallen, nämlich an Alheyd, die Tochter Bernd Kieffinges. Sozusagen im Umkehrschluß hinterläßt Adelheid Seidentopf ihren Rock ihrem Ohm Lippold. Drei Testatorinnen beschreiben ihre zu vergebenden Röcke genauer: Der Rock Soffeke Springintguts ist mit Seidenfutter unterlegt, also mit einem kostbaren, den sozialen Rang seiner Trägerin repräsentierenden Futter. Bei diesem braunen Rock handelt es sich um eine wertvolle Hinterlassenschaft, genauso wie bei dem weiten braunen Rock, den Cyeke Witting vererbt, dessen Wert in der durch den weiten Schnitt erforderlichen Stoffülle besteht. Die beiden anderen, von Cyeke Witting vererbten Röcke sind ein brauner Alltagsrock und ein Rock, de gemaket ward van oldem unde nyen wande, also ein offensichtlich ausgebesserter Rock ${ }^{59}$. Deutlich wird hier das Verwendungsspektrum von Röcken brauner Farbigkeit, das von Alltags- bis Festtagsbekleidung reicht. Einstmals eher der Festtagsbekleidung zuzuordnen war auch der braune Rock Geseke Leyferds, der lange der beste (braune?) Rock der Testatorin war, nun aber durchaus noch verwendbar zu sein scheint, wie das Bedenken Gesekes, der Schwester Rolf von Kalles, mit eben diesem Kleidungsstück beweist.

Im letzten Dezennium des fünfzehnten Jahrhunderts werden die einzigen Unterröcke testamentarisch erwähnt. Die Bezeichnung verrät, daß Röcke auch übereinander getragen

\footnotetext{
${ }^{58}$ H. NIXDORF, H. MÜLLER, Weiße Westen - weiße Roben, ebd.
} 
wurden, wobei durch Freilassungen am Halsausschnitt oder/und den Ärmeln das Untergewand sichtbar werden konnte.

1494 hinterläßt Gesche Henning ihrer Schwester einen schwarzen gefütterten Unterrock, und fünf Jahre später bedenkt Hilleke Blickershusen ihre Magd Metteke mit einem braunen undderrock. Da Metteke gleichzeitig eine grüne Londoner Hoike und einen grünen Leidenschen Rock erhält, kann man sich eine mögliche Kleiderkombination vorstellen, komplett bestehend aus den Bekleidungselementen Obergewand/Obergewändern Übergewand, bestimmt von den Farben grün/braun.

Im alltäglichen Leben wurde der Unterrock auch von wohlhabenderen Bürgersfrauen gegürtet oder ungegürtet im Haus getragen, sein Tragen in der Öffentlichkeit galt bei (verheirateten) Frauen als unschicklich. Gleichwohl ist sein Schnitt, seine Farbigkeit und die Beschaffenheit seiner (oft annesselbaren) Ärmel nur im Zusammenhang mit dem darübergetragenen zweiten Rock oder anderem Obergewand zu verstehen. Durch Aussparungen im Obergewand/Rock konnte man Farbe, Tuchart, Verzierungen und Ärmel des Untergewandes/Unterrocks sehen. Durch das farbliche und schnittechnische Zusammenspiel beider Kleidungsstücke entstand der auf Farb - und Schnittkombination beruhende Gesamteindruck.

In drei Fällen wird ein grauer Rock vererbt: Mit seinem besten grauen Rock bedenkt 1421 Albert Koch seinen Bruder Henneke. Vier Jahre später testiert Heinrich Müller, dessen Testament einem - wenn auch sehr knappen - Inventar ähnelt, wirkt es doch so, als habe der Testator weder Ehefrau noch direkte Nachfahren und vererbe infolgedessen alles inm wertvoll Erscheinende. Neben Haushalts - und Handwerksgerät nennt er fünf Röcke, zwei graue und drei zweifarbige.

Vier weiße Röcke werden von drei Testatoren hinterlassen. Aus dem vierzehnten Jahrhundert stammt das Testament des Ratsherrn Johann Beves, in dem er zwei weiße Röcke je einem seiner Knechte hinterläßt. Die Röcke unterscheiden sich durch unterschiedlichen Faltenwurf: Während Ludolf einen eingefalteten weißen Rock erhalten soll, wird Vicke ein zweigefalteter zugewendet. Der Wert eines Kleidungsstücks stieg mit zunehmendem Faltenwurf auf eine bestimmte Breite Stoff. In den Lüneburger Testamenten wird nie ein höherer Faltenwurf als der zweifaltige genannt ${ }^{60}$. Den besten weißen Rock schenkt Hans Junge 1430 seinem Sohn Yorden. Um 1440 hinterläßt Alheid Weidelerche ihrer Base Grete einen weißen Rock.

${ }^{59}$ U. REINHARDT, Testamente, Nr.204, S.288. 
Die Farben rot, grün und blau sind Farben, die besonders unter wohlhabenden Bürgern vererbt werden $^{61}$. Dafür hat es vornehmlich zwei Gründe gegeben: Der erste liegt in der Kunst des Färbens bzw. in der Exklusivität der für den Färbevorgang wesentlichen Ingredienzien, der zweite Grund in der Farbsymbolik ${ }^{62}$. Jede dieser Farben hatte sowohl im religiösen als auch im weltlichen Bereich eine Bedeutung, die in direktem Zusammenhang mit der je anderen stand. Die Testatoren haben wie all ihre Zeitgenossen die aus der neuzeitlich - heutigen Terminologie stammende Unterscheidung von Religion und Welt nicht empfunden, insofern werden sie mit den Farben eine in diesem Punkt unteilbare Konnotation empfunden haben. Rot steht in religiösem Bereich für das Blut des Herrn und das der Märtyrer. Diese aus der Hochachtung vor der Opferbereitschaft resultierende Wertschätzung der Farbe rot zeigt sich in der Sakralkunst in der Zuordnung roter Gewänder zu Christus und den Märtyrern. Im weltlichen Bereich setzt sich diese Wertschätzung fort in den roten Herrschafts - und Festroben. Grün steht für den bekennend Gläubigen, der sich durch Standfestigkeit auszeichnet. Die Klammer zur profanen Bedeutung von Verliebtheit mag in dem Spektrum von Standfestigkeit und Bekennertum (zur Liebe) liegen. Blau verweist zunächst auf den Himmel (blau gefütterter Mantel der Himmelskönigin Maria auf dem Marienleuchter in der Johanniskirche/Lüneburg, um 1490), in der weltlichen Symbolik steht es für Treue. Neben diesen Bedeutungen gibt es archetypische Empfindungen, die mit den Farben verbunden werden: Blau steht für Kälte, so wie Rot für Wärme steht. Unbeantwortet muß wohl die Frage nach dem Bewußtsein bleiben, in dem ein spätmittelalterlicher Stadtbürger die Farben trug.

Blaugefärbte Röcke kommen sechsmal in Lüneburger Testamenten vor. Ein Rock wird im vierzehnten Jahrhundert vergabt, drei in der Zeit von abgerundet 1410 bis 1420 und zwei weitere in den siebziger Jahren des fünfzehnten Jahrhunderts. In seinem 1367 ausgestellten Testament verfügt Johann Beve, daß Everd, sein Junge, den blawen mengheden rok erhalten soll ${ }^{63}$. Gemeint ist damit ein aus verschiedenen Stoffen gemischter Rock $^{64}$. Ihrem Ohm Lippold hinterläßt Adelheid Seidentopf ihren blauen Rock, und Geseke Rosemberg wendet ihren Rock der Vogtin Metteke zu. Den besten blauen Rock schenkt Werner Malstorp Herrn Arnd. Johann von Lippinghausen bedenkt Borchard Badelenborg mit seiner blauen Tunica aus Arras, und Ludolf Mangards kleine blaue Tunica soll an seine

\footnotetext{
${ }^{60}$ Nach meinem Informationsstand unterscheidet man auch nur ein - oder zweigefaltete Röcke.

${ }^{61}$ P. BAUR, Testament und Bürgerschaft, S.238.

${ }^{62}$ Angaben über die Bedeutungen der Farben bei J. HUIZINGA, Herbst des Mittelalters, S.396 - 400 ; E. VAVRA, Kunstwerke als Quellenmaterial, in: Europäische Sachkultur des Mittelalters, (=Österreichische Akademie der Wissenschaften, Philologisch-Historische Klasse, Bd. 374, Veröffentlichungen des Instituts für mittelalterliche Realienkunde Österreichs, Bd.4),Wien 1980, S.229 - 232; H. NIXDORF, H. MÜLLER, Weiße Westen - Rote Roben, S. 57 - 60, S. 83ff; P. BAUR, Testament und Bürgerschaft, S.239.

${ }^{63}$ U. REINHARDT, Testamente, Nr.26, S.34.

${ }^{64}$ SCHILLER - LÜBBEN, Mittelniederdeutsches Wörterbuch, Bd. 3, 1877, S.68f
} 
Tante Wobbeke Abbinghes fallen. Grüne Röcke werden im Untersuchungszeitraum relativ spät erwähnt: 1490 und 1499 wird je ein grüner Rock testamentarisch vererbt. Heinrich Wangelo gibt den grünen Rock seiner offenbar verstorbenen Frau dem ältesten Kind von Smets Tochter, Hilleke Blickershusen bedenkt ihre Magd Metteke mit einem Leidenschen Rock. Die beiden einzigen, 1439 und 1472 vergabten roten Röcke sind beide mit Fell gefüttert, ein Hinweis auf ihren besonderen Wert, denn außer innen gibt es nur noch zwei schwarze mit Fell gefütterte Röcke. Heinrich Hagen schenkt seinem Bruder Heinrich den roten, mit Grauwerk gefütterten Rock, und Hans Jagow hinterläßt Hermann von Geseke seinen roten Rock mit dem Iltisfutter. Von einer Ausnahme abgesehen (1499 Hilleke Blickershusen) sorgen die Testatoren dafür, daß rote, grüne und blaue Röcke nicht an Bedienstete, sondern an Verwandte und (nahe?) Bekannte fallen. Daß gerade die leuchtenden Farben blau, rot und grün in besonderem Maße unter wohlhabenden Bürgern vererbt werden, ist keine Zufälligkeit. Neben den oben genannten Konnotationsmöglichkeiten weisen die leuchtenden Farben eine größere Nähe zu der Lichtfarbe Weiß auf, sie gelten als schöne Farben, die eine gewisse Nähe zum Heilsgeschehen ausdrücken.

Ein Testator konnte ein Kleidungsstück derselben Farbe mindestens zweifach besitzen, denn wenn 1485 Geseke Leyferd ihren braunen Rock vererbt, der - wie sie schreibt - lange ihr bester war, so taucht doch die berechtigte Frage auf, ob sie diesen offensichtlich abgenutzten Rock nicht bereits durch einen besseren braunen Rock ersetzt hat, der dann vielleicht lieber in den Händen eines engen Familienmitgliedes wie Tochter oder Enkelin bleiben soll. Offensichtlich ist der Besitz mindestens drei brauner Röcke im Testament der Cyeke Witting 1444. Heinrich Müller erwähnt in seinem Testament zwei graue Röcke, deren einer gefüttert war. Fünf Testatoren nennen ihren Rock jeweils den besten blauen, grauen, weißen oder schwarzen Rock, womit entweder der beste Rock aus einer Menge überhaupt vorhandener Röcke gemeint sein könnte oder der beste Rock aus einer Menge je gleichfarbiger Röcke.

Neben den einfarbigen werden auch mehrfarbige Röcke testamentarisch vererbt, allerdings in wesentlich geringerem Ausmaße: Seinen Knecht Vicke bedenkt 1367 Johann Beve mit einem stripenden scharlakens $r^{65}{ }^{65}$. Heinrich Müller verfügt in seinem Testament über drei zweifarbige Röcke, die durch Einsetzen seiner Brüder als Erbnehmer im Kreis der Familie bleiben werden. Es handelt sich um einen rot - grauen Rock, um einen rot - grünen und einen schwarz - grünen Rock. Vicke Bottermann hingegen nennt die Farbkombination 
seiner beiden 1476 in seinem Testament aufgeführten Röcke: Es handelt sich in beiden Fällen um einen rot - blauen Rock. Allein dieser kurze Einblick in die Farbigkeit der Röcke vermittelt einen Eindruck großer Farbenfreude.

\section{Herkunftsorte und Art der verwendeten Stoffe}

Einige Testatoren aus dem fünfzehnten Jahrhundert haben den Herkunftsort des Tuches oder des Rocks genannt. 1432 verfügt Johann Welsrode über sieben Ellen von einem Ekloveschen für die Anfertigung eines Rocks. Wahrscheinlich meint er Tuch aus dem flämischen Eeclo, das bereits im vierzehnten Jahrhundert in den Büchern der Lübecker Herrmann und Johann Wittenborg als auch in denen des Hamburgers Vicko von Geldersen als eingeführtes Tuch verzeichnet ist, also zumindest seit dieser Zeit im hansischen Bereich vertreten war. Zwei Röcke stammen aus dem ebenfalls flämischen Arras, erwähnt werden sie in der ersten Hälfte des fünfzehnten Jahrhunderts. Drei Röcke aus Leiden werden 1472 und 1499 testamentarisch vererbt, einer von innen ist grün gefärbt. Weitere zwei Röcke haben den Herkunftsort Hardewijk, wie die Testamente von 1471 und 1490 bezeugen. Drei Röcke sind demzufolge aus flämischen Tuchen hergestellt und fünf aus Tuchen des niederländischen Gebiets. Aufgrund des geringen Zahlenmaterials kann man aus diesem Ergebnis keine Dominanz des einen Tuchbereichs über den anderen ableiten. Die hier getätigte Beobachtung reint sich jedoch ein in das Forschungsergebnis, daß flämische Tuche im hansischen Bereich Norddeutschlands vorrangig vertreten waren, und gerade im fünfzehnten Jahrhundert holländische Tuche wie das Leidener und Hardewijker Tuch hier in weitaus stärkerem Maße vertreten waren als in oberdeutschen Städten ${ }^{66}$.

Neben Angaben über die Herkunft der Tuche finden sich in den Testamenten auch Angaben über das Material selbst. Johann Beve, Ratsherr und einstiger Bürgermeister, verfügt in seinem Testament 1367 über dhen stripenden scharlakens rok ${ }^{67}$. Der Scharlach war aufgrund seiner Feinheit ein besonders wertvolles Wollgewebe. Es stammte ursprünglich aus Gent, Arras, Ypern und Douai ${ }^{68}$, wobei vorwiegend Gent als Herkunftsort erwähnt wird. Bekannt waren verschiedene Farben wie weiß, rot, braun, grün und blau sowie gestreifte Formen $^{69}$. Angesichts des Werts des Scharlachs erscheint es nicht

\footnotetext{
${ }^{65}$ Es kann nicht geklärt werden, ob es sich hier um einen zweifarbigen Scharlach oder um einen von der Webart her unterschiedlichen Stoff handelt.

${ }^{66}$ H. AMMANN, Deutschland und die Tuchindustrie, S.117.

${ }^{67}$ U. REINHARDT, Testamente, Nr.26, S.34.

${ }^{68}$ H. AMMANN, Deutschland und die Tuchindustrie, S. 58; L. v. WILCKENS, Textilien im Blickfeld des Braunschweiger Hofes, in: Kat. „Heinrich der Löwe und seine Zeit“, Bd.2, S.295f.

${ }^{69}$ L. C. EISENBART, Kleiderordnungen der deutschen Städte zwischen 1350 und 1700 (=Göttinger Bausteine zur Geschichtswissenschaft 32), Göttingen/Berlin/Frankfurt a.M. 1962, S. 128f.
} 
alltäglich, daß ein Knecht Empfänger dieses Legats war ${ }^{70}$. Auch wenn man die Möglichkeit einkalkuliert, daß es sich hier um einen abgenutzteren Rock gehandelt haben könnte, und eine enge Beziehung zwischen Beve und seinem Knecht bestanden haben könnte, so bleibt dieses Geschenk doch ein Indiz für den außergewöhnlichen Wohlstand des Testators. 1413 vererbt der Ratsherr Johann von der Mölen einen saynsrogke, ebenfalls einen Rock aus besonders feiner Wolle ${ }^{71}$. Diesen Rock vererbt der Testator Herrn Johann Malstorp, Vikar in der Johanniskirche, als Meßgewand, ein Zeichen für den Wert des Tuchs.

\section{Aussehen und Verwendung}

Über das mögliche Aussehen der Röcke können die erwähnten modischen Schnittformen ebenso wie die Nennung von Futter Auskunft geben. Erwähnenswert schien einigen Testatoren die Enge oder Weite ihres Rockes sowie die Zahl des Faltenwurfs. Beim Rock wird nach ein - oder zweigefaltetem Stoff unterschieden, und diese Unterscheidung findet sich allein im Testament Johann Beves aus dem Jahr 1367. Das Kriterium der Enge oder Weite eines Rocks wird ausschließlich von Testatorinnen aufgeführt. 1418 und 1430 wird je ein enger Rock testamentarisch vererbt, weite Röcke 1418, 1430 und 1444. Die Kleiderordungen anderer Städte lehnten oft enge, körperbetonte und damit als modisch gewertete Kleidungsstücke ab, während in Lüneburg keine diesbezügliche Verordnung galt. Den Verwendungszweck des Rockes geben zwei Testatorinnen an, indem sie inn als Alltagsrock (1444 Cyeke Witting) und Sonntagsrock (1460 Hilleke von Erpensen) bezeichnen.

Ausschließlich in Testamenten des fünfzehnten Jahrhunderts sind Röcke - in einer Anzahlstärke von fünfzehn - mit Futter versehen. Sechs Röcke sind mit Pelz unterlegt, davon sind drei Iltisfellfutter, eines besteht aus Grauwerk und die beiden übrigen werden als Pelzfutter bezeichnet. In sechs Fällen wurde die Farbe des Tuchfutters angegeben, die in je zwei Fällen weiß und blau war, je einmal grün und rot. Ein einziger Rock ist mit Seidenfutter versehen.

Über den finanziellen Wert eines Rockes ist in den Testamenten kaum etwas zu erfahren, lediglich Dietrich Trost setzt 1423 ein Legat von vier Mark für einen offenbar anzufertigenden Rock aus. Umso häufiger, nämlich vierzehnmal, findet man in den Testamenten die Formulierung, hier handele es sich um den (zweit-) besten Rock. Aus dem Heute heraus kann nicht mehr unterschieden werden, ob diese Angabe sich auf den finanziellen oder ideellen Aspekt bezieht, es mag jedoch oft eine Mischform gewesen sein.

\footnotetext{
${ }^{70}$ J.ZANDER - SEIDEL weist darauf hin, daß Scharlach aufgrund seiner Hochwertigkeit während des Mittelalters ständischen Beschränkungen unterlag. J. ZANDER - SEIDEL, Textiler Hausrat. Kleidung und Haustextilien in Nürnberg von 1500-1650, München 1990, Stichwort Scharlach, S.402.

${ }^{71}$ U. REINHARDT, Testamente, Nr.95, S.134.
} 


\section{d. Wams}

Ein Wams wird in den Lüneburger Testamenten zwischen 1323 und 1500 nur ein einziges Mal erwähnt. Heinrich Tetendorp, Vikar in St. Lamberti, will 1441 suum melius wambasium Helmold Tetendorp zugewendet wissen ${ }^{72}$. Die Namensgleichheit von Donator und Empfänger deutet darauf hin, daß das Kleidungsstück in den Händen der Familie bleibt. Das Wams zählt zur Oberbekleidung, d.h. daß über ihm ein Übergewand getragen werden konnte, welches möglicherweise die Ärmel des Wamses sichtbar ließ. Seinerseits wurde das Wams über einem Unterbekleidungsstück getragen, das je nach Auslassungen am Halsausschnitt mehr oder weniger unbedeckt blieb und durch Feinheit des Materials oder zusätzliche Verzierungen Wirkung erzielte. Weiteres Kennzeichen ist seine Kürze, denn das Wams entstand, „als die "Schecke“ immer kürzer wurde“73. Seine Form konnte die eines in Röhrenfalten gelegten oder taillierten Gewandes sein, das am Oberkörper eng anlag und von der Taille an weiter wurde. Getragen wurde das Wams ausschließlich von Männern, vor allem von jungen Männern, die die engen und kurzen Schnittformen mit gepufften und/oder geschlitzten Ärmeln bevorzugten. Die durch das Wams mögliche Betonung und Enthüllung des männlichen Körpers stieß nicht nur auf Kritik seitens der Kirche und Stadtobrigkeit, sie führte auch dazu, daß auf den Bildwerken des Spätmittelalters Personen, die von einer beruflichen, moralischen oder gesellschaftlichen Norm abwichen, oft mit Wams bekleidet dargestellt wurden ${ }^{74}$. Der Testator selbst hat über den Schnitt oder das Material seines Wamses keine Angaben gemacht. Fraglich ist, ob man ihm, dem Vikar an St. Lamberti, das Tragen einer extrem aufreizenden Ausführung unterstellen darf, aber man kann davon ausgehen, daß seine Einstellung Kleidungsstücken gegenüber mit dem heutigen Begriff des Modebewußtseins bezeichnet werden darf, zumal das Wams um die Wende des 14./15. Jahrhunderts aufkam und erst im 15. Jahrhundert entsprechende Verbreitung fand ${ }^{75}$. Heinrich Tetendorp schätzte offensichtlich dieses Kleidungsstück, besaß er doch zumindest noch ein weiteres Wams, wie aus dem Komparativ melius ersichtlich ist. Daß Kleriker - ob Ordens- oder Weltgeistliche - sich überhaupt und seit längerem zu extravaganten modischen Schnitten hingezogen fühlten,

\footnotetext{
${ }^{72}$ U. REINHARDT, Testamente, Nr.198, S.279.

${ }^{73}$ G. JAACKS, Städtische Kleidung im Mittelalter, in: Kat. „, Aus dem Alltag der mittelalterlichen Stadt“, S.222.

${ }^{74}$ E. VAVRA, Kunstwerke als Quellenmaterial, in: Europäische Sachkultur des Mittelalters, S. 227ff. Ein Beispiel für Lüneburg ist der Altar Hinrik Funhofs (1483) in der Johanniskirche. Hier ist im Bildausschnitt „Enthauptung des Johannes“ der Henker mit einem Wams bekleidet. Detaillierte Beschreibung und Abbildung bei H.G. GMELIN, Spätgotische Tafelmalerei in Niedersachsen und Bremen, München 1974, S.120f.

${ }^{75}$ G. JAACKS, Städtische Kleidung im Mittelalter, S.225; J. LEHNER, Die Mode im alten Nürnberg, Nürnberg 1984, S. 78.
} 
beweist das auf dem Konzil von Vienne 1311/12 ausgesprochene Verbot, (allzu?!) kurze Röcke mit Zaddelwerk zu tragen, bei denen das Untergewand sichtbar wurde ${ }^{76}$.

e. Jacke

Das einzige in den Lüneburger Testamenten des 14. und 15. Jahrhunderts als iacke bezeichnete Kleidungsstück vererbt Johann Holeborn $1412^{77}$. Empfänger des Legats ist Hans Holeborn, wahrscheinlich der Sohn des Testators. Der Testator selbst war noch nicht lange im Besitz dieses Kleidungsstücks, denn er bezeichnet sie als nye iacke. Über ihr weiteres Aussehen werden keine Angaben gemacht. Allgemein wird der kurze, enge Rock als Jacke bezeichnet, wobei der Name auf die Herkunft aus dem Französischen verweist „jaquette“ - und eingedeutscht als Schecke übernommen wurde ${ }^{78}$.

\section{f. Hoike}

Über Hoiken verfügen neununddreißig Testatoren, darunter sind dreiundzwanzig Frauen. Von den sechzehn über Hoiken verfügenden Männer sind sechs geistlichen Standes. Die Testatoren benutzen das Wort hoyke, hoike oder toga ${ }^{79}$, eine Testatorin schreibt mante ${ }^{80}$. Die lateinische Bezeichnung wird ausschließlich von den fünf Klerikern in ihren Notariatsinstrumenten verwendet. Im folgenden wird die Bezeichnung Hoike verwendet.

Die Hoike ist ein glockenförmig geschnittener Umhang ohne Ärmel. Bekannt sind unterschiedliche Formen. Hoiken konnten geknöpft werden, wobei Männer die Hoike an der Schulter knöpften. Frauenhoiken wurden oft über die Schultern sowie über den Kopf gelegt; bei dieser Tragart wurden sie an einer Scheibe oder einer Kappe befestigt. Besonderer Beliebtheit erfreute sich die Hoike im norddeutschen Bereich, und dies noch weit über den Untersuchungszeitraum hinaus ${ }^{81}$.

Tabelle: Testamentarische Verfügungen über Hoiken

\footnotetext{
${ }^{76}$ H. KÜHNEL, Bildwörterbuch, S. XXXVII.

${ }^{77}$ U. REINHARDT, Testamente, Nr.87, S.123.

${ }^{78}$ H. HUNDSBICHLER, ,, Kleidung“, in: Alltag im Spätmittelalter,hg. v. H. KÜHNEL, Graz/wien/Köln 1984, S.237; G. JAACKS, Städtische Kleidung im Mittelalter, S. 222.

${ }^{79}$ Gleichsetzung von Toga und Hoike bei M. HASSE, Neues Hausgerät, neue Häuser, neue Kleider , S.56.

${ }^{80}$ Es muß darauf hingewiesen werden, daß der Mantel eine andere Schnittform als die der Hoike gehabt haben könnte. Die Zuordnung zur Hoike erfolgt auf der Grundlage von von WILCKENS Definition: „Ein Mantel des Mittelalters ist ärmellos und besteht in seiner Normalform aus einem nicht zugeschnittenen rechteckigem Gewebestück oder aus einem zugeschnittenen kreisförmigen“. L.v.WILCKENS, Terminologie und Typologie spätmittelalterlicher Kleidung, in: Terminologie und Typologie Mittelalterlicher Sachgüter: Das Beispiel der Kleidung, S.53.

${ }^{81}$ E. VAVRA, ,Kleidung“, in: Lexikon des Mittelalters, Bd. V, Sp.1199.
} 


\begin{tabular}{|c|c|}
\hline Jahre & Anzahl der Testatoren und Verfügungen \\
\hline $1300-1325$ & - \\
\hline $1326-1350$ & - \\
\hline $1351-1375$ & 1 Testator mit 1 Hoike \\
\hline $1376-1400$ & 4 Testatoren mit 6 Hoiken \\
\hline $1401-1425$ & 16 Testatoren mit 22 Hoiken \\
\hline $1426-1450$ & 11 Testatoren mit 21 Hoiken \\
\hline $1451-1475$ & 7 Testatoren mit 24 Hoiken \\
\hline $1476-1500$ &
\end{tabular}

Bereits bei der Grobauswertung fällt auf, daß in nur einem Testament des vierzehnten Jahrhunderts eine Hoike erwähnt wird. In den Testamenten des fünfzehnten Jahrhunderts werden dann insgesamt dreiundsiebzig Hoiken aufgeführt. Sieht man sich die Verfügungen bezogen auf Zeiträume von 25 Jahren an, so erweist sich das erste Jahrhundertviertel mit sechs Hoiken als der Zeitraum mit der geringsten Anzahl, während in den drei folgenden Vierteln mit zweiundzwanzig, einundzwanzig und vierundzwanzig Verfügungen die Zahlenwerte konstant bleiben. Derart konstante Werte über einen Zeitraum von fünfundsiebzig Jahren werden von keinem anderen testamentarisch vergabten Kleidungsstück erreicht.

Vererbt werden die Hoiken in erster Linie an Familienmitglieder (zweiundzwanzig Mal) und an Bekannte (dreiundzwanzig Fälle). Wenn diese Zahlen aufgrund von Zuordnungsschwierigkeiten nicht absolut zu setzen sind, so zeigen sie doch die Tendenz, Hoiken im Besitz der Familie oder zumindest der engen Bekanntschaft zu halten. Mehr noch als männliche wurden weibliche Familienmitglieder und bekannte Frauen bedacht. Von den im Familienkreis Bedachten sind siebzehn Frauen und fünf Männer; Empfänger sind weiterhin achtzehn bekannte Frauen und vier Männer aus dem Bekanntenkreis. Diese vorrangige Zuwendung an Frauen zeigt sich auch in den Zuwendungen an Bedienstete: Bei den zwölf Bedachten handelt es sich ausschließlich um Frauen. Die Mägde werden nicht mit den schlechtesten Hoiken bedacht, die sonst keinem Familienmitglied mehr zumutbar gewesen wären, im Gegenteil erhalten sie fallweise die bessere Hoike (1414 Johannes von Lippinghausen), die zweitbeste Hoike der Testatorin (1459 Adelheid Miils), die bessere Hoike (1461 Heinrich Geismar), eine Sonntagshoike ohne Futter (1469 Tibbeke Godenstedt, allerdings für die Magd, die am längsten mit ihr zusammen war!) und die nächstbeste Hoike ohne Futter (1469 Tibbeke Godenstedt). Nur ein Fall ist bekannt, in dem ein Kleriker einem anderen Kleriker seine Hoike vererbt (1414 Johannes von 
Lippinghausen). Acht Hoiken werden zur Finanzierung von Kirchbauten vergabt. Im Vergleich zu anderen Kleidungsstücken handelt es sich bei Hoiken um das Kleidungsstück, das als Finanzierungsträger am häufigsten von den Testatoren eingesetzt wird. Das durch den Verkauf einer Hoike erzielte Geld stand der Baukasse der betreffenden Kirche zur Verfügung. Bedacht werden fast alle Kirchen wie St. Johannis, St. Lamberti, St. Michaelis, St. Marien sowie die Ratskapelle. Cyeke Witting gibt 1444 an, sie erwarte vom Verkauf ihrer Hoike vier Mark Pfennige. So darf man unterstellen, daß der Hoikenverkauf je nach Beschaffenheit des Kleidungsstücks einiges Geld erbrachte. Wenn auch Kleidung allgemein neben dem Gebrauchswert einen Geldwert hatte, der nicht zuletzt auch auf Diebe großen Reiz ausübte ${ }^{82}$, so erscheinen Hoiken im Spiegel der Lüneburger Testamente in besonderem Maße ihr Geld wert gewesen zu sein. Die Wertstabilität der Hoiken, die sich in den auf Verkauf angelegten Verfügungen zeigt, läßt sich in über das gesamte fünfzehnte Jahrhundert verteilten Testamenten nachweisen; sie wird nicht zuletzt in der (engen) Fältelung des Gewandes begründet sein. Die Möglichkeit des Einfrierens und Verflüssigens eines bestimmten Finanzwertes in Form einer Hoike wurde nicht allein für Kirchbauten genutzt, sondern auch für Geldzuwendungen an Arme (1469 Tibbeke Godenstedt, Verkauf zweier Hoiken aus Arras) und für Geldlegate für Bedienstete (1473 Metteke von Dassel, Verkauf zweier Tuchhoiken) eingesetzt sowie für die Ausrichtung einer Pilgerfahrt nach Wilsnak (1429 Tibbeke Poterow). In zwei Fällen soll der Erlös für den Unterhalt eines (ewigen) Kirchenlichts verwendet werden (1466 Beke von dem Berge dem Sakramentslicht in St. Lamberti; 1490 Heinrich Winthe, für das ewige Licht und den Chor im Kleinen Heiligen Geist).

Farben

Die in den Testamenten erwähnten Hoiken sind vorwiegend einfarbig. Dominant ist die dreizehnmal vertretene Farbe schwarz, der dann mit sechs Verfügungen braun folgt. Diesen zusammengenommen neunzehn Hoiken in gedeckteren Farben stehen acht Hoiken auffälligerer Farbgebung gegenüber: fünf blaugefärbte und zwei grüne Hoiken sowie eine rote Hoike. Bemerkenswerterweise werden diese acht Hoiken von Frauen an Frauen vererbt: Blaue Hoiken 1429 von Tibbeke Poterow an die Berndesche, 1483 von Ymmeke Spranse an die Schwestern (?) Greteke und Wunneke und 1494 von Gesche Henning an Metteke von Rode, grüne Hoiken 1429 von Tibbeke Poterow an ihre Magd Wulmeke und 1499 von Hilleke Blickershusen an ihre Magd Metteke, und die rote Hoike 1485 von Geseke

\footnotetext{
${ }^{82}$ In dem strafrechtliche Handlungen aufzeichnenden Verfestungsregister Lüneburgs ist gegen Ende des 13. Jahrhunderts als 7. Verfestung festgehalten, daß die Diebe Rolf, Bodo und Kalibe nachts in das Haus der Kerzengießerin Margarete eindrangen und außer Geld auch Kleider, darunter eine Hoike, erbeuteten. W. REINECKE, Lüneburgs ältestes Stadtbuch und Verfestungsregister ( = Quellen und Darstellungen zur Geschichte Niedersachsens, Bd. VIII ), Hannover. Leipzig 1903, S. XCIX, S. 269.
} 
Leyferd an die Frau Cord von der Heides. Das Beispiel Bekes von dem Berges zeigt, daß eine Hoike auffälligerer Farbigkeit nicht automatisch gleichzusetzen ist mit einer Hoike höchster Wertigkeit; Beke von der Berges Sonntagshoike ist schwarz und erzielt ihre Wirkung offensichtlich durch ihre im Verhältnis zu leuchtenderen Farben kontrastierende Schlichtheit. Der Testaror Hans Jagow überläßt 1472 dem Bedachten die Wahl der Farbe der für ihn offensichtlich anzufertigenden oder zu kaufenden Leidenschen Hoike. Aus dem Jahr 1430 stammt das einzige Beispiel einer mehrfarbigen Hoike: Hans Junges Sohn Yorden soll eine rote und schwarze Hoike erhalten.

\section{Aussehen und Verwendung der Hoiken}

Der Schnitt der Hoiken wird in den Testamenten durch das Kriterium Länge beschrieben, nur in den Klerikertestamenten Dietrich Lembekes 1386 und Johannes von Lippinghausens 1414 als toga duplici, also mit der durch Faltenwurf evozierten Stoffülle. Man darf annehmen, daß in Lüneburg wie in anderen hansischen Städten die Hoike faltig gearbeitet sein konnte, und der Träger gerade durch den Faltenreichtum auch finanziellen Reichtum dokumentierte ${ }^{83}$. Im letzten Jahrzehnt des fünfzehnten Jahrhunderts charakterisiert Gesche Henning ihre beiden Hoiken als kurze Hoiken, und Hilleke Blickershusen nennt ihr Legat ihre beste lange Hoike. Ungefähr ein Drittel aller testamentarisch vergabten Hoiken wird mit dem Zusatz beste Hoike (zwölfmal) und zweitbeste Hoike (zehnmal) versehen.

In sieben Fällen werden Hoiken in Zusammenhang mit Futter genannt. Männer wie Frauen erwähnen gefütterte Hoiken in einer über das gesamte fünfzehnte Jahrhundert reichenden Verteilung. Die Erwähnung von Futter ist keineswegs gleichzusetzen mit dem Vorhandensein von Futter. Drei Testatorinnen, Adelheid Kolse, Metteke Bere und Tibbbeke Godenstedt, heben hervor, daß sich unter ihren testamentarisch vergabten Hoiken kein Futter befindet oder mehr befinden soll. Von den vier ohne Futter vergabten Hoiken sind drei Hoiken besserer Qualität gewesen, denn sie wurden beschrieben als beste oder zweitbeste Hoike und als Sonntagshoike ${ }^{84}$. Hans Jagow ist der einzige, der eine mit Fell gefütterte Hoike testamentarisch vererbt, der Futterstoff besteht aus Otternfell. Wobbeke Boltzen gibt weder Farbe noch Material ihres Futters an. Die Vikare Johannes von Lippinghausen und Heinrich Steinhagen sind die einzigen Testatoren, die die Farbigkeit der Innen- und Außenseite der Hoike angeben: Unter ihrer in beiden Fällen schwarzen Hoike befindet sich einmal weißes, einmal graues Tuchfutter.

\footnotetext{
${ }^{83}$ Faltige Hoiken in Lübeck, L. C. EISENBARTH, Kleiderordnungen, S.135. Zur Fältelung G. JAACKS, Bekleidung in den Hansestädten, in: Kat. „,Die Hanse“, Bd. 1, S.403.

${ }^{84}$ Ich bin mir wohl der Subjektivität der Klassifizierung der Testatorin bewußt, unterstelle aber, daß es sich in der Regel wohl um ein wertvolleres Kleidungsstück handelte.
} 
Es sind stets Testatorinnen, die die spezielle Funktion ihrer Hoiken angeben. Adelheid Kolse (1430), Beke von dem Berge (1466), Tibbeke Godenstedt (1469) vergeben ihre sondaghes hoyken, Alheid Weidelerche (um 1400), Cyeke Witting (1444), Geseke Rosemberg (1472) und Ymmeke Spranse (1483) ihre Alltagshoiken oder ihre werkeldaghes hoyken, und Hilleke Blickershusen (1499) vergibt ihre wechhoike. Gerade die letztgenannte Hoike ist von besonderem Interesse, da die ältere Forschung das Fehlen von weiblicher Reisebekleidung konstatierte und mit dem geringen Reiseradius der Frau begründet ${ }^{85}$. Diese Argumentation unterschätzt die Mobilität der Frau im Spätmittelalter, die aus wirtschaftlichen, religiösen ${ }^{86}$ und familiären Gründen unterwegs sein konnte. Der Grund für eine Reisetätigkeit Hilleke Blickershusens liegt - dem Testament zufolge - nicht im Pilgertum $^{87}$. Wenn ihre Verfügungen über Renten, Schulden und eine Hausstiftung für die Armen auch von einer gewissen Erfahrung in finanziellen Dingen zeugen, kann damit noch keine aus kaufmännischer Notwendigkeit erwachsende Mobilität hinreichend bewiesen werden. Wahrscheinlicher ist die aus familiären Gründen erwachsene Reisetätigkeit, denn ein ihr eng verwandtes Familienmitglied, Hans Blickershusen (ihr Sohn?), lebte in Lübeck. Einige Testamente zeugen z.B. von Eheschließungen zwischen verschiedenen (Hanse)Städten ${ }^{88}$, und auch hier darf man persönliche Kontakte vermuten. Als Reisebekleidung für Männer ist die Hoike - allerdings „in zweckmäßiger Aufmachung“ - bekannt; als vor der Witterung schützendes Material wurde Filz verwendet ${ }^{89}$.

\section{Wert der Hoiken}

Über den finanziellen Wert der Hoiken ist dem Testament Cyeke Wittings $1444 \mathrm{zu}$ entnehmen, daß sie sich vom Verkauf ihrer Hoike mindestens vier Mark Erlös verspricht. Aus dem gleichen Jahr stammt Grete von der Heides Angabe, sie gebe als Hilfe für einen neuen Mantel fünf Mark Pfennige.

Von entscheidender Bedeutung für den Wert der Hoiken ist der Herkunftsort des verarbeiteten Materials. In sechzehn Fällen läßt sich der Herkunftsort der Hoiken oder zumindest doch ihres Tuchs feststellen. Zwei Drittel der Hoiken stammt aus Arras. Sie

\footnotetext{
${ }^{85}$ E. WURMBACH, Das Wohnungs- und Kleidungswesen des Kölner Bürgertums um die Wende des Mittelalters (=Veröffentlichungen des Historischen Museums der Stadt Köln 1), Bonn 1932, S.93.

${ }^{86}$ Ein Viertel bis ein Drittel der Wallfahrer waren Frauen. N. OHLER, Reisen im Mittelalter, München 1993/3, S.285.

${ }^{87}$ Von dieser Möglichkeit berichtet das Testament Tibbeke Poterows 1429 Okt. 30 :" Item ik gheve der Berndeschen mynen blawen hoyken, dar schal se vore gan to der Wilsnak". U. REINHARDT, Testamente, Nr.161, S.222. Es ist darauf hinzuweisen, daß allein der Wunsch der Testatorin nicht die tatsächliche Pilgerreise der Berndschen beweist; denkbar ist, daß die Beauftragte ihrerseits einen Pilger für die Erfüllung der Verfügung bezahlt.

${ }^{88}$ Elisabeth Stöterogge aus Dambeck bei Salzwedel, Testament 1385 Juli 11; Metteke Schermbeck war zunächst in Salzwedel verheiratet, ehe sie nach Lüneburg kam, Testament 1451 Juli 1.

${ }^{89}$ E. WURMBACH, Wohnungs - und Kleidungswesen, S.77.
} 
werden in über das Jahrhundert annähernd gleich verteilten Testamenten genannt, demzufolge ist Tuch aus Arras mindestens im fünfzehnten Jahrhundert in Lüneburg eingeführt und verbreitet. Die Repräsentabilität des Tuchs aus Arras verdeutlicht Adelheit Kolse, die 1430 in ihrem Testament die Hoike aus Arras als Sonntagshoike bezeichnet. Der Sonntag war mehr als die anderen Wochentage der Tag des Kirchgangs, der in besonderem Maße der Zurschaustellung des (Kleider-) Luxus diente ${ }^{90}$. Die Farbigkeit des Tuchs aus Arras geben die Testatorinnen mit schwarz (zweimal), braun (einmal), blau (einmal) und rot (einmal) an. Neben den elf Hoiken aus Arras stehen zwei Leidener Hoiken, von denen im letzten Drittel des fünfzehnten Jahrhunderts die Rede ist. Ihre Farbe ist nicht bekannt, kann in einem Fall auch gar nicht bekannt sein, da der Bedachte sich die Farbe seiner Wahl aussuchen darf. Aus dem letzten Jahr des fünfzehnten Jahrhunderts stammt die einzige Hoike aus Londoner Tuch, das grüngefärbt ist. Vor allem Arras und Leiden sind als Lieferanten besonders feiner Wollstoffe bekannt.

\section{g. Schaube}

Bei der zur Überbekleidung zählenden Schaube handelt es sich um ein stoffreiches Übergewand, knie - oder wadenlang, vorne größtenteils offen ${ }^{91}$, mit Ärmeln versehen und mit einem pelzgefütterten oder verbrämten Kragen ausgestattet ${ }^{92}$.

Alle Testatoren bezeichnen ihre Schaube als sube.

Tabelle: Testamentarische Verfügungen über Schauben

\begin{tabular}{|l|c|}
\hline Jahre & Anzahl der Testatoren und Verfügungen \\
\hline $1400-1425$ & - \\
\hline $1426-1450$ & 2 Testatoren mit 2 Schauben \\
\hline $1451-1475$ & - \\
\hline $1476-1500$ & 4 Testatoren mit 5 Schauben \\
\hline
\end{tabular}

Im 14. Jahrhundert finden Schauben keine testamentarische Erwähnung. Großer Beliebtheit erfreut sich die Schaube in der zweiten Hälfte des 15 . Jahrhunderts ${ }^{93}$, zu der

\footnotetext{
${ }^{90}$ Über das Verhalten der Gläubigen in der Kirche siehe J. HEERS, Vom Mummenschanz zum Machttheater, Europäische Festkultur im Mittelalter, Frankfurt 1986, bes. Kap. I/5. Gottesdienste, geistliches Theater, Prozessionen und Tänze, S.62 - 65.

${ }^{91}$ J. LEHNER fand in Nürnberger Kleiderordnungen Belege dafür, daß zumindest Frauenschauben mit Spangen und Knöpfen verschlossen sein konnten. J. LEHNER, Mode im alten Nürnberg. Modische Entwicklung und sozialer Wandel in Nürnberg, aufgezeigt an den Nürnberger Kleiderordnungen (=Nürnberger Werkstücke zur Stadt- und Landesgeschichte 36), Nürnberg 1984, S.96.
} 
Zeit, in der auch das Gros der Testamente ausgestellt wurde. Das aus dem Jahr 1430 stammende Testament Adelheid Kolses deutet darauf hin, daß die Schaube in Lüneburg bereits in der ersten Hälfte des Jahrhunderts bekannt war.

Vererbt werden die Schauben überwiegend von Frauen (Adelheid Kolse 1430, Cyeke Witting 1444, Geseke Leyferd 1485, Gesche Henning 1494 und Hilleke Blickershusen 1499), Heinrich Winthe ist der einzige männliche Testator; allerdings schenkt er die Schaube seiner Frau.

Parallel zum Frauenüberhang auf der Donatorenseite gibt es eine Frauenmajorität auf der Empfängerseite. Drei der bedachten Frauen können eindeutig dem engeren Familienkreis der Testatorin zugeordnet werden (Cyeke Wittings Schwester Hempeke und Gesche Hennings Nichten Wobbeke Wichtenbeke und Metteke von Rade), zwei weitere werden mindestens zum Bekanntenkreis der Testatorinnen gehören (Frau Klaus Pepers im Testament der Geseke Leyferd und die Gronebergesche im Testament der Hilleke Blickershusen). Heinrich Winthe, der einzige Testator, bedenkt keine Frau mit der Schaube seiner Ehefrau, er wendet das Kleidungsstück dem Bau St. Marien, also der Klosterkirche der Franziskaner, zu.

Diese in den Lüneburger Testamenten zu beobachtende Dominanz der Frauen sowohl auf der Donatoren- als auch auf der Empfängerseite und die zeitlich Abfassung der relevanten Testamente widersprechen zwar den bislang vorliegenden Erkenntnissen über die Schaube nicht grundsätzlich, bedeuten aber zumindest für Lüneburg eine Verschiebung des Geschlechteraspekts und der zeitlichen Einordnung. EISENBARTH bezeichnete die Schaube als „das gebräuchlichste Männerobergewand seit der zweiten Hälfte des 15. Jahrhunderts" und weist auch auf die Verbreitung unter Frauen hin, kann hierfür mit der Nennung von Leipzig (1478) und Nürnberg (vor 1480) Beispiele allein aus der zweiten Hälfte des 15. Jahrhunderts anführen ${ }^{94}$. WURMBACH nennt die Zeit um das Jahr 1500 als Anfangszeitpunkt für die Verwendung der Schaube in der weiblichen Garderobe ${ }^{95}$. JAACKS gibt das 16. Jahrhundert als die Zeit an, in der die Schaube auch von Frauen in den Hansestädten übernommen wurde ${ }^{96}$. Wenn auch aufgrund der geringen Zahlenwerte keine ausreichend gesicherten Ergebnisse formuliert werden können, so bleibt doch die Auffälligkeit der zwei bereits in der ersten Hälfte des 15. Jahrhunderts testamentarisch erwähnten Schauben, die hier eben nicht der männlichen, sondern der weiblichen Garderobe zugehören. Schauben in den Lüneburger Testamenten gehören aussschließlich

\footnotetext{
${ }^{92}$ G. JAACKS, Städtische Bekleidung im Mittelalter, S.223.

${ }^{93}$ E. VAVRA, ,Kleidung“, in: Lexikon des Mittelalters, Bd. V, Sp.1200; J. LEHNER, Mode im alten Nürnberg, S.96. Hier ist sogar von den letzten Jahrzehnten des 15. Jahrhunderts die Rede.

${ }^{94}$ L. C. EISENBARTH, Kleiderordnungen, S.138.

${ }^{95}$ E. WURMBACH, Wohnungs - und Kleidungswesen, S.87.

${ }^{96}$ G. JAACKS, Bekleidung in den Hansestädten, S.404.
} 
zur Frauengarderobe, während Hoiken sowohl von Männern und Frauen erwähnt und damit getragen wurden.

\section{Aussehen und Verwendung}

Fünf der sieben Schauben werden von den Testatoren näher beschrieben: Farbangaben enthalten die Testamente Geseke Leyferds (schwarze Schaube) und Heinrich Winthes (grüne Schaube). In eine qualitative Hierarchie ordnen Geseke Leyferd und Gesche Henning ihre Schauben ein, wobei die qualifizierenden Kriterien einmal Farbe, dann Faltenwurf und Futter sind. Geseke Leyferd vererbt ihre beste schwarze Schaube, Gesche Henning ihre zweitbeste entfoldigen Schaube ${ }^{97}$ und ihre beste gefütterte Schaube. Die komparativen Formulierungen lassen vermuten, daß die Testatorinnen vergleichbare Kleidungsstücke besessen haben müssen. Hilleke Blickershusens Schaube ist eine im Alltag zu tragende.

h. Pelz

Als Pelz vererbende Testatoren treten drei Männer, darunter ein Kleriker, und fünf Frauen auf. Sie bezeichnen den Pelz als pils, pilss oder pyls.

Tabelle: Testamentarische Verfügungen über Pelz

\begin{tabular}{|c|c|}
\hline Jahre & Anzahl der Testatoren und Verfügungen \\
\hline $1300-1325$ & - \\
\hline $1326-1350$ & 1 Testator mit 1 Pelz \\
\hline $1351-1375$ & 1 Testator mit 1 Pelz \\
\hline $1376-1400$ & - \\
\hline $1401-1425$ & 4 Testatoren mit 5 Pelzen \\
\hline $1426-1450$ & 1 Testator mit 2 Pelzen \\
\hline $1451-1475$ & 1 Testator mit 1 Pelz \\
\hline $1476-1500$ &
\end{tabular}

Weil die in den Kleidungsstücken inwändig getragenen Pelze in den Testamenten stets als Futter kenntlich gemacht werden, liegt der Schluß nahe, daß es sich hier um nach außen

\footnotetext{
${ }^{97}$ U. REINHARDT, Testamente, Nr.283, S.453.
} 
getragene Pelzteile (Verbrämungen, Kragen) oder um ein doch überwiegend oder gänzlich aus Pelz bestehendes Kleidungsstück wie z.B. eine Kürse, einen Pelzmantel ${ }^{98}$, handelt.

Wildtierpelze waren als Kleidungszierat begehrt. Vorrangiges Jagdrevier waren die riesigen Waldgebiete Ost - und Nordeuropas, aus denen die Pelze im Regelfall über die Route Novgorod, die baltischen Hansestädte und Lübeck an den Kürschner, dann an den Verbraucher in Lüneburg kamen. Auf diesem von Lübeck nach London, Brügge und Venedig weiterführenden Weg wurden gegen Ende des 14. Jahrhunderts mehrere zehntausend Edelpelze und über eine Million Fehpelze (Eichhörnchenpelz; Winterfell blaugrau, Sommerfell rötlich) vertrieben ${ }^{99}$. Beliebt war weißes Wiesel und Eichhörnchenpelz, bei dem durch das Aneinanderfügen von Rückenpelz und hellerem Bauchpelz der Farbeindruck erzielt wurde. Ebenfalls begehrt, aber seltener anzutreffen waren Zobel und Luchs, während Hermelin, Iltis und Nerz seltener vorkamen.

Über die in Relation zu Schoßzahlungen stehende, erlaubte Breite der Pelzverbrämungen bestimmt die Lüneburger Polizeiverordnung Ende des 14. Jahrhunderts: Die Frau des Bürgers, der seine Besitztümer mit 1000 M.Pf. verschosst, darf bremelse twyer lasteken ${ }^{100}$ bret tragen. Bei einer Versteuerung mit 400 M.Pf. darf die Verbrämung anderthalf lasteken bret sein, bei einer Versteuerung von über 100 M.Pf. ener lasteken bret, bei nicht weniger als 60 M.Pf. darf Buntwerk nur ohne Verbrämung getragen werden, und überhaupt kein Buntwerk ist gestattet bei einer Versteuerung, die weniger als 60 M.Pf. beträgt. Bei jeder Zuwiderhandlung sind je drei lötige Mark zu zahlen. Das Maß des lasteken befindet sich bei den städtischen Kürschnern ${ }^{101}$. In den Kleiderordnungen werden Kürsen selten erwähnt ${ }^{102}$, und auch die Lüneburger Luxusgesetze geben keine Hinweise auf sie.

Wenn auch in Lübecker Testamenten Pelz gleichbedeutend mit Kürse verwendet wird, und auch Konstanzer Testamente Kürsen erwähnen ${ }^{103}$, so kann man für die Lüneburger Testamente nicht mit absoluter Gewißheit entscheiden, ob mit dem Begriff "Pelz“ Verbrämungen oder Pelzmäntel gemeint sind ${ }^{104}$. Wobbeke Boltze bedenkt 1428 die Schwester eines gewissen Hans mit einem zum Zeitpunkt der Eheausstattung auszuhändigenden Pelz: Meint sie mit diesem Legat das Hinzufügen eines weiteren

\footnotetext{
${ }^{98}$ G. JARITZ, „Kürse“, in: Bildwörterbuch der Kleidung und Rüstung, hg. v. H. KÜHNEL, S.152. In den Kleiderordnungen werden Kürsen selten erwähnt. L. C. EISENBARTH, Kleiderordnungen, S.137.

${ }^{99}$ R. DELORT, „Pelze“, in: Lexikon des Mittelalters, Bd. VI, Sp.1867.

${ }^{100}$ last bezeichnet eine nach Gattung unterschiedliche Warenmenge. SCHILLER - LÜBBEN, Mittelniederdeutsches Wörterbuch, S.198.

${ }^{101}$ W. Fr. VOLGER, UB LG, Bd. III, S.432f.

${ }^{102}$ L. C. EISENBARTH, Kleiderordnungen, S.137.

${ }^{103}$ M. HASSE, Neues Hausgerät, neue Häuser, neue Kleider, S.56.

${ }^{104}$ E. WURMBACH versteht unter ,pelz“ einen Umlegekragen aus Pelz. dies., Wohnungs- und Kleiderungswesen, S.86. J. ZANDER - SEIDEL sieht im Pelz den fellgefütterten Frauenrock, der vorwiegend in „Handwerkerfamilien und der unterbürgerlichen Stadtbevölkerung“ nachzuweisen ist. dies., Textiler Hausrat, S.67f Während ZANDER - SEIDELs für Nürnberg erstellte Definition für Lüneburg nicht zutrifft, kann WURMBACHs Darlegung nicht ohne weiteres von der Hand gewiesen werden.
} 
Kleidungstücks im Sinne der Vervollkommnung der Garderobe oder die Möglichkeit einer Zuordnung zu einem zu verbrämenden Kleidungsstück?! In seinem 1490 errichteten Testament wünscht Heinrich Winthe, daß für eine inm bekannte/verwandte Frau ein Pelz angefertigt werde; auch hier kann gleich gefragt werden.

Einige Testatoren beschreiben ihren Pelz, allerdings nach z.T. unterschiedlichen Kriterien. Johann Beve nennt 1367 sein Legat synen groten pils ${ }^{105}$; da er als Vergleichsmaßstab die Größe wählt, besaß er offensichtlich noch einen weiteren, folglich jedoch kleineren Pelz. Als besten Pelz bezeichnen Cyeke Witting und Geseke Rosemberg ihr Erbstück, und Cyeke Wittings Testament beweist, daß sie einen zweiten Pelz besessen hat, den sie als ihren anderen Pelz vererbt. Heinrich Winthe nennt in seinem Testament 1490 den von ihm zu vererbenden Pelz einen weißen Pelz (weißes Wiesel?!). Auffällig ist, daß kein Testator hinzufügt, um welche Pelzart es sich handelte ${ }^{106}$. Möglicherweise darf dies als Indiz für einen individuell überschaubaren Pelzbesitz gewertet werden, den zu differenzieren der Testator nicht für nötig hielt.

Während auf der Donatorenseite überwiegend (verwitwete) Frauen stehen, stehen auf der Empfängerseite ausschließlich Frauen. Zweimal sind Mägde die Bedachten (Dietrich Lembeke 1386, Adelheid Seidentopf 1423/31), dann eine werdinnen ${ }^{107}$ (Alheid Weidelerche, um 1440), und von den restlichen Bedachten können zwei Frauen zweifelsohne der Verwandtschaft zugeordnet werden, während die übrigen fünf zumindest zum Bekanntenkreis gehört haben. Das Ergebnis der vorrangigen (testamentarischen) Zuordnung zur Frauengarderobe wird unterstrichen von den Bestimmungen der Lüneburger Kleidergesetzgebung, die ausschließlich Frauen als Trägerinnen pelzverbrämter Kleider nennt. So mag es kein Zufall sein, daß eine der wenigen Darstellungen eines gänzlich aus Pelz bestehenden Kleidungsstücks von 1480 ebenfalls eine Frau als Trägerin des Zobelmantels zeigt ${ }^{108}$. Festgehalten werden kann, daß der Besitz von Pelz bzw. das Verzieren der Garderobe mit Pelz sichtbares Zeichen des sozialen Ranges seines Trägers ist. In diesem Sinne sind die Pelzlegate in den Testamenten des Ratsherrn Johann Beve 1367 und der Ratsherrnwitwe Wobbeke Boltzen 1428 der Norm entsprechende.

\section{j. Futter}

\footnotetext{
${ }^{105}$ U. REINHARDT, Testamente, Nr.26, S.34.

${ }^{106}$ Ein Überblick über die verschiedenen Pelzsorten und deren Verarbeitung R. DELORT, „Pelze“, in: Lexikon des Mittelalters, Bd. VI, Sp.1866.

${ }^{107}$ U. REINHARDT; Testamente, Nr.194, S.274.

${ }^{108}$ H. BOOCKMANN, Die Stadt im späten Mittelalter, Nr.334; S.215.
} 
Die Testatoren beschreiben Futter als voder ${ }^{109}$ oder umschreiben ein Kleidungsstück als subducta cum ... panno ${ }^{110}$. Futter oder gefütterte Kleidungsstücke treten erst in den Testamenten des 15. Jahrhunderts auf.

\section{0 - 1500: 17 Testatoren mit 28 Futter / gefütterten Kleidungsstücken \\ 1400 - 1425 : 3 Testatoren mit 5 Futter / gefütterten Kleidungsstücken \\ 1426 - 1450 : 10 Testatoren mit 16 Futter / gefütterten Kleidungsstücken \\ 1451 - 1475 : 3 Testatoren mit 5 Futter / gefütterten Kleidungsstücken \\ 1476 - 1500 : 1 Testator mit 2 Futter / gefütterten Kleidungsstücken}

Siebzehn Testamente enthalten insgesamt achtundzwanzig Verfügungen über mit Futter versehene Kleidungsstücke oder über Futter selbst.

Unter den Donatoren befinden sich sieben Frauen und vier Kleriker.

In den achtundzwanzig Verfügungen benennen die Testatoren sechsundzwanzig Verwandte und Bekannte als Empfänger des Kleidungslegats; in dreizehn dieser Fälle lassen die Formulierungen der Testatoren eine nahe Familienverwandtschaft wie Schwester, Tante oder Enkel erkennen.Nur zweimal wird eine Magd bedacht, bei der es sich in einem Fall um eine Vertraute der Testatorin gehandelt haben muß, denn sie bedenkt die Magd, die am längsten mit ihr zusammen war. Zwei gefütterte Kleidungsstücke werden keiner Person, sondern zumindest vom Rechtsverständis her einer Sache zugewendet, nämlich dem denst des Heinrich Steinhagen ${ }^{111}$. Da Steinhagen ständiger Vikar der Johanniskirche und der Gertrudenkapelle war, mag dieser denst möglicherweise ein geistlicher gewesen sein. Die Mehrzahl der Testatoren sorgte also in den Testamenten dafür, daß das Futter oder gefütterte Kleidungsstück im engeren oder weiteren Familienkreis oder in den Händen von Bekannten bleibt.

Die erste quantifizierende Grobauswertung zeigt drei Arten auf, in denen die Lüneburger Testatoren ihr Kleiderfutter oder gefütterte Kleidung vererbten: Entweder bestimmten sie über das Futter allein oder es wurde in Verbindung mit einem Kleidungsstück vererbt oder das Kleidungsstück wurde explizit ohne Futter vererbt.

Futter ohne Kleidungsstück

\footnotetext{
109 z.B. 1413 Aug. 15 Johann von der Mölen.

${ }^{110}$ z.B. 1414 Feb. 4 Johannes von Lippinghausen.

${ }^{111}$ U. REINHARDT, Testamente, Nr.189, S.264. denst meint entweder eine freiwillige Leistung oder e.ine Leistung, zu der man verpflichtet ist; die Leistung kann sich sowohl auf den weltlichen wie den geistlichen Bereich (Gottesdienst) bezeihen.
} 
Sechs Testatoren, Johann von der Mölen 1413, Geseke Springintgut 1425, Adelheid Kolse 1430 und Johann Rese 1431, Heinrich Steinhagen 1439 und Tibbeke Godenstedt 1469, vererben ausschließlich Futter ohne zugehörendes Kleidungsstück.

Die Futter können von beträchtlichem Wert sein: so notiert Geseke Springintgut, sie habe twe voder in Lübeck, deren Verkauf sie zusammen mit einem silbernen Gehänge wünscht, um eine Rente von vier Mark kaufen zu können ${ }^{112}$.

1469 testiert Tibbeke Godenstedt, die ihre Sonntagshoike ohne Futter und die nächstbeste Hoike ohne Futter je an eine Magd vererbt. Diese Formulierungen zeigen, daß diese beiden Kleidungsstücke bis zum Zeitpunkt des Erbfalls entweder selbst gefüttert waren oder es zumindest nicht unüblich war, gefütterte Hoiken zu tragen, zumal dann, wenn es sich um die besten Hoiken handelt.

Eine andere Regelung wählt Heinrich Steinhagen; er hinterläßt einer Schwester einen mit Pelzfutter gefütterten Rock, dessen Futter aber herausgeschnitten werden soll und einem armen Priester zu geben ist.

\section{Verbindung von Futter und Kleidungsstück}

Die übrigen Testamente beinhalten ausschließlich oder unter anderem Verfügungen über gefütterte Kleidungsstücke, also über die Verbindung von Kleidungsstück und Futter. Die gefütterten Kleidungsstücke sind einmal ein Mantel, ein Unterrock, eine Sube und sechsmal eine Hoike und zwölfmal ein Rock.

Mit Ausnahme der Verfügungen über Hoiken beschreiben die Testatoren die zu vererbenden gefütterten Kleidungsstücke im Regelfall wertneutral. Bei den sechs genannten Hoiken handelt es sich in drei Fällen um die - aus der Sicht des jeweiligen Testators - beste Hoike, in zwei Fällen um die zweitbeste Hoike, und nur in einem Fall wird das Kleidungsstück ohne qualifizierendes Adjektiv beschrieben. Es erscheint auf der einen Seite einleuchtend, daß nur Hoiken besserer Qualität gefüttert wurden, bleibt aber auf der anderen Seite eine auffallende Formulierungsweise, zumal man unterstellen darf, daß auch die anderen gefütterten Kleidungsstücke nicht die schlechtesten ihrer Art waren.

\section{Futtermaterialien: Tuch und Pelz}

Eine Vielzahl der Testatoren schrieb sozusagen als Gattungsbezeichnung voder, ohne das Material des Futters näher zu bezeichnen. Materialien für Futter waren, soweit näher bestimmt, Tuch und Pelze. Diese Materialwahl war zweckbestimmt, da Futter zunächst als Wärmespender bzw. Wärmespeicher diente, dann jedoch auch als schmückendes Beiwerk gesehen wurde, das durch kontrastierende Farblichkeit oder wertvolle

\footnotetext{
${ }^{112}$ U. REINHARDT, Testamente, Nr.152, S.208.
} 
Materialbeschaffenheit nicht nur dem äußeren Erscheinungsbild des Trägers, sondern auch seinem gesellschaftlichen Ansehen schmeicheln konnte. So liegt es im Rahmen des Gesagten, daß das von den Testatoren erwähnte Tuch - oder Stoffutter mit den Farben weiß, rot und blau auffallend war und sogar Seide als Futterstoff erwähnt wird. Tuch - oder Stoffutter wird in den Lüneburger Testamenten niemals vererbt, ohne in ein Kleidungsstück eingearbeitet zu sein ${ }^{113}$.

Pelzfutter hingegen wird in drei Fällen alleine vererbt, soll in einem weiteren Fall aus dem vererbten Kleidungsstück herausgetrennt und an einen anderen Erbnehmer als dem Kleidungsstückempfänger gegeben werden. Diese Beobachtung läßt das Ergebnis zu, daß Pelzfutter und Kleidungsstück - einmal zusammengefügt - keine unveränderbare Einheit bildeten, nicht zu einem einzigen Kleidungsstück verschmolzen, sondern auf gewisse Weise ihre Eigenständigkeit bewahrten. Grund dafür mag gerade beim Pelz sein hoher Wert sein, aber auch die durable Beschaffenheit des Materials, das sich im Vergleich zu leichter zerreißbaren (Seiden-) Stoffen eher und häufiger in ein weiteres Kleidungsstück einarbeiten läßt, darüberhinaus auch, allein für sich getragen, wärmend wirkt.

Die wertvollste der in den Testamenten vererbten Pelzarten ist die des braungelben bis schwarzbraunen Marderfells, dessen Wert in der Nicht-Alltäglichkeit des aus Nordeuropa zu importierenden Fells lag und durch die unterschiedliche Wertschätzung der verschiedenen Fellteile - die Kehle galt als kostbarer als der Rücken - unterstrichen wurde ${ }^{114}$. Neben den zwei Marderfuttern wurden drei Iltisfutter vererbt. Iltisfutter war als Fell des einheimischen Iltis nicht so wertvoll wie Marderfell, hob sich aber deutlich von den alläglicheren einheimischen Fellsorten wie Kaninchen - und Schaffell ab. Zwei weitere Fellsorten werden je einmal als Futterstoff vererbt: eine mit Otternfell gefütterte Hoike und ein mit Grauwerk versehener Rock. Grauwerk ist das einfarbige (Rücken-) Fell des grauen Eichhörnchens, von dem man Buntwerk unterschied, der durch abwechselndes Aneinandersetzten von Rückenpelzen und weißem Bauchpelzen mehrfarbigen Pelzfläche.

Auffallend ist, daß in den Testamenten annähernd ausschließlich Röcke mit Pelz gefüttert waren, während bei Hoiken, von der eben erwähnten Ausnahme abgesehen, das Futter ohne genauere Angabe des Materials gleichsam als Oberbegriff genannt wird. Hier scheint der Schluß zulässig, daß es sich wohl größtenteils um Stoffutter gehandelt haben wird, denn eine gewollte Ungleichheit der Materialbeschreibung bei Röcken oder Hoiken

\footnotetext{
${ }^{113}$ M. HASSE zufolge wurde Stoffutter als ,abnehmbarer Teil der Kleidung betrachtet“. M. HASSE, Neues Hausgerät, neue Häuser, neue Kleider, S.56.

114 Über den Import von Pelzsorten siehe M.P. LESNIKOW, Der Hansische Pelzhandel zu Beginn des 15. Jahrhunderts, in: Hansische Studien. Heinrich Sproemberg zum 70. Geburtstag, Berlin 1961, S.219 - 272 , bes. S.222f
} 
erscheint wenig einleuchtend ${ }^{115}$. Hoiken sind weit geschnittene, z.T. mehrgefaltelte Capes, die mit Pelzfutter zu versehen zwar nicht unmöglich, jedoch nicht leicht gewesen wäre. Da es sich bei der Hoike um kein eng am Körper anliegendes Gewand handelt, käme die Wärmefunktion des Pelzfutters nicht vollends zum Tragen. Röcke sind zumindest am Oberkörper mehr oder minder eng anliegende Bekleidungsstücke, die mit Pelz zu füttern aufgrund der Körpernähe Sinn hatte ${ }^{116}$.

\section{Farbigkeit der gefütterten Kleidungsstücke}

Kurz noch ein Wort zur Farblichkeit der verschiedenen Kleidungsstücke: Fünf der sechs pelzgefütterten Röcke sind farblich bestimmt; es gibt drei schwarze Röcke (zweimal Iltisfutter) und zwei rote Röcke (mit Grauwerk und Iltisfutter). Die Farbigkeit der mit Stoff gefütterten Röcke wird in zwei Fällen mit schwarz, einmal mit braun angegeben. Die Futterstoffe in den Farben weiß (einmal), blau (zweimal) und rot (einmal) waren dagegen von hellerer Farbigkeit. Ein gefütterter Unterrock ist schwarz. Auf die Farbnennung der Hoiken haben die Testatoren im wesentlichen zugunsten der Qualitätsbeschreibung verzichtet, lediglich eine Hoike wird als schwarz und ein Futter wird als weißes bezeichnet. Die einzigen von den Testatoren konkretisierten Farbkombinationen sind schwarzer Mantel mit grauem Tuch, schwarzer Rock und weißes Futter und schwarzer Rock mit blauem Futter. Die Futterstoffe sind demzufolge überwiegend von auffallender Farbigkeit, während das gefütterte Kleidungsstück von dunkler Farbigkeit war.

\section{Futter im Spiegel der Lüneburger Luxusgesetzgebung}

Die besondere Bedeutung, die der gefütterten Kleidung in Lüneburg beigemessen wurde, zeigt sich in der Lüneburger Kleiderordnung, die nach 1401 Geltung hatte: Hier heißt es paraphrasiert, wenn eine Frau eine Hoike oder einen Rock mit buntwerke oder mit Seidenfutter tragen will, so kann sie dies tun, aber das Kleidungsstück darf nicht mit zusätzlichem Schmuck wie parlewerk, spangen smyde oder borden versehen sein; lediglich ein Knopf darf noch daran sein ${ }^{117}$. Trägt eine Frau keinen gefütterten Rock oder Seidentuch, dann darf sie schmückende Accessoires im Werte von zunächst sechs, später sieben lötigen Mark tragen. Dieses von einem finanziellen Rahmen vorgegebene Entweder - Oder, bei dem auf der einen Seite gefütterte Kleidung als Wert für sich steht, und sozusagen als Gegengewicht Perlenschmuck, Schmuckspangen und verzierter und damit

\footnotetext{
${ }^{115}$ Allerdings übersetzt SCHILLER - LÜBBEN voder mit 1. Futter 2. Pelzwerk, einzelner Pelz dies., Mittelniederdeutsches Handwörterbuch, S.488.

${ }^{116}$ Einen pelzgefütterten Rock trägt die Pilatusfigur auf der Handwaschungsszene der Mainzer Stiftskirche St. Stefan (frühes 15. Jahrhundert). H. BOOCKMANN, Die Stadt im späten Mittelalter, Nr. 110, S.75.

${ }^{117}$ Diese Kleiderordnung wurde erst 1528 kodifiziert, allerdings mit den vorgenommenen Änderungen, W. Fr. VOLGER, UB LG, Bd. III, S.481f.
} 
wertvoller Besatz stehen, zeugt von der auffallenden Wertschätzung, die Futter bei den reicheren Lüneburger Bürgern genoß. Annähernd zeitgleich, nämlich am Schluß des vierzehnten Jahrhunderts, wurde eine „Polizeiverordnung“ verfaßt, in der sich ebenfalls die Bedeutung gefütterter Kleidungsstücke niederschlägt: Eine Frau, die cruse doke, sydene doke oder voderde kleder trägt, darf all dies nicht mehr tragen, wenn ihr Mann nach der schuldhaften Ausweisung aus der Stadt wieder zurückkehren darf; bei jeder Zuwiderhandlung sind dem Rat drei lötige Mark zu entrichten ${ }^{118}$. Diese Wertschätzung des (Kleider - ) Futters spiegelt sich in der Wahl der Bedachten wider:

\section{Verfügungen über Futter in den Testamenten anderer Städte}

Zieht man zu Vergleichszwecken die Forschungsergebnisse anderer spätmittelalterlicher Testamentsauswertungen zu Rate, so fällt auf, daß dem hier Thematisierten selten mehr als einige, in das Kapitel Kleidung integrierte Zeilen gewidmet sind. Schildhauer fand heraus, daß in den Stralsunder Testamenten Röcke oft mit Pelz und mit zum Kleidungsstück farbkontrasierendem Tuch gefüttert waren ${ }^{119}$. Weder für Lübeck noch für Hamburg liegen Vergleichswerte vor. Im süddeutschen Raum liegt für Konstanz das Ergebnis vor, die bei Testatoren beliebteste Pelzsorte sei das Marderfell gewesen, ein Ergebnis, das sich nicht ausschließlich auf Futter, sondern auch auf Pelzverbrämungen bezieht ${ }^{120}$. JARITZs Einzelerwähnung einer in Wiener Testamenten vererbten, mit roter Seide gefütterten Gugel mag als Hinweis auf die zu vermutenede Verbreitung von nicht nur wärmenden, sondern auch verzierenden Futterstoffen und Materialien gelten ${ }^{121}$. Auch bei Gesamtdarstellungen spielt Kleiderfutter eine untergeordnete Rolle; in KÜHNELs „Alltag in Spätmittelalter“ heißt es zu diesem Thema: „Unter dem Mantel können die Domherren „nach gelegenheit des jars an hitzen und kelten“ - ein Seidentuch oder einen Pelz tragen ${ }^{122}$. Aufgrund fehlender Vergleichsdaten läßt sich nicht sagen, ob in Lüneburg Futter oder gefütterte Kleidungsstücke häufiger als in anderen Städten testamentarisch vererbt wurden. Festzuhalten bleibt, daß Futter sowohl aus Witterungsgründen als auch aus Prestigedenken benutzt und vererbt wurde. Pelzfutter konnte - anders als Tuchfutter getrennt vom Kleidungsstück vererbt werden. Mit Pelzfutter versehen waren in Lüneburger Testamenten im Regelfall Röcke, während Hoiken wohl überwiegend mit Tuchfutter unterlegt waren. Die oft zum Kleidungsstück farbkontrastierende Wirkung des Futters

\footnotetext{
${ }^{118}$ W. Fr. VOLGER, UB der Stadt Lüneburg, Bd. III, Polizeiordnung aus dem Schlusse des vierzehnten Jahrhunderts, kodifiziert 1480, S. 431ff.

${ }^{119}$ J. SCHILDHAUER, Hansestädtischer Alltag, S.79.

${ }^{120}$ P. BAUR, Testament und Bürgerschaft, S.235f.

${ }^{121}$ G. JARITZ, Die Aussagen der sog. „,Wiener Testamentsbücher“, S.178.

${ }^{122}$ H. KÜHNEL, Alltag im Spätmittelalter, S.252.
} 
spielte im Rahmen der vielfältigen modischen Farbgebung eine nicht zu unterschätzende Rolle.

\section{j. Kleidungszubehör}

\section{Kopfbedeckungen}

Einen sloyger vererbt 1490 Heinrich Winthe seiner Base ${ }^{123}$, der Arbergschen. Schleier sind eine von Frauen oft getragene Kopfbedeckung, die nicht nur alleine kopftuchartig lose übergelegt wird, sondern auch in Kombination mit Haube, Gebände oder Schapel Verwendung findet. Hergestellt wurden Schleier aus Leinen, Baumwolle oder Seide. Seit Mitte des vierzehnten Jahrhunderts kommt die Vielfältelung des Schleiers in Mode, deren Wirkung sich nur bei leicht fallenden Stoffen wie der Seide entfalten kann. Gebräuchlich ist die Verzierung der Schleier mit Kantenbesatz oder Zierapplikationen. Angaben über Aussehen und Beschaffenheit des Schleiers enthält das Testament Winthes nicht.

Nur ein Testament enthält eine Verfügung über Hauben: 1493 erwähnt Hans Tedendorp sein Leinentuch, von dem Hebele von der Mölen jeweils zwei Paar Laken, Hemden, Kragen und eben Hauben bekommen soll. Hauben sind das Haar vollständig oder doch größtenteils verhüllende Kopfbedeckungen. Im Gegensatz zum Gebände sind Hauben festgearbeitet. Gebände werden vorwiegend in 12. und 13. Jahrhundert getragen, während die Haube als weibliche Kopfbedeckung seit dem vierzehnten Jahrhundert Verbreitung findet. Im Vergleich zu den durchaus üblichen Anfertigungen aus kostbaren Stoffen, die zudem mit Silber, Gold, Perlen oder Spangen verziert werden konnten, ist eine Leinenhaube eine bescheidene Ausführung. Diese Schenkung mag auf den ersten Blick umsomehr verwundern, da die Empfängerin des Legats Angehörige einer der führenden Familien Lüneburgs ist. Erklärbar wird sie vor dem Hintergrund der zeitgenössischen Sitte, daß verheiratete Frauen den Kopf $\mathrm{zu}$ bedecken hatten ${ }^{124}$, und es nur unverheirateten Jungfrauen gestattet war, die Haare unverhüllt zu zeigen. Angesichts der nicht unbeträchtlichen Zeit, die Frauen im Haus und nicht in der doch mehr auf Repräsentation ausgerichteten Öffentlichkeit verbrachten, war es sinnvoll, Hauben aus leichteren, formbaren, aber nicht zu empfindlichen Stoffen zu tragen. So ist verständlich, daß in Nürnberg die Mehrzahl der Hauben, zumindest bis zum sechzehnten Jahrhundert, aus Leinen - und Baumwollgeweben bestehen ${ }^{125}$.

\footnotetext{
${ }^{123}$ U. REINHARDT, Testamente, Nr.276, S.440.

${ }^{124}$ So gehört zur Frauengerade in Lüneburg ,ere besten wumpel“ ( = Kopftuch, Haarbinde). W. Fr. VOLGER, UB der Stadt Lüneburg, Bd.III, S.436.

${ }^{125}$ J. ZANDER - SEIDEL, Textiler Hausrat, S.105.
} 
Fünf Testatoren verfügen über kapuzenartige Kopfbedeckungen. Im vierzehnten Jahrhundert ist es Johann Beve, der seinen beiden Knechten und Everd, seinem Jungen, je eine koghele hinterläßt ${ }^{126}$. Um 1440 testierte Alheid Weidelerche, die ihrer Base Grete ebenfalls eine koghel vererbt ${ }^{127}$. Die Kogel oder Gugel ist eine zunächst am Mantel befestigte, dann losgelöst benutzte Kapuze mit angeschnittenen Schulterkragen, die lange Zeit viel getragen wurde, ab 1450 aber zugunsten anderer Kopfbedeckungen in den Hintergrund tritt ${ }^{128}$. Die Kogel konnte in einen langen Zipfel auslaufen, der vorn über die Schulter hängend getragen wurde. Seit dem ersten Viertel des vierzehnten Jahrhunderts gilt es sozusagen als „dernier cri“, die Gesichtsöffnung auf den Kopf gezogen zu tragen und die freiliegende Kopfpartie dann mit dem Zipfel zu verhüllen. Eine Niederschrift über Heergewät und Frauengerade aus dem Jahr 1481 zählt auch die beste koghelen zur Frauengerade und zeigt, daß eine solche Kapuze im Regelfall zur Grundausstattung der Frauenkleidung gehörte ${ }^{129}$.

Johannes Weidenknepel vererbt 1444 eine gefütterte Tunica von den schlechteren mit capusio $^{130}$. Eine braune timpede hinterläßt Vicke Bottermann seinem Bruder Make ${ }^{131}$. Eine timpede ist eine spitz zulaufende Kapuze. Empfänger der Kopfbedeckungen sind Verwandte oder nahe Bekannte der Testatoren.

Eine für den Untersuchungszeitraum einzigartige Verfügung trifft 1441 Hermann Kruse in seinem Testament: Er hinterläßt seinen drei Töchtern die parleden kronen, die seine verstorbene Frau für die Töchter anfertigen ließ ${ }^{132}$. Auch die Frauen seiner Söhne dürfen diese Krone tragen, aber die Töchter bleiben die Eigentümerinnen dieser Kostbarkeit. Eine derartige reifartige, mit Perlen besetzte Kopfzierde ist auch für die reiche Oberschicht keine Alläglichkeit, denn die „kleinen Kränze aus Gold, Silber und Perlen waren die kostbarsten“"133. Insofern ist es nicht weiter verwunderlich, daß das Tragen dieser wertvollen Zierstücke in etlichen Städten verboten ist. Die Lüneburger Kleiderordnung enthält keine diesbezügliche Klausel.

\footnotetext{
${ }^{126}$ U. REINHARDT, Testamente, Nr.26, S.34.

${ }^{127}$ U. REINHARDT, Testamente, Nr.194, S.274.

${ }^{128}$ L. C. EISENBART, Kleiderordnungen, S.150f; H. KÜHNEL, Alltag im Spätmittelalter, S. 239. Die Entwicklung dieses Kleidungsstücks erklärt, warum gelegentlich Gugel als „,Mantel und Kopfbedeckung zugleich" bezeichnet wird. Hier als Beispiel H. KÜHNEL, Die materielle Kultur des Spätmittelalters im Spiegel der zeitgenössischen Ikonographie, in: Kat. „Gotik in Österreich“, S. 21.

${ }^{129}$ W. Fr. VOLGER, UB LG, Bd. III, S. 435f . REINECKE übersetzt kogele als Mantel, Geschichte der Stadt Lüneburg, W. REINECKE, Geschichte der Stadt Lüneburg, Bd.I, S.119. Die Kombination von Mantel und ( angenähter ) Kapuze war nicht unüblich; so gab es z.B. in Braunschweig kurze Hoiken, die stets im Zusammenhang mit kogheln genannt werden, so daß eine stetige Verbindung beider angenommen wird L. C. EISENBARTH, Kleiderordnungen, S.135.

${ }^{130}$ U. REINHARDT, Testamente, Nr.206, S.296.

${ }^{131}$ U. REINHARDT, Testamente, Nr.252, S.386.

${ }^{132}$ U. REINHARDT, Testamente, Nr.200, S.282. Bei der Drucklegung wurde irrtümlicherweise ein Leerzeichen eingefügt.

${ }^{133}$ L. C. EISENBART, Kleiderordnungen, S.155.
} 


\section{Kragen}

Drei Testamente aus den letzten zwei Jahrzehnten des fünfzehnten Jahrhunderts enthalten Verfügungen über Kragen. 1493 hinterläßt - wie bereits erwähnt - Heinrich Tedendorp Hebele von der Mölen sein Leinentuch, zu dem auch zwei Paar kragen gehören ${ }^{134}$. Geseke Leyferd wollte in ihrem 1485 errichteten Testament ihrer Magd bur für einen hoyken kragen hinterlassen, hatte aber - wie sie schreibt - kein Tuch mehr übrig, so daß sie Aleke Reinstorp dann einen Pfühl hinterläßt ${ }^{135}$. Möglicherweise hatte sich die Magd einen die Hoike ehrbarer Frauen zierenden Kragen gewünscht, wie er in Hamburg bekannt war. JAACKS beschreibt den Hamburger Hoikenkragen als einen eng gefältelten, steif nach hinten abstehenden Kragen $^{136}$.

\section{hovedgad}

Unter hovedgad versteht man die Öffnung der Bekleidung, durch die beim An- und Ausziehen der Kopf gesteckt wird ${ }^{137}$. Dieses Kopfschlupfloch konnte Objekt der Verzierung sein, wie das Testament der Geseke Springintgud aus dem Jahr 1425 zeigt: Die Testatorin hinterläßt den beiden Söhnes ihres Ehemanns Nicolaus von Urden u.a. eyn gefiled vorguldet hovedgad, aus dem oder von dessen Erlös ein Fuß für eine Schale angefertigt werden soll ${ }^{138}$. Offensichtlich handelt es sich hierbei um eine prachtvoll bestickte Kopföffnung, die entweder mit vergoldetem Besatz oder einem vergoldeten Garn bestickt ist. Der Wert dieser Verzierung offenbart sich im Wert des von inm zu finanzierenden Schalenfußes. Aussagekräftig ist, daß ein solches Stück von einer Frau vererbt wird, die aus einer der führenden und dementsprechend reichen Familien Lüneburgs stammt.

\section{Ärmel}

Ärmel sind während des (Spät-) Mittelalters vorwiegend bei der Oberbekleidung modischen Veränderungen unterworfen ${ }^{139}$. Diese Veränderungen bewegen sich im Rahmen von eng bis (übertrieben) weit, von kurz bis (übertrieben) lang ${ }^{140}$. Ärmel waren - anders als heute -

\footnotetext{
${ }^{134}$ U. REINHARDT, Testamente, Nr.282, S.451.

${ }^{135}$ U. REINHARDT, Testamente, Nr.270, S.427.

${ }^{136}$ G. JAACKS, Städtische Kleidung, S.229f.

${ }^{137}$ Zur Bedeutung in der Rechtsgeschichte siehe R. SCHMIDT - WIEGAND, Kleidung, Tracht und Ornat nach den Handschriften des ,,sachsenspiegels“, in: Terminologie und Typologie mittelalterlicher Sachgüter: Das Beispiel der Kleidung, S.164.

${ }^{138}$ U. REINHARDT, Testamente, Nr.152, S.208.

${ }^{139}$ Bei der Unterbekleidung tritt vorrangig der lange, nicht übertrieben weite Ärmel auf. H. HUNDSBICHLER, „Ärmel“, in: Bildwörterbuch der Kleidung, hg. v. H. KÜHNEL, S.14 Unter diesem Stichwort findet sich ein knapper, informativer Überblick über Ärmel.

${ }^{140}$ Etliche Bildquellen des Spätmittelalters zeigen die langen Ärmel zusammengebunden hinter dem Rücken des Trägers. Als Beispiel H. BOOCKMANN, Die Stadt im Späten Mittelalter, Nr. 253, S.161.
} 
nicht immer fest angenähter Kleidungsteil, sondern konnten durch Knöpfung oder Nesteln, also Bindung, ausgewechselt werden. Dieser problemlose Ärmelwechsel trug-gerade in der Frauenbekleidung-zu vielfältigen Änderungsmöglichkeiten und damit zu hoher Varianz des optischen Eindrucks bei. Weite Ärmel im Vergleich zur eng ansitzenden Kleidung des Adels gelten zunächst als Reminiszenz an den arbeitenden Stadtbürger, der Bewegungsfreiheit brauchte. Neben das Nützliche trat dann das Schöne, und Ärmelschnitte, verarbeitetes Material sowie schmückendes Beiwerk machten aus dem Ärmel ein in der Regel kostbares Kleidungszubehör, dessen Ausführung mitnichten nur praktisch war. Ärmel konnten mit Pelz gefüttert oder aus kostbaren Stoffen genäht sein.

Ärmel werden im relevanten Zeitraum relativ spät und selten in den Testamenten erwähnt. 1469 hinterläßt Tibbeke Godenstedt zwei Mägden je einen Rock mit luttiken mouwen, und 1490 vererbt Heinrich Winthe Aleke Helmold ein par roder mouwen mit dem symde ${ }^{141}$. Mit dem Wort mouwe ist besonders der weite Ärmel gemeint ${ }^{142}$. Sein Schnitt erlaubt das Einstecken der Hände zum Schutz gegen Kälte ${ }^{143}$. Zumindest im Schlußzeitraum der vorliegenden Auswertung scheinen Ärmel als Muff getragen worden zu sein. Über das Material, aus dem die Ärmel bestehen, sagen die Testatoren nichts aus. Den Bildquellen zufolge handelt es sich bei mit smyde verzierten Ärmeln um mit einer prachtvoll bestickten Borde versehene Ärmel, wobei die Borde am unteren Ende des Ärmels befestigt ist. In jedem Fall sind Ärmel Kleidungsteile, die mehr als einige andere die Modebewußtheit des Trägers oder der Trägerin zu unterstreichen vermögen, vor allem dann, wenn sie - wie im Testament Heinrich Winthes - mit smyde verziert und auffallend rot sind. Und so ist es nicht weiter verwunderlich, daß Heinrich Winthe zu der überaus überschaubaren Testatorengruppe gehört, die nicht nur relativ viele (acht Stück), sondern auch wertvolle Kleidungsstücke vererben. Tibbeke Godenstedt verfügt in ihrem Testament über einige Kleidungsstücke, unter denen sich auch wertvolle befinden. Man darf vermuten daß die Testatorin die Schenkung der beiden kurzarmigen Röcke gerade an zwei arbeitende Frauen, ihre Mägde, mit Umsicht getätigt hat.

\section{Knöpfe}

Zwei Testatoren vererben Knöpfe: 1447 Nickel Lesnis und 1485 Geseke Leyferd. HUNDSBICHLER zufolge sind Knöpfe eine Errungenschaft der Kreuzzüge, während das Knopfloch eine Erfindung der Europäer sei ${ }^{144}$. Die Beliebtheit der Knöpfe als Kleidungszierat spiegelt sich in den Lüneburger Kleiderordnungen wider, die dem Tragen

\footnotetext{
${ }^{141}$ U. REINHARDT, Testamente, Nr.235, S.350; Nr.276, S.440.

${ }^{142}$ SCHILLER - LÜBBEN, Mittelniederdeutsches Handwörterbuch, S.236.

${ }^{143}$ Entsprechende Darstellung auf dem Winterbild des Jahreszeitenzyklus des Jörg Breu bei J. ZANDER SEIDEL, Textiler Hausrat, Nr.143, S.151.
} 
goldener und vergoldeter Knöpfe sowie dem Tragen von Perlenknöpfen Beschränkungen auferlegen. Kriterium dieser Beschränkungen sind die Höhe der Schoßzahlungen des Ehemannes und die beruchtinge, der (schlechte) Ruf einer Frau. Kleiderordnungen wie Testamente zeigen, daß Knöpfe losgelöst von der Kleidung als Wert per se zählten. Angesichts der Tatsache, daß Knöpfe gerngetragenes Kleidungsbeiwerk waren und einzeln vererbbar sein konnten, fältt ihre seltene Erwähnung in den Testamenten auf.

Nickel Lesnis bestimmt seine silbernen Knöpfe zusammen mit anderem Silberwerk wie Spangen und altem Geld zur Herstellung eines Kelchs. Geseke Leyferd bedenkt ihre Magd Aleke von Reinstorf mit fünf vergoldeten Knöpfen. Mägden Lüneburger Bürger war es erlaubt, vergoldete Knöpfe im Wert einer halben lötigen Mark an ihren Hoiken zu tragen, dann allerdings mußten sie auf anderen Zierat verzichten ${ }^{145}$.

smyde

Der Begriff smyde bezeichnet im Kontext der Bekleidung Gewandschmuck. Den weitaus größeren Teil nimmt smyde in der Bedeutung von Tafelschmuck und repräsentativen Schmuckstücken in den Testamenten ein. rocksmyde vererbt Nickel Wulfferam 1483 seiner Tochter Greteke ${ }^{146}$. Das Testament verzeichnet genau den Wert des rocksmydes, nämlich 3 Mark, weil es Pfand der Elverschen und der Beckerschen sei. Heinrich Winthe benutzt in seinem Testament 1490 den Begriff smyde, der in Zusammenhang mit vier zu vererbenden Kleidungsstücken fällt. Hier heißt es: myner huszfrouwen hoyken, smyde nogest deme besten; myner huszfrouwen nagest deme besten hoyken sunder dat smyde, myner frouwen besten hoyken sunder dat smyde und en par roder mouwen mit deme smyde ${ }^{147}$. Nur diese beiden Testatoren erwähnen Gewandschmuck. In den beiden Testamenten wird Gewandschmuck genau der Kleidungsstücke vererbt, die in der Regel von wohlhabenden Bürger verziert getragen wurden: Rock, Hoike und Ärmel. Fraglich ist, warum nur zwei Testamente mit entsprechenden Formulierungen überliefert sind. Angesichts des nicht unbeträchtlichen Reichtums einiger Testatoren muß davon ausgegangen werden, daß auch sie kostbar verzierte Gewänder besessen haben. Möglicherweise haben sie mit der Bezeichnung "beste Hoike/bester Rock" mit verzierten Borden geschmückte Kleidungsstücke gemeint, ohne das smyde extra zu erwähnen. Etliche mit smyde versehene Gewänder werden außerhalb des testamentarisch geregelten Erbganges vererbt oder auch verschenkt worden sein.

\footnotetext{
${ }^{144}$ H. HUNDSBICHLER, Kapitel „Kleidung“, in.: Alltag in Spätmittelalter, hg. v. H. KÜHNEL, S.247.

${ }^{145}$ W. Fr. VOLGER, UB Lüneburg, Bd. III, S.434.

${ }^{146}$ U. REINHARDT, Testamente, Nr.266, S.418.

${ }^{147}$ U. REINHARDT, Testamente, Nr.276, S.438ff.
} 
Gürtel

Unter dem heutigen Begriff Gürtel ist hier subsumiert, was die Testatoren als cingulum ${ }^{148}$, gordel, ghordel, gordell, kede und borden bezeichneten.

Tabelle: Testamentarische Verfügungen über Gürtel

\begin{tabular}{|c|c|}
\hline Jahre & Anzahl der Testatoren und Verfügungen \\
\hline $1300-1325$ & 1 Testator mit 2 Gürteln \\
\hline $1326-1350$ & 2 Testatoren mit 2 Gürteln \\
\hline $1351-1375$ & 1 Testator mit 3 Gürteln \\
\hline $1376-1400$ & 2 Testatoren mit 3 Gürteln \\
\hline $1401-1425$ & 2 Testatoren mit 2 Gürteln \\
\hline $1426-1450$ & 3 Testatoren mit 4 Gürteln \\
\hline $1451-1475$ & 2 Testatoren mit 3 Gürteln \\
\hline $1476-1500$ & \\
\hline
\end{tabular}

Der Blick auf die Verteilung der Verfügung über die Vierteljahrhunderte des Untersuchungszeitraums läßt keine bemerkenswerten Schwankungen erkennen. Der Schluß ist zulässig, daß Gürtel ein kontinuierlich in den Testamenten vertretener Bekleidungsfaktor sind.

Drei der dreizehn Testatoren waren Frauen (1439 Soffeke Springintgut, 1451 Beke Groning und 1473 Metteke von Dassel). Beke Groning ist die einzige der Testatoren, die in ihrem Testament das Wort kede verwendet, indem sie den Gürtel als keden beschreibt, da man sik mede gordet ${ }^{149}$. Vier der Testatoren waren Kleriker (1339 Presbyter Leo, 1385 Segeband von Thune, 1414 Johannes von Lippinghausen und 1484 Hartwig Hannover); sie verwenden in ihren Testamenten den Begriff cingulum, da sie den zur Albe gehörenden liturgischen Gürtel vererbten. Wie auch immer die Testatoren ihr Erbstück bezeichneten, so meinten sie doch jeweils ein in seiner Funktion gleiches, die Kleidung raffendes Band.

Alle weiblichen, über Gürtel verfügenden Testatoren sorgen in ihrem Testament dafür, daß ihre Gürtel in die Hände ihrer Kinder oder Geschwister übergehen. Soffeke Springintgut

\footnotetext{
148 „,cingulum“ meint im Regelfall den liturgischen Gürtel. Dieser liturgische Gürtel ist per definitionem „ein einfacher Strick od. ein oft durch Quasten und Stickerei verziertes weißes oder buntes .. Band aus Leinen, Wolle, Baumwolle od. Seide“ J. WAGNER, „cingulum“, in: LThK,Bd. 2, Sp.1205. Ähnlich bei A. REINLE, Die Austattung deutscher Kirchen im Mittelalter, S.154. Da aber von den sieben als cingulum bezeichneten Gürteln nur einer als cingulum lineum bezeichnet ist und nur hier die klassische Definition zutrifft, während die übrigen vergoldete und silberne sind, die zu Kelchen umgearbeitet werden sollen, kann davon ausgegangen werden, daß es sich um aufwendigere Ausstattungen handelt.

${ }^{149}$ U. REINHARDT, Testamente, Nr.217, S.313.
} 
bedenkt zunächst zwar ihre Schwester Geseke mit ihrem besten Gürtel, den sie von Dietrich Springintgut, ihrem zweiten Ehemann, geschenkt bekommen hatte, räumt aber ihren Töchtern ein Rückkaufsrecht mit zwei Mark Leibgedinge ein. Beke Gronings grüner Seidengürtel mit den silbernen Beschlägen soll an ihre Tochter Rikele Springinggut fallen, und die Frau Rokswales soll den roten Gürtel mit den Silberbeschlägen in dem Fall seiner, also Rokswales, Veränderung erhalten - da Hans Rokswal ihr Sohn ist, trifft Beke Groning hier Vorsorge für ihre Schwiegertochter. Dann denkt sie wieder an eine eigene Tochter, diesmal eine verheiratete Semmelbecker, die die silberne Kette, mit der man sich gürtet, erhalten soll. Mit diesen drei Legaten ist Beke Groning die Testatorin, die aus der Menge aller über Gürtel verfügenden Testatoren über die größte Quantität verfügt. Metteke von Dassel hinterläßt ihrem Sohn Albert ihren silbernen Gürtel mit der Auflage, aus ihm unter Zuhilfenahme von 20 Rheinischen Gulden - ebenfalls eine Hinterlassenschaft der Mutter eine silberne Schale anfertigen zu lassen.

Vicke Bottermann ist der einzige Testator, der (seine?) Kinder bedenkt; sie sollen einen Gürtel mit vergoldetem Besatz erhalten. Segeband von Thune schenkt seinen silbernen Gürtel der Frau Ludolf Rushers, einer ihm offenbar bekannten Dame. Thunes vergoldeter Gürtel befindet sich, so vermerkt das Testament, zusammen mit Dekretalen und zwei silbernen Trinkschalen in den Händen Heinrichs von Rameslo, dem der Testator 20 Mark Denare schuldet. Die zu dem Gürtel gehördende Spange befindet sich noch im Besitz Thunes. Einen Gürtel im nicht unbeträchtlichen Wert von 16 Mark Denaren schuldet ihm der Propst in Overnkerken. Die beiden zuletztgenannten Klauseln in Thunes Testament zeigen die Werthaftigkeit und Wertbeständigkeit kostbarer Gürtelausführungen, die als Pfand für nicht unbeträchtliche Geldsummen einstanden.

Keine Aussagen enthalten die Testamente über die Tragweise der Gürtel oder über deren Länge $^{150}$.

Fertigungsmaterial und Aussehen der Gürtel

Über das Material bzw. über das Erscheinungsbild ihrer Gürtel schweigen sich lediglich zwei Testatoren, der Priester Leo und der Vikar Hartwig Hannover, aus. In acht Fällen wird der Gürtel als silberner (sulvern, argenteum) beschrieben. Damit könnten Platten - oder Scharniergürtel aus Silber gemeint sein, aber auch mit Silberversatzstücken verzierte Stoffbänder. Diese als borde bezeichneten Stoffgürtel vererben Beke Groning und Vicke Bottermann, die ihre Erbstücke konkret als ene grone siden borden mit sulvere beslaghen, ene roden borden mit sulvere beslaghen (Beke Groning) und eyne borden mit vorguldeme

\footnotetext{
${ }^{150}$ Eine gute Kurzinformation gibt E. VAVRA unter dem Stichwort „Gürtel“ im Lexikon des Mittelalters, Bd.IV, Sp.1796 f.
} 
smyde (Vicke Bottermann) bezeichnen ${ }^{151}$. Segeband von Thune nennt zwei seiner drei testamentarisch zu vererbenden Gürtel vergoldete Gürtel, deren einer 16 Mark Denare wert ist. Johannes von Lippinghausens einer Gürtel ist von roter Farbe und mit Messing versehen, während er seinen zweiten als Leinengürtel beschreibt. Insgesamt gesehen sind als Stoffmaterialien Leinwand und Seide genannt sowie die Metalle Gold, Silber und als Metall in weiterem Sinne Messing.

Die in den Testamenten erwähnten wertvollen Gürtelausführungen zeigen, daß der Gürtel ein Bekleidungszubehör von hoch repräsentablem Charakter sein konnte. Diese Beobachtung korrespondiert mit den wertvollen überlieferten Exemplaren ${ }^{152}$ und der Darstellungen auf Bildwerken des (Spät - ) Mittelalters. Die Lüneburger Polizeiverordnung aus dem 14. Jahrhundert spiegelt die (übermäßige) Beliebtheit des Tragens prachtvoller Gürtel wider: „Welk unser borgher wel dreghen en sulverne gordel van dren lodigen marken edder enen dusing ane klocken edder ene vatinge ane klocken, so swar de dre mark, mach he in der stucke enem allenen und nicht in der stucke twen edder alle dren tosamende hebben edder dreghen. Were ok, dat we van der stad edder syner eghenen weghene wor buten Luneborg riden wolde, de scholde noch dusing noch vatinge, icht he der stucke welk hadde van dre lodigen marken in den hals edder uppe de schuldern hengen unde de daruppe hebben und voren, men enen dusing, icht he dene hedde van den dren lodigen marken, den mochte he in dem holen live voren, edder hedde he en gordel van den dren lodigen marken, dat mochte he umme syne syden hebben. Wolde ok we smyde dreghen uppe synem gordele und uppe syner taschen en half lodige mark swar, dat mochte he don, und wat he denne darto hebben wolde, id were eyn sulverne gordel edder en dusing edder vatinge, dar scholde de halve lod. mark wedder ane affgan, also dat denne men driddehalf lod. mark sulver en were“. ${ }^{153}$ Der funktionale Aspekt des Gürtels liegt in der Gewandraffung, die nicht allein beim vertikalen Faltenwurf angewendet wurde, sondern auch ein Hochraffen des Gewandes als Verschmutzungsprävention beinhalten konnte ${ }^{154}$. Daneben diente der Gürtel-wie zahlreiche Bildwerke belegen-als Aufhängemöglichkeit von Schlüsseln, Rosenkranz, Messern, Beuteln oder Taschen, in denen benötigte Kleinigkeiten problemlos

\footnotetext{
${ }^{151}$ U. REINHARDT, Testamente, Nr.217, S.313; Nr.252, S.386. In der Drucklegung wurde bei der Beschreibung des roten Gürtels in Beke Gronings Testament ein Buchstabe vertauscht.

${ }^{152}$ Als Beispiele für Seidengürtel im Katalog „Stadt im Wandel“", Bd. 1, Nr. 249 und Nr. 250; vgl. auch das Fundstück „Gürtel“ in Lübeck, G. JAACKS, Seidenes Bekleidungsbeiwerk aus den Lübecker Altstadtgrabungen, in: LSAK 23 1993, S.296ff.

${ }^{153}$ W. Fr. VOLGER, UB Lüneburg, Bd. III, S.431f.

${ }^{154}$ Darstellung in der Tafel „Leben Johannes des Täufers“, gemalt von Hinrik Funhof, St. Johannis, Lüneburg. Abbildung in: H. G. GMELIN, Spätgotische Tafelmalerei in Niedersachsen und Bremen, Hannover 1974, S.121.
} 
mitgeführt werden konnten ${ }^{155}$. Eine solche am Gürtel zu befestigende Tasche könnte Johannes von Lippinghausen in seinem an Dietrich Betken fallenden Legat gemeint haben, das er als peram meam cum cingulo beschrieb ${ }^{156}$. Daß solche Taschen aus kostbarem Material gefertigt und mit inm verziert sein konnten, ist neben dem optischen Eindruck spätmittelalterlicher Bildwerke umfassend durch ZANDER-SEIDELs Auswertung Nürnberger Schriftquellen belegt worden ${ }^{157}$.

Nutzung der Gürtel für die Herstellung von Kelchen

Vorwiegend verwenden die Testatoren ihre Gürtel als Grundmaterial oder/und als Finanzierungsmittel zur Anfertigung eines oder auch mehrerer Kelche. Acht Gürtel werden in diesem Sinne vergabt (1339 Priester Leo, 1366 Heinrich Miles, 1367 Johann Beve, 1413 Johann von Tespe, 1430 Hans Junge und 1484 Hartwig Hannover). Für Hans Jagow (Testament 1472) erscheint die Verwendung seines Gürtels zur Vergoldung eines Kelchs als eine Alternativmöglichkeit zum Kauf eines Missales. Zur Anfertigung eines Kelchs bedurfte es in der Regel eines entsprechenden Gegenwerts, und so nimmt es nicht wunder, daß sechs Gürtel von den Testatoren als silberne bezeichnet wurden. Hans Junge bestimmte, aus seinem silbernen Gürtel solle nicht nur ein Kelch, sondern gleichzeitig eine Patene hergestellt werden, die der Rat der Stadt Lüneburg für den Hochaltar der Ratskapelle im Rathaus anfertigen lassen solle. Den Auftrag zur Anfertigung und die Überwachung der Arbeiten legen drei Testatoren in die Hände ihrer engsten Familienangehörigen: Johann Beve beauftragt seinen Sohn Hartwig, Johann von Tespe seine Tochter Kerstin, und Heinrich Miles legt die Bezahlung der Arbeiten in die Hände seiner Frau. Johann Beve weist in seinem Testament die Finanzierung mit seinem Gut an; hinzunehmen solle man als Material neben seinem Gürtel den Schmuck, der seiner Ehefrau Grete gehört hatte - immerhin genug, um die gewünschten drei Kelche anfertigen zu lassen.

Bis auf die Testamente des Priesters Leo (die TV können selbst den Altar bestimmen) und Johanns von Tespe enthalten die Testamente konkrete Angaben über den Bestimmungsort der anzufertigenden Kelche. Heinrich Miles nennt eine in St. Johannis zu errichtende Vikarie als Empfängerin des Kelchs, Beve eine von Elisabeth Meweke gegründete Vikarie, beschreibt dann in einer direkt personenbezogenen Schenkung seinen Sohn Hartwig und Ludolf Floreke als Bedachte, Hans Junges Bestimmungsort ist bereits erwähnt, und Hans

\footnotetext{
${ }^{155}$ Deutliche Darstellung eines weißen Geldbeutels mit roten Bändern am Gürtel der Figur des Judas in der Abendmahlszene des für das Kloster Heiligenthal von Hans Bornemann 1444 - 47 angefertigten Altars, jetzt in St. Nikolai, Lüneburg, Abbildung H. G. GMELIN, Spätgotische Tafelmalerei, Abb.2.13.

${ }^{156}$ U. REINHARDT, Testamente, Nr.103, S.144.

${ }^{157}$ J. ZANDER - SEIDEL, Textiler Hausrat, Kapitel über „, Gürtelutensilien: Beutel - Messer - Schlüsel Nadelband", S.145 - 149, bes. S.146.
} 
Jagow will für eine zu gründende Kommende am St. Thomasaltar in der Hamburger Katherinenkirche entweder ein Missale oder die Vergoldung eines Kelchs finanziert wissen. Hartwig Hannover bedenkt eine Vikarie am Katherinenaltar in St. Lamberti mit dem aus zwei Gürteln cum fibulis anzufertigenden Kelch ${ }^{158}$.

Die Testamente zeigen, daß einige, aber in Relation zum Untersuchungszeitraum von 200 Jahren nicht übermäßig viele Gürtel ihrem profanen Verwendungszweck entzogen und durch Umarbeiten in sakrale Kulturgüter umgewandelt wurden und damit in die tote Hand kamen.

Gürtel in den Testamenten anderer Städte

In Stralsunder Testamenten ist der silberne Gürtel im 14. und 15. Jahrhundert mit 89 Legaten häufig vertreten ${ }^{159}$. Fünfmal werden vergoldete Gürtel genannt, und zehnmal einfache Gürtel. In Konstanz dagegen ist lediglich ein Legat eines silbernen Gürtels überliefert ${ }^{160}$. In den Testamenten österreichischer Bürger nahm der silberbestückte Gürtel eine führende Position unter den Schmucklegaten ein ${ }^{161}$.

\section{Liturgische Gewänder}

Liturgische Kleidungsstücke gehen in ihren Grundformen auf die spätantike Tracht zurück und behalten diese nicht nur terminologisch, sondern auch in ihren Schnitten rudimentär bei. Die durch die kirchliche Vorschrift festgelegte Anzahl der Gewänder bleibt konstant, lediglich Austattung und Form konnten zeitgemäßem Wandel unterliegen, ohne jedoch im wesentlichen verändert zu werden.

Tabelle: Verfügungen über liturgische Gewänder

\begin{tabular}{|l|l|}
\hline Jahre & Anzahl der Testamente \\
\hline $1300-1325$ & - \\
\hline $1326-1350$ & 1 Testament \\
\hline $1351-1375$ & 1 Testament \\
\hline $1376-1400$ & - \\
\hline $1401-1425$ & 8 Testamente \\
\hline
\end{tabular}

\footnotetext{
${ }^{158}$ U. REINHARDT, Testamente, Nr.269, S.424.

${ }^{159}$ J. SCHILDHAUER, Hansestädtischer Alltag, S.76.

${ }^{160}$ P. BAUR, Testament und Bürgerschaft, S.240.

${ }^{161}$ G. JARITZ, Österreichische Bürgertestamente, S.258.
} 


\begin{tabular}{|l|l|}
\hline $1426-1450$ & 6 Testamente \\
\hline $1451-1475$ & 3 Testamente \\
\hline $1476-1500$ & 4 Testamente \\
\hline
\end{tabular}

Verfügungen über liturgische Gewänder treten im 15. Jahrhundert häufiger auf als im vorhergehenden Jahrhundert. Hier allerdings ist ein Priestergewand Bestandteil der Erbmasse eines der ersten in Lüneburg überlieferten Testamente, nämlich des Testaments des Priesters Leo aus dem Jahr 1339. Im 15. Jahrhundert ist eine abnehmende Tendenz der Verfügungen zu beobachten.

23 Testatoren nehmen in ihr Testament Verfügungen über (anzuschaffende) liturgische Gewänder auf. Drei der insgesamt 23 Testatoren sind Frauen. Acht Testatoren sind Kleriker (Priester Leo, Johann von Bücken/Archidiakon von Modestorpe, Johannes von Lippinghausen/Vikar in St. Johannis, Christian von Bergen/Vikar in St. Johannis und St. Lamberti, Heinrich Steinhagen/Vikar in St. Johannis und St. Gertrudis, Heinrich Tetendorp/Vikar in St. Lamberti, Dietrich Junge/Vikar in St. Johannis, Ludolf Mangard/Vikar in St. Johannis).

Empfänger der Legate sind in erster Linie Altäre, Vikarien und Kommenden stadtlüneburgischer Kirchen. St. Johannis wird bedacht von Metteke von Dassel (Philippi und Jacobialtar), von Johann von der Mölen, Johann von Bücken (Marienaltar), Christian von Bergen und Gese Lübberstedt (Vikarie am Martinsaltar). St. Lamberti erhält Priesterkleidung von Johann Hoyemann, Ludolf bi dem Sode, Christian von Bergen und Ludolf Mangard. Johann vame Lo will 1473 zwei Kommenden in St. Nikolai mit Meßgewand versehen, die Kommenden sollen in einer von ihm neuzuerrichtenden Kapelle liegen ${ }^{162}$. Die zwar vor den Toren, aber in unmittelbarer Nähe der Stadt liegende Gertrudenkapelle wird von Johannes von Lippinghausen bedacht. An den Großen Heiligen Geist, also an das Heilig Geist Hospital, gerichtet waren die Legate Hilleke Blickershusens und Heinrich Winthes. Von den Klöstern wurden nur das Franziskanerkloster bedacht, und zwar von Hans Junge, der neben der für die Brosche anzufertigende Chorkappe den Franziskanern ein silbernes Marienbildnis und eine silberne Kette überließ, dafür eine Grabstelle im Kreuzgang und Begräbnisfeierlichkeiten erhielt. Geverd Gropeshorn setzt ein Geldlegat für die Kinder seines Ohms Hans Gropeshorns aus, die im Kloster St. Marien, also bei den Franziskanern waren. Als auswärtige Kirchen werden die Martinskapelle in Oldenstadt bei Uelzen von Ludolf von Hagen und die Kirche in Bülten von Henning von Bulten sowie das Kloster in Rameslo von Lüder Bardowick bedacht.

\footnotetext{
${ }^{162}$ Die Kapelle wurde 1482 im Südbereich am Fuß des Turms zu Ehren Mariens errichtet. KRÜGER/REINECKE, Kunstdenkmale, S.133.
} 
In acht Fällen sind Personen Empfänger (liturgischer) Kleidung. Das verwandtschaftliche Verhältnis zwischen Testator und bedachter Person ist lediglich dem Testament Heinrich Steinhagens zu entnehmen, in dem des Testators Schwester Hempeke mit dem weißen Bahrtuch bedacht wird, das als Chorkappe umgearbeitet werden soll. Alle anderen, nun ausschließlich männlichen Bedachten waren vermutlich Vikare oder/und Priester. Lediglich die Ordenszugehörigkeit erschien den Testatoren erwähnenswert; Heinrich vom Hove bezeichnet den von inm bedachten Gherd Huxer als Franziskaner, und Dietrich Junge Johann Schirwater als Dominikaner.

Ein Überblick über die Testamente zeigt die verschiedenen Arten der Vererbung: Die Testatoren setzen vorwiegend Geldbeträge - in der Spanne von 5 Mark bis 100 Mark - aus, um die Anschaffung liturgischer Kleider zu finanzieren.; dagegen schöpfen in vier Fällen (1339 Priester Leo, 1414 Johannes von Lippinghausen, 1441 Heinrich Tetendorp und 1478 Ludolf Mangard) Kleriker aus ihrem Kleiderfundus. Meßgewänder werden in Direktverfügungen oder in Folgeverfügungen, also nach der vorherigen Verwendung des Stoffs als Bahrtuch, vergabt. Sie können als Einzelstücke terminologisch bezeichnet oder summarisch, damit weder zähl- noch zuordenbar, vererbt werden.

Terminologisch bezeichnete liturgische Gewänder

Zunächst sollen die genau bezeichneten Gewänder näher beleuchtet werden. Zu den liturgischen Untergewändern zählen Amikt, Albe, Cingulum und Superpellicium.

Je ein Amikt vererben Johannes von Lippinghausen 1414, Henning von Bulten 1439 und Heinrich Winthe 1490. Bei diesem Kleidungsstück handelt es sich um ein Leinentuch in rechteckiger Form, das, mit Bändern am Körper befestigt, Hals und Schultern in Falten umhüllt ${ }^{163}$. Es wurde unter der Albe, einem langen weißen Leinenrock mit langen Ärmeln, getragen. Während des Untersuchungszeitraumes war es nicht unüblich, nach dem Ankleiden den Kopf mit dem Amikt bis zum Beginn des Gebets oder der Messe bedeckt zu lassen. Der offenbar in den Köpfen der-z.T. laikalen-Testatoren verankerte Eindruck der Zusammengehörigkeit von Amikt und Albe zeigt sich in der Tatsache, daß alle drei ein Amikt vererbenden Testatoren ebenfalls eine Albe als Legat aussetzen. Insgesamt werden von sechs Testatoren Alben vergabt (1414 Johannes von Lippinghausen, 1415 Gese Lübberstedt, 1439 Henning von Bulten, 1441 Heinrich Tetendorp, 1473 Metteke von Dassel und 1490 Heinrich Winthe).

Ein der Albe verwandtes Kleidungsstück ist das Superpellicium, ebenfalls weit und langärmelig, aus Leinen oder Baumwolle gefertigt, nach REINLEs auf der Durchsicht von

${ }^{163}$ J. WAGNER, ,Amikt“, in: LThK, Bd.1, Sp.438. 
Bilddokumenten beruhendem Urteil aber wohl weniger verziert als die Albe ${ }^{164}$. Das Superpellicium ist das einzige liturgische Kleidungsstück, das als bereits vorhandenes ausschließlich von klerikalen Testatoren aus ihrem Kleiderbesitz verteilt wird: Der Priester Leo wendet ein Superpellicium, bei dem es sich offensichtlich um ein eigenes handelt, einem gewissen Meyne zu. Johannes von Lippinghausen vererbt meum superpellicium novum, quod est in mea cista. Heinrich Tetendorp verfügt über zwei Superpellicien, die beide für denselben Empfänger gedacht sind; es handelt sich hier um suum album supellicium und um suum melius suppellicium cum almusio.

Von Johannes von Lippinghausen ist das einzige Testament überliefert, in dem ein cingulum lineum vergabt wird ${ }^{165}$; Lippinghausen bedenkt die Vikarie in St. Gertrud mit Leinenstoff für Albe und Amikt, mit dem bereits vorhandenen Leinengürtel, mit Büchern und anderern Notwendigkeiten. Die Gürtel der drei anderen Kleriker waren mit besonderem Besatz verziert. Zur Umarbeitung für Kelche sollen die Gürtel der Testatoren Leo (1339) und Hartwig Hannover (1484) genutzt werden, so daß es sich hier wohl um silberne Gürtel oder Gürtel mit silberner Schnalle gehandelt haben wird.

Die Almucia ${ }^{166}$ ist eine über die Ohren reichende Kapuze oder Mütze, deren Zweck es ist, Kopf und Ohren vor allem vor Kälte zu schützen. Sie entstammt ursprünglich dem geistlichen Bereich, und wird auch im Testament Tetendorps in diesem Kontext erwähnt. Diese Kapuze ist aus Wolle oder Fell gefertigt, es gibt aber auch Anfertigungen aus Seide. Im Spätmittelalter gibt es sie in schulterbedeckenden Ausführungen.

Sieben Testatoren vererben liturgische Obergewänder, wobei fünf Verfügungen über eine Kappe, und zwei Verfügungen über eine Kasel ausgefertigt werden (Kappe: 1408 Geverd Gropeshorn, 1415 Lüder Bardewik, 1430 Hans Junge, 1439 Heinrich Steinhagen, 1452 Heinrich vom Hove und 1476 Dietrich Junge; Kasel: 1439 Christian von Bergen und 1478 Ludolf Mangard). Lüder Bardewik, Heinrich Steinhagen und Dietrich Junge wünschen, daß die von innen vererbten cappae aus dem Stoff gefertigt werden sollen, der ihnen zunächst als Sargtuch dienen soll. Es handelt sich um weißen Stoff, um Seidentuch und um schwarzes Leidener Tuch. Heinrich vom Hove setzt 11 Mark für eine Kappe oder eine alternative Anschaffung aus. Hans Junge gibt für eine Chorkappe eine silberne Brosche im Wert von 4 Lüneburger Mark. Auch die von Christian von Bergen gewünschte Kasel soll aus einem vorher als Sargtuch Verwendung findenden Goldbrokat hergestellt werden. Ludolf Mangard vermerkt in seinem Testament, er habe die seinem Nachfolger zu

\footnotetext{
${ }^{164}$ A. REINLE, Die Ausstattung deutscher Kirchen im Mittelalter, Darmstadt 1988, S. 154

${ }^{165}$ U. REINHARDT, Testamente, Nr.103, S.142.

166 Über die Almucia als Teil klerikaler Gewänder s. A. REINLE, Die Ausstattung deutscher Kirchen im Mittelalter, S.162.
} 
übergebende bessere Kasel zusammen mit Zugehörigkeiten, Kelch und Patene aus Sichherheitsgründen in dem der Vikarie am St. Marienaltar/Lambertikirche zugehörigen Haus aufbewahrt ${ }^{167}$.

Als Meßgewand oder Priesterkleidung bezeichnete liturische Gewänder

Für die allgemeine Bezeichnung von liturgischem Gewand benutzen die Testatoren die Wörter gherwe, missewede, presterkleder, indumenta und ornat. Keinem exakt bestimmten Kleidungstypus zuzuordnen sind die folgenden Verfügungen:

Über gherwe verfügen Johann Hoyemann 1401, Ludolf von Hagen 1410, Henning von Bulten 1439 und Metteke von Dassel 1473. Dieser Begriff meint priesterliche Kleidung überhaupt oder das Meßgewand ${ }^{168}$. Auffallend ist in allen vier Fällen die Farbigkeit des Stoffs; die drei erstgenannten Testatoren wünschen den Ankauf eines guldene stucke, das zumindest bei Ludolf von Hagen zunächst als Sargtuch verwendet werden soll. Aus dem Testament Johann Hoyemanns ist ersichtlich, daß der Ankauf eines solchen, vermutlich sehr wertvollen Tuchstoffs nicht jederzeit möglich war: Nach seinem Tod soll ein gud guㅇlen stuํke gekauft werden, icht me dat hebben kan, ... ; es solle in jedem Fall dann gekauft werden, wenn es erhältlich sei, damit das gherwe angefertigt werden könne ${ }^{169}$. Metteke von Dassels gherwe soll aus roter Seide hergestellt werden. Die Kostbarkeit der Stoffe und der repräsentabel - auffällige Charakter der Farben deuten auf als Oberbekleidung getragene Priesterornate wie Kasel oder Pluviale hin.

Die Testamente zeugen von der äußerst praktischen Denkweise der Testatoren. Üppige goldene oder rote Gewänder waren hohen Festen oder Würdenträgern vorbehalten; Gold als Farbe göttlicher Herrlichkeit war für die Verwendung zum liturgischen Dienst geradezu prädestiniert, und dem Stadtbürger war ihr Tragen unter Strafandrohung untersagt ${ }^{170}$. Nicht zuletzt auch aus diesem Grund mag es für den Testator erstrebenswert gewesen sein, als Sargtuch einen derart kostbaren Tuchstoff übergelegt zu bekommen, zeigt er doch den Wohlstand, aber auch die Gläubigkeit des Verstorbenen. Hier bietet sich in gewissem Sinn für den Toten wahrlich die letzte Gelegenheit, noch einmal leibhaftig, wenn auch nicht mehr lebend, ein Legat ad pias causas vorzunehmen, indem das Sargtuch als liturgisches Gewand weiterbesteht, und - gerade wenn es von verwandten oder bekannten Klerikern getragen wurde - an den Spender erinnerte und seiner in den Gebeten oder vielleicht auch in stummem Gedenken gedacht wurde.

\footnotetext{
${ }^{167}$ Diebstahl von Vikariezubehör war nicht unüblich, wie das Beispiel eines zur Vikarie am Allerapostel - und Aldegundisaltar der Johanniskirche zugehörigen Breviers zeigt; vgl. M. STÄHLI, Die theologischen Handschriften (=Handschriften der Ratsbücherei Lüneburg, Bd.3), Wiesbaden 1981, S.16.

${ }^{168}$ SCHILLER - LÜBBEN, Mittelniederdeutsches Handwörterbuch, S.118.

${ }^{169}$ U. REINHARDT, Testamente, Nr.58, S.85.

${ }^{170}$ W. Fr. VOLGER, UB LG, Bd. III, S. 431 Polizeiverordnung von 1480.
} 
Auffällig ist, daß unter den terminologisch differenzierenden Testatoren die Hälfte Kleriker sind, während unter den zehn summarisch formulierenden Testatoren nur ein Kleriker zu finden ist. Laien waren demzufolge die exakten Bezeichnungen für die unterschiedlichen liturgischen Gewänder nur fallweise geläufig. 


\section{Mobiliar und textiles Zubehör}

Im Mittelalter gilt lediglich ein Teil der Möbel ${ }^{1}$ als mobil. Immobil sind jene Möbel, die in irgendeiner Form eine Verbindung mit der Wand aufweisen, sei es durch Einfügungen in Mauernischen oder Befestigungen an der Wand, aber auch Raumausstattungen, deren Schwere ein Bewegen unmöglich macht, wie es z.T. bei den Betten mit Betthimmel der Fall ist. Wenn Testatoren Häuser vererben, dann verfügen sie im Regelfall in gleichem Zug über die dem Haus zugehörigen immobilen Einrichtungsgegenstände. Möbel können auch unter den Begriff der Frauengerade (Bett und Truhe), den Begriff des Heergewäts (Bett) und den Begriff des Ingedomes (alle Gegenstände, die sich im Hausinneren befinden) fallen. Das bedeutet, in den Testamenten wird über weitaus mehr Raumausstattungen verfügt, als es die vorliegende Auswertung präsentieren kann.

Die Testatoren verfügen über Bett, Truhe, Tisch und Sitzgelegenheiten wie Stühle und Bänke. Sie decken damit in ihren testamentarischen Verfügungen das Möbelrepertoire ab, das die spätmittelalterliche „Wohnwelt“ im wesentlichen ausmacht. Diese im Vergleich zur heutigen Situation schmale Auswahl an Möbeln kann- je nach finanzieller Lage des Einzelnen - angereichert werden mit textilem Zubehör, dem angesichts der geringeren Möbelauswahl eine bedeutende Schmuckfunktion zukommt.

\section{a. Betten und ihr textiles Zubehör}

\section{Bett - Das Möbel}

Die Palette der Bettarten bietet im Spätmittelalter verschiedene Formen: Es gibt relativ hochliegende Betten mit hohen Pfosten, auch mit hochgezogenem Kopfende, wobei sich über der Bettkonstruktion ein aus mehr oder minder kostbarem Stoff gespannter Betthimmel ausdehnen kann. Die kraft ihrer festen Bauweise sehr großen und massigen Betten gelten als fest installiert, so daß sie als Immobilien im Regelfall nicht dem testamentarischen Erbgang unterliegen².

Die Schlafauflage kann in einiger Höhe angebracht sein, so daß sie nur über eine Tritthilfe den Bildwerken zufolge eine Bank oder Truhe ${ }^{3}$ - erreicht werden kann. Die Schlafhöhe wird begründet mit der effektiveren Nutzung der nach oben steigenden Wärme und einer

\footnotetext{
${ }^{1}$ Der Begriff „Möbel“ ist bezogen auf die Zeit des Untersuchungszeitraums anachronistisch, da er im 17. Jahrhundert aus dem Französischen übernommen wird.

${ }^{2}$ B. DENEKE, „Möbel“, in: Lexikon des Mittelalters, Bd.VI, Sp.700; P. BAUR, Testament und Bürgerschaft, S.230.

${ }^{3}$ Darstellung einer Bank als Tritthilfe bei H. WENTZEL, „Bett“, in: RDK, Bd. II, Abb.4 (=Großgmain, 1499), Sp.388.
} 
Ungezieferprävention ${ }^{4}$, wobei der Schutz vor Ungeziefern angesichts der Mobilität von Mäusen, Spinnen und Käfern nur ansatzweise gewährleistet ist. Der Freiraum unter dem Bett kann als Stauraum dienen. Hier stehen oftmals Rollbetten, die durch ihre mobile Eigenart als Gäste- oder Kinderbetten genutzt werden. Im Inventar der Margarete Grönhagen steht ein Rollbett im Saal im Obergeschoß des Hauses, der als Festsaal genutzt wird, unter einem Spannbett ${ }^{5}$. Rollbetten sind belegt im Testament der Geseke Leyferd 1485, die zwei dieser Betten einer verwandten oder bekannten Frau vererbt.

Neben den hoch angelegten Betten gibt es Betten in geringerer Höhe. Aus den Lüneburger Testamenten können keine Informationen hinsichtlich der Betthöhe gefiltert werden; nicht auszuschließen ist, daß mit der Bezeichnung „große Betten“ auch höhere gemeint sein können.

Aufgeführt werden in den Testamenten Bettgestelle, die die Testatoren als sponda oder spanbedde bezeichnen. Gemeint sind damit Betten, die zusammenlegbar sind und offenbar in bewußtem Gegensatz zu den installierten Bettgestellen als Tragbetten bezeichnet werden, gleichzeitig bezeichnet man so auch Betten, deren Rost aus einem Geflecht gespannter Seile oder Gurte besteht ${ }^{6}$. Offenbar garantiert die elastische Auflagefläche ein angenehmeres Liegen als es bei einer allein aus Brettern bestehenden Fläche der Fall gewesen wäre, obgleich es auch diese Art an Liegegrundlage gibt. Spannbetten werden von vier Testatoren in fünf Testamenten erwähnt (1385 Segeband von Thune, 1414 Johannes von Lippinghausen, 1424 Johannes von Lippinghausen, 1444 Cyeke Witting, 1499 Hilleke Blickershusen). Die Kleriker Segeband von Thune und Johannes von Lippinghausen hinterlassen acht bzw. drei Bettgestelle, während die beiden Testatorinnen je ein Spannbett vererben. Die Haushalte können also mit mehreren dieser Tragbetten ausgestattet sein. Empfänger sind in diesen Testamenten der Sohn oder ein Bekannter der Testatorin, während Johannes von Lippinghausen seine Bettgestelle Vikarien zuwendet, und Segeband von Thunes Testament sie lediglich auflistet.

\footnotetext{
${ }^{4}$ G. DIMT, Haus und Wohnung, in: A. HAVERKAMP, Haus und Familie in der spätmittelalterlichen Stadt, S.87.

${ }^{5}$ K. TERLAU - FRIEMANN, Lüneburger Patrizierarchitektur, S.88.

${ }^{6}$ „,span - bedde“: zusammenlegbares Bettgestell; Tragbette, in: SCHILLER - LÜBBEN, Mittelniederdeutsches Handwörterbuch, S.364. Im mittelhochdeutschen Sprachbereich verstand man unter dieser Bezeichnung darüberhinaus ein Bett, dessen Pfühl auf untergespannten Gurten liegt: LEXER, Mittelhochdeutsches Taschenwörterbuch, S.203. Eine ausführliche Beschreibung des spanbeddes als Bett mit elastischer Grundlage liefert denn auch WURMBACHs Auswertung Kölner Testamente sowie SCHWARZ, während die jüngere, von BAUR vorgelegte Auswertung Konstanzer Testamente spanbett als Tragbett übersetzt, obwohl es sich hier auch um den südlichen Sprachraum handelt. GROEBNER sieht in der Bezeichnung lediglich das Bettgestell beschrieben. E. WURMBACH, Das Wohnungs- und Bekleidungswesen des Kölner Bürgertums, S.27; D.W.H. SCHWARZ, Sachgüter und Lebensformen, S.48; P. BAUR, Testament und Bürgerschaft, S.231; V. GROEBENER, Ökonomie ohne Haus, S.246.
} 
Es kann nicht mit Sicherheit entschieden werden, was die Testatoren im Detail unter der Bezeichnung lectum oder bedde vererben. Mit dieser Formulierung erwähnen in 39 Testamenten 38 Testatoren insgesamt 106 Betten. Meinen die Testatoren das Bettgestell, das Bettzubehör oder beides ${ }^{7}$ ? Die Mehrzahl der Testamente listet neben der Erwähnung des beddes das weitere notwendige Zubehör auf: 27 Testamenten mit der 72mal auftretenden Vererbungsformel von Bett plus Zubehör stehen 12 Testamente mit der ausschließlichen Vererbung eines beddes in 34 Fällen gegenüber ${ }^{8}$. Folglich sind mit dem Begriff „Bett“ im Spätmittelalter - wie auch in der Gegenwart - verschiedene Konnotationen verbunden: gemeint kann das Bettgestell sein, aber auch eine Kombination von Gestell und Zubehör wie auch das Zubehör allein ${ }^{9}$.

Tabelle: Testamentarische Verfügungen über bedde/lectum

\begin{tabular}{|l|c|}
\hline Jahre & Anzahl an Testatoren und Betten \\
\hline $1326-1350$ & 1 Testator mit 1 Bett \\
\hline $1351-1375$ & 2 Testatoren mit 7 Betten \\
\hline $1376-1400$ & 2 Testatoren mit 16 Betten \\
\hline $1401-1425$ & 11 Testatoren mit 36 Betten \\
\hline $1426-1450$ & 11 Testatoren mit 17 Betten \\
\hline $1451-1475$ & 3 Testatoren mit 7 Betten \\
\hline $1476-1500$ & 8 Testatoren mit 22 Betten \\
\hline
\end{tabular}

Die insgesamt 106 in den Lüneburger Testamenten aufgelisteten Betten werden von 38 Personen vergabt, von denen acht Kleriker $\operatorname{sind}^{10}$ und 30 Laien, wobei sich mit einem Gemeinschaftstestament eines Ehepaares und einer Verteilung von 15 Frauen und 14

\footnotetext{
${ }^{7} \mathrm{v}$. BRANDT vermutet hinter dieser Formulierung ,die zahlreich vorhandenen und als ausgesprochene Wertgegenstände angesehenen Federbetten sowie die Kissen, große Pfühle und kleinere Kopf- oder Ohrkissen“. Dieser Auffassung schließt sich BAUR an. Eine andere Auffassung vertritt K. TERLAU - FRIEMANN, welche bette als Bett im Sinne von zugehörigem Gestell übersetzt. A. v. BRANDT, Mittelalterliche Bürgertestamente, S.24; P. BAUR, Testament und Bürgerschaft, S.230f; K. TERLAU - FRIEMANN, Lüneburger Wohnkultur des 16. Jahrhunderts, in: Raumkunst in Niedersachsen, hgg. v. R.-J. Grote und P. Königfeld, München 1991, S.90.

${ }^{8}$ Es sind die Testamente von Segeband von Thune 1385, Engelbrecht Hoke 1407, Tibbeke Remsnyder 1418, Johann Cloke 1422, Johannes von Lippinghausen 1424, Ernst Lauenstein 1439, Meister Heinrich 1441, Cyeke Witting 1444, Geseke Rosemberg 1472, Beke van Esche 1474, Dietrich Junge 1476 und Hilleke Blickershusen 1499.

${ }^{9}$ H. WENTZEL, „Bett“, in: RDK, Bd. II, Sp.383ff; D.W.H. SCHWARZ, Sachgüter und Lebensformen, S. 48 Erschwerend für eine Auswertung ist die Tatsache, daß für das Spätmittelalter in Norddeutschland weder Bettgeselle noch Textilien im Original erhalten sind. Hinweis bei H. APPUHN und J. WITTSTOCK,

Mittelalterliche Hausmöbel in Norddeutschland, in: Kat. „Aus dem Alltag der mittelalterlichen Stadt“, S.53.
} 
Männern eine ungefähre Gleichverteilung der Geschlechter abzeichnet. Anders als hier treten in niederösterreichischen Testamenten vorrangig Frauen als Donatoren von Bettenlegaten auf ${ }^{11}$.

Empfänger der testamentarisch verankerten Bettenlegate sind 41mal Verwandte, 37 Bettenlegate sind für Bekannte bestimmt. An Vikarien fallen vier Betten. Allerdings wird nur eines dieser vier Betten von einem Laien vererbt: Ernst Lauenstein bedenkt 1439 die von inm am Katherinenaltar in St. Johannis gegründete Vikarie. Die anderen Betten hinterläßt der Vikar Johannes von Lippinghausen. Die Betten gelangen also - pointiert formuliert - nur in testamentarischem Ausnahmefall an kirchliche Institutionen oder Stiftungen; sie verbleiben in überwiegendem Maße im familiären Umfeld des Testators und in (engerem) Freundeskreis. Der in etlichen Fällen wohl nicht unbeträchtliche Wert der Betten bedingt die vorrangige Vergabe an dem Testator nahestehende Menschen. Im Regelfall werden die an die eigenen Kinder fallenden Betten in den Testamenten nicht erwähnt, da sie als Familiengut dem außertestamentarischen Erbgang unterliegen. Nur unter besonderen Umständen finden die von Vätern an ihre Söhne zu vererbenden Betten Eingang in das Testament: Johann Hintbergen sichert in seinem 1406 errichteten Testament seinen Söhnen Hermann und Bernard je ein Bett für den Fall zu, daß seine zweite Frau ein Kind erwarte, dem dann ja das Heergewät zufiele ${ }^{12}$; Johann Beve wendet einem seiner Söhne 1367 im Rahmen der Abteilung testamentarisch eines seiner größten Betten nebst Zubehör sowie zwei vœghe Betten, also ein Doppelbett, $\mathrm{zu}^{13}$.

Einige der Bedachten sind zum Zeitpunkt der testamentarischen Schenkung bereits im Besitz des Bettes, so daß die testamentarische Verfügung einer gesetzlichen Sicherung des real existierenden Zustandes gleichkommt. Die Testatoren Dietrich Lembeke 1386, Johannes Lippinghausen 1414 und Geseke Rosemberg 1472 formulieren, ihre jeweilige Magd schliefe bislang auf dem Bett, während Immeke Burmeister die Annehmlichkeit des Bettes heraushebend vermerkt, ihr Knecht schlafe gut auf dem Bett. Neben diesen vier Bediensteten zugedachten Schenkungen steht eine Schenkung, in der Heinrich Uplegger 1414 seiner Frau das Bett vererbt, in dem sie bisher schlief, sowie die Schenkung Tibbeke Remsnyders aus dem Jahr 1418, mit der sie die Tochter eines Bekannten bedenkt. Schenkungen im Sinne einer Ausstattung enthalten die Testamente Geseke Schwertfegers 1425 und Czieke Blanks 1475: Geseke Schwertfeger stattet ihre Magd im Heiratsfall mit einem Bett aus. Dieses Geschenk kommt gleichermaßen dem Bräutigam zugute, da

\footnotetext{
${ }^{10}$ Der Vikar Johannes von Lippinghausen stellte zwei Testamente 1414 und 1424 aus.

${ }^{11}$ G. JARITZ, Österreichische Bürgertestamente, S.255.

${ }^{12}$ Das Heergewät fiel - regional unterschiedlich - entweder dem ältesten oder dem jüngsten Sohn zu. W. BUNGENSTOCK, „Gerade“, in: Handwörterbuch zur Rechtsgeschichte, Sp.1529 Für Lüneburg bedeutet das das Bedenken des jüngsten Kindes.

${ }^{13}$ U. REINHARDT, Testamente, Nr.26, S.33.
} 
entsprechende Betten ja durchaus zwei Personen Platz bieten konnten. Czieke Blank nun bedenkt ihre (halb? -) verwaiste Enkelin, das Kind ihrer Tochter; neben drei Pfühlen und einem kleinen Bett erhält die Enkelin auch jene zwei Betten, auf denen die Testatorin zu schlafen pflegt ${ }^{14}$.

Haben die Lüneburger Testamente schon die in österreichischen Bürgertestamenten erkennbare Frauenmajorität als Bettendonatorin nicht bestätigt, so fällt auf der Empfängerseite in Lüneburg ein Frauenanteil ins Auge, der mit 29 Bettenlegaten weitaus geringer ausfällt als der Männeranteil mit 49 Betten. Ein möglicher Erklärungsgrund könnte in der guten Absicherung der Frauen hinsichtlich des Möbels „Bett“ bestehen, wie sie durch die Bestimmungen der Frauengerade gewährleistet wird.

Die Testatoren haben ihre Legate nach unterschiedlichen Kriterien genauer bezeichnet, wobei ein oft genutztes Kriterium die Größe des Bettes ist. Mit einer Anzahl von acht Verfügungen werden entweder große/größere oder kleine/kleinere Betten vererbt. Das Testament des Segeband von Thune listet einen Posten mit sieben großen und kleinen Betten auf. Mittlere Betten werden viermal erwähnt. Die tatsächliche Größe eines Bettes kann nur erahnt werden: Für Köln ist eine Bettenbreite von $1,50 \mathrm{~m}$ bis maximal $1,80 \mathrm{~m}$ errechnet worden ${ }^{15}$, womit ein Richtwert angegeben ist, der bezogen auf die Bettenlänge für den nördlichen Bereich mit der im Spätmittelalter dort erreichten Körpergröße des Mannes von ca. $1,70 \mathrm{~m}$ angegeben werden $\mathrm{kann}^{16}$. Neben der Nennung eines quantifizierenden, vielleicht auch qualifizierenden Adjektivs ist es möglich, die Größe eines Bettes durch die Anzahl der stripen anzugeben ${ }^{17}$. Diese Bezeichnung richtet sich nach der Anzahl der Streifen des Leinwandtuches, das als Bettbezug dient und je nach Breite des Bettes eine mehr oder minder große Streifenanzahl aufweist. In Lüneburger Testamenten werden vier Betten als gestreifte bezeichnet, ohne daß eine Anzahl der Streifen genannt wird $^{18}$. Anders ist dies bei vier weiteren gestreiften Betten: Ernst Lauenstein erwähnt in seinem Testament 1439 ein Bett von 18 stripen und ein Bett von 24 stripen, Geseke Leyferd 1485 ein Bett von 24 stripen und Gesche Henning 1494 ein Bett von 18 stripen. Diese Art der Größenbemessung ist auch für Köln überliefert, wo ca. bis zu 15 stripen ein kleines Bett darstellen, während 22 stripen ein großes Bett meinen. Vermutlich können die

\footnotetext{
${ }^{14}$ Fraglich ist, was die Testatorin mit dieser Formulierung gemeint hat. Bezieht sie sich hier auf die Zweischläfrigkeit des Bettes, also vielleicht auf das, was dem heutigen Sprachgebrauch nach ein Ehebett ist, das von der verwitweteten Testatorin nun allein genutzt wird?

${ }^{15}$ E. WURMBACH, Das Wohnungs- und Bekleidungswesen des Kölner Bürgertums, S.26.

${ }^{16}$ H. WURM, Körpergröße und Ernährung der Deutschen im Mittelalter, in: B. HERMANN (Hg.), Mensch und Umwelt im Mittelalter, Wiesbaden 1996, S.103.

${ }^{17}$ E. WURMBACH, Das Wohnungs- und Bekleidungswesen des Kölner Bürgertums, S.26, 51, nach deren Informationen sich die Darstellung richtet.

${ }^{18} 1385$ Segeband von Thune, 1414 Johannes von Lippinghausen.
} 
kleinen Betten nur einen Schlafenden aufnehmen, während die Betten mit minimal 15 stripen mehrschläfrige sind. Das würde bedeuten, daß die in den Lüneburger Testamenten mittels der stripen bezeichneten Betten zu den größeren Betten gezählt werden müssen. Eine weitere Möglichkeit der Deskription der Bettenlegate bietet sich in dem Maßstab der Güte. Nur das Testament des Vikars Heinrich Tetendorp aus dem Jahr 1441 verzeichnet ein Bett als ein besseres. Vier Betten werden von den Testatoren Grete von dem Wede 1422, Adelheid Kolse 1430, Klaus und Grete von Wening 1444 und Beke von Esche 1474 als zweitbeste tituliert, wobei die Formulierung die Bemessung an der Frauengerade bzw. dem Heergewät erkennen läßt. Die in Lüneburg 1481 kodifizierten Bestimmungen hinsichtlich einer Ausstattung mit Bett und Bettzubehör umreißen zwar im wesentlichen die aufgeführte „Prototypausstattung“ eines Bettes mit einem Paar Laken, einem Pfühl, einem Kopfkissen, einer Decke sowie einem Bettgestell, unterscheiden jedoch bei Frauengerade und Heergewät zwischen der erforderlichen Ausstattung hier mit den je besten Stücken, dort mit den je zweitbesten Exemplaren ${ }^{19}$. Die gesetzlichen Bestimmungen über die Grundausstattung des Haushalts spiegelt die Bedeutung des „Bettes“ wider und deutet gleichzeitig auf die besondere Rolle hin, die die Frau bei der außertestamentarischen Tradierung dieses Sachgutes einnimmt.

Die Testamente Heinrich Steinhagens 1439, Vicke Bottermanns 1476 und Dietrich Junges 1476 enthalten Hinweise auf einen Handel mit Betten. Steinhagen weist seine Testamentsvollstrecker an, vom Erlös seines Bettes und des Pfühls sein Begräbnis zu finanzieren. Dietrich Junge wünscht, daß seine Seelenmessen vom Verkauf seines größten Bettes finanziert würden. Über den Ankauf von zwei Betten und zwei Pfühlen berichtet das Testament Vicke Bottermanns aus dem Jahr 1476. Es muß also in Lüneburg einen Markt für gebrauchte Betten gegeben haben. Ebenso wie für Kleider gibt es einen „second hand“ - Markt für Betten und Bettzeug; insofern ist es nicht verwunderlich, daß der Beruf des Gebrauchtbettenhändlers oft mit dem des Altkleiderhändlers einhergeht ${ }^{20}$.

Textiles Zubehör: Laken, Polster, Kissen und Decken

\section{Laken}

\footnotetext{
${ }^{19}$ Die Frauengerade umfaßt: ,,ere beste bedde mit dem besten hovetpole ere besten twe orkussen ere beste par lakene ere besten dekene“, während das Heergewät aus „,eyn bedde neghest dem besten enen pol en kussen twe laken neghest den besten ene kolten neghest der besten" besteht. W.F. VOLGER, UB Lüneburg Bd.III, S.435f. ${ }^{20}$ P. ARIES und G. DUBY (Hg.), Geschichte des privaten Lebens, Bd. II, Frankfurt a.M. 1990, S.456.
} 
In das Bettgestell eingelegt ist eine Matratze ${ }^{21}$ in der Form eines Strohsacks. Über diesem Strohsack kann ein Unterbett liegen ${ }^{22}$. Vielleicht beschreibt Johannes von Lippinghausen ein solches, hier mit gestreiftem Stoff versehenes Unterbett mit der Formulierung lectum meum stripaticum super stropodio - immerhin gleicht diese Ausdrucksweise derjenigen, mit der das für Kaiser Friedrich III 1470 auf der Nürnberger Burg gerichtete Unterbett beschrieben wurde, nämlich als „zwei Federbetten über dem Strohsack“23. Über diese Unterlage wird das Laken gebreitet. Laken werden von den Testatoren beschrieben als paria lintheaminum oder als par laken. Über die Nutzung dieser sichtlich zusammengehörigen zwei Lakentücher gibt es unterschiedliche Angaben: Angenommen wird, daß eines der Laken als Bedeckung der Bettunterlage verwendet wird, das andere als „Ueberschlagbettuch für eine Woll - oder Pelzdecke“, aber auch die zur Erzielung einer bestimmten Breite zusammengenähten Laken könnten so bezeichnet worden $\operatorname{sein}^{24}$. Für die zuletzt genannte Verwendungsart spricht die unbestreitbare Notwendigkeit des Zusammensetzens zumindest zweier Stoffbahnen angesichts der möglichen Bettbreite, während der praktische Nutzen der erstgenannten Verwendung der Laken sich angesichts der Tatsache ermessen läßt, daß Betten „über mehrere Generationen hin benutzt“ wurden „- in Zeiten, die von einer chemischen Reinigung noch nichts wußten““25.

Über 59 Paar Laken verfügen drei Klerikertestamente des 14. Jahrhunderts und 18 Testamente des 15. Jahrhunderts. Angefertigt werden die einundzwanzig Testamente von zwanzig Testatoren ${ }^{26}$; dreizehn Testatoren sind Männer, darunter befinden sich fünf Kleriker, und sieben Testatoren sind weiblichen Geschlechts. Pro Testament werden ein bis drei relevante Verfügungen aufgelistet, wobei pro Verfügung im Regelfall ein oder zwei Paar Laken erwähnt werden, aber auch schon einmal vier oder sechs Paar Laken gemeint sein können. Die Laken bestehen aus Leinen. Hinsichtlich der Qualität hat es Unterschiede

\footnotetext{
${ }^{21}$ Seit dem 15. Jahrhundert übliche Bezeichnung für „Bettpolster, federnde Bettunterlage“. Das Wort ist aus dem Arabischen übernommen und bedeutet eigentlich „Ort, wohin etwas geworfen oder gelegt wird; Bodenkissen“. Etymologie, Duden Bd.7, Mannheim 1989/2, S.445.

${ }^{22}$ Eine allein mit Daunen gefüllte Matratze, wie HUNDSBICHLER sie als Alternative zur Strohmatratze erwähnt, scheint aufgrund der Weichheit und Wert des Materials im Vergleich zur Strohmatte doch recht selten. H. HUNDSBICHLER, Wohnen, in: H. KÜHNEL (Hg.), Alltag im Spätmittelalter, S.267.

${ }^{23} \mathrm{H}$. HUNDSBICHLER, ebd. Es geht hier - um das noch einmal zu betonen - allein um einen Vergleich der Formulierungsweise. U. REINHARDT, Testamente, Nr.103, S.143.

${ }^{24}$ E. WURMBACH, Das Wohnungs- und Bekleidungswesen des Kölner Bürgertums, S.51; J. ZANDER SEIDEL, Textiler Hausrat, S.343, auch S.351. Sie deutet die paarweise auftretenden Laken als Utensilien für die zweischläfrigen Betten.

${ }^{25}$ H. BOOCKMANN, Leben und Sterben, S.24. Über die großangelegte Reinigung von Bettwäsche im 16. Jahrhundert, das im Vergleich zum 15. Jahrhundert kaum veränderte Verhältnisse aufgewiesen haben wird, berichtet U. DIRLMEIER, Alltag, materielle Kultur, Lebensgewohnheiten im Spiegel spätmittelalterlicher und frühneuzeitlicher Abrechnungen, in: Mensch und Objekt im Mittelalter und in der frühen Neuzeit. LebenAlltag-Kultur (=Österreichische Akademie der Wissenschaften, Philosophisch-Historische Klasse, Sitzungsberichte, Bd. 568, Veröffentlichungen des Instituts für Realienkunde des Mittelalters und der frühen Neuzeit, Bd.13), Wien 1990, S.170.
} 
gegeben, die sich in den Lüneburger Testamenten aber kaum durch qualifizierende Angaben der Testatoren greifen lassen ${ }^{27}$; lediglich das Testament Immeke Burmeisters aus dem Jahr 1419 konkretisiert ein Paar Laken als aus Bleckede stammendes Laken. Dieses aus der unmittelbaren Umgebung Lüneburg stammende Tuch ist als ein günstigeres anzusehen, nicht zuletzt wegen des - im Vergleich zu anderen Tucharten - kürzeren Transportweges. Von teureren oder eben kostbareren Leinenlaken geben die Lüneburger Testamente keine Kunde - im Gegensatz zu den Konstanzer Testamenten, in denen durchaus „ein kölnisches Bett“ vererbt wird ${ }^{28} .31$ Paar Laken werden an Familienmitglieder vererbt, 17 Paar Laken an Bekannte. Acht Paar Laken werden in den Testamenten aufgelistet, ohne daß ein genauer Verwendungszweck oder ein Empfänger angegeben wird. Drei Paar Laken fallen an Vikarien, allerdings wurden diese Laken von einem Kleriker vererbt.

\section{Polster}

Unter diesem Begriff zusammengefaßt sind mehr oder minder breite Polsterkissen, die in den Rückenbereich des Ruhenden gelegt wurden, um eine erhöhte Liegeposition zu erzeugen, die fast schon als eine Art von Sitzen beschrieben werden kann. Das Einschätzen dieser Ruheposition teilt der Vikar Johannes von Lippinghausen in seinem aus dem Jahr 1414 stammenden Testament mit, in dem er im Rahmen einer Verfügung über ein Bett und sein Zubehör 10 cussinis sedilibus mediocribus dictis puste verzeichnet ${ }^{29}$. Allerdings beginnt im 15. Jahrhundert der Sitzwinkel flacher zu werden, so daß einige Betten eine zunehmend horizontale Liegefläche bieten können ${ }^{30}$. Je nach Breite des Bettes und gewünschter Liegehöhe variiert die Anzahl an Polstern.

Die Testatoren nennen den Pfühl pulvinar, pole oder puste ${ }^{31}$. Die als pulvinar oder pole bezeichneten Polster kommen im Regelfall in den Testamenten in einer Anzahl von einem oder zwei vor, selten sind es mehr, während die als puste registrierten Polster durchweg in höherer Anzahl bis zu maximal 15 puste in einem Testament erwähnt werden. Auffallend ist, daß etliche der über eine Gruppe von puste verfügenden Testatoren Laien sind,

\footnotetext{
${ }^{26}$ Der Vikar Johannes von Lippinghausen errichtete 1414 und 1424 ein Testament. Im folgenden wird nur noch erwähnt, wenn von einem anderen Testator als von Johannes von Lippinghausen zwei Testamente vorliegen.

${ }^{27}$ In Köln gibt es Hinweise über Qualitätsunterschiede. E. WURMBACH, Das Wohnungs- und Bekleidungswesen des Kölner Bürgertums, S.51.

${ }^{28}$ P. BAUR, Testament und Bürgerschaft, S.231. Über das Kölner Leinen informiert E. WURMBACH, Das Wohnungs- und Bekleidungswesen des Kölner Bürgertums, S.51

${ }^{29}$ U. REINHARDT, Testamente, Nr.103, S.143.

${ }^{30} \mathrm{H}$. WENTZEL, „Bett“, in: RDK, Bd. II, Sp.386.

${ }^{31}$ „,pol, pole“: SCHILLER - LÜBBEN, Mittelniederdeutsches Handwörterbuch, S.281 = Pfühl, pulvinar; „Pust“: SCHILLER - LÜBBEN, Mittelniederdeutsches Handwörterbuch, S.287 = Polster, gepolstertes, gestopftes Kissen (von Leder etc.).
} 
während sich sonst die Klerikertestamente als Horte besonders vieler gleichartiger Sachgüter hervortun.

Anzunehmen ist, daß zwischen pol und puste zwar kein prinzipieller, aber doch ein gradueller Unterschied hinsichtlich der Größe besteht. Der Nennungshäufigkeit nach zu urteilen, handelt es sich bei pole um ein breiteres, vielleicht auch längeres Polster, während puste ein dementsprechend kleineres Polster ist. Im folgenden werden die beiden Arten an Polstern zum Zweck der besseren Übersichtlichkeit unter dem Oberbegriff Polster zusammengefaßt.

Für den Untersuchungszeitraum liegen 30 von 29 Testatoren errichtete Testamente mit relevanten Verfügungen vor. Insgesamt werden 141 Polster vererbt ${ }^{32}$. Unter den Erblassern befinden sich 18 Männer, davon gehören fünf dem Klerikerstand an. Polster werden im 14. Jahrhundert testamentarisch vererbt, allerdings in nur wenigen Testamenten ${ }^{33}$. Im 15. Jahrhundert erscheinen sie in den Testamenten mit annähernd kontinuierlicher Verteilung. Auffällig ist, daß die Mehrheit der Polster in Verbindung mit einem Bett vererbt wird; 118 auf diese Weise vererbten Polster stehen 23 Polster gegenüber, die ohne Bett tradiert werden. Diese aus den Testamenten ersichtliche enge Zusammengehörigkeit weist darauf hin, daß die Testatoren Polster als notwendiges Zubehör ansehen. Die Testatoren beschreiben ihre Polster in seltenen Fällen mit erklärenden Adjektiven; entweder gibt es kaum auffällige Unterschiede zwischen den Polstern oder die deutliche Zugehörigkeit zu einem bestimmten Bett macht jedes weitere Beschreiben überflüssig. Ein sich aus der Menge der Verfügungen heraushebendes Polster hinterläßt Segeband von Thune, der sozusagen über eine Bettgarnitur aus grüner Seide verfügt. Er besitzt sowohl ein maius pulvinar viride sericum als auch eine lodicem .. sericam viridis coloris ${ }^{34}$. Eine Farbgleichheit von Polster und Decke ist offenbar nicht so unüblich, zeigt doch auch das Wochenbett der Anna am Hauptaltar der Johanniskirche zu Lüneburg (Heinrich Funhof 1483) eine in mattem Rot gehaltene Kombination, wobei die mit Goldfaden durchwirkte Decke auf den besonderen Wert verweist. In seinem Testament nun splittet der Archidiakon von Bevensen die wertvolle Kombination auf, indem er das Polster einer Bekannten zudenkt, während die Decke als schmückendes Beiwerk in der Kirche zu Verden Verwendung finden soll. Dieser in den Lüneburger Testamenten selten beschriebene Eindruck von der Farbigkeit und dem Material wird erzeugt durch den äußeren Bezug des Polsters. Zehn Polsterbezüge hinterläßt 1443 Klaus Schmied seinen Töchtern; Angaben zu Material oder Farbigkeit enthält das Testament nicht. Durch die Bildwerke des Spätmittelalters und ein erhaltenes

\footnotetext{
${ }^{32}$ Wenn die Zahl auch annähernd den in den Testamenten erfaßten Bestand wiedergibt, so bleibt sie doch eine geschätzte Zahl, da einige Testatoren von ihren Objekten ohne Zahlenangabe im Plural sprechen oder ein Bett nebst Zubehör auflisten. In diesen Fällen wird von einer Anzahl von je zwei Polstern ausgegangen.

${ }^{33}$ um 1340 Thideke Buhof, 1367 Mai 15 Johann Beve und Segeband von Thune 1385 Mai 18
} 
Exemplar aus dem Jahr 1596 ist bekannt, daß die Hüllen mittels eines Schlaufenverschlusses zusammengehalten werden ${ }^{35}$. Die Bildwerke zeigen die Bezüge als weiße, karierte oder gestreifte; blaugestreifte oder kariertes Leinen ist als Kölner Leinwand bekannt und als aus Köln stammendes auch wertvoll, wobei zu fragen bleibt, inwieweit regionale Tuchzentren Leinwand in der Kölner Machart nachzuproduzieren in der Lage $\operatorname{sind}^{36}$. Die Witwe Geseke Leyferd hinterläßt der Tochter einer Bekannten den poel, da de stripen entlangk gan, dazu passend ist offenbar das ihr ebenfalls vererbte Bett von 24 stripen $^{37}$. Ihrer Magd Wobbeke hinterläßt die Testatorin den kleinsten poel, de myt liikdoke betogen is ${ }^{38}$. Geseke Rosenberg vererbt 1472 ihr krusenades puste, also ein Polster, dessen Naht mit Kreuzstichen verziert ist ${ }^{39}$. Natürlich - aber doch vergleichsweise selten, nämlich bei nur vier Polstern - unterscheiden die Testatoren sie hinsichtlich ihrer Größe, auch wird differenziert als bestes, nächstbestes oder zweitbestes Polster.

66 Polster fallen an Familienmitglieder der Testatoren, 39 Polster an Bekannte, unter denen sich zwei Knechte und acht Mägde befinden. 12 Polster fallen an Vikarien, allerdings werden alle von dem Vikar Johannes von Lippinghausen vererbt. Zur Finanzierung seines Begräbnisses will Heinrich Steinhagen 1439 neben anderem Bettzubehör auch seine Polster verkauft wissen. Insgesamt gesehen läßt sich auch hier wieder die vorrangige Vergabe an Familienmitglieder beobachten, während Zuwendungen für Vikarien kaum vorkommen.

\section{Kissen}

Neben den Polstern erwähnen die Testatoren kussen, hovetkussene, wangenkussen, hovetpole und cussionos capitis ${ }^{40}$. Ins Auge fällt, daß bis in die 70 er Jahre des 15. Jahrhunderts der Begriff hovetpole oder hovetkussen bevorzugt wird, während ungefähr seit dieser Zeit der Begriff wangenkussen überwiegt. Ob es sich hier um einen Zufall oder den Ausdruck eines (nicht nur sprachlichen?) Wandels handelt, vermag allein auf der

\footnotetext{
${ }^{34}$ U. REINHARDT, Testamente, Nr.45, S.60f.

${ }^{35}$ Beispiel einer bildlichen Darstellung wieder eine Wochenstube der Anna, diesmal aus Ulm, aus dem Marienaltar des Ludwig Schongauer, um 1475, in: H. BOOCKMANN, Die Stadt im späten Mittelalter, Abb. 98, S.65. Im Germanischen Nationalmuseum befinden sich u.a. zwei Paar Kissenbezüge aus dem Jahr 1596, zuletzt abgebildet bei J. ZANDER - SEIDEL, Textiler Hausrat, Abb.290, S.344.

${ }^{36}$ Über dieses Übernehmen bekannter und beliebter Tucharten durch regionale Tuchbezirke berichtet $\mathrm{H}$. AMMAN, Deutschland und die Tuchindustrie, S.73f.

${ }^{37}$ U. REINHARDT, Testamente, Nr.270, S.427.

${ }^{38} \mathrm{ebd}$.

${ }^{39}$ U. REINHARDT, Testamente, Nr.237, S.354.

${ }^{40}$ Es ist durchaus möglich, daß z.B. ein mittelgroßes Polster in den Augen eines Testators ein puste war und in denen eines anderen ein kussen. So soll die hier vorgenommene Unterteilung in Polster und Kissen keine absolute sein - immerhin drückt sich das Verbundensein in Wörtern wie pole und hovetpole aus -, sondern sie ist als Hilfsmittel zur genaueren Auswertung gedacht, die sich hier nach den von den Testatoren gewählten Begriffen richtet.
} 
Grundlage der hinsichtlich dieser Fragestellung für das Ende des 15. Jahrhunderts spärlich vorhandenen Lüneburger Testamente nicht geklärt werden.

Die kleiner als die Polster ausfallenden Kissen liegen auf den Polstern. Es gibt allerdings unterschiedlich große Kissen, deren jeweils kleinste obenauf liegen und als Kopf- oder Wangenkissen als Unterlage des Kopfes dienten.

18 Testatoren stellen 19 Testamente aus, in denen über 59 Kissen verfügt wird. Unter den Testatoren befinden sich acht Frauen und zehn Männer, davon sind vier Kleriker. Die gemeinsame Verwendung von Kissen und Polster in einem Bett spiegelt sich in neun Testamenten wider, in denen über beide Utensilien verfügt wird.

Aufgrund der Zweischläfrigkeit vieler Betten werden etliche Kissen in einer Zweierzahl vererbt, wobei ausschließlich bei den wangenkussen die Zusammengehörigkeit durch die Formulierung eyn par wangenkusse $n^{41}$ hervorgehoben wird.

Pro Testament können schon einmal bis zu sechs Kissen aufgelistet werden, wobei im Regelfall aber nur je zwei an einen Erbnehmer fallen.

Mit dem Kriterium der Größe unterscheidet allein die Testatorin Geseke Leyferd 1485 ihre Erbstücke, indem sie ein kleineres von einem größeren Paar Wangenkissen absetzt. Ebenfalls ein Einzelfall ist die Einordnung seiner Kopfkissen als gute bzw. bessere, die Johannes von Lippinghausen 1414 vornimmt.

Die oben bereits thematisierte Verwendung der Kissen sozusagen als oberste Lage des Polster- und Kissenberges ermöglicht den Kopf- oder Wangenkissen eine Repräsentativfunktion. So führen die Berner Testamente „Kissen mit gewirkten und gestickten Familienwappen oder mit bildlichen Darstellungen“ auf, die in den Häusern der Wohlhabenden gleichsam als Modeartikel Einzug halten ${ }^{42}$. Auch in den Lüneburger Testamenten des ausgehenden 15. Jahrhunderts werden Kissen vergabt, die von besonderem Wert zeugen. Die Testamente Beke von Esches 1474, Luteke Nyeburs 1481 und Nickel Wulfferams 1483 drücken diesen Wert über die Angabe des Materials, nämlich Seide, aus. Geseke Leyferd beschreibt in ihrem 1485 errichteten Testament das Aussehen des kleinsten Paares Wangenkissen als dasjenige, dar dat rode Arressche vorghesettet $i s^{43}$. Das zweite Paar Wangenkissen der Geseke Leyferd wird charakterisiert als das Kissen, dar dat grone tom ende is ${ }^{44}$. Bei beiden Kissen handelt es sich um (vielleicht zum Grundton des Kissens in Kontrast stehende) Farben, die als Zierde des Kissens verwendet werden, wobei auch das verwendete Material - wie das Beispiel des Stoffs aus Arras zeigt eine wertsteigernde Funktion besitzt. Als Füllung der Kissen kommen Daunen in Frage; als

\footnotetext{
${ }^{41}$ z. B. im Testament der Geseke Leyferd 1485 Jan. 31.

${ }^{42}$ U.M. ZAHND, Spätmittelalterliche Bürgertestamente, S.66.

${ }^{43}$ U. REINHARDT, Testamente, Nr.270, S.427.

${ }^{44}$ ebd.
} 
Beleg gibt es in Lüneburg lediglich das Testament der Grete von der Heide aus dem Jahr 1444, das eine Verfügung über vier Daunenkissen enthält.

Als Erbnehmer sind fast in gleichem Maße Familienangehörige und Bekannte mit einem Zahlenverhältnis von 22 Kissen zu 23 Kissen zu verzeichnen. Sieben Kissen fallen dabei an Mägde, ein Kissen an einen Knecht.

\section{Decken}

In 20 Testamenten verfügen 19 Testatoren über 51 Decken. Die Gruppe der Testatoren setzt sich - abgesehen von einem Ehepaar, das ein Gemeinschaftstestament errichtete aus sechs Frauen und zwölf Männern, darunter fünf Klerikern, zusammen. Aus dem 14. Jahrhundert stammen vier relevante Testamente, während die restlichen des 15. Jahrhunderts annähernd kontinuierlich über das Jahrhundert verteilt sind.

Als Empfänger von Decken nennen die Testatoren 20mal Familienmitglieder und 14mal Bekannte. Drei Decken fallen an Vikarien, zwei sollen dem Kirchenschmuck dienen. 12 Decken werden ohne Angabe des weiteren Verbleibs in den Testamenten aufgelistet.

Die verwendeten Bezeichnungen hießen lodice, dekene, in nur einem Fall kolte und ab 1480 wird deckebedde verwendet. Gemeint ist eine wohl von einem leinenen Überschlaglaken geschützte Decke. Die Bettdecken können mit Federn gefüllt oder aus einem Wollgewebe gefertigt $\operatorname{sein}^{45}$. Bettdecken sind annähernd die einzigen Gegenstände, für die reine Wolle im Bereich der Wohntextilien verwendet wird ${ }^{46}$. In den Testamenten Lüneburgs gibt es bezogen auf den Untersuchungszeitraum nur das Testament des Meisters Heinrich aus dem Jahr 1441, in dem eines von zwei seiner besten Federbetten vergeben wird. Auch in Köln werden Federbetten selten aufgelistet, woraus geschlossen wurde, daß im Winter ein entsprechender „Bedarf an Pelzdecken“ geherrscht haben müsse ${ }^{47}$. Federbetten sind als Kälteschutz optimal geeignet, während die aus Wolle oder Seide gefertigten Decken in Abstufungen entsprechend weniger diesen Zweck erfüllen und entsprechend mehr als Symbol des Wohlstandes dienen. Aus Seide gefertigte Decken werden sechsmal erwähnt, wobei alleine fünf im Testament des Segeband von Thune aufgelistet werden, während die sechste ebenfalls aus einem Testament des 14. Jahrhunderts, nämlich dem des Johann Beve aus dem Jahr 1367, stammt. Der Wert und auch die nicht greifbare Schönheit der Seidendecken von Thunes, deren eine von grüner Farbe ist, spiegelt sich in der Bestimmung der Empfänger: Die Decken sollen verwendet werden als Schmuck der Kirchen in Verden und Minden. Beide Testatoren erweisen sich

\footnotetext{
${ }^{45}$ H. D. LOOSE, Leben und Kultur, S.8.

${ }^{46}$ E. WURMBACH, Das Wohnungs- und Bekleidungswesen des Kölner Bürgertums, S.54.

${ }^{47}$ E. WURMBACH, Das Wohnungs- und Bekleidungswesen des Kölner Bürgertums, S.57.
} 
durch den Gesamtinhalt ihrer Testamente als wohlhabende Männer, und beide nennen ihre Seidendecke bzw. -decken, weil sie sich in gewissem Sinn dazu verpflichtet fühlen: Für den ehemaligen Ratsherrn und Bürgermeister Johann Beve geht es um die durch die Verankerung im Testament optimal zu sichernde Abteilung seines Sohnes Hartwig, und für den Archidiakon von Bevensen, Segeband von Thune, bedeutet die inventarähnliche testamentarische Auflistung seiner Güter eine Sicherung der Erbmasse. Das bedeutet im Regelfall die außertestamentarische Vererbung von Seidendecken, was möglicherweise das Fehlen von Seidendecken in den Testamenten des 15. Jahrhunderts erklärt.

Das erwähnte Testament des Segeband von Thune ist das einzige, das einen Einblick in die Angebotspalette an unterschiedlichen Decken gewährt: Neben den Seidendecken stehen zwei weiße Decken, drei schlichte Tuchdecken sowie eine rauhe oder schmucklose. Insgesamt betrachtet überwiegen die einfacheren Decken. Die Kombination von einigen wenigen Spitzenprodukten und mehreren einfacheren Decken spiegelt den Bestand eines wohlhabenderen Haushalts wider. Angesichts der Palette an möglichen Deckenausfertigungen sind die Qualifizierungen der Decken als beste (Luteke Nyebur 1481 und Heinrich Winthe 1490), bessere (1414 Johannes von Lippinghausen) und nächstbeste (1444 Klaus und Grete von Wening) durchaus relativ, obgleich in den Testamenten schon Decken besserer Qualität vergeben werden.

Die einzige, eine Decke betreffende Farbangabe enthält das Testament Heinrich Winthes, in dem eine der besten Decken als rote identifiziert wird. Die rote Decke, die Heinrich Funhof auf dem Bildnis Annas als Wöchnerin im Altar der Johanniskirche darstellte, ist artverwandt mit den oft in schlicht geometrischem Streifenmuster gehaltenen Nürnberger Decken, die aufgrund eines angemessenen Preisniveaus als „Gebrauchsware für die tägliche Benutzung" großen Absatz finden ${ }^{48}$. Die sydenen kolten hat Johann Beve die in seinem Testament erwähnte Decke genannt; mit dieser Bezeichnung ist eine Decke besserer Machart gemeint, bei der es sich um eine gefütterte Steppdecke gehandelt haben muß ${ }^{4950}$. 1441 vererbt Hermann Kruse, Sülfmeister, Ratsherr und Bürgermeister, seiner Tochter eine Vlameschen tzarten efte dekene, eine aus wertvollstem Wollgewebe aus Arras stammende Bettdecke ${ }^{51}$. Die Beispiele Johann Beves und Hermann Kruses zeigen, daß nur sehr reiche Bürger sich entsprechend kostbares Bettzubehör leisten können.

\footnotetext{
${ }^{48}$ J. ZANDER - SEIDEL, Textiler Hausrat, S.349.

${ }^{49}$ U. REINHARDT, Testamente, Nr.26, S.33.

${ }^{50}$ Übersetzung nach LEXER, Mittelhochdeutsches Taschenwörterbuch, S.118.

${ }^{51}$ U. REINHARDT, Testamente, Nr.200, S.282. „sarte, tzarthe“: SCHILLER - LÜBBEN, Mittelniederdeutsches Handwörterbuch, S.316 = wollene Bettdecke; mhd. serge, frz. sarge. L. C. EISENBART, Kleiderordnungen, S.128, versteht unter „Sarsche, Sarge“ einen leichten, geköperten Wollstoff, der mit Seide oder Leinen gemischt ist. Über die Bedeutung der Wollstoffe aus Arras siehe J. ZANDER - SEIDEL, Textiler Hausrat, S.398.
} 


\section{Schlußfolgerungen}

Die testamentarischen Verfügungen über Betten und ihr Zubehör zeigen die unter dem Stichwort Bett zu subsumierenden Sachgüter als eine speziell im Familienkreis vererbte Gruppe. Aus diesem Testierverhalten ist der Wert ableitbar, den die Bettutensilien zweifelsohne gehabt haben. Wenn auch bei weitem nicht ein Jeder ein eigenes Bett besaß, so gilt es doch festzuhalten, daß bei Vorhandensein aber selbst die Betten ärmerer Menschen nicht als billige angesehen werden können ${ }^{52}$. Die Frage, warum man denn bereit ist, für das Bett je eine nicht unbeträchtliche Summe zu investieren, kann wohl am besten mit dem Verweis auf den Gebrauchswert beantwortet werden, denn die Betten sind eines der wesentlichen Möbelstücke des täglichen Lebens. Wer es sich leisten konnte, der stattete seine Betten mit besonders wertvollem Zubehör wie Seidendecken oder verzierten Kissen aus. Die Lüneburger Luxusgesetze versuchten, wie an ihrer detaillierten Auflistung von (Goldbrokat-) Bettzubehör zu erkennen ist, den hier offensichtlich übermäßig betriebenen Aufwand zu unterbinden oder wenigstens doch an inm durch das Bußgeld, das zweifelsohne als eine Art Luxussteuer zu begreifen ist, mitzuverdienen. Da Betten „als besonders kostspielige Textilien den Kern der mobilen Habe" bilden, entspricht die immer wieder beschworene Spitzenposition hinsichtlich der Quantität an testamentarischen Vergabungen einer gewissen inneren Logik, der die Lüneburger Testatoren - wie die Hamburger, Lübecker, Konstanzer, Wiener und Berner - folgen ${ }^{53}$. Innerhalb der Empfängergruppe bekannter Personen befindet sich eine Anzahl von Bediensteten, auch dieses findet sich in den Testamenten anderer Städte, allerdings in z.T. stärkerem Maße als in Lüneburg. Die Zuwendungen an Mägde und/oder an Mädchen sowie junge Frauen in der Verwandt -oder Bekanntschaft läßt sich ohne weiters als eine Art z.T. freiwilliger Ausstattung interpretieren, wobei die Lüneburger Testamente eindeutig darauf hinweisen, daß es auch besitzsichernde Schenkungen gibt, nämlich dann, wenn - in heutiger Terminologie gesprochen - eine Erbnehmerin das Bett bereits besitzt, aber noch kein Eigentumsrecht daran hat.

Den testamentarischen Verfügungen über Betten wird eine gewisse „Frauenspezifik“ nachgesagt, worunter die vorrangige Vergabe von Frauen an Frauen verstanden wird ${ }^{54}$. Aufgrund der Zahlenwerte läßt sich dies für Lüneburg nicht bestätigen - immerhin vererben z.B. 12 Männer, aber nur sechs Frauen Bettdecken. Sicherlich drücken die Bestimmungen

\footnotetext{
${ }^{52}$ V. GROEBNER, Ökonomie ohne Haus, S.248.

${ }^{53}$ Zitat bei V. GROEBNER, Ökonomie ohne Haus, S.250. Die entsprechenden Ergebnisse der Testamentsauswertungen bei A. v. BRANDT, Mittelalterliche Bürgertestamente, S.24; H. D. LOOSE, Leben und Kultur, S.8; P. BAUR, Testament und Bürgerschaft, S.232; G. JARITZ, Österreichische Bürgertestamente, S.253; U. M. ZAHND, Spätmittelalterliche Bürgertestamente, S.66.

${ }^{54}$ G. JARITZ, Österreichische Bürgertestamente, S.255; P. BAUR, Testament und Bürgerschaft, S.232.
} 
für Heergewäte (das zweitbeste Bett) und Frauengerade (das beste Bett) eine gewisse Einstellung zwischen Sachgut und Geschlecht aus, ob aber daraus eine scharfe Unterscheidung hinsichtlich der realen oder auferlegten Wertigkeit des Bettmobiliars für Männer wie Frauen abgeleitet werden kann, die sich dann ja auch in den Testamenten niederschlagen müßte, darf bezweifelt werden. Immerhin deutet bei den Lübecker, Hamburger und Stralsunder Testamentsauswertungen ebenfalls nichts auf ein derartiges Testierverhalten hin. Auch die auf der Grundlage Nürnberger Quellen zustandegekommene Untersuchung des Betts nebst Zubehör als Mittel der Wirtschaft, präziser als Pfandgut, deutet nicht auf die vorrangige Nutzung durch Frauen hin $^{55}$.

Wenn auch Einzelbelege wie die der Decke in Hermann Kruses Testament und des Kissens in Geseke Leyferds Testament mit einem aus Arras stammenden, zur Herstellung von Bettwäsche verwendeten Tuch nicht als ausreichende Argumentationsgrundlage dienen kann, so bleibt doch zu überlegen, ob es nicht einen umfassenden Import von fremdem, speziell zur Herstellung von Bettwäsche verwendetem Leinen gegeben hat. In Köln ist - trotz eigener Fabrikation - ein derartiger Import von vor allem niederländischer und Brabanter Leinengewebe belegt ${ }^{56}$, Tuchlandschaften, an die sich die flandrische mit Arras nahtlos anschließt! Bekannt als Lieferantin von als Haustextilien verwendeten Tuchen ist auch die oberitalienische Landschaft, in der sich besonders Cremona und Perugia, letzteres mit seinen Streifenmustern, hervortaten ${ }^{57}$. Möglich ist, daß ein Import an Bettextilien in Lüneburg zu großem Teil mit Tuch aus Flandern betrieben wurde, einer Tuchlandschaft, die den Lüneburger Testatoren als Lieferantin für Kleidungstextilien nahelag.

Als Standort des Bettes innerhalb seines Wohnbereichs gibt der Vikar Johannes von Lippinghausen 1414 seine Kammer an. Diese Angabe deckt sich mit den Erkenntnissen über die Wohnkultur im Lüneburg des 16. Jahrhunderts, wobei zu erkennen ist, daß die Schlafräumlichkeiten im Lüneburg des 15. Jahrhunderts nicht wesentlich anders sind ${ }^{58}$. Als Schlafraum dient die Kammer, der sich neben Diele (hus) und Stube (dornse) befindende Raum. In der Kammer befinden sich außer den Betten Truhen, Schränke und Laden, so daß eine gewisse Raumgröße vorausgesetzt werden darf. Der im Obergeschoß liegende, als Festraum genutzte Saal kann ebenfalls Standort für Betten sein, von denen vermutet wird, daß sie als Gästebetten dienen. Evident ist, daß über das Haus verteilt eine nicht

\footnotetext{
${ }^{55}$ V. GROEBNER, Ökonomie ohne Haus, S.251.

${ }^{56}$ E. WURMBACH, Das Wohnungs- und Bekleidungswesen des Kölner Bürgertums, S.54

${ }^{57}$ J. ZANDER - SEIDEL, Textiler Hausrat, S.343; G. JAACKS, Kleidung und Textil im Oldenburger Sachsenspiegel, S.407f. Hier der Hinweis darauf, daß die „Perugia - Tücher“ im 14. Jahrhundert „,allgemein üblich wurden".

${ }^{58}$ K. TERLAU - FRIEMANN, Lüneburger Wohnkultur des 16. Jahrhunderts, S.81 - 97.
} 
unbeträchtliche Summe an Betten verschiedenster Art zusammenkommen kann, was durch die Auflistung in einigen der Lüneburger Testamente bestätigt wird.

\section{b. Truhen}

\section{Herstellung und Aussehen der Truhen}

Die Truhe wird oft als das älteste und wesentliche Möbelstück bezeichnet ${ }^{59}$. Ihre Bedeutung liegt in ihrer vielseitigen Verwendbarkeit als Verwahr -, Transport -, Sitz- und Tischmöbel. Für die Herstellung der Truhen waren die Tischler zuständig. Die nicht zuletzt von der (täglichen) Nachfrage bestimmten Meisterstücke sind in der 1498 kodifizierten Lüneburger Zunftrolle angeführt: Anzufertigen sind sie in des jeweiligen Ältermanns Haus aus dem eigenen Holz des sich um den Meistertitel Bewerbenden und auf seine eigene Rechnung ${ }^{60}$. Gefordert wird als drittes der durch eine numerische Folge definierten Stücke eine stappede $k y s t e^{61}$, also eine mit Beinen versehene Truhe. Diese Truhenart ist als der Truhentypus des Mittelalters und der frühen Neuzeit anzusehen: die Stollentruhe ${ }^{62}$. Das Grundprinzip der Stollentruhe ist das Verbinden und Befestigen waagerechter Bretter an den als Stützen, also Stollen, dienenden Vertikalbrettern. Je nach Anordnung der Stollenbretter wird die Seitstollentruhe $^{63}$, bei der die Stollen gleichzeitig die Seitenwände sind, von der Frontstollentruhe unterschieden, bei der die Stollenbretter an den vertikalen Truhenbohlen der Längsseiten frontal befestigt sind. Dieser letztgenannte Typus ist in Norddeutschland vorherrschend. Das mögliche Aussehen der in Lüneburg vererbten Truhen ist durch die umfangreiche gegenständliche Überlieferung besonders der Lüneburg umgebenden Heideklöster vorstellbar ${ }^{64}$. Hier haben sich über 100 Truhen vom ausgehenden 12.

\footnotetext{
${ }^{59}$ E. WURMBACH, Wohnungs - und Kleiderwesen, S.21f; B. DENEKE, „Möbel“, in: Lex. d. Mittelalters, Bd.VI, Sp.700; H. APPUHN und J. WITTSTOCK, Mittelalterliche Hausmöbel in Norddeutschland, in: Kat. „Aus dem Alltag ...", S.45.

${ }^{60}$ E. BODEMANN, Ältere Zunfturkunden, 1498, Sept. 24, S.239; paraphrasiert H. REINECKE, Holz-Arbeiten, S.11f.

${ }^{61}$ E. BODEMANN, Ältere Zunfturkunden, 1498, Sept. 24, S.239.

${ }^{62}$ Gleichsetzung von ,stappede“ kiste und Stollentruhe nach H. REINECKE, Holz-Arbeiten , S. 14 Knappe Erklärung bei H. OTTENJANN, Das Sondervermögen „Gerade“ sowie Kiste und Lade im Oldenburger Sachsenspiegel und im bäuerlichen Erbrecht des Ammerlandes, in: Kat. „der sassen speygel - Sachsenspiegel Recht - Alltag“, Bd.2, S.387.

${ }^{63} \mathrm{H}$. APPUHN und J. WITTSTOCK bezeichnen die Seitstollentruhe als Wangenkiste. dies., Mittelalterliche Hausmöbel, S.44.

${ }^{64}$ Erste eingehendere Untersuchung von H. SCHRÖDER, Gotische Truhen, in: Festblätter des Museumsvereins für das Fürstentum Lüneburg, Nr.4, Lüneburg 1932, S.5-50; dann wieder bei H. APPUHN, Möbel des hohen und späten Mittelalters in den ehemaligen Frauenklöstern um Lüneburg, in: Klösterliche Sachkultur des Spätmittelalters (=Österreichische Akademie der Wissenschaften, Philosophisch-Historische Klasse, Sitzungsberichte, Bd. 367, Veröffentlichungen des Instituts für mittelalterliche Realienkunde Österreichs , Bd. 3), Wien 1980,S.342-352; H. APPUHN und J. WITTSTOCK, Mittelalterliche Hausmöbel, S.44; H.
} 
Jahrhundert bis ins 14. Jahrhundert erhalten, die von einheimischen Handwerkern angefertigt wurden. Diese von der Forschung als „Lüneburger Truhen“ bezeichneten Verwahrmöbel zeichnen sich durch folgende mögliche Komponenten aus: Es handelt sich um Frontstollentruhen, deren gesamte Forderfront durch Schnitzwerk oder in Ritztechnik verziert sein kann, aber auch schlicht ausfällt. In dem Rechteck zwischen dem Stollenfuß und der bodennähsten Truhenbohle kann ein bogig gestaltetes Zierholzelement angebracht sein. Die Stollenfüße selber können an den Innenseiten ebenfalls bogig ausgeformt sein. Zwischen dem 13. und dem 15. Jahrhundert veränderte die Stollentruhe ihre Form: Die ehemals breitstollige, gedrungen - kurze Truhe entwickelte sich zu einer langgezogen Form von ca. 2 m Ausdehnung ${ }^{65}$. Die gegenständliche Überlieferung Lüneburgs mit vier Truhen bzw. deren Vorderwand aus dem 14. und 15. Jahrhundert belegt eine Truhenlänge von ca. 1,50 $\mathrm{m}$ bis ca. 2,20 $\mathrm{m}^{66}$. Die Truhendeckel können sowohl hochgewölbt sein als auch flach ausfallen; allerdings herrscht in Lüneburg die flache Deckelform vor. Im Rahmen dieser wechselnden Ausfertigungsmöglichkeiten blieben die Truhen in einem Zeitraum von ca. 200 Jahren vom Prinzip her unverändert. Verwendet wurde überwiegend Eichenholz, zu dem seit Beginn des 15. Jahrhunderts wegen des nun eingeführten Furniers und der Einlegearbeiten auch andere Hölzer wie Walnuß und Birnenholz hinzukamen. Verboten war die Verwendung des hellen Rindenholzes zur Herstellung von Dübeln und Nuten ${ }^{67}$.

Häufigkeit der testamentarischen Vererbung, Donatoren und Empfänger

Die Truhe wird von den Testatoren als kiste oder cista bezeichnet. Vorrangig werden Truhen in das Testament aufgenommen, weil sie selbst vererbt werden sollen; gelegentlich werden sie testamentarisch erwähnt, weil sie der Aufbewahrungsort eines zu vererbenden Objekts sind. Angesichts des Lebensstandards der Testatoren ist davon auszugehen, daß die in den Testamenten erwähnten Truhen in erster Linie als Verwahrmöbel, weniger als Sitz- oder Tischmöbel verwendet wurden.

Die testamentarische Kunde über Truhen fällt für das 14. Jahrhundert mit dem Testament des Archidiakons Segeband von Thune trotz der Auflistung von elf Truhen schmal aus. Obgleich es im 14. Jahrhundert im Rahmen der Pauschalverfügungen Truhentradierung gegeben haben wird, ist doch das 15. Jahrhundert als das Jahrhundert anzusehen, in dem der bürgerliche Haushalt über zunehmend mehr Truhen verfügen konnte. Wurden im 14. Jahrhundert 11 Truhen testamentarisch vererbt, so waren es im 15. Jahrhundert bereits 22

OTTENJANN, Das Sondervermögen „Gerade“ sowie Kiste und Lade im Oldenburger Sachsenspiegel und im bäuerlichen Erbrecht des Ammerlandes,S.379-397.

${ }^{65}$ H. APPUHN, Möbel des hohen und späten Mittelalters in den ehemaligen Frauenklöstern um Lüneburg, S.346.

${ }^{66}$ G. KÖRNER, Leitfaden, Nr. E. 41, E. 42 und E. 43; Kat. „Stadt im Wandel““, Bd.2, Nr. $879=$ Archivtruhe aus der Alten Kanzlei. 
Truhen. In der zweiten Hälfte des 15. Jahrhunderts wurden durchschnittlich mehr Truhen vererbt als in der ersten Hälfte.

Die Geschlechtszugehörigkeit der Testatoren ist mit zehn Männern und neun Frauen unter Einbeziehung eines Gemeinschaftstestaments als ausgewogen zu bezeichnen. Drei der Testatoren waren Kleriker (1385 Segeband von Thune, 1424 Johannes von Lippinghausen und 1441 Heinrich Tetendorp).

In erster Linie wird die Truhe innerhalb der Familie vergabt. Diesen zwölf Truhen stehen acht gegenüber, die an den Testatoren bekannte Personen fallen sollen. Die Hälfte dieser mit dem Testator nicht verwandten Empfänger sind Mägde. Der Vikar Heinrich Tetendorp schenkt seine Truhe der Vikarie in St. Lamberti, die er selbst innehat.

Kriterien, nach denen die Testatoren die Truhen differenzieren

Truhen werden von den Testatoren mittels des Kriteriums der Truhengröße, der Truhenart und des Aussehens der Truhe beschrieben. Das Aussehen der Truhen fällt als Mittel der Beschreibung kaum ins Gewicht, was angesichts der breitgefächerten Formenpalette der Truhen verwunderlich erscheint. Daß eine mögliche, auffällig schöne Verzierung der Truhe für den Testator als Kriterium weniger ausschlaggebend ist, mag entweder in einer anderen Wahrnehmung der Möbel als der heutigen gelegen haben oder - und dies scheint das primäre Argument zu sein - an der überwiegend schlichteren Ausführung der testamentarisch vergabten Truhen; immerhin gilt es bei den immer wieder gern zitierten prachtvollen Austattungen zu berücksichtigen, daß es eben auch zahlreiche unverzierte Exemplare gab $^{68}$. Bei den schlichteren Truhen ist offensichtlich die Größe hinreichend aussagekräftiges Kriterium.

Die Testamente Czieke Blanks und Johannes von Lippinghausens sind die einzigen, in denen Truhen hinsichtlich eines durch die Verzierung auffälligen Aussehens beschrieben werden.

Die zweifelsohne bei vielen Testatoren vorhandenen Prachttruhen werden im Rahmen des außertestamentarischen Erbganges an die Familie gefallen sein und nur in Ausnahmefällen wie bei Czieke Blank Aufnahme in das Testament gefunden haben. Czieke Blank ist die einzige unter den Testatoren, die in ihrem 1475 errichteten Testament ihr Erbstück sowohl farblich als auch von der Anfertigungstechnik her beschreibt: An die Enkelin soll die rode utgegravene kisten Czieke Blanks fallen. Die rote Farbe ist typisch für die Farbgrundierung

\footnotetext{
${ }^{67}$ H. REINECKE, Holz-Arbeiten, S.12.
} 
etlicher Truhen, die allerdings heute in seltenen Fällen noch erkennbar ist ${ }^{69}$. Im Regelfall sind die Truhen farblich verziert gewesen, wovon nicht allein rote Farbreste auf etlichen überlieferten Stücken zeugen. Das Hand - in - Hand - Arbeiten von Tischler und Maler belegt die erneuerte Ordnung der Lüneburger Tischler von 1524, die Meister Hinrick de malemester unter den die Urkunde in Empfang nehmenden Tischlern nennt ${ }^{70}$. Als utgegraven werden geschnitzte Truhen bezeichnet, so daß es sich hier um eine Truhe mit Verzierungen aus einer Kombination von aufgetragener Farbe und Schnitzwerk handelt ${ }^{71}$. Im Rahmen des bürgerlichen Haushalts sind Truhen das Möbelstück, das als erstes in besonderem Maße verziert wurde ${ }^{72}$. Der Grund dafür liegt in Verwendung der Truhe als Verwahr-, aber auch als Transportmöbel, so wie es beim Einzug des Brautschatzes in das Haus des Bräutigams notwendig war. Dieser im Rahmen des städtischen Altagslebens auffällige Transport wurde offensichtlich von nicht wenigen Brautleuten bzw. deren Angehörigen recht aufwendig gestaltet, so daß ein Ratserlaß um 1400 reglementierend eingriff: „der dreghere, de dat ingedome deme brudegame bringet, mogen twelve wesen und nicht mehr. By deme ingedome moghen ghan twe vrouwen mit twen megeden; in des brudeghames huse scholen ok men twe vrouwen mit twen megeden wesen, de dat ingedome entfangen “73. Angaben über das im Rahmen einer Eheschließung mitzunehmende Mobiliar enthält eine Ratsverordnung von 1448, in der zumindest die Quantität durch das Fassungsvermögen des Transportmittels Truhe definiert wird: „van ingedome schal nemand meer medegheven men .... twe kisten unde twe dokeladen ${ }^{\text {،74 }}$. Geht man davon aus, daß in den Bestimmungen über die Frauengerade - wie auch über das Heergewät - ein vom „Normalhaushalt“ zu erreichendes Kann fixiert ist, dann handelt es sich bei dem Ratserlaß angesichts der relevanten, in Lüneburg 1481 festgeschriebenen Frauengeradeklauseln mit „ere besten kisten ere besten duklade، ${ }^{\text {،75 }}$ um eine durchaus auf den wohlhabenden Bürger zugeschnittene Regelung, die zu überschreiten sicherlich nur die Minderheit der Bürger in Versuchung kam. Von offensichtlichen Überschreitungen seitens der reichen Bürger, aber auch von der Einsicht des Rates, den Anforderungen der durch den Fortschritt der Zeit geänderten Lebensannehmlichkeiten Rechnung tragen zu müssen,

\footnotetext{
${ }^{68} \mathrm{H}$. APPUHN und J. WITTSTOCK, Mittelalterliche Hausmöbel, S.45.

${ }^{69} \mathrm{H}$. APPUHN läßt Vorsicht walten bei der Zuordnung von generellem Anstrich mit der Farbe „rot““ ders.,Möbel des hohen und späten Mittelalters in den ehemaligen Frauenklöstern um Lüneburg, S.349.

${ }^{70}$ E. BODEMANN, Ältere Zunfturkunden, S.243.

${ }^{71} \mathrm{Zu}$ korrigieren ist HASSEs Ansicht, in Lüneburg seinen geschnitzte Truhen testamentarisch nicht vergabt worden, obschon natürlich eine einzige Truhe keine wesentliche Änderung des Gesamteindrucks bedeutet. M. HASSE, Ein geschnitztes Truhenbrett aus einem Brunnen vom Schrangen zu Lübeck, in: LSAK, Bd.6, Bonn 1982, S.220.

${ }^{72}$ M. HASSE, Ein geschnitztes Truhenbrett aus einem Brunnen vom Schrangen zu Lübeck, S.220.

${ }^{73}$ H. SCHRÖDER, Gotische Truhen, S.45, Fußnote 42.

${ }^{74}$ H. SCHRÖDER, Gotische Truhen, S.45, Fußnote 42.

${ }^{75}$ W.F. VOLGER, UB Lüneburg, Bd. III, S.436.
} 
zeugt die 1488 erlassene Verordnung, die nach den Steuerzahlungen des Brautvaters differenzierend festlegte: „item eyn kleiderschapp, twe kisten unde twe dokelade nach wontliker wisze - item twe kisten unde twe dokeladen nach wontliker wisze - item eyn kleider schopp mit twen lutken byschoppen - item eyne kysten unde twe laden - item eyne kisten unde eyne laden, alles na wontliker wisze “76.

Über eine geschnitzte Truhe konnte nur eine wohlhabende Frau verfügen ${ }^{77}$, und wenn Czieke Blank nun ihre geschnitzte Truhe ihrer Enkelin vermacht, so sichert sie die Tradierung dieses Wertgegenstandes innerhalb der Familie. Der Familie soll die Truhe - wie die übrigen testamentarisch vergabten Mobilia - erhalten bleiben; stirbt ihre Enkelin - so verfügt Czieke Blank - zwar verheiratet, aber kinderlos, so sollen die Mobilia, u.a. eben auch die Truhe, an die dann nächsten Erben der Testatorin fallen. Vielleicht diente die Truhe bei der Heirat der Testatorin als Brauttruhe, die im Rahmen des Haushalts der Blanks eines der wertvolleren Möbelstücke nicht nur in materieller, sondern auch in ideeller Hinsicht war. Auch die in den Heideklöstern überlieferten geschnitzten Truhen sind in gewissem Sinne Brauttruhen! Diese Truhen sind in unterschiedlichster Motivik geschnitzt, wobei es durchaus Kombinationen verschiedender Arten gibt: Es gibt Verzierungen mit architektonischem Vorbild, figürlichen Schmuck und Tierdarstellungen in unterschiedlichster Umrahmung ${ }^{78}$. Vor allem sind die Brauttruhen aufwendig verarbeitet, und es kann durchaus vorkommen, daß eine sich bereits in Familienbesitz befindende Truhe anläßlich einer Hochzeit aufgearbeitet wird, wobei besonders beliebt das Versehen der Truhe mit den Wappen der jungen Eheleute ist. So ist in Lüneburg eine Truhe überliefert, deren Mittelteil drei Paare in den unterschiedlichen Lebensaltern zeigt: „Ein Brautpaar in übertrieben modischer Kleidung, ein Ehepaar in den mittleren Lebensjahren und eines im Greisenalter" ${ }^{\text {799 }}$. Die Kleider verweisen auf das erste Viertel des 15. Jahrhunderts, wobei die Wappen der Schomaker und Brömse auf die Hochzeit des Hermann Brömse mit Ilsabe Schomaker von 1498 hindeuten; dieser Widerspruch wird als Hinweis auf das ca. 100 Jahre nach Entstehen der Truhe erfolgte Überarbeiteten aus Anlaß der bevorstehenden Hochzeit gewertet $^{80}$.

Nicht nur das geschnitzte Holz oder die Farbigkeit konnten das Aussehen einer Truhe prägen, sondern auch der Eisenbeschlag. Beispiel dafür ist das Testament des Johannes

\footnotetext{
${ }^{76}$ H. SCHRÖDER, Gotische Truhen, S.45.

${ }^{77}$ M. HASSE, Ein geschnitztes Truhenbrett aus einem Brunnen vom Schrangen zu Lübeck, S.220.

${ }^{78}$ Gruppenbildung in Anlehnung an H. SCHRÖDER, bei dem man eine eingehende Beschreibung der Truhen findet. passim.

${ }^{79}$ H. SCHRÖDER, Gotische Truhen, S.36. Hingewiesen wird auf diese Truhe auch von H. APPUHN und J. WITTSTOCK, Mittelalterliche Hausmöbel, S.47.

${ }^{80}$ H. SCHRÖDER war nicht mit der 1927 von Kohlhausen in die Forschung eingebrachten Argumentation einverstanden, er vermutet eine verfälschende Überarbeitung des 19. Jahrhunderts. Im Dunkel bleibt bei ihm
} 
von Lippinghausen in seiner Zweitausfertigung von 1424, in der eine cistam bassam ferratam dem Pfarrer Hinrich in Bienenbüttel zugedacht wird ${ }^{81}$. Ursprünglich waren die einfachen Holztruhen ob des Bretterzusammenhalts mit Eisenbändern versehen. Wahrscheinlich wird man mit dem Eisen nicht gerade verschwenderisch umgegangen sein, denn der niedersächsische Bereich mußte Eisen importieren ${ }^{82}$. So wird die Wertschätzung einer eisenbeschlagenen Truhe nicht allein in dem handwerklichen Geschick des Bearbeitenden gelegen haben, sondern wird auch von der Verwendung von Eisenbeschlag in quantitativer Hinsicht bestimmt worden $\operatorname{sein}^{83}$. Diese eisenbeschlagenen Truhen stammen nicht aus dem Lüneburger Raum, sie wurden vor allem im Rheinland und im Westfälischen gefertigt. Ein vom Anfang des 16. Jahrhundert überkommenes Exemplar zeigt die durch die parallele Anordnung erzielte, beeindruckende Zierfunktion der Eisenbeschläge ${ }^{84}$. Mit Eisenbeschlag versehen ist auch die Archivtruhe aus der Alten Kanzlei im Rathaus zu Lüneburg ${ }^{85}$. Sie kann als Hinweis darauf gesehen werden, daß vielbenutzte Truhen festgearbeitet sein mußten, vor allem dann, wenn sie wichtiges Material enthielten. Vielleicht hat es Truhenverzierungen aus figürlichem oder ornamentalem Metallbeschlag gegeben ${ }^{86}$.

Andere Testatoren nutzen die Nennung der Truhenart zur Kennzeichnung ihres Erbstücks. Relativ oft, nämlich fünfmal, werden votkisten vergabt (1423/31 A. Seidentopf, 1430 A. Kolse, 1441 Meister Heinrich, 1472 G. Rosemberg und 1475 C. Blank). Sie sind schmale Truhen von beträchtlicher Länge, die direkt an den Betten standen - myne kisten bii mynem bedde, wie Adelheid Kolse schreibt ${ }^{87}$. Hier konnten sie bei parallelem Stand zur Bettlänge als Tritthilfe bei höheren Betten dienen, aber auch einfach als Abstellfläche genutzt werden. Von der letztgenannten Möglichkeit zeugen etliche Bildwerke, auf denen Geburtsszenen dargestellt $\operatorname{sind}^{88}$.

die Nennung der Motivation für eine späte Überarbeitung. H. APPUHN/J. WITTSTOCK hingegen übernehmen die Idee der durch die Hochzeit begründeten „Nachrüstung“.

${ }^{81}$ U. REINHARDT, Testamente, Nr.150, S.203.

${ }^{82}$ Hinweis bei der von H. APPUHN geleisteten Beschreibung des Exponats Nr.137 - Dachtruhe, Niedersachsen, 14. Jahrhundert, in: Kat. „Stadt im Wandel, Bd.1, S. 202f.

${ }^{83}$ So dient als Begründung einer möglichen Zuordnung eines aus Lüneburg stammenden Bankschranks das Argument: „,Der auf geringer Fläche dicht zusammengerückte Prunk -. Beschlag spricht vielmehr für die Herkunft aus dem wohlhabenden Lüneburger Patriziat, ..“ Kat. „Stadt im Wandel“, Bd.1, Nr. 391, S. 475.

${ }^{84}$ Heute im Bremer Landesmuseum für Kunst- und Kulturgeschichte. Abb. bei H. APPUHN/J. WITTSTOCK, Mittelalterliche Hausmöbel, Abb.8, S.47.

${ }^{85}$ Abbildung und Kurzinformation in Kat. „Stadt im Wandel“, Bd.2, Nr.879, S.1019.

${ }^{86}$ Einziger Hinweis für Lüneburg bei einer Truhenvorderwand aus Eichenholz, um 1500, bei der in Schnitzaussparungen Löcher erkennbar sind, die KÖRNER als mögliche Hinweise auf aufgedübelte Metallfiguren deutete. G. KÖRNER, Leitfaden Museum, Nr.E 43, S.73.

${ }^{87}$ U. REINHARDT, Testamente, Nr.164, S.226.

${ }^{88}$ Als Beispiel Geburt der Maria, Tafel des Eggelsberger Altars, 1481, abgebildet bei H. BOOCKMANN, Die Stadt im Späten Mittelalter, Nr.138, S.91. 
Truhen mit deutlich anderem Nutzungsbereich sind die twe schyppkisten, die 1483 Nickel Wulfferam in seinem Testament erwähnt ${ }^{89}$. Ihre Verwendung auf See hat ihr Aussehen bestimmt; sie sind unten breiter gebaut und verjüngen sich hin zum Truhendecke ${ }^{90}$. Ihr Gestaltungsprinzip gleicht dem der Hansekanne, bei der durch einen breiten Boden und tiefliegenden Schwerpunkt hohe Standfestigkeit erzielt wurde ${ }^{91}$, um ein gefährliches Umherrutschen bei schwerem Seegang möglichst zu vermeiden. Als Einsatzbereich von Schiffstruhen in den Händen Lüneburger Bürger sind die Handelswege der Hanse zu See denkbar, und wenn Nickel Wulfferam seinen Sohn Hans als Hanse, de buthen landes is beschreibt, dann spricht trotz deutlich anders als heute definiertem Landesbegriff einiges für diese Annahme ${ }^{92}$. Als kaufmännisch tätiger Bürger gibt sich der Testator durch die Vergabe des kunthors uppe der dornczen und des kunthors uppe der kameren zu erkennen ${ }^{93}$. Durch die wohl geschäftlich bedingte Abwesenheit seines Sohnes Hans kommt der Testator in die Verlegenheit, sich Gedanken über die Übergabe des Erbgutes an diesen Sohn machen zu müssen. Die anderen Kinder Klaus und Grete sowie die Enkel sind in Lüneburg greifbar, so daß hier der Erbguttransfer ohne Schwierigkeiten verlaufen wird. Nun beauftragt der Nickel Wulfferam nicht die in Lüneburg lebenden Kinder, ihrem Bruder bei seiner Heimkehr des Vaters Erbe auszuhändigen, sondern er formuliert seine Entscheidung folgendermaßen: „Unde sodane ingedome unde huszgerade, alse Hans tokumpt, schal me legghen in de groten kisten unde bidden de vorweser sunte Ciriakesz kercken, dat me de kisten in sunte Ciriaci kercken moghe setten solange, dat me voressche offt desulve Hans levendich edder dot sy. Unde weret, dat he vorstorven were, so scholde syn togetekende deell vallen an synes broders kinder, dat denne myne testamentarii ene to truwer handt scholden vorwaren, so dat er vader des nene macht hebbe to vorbringende edder to vorsettende، ${ }^{94}$.

Weniger deutlich vorstellbar ist die Bedeutung, die die lantkisten gehabt haben mag, die das Ehepaar Geseke und Lüder Wienebüttel den Kindern von Gesekes Bruder nebst Inhalt vererbte. Offen muß auch die Frage bleiben, wozu die sichtekiste (=Beuteltruhe) diente, die das Testament des Segeband von Thune 1375 verzeichnet. Eine Möglichkeit wäre die durch die Truhenverwendung bestimmte Namensgebung, denn Truhen dienten zur

\footnotetext{
${ }^{89}$ U. REINHARDT, Testamente, Nr.266, S.418.

${ }^{90}$ Beschreibung bei SCHILLER-LÜBBEN, Mittelniederdeutsches Handwörterbuch, S.329

${ }^{91}$ In jüngeren Ausstellungskatalogen wird bei Exponatbeschreibungen der Hansekanne immer wieder auf diese Eigentümlichkeit des von seiner maritimen Verwendung geprägten Gebrauchsgegenstandes hingewiesen. Als Beispiel Kat. „Die Hanse“, Bd. 2, Nr.14. 100, S.292. Von hier wurde die Argumentation hinsichtlich der Standfestigkeit der Hansekanne übernommen.

${ }^{92}$ U. REINHARDT, Testamente, Nr.266, S.418.

${ }^{93} \mathrm{ebd}$.

${ }^{94}$ ebd.
} 
Aufbewahrung etlicher Tuch- oder Lederbeutel, die mit unterschiedlichsten Geldsorten oder auch Urkunden gefüllt waren.

Die Truhengröße als Beschreibungsmittel wählten die Kleriker Segeband von Wittorf 1385 und Heinrich Tetendorp 1441 sowie Nickel Wulfferam 1483.

Truhen und das in innen Verwahrte

$\mathrm{Ob}$ die Truhen als Verwahrmöbel automatisch mit inrem Inhalt vererbt wurden, muß bezweifelt werden. Es gibt die Beispiele der Testatoren Lüder und Geseke Wienebüttels sowie der Geseke Rosemberg, die ihre Truhen ausdrücklich mit Inhalt vererbten. Es gibt aber auch anderslautende Beispiele, und genannt sei hier das des Johannes von Lippinghausen, in dem der Vikar einem Herrn Heidekin seinen neuen Chorrock hinterläßt, wobei sich das Kleidungsstück im Moment der Testamentserrichtung in Lippinghausens Truhe befindet, die jedoch nicht an den Empfänger des Chorrocks fällt.

Das Testament des Nickel Wulfferam zeigt, daß Truhen als Aufbewahrungsort von Hausgerätschaften dienen können.

Der Versuch einer "Truheninnensicht" ist eher über Inventare als mittels der Testamente leistbar $^{95}$. In Lüneburg ist das Inventar des letzten Propstes Johannes Koller überliefert, der 1535 als Siebzigjähriger starb ${ }^{96}$. Er hinterließ laut Inventar acht Truhen, die über das gesamte Haus verteilt waren: In der Diele, die entweder als „zentraler Lebensraum oder .. repräsentative Halle" genutzt wurde ${ }^{97}$, standen bereits drei Truhen; eine groten eken kisten, in der 12 Paar Bettlaken, 11 Hand- und 12 Tischtücher verwahrt wurden, und in der Nähe der Küche eine dannen kisten, die 16 Stuhlkissen und drei Decken enthielt ${ }^{98}$, zu der offensichtlich vor gar nicht allzu langer Zeit eine weitere, nämlich neue, Tannentruhe hinzugekommen war. In dieser neuen Truhe befanden sich drei Stück Leinwand, der eyn van XCVIII elen wardt Metcken der kockynnen bevalen in de bleke to bringen ${ }^{99}$. Eine weitere Eichentruhe stand in der hinteren Kammer; das ihr zugeordnete Adjektiv "groß“ wird verständlich, wenn man ihren ungefähren Inhalt auflistet: Sie enthält allein mehrere Laden mit Geld und Urkunden, Beutel mit Wertgegenständen, sieben Kleidungsstücke, darunter Ornate, aber auch profane Kleidung kostbarer Art, Tischtuch und Tuchstücke. In der Mägdekammer steht dann die nächste große Eichentruhe für die Kleider des Mädchens Katherina. Oben steht in der ersten hinteren Kammer wiederum eine Eichentruhe, aber

\footnotetext{
${ }^{95}$ Relevante Inventare Lüneburgs und Umgebung stammen aus der ersten Hälfte des 16. Jahrhunderts. Wesentliche Unterschiede in der Verwendung der Truhe wird es im Verhältnis zum Untersuchungszeitraum nicht gegeben haben.

${ }^{96}$ Th. MEYER, Inventar des Nachlasses des weiland Propstes zu St. Johann zu Lüneburg. M. Joh. Koller, 1536, in: Jahresbericht des Museumsvereins für das Fürstentum Lüneburg, Bd. 5/6, 1882/83, S.73 - 86.

${ }^{97} \mathrm{~K}$. TERLAU - FRIEMANN, Lüneburger Wohnkultur, S.85.

${ }^{98}$ Th. MEYER, Inventar, S.80.

${ }^{99}$ Th. MEYER, Inventar, S.84.
} 
auch eine alte Schiffstruhe, die 26 Stück getrocknetes Ochsenfleisch und 46 Mettwürste enthält. In der hinteren Schlafkammer stand eine sydekiste mit alten Kleidern von geringem Wert. So mag der nicht überprüfbare Versuch erlaubt sein, die menschliche Seite Kollers mit den Worten zu erfassen: „Propst Coller war eine bescheidene, vielleicht allzu bescheidene Natur, so vornehm auch sein im Annenmuseum zu Lübeck verwahrtes Bildnis im Hermelinkragen wirkt; ..., allein sein Inventar, und hier nicht zuletzt die Anzahl an Truhen, deutet gradlinig auf den sich im Hermelinkragen widerspiegelnden Wohlstand $\operatorname{hin}^{100}$. Wie dem auch sei, sein Inventar bietet einen erhellenden Einblick in die Aufnahmekapazität einer Truhe. Allen in einer Truhe aufbewahrten Gütern - z.B. textilem Hausrat oder Kleidung - ist gemeinsam, daß sie durch die liegende Aufbewahrung keinen Schaden nahmen. Kleidungstücke verlangen erst seit dem Moment nach hängender Aufbewahrung und damit nach höheren Schränken, als verwendete Stoffarten, Schnitte und besondere Applikationen eine liegende Aufbewahrung angesichts des Kleidererhalts per se verboten. So ist einprägsam formuliert worden: „Die Mode änderte also auch die Funktion und Form der Möbel“101.

Die oft doch recht unterschiedlichen Arten materieller Güter, die gemeinsam in einer Truhe verwahrt wurden, legen die Frage nahe, ob es nicht Trennvorrichtungen im Innern einer Truhe gegeben haben mag. Eine wohl der Lüneburger Ratskämmerei zugehörige Lade ist durch Brettereinzug in unterschiedliche Fächer aufgeteilt, die möglicherweise zur Aufnahme von (Steuer -) Geldern diente ${ }^{102}$. Bekannt ist, daß an den Schmalseiten des Deckels im Inneren einer Truhe eine Beilade eingearbeitet sein konnte, in der vor allem Wertgegenstände aufgehoben wurden $^{103}$. Im übrigen wird die Ordnung durch das Verwahren von Geld und Urkunden durch eine Aufteilung auf verschiedene Laden und Beutel gewährleistet worden sein. Die Testatorin Tibbeke Godenstedt verwahrt laut Testament von 1469 die nicht unerhebliche Summe von 200 Rheinischen Gulden in einer sundergen lade, die in ihrer votkisten ist $^{104}$. In den Lüneburger Testamenten werden Laden sonst nicht erwähnt.

Einige Male erwähnen die Testatoren Truhen als Aufbewahrungsort von zu vererbenden Gütern, ohne die Truhen selbst testamentarisch zu vererben. Die Testamente Gese Lübberstedts 1415 und Albert Schultes 1475 weisen wie das Testament der Tibbeke Godenstedt die Truhe als Verwahrmöbel von Geld aus. Johannes von Lippinghausen bewahrt laut Testament von 1414 ungebleichtes Leinen und ein neues Superpellicum in

\footnotetext{
${ }^{100}$ W. REINECKE, Geschichte der Stadt Lüneburg, Bd.II, S.147.

${ }^{101}$ G. BENKER, Bürgerliches Wohnen, S.17.

${ }^{102}$ H. REINECKE, Holz-Arbeiten, Nr. 45.

${ }^{103}$ H. APPUHN/J. WITTSTOCK, Mittelalterliche Hausmöbel, S.45. In Lüneburg ist eine Eichenholztruhe aus dem 14. Jahrhundert mit Beilade erhalten; Beschreibung H. REINECKE, Holz-Arbeiten, Nr. 39.
} 
Truhen auf. Gese uppe der Kulen und Geseke Rosemberg vergeben 1370 bzw. 1472 den nicht spezifizierten Inhalt ihrer Truhen.

\section{Standort}

Über den Standort ihrer Truhen sagen die Testatoren in den seltensten Fällen direkt etwas aus. Im Regelfall wird eine votkisten natürlich im Schlafgemach gestanden haben. Die votkisten der Geseke Rosemberg stand uppe den bonen, womit entweder der Boden oder ein Stockwerk gemeint sein konnte ${ }^{105}$. Johannes von Lippinghausen gibt an, seine eisenbeschlagene Truhe stehe in seiner Kammer.

\section{Truhen in Testamenten anderer Städte}

Testamente des süddeutschen Raumes geben keine Kunde von Truhen oder gar deren $V_{\text {Verwendung }}{ }^{106}$. Die Testamente Lübecks, Hamburgs und Stralsunds enthalten wie die Lüneburgs hingegen Verfügungen über Truhen in nicht unbeträchtlicher Zahl, die sich für Stralsund mit 27 vergabten Exemplaren konkretisieren läß ${ }^{107}$.

\section{c. Schränke}

\section{Die Nutzungsgeschichte}

Wie die Truhen dienen Schränke zur Aufbewahrung. Wenn Truhen und Schränke sich auch nicht zwangsläufig hinsichtlich ihres Umfangs unterscheiden, so gibt es doch die durch das Verschlußprinzip definierte Trennung: Truhen sind mit Deckeln versehen, Schränke mit Türen. Diese mit Türen versehenen Verwahrmöbel werden zunächst als armarium bezeichnet und in Klöstern und Kirchen verwendet; Schränke sind im Gegensatz zu Truhen also keine genuin profanen Möbelstücke. Das armarium konnte wohl seit dem 12 . Jahrhundert zur Aufnahme des Allerheiligsten oder von Reliquien dienen, fand in erster Linie jedoch Verwendung als Bücherschrank, denn die Bezeichnung wurde in der Folge synonym verwendet für Bibliothek und Archiv, aber auch für die Sakristei ${ }^{108}$. Die frühen

\footnotetext{
${ }^{104}$ U. REINHARDT, Testamente, Nr.235, S.349. sundergen = besonders, abgesondert, getrennt. SCHILLER LÜBBEN, Mittelniederdeutsches Handwörterbuch, S.391.

${ }^{105}$ U. REINHARDT, Testamente, Nr.237, S.353. SCHILLER - LÜBBEN, Mittelniederdeutsches Handwörterbuch, S.61.

${ }^{106}$ P. BAUR, Testament und Bürgerschaft, S.232.

${ }^{107}$ A.v. BRANDT, Bürgertestamente, S.331; H.-D. LOOSE, Leben und Kultur, S.8; J. SCHILDHAUER, Hansestädtischer Alltag, S.71.

${ }^{108}$ G. BINDING, “Armarium“, in: Lex. d. Mittelalters, Bd.I, Sp. 964.
} 
Schrankbeispiele zeugen von der Verwahrung liturgischer Kleidung ${ }^{109}$. Der Zeitpunkt der Übernahme des Schrankes in den bürgerlichen Haushalt kann nicht genau bestimmt werden; angenommen wird jedoch eine profane Verwendung um 1300, bei der die Grundformen des Möbels in beiden Verwendungsbereichen gleich waren, sich lediglich in ihrem Dekor unterschieden ${ }^{110}$. Die universelle Verwendbarkeit zeigt sich im Testament des Ratsherrn Heinrich Miles aus dem Jahr 1366: Seinen großen Schrank vererbt Miles der Johanniskirche, genauer einer dort zu errichtenden Vikarie, dat me dat misse wede inne besluote ${ }^{111}$.

\section{Herstellungsmaterial}

Die Schränke wurden wohl überwiegend aus dem in Norddeutschland vorherrschenden Eichenholz gefertigt. Immerhin ist die Verwendung von Eichenholz in der 1498 kodifizierten Zunftrolle der Tischler festgelegt ${ }^{12}$. Einzig das Testament Geseke und Lüder Wienebüttels 1451 nennt die Holzarten, aus denen die beiden testamentarisch vergabten Schränke bestehen: Neben dem grote ekene schap verfügen sie über einen aus Tannenholz gefertigten Schrank ${ }^{113}$. Wenn Segeband von Thune einen seiner Schränke nun als capsam stanneam bezeichnet, so meint er wohl kaum einen ehernen Schrank ${ }^{114}$, sondern eher einen mit auffälligem Eisenprunkbeschlag versehenen Schrank, wie inn auch wohlhabende Lüneburger besaßen ${ }^{115}$.

Häufigkeit der testamentarischen Vererbung, Donatoren und Empfänger Insgesamt 30 Schränke werden in 16 Testamenten von 15 Testatoren erwähnt ${ }^{116}$. Die relevanten Testamente werden von neun Männern, darunter vier Klerikern, und fünf Frauen sowie einem Ehepaar errichtet. Die Testatoren bezeichnen ihre Schränke als schap oder capsa $^{117}$.

Aus dem 14. Jahrhundert stammen die Testamente des Ratsherrn Heinrich Miles von 1366 und des Archidiakons von Bevensen Segeband von Thune aus dem Jahr 1385. Aufgrund

\footnotetext{
${ }^{109}$ Beschreibung der aus dem 13. und 14. Jahrhundert stammenden Schränke aus Halberstadt, Schulpforta und Doberan bei A. REINLE, Ausstattung, S.295; die frühen Schränke der Heideklöster bei H. APPUHN, Möbel des hohen und späten Mittelalters in den ehemaligen Frauenklöstern um Lüneburg, S.348f.

${ }^{110} \mathrm{H}$. APPUHN, Möbel des hohen und späten Mittelalters in den ehemaligen Frauenklöstern um Lüneburg, S.349.

${ }^{111}$ U. REINHARDT, Testamente, Nr. 24, S.30. G. MATTHAEI, Vikariestiftungen, S.171.

${ }^{112}$ E. BODEMANN, Ältere Zunfturkunden, S.239.

${ }^{113}$ U. REINHARDT, Testamente, Nr.221, S.319.

${ }^{114}$ So übersetzt D. MACK ein Legat des Jordan 1 Groper an seinen Sohn. D. MACK, Testamente Braunschweig, S.138.

${ }^{115}$ Abbildung eines aus Lüneburg stammenden Eichenschranks mit Zierbeschlag in Kat. „Stadt im Wandel“, Bd.I, Nr. 391, S.475.

${ }^{116}$ Johannes von Lippinghausen testierte 1414 und 1424.

${ }^{117}$ Übersetzung nach M. HASSE, Kleinbildwerke, S.62.
} 
des Inventarcharakters des Testaments Segeband von Thunes verzeichnet sein letzter Wille allein 11 Schränke z.T. unterschiedlichster Verwendungsart, eine Anzahl, die im Rahmen Lüneburger Testamente unübertroffen und außergewöhnlich hoch ist. Die Testamente Lüneburger Bürger verfügen im Regelfall über einen Schrank, während in Klerikertestamenten überwiegend mindestens drei Schränke aufgeführt sind ${ }^{118}$. Die erste Hälfte des 15. Jahrhunderts ist mit einer Anzahl von 10 relevanten Testamenten der Zeitraum mit den meisten Schrankverfügungen, wobei allein aus dem ersten Quartal sieben Testamente stammen, aus dem zweiten Quartal dann nur noch drei Testamente. Die beiden letzten Quartale des Jahrhunderts weisen je zwei über Schränke verfügende Testamente auf. Die Zahlenwerte korrespondieren in keiner Weise mit quantitativen Veränderungen des Schrankbesitzes Lüneburger Kleriker und Bürger. Das 15. Jahrhundert ist das Jahrhundert der Innovation hinsichtlich der Schrankbautechnik und der Schrankformen, und alles spricht dafür, daß die Lüneburger in Zeiten wirtschaftlicher Prosperität zunehmend Käufe auf dem sich erweiternden Markt an Schrankmobiliar tätigen. Angesichts der Zahlenwerte der Testamente läßt sich die Vermutung äußern, daß Schrankmobiliar in erster Linie innerhalb der Familie außertestamentarisch vergabt wird.

Schränke werden in erster Linie personenbezogen vererbt. Mit der Zuwendung von sechs Schränken liegen die Werte für Familienmitglieder knapp vor dem Wert der Legate an Bekannte mit einer Stückzahl von fünf Schränken. Vier Schränke fallen an Vikarien, wobei Heinrich Tetendorp 1441 zwei Schränke seiner eigenen Vikarie hinterläßt. Zwei Schränke gehen an Kirchen; einer fällt an die Baukasse der Johanniskirche, so daß entweder sein Verkauf oder seine dortige Verwendung angestrebt ist. Ein Schrank wird den Barfüßern geschenkt. Hans Dobbeler ordnet in seinem Testament die Zuwendung seines Schrankes für die Armen in dem von ihm gestifteten Gotteshaus an.

\section{Verwendung der Schränke}

Die Schränke im bürgerlichen Haushalt werden nicht primär als Kleiderschränke verwendet; eine derartige Verwendung ist in Testamenten anderer Städte „ausnahmsweise“ bezeugt ${ }^{119}$. Da immerhin vier der fünfzehn Lüneburger Testatoren einen clederschap vererben, zeichnet sich hier eine Diskrepanz zwischen bisherigen Erfahrungswerten und der Lüneburger Situation ab. Das über den Untersuchungszeitraum annähernd gleich verteilte Auftreten dieser Schränke (1366 Heinrich Miles - 1414 Grete Masendorp - 1460 Hilleke von

\footnotetext{
${ }^{118}$ Lediglich Geseke und Ludeke Wienebüttel vererben zwei Schränke, während der Kleriker Johannes von Lippinghausen nur einen Schrank vergabt.

${ }^{119}$ M. HASSE, Hausrat, S.44; H. APPUHN/J. WITTSTOCK, Mittelalterliche Hausmöbel, S.48.
} 
Erpensen - 1481 Hans Dobbeler) belegt die Nutzung des Schranks als Verwahrmöbel für Kleidung im relevanten Zeitraum. Das Aufhängen von Kleidung in Schränken war zunächst unbekannt, dafür gab es sogenannte Kleiderstöcke oder Kleiderständer, deren einer z.B. im Testament des Braunschweiger Bürgers Heyneke 2 Jordens 1418 vererbt wurde $^{120}$.

Die in Testamenten anderer Städte aufgeführten, dem Küchenbereich zugehörenden Schränke wie Speiseschrank (promptuarium) und Topfschrank werden zumindest im Testament des Segeband von Thune erwähnt ${ }^{121}$. Weitere Verwendungsarten geben die Testamente explizit nicht an.

Da nicht wenige Testatoren zu den reichen und reichsten Familien Lüneburgs zählten, wird sich in den Haushalten einiger Testatoren mindestens eine Schenkschive befunden haben. Dieser vertikal dreiteilige Schrank verdankt seinen Namen der an der Frontseite installierten Schenkschive, bei der es sich um eine komplett herausklappbare, dann im $90^{\circ}$ Winkel von eisernen Stangen gehaltene, einrastende Platte handelt. Die so entstehende Fläche wurde zum Aufstellen der wertvollsten Gerätschaften, über die ein Haushalt verfügte, genutzt. Das Lüneburger Rathaus beherbergt in der Gerichtslaube drei dem wertvollen Silbergerät adäquate Schenkschiven aus der Zeit von 1470 bis 1520 , die einen Eindruck von der Wirkung des schön gestalteten und verzierten Schranks und des üppigen Silbergeräts vermitteln ${ }^{122}$. Die Schenkschive war eines der drei Meisterstücke der Tischler, ein Indiz für eine gute Auftragslage. In der Anweisung für den künftigen Meister heißt es: „als int erste eyn schap myt veer doren myt dubbelden fogen, dat in deme myddel schal hebben eyne schenkeschyve, de uppe beyden enden sy gevatet unde dat id

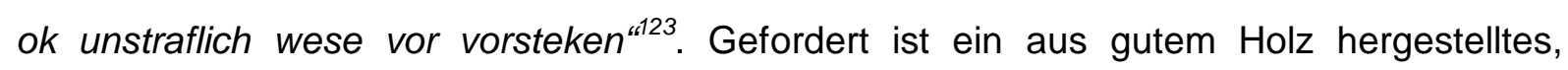
harmonisch gefügtes Möbelstück, dessen mit Schlössern und Scharnieren zu versehende Türen perfekt eingepaßt werden mußten. Freigestellt war der Grad der Schnitzwerkverzierungen, die insgesamt wohl erwünscht waren. In Hamburg hingegen

\footnotetext{
${ }^{120}$ D. MACK, Testamente der Stadt Braunschweig. Altstadt 1412 - 1420 ( = Beiträge zu Genealogien Braunschweiger Familien, Bd.4), S.152.

${ }^{121}$ Beispiel eines sehr frühen Haushaltsschranks von 1333 - 36 aus dem Kloster Medingen in Kat. „Stadt im Wandel“", Bd.I, Nr. 138, S.203f.

${ }^{122}$ Abbildung der Schenkschive von 1488 mit geöffneter Klappe und den Kopien des Ratssilbers bei S. BURSCHE, Das Lüneburger Ratssilber, S.12. Zitiert sei H. APPUHN, der die Informationen über die drei Schenkschiven nach den Kämmereirechnungen zusammengetragen hat:

„Schrank I: 1474 erhalten Jakob Knoet, der Kistenmaker, die Blekesche als Malerin und Diderik Tostede, wahrscheinlich ein Schlosser, hierfür zusammen 57 1⁄2 Mark.

Schrank II: 1488 Andreas Snitker (d.J.) 28 Mark vor dat nyge schapp uppe den radhuse, dar dat sulversmide scal inne stan sowie die Levenstedesche ( bisher: die Blekesche) für die Malerei.

Schrank III: 15213 mark 6 Schillinge Hinrik Malmester geven vor grote dröge eken delen to der schenckschyven und 53 Mark Hinrik Reimerß dem malere geven vor de schenckschyven to vorgulden und vor das snytwerck und vor de bilde to snydende mit aller to behorynge und buten und bynen angestreken myt gulden blomen. Hinrik Reimers lieferte in demselben Jahr auch die Schränke des Alten Archivs.“ H. APPUHN, Der Ort des Ratssilbers, die Schenkschiven in der Ratsstube des Lüneburger Rathauses, in: S. Bursche, Das Lüneburger Ratssilber, S.36.
} 
verlangte der Rat eine schlicht gehaltene Schenkeschive als Meisterstück, verzichtete auf den Nachweis der Schnitzkunst an diesem Möbelstück ${ }^{124}$. Ein derartiges Luxusmöbel wie die Schenkschive wird im Regelfall außertestamentarisch im Familienkreis vererbt worden sein.

Eine durchaus häufig anzutreffende Schrankart verzeichnet das Testament der Grete von dem Wede 1422; hier wird ein Schrank vererbt, der beschrieben ist als eyn scap, dat in der mure $^{125}$. Die Ausgestaltung der für Mauernischen bestimmten, mobilen Schränke entspricht ihrer Zweckbestimmtheit; sie sind oftmals schmal und weisen Verzierungen ausschließlich oder überwiegend an der Frontseite auf ${ }^{126}$. Um 1500 war es dann wohl üblich, Gesimsverzierungen an Forderfront und Seitenwänden anzubringen ${ }^{127}$. Zunächst aus bautechnischen Gründen angelegte Nischen wurden auch mit immobilen Schränken ausgefüllt, wobei entweder vor sich in der Wand befindende Borde Türen gesetzt wurden $^{128}$, oder ein genau die Maueraussparung ausfüllender Schrank aufgestellt wurde. Die Verzierung des immobilen Schrankes, den es in einer Vielzahl im Lüneburger Rathaus gibt, kann an die Raumvertäfelung angepaßt sein.

\section{Standort}

Wenn die Testamente nun keine weiteren Verwendungsmöglichkeiten der Schränke nennen, so bezeichnen sie wohl aber gelegentlich den Standort des zu vererbenden Möbelstücks. Gerade die Bezeichnung des Standortes, die häufiger das Erbstück beschreibt als es durch die direkte Nennung des Verwendungszwecks geschieht, darf als Indiz für die weniger durch eine spezielle Formgebung als vielmehr durch den Standort determinierte Nutzung des Schrankes angesehen werden. Die Nachlaßinventare des 16. Jahrhunderts zeigen als Standort der Schränke Diele, Dornse und Schlafkammer ${ }^{129}$. Bis zu einem bestimmten Grad bestimmte die Raumnutzung den Schrankinhalt. Gezeigt soll dies werden anhand des Nachlaßinventars der Margarete Grönhagen, geborene Sankenstedt,

\footnotetext{
${ }^{123}$ E. BODEMANN, Ältere Zunfturkunden, S.239.

${ }^{124}$ H. REINECKE, Holz-Arbeiten, S.12.

${ }^{125}$ U. REINHARDT, Testamente, Nr.145, S.192.

${ }^{126}$ H. APPUHN, Möbel des hohen und späten Mittelalters in den ehemaligen Frauenklöstern um Lüneburg, S. 350. Beispiel eines solchen, hier allerdings sehr kleinen Wandschranks aus Lübeck, Anfang 15. Jahrhundert, Eichenholz, in: Kat. „Die Hanse, Bd. 2, Nr. 23. 50, S.536

${ }^{127}$ Abbildung eines eichenen Zinnenschrankes aus der Zeit um 1500, Kloster Wienhausen bei H. APPUHN, Möbel des hohen und späten Mittelalters in den ehemaligen Frauenklöstern um Lüneburg, Abb. 47.

${ }^{128}$ Vermutlich beschreibt das Grönhagensche Inventar diese Schränke als steenschapp.

${ }^{129}$ Th. MEYER, Inventar Joh. Koller, S.76, 80, 84; K. TERLAU - FRIEMANN, Lüneburger Wohnkultur, S. 89f; KRAUT, Nachlaßinventar Ilsabe Schiven, S. 60; W. KRONSHAGE, Hausinventare Göttinger Bürger, S.82.
} 
aus dem Jahr $1544^{130}$. Insgesamt verzeichnet das Inventar eine Anzahl von mindestens 18 Schränken ${ }^{131}$, die verteilt waren über vier Zimmer, die Dornse, die Schreibkammer, die große Kammer im Erdgeschoß, genutzt als Schlafzimmer und eigentlicher „Privatraum der Familie Grönhagen“ ${ }^{132}$, und die hintere Kammer im Erdgeschoß. Allein der umfangreiche Schrankbesitz verweist auf den erheblichen Reichtum der Margarete Grönhagen, die genau wie ihr 1540 verstorbener Mann Heinrich aus einer sülzbegüterten Familie stammt ${ }^{133}$. Die von dem jeweiligen Hausherrn offensichtlich als eine Art gehobenes Arbeitszimmer genutzte Dornse verfügte über eine Schenkschive, die nicht mit Repräsentationsgeschirr, sondern mit Rechnungen gefüllt war. Geld und Urkunden befanden sich in zwei stenschappe, die vermutlich fest in die Mauernischen eingepaßt waren. An einer Wand in Küchennähe stand ein Schrank mit Silbergerät. Im Raum gab es weitere, allerdings leere Schränke in unbekannter Anzahl. Eine vorrangige Nutzung der Dornse als Wohnstube hat es in Norddeutschland nicht im Untersuchungszeitraum, wohl spätestens seit dem 17. Jahrhundert gegeben ${ }^{134}$. Rechnungen, Geld und Urkunden nun befanden sich auch in Schränken der Schreibkammer, die ebenfalls einen in das Mauerwerk eingefügten Schrank besaß. Ferner stand in dieser Kammer ein großer grünbemalter Schrank, in dessen drei Schüben und auf dessen Decke in Schachteln sortierte Briefe aufbewahrt wurden. Weitere Schränke in unbekannter Anzahl waren leer. In der auch zum Schlafen genutzten großen Kammer war neben dem Bett ein grau bemalter Schrank mit dem Grönhagenschen und Sankenstedtschen Wappen aufgestellt, der zur Aufnahme von Kleidungsstücken diente. Ein weiterer, mit dem Ehewappen verzierter Schrank grüner Grundierung stand neben dem Kamin und enthielt allerlei Haustextilien. Offensichtlich auf der anderen Kaminseite stand eine weiße Eichenschenkschive. Weingläser standen in den beiden oberen Fächern, während das mittlere Fach das Prunkgeschirr aufnahm, das sich aus 24 silbernen und/oder vergoldeten Bechern und Kannen zusammensetzte, aus 23 mit Wappen versehenen Silberschalen, aus zwei vergoldeten Gabel, 44 silbernen Löffeln und zwölf silbernen Gabeln. $\mathrm{Zu}$ vermuten ist, daß zu gegebenem Anlaß das (mit den Familienwappen versehene) Prunkgeschirr auf der Schenkeschive der Dornse aufgestellt wurde ${ }^{135}$. Die Aufbewahrung in der Schlafkammer bot natürlich eine größere Diebstahlprävention. Ein neben der Tür zur Hinterkammer stehender großer Eichenschrank verwahrte Kleider und

\footnotetext{
${ }^{130}$ Die Angaben richten sich nach K. TERLAU - FRIEMANN, Lüneburger Patrizierarchitektur, passim. Eigentum der Familie Grönhagen waren zwei nebeneinanderliegende Häuser am Ochsenmarkt, vis a vis des Rathauses.

${ }^{131}$ In einigen Räumen ist von einer unbestimmten Anzahl an Schränken die Rede; hier wird in diesen Fällen von mindestens zwei Schränken ausgegangen.

${ }^{132}$ K. TERLAU - FRIEMANN, Lüneburger Wohnkultur, S.89.

${ }^{133}$ WITZENDORFF, Stammtafeln, S. 47, 100; Informationen über die jeweiligen Väter bei U. DIEDERICHS, Aufruhr, Nr. 28, S.140ff und Nr. 66, S.207.

${ }^{134}$ K. TERLAU - FRIEMANN, Lüneburger Wohnkultur, S. 89; dies., Lüneburger Patrizierarchitektur, S.95.
} 
Hauben, auf ihm standen Messing - und Zinnwaren. In der hinteren Kammer des Erdgeschosses war hinter der Tür ein großer bemalter Schrank aufgestellt, in dem in überschaubarem Umfang Silbergerätschaften aufbewahrt wurden. Zinnernes Eßgerät großen Umfangs befand sich in einem viereckigen, langen Schrank. Ein weiterer großer Schrank barg unterschiedliche Güter wie Weingläser, Zinnschalen und einen auseinandergenommenen Kronleuchter aus Messing. Ein offensichtlich niedriger Schrank stand unter einem Tisch. Deutlich belegt das Inventar die durch die Raumnutzung bestimmte Verwendung der Schränke, und sei es ein Durcheinander verschiedener Gerätschaften in einem offenbar mehr als Abstellkammer genutzten Raum wie dem letztgenannten. Es zeigt aber auch die offenbar in einem wohlhabenden Haushalt bevorzugte Aufbewahrung von Metall - und Edelmetallobjekten in Schränken, weniger in Truhen. Neben dem Schaustellungseffekt scheint hier eine Abnutzungsprävention eine Rolle gespielt zu haben.

Aus den Testamenten gehen keine Informationen über Farbigkeit oder Wappenverzierung der Schranke hervor. Über die Größenverhältnisse machen die Testatoren eher Angaben: Acht Schränke sind große Schränke, dreimal werden kleine Schränke vergabt, einmal wird ein langer Schrank vererbt. Diese Angaben müssen für sich stehen bleiben, denn jede individuell geäußerte Größenangaben der Testatoren ist relativ, und die Schrankgröße sagt nichts über die tatsächliche Verwendung eines Schrankes aus. Die Schränke waren nicht immer von zur optimalen Nutzung ausreichender Höhe; durchaus üblich war ihr Anheben durch das Postieren auf Wandbänken ${ }^{136}$. Die von den Testatoren angegebenen Standorte ihrer Schränke befindet sich im Regelfall im eigenen Haus. Lediglich ein Schrank Segeband von Thunes steht in der Kirche und ein von Cyeke Witting zu vererbendes Objekt steht in einem Haus, in dem die Testatorin nicht lebt. Sonst sind die testamentarisch aufgelisteten Schränke verteilt über Kammer (mindestens 2 Schränke ${ }^{137}$ ), Dornse ( 2 Schränke), Küche (1 Schrank) und vermutlich Diele (1 Schrank ${ }^{138}$ ). Lediglich ein einziges Mal, nämlich im Testament Hillekes von Erpensen 1460, wird der Standort des Schrankes auch durch die

\footnotetext{
${ }^{135}$ K. TERLAU - FRIEMANN, Lüneburger Patrizierarchitektur, S.95.

${ }^{136}$ Beispiel eines Bankschranks in : Kat. „Stadt im Wandel“, Bd.I, S. 475, Nr. 391. Höher noch als die durch eine Wandbank zu erreichende Höhe von 45 - 50cm ist der sich in der Alten Kanzlei des Lüneburger Rathauses befindende Wandschrank aus dem Jahr 1488 angebracht. Bekannt ist die über seine Herstellung angefertigte Abrechnung: 1488 - so verzeichnet eine mittlerweile verlorene Kämmereirechnung - wurden 28 Mark dem Meister Andreas Snitker d. J. angewiesen für den neuen Rathausschrank, der für das Silbergerät bestimmt ist, dann 15 Mark für jeden der fünf Büchereischränke und 6 Mark für zwei mittelgroße Büchereischränke. Informationen aus: Kat. „Stadt im Wandel“, Bd.II,S.1016f, Nr. 877 und Bd. I, S.475, Nr. 391.

${ }^{137}$ Immeke Burmesters schreibt: myn schap, dat vor der dore steyt. In gewisser Weise sprechend, aber aufgrund der unbekannten Hausanlage nicht einzuordnen sind folgende Formulierungen: super cameram meam (1424 Johannes von Lippinghausen), an myner kameren (1430 Adelheid Kolse).

${ }^{138}$ Dietrich Junges Beschreibung ante cameram suam müßte eigentlich die Diele meinen, könnte aber auch eine weitere Kammer beschreiben.
} 
räumliche Nähe zu einem weiteren Möbelstück beschrieben; hier heißt es myn lange schap, dat darnedden by der groten trade steit ${ }^{139}$.

Auffällig ist, daß zwar die Forschung von dem Vorhandensein von Schrankmöbeln in den spätmittelalterlichen Haushalten der unteren sozialen Schichten ausgeht, die gegen Ende des 15. Jahrhunderts aufgezeichneten Bestimmungen über Heergewät und Frauengerade in Lüneburg den Schrank jedoch nicht auflisten.

\section{d. Kontor}

Ein besonderes Möbelstück, das Elemente des Tisches und des Schrankes in sich vereinigt, ist das Kontor. Es bietet eine Fläche zum Schreiben und als Geldablage und ermöglicht die Verwahrung von Schriftstücken und Geldbeträgen. Das Kontor ist die Urform des Schreibkabinetts oder Sekretärs ${ }^{140}$. Der Name dieses seit dem 15. Jahrhundert in Niederdeutschland bekannten Möbels ist durch Vermittlung des mittelniederländischen contoor und des nordfranzösischen contor dem französischen comptoir entlehnt, dem Wort, das einen Rechen- und Zahltisch bezeichnet. Aufgrund seiner Bauart ist das Kontor ein von Kaufleuten genutztes Geschäftsmöbel, dessen Name später gleichbedeutend für die Geschäftsstube verwendet wird. Spätmittelalterliche Inventare weisen als Standort des Kontors Räume aus, in denen Geschäfte abgewickelt wurden. Das Inventar der Lüneburgerin Margarete Grönhagen aus dem Jahr 1544 nennt als Standort des Kontors die Dornse $^{141}$. Zunächst mag es erstaunlich wirken, daß ihr verstorbener Mann nicht das Kontor in der Schreibkammer aufstellte. Bedenkt man aber, daß die ungleich repräsentativer eingerichtete Dornse als Empfangsraum für Geschäftspartner genutzt wurde, erscheint das Aufstellen des hier viereckigen Kontors mit eingelegten Wappen in einer Raumumgebung verständlich, die dem Kunden mittels der Einrichtung den geschäftlichen Erfolg des aufgesuchten Kaufmannes eindrücklich vor Augen führt. Der laut Ausweis seines Testaments als Geschäftsmann tätige Nickel Wulfferam vererbt 1483 zwei Kontore, und auch er hat ein kunthor uppe der dornczen, während das zweite kunthor uppe der kameren steht $^{142}$.

e.Tische und ihr textiles Zubehör

\footnotetext{
${ }^{139}$ U. REINHARDT, Testamente, Nr.229, S.333.

${ }^{140}$ G. BENKER, Bürgerliches Wohnen, S.28.

${ }^{141}$ K. TERLAU-FRIEMANN, Lüneburger Patrizierarchitektur, S.81 und S.95.

${ }^{142}$ U. REINHARDT, Testamente, Nr.266, S.418.
} 
Häufigkeit der testamentarischen Vererbung, Donatoren und Empfänger

Es gibt vier Testatoren, die über Tische verfügen. Drei der Testatoren sind Kleriker (1385 Segeband von Thune, 1414 Johannes von Lippinghausen und 1476 Dietrich Junge), und Czieke Blanks Testament von 1475 ist das einzige relevante Bürgertestament. Die Überzahl an Klerikertestamenten ist sicheres Indiz für die Aufnahme von Tischen nur dann in Testamenten, wenn durch das Fehlen direkter Nachkommen die gesetzliche Erbfolge nicht griff. Von der im Regelfall außertestamentarischen Vererbung der Tischmöbel zeugt das Testament Czieke Blanks 1475, in dem das von der Großmutter der verwaisten Enkelin zugedachte Erbe in besonderer Weise, nämlich durch das Testament, vor möglichen Ansprüchen der übrigen Verwandtschaft geschützt wird.

In den vier Testamenten werden elf Tische vererbt, die von den Testatoren überwiegend als mensa, aber auch als mensa plicale oder volde tafelen bezeichnet werden.

Das zeitlich erste Testament von 1385 verfügt allein über sechs Tische, die der Archidiakon Segeband von Thune verteilt über seine Höfe in Verden und Minden besaß. Das Testament Johannes von Lippinghausens 1414 listet drei Tische auf, während Czieke Blank 1475 und Dietrich Junge 1476 je einen Tisch testamentarisch vererben.

Die Kleriker vererben ihre Tische entweder Vikarien oder an ihnen bekannte Vikare. Czieke Blanks Tisch soll an ihre Enkelin fallen.

\section{Verwendung und Aussehen der Tische}

In der Frühzeit seiner Entwicklung wurde der Tisch als für die Ablage der Speisen und Einnahme der Mahlzeiten genutztes Möbelstück zur Essenszeit auf-, dann wieder abgebaut $^{143}$. Die nach diesen Anforderungen konzipierte Form des Schragentisches, bei dem eine Tischplatte auf Holzböcke aufgelegt wird, findet lange Zeit in graduellen, nicht prinzipiellen Veränderungen Verwendung. Eine mögliche Ausprägung ist die des Falttisches, der Folgetafel, die man je nach Größe der Tischgemeinschaft in Klapptischmechanismus verlängern konnte. Im 14. Jahrhundert zählt ein derartiger Tisch zum wertvolleren Mobiliar ${ }^{144}$. Segeband von Thune besitzt spätestens 1385 bereits zwei dieser Tische ${ }^{145}$, und annähernd einhundert Jahre später wird Czieke Blank ihre Folgetafel testamentarisch vererben, ein Zeichen für das Vorhandensein dieses Tischmöbels im Haushalt zumindest wohlhabender Lüneburger. Einer von zwei aus Niedersachsen

\footnotetext{
${ }^{143}$ D. W.H. SCHWARZ, Sachgüter und Lebensformen, S. 46; B. DENEKE, „Möbel“, in: Lex. d. Mittelalters, Bd.VI, Sp.700.

${ }^{144}$ M. HASSE, Neues Hausgerät.., S.44. Von Hasse ist der Begriff „Folgetafel“ übernommen.

${ }^{145}$ Im Testamentsformular sind direkt hinter den zwei Falttischen zwei weitere Tische im Hof in Verden als alias mensas longas bezeichnet. Der Gedanke an zwei weitere Falttische liegt nahe.
} 
stammenden Falttische ist in Lüneburg überliefert ${ }^{146}$. Der 1330 aus Eichenholz gefertigte Tisch kam vermutlich als Beutegut aus der 1371 von den Lüneburgern eingenommenen herzöglichen Burg am Kalkberg ins Rathaus, wo er 1928 „entdeckt“ wurde. Die Tischmittelplatte liegt mit den Klappen auf einem Schragengestell mit einer in sechs Rundbögen ausgesägten Zarge. „Das Vergrößern und Verkleinern vollzieht sich von der horizontalen Ebene aus, wie das Oeffnen und Schließen eines Flügelaltars von der vertikalen. Unterschobene Böcke boten den Klappen an den Schmalseiten Halt" ${ }^{\text {“147 }}$. Ausgeklappt ist der Tisch ca. 6, $60 \mathrm{~m}$, zusammengefaltet ca. 3, $30 \mathrm{~m}$ lang. Die Tischplatte ist mit Malereien verziert. Die volle Pracht des Tisches entfaltet sich im Sinne des Wortes nur bei ausgezogener Form. Auf dem grün gehaltenen Grund befinden sich in fünf Medaillons Szenen des Alten Testaments, deren Belehrungscharakter - wie er z. B. dem Salomonischen Urteil immanent ist - unübersehbar ist. An den Längs - und Schmalseiten des Tisches befinden sich Wappen von Kaisern, Königen und der Verwandtschaft der braunschweig - lüneburgischen Regenten.

Welche Verzierungen Falttische, die für den privaten Nutzen des Bürgers gefertigt waren, aufwiesen, kann in Lüneburg anhand des Inventars der Margarete Grönhagen von 1544 gezeigt werden: in der Diele des Grönhagenschen Hauses befand sich ein langer Tisch mit zwei Auslegern, der mit den Familienwappen der Grönhagen und Sanckenstede verziert war $^{148}$. Die einzig bekannte Farbverzierung eines testamentarisch vergabten Tisches ist das Grau des Tisches, den Johannes von Lippinghausen in seinem ersterrichteten Testament aufführt. Daß Grau eine gute Farbgrundierung für farbigere Embleme bzw. Wappen sein kann, zeigte der graue wappenverzierte Schrank im Inventar der Margarete Grönhagen. Feststehende Tische konnten - wie die Lüneburger Überlieferung zeigt - auch mit Schubladen versehen $\operatorname{sein}^{149}$.

Tischtuch

Häufigkeit der testamentarischen Vererbung, Donatoren und Empfänger Neun Testatoren erwähnen in ihren Testamenten Tischdecken. Die verwendeten Bezeichnungen sind mensalia, tafellaken und decke.

\footnotetext{
${ }^{146}$ Der zweite Tisch steht im Cluny - Museum in Paris. H. REINECKE, Zwei bemalte Falttische der Gotik, in: Lüneburger Blätter, Heft 1, 1950, S.7 - 14; Kurzbesprechung in G. KÖRNERs Leitfaden durch das Museum in Lüneburg, Nr. A 4, S.16f .

${ }^{147}$ H. REINECKE, Zwei bemalte Falttische der Gotik, S.7.

${ }^{148}$ K. TERLAU - FRIEMANN, Lüneburger Wohnkultur, S.84.

${ }^{149}$ Die drei mit Schubladen oder zumindest mit Schubladenvorrichtung versehenen Tische sind beschrieben bei H. REINECKE, Holz-Arbeiten, Nr. 93 - 95, S.71.
} 
Kleriker treten als Testatoren kaum in Erscheinung; ihren zwei Testamenten stehen sieben Testamente von Bewohnern Lüneburgs gegenüber. Das erste relevante Testament des 14 . Jahrhunderts ist das Testament Segeband von Thunes, der 1385 in seinem Verdener Hof acht lange und kurze Tischtücher auflistet, in seinem Mindener Hof fünf Tischtücher erwähnt. Drei Testamente folgen in der Zeit zwischen 1412-1415, eines dann 1443, während die letzten vier aus den Jahren zwischen 1475-1485 stammen.

Die Kennzeichnung der testamentarisch vergabten Tischdecke anhand des Kriteriums der Länge findet sich neben dem Testament des Segeband von Thune nur noch im Testament der Geseke Leyferd aus dem Jahr 1485, in dem die Testatorin das längste Tischtuch der Schwester eines Bekannten vererbt. Tafellaken in der Länge von zehn Ellen hinterläßt Lutke Hilmers seiner Tochter. Das Kriterium der Qualität nutzt Adelheid Knakerugge 1412 zur Bezeichnung ihrer Tischtücher, deren beste an den Hochaltar des Klosters in Scharnebeck fallen sollen, ein Legat, das einmal mehr die universelle Nutzung materieller Güter zeigt und die dem neuzeitlichen Denken entspringende Trennung von Kirche und profanem Bereich vor Augen führt. Auffällig und keineswegs zufällig ist die Schenkung gerade der besten Tischtücher an eine Kirche oder ein Kloster, vor allem dann, wenn der Hochaltar bedacht wird. Johannes von Lippinghausen bedenkt zwei Vikarien der Kapelle St. Gertrud, in der er eine Vikarie innehat, mit Tischtüchern, deren eines er zusammen mit Hand - und Tischtuch vom Vikar Johann von Bilne übernommen hatte. Alle übrigen Testatoren bedenken Verwandte und Bekannte.

\section{Herstellung und Aussehen}

Zum Essen wurden die Tische mit Tischtüchern bedeckt, die oftmals bis auf den Boden reichten. Auf Bildquellen werden gedeckte Tische häufig in der Szene des Letzten Abendmahls und des Gastmahls des Herodes gezeigt; in Lüneburg gibt es eine entsprechende Gastmahlsdarstellung auf dem um die Mitte des 15. Jahrhunderts entstandenen Heiligenthaler Altar von Hans Bornemann und eine Darstellung des Letzten Abendmahls auf dem um 1500 entstandenen zehnteiligen Zyklus der Michaeliskirche ${ }^{150}$. Die hier gezeigten Tische sind rund bzw. (recht - ) eckig und mit einander ähnelnden Tischdecken versehen, die nicht bodenlang sind. Beide Tischdecken sind weiß, vermutlich also Leinentischdecken, deren Schmuck schwarze Zierstreifen in je zwei Linienfeldern dreigebündelter Linien sind, wobei die mittlere Linie die je breitetste ist. Die Streifen dieser erst seit dem 15. Jahrhundert auf den Bildquellen nachweisbaren, im 16. Jahrhundert dann alltäglichen Tischtücher konnten eingewebt, aber auch aufgestickt sein ${ }^{151}$. Mit Stickereien -

\footnotetext{
${ }^{150}$ Abbildung bei H. GMELIN, Spätgotische Tafelmalerei in Niedersachsen und Bremen, S.94ff; D. GEHRKE, E. MICHAEL, Museum für das Fürstentum Lüneburg, S.8.

${ }^{151}$ J. ZANDER - SEIDEL, Textiler Hausrat, S.320.
} 
vielleicht ähnlicher Ausprägung - versehen war auch die rode beneyede decke, die Czieke Blank 1475 ihrer Enkelin vererbte.

Heinrich Funhof bildete auf der Tafel des Johannislebens einen langen schmalen Tisch (vielleicht einen Falttisch?) beim Gastmahl des Herodes ab, dessen schlicht weißes Tischtuch - knapp die Tischplatte bedeckend - in lockerer Fallweise Falten warf und ein fast transparentes Aussehen hatte, also den Eindruck eines edlen Stoffes erweckte ${ }^{152}$. Als vornehme Tischdecken kommen Leinendamaste oder Seidengewebe in Frage. Gerade Flandern, dessen Tuche in Lüneburg durchaus bekannt und begehrt waren, besaß seit dem 15. Jahrhundert Manufakturen entsprechenden Bekanntheitgrades. Unterstellt man eine Parallelität zwischen dem norddeutschen und dem süddeutschen Raum, dessen Märkte noch bis ins 16. Jahrhundert auf Leinendamastimporte angewiesen waren, so spricht in Lüneburg nichts gegen den vorrangigen Import flandrischer Leinendamaste. Aus den Lüneburger Kirchen sind etliche Seidengewebe prächtigster Ausstattungen überliefert, die zum Großteil aus dem orientalischen Bereich stammen, zum Teil aber auch italienischer Herkunft sind ${ }^{153}$. Ein Seidengewebe, das wohl als Altardecke Verwendung fand, schenkte Gese Lübberstedt in ihrem 1415 errichteten Testament ihrer Vikarie am St. Martinsaltar in St. Johannis.

Altardecken wurden auch in den Klöstern der unmittelbaren Nachbarschaft Lüneburgs hergestellt, und noch heute verfügt das Kloster Lüne über Altardecken, Teppiche und Banklaken aus dem Spätmittelalter ${ }^{154}$. Bei den überlieferten Altardecken handelt es sich um Weißstickereien, bei denen das feine Leinentuch folgendermaßen bearbeitet wurde: „Der Grund ist vielfach durch Zusammenziehen von drei Fäden und Umwickeln mit einem vierten durchbrochen. Die darin ausgesparten Figuren oder Ornamente wurden mit weißem Leinengarn in den verschiedensten Stichen kräftig konturiert und zum Teil ausgestickt, einige Linien ehemals auch mit schwarzen oder braunen Fäden betont“"155. Bekannt ist der

\footnotetext{
${ }^{152}$ H. GMELIN, Spätgotische Tafelmalerei in Niedersachsen und Bremen, S.120ff.

${ }^{153}$ Die ,,regelmäßig“ belegten Orient - und Ostimporte waren offensichtlich nicht nur sehr beliebt, sie dienten auch als Mustervorlage für die europäischen Tuchzentren. G. JARITZ, „Decke“, in: Lexikon des Mittelalters, Bd. III, Sp. 619. Aus St. Nikolai stammt ein orientalisches Seidengewebe des 14. Jahrhunderts, das W. REINECKE beschreibt als rotes, ,köperartiges Gewebe mit grünen horizontalen Streifen“, das sozusagen die Stoffgrundlage ausmacht, ,darin reihenweise angeordnet je ein sitzender Geier oder Adler mit großen Schwingen und je zwei dicht nebeneinander sitzende Hunde (Leoparden?), getrennt durch ein granatapfelähnliches Pflanzengebilde. Tiere und Pflanzen aus vergoldeten Häutchenfäden.“. Das Gewebe besteht aus einem Halbrund von $50: 60$ cm. Zitiert aus: W. REINECKE, Die Kirchliche Abteilung, Nr. 208. Ein aus Lucca stammendes Seidengewebe „, mit eingewebten Pfauen, Blumen und Löwen“ wurde im 15. Jahrhundert an der Oberseite mit einer rotseidenen und goldenen Borde versehen, an der unteren Seite blaue, rote und weiße Fransen. Zusätzlich wurden an die Unterseite drei Streifen angenäht, die mit Abbildungen von sechs Heiligen bestickt waren. W. REINECKE, Die Kirchliche Abteilung, Nr. 205, S. 153; G. KÖRNER, Leitfaden, Nr. H 88, S. 149.

${ }^{154}$ Informationen über den geschichtlichen Hintergrund, die Handarbeitstechniken und ein Katalog der erhaltenen Stücke bietet H. APPUHN, Bildstickereien des Mittelalters in Kloster Lüne, Dortmund 1990/3.

${ }^{155}$ H. APPUHN, Bildstickereien, S.22. Beispiele S. 27 - 52.
} 
Verkauf von Handarbeiten im Kloster Wienhausen ${ }^{156}$; für das Kloster Lüne gibt es keinen entsprechenden Hinweis, aber entscheidend ist doch die Kenntnis, daß ein bürgerlicher Haushalt möglicherweise Tischdecken ähnlicher Machart besessen haben könnte. Immerhin stellte ein Haushalt die Decken nicht ausschließlich selbst her, sondern kaufte durchaus Tischdecken an. So formuliert Klaus Schmied 1443, er vererbe seinen beiden Töchtern so viele Tischdecken, wie er für die Frauengerade angekauft habe. Auch die von Vicke Bottermann 1476 vererbten drei Decken hat der Testator laut eigenem Bekunden gekauft. Natürlich kann nicht ohne weiteres vom Bestand überlieferter Altardecken und Stoffen in kirchlichem Besitz auf den Bestand eines bürgerlichen Haushaltes geschlossen werden, aber die Verbindungen zwischen den Decken des profanen und des sakralen Bereichs sprechen auch nicht von vornherein gegen einen Vergleich ${ }^{157}$. Immerhin stammt das Tischtuch urspünglich aus dem profanen Bereich ${ }^{158}$, und die Grundformen der profanen Tischtücher unterscheiden sich im Prinzip nicht von den Altardecken, über deren Verwendung und Aussehen zum Untersuchungszeitraum keine kirchlichen Direktiven vorliegen ${ }^{159}$, deren Motivik allerdings von ihrem Verwendungszweck bei den Meßfeiern zeugt. Man darf davon ausgehen, daß die auf den kirchlichen Werken dargestellten Leinentischdecken denen nicht unähnlich waren, die die Lüneburger Testatoren vererbten. Tischtücher und Handtücher konnten je nach Bedarf gebleicht und angefertigt werden. Das setzt ein Deponieren ungebleichten Leinenstoffs im Haushalt voraus. Einen deutlichen Beweis dafür liefert das Testament Johannes von Lippinghausens aus dem Jahr 1414, in dem der Testator eine Verfügung erläßt über panno lineo non dealbato reposito in cista ${ }^{160}$. Und auch das Inventar des Johannes Koller erwähnt - wie bereits dargestellt - eine Tannentruhe, in der drei Ballen Leinwand von je 98 Ellen liegen, die die Köchin zur Bleiche bringen sollte. Insofern hat es Verfügungen wie die des obengenannten Lutke Hilmers gegeben oder auch die der Geseke Leyferd, die einer Bekannten vier lakendocke und ihrer ehemaligen Magd eines vererbte ${ }^{161}$.

\section{Servietten}

Servietten werden ausschließlich im Testament des Archidiakons Segeband von Thune als bylakene erwähnt ${ }^{162}$. Sie weisen auf den gehobenen Haushalt hin, gelten sie doch „als

\footnotetext{
${ }^{156}$ H. APPUHN, Bildstickereien, S.13.

${ }^{157}$ J. ZANDER - SEIDEL belegt die „, Parallelen“ der „liturgischen Altarbekleidung ... mit dem zum weltlichen Mahl gedeckten Tisch“. dies., Textiler Hausrat, S.306.

${ }^{158}$ A. REINLE, Ausstattung deutscher Kirchen, S.16.

${ }^{159}$ BRAUN, Joseph, ,Altardecke“, in: RDK, Bd. I, Sp.489.

${ }^{160}$ U. REINHARDT, Testamente, Nr.103, S.143.

${ }^{161}$ U. REINHARDT, Testamente, Nr.270, S.427.

${ }^{162}$ U. REINHARDT, Testamente, Nr.45, S.62.
} 
Bestandteil einer verfeinerten Eßkultur ${ }^{163}$. Verwendet werden die überwiegend aus Leinen gefertigten Servietten anstelle des Tischtuches oder neben inm als Schutz für die Kleidung und auch zum Abwischen von Händen und Mund.

f. Sitzgelegenheiten und ihr textiles Zubehör

Stühle und Bänke

Häufigkeit der testamentarischen Vererbung, Donatoren und Empfänger

Sitzgelegenheiten wie Stühle und Bänke treten in fünf Testamenten von vier Testatoren des 15. Jahrhunderts auf (1414 Johannes von Lippinghausen, 1422 Grete von dem Wede, 1424 Johannes von Lippinghausen, 1430 Adelheid Kolse und 1499 Hilleke Blickershusen). Sie spielen im Rahmen der testamentarisch vererbten Güter also eine eher marginale Rolle, und dies ist auch in den Schriftquellen anderer Städte so ${ }^{164}$. Es hat geradezu den Anschein, als erwähnten die Testatoren ihre entsprechenden Objekte nur aus der Gegebenheit einer sie dazu veranlassenden Situation: Der Vikar Johannes von Lippinghausen hinterläßt der von inm versorgten Vikarie in St. Johannis vier Stühle; die drei Testatorinnen scheinen verwitwet gewesen zu sein, wobei aber nur Hilleke Blickershusen sich als Witwe bezeichnete, während Grete von dem Wede weder Mann noch Kinder im Testament erwähnt. Der gemeinsame Nenner aller über Sitzmobiliar verfügenden Testatoren ist das Fehlen direkter Nachkommen, die als Erben eingesetzt werden konnten. Immerhin hätte Adelheid Kolse die Möglichkeit gehabt, ihren Sohn Bernd als Erben einzusetzen, aber angesichts seiner wilden und verschwenderischen Art - so zumindest die Einschätzung der Mutter - erhielt er „nur“ eine Leibrente. Ob der nun bedachte Bernd Hakensnyder ein Verwandter oder ein Bekannter war, läßt sich nicht mehr feststellen; die beiden anderen Testatorinnen setzten als Erben ihres Sitzmobiliars Verwandte ein.

Grete von dem Wede und Hilleke Blickershusen vererben summarisch ihre Sitzgelegenheiten mit der Formel myne stole und bencke ${ }^{165}$. Zahlenwerte nennt Adelheid Kolse mit drei Stühlen und Johannes von Lippinghausen mit vier Stühlen. Eine Anzahl von

\footnotetext{
${ }^{163}$ J. ZANDER - SEIDEL, Textiler Hausrat, S.310.

${ }^{164}$ J. SCHILDHAUER fand Legate über Stühle und Bänke nur „vereinzelt“ in den Stralsunder Testamenten. ders., Hansestädtischer Alltag, S.71. In Konstanzer Testamenten erhält ,der Stuhl an sich nie den Status der Vererbungswürdigkeit“. P. BAUR, Testament und Bürgerschaft, S.233. In Hamburger Testamenten werden Stühle ebenfalls erwähnt, jedoch nennt LOOSE in seiner Auswertung weder Zeitraum noch Anzahl. ders., Leben und Kultur, S.8. Auch in Berner Testamenten wurden Stühle offenbar vererbt, allerdings für das 14./15. Jahrhundert wohl in recht geringer Zahl, da ZAHND in seiner Argumentation auf ein Korneuburger Beispiel zurückgreifen muß. ders., Spätmittelalterliche Bürgertestamente, S.67.

${ }^{165}$ U. REINHARDT, Testamente, Nr.145, S.192; Nr.292, S.470.
} 
drei bis vier Stühlen in wohlhabenderen Haushalten und von ungefähr zwei Stühlen in einfacheren Haushalten läßt sich für das Köln des 15. Jahrhunderts aufgrund der Schriftquellen nachweisen ${ }^{166}$, Zahlenwerte, die sich mit denen Lüneburger Testamente decken. Ob diese Werte identisch sind mit der tatsächlichen Anzahl an Stühlen in einem Haus, kann nicht endgültig geklärt werden. Die geringe gegenständliche und schriftliche Überlieferung erweist sich hier als erschwerend, aber es wird angenommen, daß eine nicht allzu geringe Menge an Stühlen durchaus im bürgerlichen Haushalt des 15. Jahrhunderts vertreten war.

\section{Aussehen}

Es gibt die Kenntnis von verschiedenen Stuhlformen im Spätmittelalter. Bekannt sind drei oder vierbeinige Hocker oder Stühle, deren Beine gedrechselt oder eckig sein konnten und oftmals durch waagerecht montierte Streben verbunden waren ${ }^{167}$. Diese unterschiedlichen Formen sind in der bildlichen Überlieferung vorrangig dargestellt auf Abendmahlsszenen. In Lüneburg gibt es drei Abendmahlsszenen, die einen bzw. mehrere Stühle zeigen. Eine Abendmahlsdarstellung auf der Innenseite des linken Außenflügels der „Goldenen Tafel“ des Michaelisklosters (1. Viertel des 15. Jahrhunderts) zeigt einen vierbeinigen, eckigen Stuhl mit mittelhoher Lehne, die im oberen Bereich mit einem Gitterwerk fünf wohl gedrechselter Stäbe verziert ist ${ }^{168}$. Die obere Begrenzung dieses Gitterwerkes besteht sozusagen aus einem langgezogenen Dreieck, das an seiner höchsten Stelle mit Schnitzarbeit verziert ist. Eine weitere Abendmahlsdarstellung findet sich am Heiligenthaler Altar des Hans Bornemann, der zwischen 1444 und 1447 entstanden ist ${ }^{169}$. Abgebildet sind drei Stühle verschiedenen Aussehens. Zwei der Stühle sind Dreieckstühle, deren einer mit Lehne versehen ist, die aus dem rückwärtigen Stuhlbein in dann nochmals gleicher Stuhlbeinlänge erwächst, wobei ein am oberen Ende montierter Querstab ein Anlehnen ermöglicht. Als einziger der drei Stühle ist dieser Stuhl durch in gewissen Abständen eingekerbte, parallel verlaufende dreigebündelte Ringe verziert. Der vierbeinige Stuhl mit Lehne ist schlicht gehalten, allein die ebenso wie die Querstreben aus andersfarbigem Holz gearbeiteten Keile erzielen eine optische Auflockerung der Rückansicht. Eine dritte

\footnotetext{
${ }^{166}$ B. DENEKE, „Möbel“, in: Lexikon des Mittelalters, Bd. VI, Sp.702.

${ }^{167}$ Zusammenstellung der Möglichkeiten nach H. APPUHN/J. WITTSTOCK, Mittelalterliche Hausmöbel, S.53.

${ }^{168}$ Abgebildet in: F. STUTTMANN, Meisterwerke der niedersächsischen Landesgalerie Hannover, S.20.

${ }^{169}$ Kurze Einführung in Geschichte und Aussehen bei W. REINECKE, Führer durch die Sammlungen des Museumsvereins für das Fürstentum Lüneburg, Bd. II ( = Die Kirchliche Abteilung), S.7ff; Abbildung und genauere Beschreibung bei H. G. GMELIN, Spätgotische Tafelmalerei in Niedersachsen und Bremen, S.94ff; Abbildung und Beschreibung der Stuhlformen bei H. APPUHN/J. WITTSTOCK, Mittelalterliche Hausmöbel, S.52f.
} 
Abendmahlsszene zeigt eine um 1500 entstandene Altartafel aus St. Michaelis ${ }^{170}$. Der hier durch eine Tür beengte Einblick in den Raum des Abendmahls zeigt nur einen Ausschnitt des Geschehens, so daß lediglich die Lehne eines Stuhles erkennbar wird. Diese Lehne gleicht der des Dreibeinstuhles vom Heiligenthaler Altar. Diese Duplizität der Stuhlformen ist gewiß kein Zufall, denn bekannt ist die besondere Beliebtheit dieser Stühle im nordwestdeutschen Bereich ${ }^{171}$. Bekannt ist auch die impulsgebende Funktion dieses Raumes für die Lüneburger Tafelmalerei ${ }^{172}$, und wenn hier im nordostdeutschen Lüneburg dreibeinige Lehnstühle abgebildet und somit sicherlich bekannt waren oder wurden, so zeugt das von - mit aller Vorsicht formuliert - Modeerscheinungen innerhalb der Palette möglicher Stuhlausformungen. Unter den testamentarisch vergabten Stühlen konnten durchaus Formen gewesen sein, die denen der auf den Altartafeln abgebildeten Stühlen glichen.

\section{Verwendung}

Die Bildquellen weisen auch hin auf die Verwendung der Stühle: Die Gesellschaft des Letzten Abendmahls ist auf die zusätzliche Nutzung von Stühlen als Sitzgelegenheiten angewiesen, da der Sitzplatz auf dem primär verwendeten Sitzmöbel, der Bank, bei weitem nicht ausreicht. Diese fakultative Nutzung des Stuhls bei Gastmählern zeigt sich ebenfalls im Inventar der Margarete Grönhagen, das als Bestand des Festsaals im Obergeschoß neben einem langen bemalten Tisch mit fünf Schragen zwanzig hölzerne Stühle auflistet ${ }^{173}$. Stühle werden nicht nur als Sitzgelegenheit bei Tisch genutzt. Das Inventar des Johannes Koller zeigt die insgesamt zwölf Stühle verteilt über die Küche (fünf Stühle), die repräsentativ eingerichtete Vorderdornse (drei Stühle), die durch etliche Bücher als Arbeitszimmer ausgewiesene Hinterkammer (zwei Stühle) und den Hausboden mit zwei Stühlen ${ }^{174}$. Evident ist, daß die Verwendung der Stühle abhängig ist „von den unterschiedlich geprägten Bedeutungszonen der Wohnräume“"175.

Stühle als Sitzmobiliar bekamen mehr Bedeutung durch den sich allmählich vollziehenden Mobiliätswechsel zwischen Tisch und Sitzgelegenheit. War zunächst der Standort der

\footnotetext{
${ }^{170}$ Beschreibung bei W. REINECKE, Die kirchliche Abteilung (=Führer durch die Sammlungen des Museumsvereins für das Fürstentum Lüneburg, Bd.II), Lüneburg 1911, Nr.8, S.18; Abbildung bei E. MICHAEL/ D. GEHRKE, Museum für das Fürstentum Lüneburg; S.88.

${ }^{171}$ H. APPUHN/ J. WITTSTOCK, Mittelalterliche Hausmöbel, S.53.

${ }^{172}$ Der zweite, an der Goldenen Tafel arbeitende Meister stammte aus Köln. R. BLASCHKE, Die Meister der Flügelmalereien der Lüneburger Goldenen Tafel, in: Niederdeutsche Beiträge zur Kunstgeschichte, Bd.17, 1978, S.86. Den Werken des im Norddeutschen Raumes wirkenden und eventuell aus ihm stammenden Johannes Bornemann konnte ein Bezug nachgewiesen werden ,,sowohl zur älteren Bildtradition als auch zu modern westlichen Erfindungen“. S. KEMPERDICK, Zum Werk des Johannes Bornemann, in: Niederdeutsche Beiträge zur Kunstgeschichte, Bd.33, 1994, S.71.

${ }^{173}$ K. TERLAU - FRIEMANN, Lüneburger Patrizierarchitektur, S.88.

${ }^{174}$ Th. MEYER, Inventar des Nachlasses .. M. Joh. Koller, passim.

${ }^{175}$ R. E. MOHRMANN, Wohnen und Wohnkultur, S.514.
} 
Sitzgelegenheit - meist der wandfesten Bank - ausschlaggenend für das Aufstellen des Falttisches, so richtete sich im Lauf der Zeit das Aufstellen der Sitzgelegenheit, der Stühle, nach dem Standort des fest stehenden Tisches. Erst seit dem späten 15. Jahrhundert ist der Tisch feststehend ${ }^{176}$.

Die Testamente Grete von dem Wedes und Hilleke Blickershusens zeugen davon, daß die Bänke nicht immer wandfest waren, da sie über immobile Bänke-losgelöst vom Hausbesitz-schon allein aus technischen Gründen nicht verfügen konnten. Die Bildquellen zeigen des öfteren Bänke, die vor den Kamin gerückt sind, um die Wärme effektiv zu nutzen. Die Rücklehnen können mittels Scharnier auf beide Längsseiten umgelegt werden, so daß die Bank beidseitig verwendbar ist, wie ein in Lüneburg erhaltenes Exemplar zeigt $^{177}$. In Lüneburg ist eine Bank ohne Rücklehne aus der zweiten Hälfte des 15. Jahrhunderts überliefert ${ }^{178}$. Dieses aus der Großen Ratsstube des Rathauses stammende Sitzmöbel ist aus Nadelholz mit Eichenauflagen gefertigt und ähnelt im Aussehen einer Truhe. Die Ähnlichkeit verweist auf die enge Verwandtschaft von als Sitzgelegenheit genutzter Truhe und als Stauraum genutzter Bank. Im optischen Bereich setzt sich diese Ähnlichkeit fort in dem durch besondere Verzierungen hervorgehobenen Frontbereich. Auch eine weitere, einfache „Sitztruhe“, die in Lüneburg überliefert ist, besteht wie die Bank aus dem Rathaus aus Nadelholz und ist an der Vorderfront mit Rahmenprofilen aus dunklerem Eichenholz versehen ${ }^{179}$. Anders als die vorrangig zu Verwahrungszwecken genutzten Truhen bestehen die als Sitzgelegenheiten genutzten Bänke nicht überwiegend aus Eiche, sondern aus einfacherem und weniger durableren Nadel - , vermutlich wohl Tannenholz ${ }^{180}$, und sind allein aus schmucktechnischen Gründen mit Eichenholzversatzstücken versehen. Schon die Wahl des Materials zeigt die nicht allzu hoch zu veranschlagende Wertigkeit, die dem Sitzmobiliar im häuslichen Bereich beigemessen wurde. Hier liegt auch die Erklärung für die seltene Erwähnung von Stühlen und Bänken in Testamenten.

\section{Sitzkissen}

\footnotetext{
${ }^{176}$ R. E. MOHRMANN, Wohnen und Wohnkultur, S.515.

${ }^{177}$ Die Sitzbank ist um 1500 entstanden, besteht aus Eichen - und Nadelholz. Ihre Maße sind 95 (Lehne) / 50 $($ Sitz $) \times 248 \times 39,5 \mathrm{~cm}$. ,Die Sitzfläche ist eingespannt zwischen 2 eichene wangenartige Seitenlehnen mit Fußleisten. Dem Sitzbrett aus Nadelholz ( später ergänzt? ) sind unten, an der Vorder - und Hinterseite, schmale, an der Unterkante wellenförmig ausgesägte Leistenbretter angefügt. Die Rücklehne läßt sich mit Hülfe eines Scharniers über die Seitenlehnen hinweg von hinten nach vorne klappen, so daß die Bank auf beiden Seiten zu benutzen ist.“ zitiert nach H. REINECKE, Holz-Arbeiten, Nr.90, S.70.

${ }^{178}$ H. REINECKE, Holz-Arbeiten, Nr.97, S.72.

${ }^{179}$ H. REINECKE , Holz-Arbeiten, Nr.98, S.72.

${ }^{180}$ So muß darauf hingewiesen werden, daß es sich bei den in den Testamenten erwähnten Tannenholztruhen durchaus um gelegentlich oder vorrangig zum Sitzen genutzte Truhen/ Bänke gehandelt haben könnte, zumal die Trennung von Verwahrtruhe und Sitzbank neuzeitlichem Denken entspringt.
} 
Da weder Bänke noch Stühle gepolstert waren, wurden auf die Sitzflächen aus Bequemlichkeitsgründen Kissen gelegt, die als repräsentatives Schmuckobjekt genutzt werden konnten. So ist die Sitzfläche des mittleren Stuhls auf dem Heiligenthaler Altar belegt mit einem roten Kissen, an dessen Enden über die Sitzfläche hinaus Troddeln hinabhängen. Aufgrund der durch das Sitzen verursachten Abnutzung wurden die Kissen gerne aus Leder gefertigt. Aus dem Schatz des Michaelisklosters stammt ein um 1425 hergestelltes Lederkissen ${ }^{181}$. Es hat die Maße von $35 \times 30 \mathrm{~cm}$ und ist mit Daunen gefüllt. In der Technik des Lederschnitts ist das Kissen verziert mit dem Gruß des Gabriels, mit den Heiligen drei Königen, Blattzierat und der Darstellung zweier ineinander verschmolzener Drachen. Rotgefärbt heben sich diese Motive vom gelblichen Untergrund ab.

Kissen und Banklaken werden von fünf Testatoren vererbt (1385 Segeband von Thune, 1414 und 1424 Johannes von Lippinghausen, 1472 Geseke Rosemberg, 1476 Vicke Bottermann und 1485 Geseke Leyferd). Auffallend ist, daß die Sitzkissen oder Polster in bürgerlichen Testamenten ungefähr nur im letzten Viertel des 15. Jahrhunderts aufgeführt werden. Auch wenn man ein Erwähnen dieser Objekte in den bürgerlichen Testamenten nur in Ausnahmefällen, also bei Kinderlosigkeit oder rechtlicher Absicherung von nicht ehelichen Kindern wie bei Vicke Bottermann ausgeht, hat es doch den Anschein, als habe es jetzt erst „vererbungswürdige“ Kissen in entsprechender Anzahl gegeben.

Geseke Leyferd bedenkt eine ihr bekannte Frau mit sechs zweitbesten stolkussen ${ }^{182}$. Über je vier Stuhlkissen verfügen Segeband von Thune und Johannes von Lippinghausen.

Banklaken sind in den Testamenten Segeband von Thunes, Geseke Rosembergs und Vicke Bottermanns verzeichnet. Bottermann bezeichnet seine nicht ehelichen Kinder als Empfänger und Geseke Rosemberg bedenkt den Chor des Klosters Walsrode mit ihrem toppet banclaken ${ }^{183}$. Dieses Legat zeugt von der Gepflogenheit, im bürgerlichen Haushalt wie in den Klöstern an den Rückwänden der Bänke bzw. des Chorgestühls Banklaken aufzuhängen. Im Kloster Lüne ist ein Banklaken erhalten, das an der Rückwand des Propstsitzes befestigt wurde ${ }^{184}$. Die auf Leinentuch angefertigte Wollstickerei ist farbenfroh in elf verschiedenen Farben gehalten und ringsumher mit Fransen versehen. Drei in der Mitte plazierte Medaillons zeigen die Geburt Christi, die Auferstehung und den Weltenrichter. Die Medaillons sind von Inschriften umrahmt ebenso wie das gesamte Rechteck, das die Fläche der drei Medaillons ausmacht. Der außerordentlich gute Zustand des Banklakens wird auf eine möglicherweise begrenzte Verwendung nur an Festtagen der

\footnotetext{
${ }^{181}$ G. KÖRNER, Leitfaden, Nr. A 16, S.23.

${ }^{182}$ U. REINHARDT, Testamente, Nr.270, S.427.

${ }^{183}$ U. REINHARDT, Testamente, Nr.237, S.353. toppet $/$ teppet $=$ Teppich, Decke zum Überbreiten, Tapete als Wandbekleidung. A. LÜBBEN, Mittelniederdeutsches Handwörterbuch, S.402.

${ }^{184}$ H. APPUHN, Bildstickereien des Mittelalters in Kloster Lüne, S. 11; S.105ff (hier Beschreibung des Banklakens mit Abbildung).
} 
abgebildeten Heiligen zurückgeführt ${ }^{185}$. Der Chor von St. Johannis erhielt in den 70 er Jahren des 15. Jahrhunderts Rücklaken aus Leinen, die Szenen aus dem Leben des Heiligen Johannes und des Jürgens zeigen ${ }^{186}$. Wenn Geseke Leyferd nun ihr bislang offenbar privat genutztes Banklaken an der Rückwand eines Sitzes bzw. des Chorgestühls im Kloster Walsrode zu befestigen wünscht, so scheint die Motivik ihres Erbstückes ebenfalls religiöser Natur gewesen zu sein. Die überlieferten Stücke zeigen eine breite Motivpalette von Blumen, Tieren, Blattwerk, Früchten, Schrift bis hin zu Familienwappen. Überliefert ist in Lüneburg auch ein Rücklaken mit einer profanen Thematik, die vermutlich eine Verlobung darstellt ${ }^{187}$.

Einen Einblick in den Besitzbestand an Kissen und Banklaken wohlhabender Haushalte im Lüneburg des 16. Jahrhunderts gewähren die Inventare Johannes Kollers und der Margarete Grönhagen. Sitzpolster und Tischwäsche befinden sich vorwiegend im Erdgeschoß des Hauses. Im Bereich des Erdgeschosses spielte sich ein Großteil des täglichen Lebens $a b$; hier verschmolzen anders als im vorwiegend privat genutzten Obergeschoß die mehr private Sphäre der Essenszubereitung und Aufnahme mit der der Öffentlichkeit zugewandten Sphäre der Geschäfte und persönlichen Kontakte. Wo sonst, wenn nicht hier, ist es sinnvoll, Banklaken und Kissen für die Bequemlichkeit und die Lust am Repräsentieren liegen zu haben?! Allein 34 Kissen befinden sich im Erdgeschoß des Hauses von Johannes Koller. In der Diele, die ehedem als vorrangiger Wohn -und Repräsentierraum diente, im 16. Jahrhundert in ihrer Funktion von den Stuben abgelöst wurde $^{188}$, deutet das Vorhandensein je zweier Banklaken und Bankpfühle auf die ständigen Sitzmöglichkeiten (wandfester) Bänke hin, während für eine Erweiterung der Sitzgemeinschaft sechs Stuhlkissen zur Verfügung stehen. Bei einem Festmahl finden anscheinend die 16 Stuhlkissen Verwendung, die in einer Tannentruhe in der Nähe der Küche verstaut sind. Die Verlagerung des Wohnbereichs in die Stuben zeigt die Existenz wertvollerer Kissen in Vorder - und Hinterdornse, wo sich Lederkissen, Lederpfühl und semesche Kissen befinden ${ }^{189}$.

\footnotetext{
${ }^{185}$ H. APPUHN, Bildstickereien des Mittelalters in Kloster Lüne, S.11.

${ }^{186}$ F. KRÜGER/W. REINECKE, Die Kunstdenkmale der Stadt Lüneburg, S.77.

${ }^{187}$ W. REINECKE, Führer durch die Sammlungen des Museumsvereins für das Fürstentum Lüneburg, Bd. II, Nr.212, S.156ff ( mit Abbildung ).

${ }^{188}$ R. E. MOHRMANN, Wohnen und Wohnkultur, S.520; K. TERLAU - FRIEMANN, Lüneburger

Wohnkultur, S.85.

${ }^{189}$ TH. MEYER, Inventar des Nachlasses .. M. Joh. Koller, S.84.
} 


\section{Küchen- und Tischgerätschaften}

\section{a. Einleitung}

Die Küche befindet sich mit der Feuerstelle in einem Lüneburger Haus „etwa in der Mitte einer Längswand eines giebelständigen Hauses, direkt hinter der Stube“"1. Die Küche ist zunächst zur Diele hin offen, kann ab Ende des 15. Jahrhunderts auch abgetrennt sein. Die Ausstattung der Küche besteht aus einfachen, zweckdienlichen Möbeln. Gegessen wird in der Diele, die aufgrund ihrer zentralen Position im Haus multifunktional auch dem Arbeiten und Spielen der Kinder dient. Festtafeln werden - zumindest im 16. Jahrhundert - in einem größeren kaminbeheizten Raum eines Flügelbaus, dem Saal, errichtet ${ }^{2}$.

Das Ausblenden der irdenen und hölzernen Ware in den Testamenten ist bei allen Realien zu beobachten, die dem Bereich „Essen und Trinken“ zugeordnet werden können. Betroffen sind hier nicht nur die Lüneburger Testamente, sondern die Testamente einer jeden spätmittelalterlichen Stadt. So ist die Kenntnis der Keramik- und Holzrealien fast ausschließlich der Archäologie zu verdanken ${ }^{3}$. Metallgegenstände werden selten zutage gefördert; sie sind entweder zerfallen oder - und dieses scheint die vorrangige Begründung zu sein - sie wurden aufgrund ihres Wertes eingeschmolzen, dann neu verwendet.

Die heutige Forschung geht davon aus, daß das täglich verwendete Koch- und Tischgerät aus Keramik und Holz bestand und sich die bürgerlichen Haushalte nicht wesentlich voneinander unterschieden ${ }^{4}$. Ein anderes Bild bot sich wohl bei Festtagen; der reiche Bürger benutzte seine metallenen und damit repräsentativen Hausgerätschaften, die der weniger wohlhabende Bürger sich nicht leisten konnte.

Die Testatoren nehmen nur die Realien in ihr Testament auf, denen sie einen ideellen, meistens jedoch materiellen Wert beimessen. Im Bereich der Kochutensilien und des Tischgeräts erfassen sie im Regelfall die wertvollen Metallgegenstände und Gläser, die an Festtagen oder bei Feierlichkeiten benutzt werden. Aus der testamentarischen Bestandsaufnahme eine „alltägliche“ Koch- und Eßsituation abzuleiten, ist unhaltbar.

\footnotetext{
${ }^{1}$ E. RING, Das Töpferhaus. Ausgrabungen und bauarchäologische Untersuchungen des Töpferhauses in Lüneburg, in: Kat. „Ton Steine Scherben“, Lüneburg 1996, S.36.

${ }^{2}$ K. TERLAU-FRIEMANN, Lüneburger Patrizierarchitektur, Lüneburg 1996, S.96

${ }^{3}$ Nahezu alle Ausstellungen der jüngeren Zeit präsentierten derartige Funde, und auch in Lüneburg gibt es eine ansehliche Menge freigelegter Keramik. Die neusten Funde belegen erstmals, daß in Lüneburg einfache Gebrauchsware produziert wurde. Über die neusten Lüneburger Funde informitiert ${ }^{3} \mathrm{M}$. KÜHLBORN, Keramik und Glasfunde der Fundstelle „Auf der Altstadt 29“, in: Kat. „Ton Steine Scherben“, Lüneburg 1996, S.41-70. 4“'Im Gegensatz zum Bild der traditionellen Forschung ist davon auszugehen, daß der Patrizier alltäglich in seiner ständig genutzten materiellen Kultur vom einfachsten Bürger kaum unterschieden war. S. SCHÜTTE, Bürgerliches Hausgerät des Hoch- und Spätmittelalters in Nordwestdeutschland, in: Kat. „Stadt im Wandel“, S.547; ähnliche Informationen - vor allem über Holz und Keramik bei A. FALK, Haus, Wohnen und HausratPött und Pann: Der Hausrat, in: Kat. „Die Hanse“, Bd.1, S.400f.
} 
Da die Lüneburger Testatoren in ihrer Vielzahl (äußerst) wohlhabende Bürger sind, enthalten ihre Testamente etliche Verfügungen über wertvolle Küchen- und Tischgerätschaften.

b. Küchengerätschaften

$\alpha$. Grapen

Bei den Grapen handelt es sich - grob definiert - um kugelige Dreibeintöpfe ${ }^{5}$. Die Testatoren bezeichnen sie als olla oder gropen. Etliche Testatoren verfügen summarisch über Grapen. In diesen Fällen wird davon ausgegangen, daß es sich um mindestens zwei Grapen gehandelt hat, eine Zahl, die sicherlich in den meisten Testamenten zu niedrig gegriffen ist, jedoch aufgrund des automatisch spekulativen Charakters jeder höheren Zahl mit Bedacht gewählt ist.

Tabelle: Testamentarische Verfügungen über Grapen

\begin{tabular}{|l|c|}
\hline Jahre & $\begin{array}{l}\text { Anzahl der Testatoren und mindestens vererbter } \\
\text { Grapen }\end{array}$ \\
\hline $1300-1325$ & - \\
\hline $1326-1350$ & - \\
\hline $1351-1375$ & - \\
\hline $1376-1400$ & 1 Testator mit 15 Grapen \\
\hline $1401-1425$ & 9 Testatoren mit 53 Grapen \\
\hline $1426-1450$ & 9 Testatoren mit 29 Grapen \\
\hline $1451-1475$ & 3 Testatoren mit 17 Grapen \\
\hline $1476-1500$ & 9 Testatoren mit 40 Grapen \\
\hline
\end{tabular}

Fast alle Testamente, in denen über Grapen verfügt wird, stammen aus dem 15. Jahrhundert. Hier ist die Anzahl der relevanten Testamente fast gleich groß, nur die Zeit zwischen 1451 und 1475 fällt mit drei statt der sonst überlieferten acht oder neun Testamenten aus dem Rahmen.

\footnotetext{
${ }^{5}$ Umfassend zu dem Thema „Grapen“ und hier grundlegend genutzt H. DRESCHER, Zu den bronzenen Grapen des 12. - 16. Jahrhunderts aus Nordwestdeutschland, in: Kat. „Aus dem Alltag der mittelalterlichen Stadt, S.157 - 174
} 


\section{Donatoren und Empfänger}

30 Testatoren stellten 31 Testamente aus (Johannes von Lippinghausen testiert 1414 und 1424). Bei der Auswertung der Verfügungen über Grapen fallen besonders die Klerikertestamente mit ihren umfangreichen Beständen ins Auge, deren inventarähnliche Auflistung dem Umstand zu verdanken ist, daß Kleriker - zumindest den Regeln nach keine erbberechtigten Nachfahren in der vertikalen Linie besaßen. Von den über Grapen verfügenden Testamenten sind fünf von Klerikern ausgestellt worden, 26 Testamente stammen von Laien. Mit einem Zahlenverhältnis von $15: 11$ sind mehr von Frauen errichtete Testamente überliefert ${ }^{6}$.

Als Empfänger von Grapen weisen die Testamente 72mal engste Familienmitglieder wie Bruder, Schwester oder die eigenen Kinder aus. Mit 35 Legaten folgen die Zuwendungen an Bekannte, 25mal werden Vikarien bedacht, und viermal werden Grapen anderweitig für kirchliche Belange vergabt. Evident ist das vorrangige Verbleiben der Grapen in Familienhand. Von der möglichen umsichtigen Sicherung der Grapen für die Familienlinie zeugt das Testament Johann Krowels vom 21. Januar 1413, indem er in Hinblick auf den Lebensstandard seiner Frau formuliert: sovele gropenketele bruchenwes, alse se des to erer persone behovet, ok to brukende ere levedaghe. Na erem dode schal dat tosamende komen to mynen rechten erven ${ }^{7}$. Die Zuwendungen an eine Vikarie bedeuten nicht zwangsläufig den Verkauf des Topfes, es kann sich - wie im Fall des Johannes von Lippinghausen- um die Weitergabe von an die Vikarsstelle gebundenem Hausrat handeln, der von Nachfolger zu Nachfolger weiterzugeben ist. Der Hinweis, das Hausgerät sei nicht zu veräußern, deutet auf eine oft gegenteilige Praxis hin. Das Testament Ludolf Mangards zeigt, daß zu einer Vikarie ein Haus, sozusagen als Dienstwohnung des Vikars, gehören konnte, dessen Ausstattung u.a. Hausgerät umfassen konnte, das zu verkaufen auf unehrliche Amtsinhaber sicherlich großen Reiz ausübte.

Herstellungsmaterial der Grapen, Größe und Qualität

Lediglich drei der dreißig relevanten Testamente enthalten Angaben über das Material, aus dem die Grapen hergestellt wurden, ein Zeichen dafür, daß Grapen in der Regel aus ein und demselben Material verfertigt wurden, eine Materialangabe $\mathrm{zu}$ am Material ansetzenden Differenzierungszwecken überflüssig war. Die Testamente Segeband von Thunes, Archidiakon von Bevensen, und Johannes von Lippinghausens, Vikar in St. Johannis, sind nun die einzigen mit dem Hinweis, die Grapen seien eherne erea. Mit

\footnotetext{
${ }^{6}$ Unter den von Laien errichteten Testamenten befindet sich ein Gemeinschaftstestament: 1444 Klaus und Grete von Wening.

${ }^{7}$ U. REINHARDT, Testamente, Nr.94, S.130.
} 
diesem in etlichen Testamenten des Spätmittelalters verwendeten Terminus wurden aus Legierungen gegossene Gefäße bezeichnet, die als Bronzen oder als Messinge ${ }^{8}$ bezeichnet werden.

Irdene Töpfe (lebeta) spielen in den Testamenten so gut wie gar keine Rolle. Erwähnt werden sie in zwei Klerikertestamenten ohne jedweden weiterinformierenden Zusatz (1385 Segeband von Thune, 1424 Johannes von Lippinghausen).

Die ausschließlich in Klerikertestamenten anzutreffende Hervorhebung des stets verwendeten, daher eigentlich „normalen“ Materials steht mit dem vielfach auftretenden Verwandtschaftsverhältnis von Klerikertestament und Inventar in Zusammenhang, welches Testamente hervorbrachte, in denen wichtiger als die Differenzierung der Erbgüter deren möglichst genaue Deskription ist.

Das bei den Testatoren beliebteste Merkmal zur Differenzierung der zu vererbenden Stücke ist die - nicht komparativ verwendete -Größe der Grapen, die bei 62 Grapen als Maßstab angelegt wird. Die Anzahl der als groß oder klein bezeichneten Grapen hält sich annähernd die Waage; in den Testamenten begegnen acht große und neun kleine Grapen, während eine Menge von insgesamt 20 Grapen als kleine und große Grapen aufgelistet wurden. Zwischen den kleinen und den großen Grapen gab es mittelgroße Ausführungen, deren Anzahl mit 25 geringfügig über den Werten der kleinen oder der großen Grapen liegt.

Auffällig ist, daß von den insgesamt sieben relevanten Testamenten fünf Testamente aus dem ersten Quartal des 15. Jahrhunderts stammen, und hier immer neben den mittelgroßen Töpfen auch kleine und große Grapen vererbt werden, also ein gesamtes Set erwähnt wird. In den letzten beiden, im letzten Quartal des 15. Jahrhunderts ausgestellten Testamenten, in denen mittelgroße Grapen genannt werden, stehen sie für sich allein.

Das Kriterium Größe wird von vier Testatoren bezogen auf sechs Grapen superlativ gebraucht (1472 Geseke Rosemberg, 1481 Luteke Nyebur, 1485 Geseke Leyferd - ihre beiden größten Grapen, 1499 Hilleke Blickershusen - ihre zwei größten Grapen). Die je zweitgrößten Grapen werden in den Testamenten Immeke Burmesters 1419 und Grete von dem Wedes 1422 vergabt. Zwei wide gropen vererbt Immeke Burmester 1419; da sie in ihrem Testament weitere Grapen als große bezeichnet, muß sie hier weitgeschnittene

\footnotetext{
${ }^{8}$ M. HASSE zufolge handelte es sich eher um Messinge als um Bronzen, während eine 1982 beendete Untersuchung entsprechender Metallproben eher auf Kupfer - Zinn - Gemische, also auf Bronzen hinwies. Zink kam nicht vor, obwohl es durchaus als Legierungsmetall auch von Grapen bekannt ist. Solange es sich - wie im vorliegenden Fall - um die Auswertung schriftlicher Quellen handelt, erscheint HASSEs Vorschlag probat, die Terminologie der Testatoren beizubehalten. M. HASSE, Neues Hausgerät, neue Häuser, neue Kleider, S.23ff; H. DRESCHER, Zu den bronzenen Grapen des 12. - 16. Jahrhunderts aus Nordwestdeutschland, S.160f.
} 
Grapen gemeint haben, deren Öffnung sich nicht nach oben hin verengt, sondern wohl ähnlich der Pfanne ${ }^{9}$ - bei kürzerem oder längerem Körper die Weite der Grundform hält.

Eine weitere Differenzierungsvariante ist die Abstufung hinsichtlich der Qualität, wobei die Testatoren zwischen besten, nächstbesten und besseren Grapen $^{10}$ unterscheiden, und allein das Testament Klaus und Gretes von Wening (1444) nennt den Maßstab des Vergleichs, nämlich die Grapen des Heergewäts und der Frauengerade. Das Testament Lutke Hilmers aus dem Jahr 1480 beweist, daß die als besten titulierten Grapen in einigen Fällen gleichzeitig die größten Grapen waren. Die Größe des von Dietrich Junge vererbten Grapens wurde vom Testator über den Zweck definiert, indem er den Grapen als unam ollam beschrieb, in qua potest bulliri pullus ${ }^{11}$. Diese Formulierung spiegelt eine in Norddeutschland vor allem im 14. Jahrhundert vorkommende Größencharaktierisierung wider, die auf eine größere Grapenform verweist ${ }^{12}$.

Nutzung der Grapen und verschiedene Formen

$\mathrm{Daß}$ es sich bei Grapen um eine in der obigen Definition des kugeligen Dreibeintopfes angegebene Grundform handelt, von der es durchaus Variationen gibt, zeigen die Bezeichnungen gropenketel und schottelgropen, die in Testamenten aus den Jahren 1413 und 1472 verwendet werden.

Grapen können unterschieden werden nach ihrer Handhaben, also danach, ob sie mit Henkel oder Stil versehen sind ${ }^{13}$. Ein gropenketel ist ein Henkelgrapen (Johann Krowel, Testament 1413). Der Henkel dient als Aufhängevorrichtung für ein Hineinhängen ins Herdfeuer, wobei eine Hitzeregulierung durch Varianz der Aufhängehöhe möglich ist. Die Hängevorrichtung wird nicht nur zum Kochen benutzt, sondern auch hinsichtlich der Aufbewahrung verwendet, denn Bildwerke zeigen Grapen sowohl auf Wandborden stehend als auch an innen hängend aufbewahrt ${ }^{14}$. Von der Verwahrungsart in Borden berichet auch die Testatorin Geseke Rosemberg 1472, und ihr Hinweis mynen groten grapen in deme borde zeigt ${ }^{15}$, daß sie sich dem Zurschaustellungseffekt dieser Art der Aufbewahrung

\footnotetext{
${ }^{9}$ vgl. H. DRESCHER, Zu den bronzenen Grapen des 12. - 16. Jahrhunderts aus Nordwestdeutschland, Abbildung 3, S.161.

${ }^{10}$ beste Grapen: 1433 Dietrich Heket; nächstbeste: 1444 Klaus und Grete von Wening; bessere: 1441 Heinrich Tetendorp.

${ }^{11}$ U. REINHARDT, Testamente, Nr.253, S.390.

${ }^{12}$ Abbildung einer für das Lüneburger Gebiet angenommenen Form dieses „Hühnergrapens“ bei H.

DRESCHER, Zu den bronzenen Grapen des 12. - 16. Jahrhunderts aus Nordwestdeutschland, Nr. 2.3, S.159.

${ }^{13}$ M. KÜHLBORN, Keramik und Glasfunde der Fundstelle „Auf der Altstadt 29“, in. Kat. „Ton Steine Scherben, S.57.

${ }^{14}$ z.B. „,Die Verkündigung“, niedersächsisch, um 1420, Abbildung bei H. DRESCHLER, Zu den bronzenen Grapen des 12. - 16. Jahrhunderts aus Nordwestdeutschland, Nr.9, S.166.

${ }^{15}$ U. REINHARDT, Testamente, Nr.237, S.354.
} 
durchaus bewußt ist, denn es handelt sich offensichtlich um einen der besten Grapen, den die Testatorin besitzt.

Eine andere Unterscheidungsmöglichkeit ist die Gefäßform. Hier sind Schüssel- und Topfgrapen bekannt. Die Grundform des Grapens verändert sich in der Zeitspanne vom 14. bis 16. Jahrhundert von einer mehr kugeligen zu einer mehr schüsselähnlichen Form, ohne die zwei Grundformen gänzlich zu verwischen. Einen schottelgropen vererbt 1472 Geseke Rosemberg ${ }^{16}$.

Der Formenwandel steht für in fließender Weise dem Verwendungszweck angepaßte Ausführungen, deren Varianz als Beleg dafür anzusehen ist, daß der Grapen als der Kochtopf des (Spät-) Mittelalters für verschiedenste Kochvorgänge gerüstet sein mußte.

\section{$\beta$. Kessel}

Die Testatoren bezeichnen die relevanten Objekte als caldarium, kethel, ketel, kettel, kethell und sulffslegere ${ }^{17}$.

Tabelle: Testamentarische Verfügungen über Kessel

\begin{tabular}{|c|c|}
\hline Jahr & $\begin{array}{l}\text { Anzahl der Testatoren und mindestens vererbter } \\
\text { Kessel }\end{array}$ \\
\hline $1300-1325$ & - \\
\hline $1326-1350$ & - \\
\hline $1351-1375$ & 1 Testator mit 9 Kesseln \\
\hline $1376-1400$ & 7 Testatoren mit 12 Kesseln \\
\hline $1401-1425$ & 6 Testatoren mit 11 Kesseln \\
\hline $1426-1450$ & 3 Testatoren mit 7 Kesseln \\
\hline $1451-1475$ & 7 Testatoren mit 26 Kesseln \\
\hline $1476-1500$ &
\end{tabular}

Aus dem 14. Jahrhundert stammt ein Testament mit 9 Kesseln, aus dem 15. Jahrhundert 23 Testamente mit 56 Kesseln. Im 15. Jahrhundert werden Kessel relativ kontinuierlich vererbt, wobei die Vererbungsfrequenz im Zeitraum zwischen 1451 und 1475 am geringsten ist.

${ }^{16}$ U. REINHARDT, Testamente, Nr.237, S.353. 


\section{Donatoren und Empfänger}

Unter den Testatoren befinden sich 10 Frauen und 15 Männer, darunter ein Ehepaar mit einem Gemeinschaftstestament. Vier der männlichen Testatoren sind Geistliche.

Die testamentarisch vergabten Kessel bleiben überwiegend in Familienhand. 29 Kessel fallen an enge Familienmitglieder, und sechs Kessel werden Bekannten zugedacht. Vier Kessel werden als Legate ad pias causas vergabt, wobei ein Kessel einer Kirche zugedacht wird, ein anderer einer Vikarie und zwei Kessel von einem Testator in ein offenbar von inm gegründetes Gotteshaus für Arme gegeben werden.

\section{Material}

Hervorragendstes Merkmal der Kessel ist die Dünnwandigkeit der Gefäße, die aufgrund der Hitzedurchlässigkeit den Kessel für Siedevorgänge prädestiniert ${ }^{18}$. Das von den Testatoren angegebene Material der Kessel ist in 32 Fällen Messing, wobei die Deskription lediglich einmal über die Farbe Schwarz $^{19}$ geleistet wird, während sonst das Material selbst benannt wird. Zwei Kessel werden als kupferne beschrieben. Wenn HASSEs Vermutung zutrifft, daß mittelalterliche Kessel vorwiegend aus Kupfer waren, dann ist die häufige testamentarische Nennung von Messing als Hervorhebung des eben nicht „normal“ verwendeten Materials zu werten $^{20}$.

\section{Nutzung}

Die beiden genannten Materialien verweisen auf das Benutzen der testamentarisch vergabten Kessel als über dem Feuer genutzte Koch - oder Siedegeräte, im Gegensatz zu den nicht über offenem Feuer verwendeten zinnernen Brunnenkesseln ${ }^{21}$. Die Testatoren berichten von zwei Arten, den Kessel über dem Feuer zu postieren. In Cyeke Wittings Besitz befinden sich laut Testament mindestens zwei Kessel und ein oder mehrere

\footnotetext{
${ }^{17}$ M. HASSE fand in Lübeck Kessel ähnlicher Bezeichnung: sulfslegelingh. Zu bedenken wird gegeben, ob die Bezeichnung für einen ,am Ort“ geschlagen Kessel steht und sich gleichzeitig von Importware abgrenzt. M. HASSE, Neues Hausgerät, neue Häuser, neue Kleider, Fußnote Nr. 156, S. 72.

${ }^{18}$ Stichwort ,,Kessel““, in: M. HASSE, Neues Hausgerät, neue Häuser, neue Kleider, S.71f; auch S. $32 f ;$ H. DRESCHER, Zu den bronzenen Grapen des 12. - 16. Jahrhunderts aus Nordwestdeutschland, passim. Abbildung von Kesseln bei M. HASSE, Neues Hausgerät, neue Häuser, neue Kleider, Abb. 14 und 15; Abbildung eines frühen Kessels (= Waldeck um 1300) in: Kat." Das ritterliche Basel.“, Nr. 124, S. 161.

${ }^{19}$ Als Gegensatz zu den weißen Messingkesseln, die wohl zum Wasserholen dienten.

${ }^{20}$ M. HASSE, Neues Hausgerät, neue Häuser, neue Kleider, S. 25.

${ }^{21}$ Als Kochkessel wurden auch zweihenkelige Grapen genutzt, vgl. U. PIETSCH, Objektbeschreibung Grapen, in: Kat. „,Die Hanse“, Bd.2, S. 257.
} 
Kesselhaken ${ }^{22}$. Ihrem Sohn Werner hinterläßt sie den/die Kesselhaken, während ihr Neffe zwei Kessel erhält. Da ihr Sohn keine Kesselhaken ohne zugehörige Kessel nutzen konnte, deutet das auf eine für den Haushalt des Sohnes ausreichende Versorgung mit Kesseln hin, so daß die Testatorin die zwei Kessel, die sie in ihrer Bude hatte, ihrem Neffen zuwenden konnte.

Eine andere Möglichkeit sieht das Aufstellen eines Dreifußes im Feuer vor, auf den dann der Kessel gesetzt wird. Auf diese Möglichkeit deutet das Testament des Matheus Tetendorps 1491 hin, in dem mit dem Dreifuß ein Kessel von drei Zubern Wassers vererbt wird, ein Kessel von beträchtlichem Fassungsvermögen also, den an einem Kesselhaken aufzuhängen selbst bei starkem Bügel offenbar nicht ratsam ist.

\section{Anzahl und Größe der Kessel}

Die Anzahl der Kessel pro Haushalt wird im 14. Jahrhundert auf zwei bis drei Kessel geschätzt $^{23}$. Ähnliche Zahlenwerte von einem bis drei Kesseln weisen 19 Testamente des 15. Jahrhunderts auf, wobei zu bedenken ist, daß hier oft der große Kessel erwähnt wird, also wahrscheinlich noch mindestens ein weiterer, vielleicht kleinerer, vorhanden ist. Zwei Testamente verfügen über je vier Kessel (1475 Czieke Blank, 1494 Gesche Henning), zwei Testamente über je fünf Kessel (1419 Immeke Burmester, 1491 Matheus Tetendorp) und ein Testament über neun Kessel (1483 Nickel Wulfferam). Mehr als bei den über wenige Kessel verfügenden Testatoren kann man bei den über etliche Kessel verfügenden Testatoren davon ausgehen, daß sie sich aufgrund ihres Witwer-bzw. Witwentums oder aufgrund der Aufteilungsfrage angesichts mehrerer Nachkommen dazu genötigt sahen, über alle Kessel zu verfügen. So läßt sich auf der Grundlage der Lüneburger Testamente die Annahme formulieren, ein Haushalt des 15. Jahrhunderts habe vier bis fünf Kessel zur Verfügung gehabt.

Die Größe wird von den Testatoren mit den Begriffen „groß“ und „klein“ beschrieben, eine Beschreibung, die angesichts der weiten Spanne unterschiedlicher Größe - von weniger als 7 Litern bis 480 Litern - relativ und damit wenig aussagekräftig ist. Auffällig ist, daß lediglich zwei Kessel kleine Kessel genannt werden (1494 Gesche Henning), während die übrigen als große bezeichnet werden oder durch die Angabe der Maßeinheit „Zuber“ ihre Größe dargestellt wird. Die Bezeichnung eines Kessels als großer Kessel muß nicht unbedingt als Abgrenzung von kleineren Kessel gewählt worden sein, sie mag in vielen der insgesamt 13 Fälle allein die Eigenschaft des Kessels benannt haben. Im 13. Jahrhundert, als die Kessel vorwiegend aus der günstigeren Blechware verfertigt werden, hat man ihren Umfang

\footnotetext{
${ }^{22}$ Abbildung eines Kesselhakens (allerdings keine Jahreszahl), In: Kat. „Die Hanse“, Bd.2, Nr. 8.48, S. 162.
} 
vergrößert. Seit dem 14. Jahrhundert werden Kessel gegossen, und man verwendet Kessel nur dort, wo große Gefäße zum Sieden erforderlich sind. Hans Dobbeler stiftet 1481 seinen je größten Kupfer - und Messingkessel, Immeke Burmester vererbt 1419 ihren zweitgrößten Kessel. Kessel, die die Testatoren als große titulierten, werden in weitaus größerer Anzahl vererbt; insgesamt 13 Kessel werden von den Testamenten annähernd regelmäßig über das 15. Jahrhundert verteilt genannt. Die Größe von fünf Kesseln wird durch die Angabe des Fassungsvermögens definiert: Drei Kessel fassen einen Zuber Wasser (Werner Malstorp 1411, Johannes von Lippinghausen 1424 und Gesche Henning 1494), ein Kupferkessel faßt zwei Zuber Wasser (Hans Dobbeler 1481) und ein Kessel drei Zuber Wasser (Matheus Tetendorp 1491). Eine Menge von vier Kesseln, bestehend aus großen und kleinen Ausführungen, erwähnt lediglich das Testament Segeband von Thunes 1385.

\section{$\gamma$. Pfannen}

Die Testatoren nennen ihre Nachlaßstücke $\operatorname{cacabos}^{24}$, deghel und $\operatorname{schap}^{25}$. Die beiden erstgenannten Begriffe bezeichnen Pfannen, die in der Küche verwendet werden. Mit dem Begriff schap wird oft eine Feuerpfanne beschrieben.

Tabelle: Testamentarische Verfügungen über Pfannen

\begin{tabular}{|c|c|}
\hline Jahr & Anzahl der Testatoren und vererbten Pfannen \\
\hline $1300-1325$ & - \\
\hline $1326-1350$ & - \\
\hline $1351-1375$ & 1 Testator mit 2 Pfannen \\
\hline $1376-1400$ & 1 Testator mit 3 Pfannen \\
\hline $1401-1425$ & 2 Testatoren mit 5 Pfannen \\
\hline $1426-1450$ & 1 Testator mit 4 Pfannen \\
\hline $1451-1475$ & 1 Testator mit 2 Pfannen \\
\hline $1476-1500$ &
\end{tabular}

\footnotetext{
${ }^{23}$ M. HASSE, Neues Hausgerät, neue Häuser, neue Kleider, Fußnote Nr.154, S.71 Die neun im Testament des Segeband von Thune erwähnten Kessel verteilen sich auf mehrere Haushalte, die der Testator an verschiedenen Orten unterhielt.

${ }^{24}$ Segeband von Thune ist der einzige Testator, der diese Bezeichnung verwendet. cacabus kann Kochtopf oder Bratpfanne bedeuten. Da Thune in seinen Testament Grapen und Kessel nennt, erscheint es sinnvoller, cacabos als Pfannen denn als Kochtöpfe zu übersetzten.

${ }^{25}$ Übersetzungen nach M. HASSE, Neues Hausgerät, neue Häuser, neue Kleider, Stichwort „Pfanne“, S. 78. Hier auch wesentliche Informationen.
} 
Die Anzahl an Testamenten pro Vierteljahrhundert bleibt gering. Auffällig ist, daß pro Testament über mindestens zwei Pfannen verfügt wird.

Sechs Testatoren, vier Frauen und zwei Männer, verfügen in ihren Testamenten über Pfannen (1385 Segeband von Thune, 1419 Immeke Burmester, 1430 Adelheid Kolse, 1423/31 Adelheid Seidentopf, 1475 Czieke Blank, 1483 Nickel Wulfferam).

Als Empfänger weisen die Testamente sechsmal Familienmitglieder aus und siebenmal Bekannte. Die Bratpfanne bleibt also im engeren Familien- oder Bekanntenkreis.

Anders sieht es mit der einzigen testamentarisch erwähnten Feuerpfanne aus, die von der Testatorin Adelheid Seidentopf 1423/1431 an die Vikarie Herrn Johann Tzilliks vergabt wird, der Vikar an St. Nikolai ist. Wenn auch die Testatorin nicht inm persönlich, sondern eben der Vikarie die Feuerpfanne geschenkt hat, so kann ihr Testament doch nicht verhehlen, daß es ihr -vielleicht aus eigener Anschauung - auch um seine Person geht, denn sie formuliert: „en $w u^{\circ}$ rschapen ..., dar schal he wuํormede hebben by den altar, dat Hermen Tzyrenberch heft ghemaket ${ }^{26}$. Deutlich wird gesagt, daß die Feuerpfannen oder Feuerschapen im Prinzip Heizungen ${ }^{27}$ sind, bei denen der Wärmeträger und -speicher, nämlich die glühende Kohle, in die Pfanne hineingelegt wird. Kohlen werden denn auch gelegentlich als Legate da pias causas an Hospitäler und Kirchen vergabt, sozusagen als Beitrag zur Heizkostenfinanzierung, mit der bezeichnenden Formulierung tho kalenn up den schapenn $^{28}$. Die Größe der Feuerpfannen variiert ${ }^{29}$, aber unabhängig von Größe oder auch Schwere sind sie transportabel, mobil, und damit effektiv einsetzbar.

Vergabt werden in erster Linie Koch- oder Bratpfannen; die von den Testatoren gewählte Terminologie weist 15 der 16 Pfannen als für die Nahrungszubereitung verwendbare aus ${ }^{30}$.

\footnotetext{
${ }^{26}$ U. REINHARDT, Testamente, Nr.162, S.223.

${ }^{27}$ Über die Heizmöglichkeiten in einem spätmittelalterlichen/frühneuzeitlichen Haus siehe R.-E.

MOHRMANN, Wohnen und Wohnkultur in nordwestdeutschen Städten im Spätmittelalter und in der frühen Neuzeit, in: Kat. „Stadt im Wandel“, Bd.3, S. 513-530.

${ }^{28}$ z.B. aus dem Testament der Hilleke Blickershusen 1499 August 28. Sie bedenkt mit je einer Mark jährlicher Rente für Kohlenankauf die Hospitäler Heilig - Geist und Langes Haus (meint sie den Langen Hof?) sowie die Cyriacuskirche und die Ratskapelle. U. REINHARDT, Testamente, Nr.292, S.469f.

${ }_{29}$ Abb. einer auf Füßen stehenden Feuerpfanne bei M. HASSE, Neues Hausgerät, neue Häuser, neue Kleider, S.41, Nr.29; Abbildung einer auf Rollen stehenden Feuerpfanne aus dem Lübecker Rathaus in: Kat. „,Die Hanse“, Bd.2, Nr. 3.2, S. 63 Abb. mit Erläuterung Wer sich vergegenwärtigt, daß außer der Sonne offene Feuerstellen, Feuerschapen und kleinere Kohlepfännchen die einzigen Wärmespender waren, der wird ermessen können, welchen Luxus die Lüneburger Ratsherren genossen, deren Beratungsbereich im Rathaus mit einer Fußbodenheizung ausgestattet war. Funktion erklärt in: F. KRÜGER, W. REINECKE, Die Kunstdenkmale der Stadt Lüneburg, S. 235; Kurzerwähnung im Rathausführer von F. v. OSTERHAUSEN, S.11; A. TILSNER, Mittelalterliches Lüneburg, S.18 (= Abbildung der Deckel der Warmluftheizung und Kurzerklärung).

${ }^{30}$ Adelheid Seidentopf ist die einzige Testatorin, die die Begriffe schape und schapen verwendet, die eigentlich sowohl Pfanne als auch Schrank bedeuten können, vgl. SCHILLER - LÜBBEN, Mittelniederdeutsches Wörterbuch, S. 319. M. HASSE zufolge müßte es sich beim Schapen um eine zum Kochen verwendbare Pfanne gehandelt haben, M. HASSE ,Neues Hausgerät, neue Häuser, neue Kleider, Fußnote 105, S.64 Da die 3
} 
Gefertigt werden diese Pfannen aus Eisen, Bronze und Kupfer sowie aus Messing ${ }^{31}$. Über die Form der Pfannen enthalten die Testamente keine Auskunft, doch überlieferte Exemplare $^{32}$ und Bildwerke - für Lüneburg „Geburt Chrisi“ der Goldenen Tafel des Lüneburger Michaelisklosters, $1418^{33}$ - präsentieren die Pfanne als dreibeinigen, flachen Schalencorpus mit Griff. Die Testamente berichten davon, daß es unterschiedliche Größen gab, denn vererbt wird einmal die größte (1419 Immeke Burmester), ein anderes Mal die kleinste Pfanne (1483 Nickel Wulfferam).

\section{$\delta$. Mörser}

Mörser werden in den Testamenten selten erwähnt. In fünf Testamenten wird über mindestens sieben Mörser verfügt. Eines der Testamente, das des Segeband von Thune, stammt aus dem 14. Jahrhundert. Der Testator, Archidiakon von Bevensen, vererbt zwei Mörser, deren einer mit Stößel vergabt wird. Mindestens zwei Mörser, jeweils mit Stößel, erwähnt der Kleriker Johannes von Lippinghausen 1424 in seinem Testament. Die drei übrigen Testamente werden von Frauen im letzten Drittel des 15. Jahrhunderts ausgestellt. Haben die Kleriker ihre Mörser als mortarium bezeichnet, so verwenden die Testatorinnen die Begriffe den morser, enen moser und eynenn moster. Allen Frauen ist gemeinsam, daß sie zum Zeitpunkt der Testamentsabfassung ohne Ehemann leben, ob sie nun verwitwet sind wie Geseke Leyferd und Hilleke Blickershusen oder vielleicht auch niemals verheiratet waren wie es im Fall der Geseke Rosemberg gewesen zu sein scheint. In keinem von innen errichteten Testament ist von leiblichen Kindern die Rede, was auf eine - auf den Zeitpunkt der Testamentsserrichtung bezogene - Kinderlosigkeit hinweist, sie jedoch nicht zwangsläufig bedeuten muß. Geht man aber von der nicht unwahrscheinlichen Annahme der Kinderlosigkeit aus, dann liegt hier der gemeinsame Nenner, der alle über Mörser verfügenden Testatoren verbindet. Zumindest für vier dieser fünf Testatoren bedeutet das, daß sie angesichts all ihrer Nachlaßgüter dem Mörser Wert beimaßen und über seinen weiteren Verbleib selbst bestimmen wollten. Aus dieser Beobachtung läßt sich der Schluß ziehen, Mörser sind über den gesamten Untersuchungszeitraum hinweg mit wenigen Exemplaren/einem Exemplar in allen Haushalten vertreten.

schapen im Kontext von Küchengerätschaften erwähnt werden, werden sie Pfannen übersetzt, während die 2 schape neben Kleidung und Fußkiste aufgelistet werden. Sie werden als Schränke begriffen.

${ }^{31}$ Pfanne mit aus Messing getriebener Schale und eisengeschmiedetem Griff, gefertigt vor 1356, aus Bischofstein, BL, Abb. in: Kat. „,Das ritterliche Basel“, Nr.211, S.159.

${ }^{32}$ Kat. , Aus dem Alltag der mittelalterlichen Stadt“, Abb. 3.3 und 3.4, S. 161.

${ }^{33}$ Kat. „Aus dem Alltag der mittelalterlichen Stadt“, S.167. 
Die Auswertung Lübecker und Braunschweiger Testamente kommt zu vergleichbaren Ergebnissen, konstatiert die seltene testamentarische Erwähnung von Mörsern und ihre auf die Norm bezogene Singularität ${ }^{34}$.

Die Gebrauchsfunktion der Mörser ${ }^{35}$ liegt in der Zerkleinerung von Substanzen, die je nach Gefäß- und Stößelgröße/Stößeldicke auch für festere Stoffe durchführbar ist. Dieser für das menschliche Leben unabdingbare Arbeitsvorgang - insbesondere im Nahrungsbereich verweist auf das sehr frühe Einsetzen von Mörsern eben nicht allein im Haushalt, sondern auch im Gesundheitswesen.

Der Standort des Mörsers im spätmittelalterlichen Haushalt ist im Normalfall durch die Nähe zur Feuerstelle/Essenszubereitung vorgegeben ${ }^{36}$. Hergestellt werden Mörser überwiegend aus Bronzen, es gibt jedoch auch Messingmörser ${ }^{37}$. Mörser des norddeutschen Typs weisen eine auf flacher Fußplatte stehende konische Form auf, wobei die Wandung durch hervorstehende Horizontalrippen gegliedert wird ${ }^{38}$. Über Aussehen, Material und nähere Verwendung enthalten die Lüneburger Testaments keine Informationen.

Hilleke Blickershusen ist die einzige, die ihren Mörser innerhalb ihrer Familie vererbt, indem sie inn ihrem Ohm zukommen läßt. An Bekannte fallen die Mörser Johannes von Lippinghausens und Geseke Rosembergs. Geseke Leyferd, die in ihrem Testament ohnehin etliche Legate ad pias causas aussetzt, vergibt in diesem Sinn auch ihren Mörser, der an die gherwekammer der Mönche zu Winsen fällt.

\section{ع. Geräte für das Kochen am Herdfeuer}

Das Testament Segeband von Thunes enthält kraft seines Inventarcharakters eine genaue Auflistung des Kücheninventars der Küchen seiner Höfe in Verden und Minden. Neben den bereits genannten Küchengerätschaften, die oft in etlichen über den Untersuchungszeitraum verteilten Bürger- und Klerikertestamenten auftreten, und die man als geradezu testamentsklassische bezeichnen kann, finden sich bei Thune seltener genannte Utensilien in größerer Anzahl. Aufgelistet werden drei craticulas (kleine Roste), zwei ignifurcas (größere?) Gabeln, die für die Arbeit an/mit dem Feuer verwendet wurden, drei tedelia (Herdeisen), ein longale (vielleicht ein Verlängerungsgriff als Schutz vor

\footnotetext{
${ }^{34}$ M. HASSE, Neues Hausgerät, neue Häuser, neue Kleider, Stichwort „Mörser“, S.78.

${ }^{35}$ W. HÖMBERG, Spätmittelalterliche Bronzemörser aus Norddeutschland, in. Kat. „Aus dem Alltag der mittelalterlichen Stadt“", S.147 - 155.

${ }^{36}$ S. SCHÜTTE, Bürgerliches Hausgerät, S.550.

${ }^{37}$ M. WISWE, Hausrat aus Kupfer und Messing, München 1979, S.44.

${ }^{38}$ Abbildung und Erläuterung eines in bisher ungeklärter Verbindung zu Lüneburg stehenden Mörsers allerdings aus dem Jahr 1530 in: Kat. „Stadt im Wandel“, Bd.2, Nr. 181b, S. 241f Abbildung von Mörsern aus dem 14. - 16. Jahrhundert bei HÖMBERG, Spätmittelalterliche Bronzemörser aus Norddeutschland, S.150 155.
} 
Verbrennungen für die Benutzung der Herdeisen ${ }^{39}$ ), eine tenella (Zange $)^{40}$. All diese genannten Gebrauchsgegenstände werden für den über dem offenen Herdfeuer abgehaltenen Kochvorgang benötigt. Sie werden aus dem hitzebeständigen Eisen angefertigt worden sein, das vorwiegend in der Küche und im technischen Bereich ${ }^{41}$ Verwendung findet, in den Testamenten aber so gut wie gar nicht vorkommt.

Drei Testatoren (1424 Johannes von Lippinghausen, Matheus Tetendorp 1491 und Hilleke Blickershusen) vererben je einen Dreifuß, über dessen Verwendung weiter oben berichtet wurde.

Aufbewahrt werden all diese Gerätschaften in unmittelbarer Nähe zur offenen Feuerstelle ${ }^{42}$.

c. Tischzubehör

$\alpha$. Kanne

Bei den Kannen handelt es sich um Gefäße, die vielseitig verwendet wurden. Sie dienen als Schenkkannen, auch als Trinkgefäß und werden als Hohlmaß genutzt.

Tabelle: Testamentarische Vererbung von Kannen

\begin{tabular}{|c|c|}
\hline Jahre & Anzahl der Testatoren und Kannen \\
\hline $1300-1325$ & - \\
\hline $1326-1350$ & - \\
\hline $1351-1375$ & 1 Testator mit 12 Kannen \\
\hline $1376-1400$ & 4 Testatoren mit 15 Kannen \\
\hline $1401-1425$ & 5 Testatoren mit 13 Kannen \\
\hline $1426-1450$ & 2 Testatoren mit 3 Kannen \\
\hline $1451-1475$ &
\end{tabular}

\footnotetext{
${ }^{39}$ Darstellung der Verwendung des Herdeisens - präziser: der in das Feuer Hineinschiebens oder aus dem Feuer Herausholens durch Anfassen an einen langen Griff, der logischerweise im Gegensatz zu dem Rost nicht heiß gewesen sein kann - in Hans Wertingers (1465/70 - 1533) Dezemberbild, gemalt um 1525 in: Kat. „Aus dem Wirtshaus zum Wilden Mann“; Abb. 4., S.16.

${ }^{40}$ U. REINHARDT, Testamente, Nr.45, S.62.

${ }^{41}$ Wahrscheinlich über Eisenwerkzeug verfügt Heinrich Müller 1425: magnam bypennem unam securim propie byndexe, duo terrebella grossa vulgariter nevigere, due secures propie byndexen, duo terebella grossa, tria parva terebella propie spiekerbor, unam foralem propie sulexe in partibus duabus, unam sarram, tria lemgalia unum directorium ferreum propie wynkelyseren Übersetzung siehe Regest Abbildung/Beschreibung von Bohrern, in: Kat. „Das ritterliche Basel“, Nr. 153, 154 (ohne Abb.).

${ }^{42}$ Das komplette Umfeld einer offenen Feuerstelle eines Hauses der mittleren und oberen Sozialschicht in Göttingen im 15. Jahrhundert ist beschrieben von S. SCHÜTTE, Bürgerliches Hausgerät, S.549.
} 
Aus dem 14. Jahrhundert ist ein Testament mit 12 Kannen überliefert, aus dem 15. Jahrhundert 17 Testamente mit 66 Kannen. Die größte Anzahl testamentarisch vererbter Kannen stammt aus dem letzten Viertels des 15. Jahrhunderts.

\section{Donatoren und Empfänger}

Ausgestellt werden die 22 Testamente von sechs Testatorinnen und von 17 Testatoren $^{43}$, von denen sechs Kleriker sind.

Die Zuwendungen an die Familie und die Zuwendungen an Bekannte halten sich mit einem Zahlenverhältnis von 25 : 24 annähernd die Waage. Im Vergleich zu anderen Gerätschaften ist hier kein familiensicherndes Erbverhalten zu beobachten. Verschwindend gering sind mit zwei Legaten die Legate ad pias causas, für die Kannen verwendet werden.

\section{Materialien}

Silber und Zinn sind die Materialien der testamentarisch erwähnten Kannen. Daß es wohl nicht nur schlichte Kannen gegeben hat ${ }^{44}$, und sich vor allem Silberkannen zum Repräsentieren anbieten, verdeutlicht der hohe Betrag von 100 Mark Pfennigen, den Gesche Henning 1494 zur Anfertigung einer Silberkanne aussetzt. 27 Kannen werden von ihren Besitzern als zinnerne beschrieben. Darunter befinden sich eine Pipkanne, ein Halbquart, ein Quart, zwei Stübchen und 22 Zinnkannen. Anzunehmen ist, daß die übrigen, mit ihrem Herstellungsmaterial nicht genannten Kannen wohl ebenfalls Zinngefäße sind, da Keramik in den Testamenten sonst nicht erwähnt wird, Silbergefäße aufgrund ihres Wertes als solche genannt würden. Zinn wie auch Silber eignen sich aufgrund ihrer Ungiftigkeit in besonderem Maße zur Herstellung von Trinkgefäßen oder Schenkkannen.

\section{Unterschiedliche Kannenformen}

\footnotetext{
${ }^{43}$ Johannes von Lippinghausen testierte zweimal 1414 und 1424.

${ }^{44}$ Diese Ansicht vertritt W. DEXEL vor allem für Zinnkannen, aber auch bei Silbergefäßen bevorzugt er den Blick auf das Schlichte: „In Silber wurde vor allem das Prunk - und Repräsentationsgerät gebildet, dessen schmucküberladene Stilformen uns hier nicht zu beschäftigen brauchen. Doch sind daneben in Silber auch Geräte von einfach schlichter Schönheit entstanden, auf die mit Nachdruck hingewiesen werden muß“. W. DEXEL, Das Hausgerät Mitteleuropas, Berlin 1962, S.63, 68 Fraglich ist, ob nicht zumindest ab einem gewissen Zeitpunkt Repräsentationsgeschirr doch zum Haushaltsgerät gehörte, zumal HASSE nachwies, daß das Silbergeschirr durchaus benutzt wurde. M. HASSE, Neues Hausgerät, neue Häuser, neue Kleider, S.18.
} 
Neben den von den Testatoren als kanne bezeichneten Gefäßen finden sich Sonderformen wie die pipekanne und die krose oder crusibulum. Nach den Angaben einiger Testatoren sind auch amphora und vasola als Bezeichnungen für Kannen anzusehen ${ }^{45}$.

Kröse werden von zwei Testatoren in der ersten Hälfte des 15. Jahrhunderts testamentarisch vererbt. Sowohl Johannes von Lippinghausen (1414 und 1424) als auch Cyeke Witting (1444) verfügen über mehrere Exemplare. Hat das von Johannes von Lippinghausen zuerst ausgestellte Testament insgesamt fünf Krösen genannt, so zählt das zweite sieben Krösen auf. Der Testator unterscheidet zwischen kurzen und langen Gefäßen; gefertigt sind alle testamentarisch genannten aus Silber. HASSE stellte fest, daß die Krösen erst dann in den Testamenten greifbar wurden, als sie nicht mehr ausschließlich aus Ton oder Zinn, sondern ganz oder doch teilweise aus Silber hergestellt wurden ${ }^{46}$. Ob es sich bei den von Cyeke Witting vererbten Krösen um derart wertvolles Silbergerät handelt, muß bezweifelt werden, nennt die Testatorin die Krösen doch im Kontext von Hausgerätschaften wie Grapen, Kesselhaken und Truhen; Silbergefäße führt ihr Testament nicht auf. Außer den bereits aufgeführten gibt es keine weiteren konkreten Aussagen über das Aussehen der Krösen ${ }^{47}$, wohl aber den Hinweis in Lippinghausens Testament aus dem Jahr 1414, es handele sich um drei lange silberne Krösen cum cooptoriis, die mit der Kröse je an die drei Erbnehmer fallen sollten. Aus dem Testament heraus kann nicht geklärt werden, worum es sich bei diesem „Zubehör“ gehandelt hat. Vielleicht ist an eine Verzierung zu denken, in der Art der „2 crusibulos cum argento circumpositos“48? Eine derartige an die Kröse anzupassende Verzierung stünde in der Tradition der frühen Silberschmiedearbeiten, als aufgrund der nicht möglichen Verbindung von Henkel und Gefäßkörper tönerne oder zinnerne Krösen mit Silber verziert wurden. Dieses System könnte prinzipiell beibehalten, jedoch qualtitativ verändert worden sein, indem nun Silberkrösen mit z.B. vergoldeten Elementen verziert wurden ${ }^{49}$.

Bei der Pipkanne handelt es sich um eine Kanne mit röhrenartigem Ausguß. Erwähnt wird sie im Testament Segeband von Thunes 1385 und Geseke Springintguds 1425. Das

\footnotetext{
${ }^{45}$ Deutlich im Testament Segeband von Thunes 1385 Mai 18: „Item 2 amphoras stanneas, 1 de dimidio quartali et 1 propie pipkannen“ sowie „4 vasola de quartiali“ und „, 1 quartale et 1 quartale de mensura Mindensi, vascula stanea“. Testament des Dietrich Junge :"amphoram stanneam de una stopa“, „,unam amphoram stanneam de una quarte" Die hier gefällte Übersetzungsentscheidung steht in Übereinklang mit HASSEs Übersetzung Amphora - Kanne, M. HASSE, Neues Hausgerät, neue Häuser, neue Kleider, Fußnote 44, S.33.

${ }^{46}$ M. HASSE, Neues Hausgerät, neue Häuser, neue Kleider, Stichwort „Kröse“, S.75f.

${ }^{47}$ Abbildung einer langen, zinnernen Kröse aus dem 15. Jahrhundert bei M. HASSE, Neues Hausgerät, neue Häuser, neue Kleider, Abb.10, S. 21.

${ }^{48}$ von MELLE, 265/66 (1376), Zit. nach M. HASSE, Neues Hausgerät, neue Häuser, neue Kleider, Fußnote 188, S. 75.

${ }^{49}$ UB der Stadt Regensburg II Nr.1095 (1375): ein swarz beslagens krauserl; Wiener Testamentsbücher Bl. 187 (1405) : eine vergult krausen, zit. nach M. HASSE, Neues Hausgerät, neue Häuser, neue Kleider, Fußnote 188, S.75.
} 
Material, aus dem die Pipkannen bestehen, ist im Fall Thunes Zinn und bei Geseke Springintgud Silber.

Die bislang vorgestellten Kannen dienen als Schenkkannen, können auch - wenn man an die Entwicklung der Kröse denkt - als Trinkkannen verwendet werden.

Über das Aussehen der zwei von Johann Pale 1441 seinem Sohn hinterlassenen visscher kannen sind keine Angaben möglich, wenn auch der Name Assoziationen weckt, die an eine bestimmte Verwendung oder (religiöse) Motivik denken lassen, vielleicht aber auch den Hersteller (Goldschmied Heinrich Vischer ?) meinen kann ${ }^{50}$.

\section{Hohlmaßkannen}

Die nun folgende Gruppe ist definiert durch ihre Verwendung als Hohlmaße, mit denen der Haushalt über geeichte und damit über vielseitig verwendbare und zuverlässige Maßeinheiten verfügt. Auffällig ist, daß - von Segeband von Thunes Testament abgesehen - Krösen und Pipkannen in Testamenten der ersten Hälfte des 15. Jahrhunderts aufgeführt werden, die Hohlmaßkannen aus dem letzten Viertel des Jahrhunderts stammen.

Die testamentarisch genannten Hohlmaße sind Quart, Halbquart, Stübchen und Halbstübchen ${ }^{51}$. Unter den Testatoren ist Segeband von Thune der einzige, der von jeder Größe mindestens eine aufführt.

Drei Testamente verfügen über ein Quart. Segeband von Thune erwähnt in seinem Testament 1385 insgesamt sechs Quartgefäße, deren eins - nämlich das in seinem Mindener Hof stehende - von Mindener Maß ist, ein Hinweis auf den von Stadt zu Stadt divergierenden Umfang der Maßeinheiten. Kannen vom Umfang eines Quarts vererben im Jahr 1476 Vicke Bottermann und Dietrich Junge. Gerade das Testament Bottermanns zeigt die Bedeutung der Hohlmaßgefäße für den Haushalt. Er, der eine offenbar von inm schwangere Magd mit bereits vorhandenen, vermutlich dann wohl gemeinsamen Kindern hinterläßt, sorgt für eine Grundausstattung dieser Familie. In Hinblick auf den

\footnotetext{
${ }^{50}$ Zitiert nach dem Manuskript, Testament 1441 Okt.8, S.435. In der Edition heißt es „bisscher kannen“. U. REINHARDT, Testamente, Nr.199, S.280. Angesichts der Tatsache, daß es in Lüneburg einen Goldschmied mit dem Namen Vischer gab, halte ich die Lesart „visscher“ für die richtige. Erwähnung eines Meisters Hinrik Vischer mit einer Arbeit aus dem Jahr 1444, In: E. MICHAEL (Bearb.), Museum für das Fürstentum Lüneburg, Nr.H 41, S.171f. Die Verbindung von Erbgut und Namen des Herstellers?/Verkäufers? ist nicht so unüblich. Vicke Bottermann spezifiziert einige seiner Grapen als diejenigen, die er von Vrigbusch kaufte,vgl.Testament 1476 März 4.

${ }^{51}$ Relevant für die Maßeinheiten sind die Arbeiten H. WITTHÖFTs. Direkt auf Lüneburg bezogen: $1 / 2$ Stübchen $(1488)=1,8501 ; 1 / 4$ Stübchen $(1488)=0,9901 ; 1 / 2$ Stübchen (15./16. Jahrhundert $)=1,8271$ in: Die Sachüberlieferung an Normalmaßen des 13. - 15. Jahrhunderts und Stücke des 16./17. Jahrhunderts (=Anhang), in: Kat. „Die Hanse“, Bd.2, S. 553 Lüneburger Bierstübchen im 15. Jahrhundert : 3,554 1, Weinstübchen : 3,1101 H. WITTHÖFT, Umrisse einer historischen Metrologie zum Nutzen der wirtschaftsund sozialgeschichtlichen Forschung. Maße und Gewicht in Stadt und Land Lüneburg, im Hanseraum und im Kurfürstentum /Königreich Hannover vom 13. bis zum 19. Jahrhundert (Veröffentlichungen des Max - Planck - Instituts für Geschichte 60/1), Göttingen 1979, S. 168,171, siehe auch S.555 (Angabe der Flüssigkeitsmaße).
} 
Küchenbereich versorgt er Barbara mit sechs Grapen, einem Messingkessel und eben mit zwei Halbstübchenkannen sowie einer Quartkanne.

Zwei Halbquart listete Segeband von Thune in seinem Testament auf, wobei er betonte, das eine sei aus Zinn gefertigt.

Ein Hohlmaßgefäß im Umfang eines Stübchens wird wieder häufiger vererbt. Jeweils ein Stübchen hinterlassen Segeband von Thune 1385, Czieke Blank 1475, Dietrich Junge 1476 und Hilleke Blickershusen 1499. Sowohl Segeband von Thune als auch Czieke Blank vererben ebenfalls Halbstübchenkannen, wie auch Vicke Bottermann, der über zwei dieser Gefäße verfügte.

In allen anderen Fällen nennen die Testatoren ihr relevantes Erbgut hinsichtlich der Form schlicht Kanne.

\section{Kannen als Transportmittel für Flüssigkeiten}

Der Verwendungsbereich der Schenkkannen muß nicht zwangsläufig auf das eigene Haus begrenzt sein, wie das Testament des Dietrich Ellenberg aus dem Jahr 1448 zeigt. Der Testator gesteht jedem seiner drei Testamentsvollstrecker jährlich für die Nachlaßarbeit ein Stübchen Weins zu, also ca. 3,110 Liter ${ }^{52}$. Dieses Stübchen hat der jeweilige Besitzer seines jetzigen Wohnhauses in der großen Zinnkanne des Testators an jedem Martinsabend fruntliken und sunder vortoch den Testamentsvollstreckern zukommen zu lassen $^{53}$. Da die Testamentsvollstrecker der jeweilige Kämmerer des Rates zu Lüneburg, der je älteste Kirchgeschworene von St. Johannis und der jeweilige Hausbesitzer sind, geht der Testator von einer geradezu ewigen Haltdauer seiner Zinnkanne aus, ein Zeichen dafür, daß die Zinnkannen zumindest für die Dauer eines Menschenlebens einen unverwüstlichen Eindruck machen konnten!

\section{$\beta$. Flaschen}

Über Flaschen wird - wie andernorts auch ${ }^{54}$ - in den Lüneburger Testamenten sehr selten verfügt. Genannt werden Flaschen in vier Klerikertestamenten (1385 Segeband von Thune, 1414 und 1424 Johannes von Lippinghausen, 1441 Heinrich Tetendorp ${ }^{55}$ ) sowie in einem Frauentestament (1475 Czieke Blank), dessen wesentliche Bestimmung die durch die Großmutter herbeigeführte testamentarische Sicherung eines Hauses und Hausrats für ihre

\footnotetext{
${ }^{52}$ Lüneburger Weinstübchen errechnet von H. WITTHÖFT, Umrisse einer historischen Metrologie, S. 171.

${ }^{53}$ U. REINHARDT, Testamente, Nr.213, S.307.

${ }^{54}$ In den Testamentsauswertungen anderer Städte werden sie selten erwähnt, wenn dann wie bei SCHILDHAUER als ,vereinzelt“" auftretendes Objekt. J. SCHILDHAUER, Hansestädtischer Alltag, S.72.

${ }^{55}$ Im Testament des Vikars Heinrich Tetendorp aus dem Jahr 1441 ist die einschlägige Stelle unleserlich. Doch das leserliche stanneam de stopa vini weist einzig und allein auf das Substantiv Flasche hin, da ausschließlich Zinnflaschen in den Testamenten erwähnt werden und das Stübchenmaß im Kontext mit Flaschen genannt werden.
} 
(halb-) verwaiste Enkeltochter ist. In den fünf relevanten Testamenten werden 30 Flaschen erwähnt, wobei zu bedenken ist, daß der Testator Johannes von Lippinghausen im Abstand von zehn Jahren zwei Testamente errichtete, in denen er wahrscheinlich über die gleichen Flaschen verfügt.

Die Testatoren verwenden die Bezeichnung flascula, ampulla und vlassche.

Mit Ausnahme der in dem Testament von 1424 erwähnten Flaschen werden alle anderen als Zinnflaschen kenntlich gemacht. Die Testatoren richteten sich bei der Beschreibung ihrer Exemplare nicht nur nach dem Material aus, sondern auch nach dem Fassungsvermögen, das durch das Weinstübchen definiert war. Zehn Flaschen fassen ein Stübchen, Halbstübchenflaschen werden elfmal aufgelistet. Vier Zinnflaschen richten sich nach Mindener Maß, es handelt sich bei innen um das Volumen eines Quarts.

Empfänger der Legate sind zweimal Vikarien und zweimal enge Familienmitglieder. Der „Hauptdonator“ Johannes von Lippinghausen, der allein 17 Flaschen in zwei Testamenten vergabt, benennt zwar etliche Empfänger, doch ist nicht immer klar, ob sie dem Laien- oder dem Klerikerstand zugehörig sind. In drei Fällen muß die Frage offenbleiben, in fünf Fällen handelt es sich offensichtlich um Kleriker. So zeichnet sich eine Vererbungstendenz zugunsten von Klerikern ab, allerdings bei vorrangiger Schenkung von Klerikern.

\section{$\gamma$. Trinkgefäße}

Schalentrinkgefäße: Schale, Kopf und Schauer

Es gibt unterschiedliche Arten von Schalentrinkgefäßen ${ }^{56}$. Hauptunterscheidungsmerkmal ist die Tiefe der Schalenform: Flachere Ausführungen werden als Schale bezeichnet, während die Ausführungen mit größerer Tiefe Kopf oder Napf genannt werden. Handelt es sich um ein nahezu halbkugeliges Gefäß, spricht man von einem Kopf, handelt es sich um ein mehr flachbodiges Gefäß, spricht man von einem Napf.

Die Lüneburger Testatoren verwenden zur Bezeichnung dieser Trinkgefäße die Begriffe ciphus, fiala, crater, crather, cuppa, kop, scale und schale. Eine Begriff - Objekt Zuordnung ist möglich für den Kopf, der als crater, crather, kop und cuppa bezeichnet wird, und für die Schale, die entweder gleichlautend oder fiala genannt wird. Offensichtlich für beide Formen stand der Begriff ciphus, denn er steht in den Testamenten sowohl als Kontrastgefäßform zu Kopf wie zur Schale ${ }^{57}$. Die Testamente berichten darüberhinaus von

\footnotetext{
${ }^{56}$ Umfassender Überblick bei M. HASSE, Neues Hausgerät, neue Häuser, neue Kleider, S. 15f; besonders komprimiert unter den Stichwörtern „, Kopf“, S.73f und unter „Schale“, S.79f.

${ }^{57}$ Testament des Segeband von Thune 1385 listet auf: fiala proprie schale und ciphum; Testament des Hartwig Hannover 1484 spricht von crather und ciphum.
} 
einer besonderen, terminologisch eindeutig zuzuordnenden Form des Kopf, vom Doppelkopf, auch Schauer schower genannt.

\section{Schale}

Die Funktion der Schale war nicht allein auf die eines Trinkbehältnisses beschränkt, eine Schale konnte wie auch die Schauer zur Aufnahme der krude, des stark gewürzten, süßen und klebrigen Konfekts ${ }^{58}$ dienen ${ }^{59}$. Die Bezeichnung für eine solche Konfektschale war crudenap ${ }^{60}$. Der Sprachgebrauch der Testatorin Geseke Springintgud (s.u.) zeigt, daß Schale als Oberbegriff für Schauer oder crudenap stehen kann.

Für den tabellarischen Überblick sind die unterschiedlichen Formen zusammengefaßt worden, einerseits um zu aussagekräftigen Zahlen zu kommen, andererseits um angesichts der nicht durchweg eindeutig zuzuordnenden Begriffe ${ }^{61}$ Fehler zu vermeiden. In der anschließenden Auswertung wird wieder differenziert, wobei ggf. auch Zahlenwerte genannt werden.

Tabelle: Testamentarische Vererbung von Schalen

\begin{tabular}{|l|c|}
\hline Jahre & Anzahl der Testatoren und Schalen \\
\hline $1300-1325$ & - \\
\hline $1325-1350$ & 1 Testator mit 3 Schalen \\
\hline $1350-1375$ & 1 Testator mit 4 Schalen \\
\hline $1375-1400$ & 1 Testator mit 7 Schalen \\
\hline $1400-1425$ & 5 Testatoren mit 14 Schalen \\
\hline $1425-1450$ & 5 Testatoren mit 13 Schalen \\
\hline $1450-1475$ & 5 Testatoren mit 14 Schalen \\
\hline $1475-1500$ & 5 Testatoren mit 11 Schalen \\
\hline
\end{tabular}

Der tabellarische Überblick zeigt, daß Schalen bereits zu einem frühen Zeitpunkt in Lüneburger Testamenten genannt werden ${ }^{62}$. Zwar liegen aus dem 14. Jahrhundert lediglich drei Testamente mit entsprechenden Legaten vor, es zeigt sich in innen jedoch bereits das

\footnotetext{
${ }^{58}$ Erklärung, worum es sich bei Krude handelt und wie man es hätte nicht verwenden sollen bei $\mathrm{H}$. BOOCKMANN, Fürsten, Bürger, Edelleute, München 1994, S.141. Beispiel einer Konfektschale: S. BURSCHE, Das Lüneburger Ratssilber, Nr.4, S. 104ff .

${ }^{59}$ E. WURMBACH, Das Wohnungs- und Kleidungswesen des Kölner Bürgertums, S.44.

${ }^{60}$ Beschreibung bei M. HASSE, Neues Hausgerät, neue Häuser, neue Kleider, S.76.

${ }^{61}$ Über die Schwierigkeiten der Begriffsbestimmung zwecks Zuordnung zu Objekten auf der Grundlage von Testamenten siehe M. HASSE, M. HASSE, Neues Hausgerät, neue Häuser, neue Kleider, S. 60.

${ }^{62}$ Als erstes im Testament des Priesters Leo 1339.
} 
auch im 15. Jahrhundert durchgängig geltende Phänomen der ausschließlich in der Mehrzahl vererbten Schalen. Über die Dezennien hinweg bleiben die Durchschnittswerte der pro Testament vererbten Gefäße annähernd gleich.

\section{Material}

Wie andernorts bestehen auch in Lüneburg die testamentarisch vererbten Schalen vorrangig aus Silber, denn 53 der insgesamt 65 Schalen werden von den Testatoren als sulvern oder argenteum bezeichnet. Silber ist als Edelmetall zwar teuer, aber eben deutlich billiger als Gold, so daß trotz Wertimmanenz doch das eine oder andere Stück mehr gekauft werden kann. Dementsprechend umfangreich werden die (Trink - ) Geschirre etlicher Testatoren gewesen sein - allein sieben Schalen enthält das Testament Segeband von Thunes -, und einige Testamente weisen auf außertestamentarischen Besitz an Schalen $\operatorname{hin}^{63}$.

\section{Aussehen der Schalen}

Mit 32 Direktnennungen ist die Schale das am häufigsten genannte Gefäß. Sie findet in annähernd gleichmäßiger Verteilung über den Untersuchungszeitraum hinweg Erwähnung. Als Erkennungskriterium für Testamentsvollstrecker und Erbnehmer beschreiben die Testatoren ihre Schalen in einigen Fällen als große und kleinere Schalen (1367 Johann Beve, 1413 Johann von Tespe, 1427 Ludolf Bartholomeus, 1460 Hilleke von Erpensen, 1474 Matthias von der Most). Hermann Kruse ist der einzige Testator, der seine Schalen nach dem Qualitätskriterium unterscheidet. Um welch prachtvolle Ausführung es sich hier bei seiner zweitbesten Schale gehandelt haben mag, kann man angesichts der Tatsache vermuten, daß sie von ihm, der zur Zeit der Testamentserrichtung Lüneburger Bürgermeister ist, an ein Mitglied eines der führenden Geschlechter, Johann von der Mölen, zur Zeit der Testamentserrichtung Ratsherr, gegeben wird. Die in Wert und damit wohl auch Ausführung direkt folgende Schale wendet Kruse Dietrich Düsterhop zu. Vermutlich handelt es sich bei den Bedachten um seine Schwiegersöhne ${ }^{64}$. Wenn auch in diesem Fall das Aussehen der Schalen im Dunkel bleiben muß, so gibt es doch Testamente, die die in ihnen vergabten Schalen anschaulich beschreiben:

Aus dem Jahr 1425 stammt das Testament der Geseke Springintgud, in dem sie zwei je mit den Wappen ihrer Empfänger versehene Schalen vererbt, was in gewissem Maße auf eine verwandtschaftliche Beziehung hinweist. Beke Groning beschreibt ihre Schale als ene sulverne scale, dar stan dre halve manen inne ${ }^{65}$. Da sie als Empfänger Brand Tzerstede

\footnotetext{
${ }^{63} 1339$ Presbyter Leo, 1367 Johann Beve, 1413 Johann von Tespe, 1441 Heinrich Tetendorp.

${ }^{64}$ H. J. v.WITZENDORFF, Stammtafeln Lüneburger Patriziergeschlechter, S.66.

${ }^{65}$ U. REINHARDT, Testamente, Nr.217, S.313.
} 
angibt, und das Wappen des Geschlechts Tzerstede ein blauer Balken ist, der vor rotem Hintergrund steht und mit drei silbernen Halbmonden belegt ist, handelt es sich auch bei diesem Legat um eine Wappenschale. In Braunschweiger und Lübecker Testamenten werden derartige mit Wappen versehene Schalen „besonders häufig“ erwähnt ${ }^{66}$, eine Beobachtung, die für Lüneburger Testamente ebenfalls Geltung hat.

Johann Rese beschreibt 1431 die von ihm zu vererbende Schale als ene sulverne schale, dar steit en enhorning ynne ${ }^{67}$. Durch das Einhorn wird die Reinheit der Gottesmutter Maria symbolisiert $^{68}$, und so verweist das Motiv dieser Schale ebenso wie dasjenige der von Dietrich Junge ${ }^{69}$ vererbten in den religiösen Bereich. Die beiden Silberschalen des Dietrich Junge sind versehen cum ymagine beati lohannis und cum ymagine beate virginis.

Von der Most verfügte in seinem Testament 1474 die Anfertigung einer großen silbernen Schale, so de ene is, der uppe deme radhusze twe syn, unnd scholen de geven uppe dat radhusz, dar scholen se myner by dencken ${ }^{70}$. Beide Schalen, Vorbild sowie die nachzufertigende, haben sich im Verband des Lüneburger Ratssilbers bis auf den heutigen Tag erhalten. Die von Meister Cord Hagen um das Jahr 1474 angefertigte sogenannte Evangelistenschale ${ }^{71}$ muß von der Most dermaßen beeindruckt haben, daß er sie als Vorbild für eine in seinem Auftrag anzufertigende Schale benennt ${ }^{72}$, eine Schale, die als Konfektschale dienen soll. Das die Schale säulenartig tragende Figurenprogramm der vermutlich im Jahr 1476 angefertigten Schale $^{73}$ hat Cord Hagen mit den Kirchenvätern Gregorius, Hieronymus, Augustinus und Ambrosius besetzt, in die Schale ein Wappen, vermutlich das des Testators, sowie den Stiftungsspruch nebst Namensnennung des Stifters eingearbeitet, womit die wesentliche Voraussetzung für das Gedenken an den Testator geleistet ist. Nicht nur in der Ausschmückung hat Cord Hagen vorrangig das Heilsgeschehen aufgegriffen, er hat auch die Form der Schale, wie die der Evangelistenschale, brunnenartig angelegt, und damit die im Spätmittelalter verbreitete „Darstellung des Lebensbrunnens als Gnadenbrunnen“ aufgegriffen, in dessen Becken das

\footnotetext{
${ }^{66}$ M. HASSE, Neues Hausgerät, neue Häuser, neue Kleider, S.80.

${ }^{67}$ U. REINHARDT, Testamente, Nr.165, S.228. Aus für mich nicht einsichtigem Grund steht bei HASSE anstelle des Einhorns ein König, und offensichtlich sieht er in der Schale eine Kanne, M. HASSE, Neues Hausgerät, neue Häuser, neue Kleider, vgl. S.70, Fußnote 144 In dem Ratssilberinventar aus dem 1598 ist eine Schale ähnlichen Motivs verzeichnet; dargestellt ist die Jungfrau im Garten mit einem Einhorn, S. BURSCHE, Das Lüneburger Ratssilber, Nr. 119, S. 185 Hinweis auf Symbolik.

${ }^{68}$ C. ERSKINE CLEMENT, Legendary and mythological Art, S.4.

${ }^{69}$ U. REINHARDT, Testamente, Nr.253, S.390. Es gibt zwei Gründe, die hier für die Zuordnung als Schalen sprechen: 1. Junge bezeichnet diese Legate als ciphus im Gegensatz zu drei anderen Trinkgefäßen, die er crather nennt. 2. In Lüneburger Testamenten werden weder Köpfe noch Schauern, sondern nur Schalen ausführlich beschrieben.

${ }^{70}$ U. REINHARDT, Testamente, Nr.244, S.376.

${ }^{71}$ Abbildung und ausführliche Beschreibung in: S. BURSCHE, Das Lüneburger Ratssilber, Nr.4, S. 104ff .

${ }^{72}$ Meister Cord Hagen war überdies beim Testator verschuldet.

${ }^{73}$ Beschreibung in S. BURSCHE, Das Lüneburger Ratssilber, Nr.5, S. 107f.
} 
die Erlösung symbolisierende Blut Chrisi gesammelt wird ${ }^{74}$. Über die Höhe der Anfertigungskosten gibt das Testament keine weiteren Auskünfte. Das Legat Matthias von der Mosts wird eingereiht in den Bestand des Lüneburger Ratssilbers, dessen Umfang das erste umfassend erhaltene Inventar 1555/56 mit ca. 200 Stück angibt. Wenn auch der Verwendungszweck aus den Quellen nicht eindeutig hervorgeht, so weiß man doch, daß es einen zum Verschenken gedachten und einen festen Bestand gegeben hat. Das Ratssilber verkörpert einen großen materiellen Wert, der eigentlich überhaupt nicht, wenn, dann nur in Notzeiten veräußert werden soll ${ }^{75}$. Der Bestand setzt sich aus Schalen, Kannen, Bechern und Pokalen zusammen, während Teller oder Schüsseln nicht vorkommen, also anläßlich einer Mahlzeit extra beschafft werden mußten. Diese Zusammensetzung verweist auf die besondere Bedeutung der Rechtssymbolik des Tranks, und im Rahmen der Umtrünke wurde Konfekt gereicht, das auf dem crudenap gereicht und wegen seiner klebrigen Konsistenz mit crutschuffeln gegessen wurde. Bezogen auf den aktuellen Bestand des Lüneburger Ratssilbers ist das Geschenk des Matthias von der Most ein frühes Beispiel einer in Lüneburg angefertigten silbernen, teilvergoldeten Konfektschale, die von hohem Können Lüneburger Goldschmiede, aber auch von dem Wohlstand und der Umsicht des kinderlos versterbenden Lüneburger Apothekers zeugt, der im Rahmen einer Memorialstiftung seinen Namen mit dem des auf lange Zeit bestehenden Ratssilbers der Stadt verknüpft hat.

Deutlich geringer, aber immer noch von beträchtlicher Höhe fällt der Geldbetrag von 40 Mark Pfennigen aus, den Lorenz König in seinem 1494 errichteten Testament für ein Kleinod für die Schenkeschive des Rathauses vererbt. Das Inventar des Ratsilbers aus dem Jahr 1598 identifiziert dieses Kleinod als „Eine grosse silberner Schale mit Marcke, so Lorentz Königke dem Rath gegeben“76.

Neben den eben beschriebenen, aus der Erbmasse sicher herausragenden Exemplaren werden in den Testamenten auch Schalen vergeben, die von einem Wert sind, der augenscheinlich Anfertigungen in größerer Menge erlaubt. Die hierfür in den Testamenten zu findenden Beispiele sprechen von fünf bzw. von sechs Schalen, die von gleicher Machart sind. Geseke Springintguds Testament 1425 enthält keine Angaben über das Aussehen dieser Schalensammlung, verrät nur, es handele sich hier um sechs Schalen, de

\footnotetext{
${ }^{74}$ S. BURSCHE, Das Lüneburger Ratssilber, S.105. Vor allem in der Apokalypse spielt die Wassersymbolik eine große Rolle. Das himmlische Jerusalem wird von den Strömen des Lebens durchflossen, so daß das Wasser als Symbol des kommenden Endheils gilt, vgl. F. MUSSNER, Stichwort „Wasser“, in: LThK, Bd. 10, Sp.964.

${ }^{75}$ Ratsbeschluß vom 5. November 1476. Trotz etlicher Verluste blieb das Ratssilber fast 400 Jahre lang in Lüneburg, bis es 1874 nach Berlin verkauft wurde, weil in den Augen der Stadtväter offensichtlich die äußerste Notlage durch die Finanzierung eines Fahrdammes und des Bahnhofs eingetreten war. Heute befindet sich das Originalratssilber im Kunstgewerbemuseum der Stadt Berlin, während in Lüneburg Kopien ausgestellt sind.

${ }^{76}$ S. BURSCHE, Das Lüneburger Ratssilber, S. 184 mit Angabe des Standorts.
} 
van eyner makinge sint ${ }^{77}$. Vermutlich haben sich diese Schalen bis dato im Besitz der Testatorin befunden und ihr praktische Dienste oder Repräsentationsdienste erwiesen, jedenfalls erscheint es Geseke Springintgud als nicht verwerflich, den Bestand nun zu trennen, da sie die Schalen an die beiden Söhne ihres Ehemannes vererbt. Auch Matthias von der Most verteilt seinen Bestand an silbernen Schalen mit vergoldeten Rosen an seine fünf Testamentsvollstrecker.

\section{Schalen mit und ohne Fuß}

Als weiteres Beschreibungskriterium wählen die Testatoren die Unterscheidung zwischen Schalen ohne und mit Fuß. Vicke Bottermann hebt 1476 die von inm testamentarisch zu vererbende Schale mit der Bemerkung aus dem Kreis seiner Schalen hervor, sie sei eine silberne Schale mit Fuß. Wahrscheinlich handelt es sich hier um eines der wertvolleren Exemplare, das er (seinen?) Kindern zuwenden will. Im Normalfall ist wohl davon auszugehen, daß die vererbten Schalen einen Fuß hatten.

Füße konnten nachträglich durch die Technik des Bajonettverschlusses an einem Gefäß befestigt werden $^{78}$, einen Beleg dafür bieten die Lüneburger Testamente andeutungsweise. Das Testament Geseke Springintguds spiegelt nämlich die Überlegungen hinsichtlich einer Schalenanfertigung wider: Der Denkprozeß der Testatorin heißt nicht, ein Betrag finanziert eine komplette Schale, sondern sie hat die Schale gedanklich zerlegt in Kopfteil und Fuß. In ihren Ausführungen beginnt sie bei dem silbernen Fuß für eine Schauer oder einen crudennappe, was dafür spricht, daß sich der Fuß bereits in ihrem Besitz befindet, zumal sie auch keinen Geldbetrag für die Anfertigung dieses Fußes aussetzt. Die Finanzierung einer schale up den vot will sie mit einer gefiled vorguldet hovedgad bewerkstelligt wissen ${ }^{79}$. Empfänger dieses wertvollen Legats sind die beiden Söhne ihre Ehemannes, die offensichtlich nicht ihre leiblichen Kinder sind, und denen sie dieses Legat und sechs weitere Schalen (s.o.) zuwendet mit der Erklärung, dat se umme myner leve willen hebben mogen $^{80}$. Diese hier beobachtete Trennung von Schale und Fuß tritt auch im Testament Ludolf Bartholomeus auf, in dem der Testator die Umarbeitung seiner größten silbernen Schale ohne Fuß zu einem Kelch für die Vikarie seines Sohnes wünscht.

\section{Gewicht der Schalen}

Hilleke Blickershusens Testament ist das einzige Testament, das nähere Angaben zu Preis und Gewicht einer Schale enthält: eyne sulveren schalenn vann vyff mark penningen edder

\footnotetext{
${ }^{77}$ U. REINHARDT, Testamente, Nr.152, S.208.

78 „Silbern Fuss“, M. HASSE, Neues Hausgerät, neue Häuser, neue Kleider, S.81.

${ }^{79}$ U. REINHARDT, Testamente, Nr.152, S.208.

${ }^{80}$ ebd.
} 
darby de dar wycht sovendehalff loth myt eynn halb quentin ${ }^{81}$. Im Verhältnis zur Kölner Durchschnittsschale, die zwischen 8 und 10 Lot wiegt ${ }^{82}$, handelt es sich hier um eine leichtere Anfertigung. Gleiches gilt für den Vergleich mit den in Stralsunder Testamenten aufgeführten Schalen, bei denen gelegentlich eine Silbermenge von 8,25 Lot genannt wird $^{83}$. Dieser an einer einzigen Schale aufgehängte Vergleich kann nicht verallgemeinert werden. Allein die Kirchenväterschale, zugegebenermaßen sicherlich eine der wertvollsten testamentarisch vererbten Schalen, hat weit mehr als 10 Lot gewogen ${ }^{84}$.

Die Schale als Pfandobjekt

Schalen werden auch verpfändet; so hat Johann Beve von Dietrich Schiltsten offensichtlich mindestens zwei Schalen ${ }^{85}$ als Pfand angenommen und diese Schalen an Klaus Floreke bereits weitergegeben, so daß Beve in seinem Testament die Bestimmung verankert, beim Auslösen der Schalen solle Klaus Floreke den Erlös erhalten.

\section{Weiterverarbeitung der Schale}

Es gibt in den Testamenten je nur ein Beispiel dafür, daß entweder eine Schale eingeschmolzen werden soll oder $d a ß$ eine Schale aus einem anderen silbernen Gegenstand hergestellt werden soll. Als Beispiel für den Einschmelzungsprozeß einer Schale wurde eben das Testament Bartholomeus vorgestellt. Eine anders herum lautende Bestimmung enthält das Testament Mettekes von Dassel, in dem die Testatorin einen silbernen Gürtel zur Anfertigung einer ihrem Sohn zugedachten Schale anordnet.

\section{Kopf}

Der Kopf ist ein aus einer tieferen Schale bestehendes Trinkgefäß, das mit Fuß und Deckel versehen ist. Der sich hochwölbende Deckel wird seit ca. 1400 oft mit einer Figur versehen $^{86}$. In den Lüneburger Testamenten werden Köpfe 15 mal erwähnt, wobei vorwiegend die Bezeichnungen crather oder kop verwendet werden. Lediglich Johannes

\footnotetext{
${ }^{81}$ U. REINHARDT, Testamente, Nr.292, S.471.

${ }^{82}$ E. WURMBACH, Das Wohnungs- und Kleidungswesen des Kölner Bürgertums, S. 44

${ }^{83}$ J. SCHILDHAUER, Hansestädtischer Alltag, S.77.

${ }^{84}$ Legt man WURMBACHs Zahlen von 10 Lot $=468$ gr zugrunde, kommt man bei dem Gewicht der Kirchenväterschale von $2035 \mathrm{~g}$ auf gut 40 Lot.

${ }^{85}$ Eine der kleineren Schalen Dietrich Schiltstens hinterläßt Johann Beve seinem Sohn. Allerdings ist nicht vermerkt, ob die Schale als Pfand steht oder ob sie dem Testator von Schiltsten geschenkt wurde.

${ }^{86}$ M. HASSE, Neues Hausgerät, neue Häuser, neue Kleider, S.75
} 
von Lippinghausen beschreibt sein Legat in seinem Testament 1424 als cuppam meam argenteam cum cooptorio ${ }^{87}$.

Die von WURMBACH vorgelegte Definition beschreibt den aus dem Kopf hervorgehenden Pokal als ein im Prinzip vierteiliges Gefäß, dessen Fuß unten breit sei, sich nach oben verjünge; Bindeglied zwischen Fuß und dem Trinkgefäß, der Cupa, sei der Knauf, der durch zunehmend kunstvolle Anfertigungen vielfach seinem Zweck des Anfassens beraubt werde. Verschlossen werde die Cupa von einem Deckel, der in etlichen Fällen mit einer Figur versehen ist ${ }^{88}$. Angesichts dieser Definition stellt sich hinsichtlich der von Lippinghausen gewählten Formulierung die Frage, ob der Testator nicht wie auch Geseke Springintgud bei seiner Beschreibung des Legats dessen einzelne Bestandteile vor seinem geistigen Auge hat, wobei es offensichtlich eine bestimmte, von der Zweckmäßigkeit der Einzelelemente gesteuerte Rangfolge gibt, da zuerst die Cupa genannte wird und Fuß wie Deckel als „Cooptorium“ subsumiert werden.

Anders als bei den Schalen wird das Aussehen der Köpfe von den Testatoren nicht konkreter beschrieben. Aus dem Faktum, daß zwölf Testatoren ihre Köpfe als silberne beschrieben haben, darf geschlußfolgert werden, es habe sich auch hier um Silbergefäße gehandelt. Einzige Unterscheidungsmerkmale in den Testamenten sind Gewicht und Größe. Heinrich Tetendorp beschreibt 1441 seine zwei Köpfe als kleinere Köpfe. Das Gewicht und damit in gewissem Maße den Wert des Kopfes gibt Johannes von Lippinghausen 1424 mit pensantem unam marcam cum dimidia argenti puri $\mathrm{an}^{89}$. Wie Schalen auch, werden Köpfe als Pfand akzeptiert ${ }^{90}$.

\section{walsche noit}

1451 testierte die Witwe des Barmeisters Hans Groning, Beke Groning. Ihr Testament weist sie, die mit der Ratsfamilie vame Lo verwandt ist, als reiche Frau aus. Ihrem Schwiegersohn Johann Springintgud hinterläßt sie ene walsche noit ${ }^{91}$. Das Legat steht im Testament im Kontext von Trinkschalenvergabungen. Köpfe und Schauern konnten in besonderen Fällen aus kräftig gemaserten Hölzern oder Kokosnüssen angefertigt worden $\operatorname{sein}^{92}$. Das optische Erscheinungsbild kann auf die Testatorin einen durchaus welschen ${ }^{93}$, also fremden Eindruck gemacht haben, vor allem dann, wenn es sich tatsächlich um eine Kokosnuß gehandelt haben sollte. Kokosnüsse wurden selbst als Pokale genutzt, indem man inr

\footnotetext{
${ }^{87}$ U. REINHARDT, Testamente, Nr.150, S.202.

${ }^{88}$ E. WURMBACH, Das Wohnungs- und Kleidungswesen des Kölner Bürgertums S.44

${ }^{89}$ U. REINHARDT, Testamente, Nr.150, S.203.

${ }^{90}$ Testament des Segeband von Wittorf 1385.

${ }^{91}$ U. REINHARDT, Testamente, Nr.217, S.313.

${ }^{92}$ M. HASSE, Neues Hausgerät, neue Häuser, neue Kleider, S.74.

${ }^{93}$ J. und W. GRIMM, Deutsches Wörterbuch (Fotomechanischer Nachdruck), München 1984, Bd.27, S.1341 Es kann auch ,,aus der Fremde gekommenen“ bedeuten.
} 
Inneres mit einem herausnehmbaren, silbernen oder vergoldeten Becher oder einer entsprechenden Schale auskleidete ${ }^{94}$. Das „Inlay“ aus Edelmetall war dünnwandig und mit ausgearbeiteter Innenseite verziert. Aus Holz gefertigte Köpfe konnten auch mit Silber verziert sein. Ein Lübecker Eintrag aus dem Jahr 1458 zeigt, daß hölzerne, silberverzierte Trinkgefäße als Nuß bezeichnet werden ${ }^{95}$. Zwei aus Maserholz im späten 15. Jahrhundert gefertigte, mit vergoldetem Silber gefaßte Doppelköpfe aus dem Süddeutschen haben sich in Wien erhalten ${ }^{96}$.

Eine mögliche, hier allerdings weniger wahrscheinliche Alternative ist eine Gleichsetzung der walschen noit mit einer Gebetsnuß. Eine Gebetsnuß ist eine kleine aufklappbare Kapsel, die zunächst nur aus (Buchsbaum-)Holz, später auch aus (Edel-)Metallen gefertigt wurde $^{97}$. In ihrem Inneren befinden sich religiöse Figuren oder Szenen, die zum Gebet aufforderten. Die sich hieran orientierende Namensgebung ist neuzeitlichen Ursprungs (19. Jahrhundert), und in dieser terminologischen Unklarheit für das Spätmittelalter liegt die Schwierigkeit, das Legat als Gebetsnuß zu identifizieren. Wie der Bisamapfel konnte die Gebetsnuß als Anhänger an einer Kette oder einem Rosenkranz getragen werden und diente bei perforierter Außenfläche als Duftbehältnis. Besondere Verbreitung erfuhr die Gebetsnuß zwischen dem ausgehenden 15. Jahrhundert und ca. dem ersten Viertel des 16. Jahrhunderts. Aufgrund der wertvollen Ausführungen ist sie überwiegend in den Händen der Wohlhabenden zu finden. Eine aus Buchsbaum gefertigte Gebetsnuß in Form des Madonnenhauptes ist aus dem Nürnberg des beginnenden 16. Jahrhunderts überliefert ${ }^{98}$.

\section{Schauer}

Die Schauer ist hervorgegangen aus dem Kopf, dessen Deckelwölbung ebenfalls als Trinkgefäß genutzt wird ${ }^{99}$. So erklärt sich der vorrangig im Süddeutschen verwendete Name Doppelkopf. Im Vordergrund steht bei der Nutzung die Symbolik des Zusammenführens zweier Teile, zweier Menschen zu einem. Besonders beliebt ist das Gefäß bei der Brautschau, der gemeinsamen Präsentation des Brautpaares, so daß sich der Name Schauer in Norddeutschland auf das Gefäß überträgt. Die Schauer spielt auch in Freundschaft symbolisierenden Trünken in politischem Rahmen eine Rolle. Ein bezeichnender Hinweis auf die Bedeutung der Trinksymbolik ist die Dominanz der

\footnotetext{
${ }^{94}$ Kat. „Eines Fürsten Traum. Meinhard II.-Das Werden Tirols“, Dorf Tirol.Innsbruck 1995, S. 175f, Nr. 5.15.

${ }^{95}$ M. HASSE, Neues Hausgerät, neue Häuser, neue Kleider, S.21, Fußnote 23 Auch hier fällt die Bezeichnung im Kontext von Trinkgefäßen, direkt im Kontext von Kopf-Auflistung.

${ }^{96}$ M. LEITHE-JASPER, R. DISTELBERGER, Schatzkammer und Sammlung für Plastik und Kunstgewerbe (=Kunsthistorisches Museum Wien, Bd.1), London.München 1982, S.64

${ }^{97}$ K. DINGELSTEDT, „Betnuß“, in: RDK, Bd. II, Sp. 371-377.

${ }^{98}$ Kat. „Das Schnütgen-Museum. Eine Auswahl““, Köln 1964/3, Nr. 176, S. 89f (mit Abb.)

${ }^{99}$ M. HASSE, Neues Hausgerät, neue Häuser, neue Kleider, S.73.
} 
Trinkgefäße im Rahmen des Lüneburger Ratssilbers. Die von Vicke Bottermann 1476 ausgesetzten 150 Mark, die inm Herr Ludolf Garlop schuldet, sollen für ein silbernes Kleinod des Rathauses verwendet werden, und das Inventar von 1598 weist dieses Kleinod dann als „zwei silbern gedrungene Köppe in einander gestölpet“ aus ${ }^{100}$.

In den Testamenten Johann Reses 1431, Heinrich Tetendorps 1441 und Hermann Kruses 1441 werden je zwei silberne Köpfe vererbt. Es könnte sich entweder um zwei Köpfe gleicher Ausfertigung handeln oder um eine Schauer, also um eine Zusammengehörigkeit, wie sie von Segeband von Thune in seinem Testament 1385 mit der Bemerkung deutlich gemacht wurde, es handele sich um unum par ciphorum argenteorum ${ }^{101}$. Zumindest für das Testament Johann Reses muß die Annahme einer Schauer verworfen werden, da der Testator ein anderes Legat eindeutig als myne vorghuldeden schower tituliert und eine Verschiedenheit der Bezeichnungen möglich, aber unwahrscheinlich ist ${ }^{102}$.

Becher

Tabelle: Testamentarische Vererbung von Bechern

\begin{tabular}{|c|c|}
\hline Jahre & Anzahl der Testatoren und Becher \\
\hline $1400-1425$ & 1 Testator mit 3 Bechern \\
\hline $1425-1450$ & 1 Testator mit 4 Bechern \\
\hline $1450-1475$ & 6 Testatoren mit mindestens 19 Becher \\
\hline $1475-1500$ & 4 Testatoren mit mindestens 11 Becher \\
\hline
\end{tabular}

Becher werden ausschließlich in Lüneburger Testamenten des 15 Jahrhunderts erwähnt. Damit spiegelt sich in den Testamenten das für das 14. und frühe 15. Jahrhundert geltende Übergewicht schalenförmiger Trinkgefäße wider ${ }^{103}$.

Als Material aller mindestens 37 Becher wird von den Testatoren Silber angegeben. Die Einheitlichkeit des Silbers als das Material testamentarisch vergabter Becher schlechthin ist bemerkenswert, da es durchaus gläserne Becher gab, und Glas bei der Becherfertigung sogar entwicklungsgeschichtlich eine tragende Rolle einnahm ${ }^{104}$.

Die Becher werden von den Testatoren z. T. durch ihre unterschiedliche Größe und Qualität unterschieden. So vergabt Geseke Rosemberg 1472 zunächst ihren größten silbernen Becher, ehe sie dann den jeweils nächstbesten Becher zwei unterschiedlichen Empfängern

\footnotetext{
${ }^{100}$ S. BURSCHE, Das Lüneburger Ratssilber, S.186.

${ }^{101}$ U. REINHARDT, Testamente, Nr.45, S.63.

${ }^{102}$ U. REINHARDT, Testamente, Nr.165, S.228.

${ }^{103}$ M. HASSE, Neues Hausgerät, neue Häuser, neue Kleider, S.62.

${ }^{104}$ H. WENTZEL, „Becher“, in: RDK, Bd.2, Sp. 135f; M. HASSE, Neues Hausgerät, neue Häuser, neue Kleider, S.61ff.
} 
zuwendet. Hilleke von Erpensen wendet ihre zwei größten Becher dem Blauen Konvent zu, was mit den übrigen Bechern geschehen soll, wird nicht extra erwähnt. Seinen zweitbesten Becher vergabt 1472 Hans Jagow.

Ungefähr aus dem letzten Quartal des 15. Jahrhunderts stammen die einzigen in den Testamenten konkreter beschriebenen Becher. Der Ratsherr Johann vame Lo sah sich in seinem 1473 aufgesetzten Testament zur Beschreibung der von inm seinen Testamentsvollstreckern zugedachten Bechern verpflichtet, da es sich um besondere Anfertigungen handelte, die nach der Vorlage eines sich im Besitz des Testators befindenden Bechers herzustellen sein. Zu diesem Zweck solle auf Silber zurückgegriffen werden, das der Testator noch oder eigens für diesen Zweck liegen habe. Die sechs anzufertigenden Becher sollen einen Fuß und einen vergoldeten Rand haben, im übrigen sollen sie diese alse se herlikest konnen herstellen ${ }^{105}$. Gesche Hennings vier testamentarisch vergabte Becher sind mit einem goldenen Rand verziert.

Genau wie Johann vame Lo wünschen auch Gesche Henning sowie Lorenz König die Aushändigung silberner Becher an die Testamentsvollstrecker. Die von Gesche Henning verfügten Becher müssen eigens angefertigt werden, und ihr Bruder soll die mit ihrem restlichen Gut zu finanzierende Anfertigung initiieren und überwachen. Der maximale Wert der Becher darf vier Mark Pfennige betragen. Ungefähr gleichwertig, nämlich fünf Mark Pfennige, sind die von Lorenz König seinen Testamentsvollstreckern zugedachten Becher. Allerdings geht es hier weniger um die Becher als um ihren Wert, denn aus jedem Becher soll ein Kleinod für jeden Testamentsvollstrecker hergestellt; die Kosten des Umarbeitens übernimmt die Frau des Testators.

\section{Gläser}

Gläser werden in den Lüneburger Testamenten in verschwindend geringem Umfang genannt. Gläser treten in drei Testamenten auf, von denen zwei von ein und demselben Testator aufgesetzt sind (1385 Segeband von Wittorf, 1414 Johannes von Lippinghausen, 1424 Johannes von Lippinghausen). Bei beiden Testatoren handelt es sich um Kleriker. Die Vermutung liegt nahe, daß im Gegensatz zu Klerikern Testatoren, die Nachfahren haben (dürfen), Gläser außerhalb des Testaments vergeben.

Mit einiger Wahrscheinlichkeit darf man von Glasbesitz gerade der wohlhabenden unter den Lüneburger Testatoren ausgehen, immerhin liegen die Glaszentren Südniedersachsens und des Spessarts nicht allzuweit von Lüneburg entfernt, ferner zeigt die Bildquelle eines Altarflügels der Goldenen Tafel aus dem Michaeliskloster von ungefähr

\footnotetext{
${ }^{105}$ U. REINHARDT, Testamente, Nr.240, S.366.
} 
1418 einen hohen Becher des böhmischen Typs ${ }^{106}$, was zumindest auf die Kenntnis, wahrscheinlich auf den Import derartiger Glaserzeugnisse nach Lüneburg schließen läßt.

Aus dem Testament Segeband von Thunes geht nur hervor, daß er Gläser vererbt hat. Genaueres ist hingegen dem Testament Johannes von Lippinghausens zu entnehmen: Er beschreibt 1414 sein zu vererbendes Glas als vitrum Venetianum cum pedibus argenteis und 1424 als vitrum meum Veneticum cum argenteo pede ${ }^{107}$.

Gläser aus Italien, vor allem natürlich aus Venedig/Murano, genossen höchste Wertschätzung ${ }^{108}$, und waren nicht zuletzt wegen des langen und für das Glas aufgrund der Bruchgefahr risikoreichen Transports teuer und wertvoll. Die Gläser zeichnen sich durch Transparenz ${ }^{109}$ und ein Minimum an Bläschen und Einschlüssen aus. Ob der Stiel und der Standteller des Glases wirklich aus Silber gearbeitet sind, muß angesichts der oft zu beobachtenden undeutlichen Bezeichnung des Materials (Silber, Zinn oder Glas) bezweifelt werden $^{110}$. Da Stiel und Standteller häufig aus leicht gefärbtem Glas bestehen ${ }^{111}$, kann der Testator auch den Farbeindruck wiedergegeben haben.

Erst seit dem 16. Jahrhundert gelingt es, auch nördlich der Alpen „Façon de Venise" Gläser herzustellen. Zeitgenössische Vergleichsstücke haben sich nicht erhalten, so daß man über das Aussehen venezianischer Gläser im Mittelalter annähernd keine Kenntnis besitzt $^{112}$. In Lüneburg sind „Façon de Venise“ - Gläser aus der frühen Neuzeit gefunden worden ${ }^{113}$, so daß man sich von ihnen einen Eindruck machen kann, der auf die Kostbarkeit eines echt Venezianischen Glases schließen läßt.

Eine andere Glasart liegt vor, wenn der Testator mit seiner Formulierung syro-fränkisches Glas meint. Das sogenannte syro-fränkische Glas ist emailliertes Glas, das seinen Ursprung im Orient hat und durch Vermittlung der Kreuzfahrer im europäischen Bereich bekannt wird. Überlieferte Objekte und Fundstücke vermitteln das Bild vorrangig in Becherform angefertigter Gläser, die anders als die oft als Kelchgläser überlieferten „Façon de Venise“ Gläser mit einem Fuß aus Edelmetall versehen sein können ${ }^{114}$. Zunächst wird diese Glasart

\footnotetext{
${ }^{106}$ Abbildung und genaue Beschreibung des böhmischen Typs bei R. KAHSNITZ, Formen mittelalterlicher Gläser, in: Kat. „Aus dem Wirtshaus zum Wilden Mann“, S. 42; SCHÜTTE, Sven, Glas in der mittelalterlichen Stadt, in: Kat. „Aus dem Alltag der mittelalterlichen Stadt“, Bremen 1982, S.136.

${ }^{107}$ U. REINHARDT, Testamente, Nr.103, S.143; Nr.150, S.203.

${ }^{108}$ S. SCHÜTTE, Bürgerliches Hausgerät S. 556.

${ }^{109}$ In Venedig gelang es, ,, mit Hilfe der sodahaltigen in der Lagune gedeihenden Seepflanzen klares Sodaglas herzustellen“. R. KAHSNITZ, Formen mittelalterlicher Gläser, S.41.

${ }^{110}$ R. KAHSNITZ, Formen mittelalterlicher Gläser, S. 38.

${ }^{111}$ R. KAHSNITZ, Formen mittelalterlicher Gläser, S.42.

${ }^{112}$ R. KAHSNITZ, Formen mittelalterlicher Gläser, S. 38.

${ }^{113}$ M. KÜHLBORN, Keramik und Glasfunde der Fundstelle „Auf der Altstadt 29“, in: Kat. „Ton Steine Scherben“, S.68f; Abbildung und Beschreibung eines Lüneburger Fundes im Kat. „Stadt im Wandel“, Nr. 203.

${ }^{114}$ H. WENZTEL, „Becher“, in: RDK, Sp.137f, Abb.3 (=Syrischer Glasbecher aus dem 14. Jahrhundert mit Edelmetallfuß).
} 
über Venedig importiert, später dann in Venedig hergestellt, was die eine eindeutige Kategorisierung als syro-fränkisches Glas oder venezianisches Glas unmöglich macht ${ }^{115}$.

$\mathrm{Da}$ beide Glasarten äußerst wertvoll und selten sind, reicht für den Testator die Beschreibung als venezianisches Glas völlig aus.

Neuste Grabungen haben ergeben, daß in Lüneburg im 15. Jahrhundert Gläser hoher Qualität bekannt sind ${ }^{116}$.

Die Empfänger von Trinkgefäßlegaten

Insgesamt 29 Testamente enthalten zusammen 73 Verfügungen über Trinkgefäße oder Konfektschalen. Die Testatoren haben bei der Wahl der Empfänger dieser Legate vorwiegend Familienmitglieder gewählt. In 30 Fällen werden die Ehefrau, Sohn, Tochter, Bruder, Schwester, Neffe oder Schwiegersöhne als Bedachte genannt, in 22 Fällen handelt es sich um nahe Verwandte; mindestens 52 Legate gehen in den näheren Familien - oder Bekanntenkreis.

Die nun folgende, mit sechs zu belegenden Beispielen zahlenmäßig weit abfallende Empfängergruppe sind die Testamentsvollstrecker. Becher oder Schalen sind beliebte Dankes- und Erinnerungsgaben, mit denen nicht nur die Arbeit der Testamentsvollstrecker gleichsam als Vorausleistung honoriert wurde, sondern mittels derer durch die gelegentlich vorkommende Gleichheit der Ausführung eine vom Testament ausgehende Gemeinschaft impliziert wurde.

Das Rathaus als Empfänger ist zwar hinsichtlich der hier relevanten Legate in nur einem Fall genannt, aber die Auswertung hat gezeigt, daß mindestens zwei weitere Testamente die Anfertigung eines Kleinods vergleichbarer Art anordneten. Als religiöse Stiftungen werden Trinkgefäße in lediglich zwei Fällen vererbt, wobei es im Testament des Ludolf Bartholomeus sich in gewissem Sinn auch um eine Schenkung für seinen Sohn handelt, da der Testator der neuen Vikarie seines Sohnes einen Kelch stiftet, der aus der größten Schale ohne Fuß hergestellt werden soll.

Angesichts dieser Vergabungsart klärt sich die Frage, ob die Silbergefäße zum Zeitpunkt des Testierens bereits vorhanden oder noch anzufertigen waren, weitestgehend von selbst. Unübersehbar ist die vorherrschende Tendenz, familiensichernd zu vererben, und gerade die mit dem Familienwappen verzierten Silbergefäße deuten auf ein Herkommen aus und ein vom Testator gewünschtes Verbleiben in der Familientradition hin.

Als aussagekräftig erweist sich die Gegenüberstellung von anzuschaffenden und einzuschmelzenden Silbergerätschaften: Fünf Testatoren $^{117}$ wünschen die Anschaffung

\footnotetext{
${ }^{115}$ Thematisierung des Problems bei R. KAHSNITZ, Formen mittelalterlicher Gläser, S.40f

${ }^{116}$ M. KÜHLBORN, Keramik und Glasfunde der Fundstelle, S.69.
} 
einer Schale oder eines Bechers, und drei Testatoren ${ }^{118}$ befehlen das Einschmelzen zugunsten der Anfertigung eines Kelchs.

Der Grund für die Attraktivität der Silbergefäße mag in der Repräsentabilität größerer oder/und besonders kunstvoll gearbeiteter Exemplare gelegen haben. Wenn man es auch durchweg bei aus Silber gefertigten Gegenständen mit Wertgütern zu tun hat, so darf man doch nicht die Wertspanne, die sich von Ausführung zu Ausführung zeigen konnte, unterschätzen. Vielleicht liegt gerade hier eine bislang unterschätzte Erklärungsmöglichkeit für die Beliebtheit der silbernen Gefäße. Es stand eben nicht jede Silberschale gut sichtbar auf einer Schenkeschive, dort standen die Spitzenbesitztümer oder eventuell dem Besitzer besonders lieb gewordene Stücke, aber etliche Silberschalen liegen, verborgen für das Auge, in einer Lade, zusammen mit anderen Kleinoden, wie der Apotheker von der Most seine Aufbewahrungsart beschreibt. Bei der Inventarisierung des Nachlasses Dietrich Junges 1478 befinden sich seine Silberbecher eben auch in einer Truhe, zusammen mit anderen Schmuckstücken. Das beweist, daß nicht für jedes Silbergefäß ein möglicher Repräsentationscharakter als alleiniger Besitztumsgrund in Frage kommt.

In den Silbergefäßen können unterschiedlich große Geldbeträge investiert werden, wie die für Verwandte/Bekannte und Testamentsvollstrecker gedachten Ausführungen zwischen 3 bis 5 Mark Pfennigen und die für ein Kleinod des Ratssilbers in Höhe von 40 bis 150 Mark Pfennigen beweisen. Das Geld wird relativ wertsicher festgefroren und kann in Notzeiten wieder verflüssigt werden.

\section{$\delta$. Besteck: Löffel, Messer und Gabel}

19 Testatoren nehmen in 20 Testamenten ${ }^{119} 32$ Verfügungen über Löffel, Gabel oder Messer auf, wobei sie in ihrer Mehrzahl mehrere Besteckteile pro Testament vergeben.

Während Löffel in den Testamenten in großer Anzahl kontinuierlich über das 15. Jahrhundert verteilt Erwähnung finden, werden Messer und Gabel in sehr wenigen, um die Mitte des 15. Jahrhunderts verfaßten Testamenten genannt.

\section{Löffel}

Die von den Testatoren zur Bezeichnung von Löffeln verwendeten Begriffe sind lepel und coclear.

\footnotetext{
${ }^{117} 1425$ März 21 Geseke Springintgud, 1473 Juli 23 Metteke von Dassel, 1473 Sept. 29, Johann van dem Lo, 1474 Sept. 22 Matthias von der Most, 1494 Sept. 10 Gesche Henning.

${ }^{118} 1339$ Juli 24 Presbyter Leo, 1427 April 4 Ludeke Bartholomeus, 1484 Jan. 3 Hartwig Hannover.

${ }^{119}$ Johannes von Lippinghausen testiert 1414 und 1424.
} 
Tabelle: Testamentarische Verfügungen über Löffel

\begin{tabular}{|c|c|}
\hline Jahre & $\begin{array}{l}\text { Anzahl der Testatoren und mindestens vergabter } \\
\text { Löffel }\end{array}$ \\
\hline $1300-1325$ & - \\
\hline $1326-1350$ & - \\
\hline $1351-1375$ & 1 Testator mit 5 Löffeln \\
\hline $1376-1400$ & 3 Testatoren mit mindestens 41 Löffeln \\
\hline $1401-1425$ & 4 Testatoren mit 6 Löffeln \\
\hline $1426-1450$ & 3 Testatoren mit 14 Löffeln \\
\hline $1451-1475$ & 7 Testatoren mit 68 Löffeln \\
\hline $1476-1500$ &
\end{tabular}

\section{Material}

Alle 146 testamentarisch vergabten Löffel werden als silberne beschrieben. Der Löffel, aufgrund seiner Gebrauchsfunktion eines der ältesten, wenn nicht das älteste Eßwerkzeug ${ }^{120}$, wird ursprünglich aus Holz oder Horn gefertigt, und erst in dem Maße, in dem andere Tischutensilien aus Silber gefertigt werden und in den bürgerlichen Haushalt Einzug halten, nimmt der bürgerliche Besitz an Silberlöffeln zu.

\section{Anzahl und Aussehen der Löffel}

In den Testamenten werden Mengen von maximal 12 Löffeln aufgeführt. Neunmal werden die Empfänger mit einem einzigen Löffel bedacht, während sechzehnmal zwei und mehr Löffel vergabt werden. Folgendermaßen setzen sich diese sechzehn Legate zusammen: sechsmal wird eine Menge von je sechs Löffeln verschenkt, je zweimal eine Menge von zwei, drei und zwölf Löffeln, während mit Ausnahme der Zahlen sieben und elf die übrigen in der Skala von zwei bis zwölf je einmal vertreten sind.

Angesichts der nicht unbeträchtlichen Menge testamentarisch vergabter Silberlöffel zeigt sich, daß im 15. Jahrhundert wohlhabende Lüneburger zumindest bei Gastmählern nicht immer auf den oft in verziertem Lederfutteral am Gürtel befestigten, ständig bei sich getragenen Löffel angewiesen sind. Weniger wohlhabende Menschen sind sicherlich wesentlich länger auf das Mitführen des (Holz-) Löffels angewiesen, und die noch dem heutigen Sprachgebrauch bekannte Gleichsetzung des Löffelabgebens mit dem Tod zeugt

\footnotetext{
${ }^{120}$ E. MEYER, ,Besteck“, in: RDK, Bd.2, Sp. 356.
} 
von der durch die Tradition eingeprägten Vorstellung vom stets mitgeführten Besteck, dessen oft gebrauchter Bestandteil der Löffel ist.

Angesichts dieser Vielzahl umfangreicher Löffellegate ist es nicht unwahrscheinlich, daß einige der summarisch vergabten Löffel gleicher Machart gewesen sind. Die Testamente sagen über eine mögliche Zusammengehörigkeit einer bestimmten Löffelmenge nur indirekt etwas aus, und zwar im Moment der Bestimmung des Erbnehmers. So gibt z.B. Johannes von Lippinghausen 1414/1424 an, er habe seine zwölf Löffel, über die er im Testament verfügen wolle, von Johann de Bilne erhalten; diesen Bestand teilt er nicht unter verschiedenen Erbnehmern auf, sondern wendet ihn geschlossen einer Verwandten/Bekannten zu. Wenn auch die Testamente Vicke Bottermanns 1476, Luteke Nyeburs 1481 und Nickel Wulfferams 1483, in denen Väter ihre Kinder bedenken, einen ähnlichen Eindruck des bewußten Zusammenhalts eines Bestandes vermitteln, so kann man doch nicht die Tatsache außer acht lassen, daß sich eine größere Menge in gewissem Sinn zum Aufteilen anbietet, zumal dann, wenn ein Testator Kleriker ist und damit kinderlos verstirbt. So ist es im Fall des Dietrich Junge, der in seinem 1476 aufgesetzten Testament je sechs Silberlöffel an Bekannte vergibt. In seinem zwei Jahre später aufgelisteten Nachlaßinventar sind sie inventarisiert als duodecim coclearia argentea in una foderatura ${ }^{121}$. $\mathrm{Ob}$ es sich bei innen um einen einheitlichen Bestand gehandelt hat, ist freilich nicht eindeutig zu klären, obwohl die gemeinsame Aufbewahrung in einem Futteral und die in Lübecker Testamenten häufig anzutreffende Zwölfzahl der Löffel ${ }^{122}$ nicht gerade gegen eine derartige Annahme sprechen. Aus Gründen des Schutzes, aber auch als Verlustprävention können Löffel in einem Futteral verwahrt werden, und möglicherweise verfügt Johann Beve 1367 sozusagen stillschweigend über ein solches mit der Formulierung, er vergebe fünf Löffel, dhe tosamne bunden sund ${ }^{123}$.

Gleiches Aussehen nun haben in jedem Fall die vier Löffel, die Tibbeke Godenstedt 1469 ihren vier Testamentsvollstreckern zuwendet, wobei das gleiche Aussehen den bereits beschriebenen einheitsstiftenden Effekt hat, der die Testamentsvollstrecker zur gemeinsam zu verrichtenden Ausführung des letzten Willens der Testatorin gemahnen soll.

Tibbeke Godenstedt ist eine der fünf Testatoren, die das Aussehen ihrer testamentarisch zu vergabenden Löffel beschreibt. Angesichts des bereits für das 14. Jahrhundert anzunehmenden Besitzstandes von „ein, zwei Dutzend oder noch mehr" silberner Löffel vermögender Bürger ${ }^{124}$ erscheint es geradezu zwingend notwendig, die testamentarisch zu

\footnotetext{
${ }^{121}$ StA LG c 1478.

${ }^{122}$ M. HASSE, Neues Hausgerät, neue Häuser, neue Kleider, S. 77, Fußnote 196.

${ }^{123}$ U. REINHARDT, Testamente, Nr.26, S.33.

${ }^{124}$ M. HASSE, Neues Hausgerät, neue Häuser, neue Kleider, S. 77.
} 
vergabenden Stücke durch Deskription von den übrigen Nachlaßstücken unterscheidbar zu machen.

Hans Junge bezeichnet 1430 einen seiner beiden Löffel als Löffel mit einem vergoldeten Knopf. Von dieser Verzierungsart eines in Knopfform endenden Stiels berichten zwei weitere Testamente. Geseke Rosemberg verfügt 1472 über neun mit Knopfstil versehene Silberlöffel, während bei dem von Vicke Bottermann vererbten Löffel der Knopf ebenso wie bei Hans Junges Löffel vergoldet ist.

Eine weitere Gestaltungsart des Stiels begegnet in Tibbeke Godenstedts Testament 1469, in dem vier Löffel mit gewundenem Stiel aufgeführt sind. Dieser gewundene Stiel ist eine Abwandlung des runden oder kantigen Stiels, der sich durch den ständigen Gebrauch ausprägte. Die Form des gewundenen Stiels ist stärker auf Repräsentation denn auf die Gebrauchsfunktion ausgerichtet. Neben den hier in den Testamenten beschriebenen Stielverzierungen hat es andere gegeben, wie der Bodenfund in Göttingen mit einem durch eine Kerbe geteilten Stiel beweist ${ }^{125}$.

Die Stielform kann durch Veränderung der Länge variiert werden. Wenn es auch stets ein Miteinander von kurz - und langstieligen Löffeln gegeben hat, so tritt doch das ausgehende 15. und das beginnende 16. Jahrhundert als die Zeit hervor, in der man eine besondere Vorliebe für kurzstielige Löffel hegte. Diese Vorliebe spiegelt sich in den Testamenten wider, in denen zeitgleich, nämlich 1476 von Vicke Bottermann und 1494 von Gesche Henning, über je einen kurzstieligen Silberlöffel verfügt wird.

Kein Testator außer Hans Junge gibt das Gewicht der Silberlöffel an. Wenn es sich bei seiner Person - wie HASSE vermutet ${ }^{126}$ - um den Sohn des Lübecker Goldschmieds Stephan Junge handelt, dann ist erklärlich, daß er als ein mehr als andere Testatoren vom Kunsthandwerk Geprägter Wert auf die Gewichtsangaben legt. Der eine seiner beiden testamentarisch erwähnten Silberlöffel wiegt vier Lot, und das Gewicht des anderen Silberlöffels beträgt drei Lot, jedoch hat er einen mit einem vergoldeten Knopf verzierten Stiel.

\section{Messer}

Messer $^{127}$ werden im Rahmen des Untersuchungszeitraumes relativ spät in den Testamenten erwähnt. Es sind drei Testamente aus dem zweiten Quartal des 15. Jahrhunderts, in denen über insgesamt vier Messer verfügt wird. Hans Junge verfügt 1430 über en par sulverner meste, das um die neun Lot Silbers wiege. Die vom Testator

\footnotetext{
${ }^{125}$ Beschreibung von S. SCHÜTTE, in: „Kat. Stadt im Wandel“, Bd.2, Nr. 214.

${ }^{126}$ M. HASSE, Kleinbildwerke in deutschen und skandinavischen Testamenten des 13., 14. und frühen 15. Jahrhunderts, in: Niederdeutsche Beiträge zur Kunstgeschichte, Bd.20, 1981, S.66.

${ }^{127}$ Informativer Überblick unter Absatz „Messer“ bei dem Stichwort „Besteck“ von E. MEYER, In: RKG, Sp.

359 - 362; siehe auch M. HASSE, Neues Hausgerät, neue Häuser, neue Kleider, S.77.
} 
herausgestellte Zusammengehörigkeit der beiden Messer wird sich nicht auf Tischmesser beziehen, sondern eher auf eine Kombination von Tranchier - und Vorlegemesser ${ }^{128}$, die dem Empfänger, dem Rat der Stadt Lüneburg, dienlicher gewesen wäre als zwei Tischmesser. Im übrigen trug ein Jeder, Männer wie Frauen, das Tischmesser stets bei sich, befestigt am Gürtel. Das Inventar des Ratssilbers von 1598 führt keine Messer auf, so daß hier der endgültige Beweis, um welche Art Messer es sich handelte, nicht geführt werden kann.

Ganz offensichtlich handelt es sich auch bei den beiden anderen testamentarisch vergabten Messern nicht um einfache Tischmesser: Heinrich Tetendorps 1441 aufgeführtes Messer war ein vergoldetes, während das des Johannes Weidenknepel durch seinen als cristallino deaurato beschriebenen Griff besticht ${ }^{129}$.

\section{Gabel}

Eine sulverne forcken wird nur einmal erwähnt, und zwar im Testament der Czieke Blank, die die Gabel 1475 zusammen mit neun Löffeln ihrer Enkelin zuwendet ${ }^{130}$. Die späte Erwähnung ist auf die späte Einführung der Gabel in den deutschsprachigen Kulturkreis zurückzuführen, jedoch ist sie im Gegensatz zu Lüneburger Testamenten in den Testamenten anderer Städte wie Braunschweig und Lübeck bereits im 14. Jahrhundert präsent ${ }^{131}$. Daß Gabeln nicht auf repräsentativen Tafeln fehlen, zeigt die Tatsache, daß das Lüneburger Ratssilber auch Gabeln umfaßt ${ }^{132}$. Hier dienen die Gabeln nicht nur zum Vorlegen, sondern auch zum Auftun des klebrigen Konfekts. Die Bezeichnung „Krutschuffeln“ und „Confektleffel“ und das Beispiel der beiden in Lüneburg erhaltenen Objekte aus dem Jahr 1480 zeigen die Kombination löffel- und gabelartiger Funktion ${ }^{133}$. Fast ein Jahrhundert früher hat Elisabeth Stöterogge im Rahmen ihrer Testamentserrichtung dem Rat der Stadt Lüneburg noch Löffel zum Essen der krude zugesandt ${ }^{134}$, die das Inventar von 1598 als „sechs und Zwanzig silbern Leffel mit langen Stehlen, die Elisabeth Stötteroggin geben“ beschrieb ${ }^{135}$.

\section{Donatoren und Empfänger der Bestecklegate}

\footnotetext{
${ }^{128}$ U. REINHARDT, Testamente, Nr.163, S.224. Abbildungen bei E. MEYER, „Besteck“, in: RDK, Sp. 359362.

${ }^{129}$ U. REINHARDT, Testamente, Nr.206, S.294.

${ }^{130}$ U. REINHARDT, Testamente, Nr.245, S.378.

${ }^{131}$ M. HASSE, Neues Hausgerät, neue Häuser, neue Kleider, S.66.

${ }^{132}$ Inventare von 1555/56 und 1598: „Acht kleine vergulte Forcken mit sambt Zwehn silbern Leffel mit langen ausgegraben Stehlen“, S. BURSCHE, Das Lüneburger Ratssilber, Fußnote 4, S. 115.

${ }^{133}$ S. BURSCHE, Das Lüneburger Ratssilber, Nr.10, S.114f.

${ }^{134}$ StA LG b 1386 - 1388.

${ }^{135}$ S. BURSCHE, Das Lüneburger Ratssilber, Inv.Nr. 177 - 202, S.186.
} 
Als Donatoren treten sechs Frauen und dreizehn Männer in Erscheinung, darunter befinden sich drei Kleriker.

Die Testatoren bedenken hauptsächlich Bekannte mit Löffeln, Messer und Gabel. Insgesamt 21 Fälle derartigen Testierverhaltens stehen acht Zuwendungen an enge Familienmitglieder gegenüber. Aus diesem Zahlenverhältnis läßt sich der Schluß ziehen, daß das wertvolle Silberbesteck, allem voran Löffel, normalerweise außerhalb des testamentarischen Erbganges tradiert wurde. Anzunehmen ist, daß das Gros der wertvollen Ausführungen in den Händen der Familien bleibt.

Die vielen Zuwendungen an Bekannte deuten jedoch auf Bestände an Löffeln hin, deren Umfang im 15. Jahrhundert so groß ist, daß aus ihnen Geschenke für Bekannte gespeist werden können.

In drei Fällen ist der Rat Empfänger entweder bereits verfertigter Objekte (Hans Junge zwei Messer) oder anzufertigender Teile (Vicke Bottermann, Lorenz König).

Eine Schenkung von Löffeln im Rahmen einer religiösen Stiftung enthalten nur die Testamente Hans Junges 1430 (für Bau St. Johannis) und 1484 Hartwig Hannovers ( für Vikarie in St. Lamberti ).

Von der Möglichkeit des Verkaufs silberner Löffel berichtet das Testament Geseke Springuintguds, in dem der Erlös der Tochter ihres Mannes zugewendet wird. Im Unklaren bleibt, ob es sich hier um ältere Löffel handelte, die eingeschmolzen wurden ${ }^{136}$ oder um gut erhaltene, die einen neuen Besitzer fanden.

d. Handwaschgeräte und textiles Zubehör

Handfaß

Da das Essen vorwiegend mit den Fingern eingenommen wird, gehören Handwaschgeräte zum Bereich der Tischhygiene. Für den Waschvorgang verwendet man einen Wasserbehälter und ein Auffangbecken für das Wasser.

Material und Aussehen

Als Gießgefäß dient in frühen Zeiten ein Keramikkrug, dessen Verwendung noch zur Zeit des Untersuchungszeitraumes für ärmste und ärmere Zeitgenossen vorausgesetzt werden kann. Reichere Bürger lassen das Gießgefäß aus Erz, Messing und - vor allem in südlicheren Bereichen - aus Zinn fertigen; sehr wertvolle Ausführungen können auch aus Silber hergestellt sein. Die einzige Äußerung eines Testators hinsichtlich des Materials

\footnotetext{
${ }^{136}$ Hinweis auf das Einschmelzen alter Löffel in der Kämmereiabrechnung von 1480 in S. BURSCHE, Das Lüneburger Ratssilber, S.114.
} 
stammt von Dietrich Junge aus dem 1476, in der er sein kleines Handwaschgefäß als ehernes bezeichnet, womit sowohl Bronze als auch Messing gemeint sein kann.

Die Testatoren arbeiten mit den Begriffen lavatorium, lavacum und handvath, handfath, handfat. Diese Bezeichnungen informieren nicht über das genauere Aussehen der Gießgefäße, da das Wort fat in seinen verschiedenen Schreibvariationen „Gefäß" bedeutet. Bekannt sind Kannen, in zylindrischer Form oder auf drei Beinen stehende, Handfässer in Grapenform, Schwenktöpfe und Handfässer in Tier -, vor allem in Löwenform ${ }^{137}$. Löwenaquamanile werden aufgrund ihres seltenen Vorkommens und aufgrund ihrer Verwendung in öffentlich - repräsentativem Rahmen - wie z.B. im Lüneburger Rathaus ${ }^{138}$ als besondere Handfässer ${ }^{139}$ angesehen. Als um so bezeichnender mag es erscheinen, daß der einzige genannte Löwe (,2 lavaroria, quorum 1 in modum leonis factum ") in einem Klerikertestament, in dem des Archidiakons von Bevensen Segeband von Thune 1385, genannt wird $^{140}$.

\section{Donatoren und Empfänger}

Insgesamt verfügen acht Testatoren über elf Handfässer. Den Beginn macht das Testament Segeband von Thunes aus dem Jahr 1385, ein Testament, das die vielleicht schönste Form der Löwenaquamanile erwähnt. Im Abstand von gut fünfzig Jahren folgt dann das nächste Testament, das des Vikars Heinrich Tetendorp aus dem Jahr 1441. Testamentarisch vergabte Handgießgefäße aus bürgerlichem Besitz treten erst seit den 70 ger Jahren des 15. Jahrhunderts in Lüneburg auf; zu nennen sind hier die Testamente Geseke Rosembergs 1472, Hans Dobbelers 1481, Geseke Leyferds 1485, Matheus Tetendorps 1491 und Hilleke Blickershusens 1499.

Als Empfänger werden für drei Handfässer Sohn oder Bruder angegeben (1472 Geseke Rosemberg, 1491 Matheus Tetendorp, 1499 Hilleke Blickershusen), drei weitere fallen an dem Testator bekannte Personen (1441 Heinrich Tetendorp, 1476 Dietrich Junge, 1485 Geseke Leyferd). Ihr jeweils größtes Handfaß vergeben Hans Dobbeler und Geseke Leyferd als Legate ad pias causas, wobei Dobbeler die Armen in dem offensichtlich von inm gestifteten Gotteshaus, Leyferd die Mönche in Winsen bedenkt.

\footnotetext{
${ }^{137}$ Grundlegende Informationen wieder bei M. HASSE, Neues Hausgerät, neue Häuser, neue Kleider, S. 67ff, Abbildung entsprechender Objekte im Text ab S. 28 passim. Hier die Abbildung eines vollendet gefertigten Löwenaquamanils aus dem 13. Jahrhundert.

${ }^{138}$ Bekannt sind zwei Löwenaquamanilen des Lüneburger Ratssilbers, allerdings stammen beide Exemplare aus dem 16. Jahrhundert. Abbildung und Beschreibung in: S. BURSCHE, Das Lüneburger Ratssilber, Nr. 24 und Nr.25.

${ }^{139}$ In den Hildesheimer Stadtrechnungen als handvateslouwen bezeichnet. Nach M. HASSE, Neues Hausgerät, neue Häuser, neue Kleider, Fußnote Nr.130, S. 68.

${ }^{140}$ U. REINHARDT, Testamente, Nr.45, S.62.
} 
Mit Ausnahme der Testamente Heinrich Tetendorps 1441 und Hans Dobbelers 1481 enthalten alle über Handfässer verfügenden Testamente auch Verfügungen über Handbecken.

\section{Größe und Anzahl}

Es ist wiederum die Größe, mittels derer die Testatoren das testamentarisch zu vergabende Erbstück von weiteren Objekten gleicher Art unterscheiden. In drei Fällen ist es das größte Handfaß (1481 Hans Dobbeler, 1485 Geseke Leyferd und 1499 Hilleke Blickershusen), einmal das große Handfaß (Geseke Rosemberg 1472), zweimal kleine Handfässer (1441 Heinrich Tetendorp, 1476 Dietrich Junge) und in einem Fall das kleinste (1485 Geseke Leyferd). Allein sechs der acht Testatoren zeigen durch die Größendifferenzierung das Vorhandensein weiterer Handfässer, zumindest doch eines Faßes im Haushalt an. Die offenbar in fast allen Testamenten unterbleibende ausführlichere Beschreibung der Handfässer führt HASSE auf den Umstand zurück, daß fast alle Haushalte nur ein oder zwei Handfässer gehabt hätten ${ }^{141}$.

\section{Becken}

Unter Becken ${ }^{142}$ wird im Vergleich zu den dickwändigen Gefäßen, die als schape bezeichnet wurden, die dünnwändige Blechware verstanden.

Tabelle: Testamentarische Verfügungen über Becken

\begin{tabular}{|c|c|}
\hline Jahre & Anzahl der Testatoren und vererbten Becken \\
\hline $1300-1325$ & - \\
\hline $1326-1350$ & - \\
\hline $1351-1375$ & 1 Testator mit 9 Becken \\
\hline $1376-1400$ & 2 Testatoren mit 3 Becken \\
\hline $1401-1425$ & \\
\hline
\end{tabular}

${ }^{141}$ M. HASSE, Neues Hausgerät, neue Häuser, neue Kleider. S.33.

${ }^{142}$ M. HASSE, Neues Hausgerät, neue Häuser, neue Kleider, Stichwort „Becken (pelvis)“, S. $63 \mathrm{f}$ 


\begin{tabular}{|l|l|}
\hline $1426-1450$ & 2 Testatoren mit 2 Becken \\
\hline $1451-1475$ & 1 Testator mit 2 Becken \\
\hline $1476-1500$ & 6 Testatoren mit 13 Becken \\
\hline
\end{tabular}

Die gewählte Begrifflichkeit umfaßt die Worte pelvis und becken, wobei oft zusätzlich der Verwendungszweck der Objekte mit in die Bezeichnung einfließt.

Mit sieben Testatorinnen und fünf Testatoren (drei Kleriker) ist der Frauenanteil unter den Testatoren gemessen an dem Frauenanteil bei anderen der Küche zuzuordnenden Erbgütern mit über $50 \%$ hoch.

Als Empfänger werden für 12 Becken Familienmitglieder benannt, für 10 Becken Verwandte, in einem Fall (Adelheid Kolse 1430) ist eine Zuordnung nicht möglich.

In den Testamenten sind Becken unterschiedlicher Verwendungsart erwähnt.

\section{Handbecken}

Die von den Testatoren am häufigsten testamentarisch vergabte Beckenart ist die des Handbeckens (pelvis manualis, handbecken), das der Körperpflege diente. Genannt werden 18 Handbecken in 11 Testamenten. Seine Funktion war die eines Auffangbeckens für das aus dem Handfaß laufende Wasser, das so nach der Nutzung entsorgt werden konnte.

Da die Ganzkörperhygiene ihren Platz in öffentlichen Badehäusern ${ }^{143}$, seltener wohl in den Häusern selbst Wohlhabender hat, spielen diese Waschutensilien im häuslichen Bereich eine wichtige Rolle, die durch den Standort in der Dornse, der heizbaren Stube, unterstrichen wird. Hier, wo sich ein großer Teil des täglichen Lebens abspielt, werden sie besonders genutzt, und formschöne Ausführungen sorgen für den Gleichklang von Praktischem und Ästhetischem. Eine Vorstellung von dem unterschiedlichen Aussehen vermitteln vor allem die Bildwerke, auf den Handfaß und -becken oft abgebildet sind ${ }^{144}$.

\footnotetext{
${ }^{143}$ Entwurf eines Badehauses, 1405, in: Kat. „Die Hanse“, Bd.2, S. 420; Über Badehäuser auch C. MECKSEPER, Kleine Kunstgeschichte der Stadt im Mittelalter, S.199f.

${ }^{144}$ Lavarium, sog. „Hanseschüssel“, Messing, Bodenfund aus Groningen, in: Kat. „Die Hanse“, Bd.2, Nr. 14.80, S. 281 Häufige Darstellung beim Motiv der Handwaschung des Pilatus, hier als Beispiel: Ausstellung Christi, Mitteltafel des Flügelaltars aus dem Braunschweiger Dom, um 1505/06?, In: Kat. „Stadt im Wandel“ Kurzführer, Abb. 118, S. 54; Darstellung eines Beckens bei der Fußwaschungsszene, Tafelmalerei mit Szenen aus der Passion Christi aus dem Michaeliskloster, um 1500, in. Museum für das Fürstentum Lüneburg, S.88. Dem heutigen Betrachter mag es als unfreiwillige Komik erscheinen, daß Fußwaschbecken und Vorlegeschüssel in denen als zeitlicher Ablauf gedachten Szenenbildern sich sehr ähneln!
} 
$\mathrm{Zu}$ unterscheiden von den einfacheren, zumeist steilwandigen Becken sind die sogenannten Hanseschüsseln, deren Form flachwandiger und schalenförmiger ausfällt ${ }^{145}$. Bei ihnen handelt es sich in der Regel um verzierte, teils auch vergoldete Stücke.

Als einzige Testatorin beschreibt Geseke Leyferd 1485 eines ihrer Becken als dat stanenbecken myt der rosen ${ }^{146}$. Mit einiger Wahrscheinlichkeit werden verzierte Becken eher als schlichte ${ }^{147}$ in dem auch Gästen zugänglichen Wohnbereich gestanden haben.

Geseke Leyferd ist weiterhin die einzige Testatorin, die das Material, aus dem ihre Handbecken verfertigt wurden, angibt; in ihrem Testament handelt es sich um drei Zinnbecken. Handbecken werden nicht nur aus Zinn, sondern auch aus Messing hergestellt. Bislang ungeklärt ist, ob es mehr als ein Zufallsprodukt ist, daß die Forschung für den norddeutschen Bereich überwiegend Messing als Material nennt ${ }^{148}$, während zumindest für Göttingen - Repräsentantin des südlicheren Bereichs - im 15. Jahrhundert in erster Linie Zinnbecken aufgeführt werden ${ }^{149}$. Entspricht es angesichts dieser Verteilung nicht einer gewissen Logik, daß die Testatorin Geseke Leyferd betont, ihre testamentarisch zu vergabenden Becken seien Zinnbecken, um durch die Nennung des Materials Zinn zum vorwiegend verwendeten Messing abzugrenzen?!

Eine weitere Form der Unterscheidung beruht für die Testatoren in der Bemessung der Größe. Fünfmal werden Handbecken als kleine bezeichnet, wobei es sich zweimal um die kleinsten handelte.

Für die zur Benutzung notwendige Höhe sorgen Mauernischen oder Untersatzgestelle ${ }^{150}$, auf denen die Handbecken postiert werden, so daß die Nutzung erleichtert und auch der für die Wertschätzung der Ausführung notwendige Blickwinkel gewährleistet ist.

\section{Rasierbecken}

Von Männern werden die Becken zur Rasur verwendet. Die Kleriker Segeband von Thune (1385) und Dietrich Junge (1476) registrieren in ihren Testamenten das Vorhandensein derartiger Becken, die - wie Junge formuliert - solite utuntur barbitonsores ${ }^{151}$. Fraglich ist, ob diese Becken dieselbe runde Form aufwiesen, die die Handbecken haben. Praktischer für

\footnotetext{
${ }^{145}$ M. HASSE warf angesichts der Form der Hanseschüsseln die Frage auf, ob sie allerorten denn auch als Handbecken verwendet würden? M. HASSE, Neues Hausgerät, neue Häuser, neue Kleider, S.63. Siehe dazu Fußnote 96/Beispiel aus St. Michaelis.

${ }^{146}$ U. REINHARDT, Testamente, Nr.270, S.427.

${ }^{147}$ Diese Argumentation beruht auf der Voraussetzung, daß ein Haushalt mehrere, mindestens zwei Becken besaß.

${ }^{148}$ M. HASSE, Neues Hausgerät, neue Häuser, neue Kleider, S.63; U. PIETSCH, in: Kat. „Die Hanse“, Bd.2, S.63f (= Kommentar zu Exponat 3.3).

${ }^{149}$ Ergebnis einer Studie von H. STEENWEG über Zinngerät in mittelalterlichen Haushalten. Zit. nach S. SCHÜTTE, Bürgerliches Hausgerät, in: Kat. „Stadt im Wandel“, Bd.3, S. 555.

${ }^{150}$ Abbildung eines offenbar aus dem 16. Jahrhundert stammenden Gestells in: Kat. „Die Hanse“, Bd.2, Nr. 23.36, S. 527.

${ }^{151}$ U. REINHARDT, Testamente, Nr.253, S.391.
} 
den Zweck des Rasierens wären kleinere, schmalere, vielleicht ovale Formen gewesen. Informationen, die hier oder für die Materialfrage Klärung ergeben hätten, bieten die Testamente nicht.

„Toilettenbecken“

Von einer anderen Verwendungsart berichtet das Testament Segeband von Thunes, in dem der Testator seine drei pelves urinales auflistet ${ }^{152}$.

\section{stovenbecken}

Wozu die zwei von Immeke Burmester 1419 vererbten stovenbecken dienten, kann nicht genau gesagt werden. stoven bezeichnet ein warmes Bad; das Einsatzfeld des Beckens ist insofern klar konturiert. Nicht klar ist die genaue Verwendung, sicher ist jedoch die Verwendung im Bereich der Hygiene.

\section{Handtücher}

Handtücher werden in sechs Testamenten vererbt (1385 Segeband von Thune, 1412 Adelheid Knakerugge, 1414 Johannes von Lippinghausen, 1443 Klaus Schmied, 1475 Czieke Blank und 1485 Geseke Leyferd). Drei der Testamente werden von Frauen errichtet, drei von Männern, darunter befinden sich zwei Kleriker. Die Testatoren verwendeten die Begriffe manutergium, dwele und hantdwele. Lediglich Adelheid Knakerugge und Johannes von Lippinghausen vererben testamentarisch nur ein Handtuch, bei den übrigen Testatoren wird in der Mehrzahl von Handtüchern gesprochen, während Segeband von Thune die Zahl von sechs Handtüchern nennt. Dreimal sollen Handtücher an verwandte oder bekannte Frauen fallen, und genauso oft werden sie als Legate ad pias causas vergabt. Während Johannes von Lippinghausen ein Handtuch seiner Vikarie in St. Johannis hinterläßt, bedenkt Adelheid Knakerugge den Hochaltar des Klosters in Scharnebeck mit ihrem besten Handtuch. Wenn Handtücher für den täglichen Gebrauch auch aus einfachem Leinen bestanden, so gab es doch prachtvolle Ausführungen mit besonderem Webmuster, mit Borden oder aus edlen Stoffen ${ }^{153}$, die sich zumeist über einen an der Wand montierten Holzstab gehängt in der Nähe des Handfasses und des Beckens befanden und zu den Prachttextilien des Haushalts gehörten.

\footnotetext{
${ }^{152}$ U. REINHARDT, Testamente, Nr.45, S.62.

${ }^{153}$ J. ZANDER - SEIDEL, Textiler Hausrat, S. 318 ff.
} 


\section{Schlußbemerkung}

Die Testamente weisen einen Großteil der Donatoren als Bürger aus. Etliche dieser Bürger sind Angehörige der ratsfähigen Sülfmeisterfamilien, die zu der wirtschaftlichen, politischen und gesellschaftlichen Elite der Stadt Lüneburg zählen. Der der Saline zu verdankende Wohlstand wirkt sich integrativ auf die Lüneburger Bevölkerung aus, so daß die Sülfmeisterelite weitgehend unangefochten die innerstädtischen Geschicke während des Spätmittelalters bestimmen kann. Während des 14. und 15. Jahrhunderts treten nicht nur immer wieder Angehörige der Sülfmeisterfamilien als Testatoren auf, es lassen sich darüberhinaus zahlreiche Verwandtschaftsverhältnisse zwischen diesen Testatoren nachweisen. Im Verhältnis zu den Testamenten von Stadtbewohnern der mittleren und unteren Gesellschaftsschicht sind die Testamente reicher Bürger - gemessen an dem Aufbau der Gesamtbevölkerung - überproportional vertreten. Es testiert in besonderem Maße der Stadtbewohner, der aufgrund seines Wohlstandes eine Vielzahl selbstfinanzierter Sachgüter besitzt. Wahrscheinlich, aber schwer überprüfbar ist die Vermutung, daß gerade die oft juristisch gebildeten Ratsherrn sich des Rechtsinstituts „Testament“ bedienen und so ihre Familienmitglieder und ihre Freunde mit dieser Einrichtung zunehmend vertraut machen

Einem Großteil der Lüneburger Testatoren erscheinen materielle Güter als testamentswürdig. Seit dem 14. Jahrhundert ist bis Ende des 15. Jahrhunderts die Zahl an sachgutfreien Testamenten in z.T. großen Sprüngen rückläufig. Eine Ausnahme ist lediglich der Zeitraum von 1451 bis 1475; hier gibt es eine für das 15. Jahrhundert relativ hohe Anzahl an Testamenten ohne Realienverfügungen, gleichzeitig aber auch eine nicht unbeträchtliche Zahl von Testatoren der unteren Mittelschicht und der Unterschicht. Die Zunahme an Testamenten mit Sachgutverfügungen setzt Testatoren voraus, die zum einen genügend selbst erarbeitetes Kapital besitzen, zum anderen dieses Kapital für Realien ausgeben wollen und können. Das Lüneburg des 14. Jahrhunderts bietet als Anlage den zu dieser Zeit für Kapitalanleger noch offenen Sülzrentenmarkt, und die testamentarischen Verfügungen des 14. Jahrhunderts bezeugen hier getätigte Käufe. Der Sülzrentenmarkt ist gegenüber dem Grundrentenmarkt der attraktivere, weil er sichere und höhere Renditen erbringt. Aufgrund der wirtschaftlichen Attraktivität werden einmal gekaufte Anteile nicht wieder veräußert, so daß es einen Markt an Sülzrenten im 15. Jahrhundert nicht mehr gibt. Seit der Mitte des 14. Jahrhunderts entwickelt sich der Markt materieller Kulturgüter, die wegen des verwendeten Materials und des hohen Könnens des Herstellers sowohl eine repräsentativ-ästhetische als auch eine wirtschaftliche Komponente enthalten. Die in den Testamenten immer wiederkehrenden Hinweise auf ihre Akzeptanz als Pfand- oder 
Verkaufsgut belegen dies. Diese Marktentwicklung kann neben dem Zuwachs an Reichtum und der Intensivierung des Handels eine individuell je unterschiedlich gewichtete Rolle bei der testamentarischen Verfügung über Realien gespielt haben.

Die Betrachtung der Art und Weise des Verfügens über Sachgüter führt zu der Erkenntnis, daß gut die Hälfte der Testatoren Sachgüter ausschließlich oder teilweise subsumieren, in dem sie z.B. pauschal über ihr bewegliches und unbewegliches Gut verfügen. Auf diese Pauschalformel greifen Testatoren vor allem bei der Einsetzung ihrer Frau als Gesamterbin oder bei der Vergabe von Heergewät und Frauengerade zurück.

Bei der Analyse der einzeln aufgelisteten Sachgüter zeigt sich, daß oftmals die Spitzenprodukte Eingang in die Testamente finden, vor allem im Bereich der Tischkultur, des Schmucks und des Kleidungswesens. Vor dem Hintergrund des überproportionalen Anteils an Testamenten der Oberschicht und des hohen Anteils an Spitzenprodukten ist zu fragen, welche Schlüsse erlaubt sind, wenn das Besondere ein übermäßiges Gewicht erhält. Als Negativabgrenzung bestätigt sich, daß allein aus den Testamenten nicht unkritisch eine "Grundebene der alläglichen materiellen Kultur" abgeleitet werden darf, auch wenn die wertvollen Gebrauchsgüter nicht alltäglich benutzt wurden.

Die testamentarische Abbildung hochwertiger Sachgüter vermittelt einen Eindruck des oberen Spektrums unterschiedlicher Realienarten, und sie zeugt von dem hohen Können der Hersteller. Sie belegt gleichfalls die hohe Wertigkeit, die die Testatoren innen beimessen.

Über Bücher verfügen verhältnismäßig wenige Testatoren. Als Donatoren treten vorwiegend Kleriker, selten Frauen auf. Empfänger sind Kirchen, Vikarien und Kirchensowie Klosterbibliotheken, während die Laien offensichtlich ihre Bücher bei beerbter Ehe außertestamentarisch ihren Nachkommen hinterlassen. Bücher, die als Legate ad pias causas vergabt werden, dienen nicht nur als Gebetsvorlage, sie werden auch bei der (Aus-)Bildung genutzt. Testamentarisch vererbt werden zum Großteil Bücher geistlichen Inhalts, vor allem Stundenbücher. Die zeitgenössische Wertschätzung der Passionalliteratur schlägt sich kaum in den Testamenten nieder.

Die Testamente künden auch vom Umgang mit Büchern: Einige Testatoren nutzen das Testament als juristisches Mittel zur Mißbrauchsprävention von Büchern. Sie legen mit ihren Bemühungen ein Zeugnis ab von einer offenbar weitverbreiteten Unsitte, der Vikare und Geistliche kirchlicher Einrichtungen verfallen sind. Ähnlich wie bei Bestellern der heutigen Zeit reicht es bei weitverbreiteten Büchern aus, sie allein mittels des Autorennamens oder des Titels zu kennzeichnen. In Ausnahmefällen sind den Testamenten Informationen über den Gebrauch der Texte zu entnehmen; so weisen die Bestimmungen über das Verlesen 
des Goldenen Psalters auf einen Ritus hin, der in Gegenwart des aufgebahrten Leichnams zelebriert wurde.

Die testamentarischen Verfügungen über Mobiliar und die Verfügungen über textiles Zubehör sind gemeinsam ausgewertet worden, weil dem textilen Zubehör angesichts einer überschaubaren Anzahl an Möbelformen und Formvariationen eine gewichtige Schmuckfunktion zukommt. Wie die Testatoren anderer Städte verfügen die Lüneburger vorrangig über Betten, die mitsamt ihrem Zubehör einen nicht unbeträchtlichen Wert darstellen, so daß sie als Pfandgut akzeptiert werden. Im Normalfall bleiben die Betten im familiären Umfeld. Anders als in österreichischen Testamenten treten Frauen in Lüneburg mehrheitlich weder als Donatorinnen noch als Empfängerinnen auf. Der möglich Grund dafür mag in den Bestimmungen der Frauengerade gelegen haben, die der Frau die je beste Ausführung zuweisen (Das Heergewät umfaßt die je zweitbeste Ausführung).

Die Truhen des (ausgehenden) Mittelalters sind in erster Linie Frontstollentruhen, die sich vielfach in den Heideklöstern erhalten haben. Ihre Überlieferung erlaubt die genaue Vorstellung vom Aussehen der Truhen, wobei es sich bei ihnen überwiegend um prächtige Exemplare handelt. Derart prachtvoll verzierte Objekte scheinen testamentarisch nur in Ausnahmefällen vergeben worden zu sein. Wahrscheinlich sind die ideell und materiell wertvollen Ausführungen wie die Hochzeitstruhen außertestamentarisch an enge Familienmitglieder gefallen.

Die testamentarischen Verfügungen über Schränke zeugen von der in der Frühzeit des Schrankmobiliars anzusetzenden Verwendung im Profan- und im Sakralbereich, aus dem das Schrankmöbel ursprünglich stammt. Die Verfügungen über Schränke korrespondieren in keiner Weise mit der Zunahme an Schrankmobiliar, wie sie für das 15. Jahrhundert aufgrund technischer Innovationen zu verzeichnen ist.

Tische werden im Regelfall außertestamentarisch vergabt. Die von den Testatoren erwähnten mobilen Tische sind Zeugen einer Zeit, in der der Tisch als bewegliches Möbelstück sich den Gegebenheiten der wandfesten Sitzgelegenheiten anzupassen hatte. Sitzgelegenheiten werden kaum aufgelistet.

Schmuckstücke werden weniger als einzeln faßbare Objekte der Bereiche Kleiderschmuck, Körperschmuck oder Tafelschmuck aufgeführt, sondern mehr mit der Formel smyde und sulvern smyde pauschal genannt. Derartige Verfügungen treffen in erster Linie die männlichen Bürger, die die Abteilung des Vermögens ihrer Ehefrau von dem Gesamtvermögen bewerkstelligen wollen. $\mathrm{Da}$ das Erbrecht bereits für die Vermögenssicherung der Frau nach dem Tod ihres Ehemannes sorgt, stellt die testamentarische Verfügung eine doppelte Sicherung dar, die die besondere 
Wertschätzung der Wertgegenstände aus Edelmetall herausstellt. Einzeln greifbare Schmuckstücke treten erst in den Testamenten des 15. Jahrhunderts auf. Insgesamt bieten die Testamente einen Einblick in die Auswahl gängiger Schmuckobjekte wie Armreif, Kette, Brosche, Rosenkranz, Agnus Dei und Bisamapfel. Am häufigsten wird über Ringe verfügt. Schmuckstücke werden gerne Kirchen, Klöstern und kirchlichen Einrichtungen gestiftet. In diesen Stiftungen manifestiert sich nahezu bildlich die Überwindung weltlicher Eitelkeit durch den Tod. Gestiftet werden auf die spezielle liturgische und kirchliche Nutzung zugeschnittene Wertgegenstände wie Kelche, Kreuze, ein Tragaltar und Geld für einen Hostienschrein. Für die private Andacht bestimmt ist ein Andachtsbild, vermutlich ein Bildrelief.

Lüneburg war aufgrund seiner günstigen Verkehrslage in besonderem Maße ein Markt der Tuche. Hiervon zeugen die Testamente, in denen Tuchverfügungen vor allem für die Bekleidung armer Menschen ausgestellt werden. Als Kaufdatum für das Tuch tritt häufig das Fest Michaelis auf, an dem nicht nur viele Zinszahlungen fällig werden, sondern das der Jahresmarkt in Lüneburg schlechthin ist, an dem es eine maximale Tuchauswahl gibt. Besonders wertvolles Tuch aus dem Besitz des Testators kommt in erster Linie nahen Familienmitgliedern zu. Die erwähnten Tuchstoffe scheinen zur Bekleidung dienende Wollstoffe gewesen zu sein, denn die Testatoren markieren das zur Tuchherstellung verwendete Grundmaterial nur bei Leinentuch, das mehr Haushaltszwecken dient.

Testamentarisch registrierte Kleidungsstücke sind sich bereits im Eigentum des Testators befindende Objekte; in den seltensten Fällen handelt es sich um herzustellende oder/und anzuschaffende Kleidung. Farblich überwiegen die dunklen Töne. Schwarz ist eine kostspielige Farbe, die gerne von wohlhabenden Bürgern getragen wird. Angesichts der Bedeutung der prägenden Kraft der Farben wird begreifbar, daß das zu leuchtenden Farben optimal kontrastierende Schwarz eine der gängigen Modefarben des Spätmittelalters ist.

Hinter den Verfügungen der als „Kleid“ bezeichneten Objekte steht der Wille des Testators, für eine Abteilung und Sicherung des Vermögens der Ehefrau zu sorgen. Auch hier ist angesichts der gesetzlichen Bestimmungen von den Erbteilungen die rechtlich doppelte Sicherung und die besondere Wertschätzung erkennbar, die die Kleidungsstücke besitzen. Rock und Hoike sind die am häufigsten verzeichneten Kleidungsarten. Röcke werden zu 2/3 von Männern vererbt. Hergestellt werden die Röcke aus flämischem oder holländischem Tuch. Als Futterstoffe kommen Pelze und (edles) Tuch in frage. Die verwitweten Testatorinnen vererben gerne braune Röcke; erklärbar ist dies vor dem Hintergrund der Tatsache, daß als Witwentracht des Spätmittelalters Kleider aus ungefärbter dunkler Wolle 
gelten, die einen bräunlichen Eindruck vermitteln. Hoiken werden hauptsächlich von Frauen an Frauen vergabt. In den Testamenten werden die Hoiken mehr als alle anderen Kleidungsstücke als Finanzierungsmittel eingesetzt. Das zeugt von qualitativ anspruchsvollen Ausfertigungen und der großen Nachfrage, also von der besonderen Wertstabilität der Hoiken. Hier klingt die Frage an, ob Frauen-vielleicht aus finanzieller Notwendigkeit- eher als Männer Kleidungsstücke als Mittel der Finanzierung letzter Willensäußerungen nutzen. Auf der Grundlage der Lüneburger Testamente entsteht der Eindruck, die Frage sei zu bejahen, aber erst weitere Untersuchungen können eine eindeutige Antwort erbringen. Eine gewisse Skepsis hinsichtlich der Mann-Frau-Einteilung bleibt hingegen angebracht, da die geschlechtsbedingte Zuordnung einiger Sachgüter, z.B. des Betts, als „Domäne“ der Frauen nicht mehr ohne weiteres aufrechtzuerhalten sind.

Die Schaube kommt selten in den Lüneburger Testamenten vor. Interessant ist die Botschaft, die ihr Vorkommen vermittelt: Die Frauenmajorität auf der Donatoren- wie auf der Empfängerseite korrigiert den Eindruck, die Schaube sei in den Hansestädten erst im 16. Jahrhundert von den Frauen übernommen worden. Unbestreitbar ist ihre genuine Verankerung in der Männergarderobe. Auffällig ist „das Schweigen“ der männlichen Testatoren bei einem Kleidungsstück, das in der Männerbekleidung weit verbreitet war und auf dessen außertestamentarische Erwähnung die Lüneburger Quellen keinen Hinweis geben. Die Röcke sind laut Auskunft der Testamente vorwiegend mit Pelz gefüttert, was aufgrund des körpernahen Schnitts hinsichtlich einer Wärmefunktion einleuchtend erscheint. Die weiter geschnittenen Hoiken sind mit Tuchstoff gefüttert, dessen oft leuchtende Andersfarbigkeit einen modischen Eindruck erzielt. Futter, egal ob Pelz oder Seide, gilt als Wertaccessoire, das durch die Lüneburger Luxusgesetzgebung reglementiert wurde.

Als Empfänger der Kleidungsstücke werden in erster Linie enge Familienmitglieder beiderlei Geschlechts benannt. Bedienstete, vor allem Mägde, treten auch als Beschenkte auf, allerdings in eher überschaubarer Zahl. Die innen zugewendeten Objekte sind oftmals zwar getragen, aber von bester Qualität.

Bei der Vergabe liturgischer Gewänder treten nur wenige Testatorinnen als Donatoren auf. Als Empfänger derartiger Stiftungen werden Altäre und Vikarien benannt. Ausgesetzt werden zum Großteil Geldlegate in z.T. beträchtlicher Höhe für die Anschaffung der Kleidung. Vorhandene Gewänder werden ausschließlich von Klerikern vergabt. Die Testamente zeigen, daß die exakten Bezeichnungen der liturgischen Kleidungsstücke den Laien lediglich in Einzelfällen geläufig sind. 
Bei den Küchen- und Hausgerätschaften ist das Ausblenden der irdernen und hölzernen Ware in den Testamenten in Lüneburg wie auch in den anderen Städten zu beobachten. Hier zeigt sich am deutlichsten, daß aus der testamentarischen Bestandsaufnahme keine „alltägliche“ Lebenssituation abgeleitet werden kann. Bei den rein in der Küche zu verwendenden Gerätschaften wie Grapen, Kessel, Pfannen und Mörsern gibt es keine auffällige Frauenmajorität unter den Donatoren. Als Empfänger werden von den Testatoren überwiegend Familienmitglieder benannt. Gelegentlich werden auch Vikarien als Erbnehmer eingesetzt, da mit der Vikarsstelle ein Haushalt gekoppelt sein kann. Werden Grapen und Kessel recht häufig in den Testamenten erwähnt, so finden Pfannen seltener Eingang in die Testamente, und Mörser werden in verschwindend geringem Maße aufgelistet. Offenbar unterliegen sie, von denen es ohnehin nur ein oder zwei Exemplare pro Haushalt gibt, einem außertestamentarischen Erbgang, denn die sie erwähnenden Testatoren sind zum Zeitpunkt der Testamentserrichtung kinderlos, so daß sie sich gezwungen sehen, per Testament einen Erbnehmer zu bestimmen. Die zahlreichen Verfügungen über metallene Küchengeräte in den letzten 25 Jahren des 15. Jahrhunderts beweist die stetige Zunahme dieser Objekte in den Haushalten.

Tischzubehör wie Kanne, Flasche, Trinkgefäße und Besteck werden in weiten Teilen von Männern vererbt. Ob sich hier ein mit Vorsicht zu behandelnder Geschlechterunterschied präsentiert, vermag allein auf der Grundlage der Lüneburger Testamente nicht geklärt werden; die Forschung mag in diesem Punkt weitere Aufklärung leisten. Bei den z.T. aus Silber, vorwiegend jedoch aus Zinn bestehenden Kannen ist kein überwiegend familiensicherndes Erbverhalten wie bei den anderen Gerätschaften zu beobachten; die Testatoren setzen gern Bekannte als Empfänger ihrer Kannen ein. Flaschen werden ausschließlich in Klerikertestamenten vergabt, so daß von einer außertestamentarischen Tradierung bei beerbter Ehe ausgegangen werden kann.

Auf dem Sektor der Trinkgefäße zeugen die Testamente von der vorrangigen Nutzung schalenförmiger Trinkgefäße wie Schale, Kopf und Schauer während des 14. und frühen 15. Jahrhunderts. Sie sind ebenso wie die erst im 15. Jahrhundert testamentarisch erwähnten Becher vorwiegend aus Silber gefertigt. Als Verzierung kommen Wappen und religiöse Motive in Frage. Aufgrund des Werts des Grundmaterials liegt die Verwendung als Pfandgut auf der Hand. Die in den Testamenten deutlich werdende Wertspanne der Objekte zeigt, daß die Repräsentatitvität der Gefäße als alleiniger Besitzgrund keine ausreichende Erklärung bietet. Es tritt in jedem Fall die beständige, krisensichere Wertanlagemöglichkeit hinzu. Die Trinkgefäße fallen mehrheitlich den Familienmitgliedern der Testatoren zu. 
Selten werden Gläser erwähnt, obschon die neuesten Grabungen Gläser hoher Qualität im Lüneburg des 15. Jahrhunderts nachweisen konnten. Insofern ist eine vorrangige außertestamentarische Vergabe anzunehmen.

Die überwiegende Mehrzahl der materiellen Kulturgüter, die Lüneburger Testatoren in ihrem Testament verzeichnen, bleibt in den Händen der Familie. In den privaten Haushalten finden sie Verwendung, ob als vielgenutztes Utensil oder als repräsentatives Zierobjekt. Vielen von innen ist gemein, daß sie als Mittel der Wirtschaft zur Verfügung stehen. Natürlich repräsentieren sie die Pfand- und Geldwirtschaft nur ausschnitthaft, gleichwohl sind sie ein in ansprechendes Gewand gehüllter Notgroschen. Eine hauptsächlich auf wirtschaftliche Faktoren ausgerichtete Argumentation greift jedoch zu kurz. Eine nicht zu unterschätzende Rolle bei der testamentarischen Vergabe wird die ideelle Wertigkeit gespielt haben, die die einzelnen Sachgüter in den Augen ihrer Erblasser besitzen. Auch wenn dieses Ideelle in den Testamente nur ansatzweise zu erkennen ist, darf es nicht verschwiegen oder verkannt werden.

Der Weg, Testamente auf die Lebenswelten spätmittelalterlicher Stadtbewohner in materieller Hinsicht zu befragen, ergibt in weiten Ausschnitten ein farbiges Bild der Lebensnotwendigkeiten und der Lebensannehmlichkeiten, die sich in der materiellen Kultur manifestieren. 
Anhang:

Tabelle I: Tabellarischer Überblick über die Sachgutverfügungen in den Lüneburger Testamenten 1323-1500

Erklärungen: Die in Klammern gesetzten Zahlen unter der Jahresangabe geben die Anzahl aller von demselben Testator angefertigter Testamente an. Die in Klammer gesetzten Berufsbezeichnungen sind der Sekundärliteratur entnommen.

\begin{tabular}{|c|c|c|c|c|c|}
\hline Jahr & Name & Stellung/Beruf & $\begin{array}{l}\text { Sachgut } \\
\text { in Pau - } \\
\text { schalverf. }\end{array}$ & $\begin{array}{l}\text { Sachgut } \\
\text { namentl. } \\
\text { genannt }\end{array}$ & $\begin{array}{l}\text { kein } \\
\text { Sachgut }\end{array}$ \\
\hline 1323 März 10 & $\begin{array}{l}\text { B. u. H. v. } \\
\text { Erpensen }\end{array}$ & Bürger & & & $\mathrm{X}$ \\
\hline 1330 April 7 & $\begin{array}{l}\text { Bode von } \\
\text { Brokelde }\end{array}$ & Bürger & & & $\mathrm{X}$ \\
\hline 1332 Dez. 10 & $\begin{array}{l}\text { Dedeko } \\
\text { Widenvelt }\end{array}$ & Ratsherr zu BS & & & $\mathbf{x}$ \\
\hline 1339 Juli 24 & $\begin{array}{l}\text { Presbyter } \\
\text { Leo }\end{array}$ & Scholastiker & & $\mathrm{X}$ & \\
\hline 1340 April 20 & $\begin{array}{l}\text { Ludolf von } \\
\text { Putensen }\end{array}$ & & $\mathrm{X}$ & & \\
\hline um 1340 & $\begin{array}{l}\text { Thideke } \\
\text { Buhof }\end{array}$ & $\begin{array}{l}\text { Auswärtiger aus } \\
\text { Stockholm }\end{array}$ & & $\mathrm{X}$ & \\
\hline 1343 Juli 28 & $\begin{array}{l}\text { Johannes } \\
\text { Edebert }\end{array}$ & Sülfmeister & & & $\mathrm{X}$ \\
\hline 1346 April 4 & Konrad & Priester & & & $\mathrm{X}$ \\
\hline
\end{tabular}




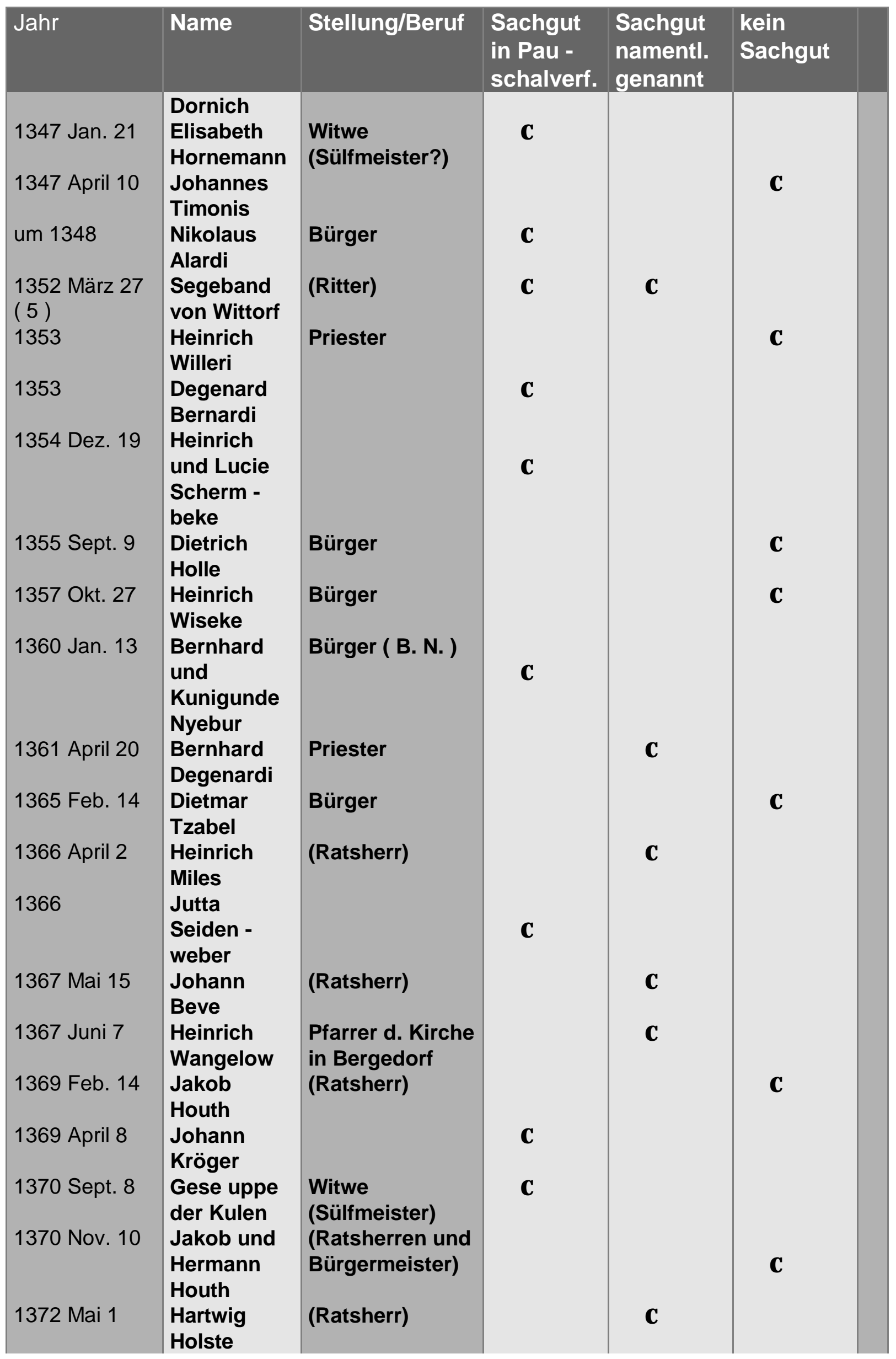




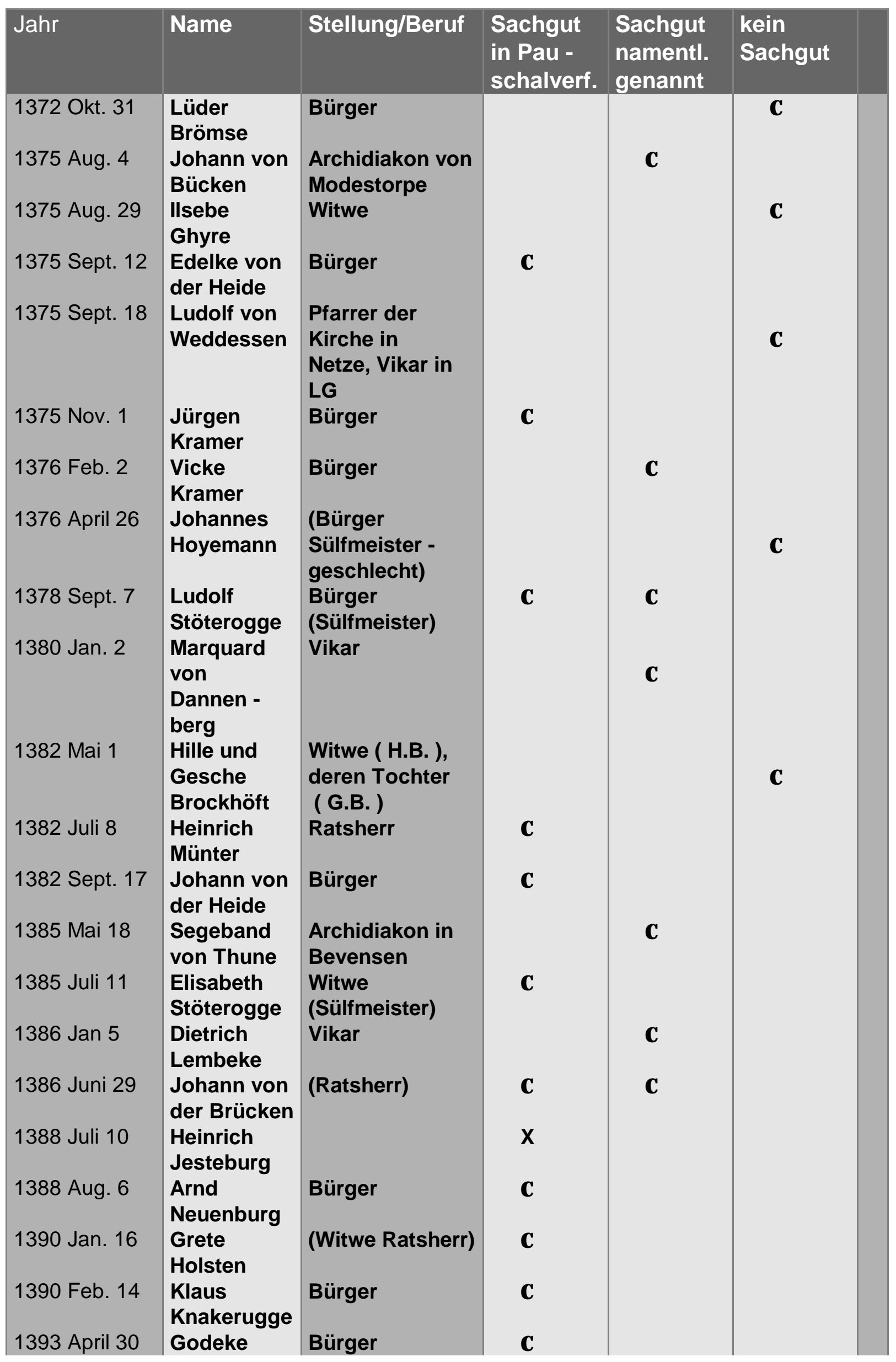




\begin{tabular}{|c|c|c|c|c|c|}
\hline Jahr & Name & Stellung/Beruf & $\begin{array}{l}\text { Sachgut } \\
\text { in Pau - } \\
\text { schalverf. }\end{array}$ & $\begin{array}{l}\text { Sachgut } \\
\text { namentl. } \\
\text { genannt }\end{array}$ & $\begin{array}{l}\text { kein } \\
\text { Sachgut }\end{array}$ \\
\hline 1396 Feb. 26 & $\begin{array}{l}\text { Frederik } \\
\text { Hartwig } \\
\text { Abbenburg }\end{array}$ & Ratsherr & & & $\mathrm{X}$ \\
\hline 1398 Nov. 11 & $\begin{array}{l}\text { Johann } \\
\text { Pattensen }\end{array}$ & (Vogt?) & $\mathrm{X}$ & $\mathrm{X}$ & \\
\hline 1399 Juli 8 & $\begin{array}{l}\text { Gebe } \\
\text { Schmalau }\end{array}$ & Witwe & & & $\mathrm{X}$ \\
\hline 1401 Juli 15 & $\begin{array}{l}\text { Klaus } \\
\text { Hoyke }\end{array}$ & Bürger & $\mathrm{X}$ & & \\
\hline 1401 Juli 21 & $\begin{array}{l}\text { Johann } \\
\text { Hoyemann }\end{array}$ & Ratsherr & $X$ & $X$ & \\
\hline 1401 Aug. 16 & $\begin{array}{l}\text { Volrad } \\
\text { Lassan }\end{array}$ & Vikar (Magister) & & $\mathrm{X}$ & \\
\hline 1401 Aug. 27 & $\begin{array}{l}\text { Nikolaus } \\
\text { von Thune }\end{array}$ & Priester & & & $X$ \\
\hline 1402 Mai 25 & $\begin{array}{l}\text { Curd von } \\
\text { Boltzen }\end{array}$ & Ratsherr & $\mathrm{X}$ & $\mathrm{X}$ & \\
\hline 1403 März 26 & $\begin{array}{l}\text { Dietrich } \\
\text { Burmester }\end{array}$ & Bürger & $\mathrm{X}$ & $\mathrm{X}$ & \\
\hline 1406 Mai 26 & $\begin{array}{l}\text { Johann } \\
\text { Hintbergen }\end{array}$ & & & $\mathrm{X}$ & \\
\hline 1406 Sept. 17 & $\begin{array}{l}\text { Dietrich } \\
\text { Bardowick }\end{array}$ & Bürger & $\mathrm{X}$ & & \\
\hline 1406 Sept. 23 & $\begin{array}{l}\text { Tibbeke von } \\
\text { Netze }\end{array}$ & $\begin{array}{l}\text { (Vorsteherin des } \\
\text { ewigen } \\
\text { Lichts am } \\
\text { Marienaltar } \\
\text { in St. Johannis) }\end{array}$ & $\mathrm{X}$ & & \\
\hline 1406 Okt. 19 & $\begin{array}{l}\text { Klaus } \\
\text { Salzhausen }\end{array}$ & Bürger & $\mathrm{X}$ & & \\
\hline 1407 Juni 13 & $\begin{array}{l}\text { Engelbrecht } \\
\text { Hoke }\end{array}$ & (Bürger) & $\mathrm{X}$ & $\mathrm{X}$ & \\
\hline 1407 Juni 28 & $\begin{array}{l}\text { Johann } \\
\text { Swende - } \\
\text { beke }\end{array}$ & Bürger & $X$ & & \\
\hline 1408 Jan. 7 & $\begin{array}{l}\text { Klaus } \\
\text { Pluckemus }\end{array}$ & Bürger & $X$ & & \\
\hline 1408 April 2 & $\begin{array}{l}\text { Metteke } \\
\text { Schwert - } \\
\text { feger }\end{array}$ & & & $\mathrm{X}$ & \\
\hline 1408 April 17 & $\begin{array}{l}\text { Gebeke } \\
\text { Gosmann }\end{array}$ & (Witwe ?) & & & $X$ \\
\hline 1408 Mai 28 & $\begin{array}{l}\text { Bernhard } \\
\text { Stöterogge }\end{array}$ & Bürger & $\mathrm{X}$ & $\mathrm{X}$ & \\
\hline 1408 Aug. 18 & $\begin{array}{l}\text { Geverd } \\
\text { Gropeshorn }\end{array}$ & Bürger & & $\mathrm{X}$ & \\
\hline $\begin{array}{l}1409 \text { Jan. } 24 \\
1409 \text { März } 7\end{array}$ & $\begin{array}{l}\text { Johann } \\
\text { Schomaker } \\
\text { Johann }\end{array}$ & $\begin{array}{l}\text { Bürger } \\
\text { (Ratsherr, }\end{array}$ & X & $X$ & $X$ \\
\hline
\end{tabular}




\begin{tabular}{|c|c|c|c|c|c|}
\hline Jahr & Name & Stellung/Beruf & $\begin{array}{l}\text { Sachgut } \\
\text { in Pau - } \\
\text { schalverf. }\end{array}$ & $\begin{array}{l}\text { Sachgut } \\
\text { namentl. } \\
\text { genannt }\end{array}$ & $\begin{array}{l}\text { kein } \\
\text { Sachgut }\end{array}$ \\
\hline 1409 Juli 10 & $\begin{array}{l}\text { Semmel - } \\
\text { becker } \\
\text { Ludolf } \\
\text { Burmester }\end{array}$ & $\begin{array}{l}\text { Sodmeister) } \\
\text { (Sohn von } \\
\text { Ratsbe - } \\
\text { dienstetem) }\end{array}$ & $\mathrm{X}$ & & \\
\hline 1409 Okt. 8 & $\begin{array}{l}\text { Heinrich } \\
\text { von dem } \\
\text { Wede }\end{array}$ & Bürger & $\mathrm{X}$ & & \\
\hline 1409 Okt. 27 & $\begin{array}{l}\text { Ludolf bi } \\
\text { dem Sode }\end{array}$ & & & $\mathrm{X}$ & \\
\hline 1410 Feb. 9 & $\begin{array}{l}\text { Hans } \\
\text { Melbeck }\end{array}$ & & $\mathrm{X}$ & & \\
\hline 1410 Juli 14 & $\begin{array}{l}\text { Ludolf von } \\
\text { Hagen }\end{array}$ & $\begin{array}{l}\text { Bürger } \\
\text { (Sülfmeister) }\end{array}$ & $\mathrm{X}$ & $\mathrm{X}$ & \\
\hline 1410 Aug. 9 & $\begin{array}{l}\text { Johann von } \\
\text { Dolde }\end{array}$ & Bürger & & & $\mathrm{X}$ \\
\hline 1411 April 11 & $\begin{array}{l}\text { Werner } \\
\text { Malstorp }\end{array}$ & & & $\mathrm{X}$ & \\
\hline 1411 April 30 & $\begin{array}{l}\text { Klaus } \\
\text { Garlop }\end{array}$ & $\begin{array}{l}\text { Bürger } \\
\text { (Ratsherrenfa - } \\
\text { milie) }\end{array}$ & $\mathrm{X}$ & $\mathrm{X}$ & \\
\hline 1411 Juni 6 & $\begin{array}{l}\text { Alard von } \\
\text { Pattensen }\end{array}$ & Bürger & $\mathrm{X}$ & & \\
\hline 1411 Juli 13 & $\begin{array}{l}\text { Hermann } \\
\text { von Rethem }\end{array}$ & Bürger & $\mathrm{X}$ & & \\
\hline 1412 Feb. 29 & $\begin{array}{l}\text { Adelheid } \\
\text { Knakerugge }\end{array}$ & Witwe & & $\mathrm{X}$ & \\
\hline 1412 März 6 & $\begin{array}{l}\text { Johann } \\
\text { Holeborn }\end{array}$ & Bürger & & $X$ & \\
\hline 1412 März 15 & $\begin{array}{l}\text { Dietrich } \\
\text { Erbstorf }\end{array}$ & Bürger & $\mathrm{X}$ & & \\
\hline 1412 März 27 & Adelheit & $\begin{array}{l}\text { Witwe eines } \\
\text { Malers }\end{array}$ & & $\mathrm{X}$ & \\
\hline 1412 Mai 15 & $\begin{array}{l}\text { Hans von } \\
\text { Munster }\end{array}$ & Bürger & $X$ & & \\
\hline 1412 Juni 13 & $\begin{array}{l}\text { Johann } \\
\text { Heyne }\end{array}$ & Bürger & $\mathrm{X}$ & $\mathrm{X}$ & \\
\hline 1412 Juni 29 & $\begin{array}{l}\text { Hans } \\
\text { Trebbow }\end{array}$ & Kannengießer & $\mathrm{X}$ & & \\
\hline 1412 Nov. 10 & $\begin{array}{l}\text { Helmich } \\
\text { Rorbag }\end{array}$ & Bürger & $\mathrm{X}$ & & \\
\hline 1413 Jan. 21 & $\begin{array}{l}\text { Johann } \\
\text { Krowel }\end{array}$ & Bürger & $\mathrm{X}$ & $\mathrm{X}$ & \\
\hline 1413 Aug. 15 & $\begin{array}{l}\text { Johann von } \\
\text { der Mölen }\end{array}$ & $\begin{array}{l}\text { Ratsherr } \\
\text { (Sülfmeister ?) }\end{array}$ & & $\mathrm{X}$ & \\
\hline 1413 Aug. 24 & $\begin{array}{l}\text { Heinrich } \\
\text { von Hertber }\end{array}$ & Bürger & $\mathrm{X}$ & & \\
\hline 1413 Aug. 29 & $\begin{array}{l}\text { Heinrich } \\
\text { von dem }\end{array}$ & Bürger & $\mathrm{X}$ & & \\
\hline
\end{tabular}




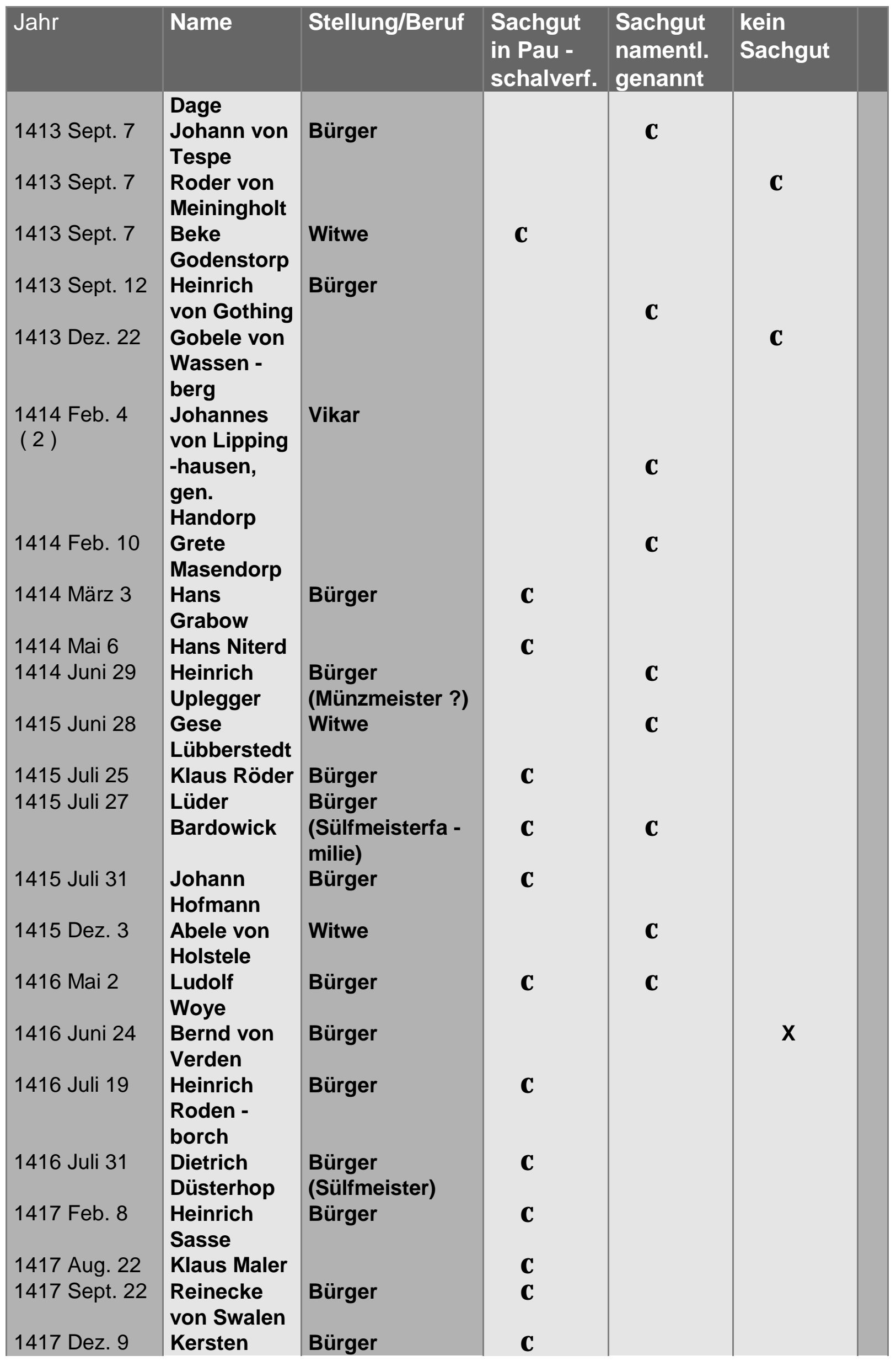




\begin{tabular}{|c|c|c|c|c|c|}
\hline Jahr & Name & Stellung/Beruf & $\begin{array}{l}\text { Sachgut } \\
\text { in Pau - } \\
\text { schalverf. }\end{array}$ & $\begin{array}{l}\text { Sachgut } \\
\text { namentl. } \\
\text { genannt }\end{array}$ & $\begin{array}{l}\text { kein } \\
\text { Sachgut }\end{array}$ \\
\hline 1417 & $\begin{array}{l}\text { Drespe } \\
\text { Meyne von } \\
\text { dem Moyde }\end{array}$ & Bürger & & $X$ & \\
\hline 1418 April 30 & $\begin{array}{l}\text { Werner } \\
\text { Volkmer }\end{array}$ & Bürger & & $\mathrm{X}$ & \\
\hline 1418 Aug. 12 & $\begin{array}{l}\text { Tibbeke } \\
\text { Remsnyder }\end{array}$ & Witwe & & $\mathrm{X}$ & \\
\hline 1419 März 17 & $\begin{array}{l}\text { Immeke } \\
\text { Burmester }\end{array}$ & Witwe & & $\mathrm{X}$ & \\
\hline 1419 April 3 & $\begin{array}{l}\text { Borchard } \\
\text { Trumper }\end{array}$ & Ratsdiener & $\mathrm{X}$ & & \\
\hline 1419 Juni 11 & $\begin{array}{l}\text { Wibke } \\
\text { Saffan }\end{array}$ & $\begin{array}{l}\text { (Sohn evtl. } \\
\text { Bäcker) }\end{array}$ & $\mathrm{X}$ & & \\
\hline 1419 Juni 13 & $\begin{array}{l}\text { Hans } \\
\text { Kämmerer }\end{array}$ & - & & & $\mathrm{X}$ \\
\hline 1419 Juni 28 & $\begin{array}{l}\text { Klaus } \\
\text { Remstede }\end{array}$ & Bürger & $\mathrm{X}$ & & \\
\hline $\begin{array}{l}1420 \text { Nov. } 14 \\
\text { ( } 3 \text { ) }\end{array}$ & $\begin{array}{l}\text { Hermann } \\
\text { Zierenberg }\end{array}$ & $\begin{array}{l}\text { Bürger zu } \\
\text { Lübeck, } \\
\text { (allerdings aus } \\
\text { der Stadt } \\
\text { vertrieben) }\end{array}$ & & $\mathrm{X}$ & \\
\hline 1420 Dez. 32 & $\begin{array}{l}\text { Aldich von } \\
\text { Schnever - } \\
\text { ding }\end{array}$ & $\begin{array}{l}\text { Bürger } \\
\text { (Schmied) }\end{array}$ & $X$ & & \\
\hline 1421 Feb. 12 & $\begin{array}{l}\text { Adelheid } \\
\text { Hagemann }\end{array}$ & & $\mathrm{X}$ & & \\
\hline 1421 April 22 & $\begin{array}{l}\text { Johann } \\
\text { Wokersinn }\end{array}$ & Bürger & $\mathrm{X}$ & & \\
\hline 1421 Juni 9 & $\begin{array}{l}\text { Heinrich } \\
\text { Salzhausen }\end{array}$ & Bürger & $X$ & & \\
\hline 1421 Juni 24 & $\begin{array}{l}\text { Meinhard } \\
\text { Vischer }\end{array}$ & Bürger & $\mathrm{X}$ & & \\
\hline 1421 Juli 17 & $\begin{array}{l}\text { Heinrich } \\
\text { Hudekoper }\end{array}$ & Bürger & & & $X$ \\
\hline 1421 Juli 20 & $\begin{array}{l}\text { Johann } \\
\text { Soltau }\end{array}$ & Bürger & $X$ & & \\
\hline 1421 Juli 25 & $\begin{array}{l}\text { Tyle } \\
\text { Schutte }\end{array}$ & $\begin{array}{l}\text { Bürger zu Nord - } \\
\text { hausen }\end{array}$ & $\mathrm{X}$ & $\mathrm{X}$ & \\
\hline 1421 Aug. 2 & $\begin{array}{l}\text { Dietrich von } \\
\text { Bevensen }\end{array}$ & & & $\mathrm{X}$ & \\
\hline 1421 Aug. 23 & $\begin{array}{l}\text { Ludolf von } \\
\text { dem Borstel }\end{array}$ & Bürger & $\mathrm{X}$ & & \\
\hline 1421 Okt. 13 & Albert Koch & Bürger & $\mathrm{X}$ & $\mathrm{X}$ & \\
\hline 1421 Nov. 9 & $\begin{array}{l}\text { Dietrich } \\
\text { Rogge }\end{array}$ & Bürger & $\mathrm{X}$ & & \\
\hline 1422 Jan. 22 & Berta Koch & (Bürger-) Witwe & $\mathrm{X}$ & & \\
\hline 1422 März 17 & $\begin{array}{l}\text { Johann } \\
\text { Cloke }\end{array}$ & Bürger & $\mathrm{X}$ & $X$ & \\
\hline
\end{tabular}




\begin{tabular}{|c|c|c|c|c|c|}
\hline Jahr & Name & Stellung/Beruf & $\begin{array}{l}\text { Sachgut } \\
\text { in Pau - } \\
\text { schalverf. }\end{array}$ & $\begin{array}{l}\text { Sachgut } \\
\text { namentl. } \\
\text { genannt }\end{array}$ & $\begin{array}{l}\text { kein } \\
\text { Sachgut }\end{array}$ \\
\hline 1422 Nov. 12 & $\begin{array}{l}\text { Grete von } \\
\text { dem Wede }\end{array}$ & (Bürger-) Witwe & & $\mathrm{X}$ & \\
\hline 1423 März 30 & Cord Boltze & Bürger & $\mathrm{X}$ & & \\
\hline 1423 April 18 & $\begin{array}{l}\text { Dietrich } \\
\text { Trost }\end{array}$ & Bürger & $\mathrm{X}$ & $\mathrm{X}$ & \\
\hline 1423 Aug. 16 & $\begin{array}{l}\text { Johann von } \\
\text { Hasle }\end{array}$ & Bürger & $\mathrm{X}$ & $\mathrm{X}$ & \\
\hline 1425 Feb. 28 & $\begin{array}{l}\text { Marquard } \\
\text { Twedorpp }\end{array}$ & Bürger & & & $\mathrm{X}$ \\
\hline 1425 März 21 & $\begin{array}{l}\text { Geseke } \\
\text { Springint - } \\
\text { gud }\end{array}$ & Ratsherrnwitwe & $X$ & $\mathrm{X}$ & \\
\hline 1425 März 31 & $\begin{array}{l}\text { Heinrich } \\
\text { Müller }\end{array}$ & $\begin{array}{l}\text { laycus opidanus } \\
\text { in } \\
\text { Medingen }\end{array}$ & & $\mathrm{X}$ & \\
\hline 1425 April 18 & $\begin{array}{l}\text { Grete von } \\
\text { dem Sande }\end{array}$ & & $\mathrm{X}$ & & \\
\hline 1425 Juli 23 & $\begin{array}{l}\text { Albert von } \\
\text { der Mölen }\end{array}$ & Bürgermeister & $\mathrm{X}$ & $X$ & \\
\hline 1425 Okt. 1 & $\begin{array}{l}\text { Dietrich } \\
\text { Rosenhop }\end{array}$ & $\begin{array}{l}\text { Bürger } \\
\text { Glaser }\end{array}$ & $\mathrm{X}$ & & \\
\hline 1426 April 2 & $\begin{array}{l}\text { Johann von } \\
\text { Sprakelsen }\end{array}$ & Bürger & $\mathrm{X}$ & & \\
\hline 1427 April 4 & $\begin{array}{l}\text { Ludolf } \\
\text { Bartolo - } \\
\text { mäus }\end{array}$ & Bürger & $X$ & $X$ & \\
\hline 1428 Mai 22 & $\begin{array}{l}\text { Hans von } \\
\text { Klentze }\end{array}$ & Bürger & $\mathrm{X}$ & & \\
\hline 1428 Okt. 27 & $\begin{array}{l}\text { Wobbeke } \\
\text { Boltzen }\end{array}$ & Ratsherrnwitwe & & $\mathrm{X}$ & \\
\hline 1429 Okt. 30 & $\begin{array}{l}\text { Tibbeke } \\
\text { Poterow }\end{array}$ & & & $\mathrm{X}$ & \\
\hline 1430 Feb. 24 & Hans Junge & $\begin{array}{l}\text { (Ratsbedienstet } \\
\text { er, evtl. Gold - } \\
\text { schmiedssohn } \\
\text { aus Lübeck) }\end{array}$ & & $X$ & \\
\hline 1430 Juni 12 & $\begin{array}{l}\text { Adelheid } \\
\text { Kolse }\end{array}$ & & & $\mathrm{X}$ & \\
\hline $1423 / 1431$ & $\begin{array}{l}\text { Adelheid } \\
\text { Seidentopf }\end{array}$ & & & $\mathrm{X}$ & \\
\hline 1431 Jan. 15 & $\begin{array}{l}\text { Johann } \\
\text { Rese }\end{array}$ & Ratsherr & & $\mathrm{X}$ & \\
\hline 1431 Juni 15 & $\begin{array}{l}\text { Margareta } \\
\text { von der } \\
\text { Mölen }\end{array}$ & Witwe (Ratsherr) & $\mathrm{X}$ & $\mathrm{X}$ & \\
\hline 1431 & $\begin{array}{l}\text { Bernd von } \\
\text { Erpensen }\end{array}$ & $\begin{array}{l}\text { Bürger } \\
\text { (Sülfmeister) }\end{array}$ & $\mathrm{X}$ & & \\
\hline 1432 Jan. 17 & $\begin{array}{l}\text { Johann } \\
\text { Molne }\end{array}$ & $\begin{array}{l}\text { Bürger } \\
\text { (Bäcker) }\end{array}$ & $\mathrm{X}$ & & \\
\hline
\end{tabular}




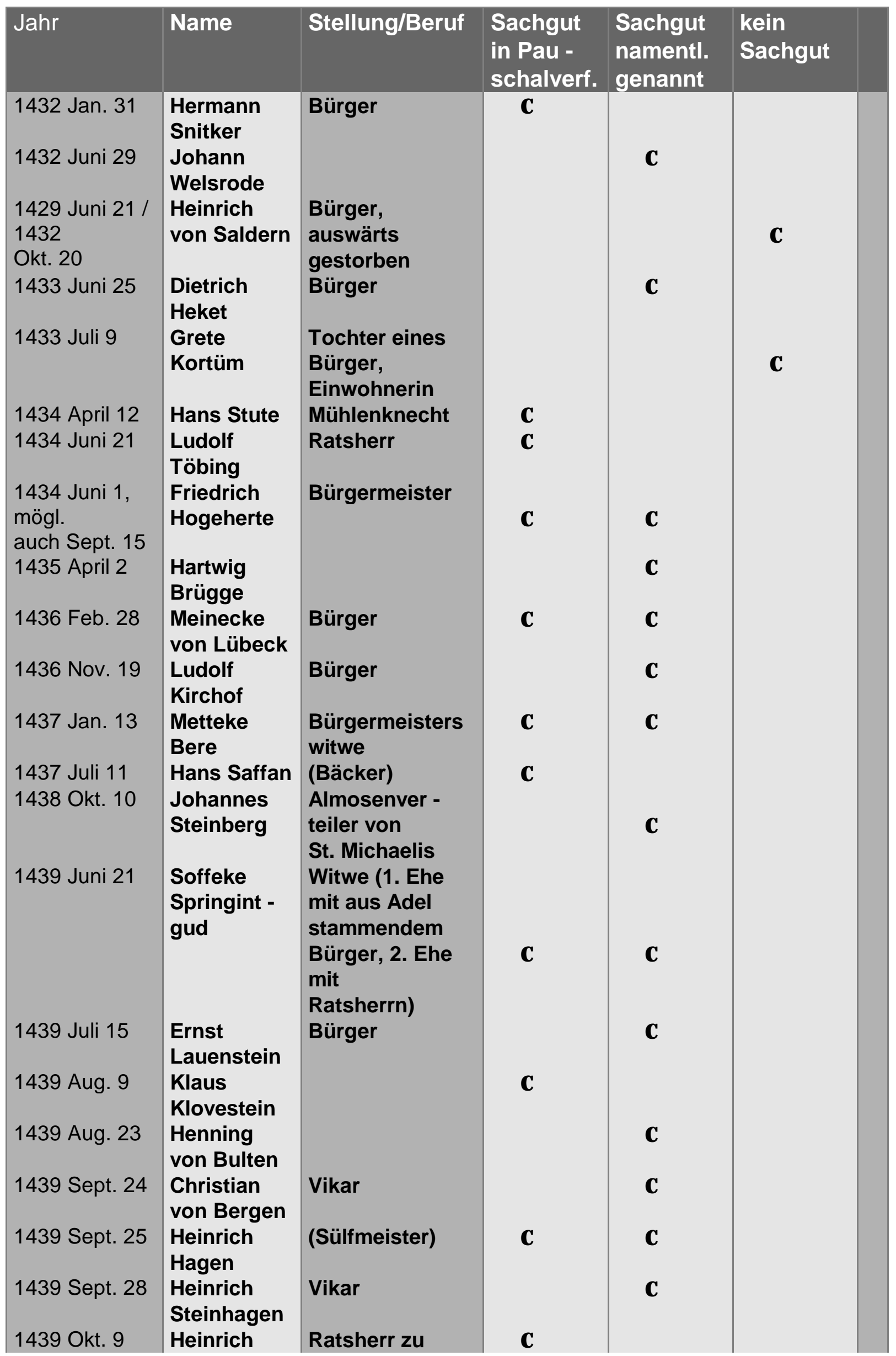




\begin{tabular}{|c|c|c|c|c|c|}
\hline Jahr & Name & Stellung/Beruf & $\begin{array}{l}\text { Sachgut } \\
\text { in Pau - } \\
\text { schalverf. }\end{array}$ & $\begin{array}{l}\text { Sachgut } \\
\text { namentl. } \\
\text { genannt }\end{array}$ & $\begin{array}{l}\text { kein } \\
\text { Sachgut }\end{array}$ \\
\hline 1439 Nov. 30 & $\begin{array}{l}\text { Blickwedel } \\
\text { Eckhard }\end{array}$ & $\begin{array}{l}\text { Uelzen } \\
\text { Vikar }\end{array}$ & & $\mathrm{X}$ & \\
\hline 1440 Feb. 23 & Stein & & & & \\
\hline 1440 April 25 & $\begin{array}{l}\text { Gese von } \\
\text { Gandersen }\end{array}$ & Bürgerswitwe & $\mathrm{X}$ & $X$ & \\
\hline 1440 Dez. 17 & $\begin{array}{l}\text { Curd } \\
\text { Dalhusen }\end{array}$ & Bürger & $\mathrm{X}$ & & \\
\hline um 1440 & $\begin{array}{l}\text { Alheid } \\
\text { Weiden - } \\
\text { lerche }\end{array}$ & & & $\mathrm{X}$ & \\
\hline um 1440 & $\begin{array}{l}\text { Johann } \\
\text { Tabel }\end{array}$ & $\begin{array}{l}\text { Bürger } \\
\text { (mögl. Studium } \\
\text { in Erfurt) }\end{array}$ & $\mathrm{X}$ & & \\
\hline 1441 Feb. 12 & $\begin{array}{l}\text { Alheid } \\
\text { Salzenhau- } \\
\text { sen }\end{array}$ & & $\mathrm{X}$ & & \\
\hline 1441 April 22 & $\begin{array}{l}\text { Meister } \\
\text { Heinrich }\end{array}$ & $\begin{array}{l}\text { Werkmeister des } \\
\text { Rats }\end{array}$ & & $\mathrm{X}$ & \\
\hline 1441 Aug. 24 & $\begin{array}{l}\text { Heinrich } \\
\text { Tetendorp }\end{array}$ & Vikar & & $\mathrm{X}$ & \\
\hline 1441 Okt. 8 & Johann Pale & Bürger & & $\mathrm{X}$ & \\
\hline 1441 Nov. 20 & $\begin{array}{l}\text { Hermann } \\
\text { Kruse }\end{array}$ & Bürgermeister & $\mathrm{X}$ & $\mathrm{X}$ & \\
\hline $\begin{array}{l}1442 \text { Feb. } 14 \\
\text { oder } 21\end{array}$ & $\begin{array}{l}\text { Hermann } \\
\text { Stekeberg }\end{array}$ & Bürger & $\mathrm{X}$ & & \\
\hline 1443 Feb. 10 & $\begin{array}{l}\text { Klaus } \\
\text { Schmied }\end{array}$ & Bürger & $\mathrm{X}$ & $\mathrm{X}$ & \\
\hline 1444 Mai 8 & $\begin{array}{l}\text { Bernd von } \\
\text { dem Brake }\end{array}$ & Bürger & $\mathrm{X}$ & & \\
\hline 1444 Mai 23 & $\begin{array}{l}\text { Cyeke } \\
\text { Witting }\end{array}$ & (Witwe ?) & & $\mathrm{X}$ & \\
\hline 1444 Okt. 18 & $\begin{array}{l}\text { Grete von } \\
\text { der Heide }\end{array}$ & $\begin{array}{l}\text { Konventualin im } \\
\text { Blauen Konvent }\end{array}$ & & $\mathrm{X}$ & \\
\hline 1444 Nov. 27 & $\begin{array}{l}\text { Johannes } \\
\text { Weiden - } \\
\text { knepel }\end{array}$ & $\begin{array}{l}\text { Lübecker } \\
\text { Kanoniker }\end{array}$ & & $\mathrm{X}$ & \\
\hline 1444 Dez. 13 & $\begin{array}{l}\text { Klaus und } \\
\text { Grete } \\
\text { von Wening }\end{array}$ & $\begin{array}{l}\text { Bürger (K. v. } \\
\text { Wening) }\end{array}$ & & $\mathrm{X}$ & \\
\hline $\begin{array}{l}1445 \\
1447 \text { Jan. } 9\end{array}$ & $\begin{array}{l}\text { Lange } \\
\text { Ludolf } \\
\text { Peter } \\
\text { Schütte }\end{array}$ & $\begin{array}{l}\text { Bürger } \\
\text { (Sülfmeister) }\end{array}$ & $\mathrm{X}$ & $\mathrm{X}$ & \\
\hline 1447 Mai 29 & Hans Tespe & Bürger & & $\mathrm{X}$ & \\
\hline 1447 Aug. 12 & $\begin{array}{l}\text { Nickel } \\
\text { Lesnis }\end{array}$ & & & $\mathrm{X}$ & \\
\hline 1447 Dez. 14 & Hans Kruse & (Sülfmeister) & & $\mathrm{X}$ & \\
\hline 1448 Mai 17 & $\begin{array}{l}\text { Dietrich } \\
\text { Ellenberg }\end{array}$ & Bürger & & $\mathrm{X}$ & \\
\hline
\end{tabular}




\begin{tabular}{|c|c|c|c|c|c|}
\hline Jahr & Name & Stellung/Beruf & $\begin{array}{l}\text { Sachgut } \\
\text { in Pau - } \\
\text { schalverf. }\end{array}$ & $\begin{array}{l}\text { Sachgut } \\
\text { namentl. } \\
\text { genannt }\end{array}$ & $\begin{array}{l}\text { kein } \\
\text { Sachgut }\end{array}$ \\
\hline 1448 Juni 22 & $\begin{array}{l}\text { Alerd } \\
\text { Golstede }\end{array}$ & Bürger & & & $\mathrm{X}$ \\
\hline 1449 Okt. 9 & $\begin{array}{l}\text { Heinrich } \\
\text { Dreyling }\end{array}$ & Bürger & $\mathrm{X}$ & & \\
\hline 1450 Okt. 10 & $\begin{array}{l}\text { Ludolf von } \\
\text { Lafferd }\end{array}$ & Bürger & & $\mathrm{X}$ & \\
\hline 1451 März 12 & $\begin{array}{l}\text { Beke } \\
\text { Groning }\end{array}$ & $\begin{array}{l}\text { Witwe } \\
\text { (Barmeister) }\end{array}$ & & $\mathrm{X}$ & \\
\hline 1451 Mai 15 & $\begin{array}{l}\text { Ludolf } \\
\text { Ossendorf }\end{array}$ & Bürger & $\mathrm{X}$ & & \\
\hline 1451 Juni 11 & $\begin{array}{l}\text { Robke van } \\
\text { dem } \\
\text { Jettebrok }\end{array}$ & & $\mathrm{X}$ & & \\
\hline 1451 Juli 1 & $\begin{array}{l}\text { Metteke } \\
\text { Scherm - } \\
\text { beke }\end{array}$ & $\begin{array}{l}\text { Ratsherrnwitwe, } \\
\text { insgesamt drei } \\
\text { Ehen mit } \\
\text { Ratsherrn }\end{array}$ & & & $\mathrm{X}$ \\
\hline 1451 Juli 7 & $\begin{array}{l}\text { Ludolf und } \\
\text { Geseke } \\
\text { Wienebüttel }\end{array}$ & $\begin{array}{l}\text { Bürger (L.W.) } \\
\text { (möglw. } \\
\text { Sülfmeister) }\end{array}$ & & $X$ & \\
\hline 1451 Aug. 12 & $\begin{array}{l}\text { Heinrich } \\
\text { vom Hove }\end{array}$ & Bürger & & $\mathrm{X}$ & \\
\hline 1451 Sept. 26 & $\begin{array}{l}\text { Heinrich } \\
\text { Hoyer }\end{array}$ & $\begin{array}{l}\text { Ratsherr } \\
\text { (Sülfmeister, } \\
\text { Barmeister) }\end{array}$ & & $\mathrm{X}$ & \\
\hline 1452 März 22 & $\begin{array}{l}\text { Geseke } \\
\text { Zimmer - } \\
\text { mann }\end{array}$ & Einwohnerin & $\mathrm{X}$ & & \\
\hline 1452 Juli 4 & $\begin{array}{l}\text { Johannes } \\
\text { von Wintem }\end{array}$ & $\begin{array}{l}\text { Bürger } \\
\text { (Ratsherr) }\end{array}$ & $\mathrm{X}$ & & \\
\hline 1456 April 10 & $\begin{array}{l}\text { Cord von } \\
\text { Rettmer }\end{array}$ & Bürger & $\mathrm{X}$ & & \\
\hline 1458 April 6 & $\begin{array}{l}\text { Adelheid } \\
\text { Kale }\end{array}$ & $\begin{array}{l}\text { Witwe des Rats - } \\
\text { zimmermeisters }\end{array}$ & & $\mathrm{X}$ & \\
\hline 1459 Feb. 10 & $\begin{array}{l}\text { Adelheid } \\
\text { Miils }\end{array}$ & $\begin{array}{l}\text { Bürgers- } \\
\text { witwe }\end{array}$ & & $X$ & \\
\hline 1460 Mai 30 & $\begin{array}{l}\text { Hilleke von } \\
\text { Erpensen }\end{array}$ & $\begin{array}{l}\text { Bewohnerin des } \\
\text { Blauen } \\
\text { Konvents }\end{array}$ & & $\mathrm{X}$ & \\
\hline 1461 Dez. 14 & $\begin{array}{l}\text { Heinrich } \\
\text { Geismar }\end{array}$ & $\begin{array}{l}\text { Pfarrer in } \\
\text { Böken, } \\
\text { Diö. Ratzeburg, } \\
\text { Vikar } \\
\text { KI. HI. Geist, Lg }\end{array}$ & & $X$ & \\
\hline $\begin{array}{l}1462 \text { Juli } 22 \\
1464 \text { April } 11\end{array}$ & $\begin{array}{l}\text { Konrad } \\
\text { Hogestern } \\
\text { Johann von } \\
\text { Minden }\end{array}$ & $\begin{array}{l}\text { Domherr zu } \\
\text { Lübeck, } \\
\text { Stadtschreiber }\end{array}$ & & & $\mathrm{X}$ \\
\hline
\end{tabular}




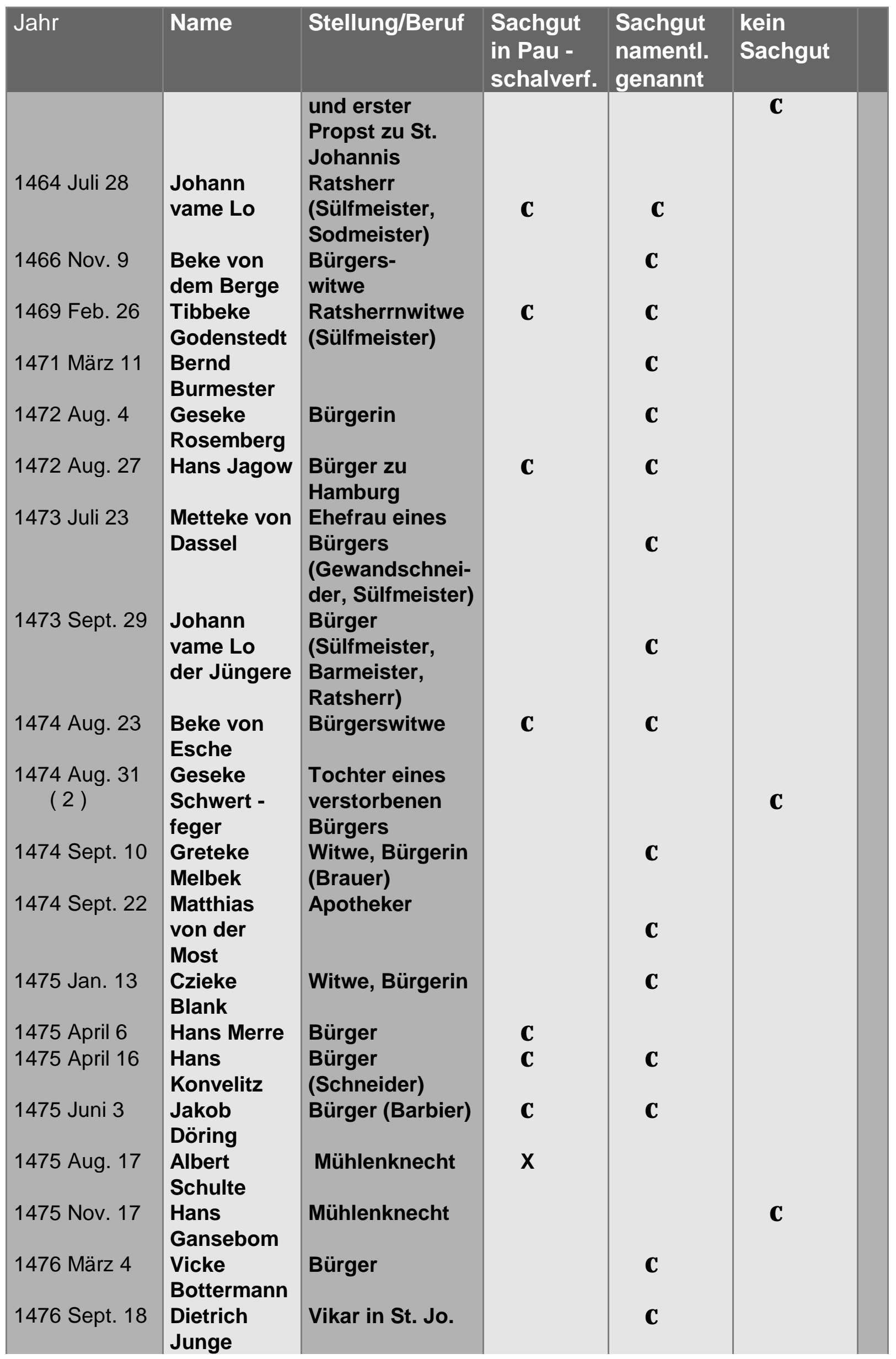




\begin{tabular}{|c|c|c|c|c|c|}
\hline Jahr & Name & Stellung/Beruf & $\begin{array}{l}\text { Sachgut } \\
\text { in Pau - } \\
\text { schalverf. }\end{array}$ & $\begin{array}{l}\text { Sachgut } \\
\text { namentl. } \\
\text { genannt }\end{array}$ & $\begin{array}{l}\text { kein } \\
\text { Sachgut }\end{array}$ \\
\hline 1477 März 7 & $\begin{array}{l}\text { Herzog } \\
\text { Friedrich } \\
\text { der Ältere } \\
\text { Hans von }\end{array}$ & Bürger & $X$ & $\mathrm{X}$ & \\
\hline 1477 Juni 4 & $\begin{array}{l}\text { Rethen } \\
\text { Bernd } \\
\text { Freese }\end{array}$ & Bürger & $\mathrm{X}$ & & \\
\hline 1478 Mai 13 & $\begin{array}{l}\text { Ludorf } \\
\text { Mangard }\end{array}$ & $\begin{array}{l}\text { Priester und } \\
\text { Vikar } \\
\text { in St. Jo. }\end{array}$ & & $\mathrm{X}$ & \\
\hline 1480 Aug. 13 & $\begin{array}{l}\text { Lutke } \\
\text { Hilmers }\end{array}$ & Einwohner & & $\mathrm{X}$ & \\
\hline 1481 April 19 & $\begin{array}{l}\text { Bethman } \\
\text { von Drubke }\end{array}$ & Ratsdiener & $\mathrm{X}$ & & \\
\hline 1481 Mai 24 & $\begin{array}{l}\text { Luteke } \\
\text { Nyebur }\end{array}$ & Bürger & & $X$ & \\
\hline 1481 Juni 5 & $\begin{array}{l}\text { Hans } \\
\text { Dobbeler }\end{array}$ & Bürger & $\mathrm{X}$ & $\mathrm{X}$ & \\
\hline 1482 Mai 7 & $\begin{array}{l}\text { Helmold von } \\
\text { Lyderen }\end{array}$ & Arzt & & $X$ & \\
\hline 1482 Juni 30 & $\begin{array}{l}\text { Heinrich } \\
\text { Erpensen }\end{array}$ & $\begin{array}{l}\text { Ratsherr } \\
\text { (Sülfmeister) }\end{array}$ & $\mathrm{X}$ & $\mathrm{X}$ & \\
\hline 1482 Juli 23 & $\begin{array}{l}\text { Greteke } \\
\text { Brockhoved }\end{array}$ & Bürgerswitwe & $\mathrm{X}$ & & \\
\hline 1482 Nov. 18 & $\begin{array}{l}\text { Dietrich } \\
\text { Döring }\end{array}$ & $\begin{array}{l}\text { Ratsherr } \\
\text { (Sülfmeister, } \\
\text { Barmeister) }\end{array}$ & & $\mathrm{X}$ & \\
\hline 1483 Mai 28 & $\begin{array}{l}\text { Nickel } \\
\text { Wulfferam }\end{array}$ & Bürger & & $\mathrm{X}$ & \\
\hline 1483 Juni 10 & $\begin{array}{l}\text { Heinrich } \\
\text { Meding }\end{array}$ & Bürger & $\mathrm{X}$ & & \\
\hline 1483 Juli 12 & $\begin{array}{l}\text { Ymmeke } \\
\text { Spranse }\end{array}$ & Witwe & & $\mathrm{X}$ & \\
\hline 1483 Aug. 27 & Titke Prilep & & & & $\mathrm{X}$ \\
\hline 1484 Jan. 9 & $\begin{array}{l}\text { Hartwig } \\
\text { Hannover }\end{array}$ & $\begin{array}{l}\text { Priester in St. } \\
\text { Michaelis, } \\
\text { Benediktiner }\end{array}$ & & $\mathrm{X}$ & \\
\hline 1485 Jan. 31 & $\begin{array}{l}\text { Geseke } \\
\text { Leyferd }\end{array}$ & Witwe & & $\mathrm{X}$ & \\
\hline 1486 Mai 1 & $\begin{array}{l}\text { Gevehard } \\
\text { Grone - } \\
\text { hagen }\end{array}$ & Priester & $\mathrm{X}$ & & \\
\hline 1487 Dez. 6 & $\begin{array}{l}\text { Geseke } \\
\text { Wangelow }\end{array}$ & Witwe (Ratsherr) & & $\mathrm{X}$ & \\
\hline 1489 April 1 & $\begin{array}{l}\text { Christofel } \\
\text { Rekel }\end{array}$ & Bürger & $\mathrm{X}$ & & \\
\hline 1489 Dez. 12 & $\begin{array}{l}\text { Hans } \\
\text { Reimstorp }\end{array}$ & Bürger & $X$ & & \\
\hline 1490 Jan. 15 & Heinrich & Bürger & $X$ & & \\
\hline
\end{tabular}




\begin{tabular}{|c|c|c|c|c|c|}
\hline Jahr & Name & Stellung/Beruf & $\begin{array}{l}\text { Sachgut } \\
\text { in Pau - } \\
\text { schalverf. }\end{array}$ & $\begin{array}{l}\text { Sachgut } \\
\text { namentl. } \\
\text { genannt }\end{array}$ & $\begin{array}{l}\text { kein } \\
\text { Sachgut }\end{array}$ \\
\hline 1490 Mai 11 & $\begin{array}{l}\text { Elver } \\
\text { Heinrich } \\
\text { Winthe }\end{array}$ & Bürger & - & $\mathrm{X}$ & \\
\hline 1491 Feb. 8 & $\begin{array}{l}\text { Heinrich } \\
\text { Töbing der } \\
\text { Ältere }\end{array}$ & Bürger & $\mathrm{X}$ & & \\
\hline 1491 Juni 25 & $\begin{array}{l}\text { Matheus } \\
\text { Tetendorp }\end{array}$ & Bürger & $\mathrm{X}$ & $\mathrm{X}$ & \\
\hline 1491 Aug. 13 & Gerd Lowe & $\begin{array}{l}\text { Bürger } \\
\text { (Goldschmied ?) }\end{array}$ & $X$ & & \\
\hline 1492 Feb. 20 & $\begin{array}{l}\text { Hans } \\
\text { Meyger }\end{array}$ & Bürger & $\mathrm{X}$ & & \\
\hline 1493 Juli 8 & $\begin{array}{l}\text { Dietmar } \\
\text { Daldorp }\end{array}$ & Bürger & $X$ & & \\
\hline 1493 Okt. 26 & $\begin{array}{l}\text { Hans } \\
\text { Tetendorp }\end{array}$ & Bürger & $\mathrm{X}$ & & \\
\hline 1494 Sept. 10 & $\begin{array}{l}\text { Gesche } \\
\text { Henning }\end{array}$ & Witwe & & $\mathrm{X}$ & \\
\hline 1494 Sept. 18 & Hans Duvel & $\begin{array}{l}\text { Laie des Stifts } \\
\text { Verden }\end{array}$ & & & $\mathrm{X}$ \\
\hline 1494 & $\begin{array}{l}\text { Lorenz } \\
\text { König }\end{array}$ & Bürger & $\mathrm{X}$ & $\mathrm{X}$ & \\
\hline 1495 März 12 & $\begin{array}{l}\text { Ludolf } \\
\text { Broder - } \\
\text { mann }\end{array}$ & & $X$ & & \\
\hline 1495 Sept. 24 & $\begin{array}{l}\text { Hans } \\
\text { Duderstadt }\end{array}$ & Bürger & $\mathrm{X}$ & $\mathrm{X}$ & \\
\hline 1497 Juli 21 & $\begin{array}{l}\text { Hans } \\
\text { Rodenborg }\end{array}$ & Bürger & $\mathrm{X}$ & & \\
\hline 1497 Dez. 28 & $\begin{array}{l}\text { Dietrich } \\
\text { Vloetwedel }\end{array}$ & Bürger & $\mathrm{X}$ & & \\
\hline 1498 April 5 & $\begin{array}{l}\text { Tibbeke } \\
\text { Harendorp }\end{array}$ & Witwe & & $\mathrm{X}$ & \\
\hline 1499 März 28 & $\begin{array}{l}\text { Meinecke } \\
\text { Schnever - } \\
\text { ding }\end{array}$ & & & & $\mathbf{x}$ \\
\hline 1499 Aug. 28 & $\begin{array}{l}\text { Hilleke } \\
\text { Blickers - } \\
\text { husen }\end{array}$ & Witwe & & $\mathrm{X}$ & \\
\hline 1500 Feb. 1 & $\begin{array}{l}\text { Hans } \\
\text { Holstenland }\end{array}$ & Bürger & $X$ & & \\
\hline
\end{tabular}


Tabelle II: Empfänger der Sachgüter

\begin{tabular}{|c|c|c|c|c|}
\hline Jahr & Name & Stellung/Beruf & $\begin{array}{l}\text { Sachgüter in } \\
\text { Legaten ad } \\
\text { pias causas }\end{array}$ & $\begin{array}{l}\text { Sachgüter in } \\
\text { Verfüg. für } \\
\text { Verwandte/ } \\
\text { Bekannte }\end{array}$ \\
\hline 1323 März 10 & $\begin{array}{l}\text { B. u. H. v. } \\
\text { Erpensen }\end{array}$ & Bürger & & \\
\hline 1330 April 7 & $\begin{array}{l}\text { Bode von } \\
\text { Brokelde }\end{array}$ & Bürger & & \\
\hline 1332 Dez. 10 & $\begin{array}{l}\text { Dedeko } \\
\text { Widenvelt }\end{array}$ & Ratsherr zu BS & & \\
\hline 1339 Juli 24 & $\begin{array}{l}\text { Presbyter } \\
\text { Leo }\end{array}$ & Scholastiker & $\mathrm{X}$ & $\mathrm{X}$ \\
\hline 1340 April 20 & $\begin{array}{l}\text { Ludolf von } \\
\text { Putensen }\end{array}$ & & & $\mathrm{X}$ \\
\hline um 1340 & $\begin{array}{l}\text { Thideke } \\
\text { Buhof }\end{array}$ & $\begin{array}{l}\text { Auswärtiger aus } \\
\text { Stockholm }\end{array}$ & & $\mathrm{X}$ \\
\hline 1343 Juli 28 & $\begin{array}{l}\text { Johannes } \\
\text { Edebert }\end{array}$ & Sülfmeister & & \\
\hline 1346 April 4 & $\begin{array}{l}\text { Konrad } \\
\text { Dornich }\end{array}$ & Priester & & \\
\hline 1347 Jan. 21 & $\begin{array}{l}\text { Elisabeth } \\
\text { Hornemann }\end{array}$ & $\begin{array}{l}\text { Witwe } \\
\text { (Sülfmeister?) }\end{array}$ & & $\mathrm{X}$ \\
\hline 1347 April 10 & $\begin{array}{l}\text { Johannes } \\
\text { Timonis }\end{array}$ & & & \\
\hline um 1348 & $\begin{array}{l}\text { Nikolaus } \\
\text { Alardi }\end{array}$ & Bürger & & \\
\hline $\begin{array}{l}\text { 1352 März } 27 \\
\text { ( } 2 \text { ) }\end{array}$ & $\begin{array}{l}\text { Segeband } \\
\text { von Wittorf }\end{array}$ & (Ritter) & $\mathrm{X}$ & $X$ \\
\hline 1353 & $\begin{array}{l}\text { Heinrich } \\
\text { Willeri }\end{array}$ & Priester & & \\
\hline 1353 & $\begin{array}{l}\text { Degenard } \\
\text { Bernardi }\end{array}$ & & & $\mathrm{X}$ \\
\hline 1354 Dez. 19 & $\begin{array}{l}\text { Heinrich } \\
\text { und Lucie } \\
\text { Scherm - } \\
\text { beke }\end{array}$ & & & $\mathrm{X}$ \\
\hline 1355 Sept. 9 & $\begin{array}{l}\text { Dietrich } \\
\text { Holle }\end{array}$ & Bürger & & \\
\hline 1357 Okt. 27 & $\begin{array}{l}\text { Heinrich } \\
\text { Wiseke }\end{array}$ & Bürger & & \\
\hline
\end{tabular}




\begin{tabular}{|c|c|c|c|c|}
\hline Jahr & Name & Stellung/Beruf & $\begin{array}{l}\text { Sachgüter in } \\
\text { Legaten ad } \\
\text { pias causas }\end{array}$ & $\begin{array}{l}\text { Sachgüter in } \\
\text { Verfüg. für } \\
\text { Verwandte/ } \\
\text { Bekannte }\end{array}$ \\
\hline 1360 Jan. 13 & $\begin{array}{l}\text { Bernhard } \\
\text { und } \\
\text { Kunigunde } \\
\text { Nyebur }\end{array}$ & Bürger ( B. N. ) & & $\mathbf{X}$ \\
\hline 1361 April 20 & $\begin{array}{l}\text { Bernhard } \\
\text { Degenardi }\end{array}$ & Priester & $X$ & \\
\hline 1365 Feb. 14 & $\begin{array}{l}\text { Dietmar } \\
\text { Tzabel }\end{array}$ & Bürger & & \\
\hline 1366 April 2 & $\begin{array}{l}\text { Heinrich } \\
\text { Miles }\end{array}$ & (Ratsherr) & $\mathrm{X}$ & $\mathrm{X}$ \\
\hline 1366 & $\begin{array}{l}\text { Jutta } \\
\text { Seiden - } \\
\text { weber }\end{array}$ & & & $\mathrm{X}$ \\
\hline 1367 Mai 15 & $\begin{array}{l}\text { Johann } \\
\text { Beve }\end{array}$ & (Ratsherr) & $\mathrm{X}$ & $\mathrm{X}$ \\
\hline 1367 Juni 7 & $\begin{array}{l}\text { Heinrich } \\
\text { Wangelow }\end{array}$ & $\begin{array}{l}\text { Pfarrer d. Kirche } \\
\text { in Bergedorf }\end{array}$ & $\mathrm{X}$ & $\mathrm{X}$ \\
\hline 1369 Feb. 14 & $\begin{array}{l}\text { Jakob } \\
\text { Houth }\end{array}$ & (Ratsherr) & & \\
\hline 1369 April 8 & $\begin{array}{l}\text { Johann } \\
\text { Kröger }\end{array}$ & & & $\mathrm{X}$ \\
\hline 1370 Sept. 8 & $\begin{array}{l}\text { Gese uppe } \\
\text { der Kulen }\end{array}$ & $\begin{array}{l}\text { Witwe } \\
\text { (Sülfmeister) }\end{array}$ & & $\mathbf{x}$ \\
\hline 1370 Nov. 10 & $\begin{array}{l}\text { Jakob und } \\
\text { Hermann } \\
\text { Houth }\end{array}$ & $\begin{array}{l}\text { (Ratsherren und } \\
\text { Bürgermeister) }\end{array}$ & & \\
\hline 1372 Mai 1 & $\begin{array}{l}\text { Hartwig } \\
\text { Holste }\end{array}$ & (Ratsherr) & $\mathrm{X}$ & \\
\hline 1372 Okt. 31 & $\begin{array}{l}\text { Lüder } \\
\text { Brömse }\end{array}$ & Bürger & & \\
\hline 1375 Aug. 4 & $\begin{array}{l}\text { Johann von } \\
\text { Bücken }\end{array}$ & $\begin{array}{l}\text { Archidiakon von } \\
\text { Modestorpe }\end{array}$ & $\mathrm{X}$ & \\
\hline 1375 Aug. 29 & $\begin{array}{l}\text { Ilsebe } \\
\text { Ghyre }\end{array}$ & Witwe & & \\
\hline 1375 Sept. 12 & $\begin{array}{l}\text { Edelke van } \\
\text { der Heide }\end{array}$ & Bürger & & $\mathrm{X}$ \\
\hline 1375 Sept. 18 & $\begin{array}{l}\text { Ludolf von } \\
\text { Weddessen }\end{array}$ & $\begin{array}{l}\text { Pfarrer der } \\
\text { Kirche in } \\
\text { Netze, Vikar in } \\
\text { LG }\end{array}$ & & \\
\hline 1375 Nov. 1 & $\begin{array}{l}\text { Jürgen } \\
\text { Kramer }\end{array}$ & Bürger & & $\mathrm{X}$ \\
\hline 1376 Feb. 2 & $\begin{array}{l}\text { Vicke } \\
\text { Kramer }\end{array}$ & Bürger & $\mathrm{X}$ & \\
\hline 1376 April 26 & $\begin{array}{l}\text { Johannes } \\
\text { Hoyemann }\end{array}$ & $\begin{array}{l}\text { (Bürger } \\
\text { Sülfmeister - } \\
\text { geschlecht) }\end{array}$ & & \\
\hline 1378 Sept. 7 & Ludolf & Bürger & & $X$ \\
\hline
\end{tabular}




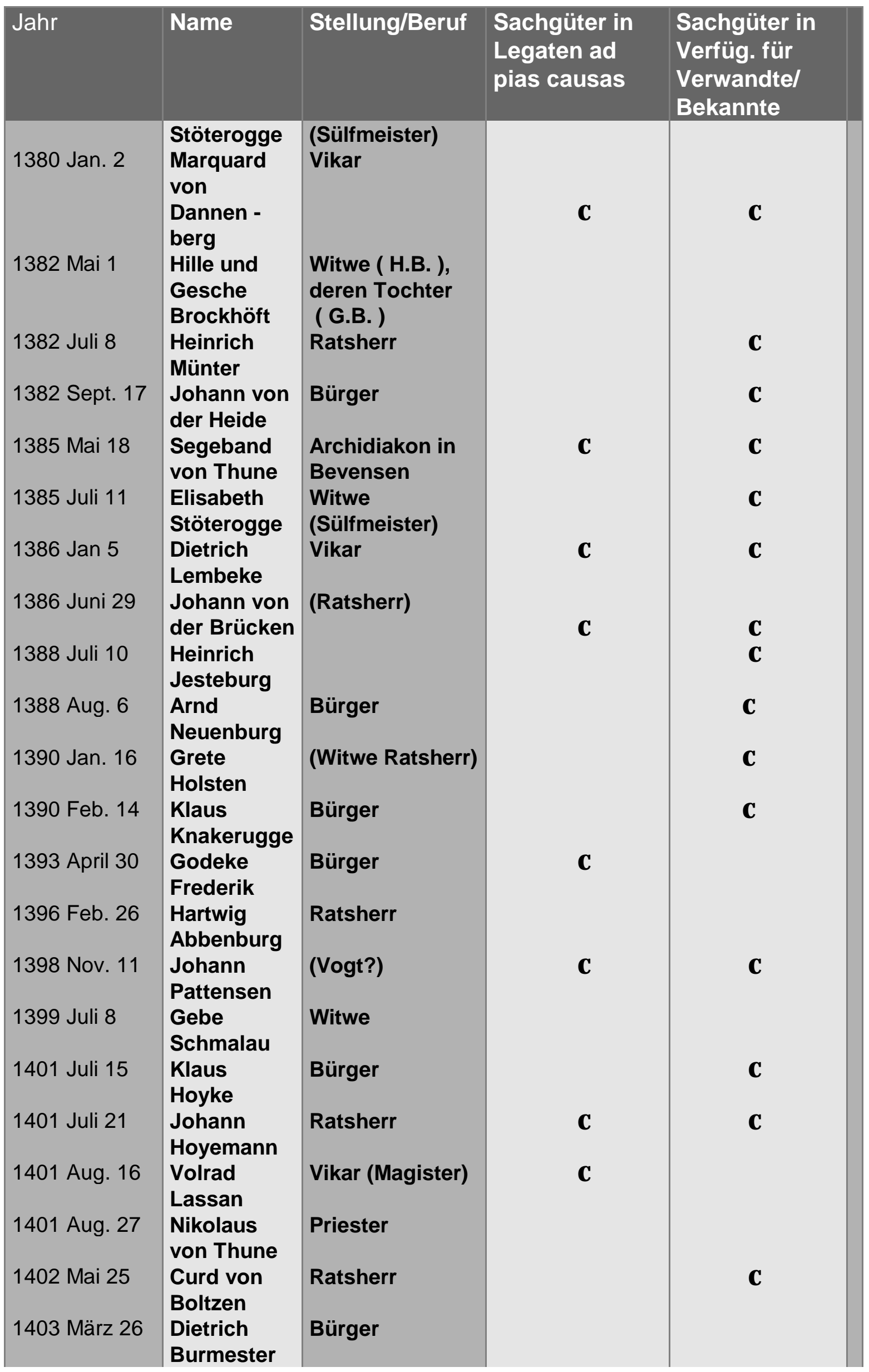




\begin{tabular}{|c|c|c|c|c|}
\hline Jahr & Name & Stellung/Beruf & $\begin{array}{l}\text { Sachgüter in } \\
\text { Legaten ad } \\
\text { pias causas }\end{array}$ & $\begin{array}{l}\text { Sachgüter in } \\
\text { Verfüg. für } \\
\text { Verwandte/ } \\
\text { Bekannte }\end{array}$ \\
\hline 1406 Mai 26 & $\begin{array}{l}\text { Johann } \\
\text { Hintbergen }\end{array}$ & & & $\mathrm{X}$ \\
\hline 1406 Sept. 17 & $\begin{array}{l}\text { Dietrich } \\
\text { Bardowick }\end{array}$ & Bürger & & $\mathrm{X}$ \\
\hline 1406 Sept. 23 & $\begin{array}{l}\text { Tibbeke von } \\
\text { Netze }\end{array}$ & $\begin{array}{l}\text { (Vorsteherin des } \\
\text { ewigen } \\
\text { Lichts am } \\
\text { Marienaltar } \\
\text { in St. Johannis) }\end{array}$ & & \\
\hline 1406 Okt. 19 & $\begin{array}{l}\text { Klaus } \\
\text { Salzhausen }\end{array}$ & Bürger & & $\mathrm{X}$ \\
\hline 1407 Juni 13 & Engelbrecht & (Bürger) & $\mathrm{X}$ & \\
\hline 1407 Juni 28 & $\begin{array}{l}\text { Johann } \\
\text { Swende - } \\
\text { beke }\end{array}$ & Bürger & & $\mathrm{X}$ \\
\hline 1408 Jan. 7 & Klaus & Bürger & & $X$ \\
\hline 1408 April 2 & $\begin{array}{l}\text { Metteke } \\
\text { Schwert - } \\
\text { feger }\end{array}$ & & & $\mathrm{X}$ \\
\hline 1408 April 17 & $\begin{array}{l}\text { Gebeke } \\
\text { Gosmann }\end{array}$ & (Witwe ?) & & \\
\hline 1408 Mai 28 & $\begin{array}{l}\text { Bernhard } \\
\text { Stöterogge }\end{array}$ & Bürger & & $X$ \\
\hline 1408 Aug. 18 & $\begin{array}{l}\text { Geverd } \\
\text { Gropeshorn }\end{array}$ & Bürger & $\mathrm{X}$ & $\mathrm{X}$ \\
\hline $\begin{array}{l}1409 \text { Jan. } 24 \\
1409 \text { März } 7\end{array}$ & $\begin{array}{l}\text { Johann } \\
\text { Schomaker } \\
\text { Johann }\end{array}$ & $\begin{array}{l}\text { Bürger } \\
\text { (Ratsherr. }\end{array}$ & & \\
\hline 140 S IVIal & $\begin{array}{l}\text { Semmel - } \\
\text { becker }\end{array}$ & Sodmeister) & $\mathrm{X}$ & $\mathrm{X}$ \\
\hline 1409 Juli 10 & $\begin{array}{l}\text { Ludolf } \\
\text { Burmester }\end{array}$ & $\begin{array}{l}\text { (Sohn von } \\
\text { Ratsbe - } \\
\text { dienstetem) }\end{array}$ & & $\mathrm{X}$ \\
\hline 1409 Okt. 8 & $\begin{array}{l}\text { Heinrich } \\
\text { von dem } \\
\text { Wede }\end{array}$ & Bürger & & $\mathrm{X}$ \\
\hline 1409 Okt. 27 & $\begin{array}{l}\text { Ludolf bi } \\
\text { dem Sode }\end{array}$ & & $X$ & \\
\hline 1410 Feb. 9 & $\begin{array}{l}\text { Hans } \\
\text { Melbeck }\end{array}$ & & & $X$ \\
\hline $\begin{array}{l}1410 \text { Juli } 14 \\
1410 \text { Aug. } 9\end{array}$ & $\begin{array}{l}\text { Ludolf von } \\
\text { Hagen } \\
\text { Johann von } \\
\text { Dolde }\end{array}$ & $\begin{array}{l}\text { Bürger } \\
\text { (Sülfmeister) } \\
\text { Bürger }\end{array}$ & $\mathrm{X}$ & $\mathrm{X}$ \\
\hline 1411 April 11 & $\begin{array}{l}\text { Werner } \\
\text { Malstorp }\end{array}$ & & $\mathrm{X}$ & $X$ \\
\hline
\end{tabular}




\begin{tabular}{|c|c|c|c|c|}
\hline Jahr & Name & Stellung/Beruf & $\begin{array}{l}\text { Sachgüter in } \\
\text { Legaten ad } \\
\text { pias causas }\end{array}$ & $\begin{array}{l}\text { Sachgüter in } \\
\text { Verfüg. für } \\
\text { Verwandte/ } \\
\text { Bekannte }\end{array}$ \\
\hline 1411 April 30 & $\begin{array}{l}\text { Klaus } \\
\text { Garlop }\end{array}$ & $\begin{array}{l}\text { Bürger } \\
\text { (Ratsherrenfa - } \\
\text { milie) }\end{array}$ & & $\mathrm{X}$ \\
\hline 1411 Juni 6 & $\begin{array}{l}\text { Alard von } \\
\text { Pattensen }\end{array}$ & Bürger & & $\mathrm{X}$ \\
\hline 1411 Juli 13 & $\begin{array}{l}\text { Hermann } \\
\text { von Rethem }\end{array}$ & Bürger & & $\mathrm{X}$ \\
\hline 1412 Feb. 29 & $\begin{array}{l}\text { Adelheid } \\
\text { Knakerugge }\end{array}$ & Witwe & $\mathrm{X}$ & \\
\hline 1412 März 6 & $\begin{array}{l}\text { Johann } \\
\text { Holeborn }\end{array}$ & Bürger & & $\mathrm{X}$ \\
\hline 1412 März 15 & $\begin{array}{l}\text { Dietrich } \\
\text { Erbstorf }\end{array}$ & Bürger & & $\mathrm{X}$ \\
\hline 1412 März 27 & Adelheit & $\begin{array}{l}\text { Witwe eines } \\
\text { Malers }\end{array}$ & & $\mathrm{X}$ \\
\hline 1412 Mai 15 & $\begin{array}{l}\text { Hans von } \\
\text { Munster }\end{array}$ & Bürger & & $\mathrm{X}$ \\
\hline 1412 Juni 13 & $\begin{array}{l}\text { Johann } \\
\text { Heyne }\end{array}$ & Bürger & $\mathrm{X}$ & $\mathrm{X}$ \\
\hline 1412 Juni 29 & $\begin{array}{l}\text { Hans } \\
\text { Trebbow }\end{array}$ & Kannengießer & & $\mathrm{X}$ \\
\hline 1412 Nov. 10 & $\begin{array}{l}\text { Helmich } \\
\text { Rorbag }\end{array}$ & Bürger & & $\mathrm{X}$ \\
\hline 1413 Jan. 21 & $\begin{array}{l}\text { Johann } \\
\text { Krowel }\end{array}$ & Bürger & & $\mathrm{X}$ \\
\hline 1413 Aug. 15 & $\begin{array}{l}\text { Johann von } \\
\text { der Mölen }\end{array}$ & $\begin{array}{l}\text { Ratsherr } \\
\text { (Sülfmeister ?) }\end{array}$ & $\mathrm{X}$ & $\mathrm{X}$ \\
\hline 1413 Aug. 24 & $\begin{array}{l}\text { Heinrich } \\
\text { von Hertber }\end{array}$ & Bürger & & $\mathrm{X}$ \\
\hline 1413 Aug. 29 & $\begin{array}{l}\text { Heinrich } \\
\text { von dem } \\
\text { Dage }\end{array}$ & Bürger & & $X$ \\
\hline 1413 Sept. 7 & $\begin{array}{l}\text { Johann von } \\
\text { Tespe }\end{array}$ & Bürger & & $\mathrm{X}$ \\
\hline 1413 Sept. 7 & $\begin{array}{l}\text { Roder von } \\
\text { Meiningholt }\end{array}$ & & & \\
\hline 1413 Sept. 7 & $\begin{array}{l}\text { Beke } \\
\text { Godenstorp }\end{array}$ & Witwe & & $\mathrm{X}$ \\
\hline & $\begin{array}{l}\text { Heinrich } \\
\text { von Gothing }\end{array}$ & Bürger & & $\mathrm{X}$ \\
\hline $\begin{array}{l}1414 \text { Feb. } 4 \\
\text { ( } 2 \text { ) }\end{array}$ & $\begin{array}{l}\text { Gobele von } \\
\text { Wassen - } \\
\text { berg } \\
\text { Johannes } \\
\text { von Lipping } \\
\text {-hausen, } \\
\text { gen. } \\
\text { Handorp }\end{array}$ & Vikar & $\mathrm{X}$ & $\mathrm{X}$ \\
\hline
\end{tabular}




\begin{tabular}{|c|c|c|c|c|}
\hline Jahr & Name & Stellung/Beruf & $\begin{array}{l}\text { Sachgüter in } \\
\text { Legaten ad } \\
\text { pias causas }\end{array}$ & $\begin{array}{l}\text { Sachgüter in } \\
\text { Verfüg. für } \\
\text { Verwandte/ } \\
\text { Bekannte }\end{array}$ \\
\hline 1414 Feb. 10 & $\begin{array}{l}\text { Grete } \\
\text { Masendorp }\end{array}$ & & $\mathrm{X}$ & $X$ \\
\hline 1414 März 3 & $\begin{array}{l}\text { Hans } \\
\text { Grabow }\end{array}$ & Bürger & & $\mathrm{X}$ \\
\hline 1414 Mai 6 & Hans Niterd & & & $\mathrm{X}$ \\
\hline 1414 Juni 29 & $\begin{array}{l}\text { Heinrich } \\
\text { Uplegger }\end{array}$ & $\begin{array}{l}\text { Bürger } \\
\text { (Münzmeister ?) }\end{array}$ & & $\mathrm{X}$ \\
\hline 1415 Juni 28 & $\begin{array}{l}\text { Gese } \\
\text { Lübberstedt }\end{array}$ & Witwe & $\mathrm{X}$ & $\mathrm{X}$ \\
\hline 1415 Juli 25 & Klaus Röder & Bürger & & $\mathrm{X}$ \\
\hline 1415 Juli 27 & $\begin{array}{l}\text { Lüder } \\
\text { Bardowick }\end{array}$ & $\begin{array}{l}\text { Bürger } \\
\text { (Sülfmeisterfa - } \\
\text { milie) }\end{array}$ & $\mathrm{X}$ & $\mathrm{X}$ \\
\hline 1415 Juli 31 & $\begin{array}{l}\text { Johann } \\
\text { Hofmann }\end{array}$ & Bürger & & $\mathrm{X}$ \\
\hline 1415 Dez. 3 & $\begin{array}{l}\text { Abele von } \\
\text { Holstele }\end{array}$ & Witwe & & $X$ \\
\hline 1416 Mai 2 & $\begin{array}{l}\text { Ludolf } \\
\text { Woye }\end{array}$ & Bürger & & $\mathrm{X}$ \\
\hline 1416 Juni 24 & $\begin{array}{l}\text { Bernd von } \\
\text { Verden }\end{array}$ & Bürger & & \\
\hline 1416 Juli 19 & $\begin{array}{l}\text { Heinrich } \\
\text { Roden - } \\
\text { borch }\end{array}$ & Bürger & & $X$ \\
\hline 1416 Juli 31 & $\begin{array}{l}\text { Dietrich } \\
\text { Düsterhop }\end{array}$ & $\begin{array}{l}\text { Bürger } \\
\text { (Sülfmeister) }\end{array}$ & & $\mathrm{X}$ \\
\hline 1417 Feb. 8 & $\begin{array}{l}\text { Heinrich } \\
\text { Sasse }\end{array}$ & Bürger & $\mathrm{X}$ & \\
\hline 1417 Aug. 22 & Klaus Maler & & & \\
\hline 1417 Sept. 22 & $\begin{array}{l}\text { Reinecke } \\
\text { von Swalen }\end{array}$ & Bürger & & $\mathrm{X}$ \\
\hline 1417 Dez. 9 & $\begin{array}{l}\text { Kersten } \\
\text { Drespe }\end{array}$ & Bürger & & $\mathrm{X}$ \\
\hline 1417 & $\begin{array}{l}\text { Meyne von } \\
\text { dem Moyde }\end{array}$ & Bürger & $\mathrm{X}$ & \\
\hline 1418 April 30 & $\begin{array}{l}\text { Werner } \\
\text { Volkmer }\end{array}$ & Bürger & & $\mathrm{X}$ \\
\hline 1418 Aug. 12 & $\begin{array}{l}\text { Tibbeke } \\
\text { Remsnyder }\end{array}$ & Witwe & & $\mathrm{X}$ \\
\hline 1419 März 17 & $\begin{array}{l}\text { Immeke } \\
\text { Burmester }\end{array}$ & Witwe & & $\mathrm{X}$ \\
\hline 1419 April 3 & $\begin{array}{l}\text { Borchard } \\
\text { Trumper }\end{array}$ & Ratsdiener & & $\mathrm{X}$ \\
\hline 1419 Juni 11 & $\begin{array}{l}\text { Wibke } \\
\text { Saffan }\end{array}$ & $\begin{array}{l}\text { (Sohn evtl. } \\
\text { Bäcker) }\end{array}$ & & $\mathrm{X}$ \\
\hline $\begin{array}{l}1419 \text { Juni } 13 \\
1419 \text { Juni } 28\end{array}$ & $\begin{array}{l}\text { Hans } \\
\text { Kämmerer } \\
\text { Klaus }\end{array}$ & Bürger & & $X$ \\
\hline
\end{tabular}




\begin{tabular}{|c|c|c|c|c|}
\hline Jahr & Name & Stellung/Beruf & $\begin{array}{l}\text { Sachgüter in } \\
\text { Legaten ad } \\
\text { pias causas }\end{array}$ & $\begin{array}{l}\text { Sachgüter in } \\
\text { Verfüg. für } \\
\text { Verwandte/ } \\
\text { Bekannte }\end{array}$ \\
\hline $\begin{array}{c}1420 \text { Nov. } 14 \\
\text { ( } 3 \text { ) }\end{array}$ & $\begin{array}{l}\text { Remstede } \\
\text { Hermann } \\
\text { Zierenberg }\end{array}$ & $\begin{array}{l}\text { Bürger zu } \\
\text { Lübeck, } \\
\text { (allerdings aus } \\
\text { der Stadt }\end{array}$ & $\mathrm{X}$ & \\
\hline 1420 Dez. 32 & $\begin{array}{l}\text { Aldich von } \\
\text { Schnever - } \\
\text { ding }\end{array}$ & $\begin{array}{l}\text { Bürger } \\
\text { (Schmied) }\end{array}$ & & $X$ \\
\hline 1421 Feb. 12 & $\begin{array}{l}\text { Adelheid } \\
\text { Hagemann }\end{array}$ & & & $\mathrm{X}$ \\
\hline 1421 April 22 & $\begin{array}{l}\text { Johann } \\
\text { Wokersinn }\end{array}$ & Bürger & & $\mathrm{X}$ \\
\hline 1421 Juni 9 & $\begin{array}{l}\text { Heinrich } \\
\text { Salzhausen }\end{array}$ & Bürger & & $\mathrm{X}$ \\
\hline 1421 Juni 24 & $\begin{array}{l}\text { Meinhard } \\
\text { Vischer }\end{array}$ & Bürger & & $\mathrm{X}$ \\
\hline 1421 Juli 17 & $\begin{array}{l}\text { Heinrich } \\
\text { Hudekoper }\end{array}$ & Bürger & & $\mathrm{X}$ \\
\hline 1421 Juli 20 & $\begin{array}{l}\text { Johann } \\
\text { Soltau }\end{array}$ & Bürger & & $\mathrm{X}$ \\
\hline 1421 Juli 25 & $\begin{array}{l}\text { Tyle } \\
\text { Schutte }\end{array}$ & $\begin{array}{l}\text { Bürger zu } \\
\text { Nordhausen }\end{array}$ & & $\mathrm{X}$ \\
\hline 1421 Aug. 2 & $\begin{array}{l}\text { Dietrich von } \\
\text { Bevensen }\end{array}$ & & & $\mathrm{X}$ \\
\hline 1421 Aug. 23 & $\begin{array}{l}\text { Ludolf von } \\
\text { dem Borstel }\end{array}$ & Bürger & & $\mathrm{X}$ \\
\hline 1421 Okt. 13 & Albert Koch & Bürger & & $\mathrm{X}$ \\
\hline 1421 Nov. 9 & $\begin{array}{l}\text { Dietrich } \\
\text { Rogge }\end{array}$ & Bürger & & $\mathrm{X}$ \\
\hline 1422 Jan. 22 & Berta Koch & (Bürger-) Witwe & & $\mathrm{X}$ \\
\hline 1422 März 17 & $\begin{array}{l}\text { Johann } \\
\text { Cloke }\end{array}$ & Bürger & & $\mathrm{X}$ \\
\hline 1422 Nov. 12 & $\begin{array}{l}\text { Grete von } \\
\text { dem Wede }\end{array}$ & (Bürger-) Witwe & & $\mathrm{X}$ \\
\hline 1423 März 30 & Cord Boltze & Bürger & & $\mathrm{X}$ \\
\hline 1423 April 18 & $\begin{array}{l}\text { Dietrich } \\
\text { Trost }\end{array}$ & Bürger & & $\mathrm{X}$ \\
\hline 1423 Aug. 16 & $\begin{array}{l}\text { Johann von } \\
\text { Hasle }\end{array}$ & Bürger & $\mathrm{X}$ & $\mathrm{X}$ \\
\hline 1425 Feb. 28 & $\begin{array}{l}\text { Marquard } \\
\text { Twedorpp }\end{array}$ & Bürger & & \\
\hline 1425 März 21 & $\begin{array}{l}\text { Geseke } \\
\text { Springint - } \\
\text { gud }\end{array}$ & Ratsherrnwitwe & $\mathrm{X}$ & $X$ \\
\hline 1425 März 31 & $\begin{array}{l}\text { Heinrich } \\
\text { Müller }\end{array}$ & $\begin{array}{l}\text { laycus opidanus } \\
\text { in } \\
\text { Medingen }\end{array}$ & & $\mathrm{X}$ \\
\hline
\end{tabular}




\begin{tabular}{|c|c|c|c|c|}
\hline Jahr & Name & Stellung/Beruf & $\begin{array}{l}\text { Sachgüter in } \\
\text { Legaten ad } \\
\text { pias causas }\end{array}$ & $\begin{array}{l}\text { Sachgüter in } \\
\text { Verfüg. für } \\
\text { Verwandte/ } \\
\text { Bekannte }\end{array}$ \\
\hline 1425 April 18 & $\begin{array}{l}\text { Grete von } \\
\text { dem Sande }\end{array}$ & & & $X$ \\
\hline 1425 Juli 23 & $\begin{array}{l}\text { Albert von } \\
\text { der Mölen }\end{array}$ & Bürgermeister & $\mathrm{X}$ & $\mathrm{X}$ \\
\hline 1425 Okt. 1 & $\begin{array}{l}\text { Dietrich } \\
\text { Rosenhop }\end{array}$ & $\begin{array}{l}\text { Bürger } \\
\text { Glaser }\end{array}$ & & $\mathrm{X}$ \\
\hline 1426 April 2 & $\begin{array}{l}\text { Johann von } \\
\text { Sprakelsen }\end{array}$ & Bürger & & $\mathrm{X}$ \\
\hline 1427 April 4 & $\begin{array}{l}\text { Ludolf } \\
\text { Bartolo - } \\
\text { mäus }\end{array}$ & Bürger & $\mathrm{X}$ & $X$ \\
\hline 1428 Mai 22 & $\begin{array}{l}\text { Hans von } \\
\text { Klentze }\end{array}$ & Bürger & & $\mathrm{X}$ \\
\hline 1428 Okt. 27 & $\begin{array}{l}\text { Wobbeke } \\
\text { Boltzen }\end{array}$ & Ratsherrnwitwe & & $\mathrm{X}$ \\
\hline 1429 Okt. 30 & $\begin{array}{l}\text { Tibbeke } \\
\text { Poterow }\end{array}$ & & & $\mathrm{X}$ \\
\hline 1430 Feb. 24 & Hans Junge & $\begin{array}{l}\text { (Ratsbedienstet } \\
\text { er, evtl. Gold - } \\
\text { schmiedssohn } \\
\text { aus Lübeck) }\end{array}$ & $\mathrm{X}$ & $\mathrm{X}$ \\
\hline 1430 Juni 12 & $\begin{array}{l}\text { Adelheid } \\
\text { Kolse }\end{array}$ & & $\mathrm{X}$ & $\mathrm{X}$ \\
\hline $1423 / 1431$ & $\begin{array}{l}\text { Adelheid } \\
\text { Seidentopf }\end{array}$ & & $\mathrm{X}$ & $\mathrm{X}$ \\
\hline 1431 Jan. 15 & $\begin{array}{l}\text { Johann } \\
\text { Rese }\end{array}$ & Ratsherr & & $\mathrm{X}$ \\
\hline 1431 Juni 15 & $\begin{array}{l}\text { Margareta } \\
\text { von der } \\
\text { Mölen }\end{array}$ & Witwe (Ratsherr) & $\mathrm{X}$ & \\
\hline 1431 & $\begin{array}{l}\text { Bernd von } \\
\text { Erpensen }\end{array}$ & $\begin{array}{l}\text { Bürger } \\
\text { (Sülfmeister) }\end{array}$ & & $X$ \\
\hline 1432 Jan. 17 & $\begin{array}{l}\text { Johann } \\
\text { Molne }\end{array}$ & $\begin{array}{l}\text { Bürger } \\
\text { (Bäcker) }\end{array}$ & & $\mathrm{X}$ \\
\hline 1432 Jan. 31 & $\begin{array}{l}\text { Hermann } \\
\text { Snitker }\end{array}$ & Bürger & & $\mathrm{X}$ \\
\hline 1432 Juni 29 & $\begin{array}{l}\text { Johann } \\
\text { Welsrode }\end{array}$ & & & $\mathrm{X}$ \\
\hline $\begin{array}{l}1429 \text { Juni } 21 \text { / } \\
1432 \\
\text { Okt. } 20\end{array}$ & $\begin{array}{l}\text { Heinrich } \\
\text { von Saldern }\end{array}$ & $\begin{array}{l}\text { Bürger, } \\
\text { auswärts } \\
\text { gestorben }\end{array}$ & & \\
\hline 1433 Juni 25 & $\begin{array}{l}\text { Dietrich } \\
\text { Heket }\end{array}$ & Bürger & $\mathrm{X}$ & $\mathrm{X}$ \\
\hline 1433 Juli 9 & $\begin{array}{l}\text { Grete } \\
\text { Kortüm }\end{array}$ & $\begin{array}{l}\text { Tochter eines } \\
\text { Bürger, } \\
\text { Einwohnerin }\end{array}$ & & \\
\hline $\begin{array}{l}1434 \text { April } 12 \\
1434 \text { Juni } 21\end{array}$ & $\begin{array}{l}\text { Hans Stute } \\
\text { Ludolf }\end{array}$ & $\begin{array}{l}\text { Mühlenknecht } \\
\text { Ratsherr }\end{array}$ & & $\begin{array}{l}X \\
X\end{array}$ \\
\hline
\end{tabular}




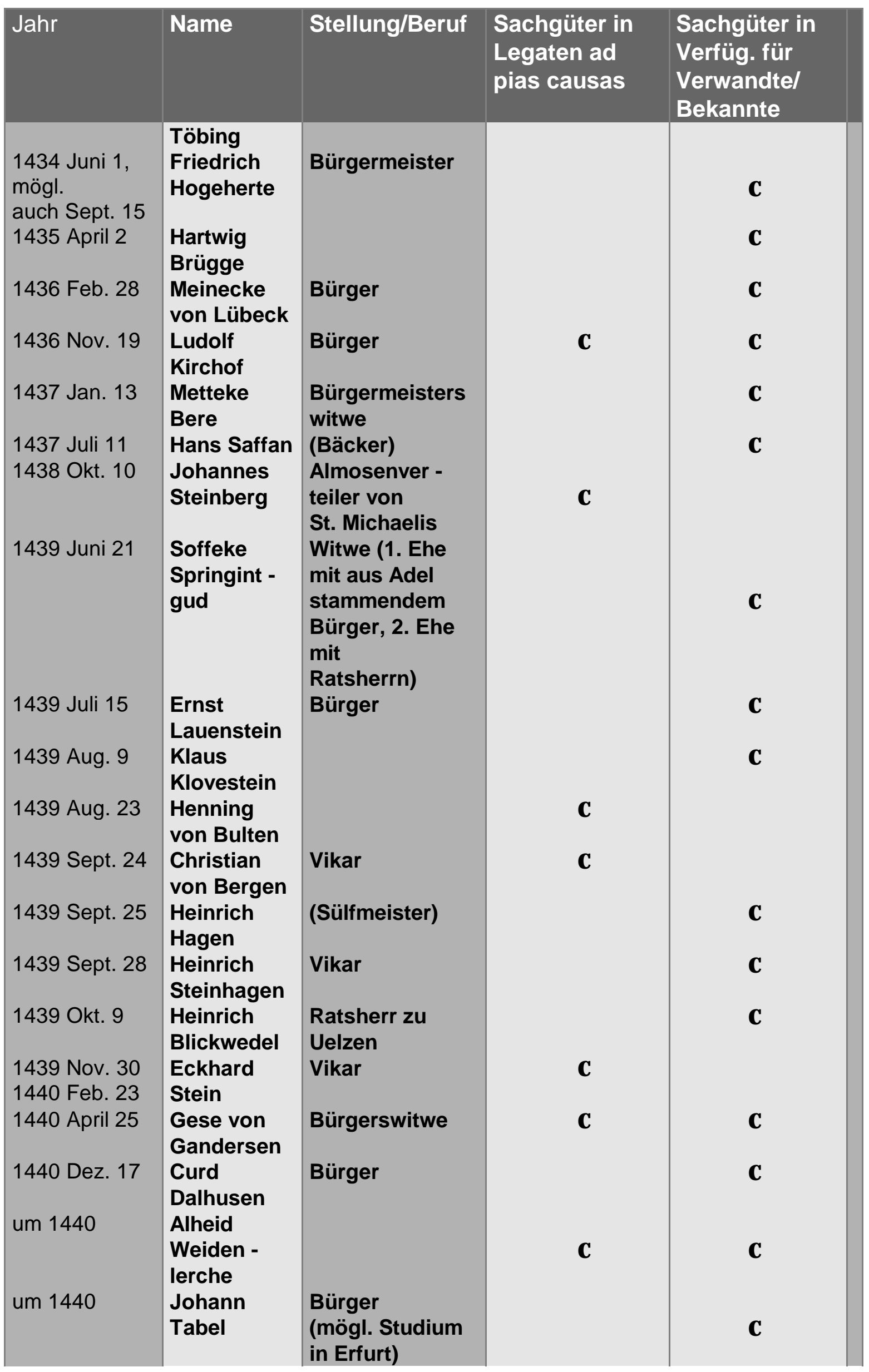




\begin{tabular}{|c|c|c|c|c|}
\hline Jahr & Name & Stellung/Beruf & $\begin{array}{l}\text { Sachgüter in } \\
\text { Legaten ad } \\
\text { pias causas }\end{array}$ & $\begin{array}{l}\text { Sachgüter in } \\
\text { Verfüg. für } \\
\text { Verwandte/ } \\
\text { Bekannte }\end{array}$ \\
\hline 1441 Feb. 12 & $\begin{array}{l}\text { Alheid } \\
\text { Salzenhau- } \\
\text { sen }\end{array}$ & & & $X$ \\
\hline 1441 April 22 & $\begin{array}{l}\text { Meister } \\
\text { Heinrich }\end{array}$ & $\begin{array}{l}\text { Werkmeister des } \\
\text { Rats }\end{array}$ & $X$ & $\mathrm{X}$ \\
\hline 1441 Aug. 24 & $\begin{array}{l}\text { Heinrich } \\
\text { Tetendorp }\end{array}$ & Vikar & $\mathrm{X}$ & $\mathrm{X}$ \\
\hline 1441 Okt. 8 & Johann Pale & Bürger & & $\mathrm{X}$ \\
\hline 1441 Nov. 20 & $\begin{array}{l}\text { Hermann } \\
\text { Kruse }\end{array}$ & Bürgermeister & $\mathrm{X}$ & $\mathrm{X}$ \\
\hline $\begin{array}{l}1442 \text { Feb. } 14 \\
\text { oder } 21\end{array}$ & $\begin{array}{l}\text { Hermann } \\
\text { Stekeberg }\end{array}$ & Bürger & & $X$ \\
\hline 1443 Feb. 10 & $\begin{array}{l}\text { Klaus } \\
\text { Schmied }\end{array}$ & Bürger & $\mathrm{X}$ & $\mathrm{X}$ \\
\hline 1444 Mai 8 & $\begin{array}{l}\text { Bernd von } \\
\text { dem Brake }\end{array}$ & Bürger & & $\mathrm{X}$ \\
\hline 1444 Mai 23 & $\begin{array}{l}\text { Cyeke } \\
\text { Witting }\end{array}$ & (Witwe ?) & $\mathrm{X}$ & $\mathrm{X}$ \\
\hline 1444 Okt. 18 & $\begin{array}{l}\text { Grete von } \\
\text { der Heide }\end{array}$ & $\begin{array}{l}\text { Konventualin im } \\
\text { Blauen Konvent }\end{array}$ & & $\mathrm{X}$ \\
\hline 1444 Nov. 27 & $\begin{array}{l}\text { Johannes } \\
\text { Weiden - } \\
\text { knepel }\end{array}$ & $\begin{array}{l}\text { Lübecker } \\
\text { Kanoniker }\end{array}$ & $\mathrm{X}$ & $\mathrm{X}$ \\
\hline 1444 Dez. 13 & $\begin{array}{l}\text { Klaus und } \\
\text { Grete } \\
\text { von Wening }\end{array}$ & $\begin{array}{l}\text { Bürger (K. v. } \\
\text { Wening) }\end{array}$ & & $X$ \\
\hline 1445 & $\begin{array}{l}\text { Lange } \\
\text { Ludolf }\end{array}$ & & & $X$ \\
\hline 1447 Jan. 9 & $\begin{array}{l}\text { Peter } \\
\text { Schütte }\end{array}$ & $\begin{array}{l}\text { Bürger } \\
\text { (Sülfmeister) }\end{array}$ & $\mathrm{X}$ & \\
\hline 1447 Mai 29 & Hans Tespe & Bürger & & $\mathrm{X}$ \\
\hline 1447 Aug. 12 & $\begin{array}{l}\text { Nickel } \\
\text { Lesnis }\end{array}$ & & $\mathrm{X}$ & $\mathrm{X}$ \\
\hline 1447 Dez. 14 & Hans Kruse & (Sülfmeister) & & $X$ \\
\hline 1448 Mai 17 & $\begin{array}{l}\text { Dietrich } \\
\text { Ellenberg }\end{array}$ & Bürger & & $\mathrm{X}$ \\
\hline 1448 Juni 22 & $\begin{array}{l}\text { Alerd } \\
\text { Golstede }\end{array}$ & Bürger & & \\
\hline 1449 Okt. 9 & $\begin{array}{l}\text { Heinrich } \\
\text { Dreyling }\end{array}$ & Bürger & & $X$ \\
\hline 1450 Okt. 10 & $\begin{array}{l}\text { Ludolf von } \\
\text { Lafferd }\end{array}$ & Bürger & & $\mathrm{X}$ \\
\hline 1451 März 12 & $\begin{array}{l}\text { Beke } \\
\text { Groning }\end{array}$ & $\begin{array}{l}\text { Witwe } \\
\text { (Barmeister) }\end{array}$ & & $\mathrm{X}$ \\
\hline $\begin{array}{l}1451 \text { Mai } 15 \\
1451 \text { Juni } 11\end{array}$ & $\begin{array}{l}\text { Ludolf } \\
\text { Ossendorf } \\
\text { Robke van } \\
\text { dem }\end{array}$ & Bürger & & $\mathrm{X}$ \\
\hline
\end{tabular}




\begin{tabular}{|c|c|c|c|c|}
\hline Jahr & Name & Stellung/Beruf & $\begin{array}{l}\text { Sachgüter in } \\
\text { Legaten ad } \\
\text { pias causas }\end{array}$ & $\begin{array}{l}\text { Sachgüter in } \\
\text { Verfüg. für } \\
\text { Verwandte/ } \\
\text { Bekannte }\end{array}$ \\
\hline 1451 Juli 7 & $\begin{array}{l}\text { Jettebrok } \\
\text { Metteke } \\
\text { Scherm - } \\
\text { beke } \\
\text { Ludolf und } \\
\text { Geseke } \\
\text { Wienebüttel }\end{array}$ & $\begin{array}{l}\text { Ratsherrnwitwe, } \\
\text { insgesamt drei } \\
\text { Ehen mit } \\
\text { Ratsherrn } \\
\text { Bürger (L.W.) } \\
\text { (möglw. } \\
\text { Sülfmeister) }\end{array}$ & $X$ & $X$ \\
\hline 1451 Aug. 12 & $\begin{array}{l}\text { Heinrich } \\
\text { vom Hove }\end{array}$ & Bürger & $\mathrm{X}$ & $\mathrm{X}$ \\
\hline 1451 Sept. 26 & $\begin{array}{l}\text { Heinrich } \\
\text { Hoyer }\end{array}$ & $\begin{array}{l}\text { Ratsherr } \\
\text { (Sülfmeister, } \\
\text { Barmeister) }\end{array}$ & $\mathrm{X}$ & \\
\hline 1452 März 22 & $\begin{array}{l}\text { Geseke } \\
\text { Zimmer - } \\
\text { mann }\end{array}$ & Einwohnerin & & $X$ \\
\hline 1452 Juli 4 & $\begin{array}{l}\text { Johannes } \\
\text { von Wintem }\end{array}$ & $\begin{array}{l}\text { Bürger } \\
\text { (Ratsherr) }\end{array}$ & & $\mathrm{X}$ \\
\hline 1456 April 10 & $\begin{array}{l}\text { Cord von } \\
\text { Rettmer }\end{array}$ & Bürger & & $\mathrm{X}$ \\
\hline 1458 April 6 & $\begin{array}{l}\text { Adelheid } \\
\text { Kale }\end{array}$ & $\begin{array}{l}\text { Witwe des Rats - } \\
\text { zimmermeisters }\end{array}$ & $\mathrm{X}$ & \\
\hline 1459 Feb. 10 & $\begin{array}{l}\text { Adelheid } \\
\text { Miils }\end{array}$ & $\begin{array}{l}\text { Bürgers- } \\
\text { witwe }\end{array}$ & & $\mathrm{X}$ \\
\hline 1460 Mai 30 & $\begin{array}{l}\text { Hilleke von } \\
\text { Erpensen }\end{array}$ & $\begin{array}{l}\text { Bewohnerin des } \\
\text { Blauen } \\
\text { Konvents }\end{array}$ & $\mathrm{X}$ & $\mathrm{X}$ \\
\hline 1461 Dez. 14 & $\begin{array}{l}\text { Heinrich } \\
\text { Geismar }\end{array}$ & $\begin{array}{l}\text { Pfarrer in } \\
\text { Böken, } \\
\text { Diö. Ratzeburg, } \\
\text { Vikar } \\
\text { KI. HI. Geist, Lg }\end{array}$ & $\mathrm{X}$ & $\mathrm{X}$ \\
\hline 1462 Juli 22 & $\begin{array}{l}\text { Konrad } \\
\text { Hogestern }\end{array}$ & 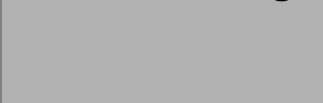 & & \\
\hline 1464 April 11 & $\begin{array}{l}\text { Johann von } \\
\text { Minden }\end{array}$ & $\begin{array}{l}\text { Domherr zu } \\
\text { Lübeck, } \\
\text { Stadtschreiber } \\
\text { und erster } \\
\text { Propst zu St. } \\
\text { Johannis }\end{array}$ & & \\
\hline 1464 Juli 28 & $\begin{array}{l}\text { Johann } \\
\text { vame Lo }\end{array}$ & $\begin{array}{l}\text { Ratsherr } \\
\text { (Sülfmeister, } \\
\text { Sodmeister) }\end{array}$ & $\mathrm{X}$ & $X$ \\
\hline 1466 Nov. 9 & $\begin{array}{l}\text { Beke von } \\
\text { dem Berge }\end{array}$ & $\begin{array}{l}\text { Bürgers- } \\
\text { witwe }\end{array}$ & $\mathrm{X}$ & $\mathrm{X}$ \\
\hline 1469 Feb. 26 & $\begin{array}{l}\text { Tibbeke } \\
\text { Godenstedt }\end{array}$ & $\begin{array}{l}\text { Ratsherrnwitwe } \\
\text { (Sülfmeister) }\end{array}$ & & $\mathrm{X}$ \\
\hline 1471 März 11 & Bernd & & & $X$ \\
\hline
\end{tabular}




\begin{tabular}{|c|c|c|c|c|}
\hline Jahr & Name & Stellung/Beruf & $\begin{array}{l}\text { Sachgüter in } \\
\text { Legaten ad } \\
\text { pias causas }\end{array}$ & $\begin{array}{l}\text { Sachgüter in } \\
\text { Verfüg. für } \\
\text { Verwandte/ } \\
\text { Bekannte }\end{array}$ \\
\hline 1472 Aug. 4 & $\begin{array}{l}\text { Burmester } \\
\text { Geseke } \\
\text { Rosemberg }\end{array}$ & Bürgerin & & $\mathrm{X}$ \\
\hline 1472 Aug. 27 & Hans Jagow & $\begin{array}{l}\text { Bürger zu } \\
\text { Hamburg }\end{array}$ & $\mathrm{X}$ & $\mathrm{X}$ \\
\hline 1473 Juli 23 & $\begin{array}{l}\text { Metteke von } \\
\text { Dassel }\end{array}$ & $\begin{array}{l}\text { Ehefrau eines } \\
\text { Bürgers } \\
\text { (Gewandschnei- } \\
\text { der, Sülfmeister) }\end{array}$ & $\mathrm{X}$ & $\mathrm{X}$ \\
\hline 1473 Sept. 29 & $\begin{array}{l}\text { Johann } \\
\text { vame Lo } \\
\text { der Jüngere }\end{array}$ & $\begin{array}{l}\text { Bürger } \\
\text { (Sülfmeister, } \\
\text { Barmeister, } \\
\text { Ratsherr) }\end{array}$ & $\mathrm{X}$ & $\mathrm{X}$ \\
\hline 1474 Aug. 23 & $\begin{array}{l}\text { Beke von } \\
\text { Esche }\end{array}$ & Bürgerswitwe & $\mathrm{X}$ & $\mathrm{X}$ \\
\hline $\begin{array}{l}1474 \text { Aug. } 31 \\
\text { ( } 2 \text { ) }\end{array}$ & $\begin{array}{l}\text { Geseke } \\
\text { Schwert - } \\
\text { feger }\end{array}$ & $\begin{array}{l}\text { Tochter eines } \\
\text { ver - } \\
\text { storbenen } \\
\text { Bürgers }\end{array}$ & & \\
\hline 1474 Sept. 10 & $\begin{array}{l}\text { Greteke } \\
\text { Melbek }\end{array}$ & $\begin{array}{l}\text { Witwe, Bürgerin } \\
\text { (Brauer) }\end{array}$ & $\mathrm{X}$ & $\mathrm{X}$ \\
\hline 1474 Sept. 22 & $\begin{array}{l}\text { Matthias } \\
\text { von der } \\
\text { Most }\end{array}$ & Apotheker & $\mathrm{X}$ & $\mathrm{X}$ \\
\hline 1475 Jan. 13 & $\begin{array}{l}\text { Czieke } \\
\text { Blank }\end{array}$ & Witwe, Bürgerin & & $\mathrm{X}$ \\
\hline 1475 April 6 & Hans Merre & Bürger & & $\mathrm{X}$ \\
\hline 1475 April 16 & $\begin{array}{l}\text { Hans } \\
\text { Konvelitz }\end{array}$ & $\begin{array}{l}\text { Bürger } \\
\text { (Schneider) }\end{array}$ & & $\mathrm{X}$ \\
\hline 1475 Juni 3 & $\begin{array}{l}\text { Jakob } \\
\text { Döring }\end{array}$ & Bürger (Barbier) & & $\mathrm{X}$ \\
\hline 1475 Aug. 17 & $\begin{array}{l}\text { Albert } \\
\text { Schulte }\end{array}$ & Mühlenknecht & & $\mathrm{X}$ \\
\hline 1475 Nov. 17 & $\begin{array}{l}\text { Hans } \\
\text { Gansebom }\end{array}$ & Mühlenknecht & & \\
\hline 1476 März 4 & $\begin{array}{l}\text { Vicke } \\
\text { Bottermann }\end{array}$ & Bürger & & $\mathrm{X}$ \\
\hline 1476 Sept. 18 & $\begin{array}{l}\text { Dietrich } \\
\text { Junge }\end{array}$ & Vikar in St. Jo. & $\mathrm{X}$ & $\mathrm{X}$ \\
\hline 1477 Feb. 25 & $\begin{array}{l}\text { Herzog } \\
\text { Friedrich } \\
\text { der Ältere }\end{array}$ & & & \\
\hline 1477 März 7 & $\begin{array}{l}\text { Hans von } \\
\text { Rethen }\end{array}$ & Bürger & $\mathrm{X}$ & $\mathrm{X}$ \\
\hline 1477 Juni 4 & $\begin{array}{l}\text { Bernd } \\
\text { Freese }\end{array}$ & Bürger & & $\mathrm{X}$ \\
\hline 1478 Mai 13 & $\begin{array}{l}\text { Ludorf } \\
\text { Mangard }\end{array}$ & $\begin{array}{l}\text { Priester und } \\
\text { Vikar }\end{array}$ & $\mathrm{X}$ & $\mathrm{X}$ \\
\hline
\end{tabular}




\begin{tabular}{|c|c|c|c|c|}
\hline Jahr & Name & Stellung/Beruf & $\begin{array}{l}\text { Sachgüter in } \\
\text { Legaten ad } \\
\text { pias causas }\end{array}$ & $\begin{array}{l}\text { Sachgüter in } \\
\text { Verfüg. für } \\
\text { Verwandte/ } \\
\text { Bekannte }\end{array}$ \\
\hline 1480 Aug. 13 & $\begin{array}{l}\text { Lutke } \\
\text { Hilmers }\end{array}$ & $\begin{array}{l}\text { in St. Jo. } \\
\text { Einwohner }\end{array}$ & & $\mathrm{X}$ \\
\hline 1481 April 19 & $\begin{array}{l}\text { Bethman } \\
\text { von Drubke }\end{array}$ & Ratsdiener & & $\mathrm{X}$ \\
\hline 1481 Mai 24 & $\begin{array}{l}\text { Luteke } \\
\text { Nyebur }\end{array}$ & Bürger & $\mathrm{X}$ & $\mathrm{X}$ \\
\hline 1481 Juni 5 & $\begin{array}{l}\text { Hans } \\
\text { Dobbeler }\end{array}$ & Bürger & & $\mathrm{X}$ \\
\hline 1482 Mai 7 & $\begin{array}{l}\text { Helmold von } \\
\text { Lyderen }\end{array}$ & Arzt & & $\mathrm{X}$ \\
\hline 1482 Juni 30 & $\begin{array}{l}\text { Heinrich } \\
\text { Erpensen }\end{array}$ & $\begin{array}{l}\text { Ratsherr } \\
\text { (Sülfmeister) }\end{array}$ & & $\mathrm{X}$ \\
\hline 1482 Juli 23 & $\begin{array}{l}\text { Greteke } \\
\text { Brockhoved }\end{array}$ & Bürgerswitwe & & $\mathrm{X}$ \\
\hline 1482 Nov. 18 & $\begin{array}{l}\text { Dietrich } \\
\text { Döring }\end{array}$ & $\begin{array}{l}\text { Ratsherr } \\
\text { (Sülfmeister, } \\
\text { Barmeister) }\end{array}$ & $\mathrm{X}$ & \\
\hline 1483 Mai 28 & $\begin{array}{l}\text { Nickel } \\
\text { Wulfferam }\end{array}$ & Bürger & & $\mathrm{X}$ \\
\hline 1483 Juni 10 & $\begin{array}{l}\text { Heinrich } \\
\text { Meding }\end{array}$ & Bürger & & \\
\hline 1483 Juli 12 & $\begin{array}{l}\text { Ymmeke } \\
\text { Spranse }\end{array}$ & Witwe & & $\mathrm{X}$ \\
\hline 1483 Aug. 27 & Titke Prilep & & & \\
\hline 1484 Jan. 9 & $\begin{array}{l}\text { Hartwig } \\
\text { Hannover }\end{array}$ & $\begin{array}{l}\text { Priester in St. } \\
\text { Michaelis, } \\
\text { Benediktiner }\end{array}$ & $\mathrm{X}$ & $\mathrm{X}$ \\
\hline 1485 Jan. 31 & $\begin{array}{l}\text { Geseke } \\
\text { Leyferd }\end{array}$ & Witwe & $\mathrm{X}$ & $\mathrm{X}$ \\
\hline 1486 Mai 1 & $\begin{array}{l}\text { Gevehard } \\
\text { Grone - } \\
\text { hagen }\end{array}$ & Priester & $\mathrm{X}$ & $\mathrm{X}$ \\
\hline 1487 Dez. 6 & $\begin{array}{l}\text { Geseke } \\
\text { Wangelow }\end{array}$ & Witwe (Ratsherr) & & $\mathrm{X}$ \\
\hline 1489 April 1 & $\begin{array}{l}\text { Christofel } \\
\text { Rekel }\end{array}$ & Bürger & & $\mathrm{X}$ \\
\hline 1489 Dez. 12 & $\begin{array}{l}\text { Hans } \\
\text { Reimstorp }\end{array}$ & Bürger & & $\mathrm{X}$ \\
\hline 1490 Jan. 15 & $\begin{array}{l}\text { Heinrich } \\
\text { Elver }\end{array}$ & Bürger & & $\mathrm{X}$ \\
\hline 1490 Mai 11 & $\begin{array}{l}\text { Heinrich } \\
\text { Winthe }\end{array}$ & Bürger & $\mathrm{X}$ & $\mathrm{X}$ \\
\hline 1491 Feb. 8 & $\begin{array}{l}\text { Heinrich } \\
\text { Töbing der } \\
\text { Ältere }\end{array}$ & Bürger & & $\mathrm{X}$ \\
\hline 1491 Juni 25 & $\begin{array}{l}\text { Matheus } \\
\text { Tetendorp }\end{array}$ & Bürger & & $X$ \\
\hline
\end{tabular}




\begin{tabular}{|c|c|c|c|c|}
\hline Jahr & Name & Stellung/Beruf & $\begin{array}{l}\text { Sachgüter in } \\
\text { Legaten ad } \\
\text { pias causas }\end{array}$ & $\begin{array}{l}\text { Sachgüter in } \\
\text { Verfüg. für } \\
\text { Verwandte/ } \\
\text { Bekannte }\end{array}$ \\
\hline 1491 Aug. 13 & Gerd Lowe & $\begin{array}{l}\text { Bürger } \\
\text { (Goldschmied ?) }\end{array}$ & & $\mathrm{X}$ \\
\hline 1492 Feb. 20 & $\begin{array}{l}\text { Hans } \\
\text { Meyger }\end{array}$ & Bürger & & $\mathrm{X}$ \\
\hline 1493 Juli 8 & $\begin{array}{l}\text { Dietmar } \\
\text { Daldorp }\end{array}$ & Bürger & & $\mathrm{X}$ \\
\hline 1493 Okt. 26 & $\begin{array}{l}\text { Hans } \\
\text { Tetendorp }\end{array}$ & Bürger & & $\mathrm{X}$ \\
\hline 1494 Sept. 10 & $\begin{array}{l}\text { Gesche } \\
\text { Henning }\end{array}$ & Witwe & & $\mathrm{X}$ \\
\hline 1494 Sept. 18 & Hans Duvel & $\begin{array}{l}\text { Laie des Stifts } \\
\text { Verden }\end{array}$ & $\mathrm{X}$ & \\
\hline 1494 & $\begin{array}{l}\text { Lorenz } \\
\text { König }\end{array}$ & Bürger & & $\mathrm{X}$ \\
\hline 1495 März 12 & $\begin{array}{l}\text { Ludolf } \\
\text { Broder - } \\
\text { mann }\end{array}$ & & & $X$ \\
\hline 1495 Sept. 24 & $\begin{array}{l}\text { Hans } \\
\text { Duderstadt }\end{array}$ & Bürger & & $\mathrm{X}$ \\
\hline 1497 Juli 21 & $\begin{array}{l}\text { Hans } \\
\text { Rodenborg }\end{array}$ & Bürger & & $\mathrm{X}$ \\
\hline 1497 Dez. 28 & $\begin{array}{l}\text { Dietrich } \\
\text { Vloetwedel }\end{array}$ & Bürger & & $\mathrm{X}$ \\
\hline 1498 April 5 & $\begin{array}{l}\text { Tibbeke } \\
\text { Harendorp }\end{array}$ & Witwe & $\mathrm{X}$ & \\
\hline 1499 März 28 & $\begin{array}{l}\text { Meinecke } \\
\text { Schnever - } \\
\text { ding }\end{array}$ & & & \\
\hline 1499 Aug. 28 & $\begin{array}{l}\text { Hilleke } \\
\text { Blickers - } \\
\text { husen }\end{array}$ & Witwe & $\mathrm{X}$ & $\mathrm{X}$ \\
\hline 1500 Feb. 1 & $\begin{array}{l}\text { Hans } \\
\text { Holstenland }\end{array}$ & Bürger & & $\mathrm{X}$ \\
\hline
\end{tabular}




\section{Die Testamente}

In der folgenden, regestenartig angelegten Sammlung Lüneburger Testamente sind - einem in der Form einheitlichen Schema folgend - relevante Informationen aufgelistet.

Die Kopfzeile besteht aus der Datumsangabe sowie dem Namen der Testators oder der Testatorin. Unter dem Namen ist in Klammern die Schriftsprache des Testaments angegeben, die entweder lateinisch (im folgenden „lat.“) oder mittelniederdeutsch (im folgenden „mnd.") war. Es folgt die Angabe der nicht in allen, aber doch den meisten Fällen vom Testator angegebenen Testamentsvollstreckern (im folgenden „TV“). Unter dem Punkt „Angaben zu Person und Familie“ wird zusammengefaßt, was über die Person des Testators bekannt ist. Es folgt die Zusammenstellung der Verfügungen über Sachgüter. Vermerkt sind, soweit überliefert, die Namen der Siegler und sonstige auf dem Formular verzeichnete Bemerkungen. Zum Schluß erfolgt der Verweis auf den Fundort des Testaments in der Edition der Lüneburger Testamente oder im Manuskript zur Edition. Kursiv gedruckte Wörter sind Zitate.

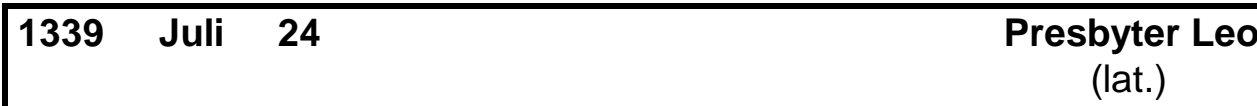

TV: Johannes von Rempstede, Kleriker; Nikolaus von Toppenstede, Bürger in Lüneburg ANGABEN ZU PERSON UND FAMILIE:

Der Testator war Presbyter und Scholasticus in Lüneburg. In Testament erwähnt ist die Schwester des Testators, Hilleke, und ihre Tochter.

VERFÜGUNGEN ÜBER SACHGÜTER:

Borstelde erhält das Bildnis der Jungfrau und einen Halbliterbecher und drei Wollkissen. Aus den übrigen zwei Bechern und zwei Gürteln soll ein Kelch angefertigt werden, der dorthin gegeben werden soll, wo er passend erscheint. Seiner Schwester Hilleke vermacht der Testator fünf Mark für Kleiderkauf. Meyne soll ein Brevier und einen Chorrock bekommen. Den kleineren Psalter erhalten die Tochter seiner Schwester und Herr Wedekin in Ebstorf, der größere Psalter ist für die Armen im Kloster gedacht.

Siegler: Presbyter Leo, Johannes von Rempstede, Nikolaus von Toppenstede Rückvermerk: Testamentum Leonis presbyteris scholastici Luneborgensis.

Reinhardt, Testamente, S.3, Nr.4 
TV: -

ANGABEN ZU PERSON UND FAMILIE:

Der Testator war der Sohn des verstorbenen Kersten von Putensen.

VERFÜGUNGEN ÜBER SACHGÜTER:

Er gibt Hardeke und dessen Ehefrau Aleke, seiner Tante, die gesamte Fahrhabe.

oberer Teil eines Chirographs mit Zickzackschnitt, ohne Beschriftung der Schnittlinie

Erste niederdeutsche Urkunde aus der städtischen Kanzlei

Reinhardt, Testamente, S.4, Nr. 5

um 1340

Thideke Buhof

(lat.)

TV: Mathias Nagel, Browinus, Ratsherren zu Stockholm; Bertold Bordemowe, Steynekinus, der Wirt des Testators

ANGABEN ZU PERSON UND FAMILIE: -

VERFÜGUNGEN ÜBER SACHGÜTER:

Der Testator gibt Katerina sein Bettzeug mit einer Mark Denare.

Siegler identisch mit den Testamentsvollstreckern.

Datum konnte nur anhand der Schrift bestimmt werden.

Reinhardt, Testamente, S.4f, Nr.6

1347 Jan. 21

Elisabeth Hornemann

(lat.)

TV: -

ANGABEN ZU PERSON UND FAMILIE:

Die Testatorin, Mutter von vier Kindern, war zum Zeitpunkt der Testamentserrichtung verwitwet. Der in ihrem Testament genannte Sohn Marquard war möglicherweise jener Marquard Hornemann, der auch Mako up der Kulen genannt wurde, Sülfmeister war und 1349 starb $^{1}$. Seine Frau Gertrud Semmelbecker, auch uppe der Kulen genannt, testierte $1370^{2}$.

VERFÜGUNGEN ÜBER SACHGÜTER:

Ihr Sohn Hermann, der Kleriker, erhält die Hälfte eines Hauses am Sande mit allem Zubehör, davon soll er seiner Schwester Beke Doreles, Nonne in Medingen, in jedem Lebensjahr eine Mark geben.

\footnotetext{
${ }^{1}$ H.-J. v. Witzendorff, Stammtafeln, S.115.

${ }^{2}$ Gese uppe der Kulen, 1370 Sept.8; U. REINHARDT, Testamente, S.58ff.
} 
Ihrem Sohn Johannes schenkt sie alle Mobilien und das Bargeld. Ihrem Sohn Marquard schenkt sie ihr Haus, Hof und Wurt mit allen Zugehörigkeiten; davon soll er der Nonne Beke in jedem Lebensjahr eine Mark Bargeld geben. Die nach ihrem Tod übrigbleibenden Gebrauchsgegenstände sollen sich ihre Kinder zu gleichen Teilen teilen.

Siegel: Rat und Bürgerschaft der Stadt Lüneburg

Reinhardt, Testamente, S.7f, Nr.9

um $1348^{3}$

Nikolaus Alardi

(lat.)

TV: Antonius, Priester in St. Johannis; Nikolaus Dedensen; Albert von der Mölen, Bürgermeister; Johannes von Moyden

ANGABEN ZU PERSON UND FAMILIE:

Nikolaus Alardi war der Sohn des Alard von Estorff, dessen Geschlecht eine Seitenlinie derer von Estorff ist, die sich auch Gruntling nannten. Alard von Estorff war seit 1301 Bürger von Lüneburg. Nikolaus Alardi war möglicherweise der Vater des Lüder Brömse, der 1372 testierte $^{4}$.

VERFÜGUNGEN ÜBER SACHGÜTER:

Die übrige mobile und immobile Habe vertraut der Testator den Testamentsvollstreckern an.

Unvollendetes, nicht vollzogenes Konzept

Reinhardt, Testamente, S.14 ff, Nr.11

1352 März 27

Segeband von Wittorf

(lat.)

TV: Anton von Thune, Pfarrer der Johanniskirche; Werner vom Berge, Ritter; Gerard Garlop, Bürger

ANGABEN ZU PERSON UND FAMILIE:

Das Geschlecht derer von Wittorf gehörte zur Gruppe der Lüneburger Ritterfamilien, die als Gefolgsleute des Herzogs am Fuße des Kalkberges, auf dem die herzögliche Burg bis zu ihrer Zerstörung 1372 stand, in der Altstadt Lüneburgs lebten ${ }^{5}$.

VERFÜGUNGEN ÜBER SACHGÜTER:

Dem einstigen Gehilfen Pepeke acht Ellen grauen Stoffs. Fünf weiße Kleider, in die die Armen am nächsten St. Michaelsfest gekleidet werden. Zur selben Zeit fünf Mark für Schuhwerk für die Armen. Und ebensoviel Mark wiederum für Schuhwerk der Armen im darauffolgenden Jahr.

\footnotetext{
${ }^{3}$ Datierung beruht auf Schriftbestimmung.

${ }^{4}$ H.-J. v. WITZENDORFF, Stammtafeln, S.18.

5 ,curiam habitationis mee sitam in antiqua civitate Luneborch ..“U. REINHARDT, Testamente, S.27.
} 
Siegler: Segeband von Wittorf

Von diesem Testament gibt es 5 Ausfertigungen, die im wesentlichen übereinstimmen. Das Testament von 1352 März 21 ist als Transsumpt in einem Notariatsinstrument von 1382 Juli 9 erhalten. Aus dem Jahr 1352 liegt noch ein weiteres Testament vom 8. Juli vor; beide Testamente werden in einem Notariatsinstrument von 1353 April 12 wiederholt.

Dem Abdruck liegt die Ausfertigung I zugrunde.

Reinhardt, Testamente, S.10ff, Nr. 12, 13 (=1352 Juli 8)

\section{$1353^{6}$}

\section{Degenard Bernardi}

(lat.)

TV: -

ANGABEN ZU PERSON UND FAMILIE:

Der Testator war möglicherweise der Vater des Priesters Bernhard Degenardi, dessen Testament aus dem Jahr 1361 überliefert ist. Für diese Vermutung spricht die Namensgleichheit einiger, in den Testamenten erwähnter Familienmitglieder: Die Ehefrau des Degenard Bernardi heißt Mechtild - gleichen Namens ist die Mutter des Bernard Degenardi; die Tochter bzw. die Schwester heißt Alheyd und ist Nonne in Ebstorf. Ferner erwähnt Degenard Bernardi die Namen seiner Söhne im Testament: Degenard und Bernard; Bernard Degenardi nennt seinerseits die Namen seines Vaters und seines Bruders: beide heißen Degenard.

VERFÜGUNGEN ÜBER SACHGÜTER:

Der Testator gibt seinem Sohn Bernard die Güter, die zurückgekauft werden können, und alle mobilen Güter mit Ausnahme der häuslichen Gebrauchsgegenständen, die nach seinem Tod seine Frau Mechtild nutzen soll; diese dürfen nicht veräußert werden. Von dem Bargeld und den Mobilien gibt er einer Tochter seines Sohnes Degenard 100 Mark, die in irgendein Kloster eintreten wird und eingekleidet werden wird.

Reinhardt, Testamente, S.16, Nr.15

1354 Dez. 19

Heinrich und Lucie Schermbeke

(mnd.)

TV: Gerd Moltmester, Siverd Oelen, Meister Dietrich von Dahlenburg

ANGABEN ZU PERSON UND FAMILIE: -

VERFÜGUNGEN ÜBER SACHGÜTER:

Des Testators Frau Lucie soll Zeit ihres Leben des Nutzungsrecht an dem Haus haben, in dem sie beide wohnen, sowie an den sich im Haus befindenden Gegenständen. Stirbt die Ehefrau vor dem Testator, so fällt das Nutzungsrecht an inn.

\footnotetext{
${ }^{6}$ Datierung ergibt sich aus der Chronologie des Amtsbuches.
} 
TV: -

ANGABEN ZU PERSON UND FAMILIE:

Bernhard Nyebur war Lüneburger Bürger.

VERFÜGUNGEN ÜBER SACHGÜTER:

Die Testatoren erteilen sich gegenseitig die volle Verfügungsfreiheit über ihr Erbe, da es sich hierbei um durch gemeinsamen Fleiß erworbene Güter handelt.

Reinhardt, Testamente, S. 26, Nr. 21

1361 April $20 \quad$ Bernhard Degenardi

(lat.)

TV: Hermann und Bartold, Vikare in St. Johannis; Nikolaus Weddessen, Priester; Dietrich Lembeke, Priester; Conrad, Sohn des Conrad Pergamentor; Johannes Goldsmet; Jakob von der Brücke

ANGABEN ZU PERSON UND FAMILIE:

Der Testator, presbyter der Diözese Verden, war möglicherweise ein Sohn des Degenard Bernardi, der 1353 testierte.

VERFÜGUNGEN ÜBER SACHGÜTER:

Zehn Mark aus den Einkünften eines Chores sind für den Kauf von Schuhwerk und Kleidung aus weißem oder grauen Tuch zu verwenden; Kleidung und Schuhwerk sind zu Michaelis an die Armen zu verteilen.

Notariatsinstrument. Die Urkunde ist auch als Vidimus in UA a 1385 März 9 überliefert.

Reinhardt, Testamente, S. 26ff, Nr. 22

\begin{tabular}{|ccc}
\hline 1366 & April 2 & $\begin{array}{c}\text { Heinrich Miles } \\
\text { (mnd.) }\end{array}$
\end{tabular}

TV: Johann Beve, Jakob Hode, Dietmar von der Mölen

ANGABEN ZU PERSON UND FAMILIE:

Der Vater des Testators, Johannes Miles, war Bürger in Hamburg. Heinrich Miles war seit 1330 Bürger in Lüneburg ${ }^{7}$, bereits zwei Jahre später war er Ratsherr. Dieses Amt übernahm

\footnotetext{
${ }^{7}$ H.-J. v. WITZENDORFF, Stammtafeln, S.77.
} 
er kontinuierlich bis 1365 in Zweijahresabständen mit Ausnahme der Jahre 1338 - 41 und 1363 - 65, in denen er durchgängig im Amt blieb ${ }^{8}$. Neben der Ratstätigkeit war er Provisor der Cyriacus- und Johanniskirche. Die Ehefrau des Testators war Beke von der Mölen, die inn - Miles starb im Jahr der Testamentserrichtung - um zwölf Jahre überlebte ${ }^{9}$. Aus der Ehe gingen acht Kinder hervor; die beiden Söhne gingen nach Hamburg, wo der ältere Domherr, der jüngere Bürgermeister wurde. Drei der sechs Töchter waren verheiratet, zwei von innen in Lüneburg, die dritte in Braunschweig; die anderen Töchter waren Nonnen, zwei lebten in Medingen, eine in Lüne ${ }^{10}$.

VERFÜGUNGEN ÜBER SACHGÜTER:

Der Testator bestimmt Kleider, Schmuck und Kleinode im Wert von zwölf Mark, die aus der Mühle in Hamburg stammen, für seine Tochter, die Frau Wasmods von Medingen. Für die in St. Johannis zu errichtende Vikarie stiftet der Testator seinen großen Schrank, in dem Meßgewänder verwahrt werden sollen, sowie einen silbernen Gürtel, der zu einem Kelch umgearbeitet werden soll. Die Kosten für diese Arbeit wird die Ehefrau des Testators tragen.

Siegler: Heinrich Miles, Klaus Garlop, Dietrich Springintgut

Reinhardt, Testamente, S. 30ff, Nr. 24

\section{6}

\section{Jutta Seidenweber}

(lat.)

TV: -

ANGABEN ZU PERSON UND FAMILIE: -

VERFÜGUNGEN ÜBER SACHGÜTER::

Alle Güter der Testatorin sollen an ihre Schwester Ghertrud fallen, die Ehefrau Nicolaus Meeldorps, sowie an deren Sohn.

Die Datierung ergibt sich aus der Stellung des Testaments in der Chronologie des Amtsbuchs.

Reinhardt, Testamente, S. 32, Nr. 25

\begin{tabular}{|lc|}
\hline $1367 \quad$ Mai 15 & $\begin{array}{c}\text { Johann Beve } \\
\text { (mnd.) }\end{array}$ \\
TV: Klaus Floreke; Albert Hoyke, Sodmeister & \\
& \\
ANGABEN ZU PERSON UND FAMILIE: & \\
Der Testator entstammte einer der führenden Ratsherrenfamilien Lüneburgs; sowohl der \\
Vater Eylemann als auch der Großvater Johann waren lange Zeit Ratsherren ${ }^{11}$. Der
\end{tabular}

\footnotetext{
${ }^{8}$ I. STAHL, Ratslinie, S.156, Nr.89.

${ }^{9}$ H.-J. v. WITZENDORFF,Stammtafeln, S. 77.

${ }^{10}$ W. REINECKE, Geschichte der Stadt Lüneburg I, S.117.

${ }^{11}$ I. STAHL, Ratslinie, S.150, Nr.28; S.154, Nr.75.
} 
Testator war von 1344 - 49 in Zweijahresabständen regierender Ratsherr, von 1350 bis 1366 bekleidete er zehn Mal das Amt eines regierenden Bürgermeisters ${ }^{12}$. Johann Beve war mit Margarete von der Mölen verheiratet. Aus dieser Ehe stammten vier Söhne, von denen zwei, Eylemann und Hartwig, dem Vorbild des Vaters folgten und Ratsherren wurden; der dritte Sohn wurde Priester, der vierte verschrieb sich als Magister der Wissenschaft ${ }^{13}$. Alheyd, eine Schwester des Testators, war seit 1353 mit dem Sodmeister Albrecht Hoyke d.J. verheiratet.

VERFÜGUNGEN ÜBER SACHGÜTER:

Des Testators Sohn Hartwig soll die silberne Schale haben, die zuvor Heinrich Miles gehört hatte, eine der kleineren Schalen Herrn Dietrich Schiltstens und fünf silberne Löffel, die zusammengebunden sind. Hartwig soll eins der großen Betten haben, ein großes Kopfkissen und die seidene Bettdecke, sechs Polster (-kissen) und zwei kleine Betten. Damit soll er von seinen Brüdern abgeteilt sein; das andere, hiernach beschriebene Gut Herrn Johann Beves sollen gemeinsam Eylemann und sein Sohn Henneke besitzen.

Von dem Schmuck, der der Ehefrau Grete gehört hatte, und von des Testators silbernem Gürtel soll man drei Kelche anfertigen lassen; die Kosten sollen aus dem Gut des Testators finanziert werden. Einen der Kelche soll sein Sohn Hartwig bekommen, den anderen die von Elisabeth Meweke errichtete Vikarie, und den dritten soll Herr Ludolf Floreke haben. Zwei silberne Schalen hat Herr Klaus Floreke, die gibt inm Herr Johann Beve, damit er sie haben und behalten soll. Werden die Pfande Herrn Dietrich Schiltstens eingelöst, so gehören die zwei silbernen Schalen dazu und die Pfennige, die die zwei Schalen einbringen, soll Klaus Floreke einnehmen und haben. Johann Beve hat Ludolf, seinem Knecht, den mit Mütze versehenen scharlachenen Rock gegeben und eine Kapuze sowie den eingefalteten weißen Rock. Vicke, seinem Knecht, hat er den gestreiften scharlachenen Rock, eine Kapuze und den zweigefalteten weißen Rock geschenkt. Everd, seinem Jungen, gibt er den blauen gemischten Rock und die Kapuze. Der Schnakenbekeschen hinterläßt er seinen großen Pelz.

gleichzeitige Abschrift

Reinhardt, Testamente, S. 32ff, Nr. 26

\begin{tabular}{|lll}
\hline 1367 & Juni 7 & Heinrich Wangelo
\end{tabular}

(lat.)

TV: Propst Johannes in Heiligenthal; Borchard, Pfarrer in Neuengamme; Hermann Dusecop, ständiger Vikar der Heilig-Kreuz-Kapelle in Bergedorf

ANGABEN ZU PERSON UND FAMILIE:

Wangelo war Pfarrer in Bergedorf, Diözese Ratzeburg.

VERFÜGUNGEN ÜBER SACHGÜTER:

Von seinen Büchern schenkt der Testator dem Propst und dem Konvent in Heilgenthal die Historia Scholastica, das Passional sowie die neuen Predigten dem Ludolf Hufnagel, seinem Onkel Hermann Dusecop ein Theologiekompendium. Alle anderen Bücher hinterläßt er seinem Neffen Heinrich. Der Propst und der Konvent in Heiligenthal mögen diese Bücher mit treuer Hand bewachen, bis sein Neffe ordiniert wird. Heinrich vererbt er ein größeres und ein kleineres Bett, vier Paar Laken und zwei Bettdecken. Hermann Dusecop soll dasselbe erhalten. Seinem Nachfolger hinterläßt der Testator zwei Betten

\footnotetext{
${ }^{12}$ I. STAHL, Ratslinie, S.157, Nr.97.

${ }^{13}$ H.-J. v. WITZENDORFF, Stammtafeln, S.11.
} 
und zwei Paar Laken. Die Predigten über die Heiligen im roten Einband erhält Johannis Dobergus sowie die Predigten des Peregrinus; diese Bücher darf sein Nachfolger weder verkaufen noch von seiner Kirche entfremden, sondern die genannten Predigten müssen bei allen Nachfolgern bleiben. Der Kochkessel soll für Heine Buke wiederhergestellt werden.

Die restlichen, unvergabten mobilen und immobilen Güter sollen die Testamentsvollstrecker nach eigenem Gutdünken für des Testators Seelenheil anlegen.

Siegler: Heinrich Wangelo; Johann von Brema, Propst zu Reinbek; Albert, Pfarrer in Curslack

Notariatsinstrument

Reinhardt, Testamente, S. $35 \mathrm{ff}, \mathrm{Nr} .27$

\section{April $8 \quad$ Johann Kröger \\ (mnd.)}

TV: Klaus Garlop; Hartwig Abbenburg; Johann Kröger, Sohn des Testators; Klaus von der Mölen und Heinrich von der Mölen, Ratsherren zu Lüneburg

ANGABEN ZU PERSON UND FAMILIE:

Mit seiner Ehefrau llsebe hatte Kröger den Sohn Johannes.

VERFÜGUNGEN ÜBER SACHGÜTER:

Der Testator hinterläßt seiner Frau Ilsebe das lebenslängliche Nutzungsrecht an seinem Haus- oder Ackergerät, seinem Hausrat und der Fahrhabe.

Siegler: Johann Viskule

Einschnitt in der Plica für eine zweite Pressel vorhanden, Kerbschnitt am oberen Rand

Reinhardt, Testamente, S. 37ff, Nr. 29

\section{September $8 \quad$ Gese uppe der Kulen \\ (mnd.)}

TV: Herr Ludolf, Domkantor in Hamburg; Klaus Brömse, Albert von Wittingen, Priester; Nikolaus Garlop, Heine Sotmester und Albert Hoyke, Ratsherren

ANGABEN ZU PERSON UND FAMILIE:

Gese uppe der Kulen war die verwitwete Frau Marquards uppe der Kulen. Bekannt ist unter diesem Namen der Sülfmeister Marquard Hornemann, der 1349 verstarb ${ }^{14}$. Als Schwester nennt die Testatorin Beke Capellen.

VERFÜGUNGEN ÜBER SACHGÜTER:

Die Testatorin gibt den Verkauf ihres Haus und Hofes mit allem Hausrat, Betten, Grapen, Kesseln und Truhen an Hans Nybur bekannt. Ruscher soll seinen Hausrat gänzlich erhalten. Ihre immobilen und mobilen Güter übergibt die Testatorin ihren

Testamentsvollstreckern.

\footnotetext{
${ }^{14}$ H.-J. v. WITZENDORFF, Stammtafeln, S.115.
} 
Reinhardt, Testamente, S. 39f, Nr. 30

$\begin{array}{rrrr}1372 \text { Mai } 1 & \text { Hartwig Holste } \\ & & \text { (mnd.) }\end{array}$

TV: Johann Fischkule; Hartwig Abbenburg, Ratsherr; Dietmar Tolner; Klaus Grawrock; Grete, Ehefrau des Testators; Benneke, Knecht

ANGABEN ZU PERSON UND FAMILIE:

Hartwig Holste war in erster Ehe verheiratet mit Adelheid Huth, in zweiter Ehe mit Grete, die 1390 testierte $^{15}$. Er war 1356, 1358, 1360, 1361, 1363 - 1366, und 1368 Ratsherr, sein Todesjahr wird mit 1368 oder 1383 angegeben ${ }^{16}$.

VERFÜGUNGEN ÜBER SACHGÜTER:

Ein Chor Salz, dessen Verwaltung der Ehefrau Grete übertragen wird, soll für die Kleidung Armer verwendet werden.

Reinhardt, Testamente/Manuskript, S. $62 f$

\section{August $4 \quad$ Johann von Bücken \\ (lat.)}

TV: Antonius, Pfarrer der Johanniskirche; Bernhard von Stedebergen, Domherr an St. Andreas zu Verden; Bernhard Scriptor, ständiger Vikar der Bremer Kirche; Dietrich Springintgut, Bürgermeister in Lüneburg; Heinrich Bruno, Kleriker Verdens und der Bremer Diözese

ANGABEN ZU PERSON UND FAMILIE:

Der Testator war Archidiakon von Modestorpe.

VERFÜGUNGEN ÜBER SACHGÜTER:

Für die Ausstattung zweier am Marienaltar in der Johanniskirche gegründeter Vikarien setzt von Bücken einen Geldbetrag von 100 Lüneburger Mark aus. Mit diesem Geld sollen Abendmahlskelche, Bücher, Kleidungsstücke, Sacerdotalia und die übrigen Notwendigkeiten für den Priesterdienst erworben werden.

Siegler: Johann von Bücken, Ludolf von Wedessen, Johann Bodem, Albert Witting, Hartwig Capelle, Johann von Winsen, Hermann Remstede, Volkmar von Braunschweig, Dietrich von Harsefeld, Diertrich Lembeke, Magister Johannes Herwici, Priester, Johann von der Brücken, Dietrich Brömse, Johann von der Mölen, Konrad von Bodenteich

Reinhardt, Testamente, S. 42ff, Nr. 33

\footnotetext{
${ }^{15}$ WITZENDORFF gibt nur die Ehe mit Adelheid Huth an. H.-J. v. WITZENDORFF, Stammtafeln , S.36.

${ }^{16}$ I. STAHL, Ratslinie, S.159, Nr.115; H.-J. v. WITZENDORFF, Stammtafeln, S.36.
} 
TV: Brand von Tzerstede, Ratsherr; Ludolf von Bergen

ANGABEN ZU PERSON UND FAMILIE:

Der Testator war Bürger der Stadt Lüneburg.

VERFÜGUNGEN ÜBER SACHGÜTER:

Elisabeth, die Nichte des Testators, erhält sein Haus mit allen zugehörigen Gebäuden. Ferner vererbt Heide ihr sein gesamtes nachgelassenes Gut, sei es mobil oder immobil, egal, wo es ist und mit wem er es besitzt.

Siegler: Anthon von Thune, Kirchherr zu St. Johannis; Hartwig von Abbenburg, Johann von der Brücken, Ratsherren zu Lüneburg

Reinhardt, Testamente, S. 45f, Nr. 35

\section{September 11 Jürgen Kramer \\ (mnd.)}

TV: Johann Westfal, Johann Gordelslegher, Heine Peine, Wulveke Vorstede, Dietrich

ANGABEN ZU PERSON UND FAMILIE:

Jürgen Kramer war Bürger der Stadt Lüneburg. Aus seiner Ehe mit Ghese entsprangen Kinder.

VERFÜGUNGEN ÜBER SACHGÜTER:

Der Testator vererbt pauschal sein gesamtes Gut seiner Ehefrau, die es für sich und ihre Kinder verwenden soll. Drei Mark sind für den Bau von St. Michaelis und drei Mark für die Glasfenster einer neuen Kapelle von St. Johannis bestimmt.

Siegler: Heine Munter, Sander Schellepeper, Jürgen Kramer

Chirograph mit beiden - besiegelten - Teilen. Rückvermerk: Dit testament is ghedodet unde heft hirvor ene kopie bi dem rade.

Reinhardt, Testamente, S. 48f, Nr. 37

\begin{tabular}{|lcc}
\hline 376 & Februar 2 & $\begin{array}{c}\text { Vicke Kramer } \\
\text { (mnd.) }\end{array}$
\end{tabular}

TV: Hartwig Capellen, Heine Peine, Johann von der Heide

ANGABEN ZU PERSON UND FAMILIE:

Der Testator wird als Bürger in Lüneburg bezeichnet. Im Testament ist seine Ehefrau genannt.

VERFÜGUNGEN ÜBER SACHGÜTER:

Die TV sollen eine Rente von vier Mark mit Zinstermin zu St. Michaelis anlegen, damit sie so viel Schuhe und Tuch kaufen können, wie man zu der Zeit dafür bekommt. Schuhe und 
Tuch sollen für des Testators Seelenheil an Bedürftige verteilt werden.

Siegler: Sander Schellepeper, Johann Rocswale

Reinhardt, Testamente, S. 49f, Nr. 38

\begin{tabular}{|llc}
\hline 378 & September 7 & $\begin{array}{c}\text { Ludolf Stöterogge } \\
\text { (mnd.) }\end{array}$
\end{tabular}

TV: Geverd Stöterogge, Bruder des Testators; die Brüder Ludolf, Klaus und Geverd Grönhagen; Bernt Stöterogge und Albert Steyn, Schwäger des Testators

ANGABEN ZU PERSON UND FAMILIE:

Ludolf Stöterogge war Bürger von Lüneburg. Ein Vorfahre des Testators ist als herzoglicher Vogt in Uelzen belegt, dessen zwei Söhne in der ersten Hälfte des 14. Jahrhunderts in Lüneburg das Bürgerrecht erwarben. 1350 ist Stöterogge urkundlich als Sülfmeister belegt. Er war zweimal verheiratet; in erster Ehe mit Alheid, deren Familienname unbekannt ist, und in zweiter Ehe mit Elisabeth von Dambeck (siehe Testament von 1385). Stöterogge starb im Jahr der Testamentserrichtung $1378^{17}$.

VERFÜGUNGEN ÜBER SACHGÜTER:

Seiner Frau Ilsebe überläßt der Testator sein Wohnhaus mit allem Zubehör mit lebenslangem Nutzrecht, egal, ob sie sich wiederverheiratet oder nicht. Nach ihrem Tod soll das Haus an den Bruder des Testators, Gheverd, und seine Kinder sowie an Grönhagen und seine Erben fallen.

Ilsebe bekommt den sich in dem Haus befindenden Hausrat. Die Hälfte von dem silbernen smyde soll sie behalten; diese Hälfte soll nach ihrem Tod bei den Hausbesitzern bleiben. Die andere Hälfte des smydes sollen die Testamentsvollstrecker an sich nehmen und sie für seine Tochter bis zu deren Volljährigkeit verwahren.

Siegler: Johann Lange, Johann von der Brücken

Reinhardt, Testamente, S. $51 \mathrm{ff}, \mathrm{Nr} .40$

\section{Januar $2 \quad$ Marquard von Dannenberg \\ (lat.)}

TV: Johannes Bodem, Johann Westfal, Priester

ANGABEN ZU PERSON UND FAMILIE:

Marquard von Dannenberg war Vikar in St. Cyriacus.

VERFÜGUNGEN ÜBER SACHGÜTER:

Dannenberg gibt Eyleke, seiner Magd, seine Herberge mit allem Zubehör und Einkünften und allen Gebrauchsgegenständen, die zu demselben Hospiz gehören. Nach dem Tod von Eyleke und des ebenfalls bedachten Johannes sollen die genannten Güter, nämlich der

\footnotetext{
${ }^{17}$ U. REINHARDT, Stiftersorgen - Das Testament des Elisabeth Stöterogge, S.380f; H.-J. WITZENDORFF; Stammtafeln, S.121.
} 
vierte Teil des Ackerzehnten, die Herberge, die Wohnung, 1/2 Plaustrum Salz zusammen mit all seinen kanonischen Stundenbüchern, mit den Märtyrergeschichten und Heiligenlegenden sowie dem Abendmahlskelch und priesterlichen Geräten ungeteilt für ewige Meßfeiern verwendet werden, und die jeweiligen Testamentsvollstrecker sollen die genannten Güter einer Vikarie am Altar der Jungfrau Maria in der Lambertikapelle zukommen lassen.

Notariatsinstrument. Signet und Unterschrift des Notars Marquard von Plön.

Reinhardt, Testamente, S. 54ff, Nr. 41

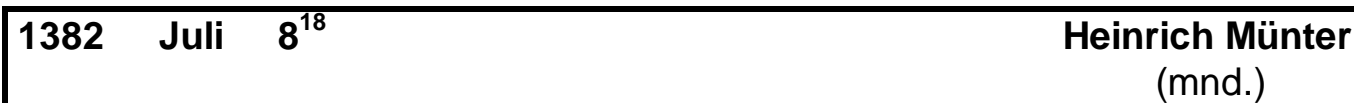

TV: Johannes Lange, Bürgermeister; Sander Schellepeper, Ratsherr; Cord van Boltzen und Johannes Elver, Bürger

ANGABEN ZU PERSON UND FAMILIE:

Münter war in der Zeit von 1371-1381 siebenmal regierender Ratsherr; er starb im Jahr der Testamentsausfertigung. Zweimal war er verheiratet; der ersten Ehe entstammen zwei Söhne, der zweiten Ehe mit Mechtild Hoyemann zwei Söhne und drei Töchter. Zwei Töchter wurden Nonnen in Lüne ${ }^{19}$.

VERFÜGUNGEN ÜBER SACHGÜTER:

Das restliche, im Testament nicht weiter spezifizierte Gut wird pauschal an Frau und Kinder vererbt.

gleichzeitige Abschrift. Datum ergänzt aus einer Abschrift des 19. Jahrhunderts

Reinhardt, Testamente, S. $57 \mathrm{ff}, \mathrm{Nr} .43$

1382 Sept. 17

Johann von der Heide

(mnd.)

TV: Gese, Frau des Testators; Johannes Bodem, Johann Westfal aus Osnabrück, Priester; Cord Wittemeyer, Heine Wezelon, Albert Wandsnider, Karsten Drespe, Bürger

ANGABEN ZU PERSON UND FAMILIE:

Der Testator war Bürger von Lüneburg.

VERFÜGUNGEN ÜBER SACHGÜTER:

\footnotetext{
${ }^{18}$ Datum aus einer Abschrift des 19. Jahrhunderts: Datum anno domini 1382 ipso die Kyliany

${ }^{19}$ I. STAHL, Ratslinie, S.160, Nr.129; H.-J. v. WITZENDORFF, Stammtafeln, S.84.
} 
Die Ehefrau des Testators Gese soll die Verfügungsgewalt über das unvergabte Gut des Testators haben bis zum Zeitpunkt einer erneuten Heirat.

Die Siegel fehlen; offensichtlich sind sie nie angebracht worden.

Reinhardt, Testamente, S. 59f, Nr. 44

\begin{tabular}{|ccc|c}
1385 & Mai & 18 & $\begin{array}{c}\text { Segeband von Thune } \\
\text { (lat.) }\end{array}$
\end{tabular}

TV: Abt Otto von Heiligenthal; Abt Johannes aus Lüne; Heinrich von Leze, Archidiakon in Salzhausen; Magister Willer, Pfarrer der Kapelle St. Spiritus; Johannes Lange und Eylemann Beve, Bürgermeister; Hermann von Brake, Johannes von Muden, Ludolf Gherseke, Priester

ANGABEN ZU PERSON UND FAMILIE:

Der Testator ist Archidiakon in Bevensen (Diözese Verden).

VERFÜGUNGEN ÜBER SACHGÜTER:

Elisabeth Rybe, Nonne in Walsrode, erhält ein Bett und ein Kissen, die Frau des Otto Grote das große, grüne Seidenkissen. Seine Seidendecke von grüner Farbe ist für den Schmuck der Kirche in Verden gedacht, die Seidendecke in Minden für den Schmuck der Kirche in Minden. Die Frau Ludolf Ruschers erhält seinen silbernen Gürtel und den neuen Wagen, der in Verden ist. Hermann von Brake vermacht er ein Bett und eine Decke mit Kissen.

Ferner hat er einen Hof in Minden, dessen Wert der Testator auf 100 Mark schwerer Denare schätzt; in diesem Hof hat er Hausgerätschaften, die im besonderen folgen: Zuerst sechs Betten, drei gestreifte und drei weiße, vier Pfühle, eine weiße Decke, drei Decken aus einfachem Stoff, drei Paar Leinwandlaken und Kopfkissen. Ferner in der Küche drei Kochkessel aus Messing, sieben eherne Grapen, zwei Keramiktöpfe, einen Mörser, drei kleine Roste, zwei Feuergabeln, drei Herdeisen, zwei Bratpfannen und ein Langholz, eine Zange, ein Handwaschbecken, zwei Becken, vier Zinnkannen, zwölf oder sechzehn (Trink) Schalen, ein Eßgeschirrschrank und einen anderern Schrank in der Küche, Zinngefäße, nämlich ein Quartale, ein Quartale von Mindener Maß und vier andere Gefäße eines Quarts und eines von einem halben Quart. Ferner zwei Zinnkannen, eine von einem halben Quart und eine Pipkanne. Ferner fünf Tischtücher, drei lange und zwei kürzere, sowie vier Servietten und zwei Tische. Ebenso zwei Sitzkissen; ferner sechs große und kleine Truhen; ebenso drei Schränke in der Kirche und ein Pult; ferner ein zinnener Schrank in dem Zimmer beim Turm, ein Abdecktuch und vier Bettgestelle. Ferner von den Braugerätschaft ein großes $F a ß$, vier kleine Fässer, drei Kühlfässer und drei Tröge. Ebenso eine Füllkelle/Schöpfkelle, ein Gerät zum Umrühren und sechs hohe Gefäße. Ferner einen Lustgarten (viridarium), einen Schleifstein und einen hohen und breiten Stein, zu dem sollen sie die Brenneisen und Gläser und die ähnlichen Sachen und jene Sachen tun, die vorausgeschickt sind mit dem übertragenen Hof dem Herrn Johannes Holtdorp. Ferner eine Beuteltruhe, zwei Banklaken und zwei Sitzkissen.

Einen Hof besitzt von Thune in Verden, dessen Wert er auf 100 Mark Bremer Denare schätzt. Dieser Hof hat keine Einkünfte und keine Lasten. An Hausrat hat er sieben große und kleine Betten, vier Kissen, fünf einfache Bettdecken, eine weiße Decke und eine rauhe/schmucklose. Ebenso drei seidene Decken, vier Stück Leinentücher und sechs Kopfkissen sowie drei Badebekleidungsstücke, deren eines Badekappe genannt wird. Ferner drei Urinalbecken, zwei Handwaschbecken, ein Rasierbecken, zwei Handfässer, 
deren eines in Form eines Löwen gearbeitet ist. Ferner zwei Banklaken, sechzehn Sitzkissen sowie sechs weitere Kissen. Ebenso zwei Falttische und zwei andere lange Tische, acht lange und kurze Tischtücher, sechs Handtücher. Ferner zwei silberne Becher und eine Schale, zwölf silberne Löffel; ferner acht Zinnflaschen, vier Stübchen und vier des Viertels Mindener Maßes, drei Zinnkannen, ein Stübchen und zwei Halbstübchen. Ebenso acht große und kleine Grapen, einen Mörser mit Mörserstößel, vier große und kleine Kochkessel und zwei Kochkessel aus Messing, zwei irdene Töpfe, drei Bratpfannen und ein perforiertes Becken und eine Anrichte aus Eiche. Ebenso von Braugeräten drei Fässer, drei Kühlfässer, einen Schemel, sechs hohe Gefäße, Füllkellen/Schöpfkellen, Geräte zum Umrühren und ein Darnlaken, vier große und kleine Schränke, vier Truhen und vier Bettgestelle. An Backgeschirr eine Beuteltruhe, einen Teigtrog und zehn Leinensäcke. Ebenso vier Karren mit Zubehör.

Der Propst in Obernkirchen schuldet inm einen vergoldeten Gürtel, der sechzehn Mark wert ist, Herr Johann Anezadel ein Paar silberner Schalen und ein Brevier im Wert von sechs Mark.

Siegler: Segeband von Thune, Jakob Buckemann, Johannes Kröger, Berthold Hadeleben, Hermann Gronau, Hermann von Rode, Johannes von Pentze

Notariatsinstrument. Signet und Unterschrift des Notars Burchard Harde

Reinhardt, Testamente, S.60ff, Nr.45

\section{Juli 11}

Elisabeth Stöterogge

(lat.)

TV: Heinrich Pistor, Vikar in St. Spiritus in Salzwedel; Albert von Dambeck, Vikar in

Bardowick und in St. Spiritus in Salzwedel; Johannes Lange, Bürgermeister

ANGABEN ZU PERSON UND FAMILIE:

Elisabeth Stöterogge ist die zweite Frau Ludolf Stöterogges, der 1378 testierte. Die testamentarischen Verfügungen deuten darauf hin, daß sie möglicherweise aus Salzwedel stammt. Sie erwähnt zwei Schwestern, die Nonnen in Wienhausen seien, und einen Bruder Curd. Ihre Tochter Elisabeth sollte mit Heinrich Viskule verheiratet werden, wurde dann aber die Frau Heinrich Schomakers ${ }^{20}$.

\section{VERFÜGUNGEN ÜBER SACHGÜTER:}

Die Testatorin hat Häuser zur Ehre der Heiligen Anna beim Kloster St. Spiritus außerhalb der Stadtmauern Salzwedels erworben und erbaut. Ihren gesamten Hausrat und ihre wertvollen Kleinodien stiftet sie armen Frauen, für die diese Häuser gedacht sind. Ihre Tochter Elisabeth soll kein Anrecht auf die Güter haben außer an dem, was ihr ihre Mutter an Hausrat, Gebrauchsgegenständen und silbernen Kleinoden gegeben hat, die im Haus der Mutter in Lüneburg zurückbleiben. Ferner erhält sie das Heergewät und die Frauengerade.

\section{ZUSÄTZLICHE INFORMATIONEN:}

StA LG b 1386-1388

Ein Beutel mit Schriftstücken (Originalbriefe und Abschriften), die sich auf das Testament der Elisabeth Stöterogge und das von ihr gegründete St. Annenhospital in Salzwedel beziehen. Darunter befindet sich ein Begleitschreiben der E. S., als diese dem Rat Löffel

\footnotetext{
${ }^{20}$ U. REINHARDT, Stiftersorgen - Das Testament der Elisabeth Stöterogge, S.360 ff.
} 
schickt, damit die Ratsherren „ere krude eten“ und des St. Annenhospitals gedächten. Das Pergamentblatt ist mit einem Beutel verbunden.

Eine gleichzeitige Kopie des Testaments ist die Vorlage. Von der Originalausfertigung sind nur noch 19 Zeilen erhalten, der Rest ist abgeschnitten.

Reinhardt, Testamente, S. 46ff, Nr. 46

1386 Januar $5 \quad$ Dietrich Lembeke

(lat.)

TV: Otto, Propst des Klosters Heiligenthal; Dietrich Steen, Vikar der Kirche in Verden; Dietrich Lembeke

ANGABEN ZU PERSON UND FAMILIE:

Lembeke war Vikar der Johanniskirche. 1377 übergab er seine Pfarrstelle in St. Cyriacus dem Archidiakon von Modestorpe ${ }^{21}$. Lembekes Vetter war Bürger in Uelzen; hier hatte Lembeke auch eine Vikarie inne.

VERFÜGUNGEN ÜBER SACHGÜTER:

Seiner Magd Wibe hinterläßt der Testator den Pelz(mantel), den Rock, die doppelt gefältete Hoike und das Bett, in dem sie selbst zu schlafen pflegt, mit allem Zubehör. Die Herren des Klosters Heiligental in Lüneburg erhalten das gesamte Hausgerät. Johannes, dem Sohn seines Vetters Dietrich Lembeke, schenkt er sein Brevier.

Notariatsurkunde. Signet und Unterschrift des Marquard von Plön

Reinhardt, Testamente, S. 70ff, Nr. 47

1386 Juni 29

Johann von der Brücken

(mnd.)

TV: Hartwig Abbenburg, Sander Schellepeper, Dietrich Brömse, Gottfried von Hagen

ANGABEN ZU PERSON UND FAMILIE:

Der Testator ist 1361 als Bürger, 1367 als Ratsherr belegt ${ }^{22}$. Er war zweimal verheiratet; in erster Ehe mit Alheid, in zweiter Ehe mit Hille. Seine vier Kinder entstammen der ersten Ehe. Seine Tochter Hille war die Ehefrau von Johann Rokswale, die Tochter Alheid Johann von der Mölens Frau.

VERFÜGUNGEN ÜBER SACHGÜTER:

Hille erhält sechs Mark Leibrente aus dem Haus Ottos und fünf Mark Rente aus dem Haus Henneke Schomakers. Nach Hilles Tod soll die Rente zehn Jahre lang für Hausarme verwendet werden, nämlich für den Kauf von Kleidung, Schuhen und Hemden. Als ewiges Almosen bleibt es nur dann bestehen, wenn weder des Testators Tochter noch ihre Kinder oder Kindeskinder leben. Hille erhält allen Hausrat bis auf das Heergewät, das an des

\footnotetext{
${ }^{21}$ W. Fr. VOLGER, Einzeldarstellungen, S.125.

${ }^{22}$ H.-J. v. WITZENDORFF, Stammtafeln, S.22.
} 
Testators Neffen fallen soll.

Reinhardt, Testamente, S. $72 f$, Nr. 48

1388 Juli 10

Heinrich Jesteburg

(mnd.)

TV: Ludolf Wardemann, Ludolf Stormer, Johann Newrade

ANGABEN ZU PERSON UND FAMILIE: -

VERFÜGUNGEN ÜBER SACHGÜTER:

Das Wohnhaus mit allem Zubehör fällt an Henneke Elers und seine Kinder. Ausgenommen ist von diesem Legat eine jährliche Rente von vier Mark.

Die Siegel fehlen, ein Einschnitt für die Pressel ist eingerissen.

Reinhardt, Testamente, S. $73 f$, Nr. 49

\section{August 6}

Arnd Neuenburg

(mnd.)

TV: Wilke, Bruder des Testators; Johann Nyenborg; Ghereke Schomaker

ANGABEN ZU PERSON UND FAMILIE:

Der Testator war Bürger von Lüneburg.

VERFÜGUNGEN ÜBER SACHGÜTER:

Im Fall der Wiederverheiratung der Frau soll sie mit 60 Mark, ihren Kleidern und ihrem Schmuck abgeteilt werden.

Das Testament ist durch Schnitte und durch Entfernung der Siegel als ungültig gekennzeichnet.

Reinhardt, Testamente, S. 74f, Nr. 50

\begin{tabular}{|l|l|}
\hline $1390 \quad$ Januar 16 & $\begin{array}{c}\text { Grete Holsten } \\
\text { (mnd.) }\end{array}$ \\
TV: Hartwig Abbenburg, Sander Schellepeper, Hartwig von der Mölen \\
ANGABEN ZU PERSON UND FAMILIE: \\
$\begin{array}{l}\text { Grete Holste war die Witwe des Ratsherrn Hartwig Holste, der } 1372 \text { testierte. Hartwig } \\
\text { Holste hatte offenbar lediglich aus seiner ersten Ehe mit Alheid Huth zumindest eine } \\
\text { Tochter, die die Frau des Ratshern Gheverd von der Mölens wurde }{ }^{23} \text {. Diese Stieftochter }\end{array}$
\end{tabular}

\footnotetext{
${ }^{23}$ H.-J. v. WITZENDORFF, Stammtafeln, S.83.
} 
der Testatorin muß gestorben sein, als ihr Sohn Hartwig noch ein Kind war. Seine Erziehung scheint Grete Holsten übernommen zu haben ${ }^{24}$.

VERFÜGUNGEN ÜBER SACHGÜTER:

Hartwig von der Mölen erhält die gesamte Fahrhabe, die sich im Haus der Testatorin befindet.

Siegler: Brand von Tzerstede, Heinrich Viskule

ZUSÄTZLICHE INFORMATIONEN:

Der Ratsherr Johann Semmelbecker hat Grete Holste und für die Zeit nach ihrem Tod dem TV des Hartwig Holste ein Chor Salz für Kleidung und Schuhwerk für Arme aufgelassen.

StA LG 1378 Feb. 1

Reinhardt, Testamente, S. 75f, Nr. 51

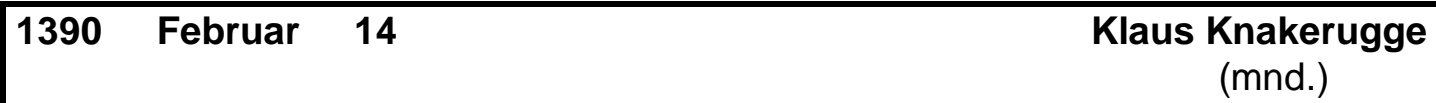

TV: Adelheid, Frau des Testators; Bernd Basedow der Jüngere; Johann Sarneholt; Albert van dem Hagen

ANGABEN ZU PERSON UND FAMILIE:

Der Testator war Bürger von Lüneburg.

VERFÜGUNGEN ÜBER SACHGÜTER:

Seine Frau erhält sein gesamtes Gut, den Hausrat, die Fahrhabe, bewegliche wie unbewegliche Güter zur freien Verfügung. Sie bekommt das ererbte Haus mit allem Zubehör, das soll sie nach Stadtrecht besitzen.

Presseleinschnitte gerissen, Siegel fehlen

Reinhardt, Testamente, S. 76f, Nr. 52

\begin{tabular}{l}
\hline $1393 \quad$ April 30 \\
TV: Johann Neurad, Heinrich Blanke \\
ANGABEN ZU PERSON UND FAMILIE: \\
Der Testator war Bürger von Lüneburg. \\
VERFÜGUNGEN ÜBER SACHGÜTER: \\
Das übrige mobile und immobile Gut sollen die TV verkaufen und in Renten anlegen, um so \\
Seelenmessen für den Testator und seine Familie zu finanzieren.
\end{tabular}

\footnotetext{
${ }^{24}$ Hartwig von der Mölen stattet Grete Holste, die Witwe seines Großvaters Hartwig Holste, mit Taschengeld aus in Dankbarkeit für treue Fürsorge. StA LG c 8131388 März 1.
} 
Siegel fehlen

Reinhardt, Testamente, S. 77f, Nr. 53

1398 November $11 \quad \begin{gathered}\text { Johann Pattensen } \\ \text { (mnd.) }\end{gathered}$

TV: Johann von Embsen, Ratsherr; Alard von Pattensen; Johann Bodenstorp; Henneke Ultzmann

ANGABEN ZU PERSON UND FAMILIE: -

VERFÜGUNGEN ÜBER SACHGÜTER:

Pattensen hinterläßt seinem Bruder Alard und dessen Frau sein Haus, Hof und die Wurd, damit sie es zu ihrer Lebzeit benutzen und besitzen. Danach soll es an die Kinder seiner Schwester und ihre Erben fallen. Das Hausgerät und die Einrichtungsgegenstände fallen zu zwei Teilen an seinen Bruder Alard, der dritte Teil fällt an Henneke Ultzman. Pattensen verfügt den Ankauf eines weißen und eines grauen Tuchs sowie den Ankauf von fünf Paar Schuhen in der Stunde nach seinem Tod; diese Güter sollen an die Armen verteilt werden.

Abschrift aus der 1. Hälfte des 16. Jahrhunderts

Reinhardt, Testamente, S. $79 \mathrm{ff}$, Nr. 55

\begin{tabular}{|ccc|c}
1401 & Juli & 15 & $\begin{array}{c}\text { Klaus Hoyke } \\
\text { (mnd.) }\end{array}$
\end{tabular}

TV: Johann Handorp, Priester; Hans Elvers, Hans Lofhagen, Hermann Snytker, Bürger zu Lüneburg

ANGABEN ZU PERSON UND FAMILIE:

Klaus Hoyke war Bürger von Lüneburg. Seine Frau hieß Gese, sein Sohn war Albert Hoyke, der in zweiter Ehe mit Tibbeke von der Mölen verheiratet war ${ }^{25}$. Aus der Ehe des Testators gingen desweiteren die Töchter Ilsabe und Alheid hervor. Hoyke starb 1404.

VERFÜGUNGEN ÜBER SACHGÜTER:

Nach der bereits vollzogenen Abteilung des Sohnes Albert fällt nun der restliche mobile und immobile Besitz an die Ehefrau Gese und die Kinder. Im Fall einer Wiederverheiratung erhält Gese ein Haus einer darauf liegenden Rente und den Hausrat sowie hundert Mark Lüneburger Pfennige. Bleibt sie unverheiratet, steht ihr zu Lebzeiten der Nutznieß an den genannten Gütern zu.

Siegler: Hasseke, Klaus Sankenstedt, Ratsherren zu Lüneburg

\footnotetext{
${ }^{25}$ H.-J. v. WITZENDORFF, Stammtafeln, S.60.
} 
Reinhardt, Testamente, S. 82f, Nr. 57

$1401 \quad$ Juli 21
TV: Beke, Frau des Testators; Albert von der Mölen, Bürgermeister; Heideke von
$\begin{aligned} & \text { Braunschweig, Priester; Heinrich Schermbeck, Klaus Semmelbecker, Johann von Ollensen, } \\ & \text { Bürger zu Lüneburg }\end{aligned}$
ANGABEN ZU PERSON UND FAMILIE:
Hoyemann war Ratsherr zu Lüneburg. Seine Ehefrau hieß Elisabeth Semmelbecker ${ }^{26}$.
VERFÜGUNGEN ÜBER SACHGÜTER:
Sein Wohnhaus mit allem Zubehör und Einrichtungsgegenständen hinterläßt der Testator
seiner Ehefrau. Nach ihrem Tod soll das Haus an an Heinrich Schermbeck, den Sohn
Johannes Schermbecks, fallen. Herrn Albert von der Molen vererbt er seine zwei Bücher
des Sachsenspiegels. Nach des Testators Tod soll - wenn möglich - Goldbrokat für ein
Meßgewand des Hochaltars in St. Lamberti gekauft werden. Kann man es zu der Zeit nicht
bekommen, so soll man es sobald wie möglich kaufen, damit das Meßgewand angefertigt
werden kann.
Siegler: Johann Hoyemann, Otto Garlop, Johann von der Mölen der Jüngere
Das Testament ist noch erhalten als
1. gleichzeitige Abschrift
2. gleichzeitige Abschrift in Heftform mit einem corpus bonorum und Nachrichten über die
vergabten Legate, insbesondere die der Schermbeck
Reinhardt, Testamente, S. 83ff, Nr. 58

1401 August 16

Volrad Lassan

(lat.)

TV: Ludolf von Heymbroke, Mönch im Kloster St. Michaelis; Johann Sinsdorp und Johann Schoneveldt, Pfarrer in Vielbaum; Gevehard Grönhagen, Bürger in Lüneburg; Johann Raynberth, Kleriker der Diözese Paderborn

ANGABEN ZU PERSON UND FAMILIE:

In seinem in Lüneburg hinterlegten Testament bezeichnet sich Lassan als Benefiziat der Heilig Geistkapelle am Neumarkt, also im Rathaus. Erhalten ist ein weiteres Testament, das in Lübeck hinterlegt war. Möglicherweise stammt der Testator aus Lassahn am Schaalsee, das ca. $35 \mathrm{~km}$ südöstlich von Lübeck liegt ${ }^{27}$. Sicher ist, daß er im Besitz des Magistergrades war. 1387 wird Lassan als Vikar des Lübecker Johannisklosters genannt. Erkennbar ist eine enge Beziehung zum Bürgermeister Warendorf und seiner Familie ${ }^{28}$. Bereits 1376 war Lassan Beneficiat in Lüneburg, später wird er als Vikar an St. Johanis|

\footnotetext{
${ }^{26}$ H.-J. v. WITZENDORFF, Stammtafeln, S. 53.

${ }^{27}$ Soweit nicht anders ausgewiesen, stammen die Informationen über Volrad Lassan aus: E. MICHAEL, Inschriften des Lüneburger St. Michaelisklosters und des Klosters Lüne, S.50f, Nr.11.

${ }^{28}$ A. v. BRANDT, Regesten, Bd.2, S.249f.
} 
und St. Cyriacus geführt.

VERFÜGUNGEN ÜBER SACHGÜTER:

Lassan vererbt sein kleineres Meßbuch und drei Meßornate mit einem Kelch für die Meßfeiern in St. Michaelis. ... Ferner wünscht Lassan, daß vom Verkauf seiner besseren Bücher ein Einkommen von fünf oder sechs Mark gekauft wird, und mit diesen die ewige Memorie im Kloster St. Michaelis finanziert wird, von denen die Herren des von inm genannten Klosters jährlich 2 Solidi dem Meßner geben sollen, 10 Solidi den armen Scholaren an seinem Anniversarium und jedem Anwesenden 4 Denare.

\section{ZUSÄTZLICHE INFORMATIONEN:}

In Lübeck ist das Testament von 1360 Nov. 21 eines Volrad Lassan überliefert. In zwei weiteren Lübecker Testamenten wird er als Bedachter in den Jahren 1352 und 1361 erwähnt. In der vorliegenden Lüneburger Ausfertigung wird zum Lübecker Testament Stellung genommen mit dem Hinweis, es handele sich hier um keinen Widerruf, sondern ein Testament solle das andere bekräftigen.

\section{Notariatsinstrument}

Das Datum ist einer unvollständigen Abschrift des als Notariatsinstruments ausgefertigten Testaments entnommen, die im 18. Jahrhundert entstand. Das Testament des Volrad Lassan wurde am 8. Dezember 1401 von dem Generalvikar Burchard von dem Berge bestätigt.

Reinhardt, Testamente, S. 86ff, Nr. 59

\section{$1402 \quad$ Mai 25}

Curd von Boltzen

(mnd.)

TV: Wobbeke, Frau des Testators; Johann Semmelbecker; Tyme von Boltzen, Bruder des Testators; Hans von der Mölen; Curd Springintgut

ANGABEN ZU PERSON UND FAMILIE:

Boltzen war Ratsherr zu Lüneburg. Genannt wird im Testament seine Ehefrau Wobeke und sein Bruder Tyme von Boltzen. Aus der Ehe mit Wobeke Semmelbecker gingen fünf Kinder hervor: Hans, der später Sülfmeister werden sollte, Cord, Albert, Beke und Wobeke $^{29}$.

VERFÜGUNGEN ÜBER SACHGÜTER:

Wird sich Wobeke nach Boltzens Tod auf Anraten ihrer Verwandtschaft wieder verheiraten, soll sie neben einer halben Pfannenherrschaft und zwölf Mark Geldes über das verfügungsberechtigt sein, was sie dann von des Testators Hausgerät, Geschmeide und Ringen haben möchte.

Siegler: Konrad von Boltzen, Heinrich Bere, Johann von der Mölen der Jüngere

Reinhardt, Testamente, S. 90ff, Nr. 61

\footnotetext{
${ }^{29}$ H.-J. v. WITZENDORFF, Stammtafeln, S.14.
} 
TV: Ludolf von Winsen, Hans von der Mölen, Jakobs Sohn, Ratsherren; Johann Heine, Ludolf Hoyke, Bürger

ANGABEN ZU PERSON UND FAMILIE:

Burmeister war Bürger zu Lüneburg. Sein Vater war der Sülfmeister Dietrich Burmeister ${ }^{30}$. Des Testators Schwägerin Immeke Burmeister testierte 1419.

VERFÜGUNGEN ÜBER SACHGÜTER:

Heinrich Viskule hat dem Testator einen Wispel Salz für 450 Mark verkauft, wobei er sich das Rückkaufsrecht vorbehielt. Verzichtet er auf den Rückkauf, so sollen die Testamentsvollstrecker vom Erlös des halben Wispel Salzes für Gottes Ehre Kleidungstücke oder Geld bedürftigen Priestern geben, Mägden und armen Leuten, Freunden und Fremden, ganz wie es innen notwendig erscheint. Kaufen jedoch Heinrich Viskule oder seine Erben den Wispel für 450 Mark zurück, sollen die TV von dem Geld eine zuverlässige ewige Rente kaufen, die - wie beschrieben - unter den armen Priestern, Mägden und armen Leuten verteilt werden soll. Das restliche unvergabte Gut des Testators besteht aus Bargeld und Fahrhabe; darum will er sich zu Lebzeiten selbst kümmern und freie Verfügungsgewalt darüber haben.

Siegler: Dietrich Burmeister, Heinrich Bere, Ludolf Töbing

Reinhardt, Testamente, S. 92f, Nr. 62

\section{Mai $26 \quad$ Johann Hintbergen (mnd.)}

TV: Johann Tzillik, Propst zu Isenhagen; Johann Godenstorp; Hans Drespe; Bertold Berskamp

ANGABEN ZU PERSON UND FAMILIE:

Im Testament erwähnt ist seine Ehefrau Metteke, die dem Anschein nach mit dem Testator keine gemeinsamen Kinder besitzt, denn die genannten Söhne Bernhard und Hermann werden als des Testators Söhne und nicht als die gemeinsamen bezeichnet.

VERFÜGUNGEN ÜBER SACHGÜTER:

Seinen Söhnen Bernhard und Hermann überläßt der Testator jeweils ein Bett, drei Federkissen, zwei Paar Laken, eine Kopfkissen und jedem eine Decke, jedoch nur für den Fall, daß seine Frau schwanger von ihm ist und den Söhnen sein Heergewät nicht zufällt. Fällt innen jedoch sein Heergewät zu, darf man es ihnen nicht geben.

Siegler: Ludolf Töbing, Ludolf von Winsen

Rückvermerk: Anno domini $M^{\circ}{ }^{\circ} C C^{\circ}{ }^{\circ}{ }^{\circ}$ feria quinta post Letare de waren hir de testamentere lohans Hintbergen unde beden de rad, dit testament bi sek to nemende,

\footnotetext{
${ }^{30}$ Auch WITZENDORFF bezeichnet ihn als unverheirtatet und kinderlos. H.-J. v. WITZENDORFF, Stammtafeln, S.23.
} 
went se dit testament vulbracht hedden.

Reinhardt, Testamente, S. 94f, Nr. 63

1406 September $17 \quad$ Dietrich Bardowick

TV: Grete, Ehefrau des Testators; Johann Basedow, des Testators Schwager, Priester; Bernd Basedow, Ratsherr zu Lüneburg; Johann Bilne, Priester; Hans Neuenburg, Stadtvogt; Lüder Bardowick, Bruder des Testators

ANGABEN ZU PERSON UND FAMILIE:

Der Bürger Dietrich Bardowick war mit Grete aus dem Geschlecht Basedow verheiratet. Aus dieser Ehe gingen zumindest die beiden Töchter Grete und Gheseke hervor ${ }^{31}$.

VERFÜGUNGEN ÜBER SACHGÜTER:

Die Ehefrau Grete erhält ihre Güter, die sie bei der Eheschließung mit sich brachte, zurück.

Nachweis: Nachlaß Manecke, Bd.27, fol.49ff, Abschrift des 19. Jahrhunderts vom Original

Reinhardt, Testamente, S. 95f, Nr. 64

\begin{tabular}{|lcc|}
\hline 1406 & September 23 & $\begin{array}{c}\text { Tibbeke von Netze } \\
\text { (mnd.) }\end{array}$
\end{tabular}

TV: Johann Tangendorp, Lemmeke Bodenau sowie deren Kollegen und Nachfolger als Vorsteher des ewigen Lichtes am Marienaltar der Johanniskirche

ANGABEN ZU PERSON UND FAMILIE:

Tibbeke von Netze war Vorsteherin des ewigen Lichtes am Marienaltar in der Johanniskirche, der von der Bruderschaft Unser Lieben Frauengilde versorgt wurde.

VERFÜGUNGEN ÜBER SACHGÜTER:

Ihr Nachlaß soll dem ewigen Licht am Altar Unser Lieben Frau in St. Johannis zugewendet werden zur syvinge und für Kleinode. Da es sich bei ihrem Nachlaß um selbsterarbeitetes Gut handelt, hat niemand das Recht, Beschwerde einzulegen.

Siegler: Hartwig Beve, Nikolaus Garlop, Ratsherren zu Lüneburg

Reinhardt, Testamente, S. 96, Nr. 65

\begin{tabular}{|llll}
1406 & Okt. & 19 & Klaus Salzhausen
\end{tabular}

\footnotetext{
${ }^{31}$ WITZENDORFF führt zwar einen Dietrich Bardowiek auf, der 1398 belegt ist und 1407 verstirbt, kann aber keine weiteren Angaben machen. Eine Grete Basedow hat WITZENDORFF nicht verzeichnet, wohl aber den Vikar und Vizerektor von St. Johannis, Johann Basedow, den Bruder der Grete. H.-J. v. WITZENDORFF, Stammtafeln, S.3, 5ff.
} 
TV: Johann Winckemann, Johann Kolkhagen, Meinecke Neuenburg, Johann Zidouwen, Bürger zu Lüneburg

ANGABEN ZU PERSON UND FAMILIE:

Der Testator war Bürger zu Lüneburg.

VERFÜGUNGEN ÜBER SACHGÜTER:

Den selbsterarbeiteten mobilen und immobilen Nachlaß gibt der Testator seinem Sohn Johann.

Siegler: Arnd Cappenberg, Johann von der Mölen

Reinhardt, Testamente, S.97, Nr.66

\begin{tabular}{|ccc}
\hline 1407 Juni 13 & $\begin{array}{c}\text { Engelbrecht Hoke } \\
\text { (mnd.) }\end{array}$
\end{tabular}

TV: Everd Hoke, Klaus Leger, Bernd Vardendorp und Ludolf Bartholomäus, Bürger zu Lüneburg

ANGABEN ZU PERSON UND FAMILIE: -

VERFÜGUNGEN ÜBER SACHGÜTER:

Die übrigen mobilen und immobilen Güter sollen verkauft werden. Der Bargelderlös soll in einem Rentenkauf investiert werden. Mit dieser Rente soll Bettzeug für den Langen Hof in Lüneburg gekauft werden, vier feine Betten oder soviel der Ertrag erlaubt. Darin soll man arme, fremde, wandernde Leute beherbergen und innen dazu Connent und Brot geben, soviel die Rente hergibt. Wenn die Frau des Testators stirbt, dann sollen ihre sechs Mark Geldes an diese Rente fallen, damit sich die beschriebenen Betten und die Gabe zu ewigen Zeiten verbessern.

Siegler: Dietrich Springintgut. Das Siegel Hartwigs on der Mölen ist abgefallen.

Reinhardt, Testamente, S.98, Nr. 67

1407 Juni 28

Johann Swendebeke

(mnd.)

TV: Ghese, Ehefrau des Testators; Godeke Tzerstede, Ratsherr; Johann von Ollensen, Klaus von Oedeme, Henning von Luderen, Bürger zu Lüneburg

ANGABEN ZU PERSON UND FAMILIE:

Der Testator war Bürger Lüneburgs; in seinem Testamentsformular nennt er seine Ehefrau Ghese und seine Kinder.

VERFÜGUNGEN ÜBER SACHGÜTER: 
Das übrige mobile und immobile Gut hinterläßt er seiner Ehefrau Ghese und den Kindern. Sie sollen es nach dem Rat seiner Testamentsvollstrecker gemeinsam gebrauchen. Im Fall von Gheses Wiederverheiratung sollen die Kinder nach ihrer Abteilung alles zu gleichen Teilen besitzen. Im Fall einer erneuten Heirat soll seine Ehefrau 100 Mark Pfennige bekommen sowie die Hälfte des Hausrates.

Siegler: Johann Swendebeke, Johann von der Mölen, Ludolf Töbing

Von diesem Testament ist auch die zweite Ausfertigung vorhanden. Diese ist gleichfalls besiegelt und weicht nur in der Schreibweise von der ersten ab. Zahlreiche Einschnitte am oberen und unteren Rand zeigen die Kassation an.

Reinhardt, Testamente, S. 99f, Nr. 68

$1408 \quad$ Januar 7
TV: -
ANGABEN ZU PERSON UND FAMILIE:
$\begin{aligned} & \text { Der Testator war Bürger von Lüneburg. Pluckemus war mit einer gewissen Ghese } \\ & \text { verheiratet und hatte zwei Kinder namens Martin und Gheseke. } \\ & \text { (mnd.) }\end{aligned}$
All seine HäGUNGN ÜBER SACHGÜTER:
Siegler: Johann von der Mölen, Ludolf Töbing
Das Testament ist auf Papier geschrieben mit aufgedrückten Siegeln
Reinhardt, Testamente, S. 100, Nr. 69

\section{April 2}

Metteke Schwertfeger

(mnd.)

TV: $\quad-$

ANGABEN ZU PERSON UND FAMILIE:

Im Testament nennt sie ihren Bruder, Hermen von Rethem, und seine Ehefrau Wulgurghe sowie deren Tochter Metteke.

VERFÜGUNGEN ÜBER SACHGÜTER:

Die Testatorin hinterläßt ihrer Nichte Metteke Rethem den Kirchstuhl in St. Johannis.

Siegler: Johann von der Mölen, Ludolf von Winsen

Papier mit aufgedrücktem Verschlußsiegel

Reinhardt, Testamente, S. 101, Nr. 70 
TV: -

ANGABEN ZU PERSON UND FAMILIE:

Der Bürger Stöterogge hatte mit seiner Frau Ghese die gemeinsamen Söhne Meyne und Johannes ${ }^{32}$.

VERFÜGUNGEN ÜBER SACHGÜTER:

Seiner Frau Geseke hinterläßt Stöterogge nicht nur Geldbesitz, sondern auch den gesamten Hausrat und alle Mobilien, wo immer er sie hat, ferner das gesamte Bettzeug und Laken sowie weiteres Zubehör, dann Kannen, Grapen, Kessel und sonstige Hausgerätschaften und Mobilien; über all diese Dinge soll seine Frau freie Verfügungsgewalt haben.

Siegler: Hartwig von der Mölen, Godeke Tzerstede

Papier mit aufgedrückten Verschlußsiegeln

Reinhardt, Testamente, S. $102 f$, Nr. 72

\begin{tabular}{|lcc|c}
\hline 1408 & August 18 & $\begin{array}{c}\text { Geverd Gropeshorn } \\
\text { (mnd.) }\end{array}$
\end{tabular}

TV: Ghereke Neuenkirchen, Hans Rullstorf, Hans Gropeshorn

ANGABEN ZU PERSON UND FAMILIE:

Gropeshorn war Bürger zu Lüneburg.

VERFÜGUNGEN ÜBER SACHGÜTER:

Mit zwanzig Mark soll man graue Laken kaufen und für Gott armen Leuten geben, die sie nötig haben. Die Kinder von Hans Gropeshorn, die im Kloster St. Marien sind, erhalten fünf Mark, damit man jedem eine Cappe kaufen kann.

Siegler: Klaus Sankenstede, Hans Schellepeper, Ratsherren

Papier mit aufgedrückten Siegeln. Urkunde durch Einschnitte ungültig gemacht.

Reinhardt, Testamente, S. 103f, Nr. 73

1409 März 7

Johann Semmelbecker

(mnd.)

TV: Heinrich Kule, Provisor der Johanniskirche; Albert von der Mölen, Ratsherr; Hans von der Mölen, Ratsherr; Klaus Semmelbecker, Bruder des Testators; Hans und Dietrich, Neffen des Testators

\footnotetext{
${ }^{32}$ WITZENDORFF verzeichnet weder Ehefrau noch Kinder des Testators. H.-J. v. WITZENDORFF, Stammtafeln, S.122.
} 
ANGABEN ZU PERSON UND FAMILIE:

Johann Semmelbecker, Ratsherr und Sodmeister, war dreimal verheiratet: In erster Ehe heiratete er Gesche Springintgud, mit der er die Kinder Johann, Cord und Dietrich hatte, seine zweite Ehefrau war Tibbeke von Grönhagen, mit der er offenbar kinderlos blieb ${ }^{33}$. Aus der dritten Ehe mit Ligeke/Lyseke Pepersack stammen Albert, Alheid und Gesche. Die Söhne Johann und Albert werden ebenfalls in den Rat aufgenommen. Cord ist nachgewiesen an der Universität zu Erfurt, in Leipzig und Bologna. Der Testator starb wenige Tage nach der Testamentserrichtung.

VERFÜGUNGEN ÜBER SACHGÜTER:

Innerhalb eines Jahres und eines Tages nach Semmelbeckers Tode sollen seiner Frau Lyseke all ihre Hausgerätschaften, Kleider, Kleinode und Schmuck ausgeliefert werden, alles, was sie mit sich in die Ehe brachte, und was er ihr seitdem gegeben hat. Die zwei goldenen Tücher, die der Testator besitzt, sollen seinem Sarg übergelegt werden; später sollen sie in den Besitz der Johanniskirche übergehen. Mit einer reinen Mark soll für St. Johannis ein vergoldetes Kreuz angefertigt werden. Ferner sollen seine Testamentsvollstrecker für St. Johannis zwei vergoldete Kelche bestellen, damit man den Pfarrleuten Absolution gebe, wenn sie die Kommunion empfangen haben.

Siegler: Johann Semmelbecker, Johann von der Mölen, Johann Schellepeper

Reinhardt, Testamente, S. 106ff, Nr. 75

\begin{tabular}{|ccc|c}
\hline 1409 & Juli & 10 & $\begin{array}{c}\text { Ludolf Burmeister } \\
\text { (mnd.) }\end{array}$
\end{tabular}

TV: Hermann Osnabrück, Meinecke Töbing, Schwäger des Testators

ANGABEN ZU PERSON UND FAMILIE:

Der Testator war der Sohn des 1385 verstorbenen Ratsangestellten Ludolf Burmester ${ }^{34}$. Zu seiner weitläufigen Verwandtschaft zählten die Testatoren Dietrich Burmester und Immeke Burmester.

VERFÜGUNGEN ÜBER SACHGÜTER:

Die Ehefrau Winneke erhält das Haus, Hof und die Wurd mit allem Zubehör, mit allen Hausgerätschaften; sie erhält ferner das mobile und immobile Gut zur freien Verfügung.

Siegler: Johann von der Mölen, Ludolf Töbing

Papier mit aufgedrückten Siegeln.

Reinhardt, Testamente, S. 108, Nr. 76

\footnotetext{
${ }^{33}$ H.-J. v. WITZENDORFF, Stammtafeln, S.116.

${ }^{34}$ H.-J. v. WITZENDORFF, Stammtafeln, S.23.
} 


\begin{tabular}{|l}
\hline $1401 \quad$ Juli 15 \\
$\begin{array}{l}\text { Klaus Hoyke } \\
\text { (mnd.) }\end{array}$ \\
Lüneburg \\
ANGABEN ZU PERSON UND FAMILIE: \\
Klaus Hoyke war Bürger von Lüneburg. Seine Frau hieß Gese, sein Sohn war Albert \\
Hoyke, der in zweiter Ehe mit Tibbeke von der Mölen verheiratet war'. Aus der Ehe des \\
Testators gingen desweiteren die Töchter Ilsabe und Alheid hervor. Hoyke starb 1404. \\
VERFÜGUNGEN ÜBER SACHGÜTER: \\
Nach der bereits vollzogenen Abteilung des Sohnes Albert fällt nun der restliche mobile \\
und immobile Besitz an die Ehefrau Gese und die Kinder. Im Fall einer Wiederverheiratung \\
erhält Gese ein Haus einer darauf liegenden Rente und den Hausrat sowie hundert Mark \\
Lüneburger Pfennige. Bleibt sie unverheiratet, steht ihr zu Lebzeiten der Nutznieß an den \\
genannten Gütern zu. \\
Siegler: Hasseke, Klaus Sankenstedt, Ratsherren zu Lüneburg \\
Reinhardt, Testamente, S. 82f, Nr. 57
\end{tabular}

\begin{tabular}{|ccc|c}
\hline 1401 & Juli & 21 & $\begin{array}{c}\text { Johann Hoyemann } \\
\text { (mnd.) }\end{array}$
\end{tabular}

TV: Beke, Frau des Testators; Albert von der Mölen, Bürgermeister; Heideke von Braunschweig, Priester; Heinrich Schermbeck, Klaus Semmelbecker, Johann von Ollensen, Bürger zu Lüneburg

ANGABEN ZU PERSON UND FAMILIE:

Hoyemann war Ratsherr zu Lüneburg. Seine Ehefrau hieß Elisabeth Semmelbecker².

VERFÜGUNGEN ÜBER SACHGÜTER:

Sein Wohnhaus mit allem Zubehör und Einrichtungsgegenständen hinterläßt der Testator seiner Ehefrau. Nach ihrem Tod soll das Haus an an Heinrich Schermbeck, den Sohn Johannes Schermbecks, fallen. Herrn Albert von der Molen vererbt er seine zwei Bücher des Sachsenspiegels. Nach des Testators Tod soll - wenn möglich - Goldbrokat für ein Meßgewand des Hochaltars in St. Lamberti gekauft werden. Kann man es zu der Zeit nicht bekommen, so soll man es sobald wie möglich kaufen, damit das Meßgewand angefertigt werden kann.

Siegler: Johann Hoyemann, Otto Garlop, Johann von der Mölen der Jüngere

Das Testament ist noch erhalten als

1. gleichzeitige Abschrift

2. gleichzeitige Abschrift in Heftform mit einem corpus bonorum und Nachrichten über die vergabten Legate, insbesondere die der Schermbeck

Reinhardt, Testamente, S. 83ff, Nr. 58

\footnotetext{
${ }^{1}$ H.-J. v. WITZENDORFF, Stammtafeln, S.60.
}

${ }^{2}$ H.-J. v. WITZENDORFF, Stammtafeln, S. 53. 
TV: Ludolf von Heymbroke, Mönch im Kloster St. Michaelis; Johann Sinsdorp und Johann Schoneveldt, Pfarrer in Vielbaum; Gevehard Grönhagen, Bürger in Lüneburg; Johann Raynberth, Kleriker der Diözese Paderborn

\section{ANGABEN ZU PERSON UND FAMILIE:}

In seinem in Lüneburg hinterlegten Testament bezeichnet sich Lassan als Benefiziat der Heilig Geistkapelle am Neumarkt, also im Rathaus. Erhalten ist ein weiteres Testament, das in Lübeck hinterlegt war. Möglicherweise stammt der Testator aus Lassahn am Schaalsee, das ca. $35 \mathrm{~km}$ südöstlich von Lübeck liegt ${ }^{3}$. Sicher ist, daß er im Besitz des Magistergrades war. 1387 wird Lassan als Vikar des Lübecker Johannisklosters genannt. Erkennbar ist eine enge Beziehung zum Bürgermeister Warendorf und seiner Familie ${ }^{4}$. Bereits 1376 war Lassan Beneficiat in Lüneburg, später wird er als Vikar an St. Johanis und St. Cyriacus geführt.

VERFÜGUNGEN ÜBER SACHGÜTER:

Lassan vererbt sein kleineres Meßbuch und drei Meßornate mit einem Kelch für die Meßfeiern in St. Michaelis. ... Ferner wünscht Lassan, daß vom Verkauf seiner besseren Bücher ein Einkommen von fünf oder sechs Mark gekauft wird, und mit diesen die ewige Memorie im Kloster St. Michaelis finanziert wird, von denen die Herren des von ihm genannten Klosters jährlich 2 Solidi dem Meßner geben sollen, 10 Solidi den armen Scholaren an seinem Anniversarium und jedem Anwesenden 4 Denare.

\section{ZUSÄTZLICHE INFORMATIONEN:}

In Lübeck ist das Testament von 1360 Nov. 21 eines Volrad Lassan überliefert. In zwei weiteren Lübecker Testamenten wird er als Bedachter in den Jahren 1352 und 1361 erwähnt. In der vorliegenden Lüneburger Ausfertigung wird zum Lübecker Testament Stellung genommen mit dem Hinweis, es handele sich hier um keinen Widerruf, sondern ein Testament solle das andere bekräftigen.

\section{Notariatsinstrument}

Das Datum ist einer unvollständigen Abschrift des als Notariatsinstruments ausgefertigten Testaments entnommen, die im 18. Jahrhundert entstand. Das Testament des Volrad Lassan wurde am 8. Dezember 1401 von dem Generalvikar Burchard von dem Berge bestätigt.

Reinhardt, Testamente, S. 86ff, Nr. 59

\begin{tabular}{|lc|}
\hline 1402 Mai 25 & $\begin{array}{c}\text { Curd von Boltzen } \\
\text { (mnd.) }\end{array}$ \\
TV: Wobbeke, Frau des Testators; Johann Semmelbecker; Tyme von Boltzen, Bruder des \\
Testators; Hans von der Mölen; Curd Springintgut
\end{tabular}

\footnotetext{
${ }^{3}$ Soweit nicht anders ausgewiesen, stammen die Informationen über Volrad Lassan aus: E. MICHAEL, Inschriften des Lüneburger St. Michaelisklosters und des Klosters Lüne, S.50f, Nr.11.

${ }^{4}$ A. v. BRANDT, Regesten, Bd.2, S.249f.
} 
ANGABEN ZU PERSON UND FAMILIE:

Boltzen war Ratsherr zu Lüneburg. Genannt wird im Testament seine Ehefrau Wobeke und sein Bruder Tyme von Boltzen. Aus der Ehe mit Wobeke Semmelbecker gingen fünf Kinder hervor: Hans, der später Sülfmeister werden sollte, Cord, Albert, Beke und Wobeke ${ }^{5}$.

VERFÜGUNGEN ÜBER SACHGÜTER:

Wird sich Wobeke nach Boltzens Tod auf Anraten ihrer Verwandtschaft wieder verheiraten, soll sie neben einer halben Pfannenherrschaft und zwölf Mark Geldes über das verfügungsberechtigt sein, was sie dann von des Testators Hausgerät, Geschmeide und Ringen haben möchte.

Siegler: Konrad von Boltzen, Heinrich Bere, Johann von der Mölen der Jüngere

Reinhardt, Testamente, S. 90ff, Nr. 61

\section{März $26 \quad$ Dietrich Burmeister (mnd.)}

TV: Ludolf von Winsen, Hans von der Mölen, Jakobs Sohn, Ratsherren; Johann Heine, Ludolf Hoyke, Bürger

ANGABEN ZU PERSON UND FAMILIE:

Burmeister war Bürger zu Lüneburg. Sein Vater war der Sülfmeister Dietrich Burmeister ${ }^{6}$. Des Testators Schwägerin Immeke Burmeister testierte 1419.

VERFÜGUNGEN ÜBER SACHGÜTER:

Heinrich Viskule hat dem Testator einen Wispel Salz für 450 Mark verkauft, wobei er sich das Rückkaufsrecht vorbehielt. Verzichtet er auf den Rückkauf, so sollen die Testamentsvollstrecker vom Erlös des halben Wispel Salzes für Gottes Ehre Kleidungstücke oder Geld bedürftigen Priestern geben, Mägden und armen Leuten, Freunden und Fremden, ganz wie es innen notwendig erscheint. Kaufen jedoch Heinrich Viskule oder seine Erben den Wispel für 450 Mark zurück, sollen die TV von dem Geld eine zuverlässige ewige Rente kaufen, die - wie beschrieben - unter den armen Priestern, Mägden und armen Leuten verteilt werden soll. Das restliche unvergabte Gut des Testators besteht aus Bargeld und Fahrhabe; darum will er sich zu Lebzeiten selbst kümmern und freie Verfügungsgewalt darüber haben.

Siegler: Dietrich Burmeister, Heinrich Bere, Ludolf Töbing

Reinhardt, Testamente, S. 92f, Nr. 62

\footnotetext{
${ }^{5}$ H.-J. v. WITZENDORFF, Stammtafeln, S.14.

${ }^{6}$ Auch WITZENDORFF bezeichnet ihn als unverheirtatet und kinderlos. H.-J. v. WITZENDORFF, Stammtafeln, S.23.
} 
TV: Johann Tzillik, Propst zu Isenhagen; Johann Godenstorp; Hans Drespe; Bertold Berskamp

ANGABEN ZU PERSON UND FAMILIE:

Im Testament erwähnt ist seine Ehefrau Metteke, die dem Anschein nach mit dem Testator keine gemeinsamen Kinder besitzt, denn die genannten Söhne Bernhard und Hermann werden als des Testators Söhne und nicht als die gemeinsamen bezeichnet.

VERFÜGUNGEN ÜBER SACHGÜTER:

Seinen Söhnen Bernhard und Hermann überläßt der Testator jeweils ein Bett, drei Federkissen, zwei Paar Laken, eine Kopfkissen und jedem eine Decke, jedoch nur für den Fall, daß seine Frau schwanger von ihm ist und den Söhnen sein Heergewät nicht zufällt. Fällt innen jedoch sein Heergewät zu, darf man es ihnen nicht geben.

Siegler: Ludolf Töbing, Ludolf von Winsen

Rückvermerk: Anno domini $M^{\circ} \mathrm{CCCC}^{\circ} \chi^{\circ}$ feria quinta post Letare de waren hir de testamentere lohans Hintbergen unde beden de rad, dit testament bi sek to nemende, went se dit testament vulbracht hedden.

Reinhardt, Testamente, S. 94f, Nr. 63

\begin{tabular}{|ccc}
\hline 1406 & September 17 & $\begin{array}{c}\text { Dietrich Bardowick } \\
\text { (mnd.) }\end{array}$
\end{tabular}

TV: Grete, Ehefrau des Testators; Johann Basedow, des Testators Schwager, Priester; Bernd Basedow, Ratsherr zu Lüneburg; Johann Bilne, Priester; Hans Neuenburg, Stadtvogt; Lüder Bardowick, Bruder des Testators

ANGABEN ZU PERSON UND FAMILIE:

Der Bürger Dietrich Bardowick war mit Grete aus dem Geschlecht Basedow verheiratet. Aus dieser Ehe gingen zumindest die beiden Töchter Grete und Gheseke hervor ${ }^{7}$.

VERFÜGUNGEN ÜBER SACHGÜTER:

Die Ehefrau Grete erhält ihre Güter, die sie bei der Eheschließung mit sich brachte, zurück.

Nachweis: Nachlaß Manecke, Bd.27, fol.49ff, Abschrift des 19. Jahrhunderts vom Original

Reinhardt, Testamente, S. 95f, Nr. 64

$1406 \quad$ September 23

\footnotetext{
${ }^{7}$ WITZENDORFF führt zwar einen Dietrich Bardowiek auf, der 1398 belegt ist und 1407 verstirbt, kann aber keine weiteren Angaben machen. Eine Grete Basedow hat WITZENDORFF nicht verzeichnet, wohl aber den Vikar und Vizerektor von St. Johannis, Johann Basedow, den Bruder der Grete. H.-J. v. WITZENDORFF, Stammtafeln, S.3, 5ff.
}

Tibbeke von Netze

(mnd.) 
TV: Johann Tangendorp, Lemmeke Bodenau sowie deren Kollegen und Nachfolger als Vorsteher des ewigen Lichtes am Marienaltar der Johanniskirche

ANGABEN ZU PERSON UND FAMILIE:

Tibbeke von Netze war Vorsteherin des ewigen Lichtes am Marienaltar in der Johanniskirche, der von der Bruderschaft Unser Lieben Frauengilde versorgt wurde.

VERFÜGUNGEN ÜBER SACHGÜTER:

Ihr Nachlaß soll dem ewigen Licht am Altar Unser Lieben Frau in St. Johannis zugewendet werden zur syvinge und für Kleinode. Da es sich bei ihrem Nachlaß um selbsterarbeitetes Gut handelt, hat niemand das Recht, Beschwerde einzulegen.

Siegler: Hartwig Beve, Nikolaus Garlop, Ratsherren zu Lüneburg

Reinhardt, Testamente, S. 96, Nr. 65

\begin{tabular}{|cccc}
1406 & Okt. 19 & $\begin{array}{c}\text { Klaus Salzhausen } \\
\text { (mnd.) }\end{array}$
\end{tabular}

TV: Johann Winckemann, Johann Kolkhagen, Meinecke Neuenburg, Johann Zidouwen, Bürger zu Lüneburg

ANGABEN ZU PERSON UND FAMILIE:

Der Testator war Bürger zu Lüneburg.

VERFÜGUNGEN ÜBER SACHGÜTER:

Den selbsterarbeiteten mobilen und immobilen Nachlaß gibt der Testator seinem Sohn Johann.

Siegler: Arnd Cappenberg, Johann von der Mölen

Reinhardt, Testamente, S.97, Nr.66

\begin{tabular}{|cccc}
\hline 1407 Juni 13 & $\begin{array}{c}\text { Engelbrecht Hoke } \\
\text { (mnd.) }\end{array}$
\end{tabular}

TV: Everd Hoke, Klaus Leger, Bernd Vardendorp und Ludolf Bartholomäus, Bürger zu Lüneburg

ANGABEN ZU PERSON UND FAMILIE: -

VERFÜGUNGEN ÜBER SACHGÜTER:

Die übrigen mobilen und immobilen Güter sollen verkauft werden. Der Bargelderlös soll in einem Rentenkauf investiert werden. Mit dieser Rente soll Bettzeug für den Langen Hof in Lüneburg gekauft werden, vier feine Betten oder soviel der Ertrag erlaubt. Darin soll man arme, fremde, wandernde Leute beherbergen und innen dazu Connent und Brot geben, soviel die Rente hergibt. Wenn die Frau des Testators stirbt, dann sollen ihre sechs Mark Geldes an diese Rente fallen, damit sich die beschriebenen Betten und die Gabe zu ewigen Zeiten verbessern. 
Siegler: Dietrich Springintgut. Das Siegel Hartwigs on der Mölen ist abgefallen.

Reinhardt, Testamente, S.98, Nr. 67

\begin{tabular}{ccc}
\hline 407 Juni 28 & Johann Swendebeke \\
& & (mnd.)
\end{tabular}

TV: Ghese, Ehefrau des Testators; Godeke Tzerstede, Ratsherr; Johann von Ollensen, Klaus von Oedeme, Henning von Luderen, Bürger zu Lüneburg

ANGABEN ZU PERSON UND FAMILIE:

Der Testator war Bürger Lüneburgs; in seinem Testamentsformular nennt er seine Ehefrau Ghese und seine Kinder.

VERFÜGUNGEN ÜBER SACHGÜTER:

Das übrige mobile und immobile Gut hinterläßt er seiner Ehefrau Ghese und den Kindern. Sie sollen es nach dem Rat seiner Testamentsvollstrecker gemeinsam gebrauchen. Im Fall von Gheses Wiederverheiratung sollen die Kinder nach ihrer Abteilung alles zu gleichen Teilen besitzen. Im Fall einer erneuten Heirat soll seine Ehefrau 100 Mark Pfennige bekommen sowie die Hälfte des Hausrates.

Siegler: Johann Swendebeke, Johann von der Mölen, Ludolf Töbing

Von diesem Testament ist auch die zweite Ausfertigung vorhanden. Diese ist gleichfalls besiegelt und weicht nur in der Schreibweise von der ersten ab. Zahlreiche Einschnitte am oberen und unteren Rand zeigen die Kassation an.

Reinhardt, Testamente, S. 99f, Nr. 68

$1408 \quad$ Januar 7
TV: -
ANGABEN ZU PERSON UND FAMILIE:
$\begin{aligned} & \text { Der Testator war Bürger von Lüneburg. Pluckemus war mit einer gewissen Ghese } \\ & \text { verheiratet und hatte zwei Kinder namens Martin und Gheseke. } \\ & \text { (mnd.) }\end{aligned}$
VERFÜGUNGEN ÜBER SACHGÜTER:
Siegler: Johann von der Mölen, Ludolf Töbing
Das Testament ist auf Papier geschrieben mit aufgedrückten Siegeln
Reinhardt, Testamente, S. 100, Nr. 69




\section{April 2}

Metteke Schwertfeger

(mnd.)

TV: -

ANGABEN ZU PERSON UND FAMILIE:

Im Testament nennt sie ihren Bruder, Hermen von Rethem, und seine Ehefrau Wulgurghe sowie deren Tochter Metteke.

VERFÜGUNGEN ÜBER SACHGÜTER:

Die Testatorin hinterläßt ihrer Nichte Metteke Rethem den Kirchstuhl in St. Johannis.

Siegler: Johann von der Mölen, Ludolf von Winsen

Papier mit aufgedrücktem Verschlußsiegel

Reinhardt, Testamente, S. 101, Nr. 70

$1408 \quad$ Mai 28

Bernhard Stöterogge

(mnd.)

TV: -

ANGABEN ZU PERSON UND FAMILIE:

Der Bürger Stöterogge hatte mit seiner Frau Ghese die gemeinsamen Söhne Meyne und Johannes ${ }^{8}$.

VERFÜGUNGEN ÜBER SACHGÜTER:

Seiner Frau Geseke hinterläßt Stöterogge nicht nur Geldbesitz, sondern auch den gesamten Hausrat und alle Mobilien, wo immer er sie hat, ferner das gesamte Bettzeug und Laken sowie weiteres Zubehör, dann Kannen, Grapen, Kessel und sonstige Hausgerätschaften und Mobilien; über all diese Dinge soll seine Frau freie Verfügungsgewalt haben.

Siegler: Hartwig von der Mölen, Godeke Tzerstede

Papier mit aufgedrückten Verschlußsiegeln

Reinhardt, Testamente, S. $102 f$, Nr. 72

\section{August 18}

Geverd Gropeshorn

(mnd.)

TV: Ghereke Neuenkirchen, Hans Rullstorf, Hans Gropeshorn

ANGABEN ZU PERSON UND FAMILIE:

Gropeshorn war Bürger zu Lüneburg.

VERFÜGUNGEN ÜBER SACHGÜTER:

\footnotetext{
${ }^{8}$ WITZENDORFF verzeichnet weder Ehefrau noch Kinder des Testators. H.-J. v. WITZENDORFF, Stammtafeln, S.122.
} 
Mit zwanzig Mark soll man graue Laken kaufen und für Gott armen Leuten geben, die sie nötig haben. Die Kinder von Hans Gropeshorn, die im Kloster St. Marien sind, erhalten fünf Mark, damit man jedem eine Cappe kaufen kann.

Siegler: Klaus Sankenstede, Hans Schellepeper, Ratsherren

Papier mit aufgedrückten Siegeln. Urkunde durch Einschnitte ungültig gemacht.

Reinhardt, Testamente, S. $103 \mathrm{f}, \mathrm{Nr} .73$

1409 März 7

Johann Semmelbecker

(mnd.)

TV: Heinrich Kule, Provisor der Johanniskirche; Albert von der Mölen, Ratsherr; Hans von der Mölen, Ratsherr; Klaus Semmelbecker, Bruder des Testators; Hans und Dietrich, Neffen des Testators

ANGABEN ZU PERSON UND FAMILIE:

Johann Semmelbecker, Ratsherr und Sodmeister, war dreimal verheiratet: In erster Ehe heiratete er Gesche Springintgud, mit der er die Kinder Johann, Cord und Dietrich hatte, seine zweite Ehefrau war Tibbeke von Grönhagen, mit der er offenbar kinderlos blieb ${ }^{9}$. Aus der dritten Ehe mit Ligeke/Lyseke Pepersack stammen Albert, Alheid und Gesche. Die Söhne Johann und Albert werden ebenfalls in den Rat aufgenommen. Cord ist nachgewiesen an der Universität zu Erfurt, in Leipzig und Bologna. Der Testator starb wenige Tage nach der Testamentserrichtung.

VERFÜGUNGEN ÜBER SACHGÜTER:

Innerhalb eines Jahres und eines Tages nach Semmelbeckers Tode sollen seiner Frau Lyseke all ihre Hausgerätschaften, Kleider, Kleinode und Schmuck ausgeliefert werden, alles, was sie mit sich in die Ehe brachte, und was er ihr seitdem gegeben hat. Die zwei goldenen Tücher, die der Testator besitzt, sollen seinem Sarg übergelegt werden; später sollen sie in den Besitz der Johanniskirche übergehen. Mit einer reinen Mark soll für St. Johannis ein vergoldetes Kreuz angefertigt werden. Ferner sollen seine Testamentsvollstrecker für St. Johannis zwei vergoldete Kelche bestellen, damit man den Pfarrleuten Absolution gebe, wenn sie die Kommunion empfangen haben.

Siegler: Johann Semmelbecker, Johann von der Mölen, Johann Schellepeper

Reinhardt, Testamente, S. $106 \mathrm{ff}, \mathrm{Nr} .75$

1409 Juli 10

Ludolf Burmeister

(mnd.)

TV: Hermann Osnabrück, Meinecke Töbing, Schwäger des Testators

ANGABEN ZU PERSON UND FAMILIE:

\footnotetext{
${ }^{9}$ H.-J. v. WITZENDORFF, Stammtafeln, S.116.
} 
Der Testator war der Sohn des 1385 verstorbenen Ratsangestellten Ludolf Burmester ${ }^{10}$. Zu seiner weitläufigen Verwandtschaft zählten die Testatoren Dietrich Burmester und Immeke Burmester.

VERFÜGUNGEN ÜBER SACHGÜTER:

Die Ehefrau Winneke erhält das Haus, Hof und die Wurd mit allem Zubehör, mit allen Hausgerätschaften; sie erhält ferner das mobile und immobile Gut zur freien Verfügung.

Siegler: Johann von der Mölen, Ludolf Töbing

Papier mit aufgedrückten Siegeln.

Reinhardt, Testamente, S. 108, Nr. 76

1409 Oktober 8

Heinrich von dem Wede

(mnd.)

TV: Ehefrau Grete, Ludolf Töbing, Ratsherr, Johann Godenstorp, Johann von Ollensen, Ghereke Neuenkirchen, Bürger zu Lüneburg

ANGABEN ZU PERSON UND FAMILIE:

Heinrich von dem Wede, Bürger zu Lüneburg, war mit Grete verheiratet; dieser Ehe entstammte der Sohn Heinrich.

VERFÜGUNGEN ÜBER SACHGÜTER:

Grete und der gemeinsame Sohn Heinrich erhalten Haus, Hof und Wurd mit allem Zubehör sowie die Hausgerätschaften. Über den gesamten mobilen und immobilen Nachlaß haben sie freie Verfügung. Stirbt der Sohn vor der Ehefrau, so soll sie alleine und ungehindert über den Nachlaß verfügen. Nach beider Tod soll das Gut unter den Verwandten geteilt werden - eine Hälfte für die Verwandten des Testators, die andere Hälfte für die Verwandten der Ehefrau, Johann Rodes Kinder in Braunschweig.

Hartwig von der Mölen, Godeke Tzerstede, Ratsherren

Papier mit aufgedrückten Siegeln.

Reinhardt, Testamente, S.109f, Nr.77

1409 Oktober 27

Ludolf bei dem Sode

(mnd.)

TV: Johann von Ollensen, Johann Kolkhagen, Hans Cywert, Wilhelm von Dassel

ANGABEN ZU PERSON UND FAMILIE:

Eine Ehefrau oder eigene Kinder werden nicht im Testament erwähnt. Genannt werden ein Neffe und ein Ohm, beide sind Priester, sowie die in Lübeck lebende Schwester der Mutter.

VERFÜGUNGEN ÜBER SACHGÜTER:

Für zwei vom Testator gestiftete Kommenden in der Lambertikirche sollen Meßgewand,

${ }^{10}$ H.-J. v. WITZENDORFF, Stammtafeln, S.23. 
Kelch und Buch und sonstige Zugehörigkeiten angeschafft werden.

Die Siegel sind abgeschnitten, um das Testament ungültig zu machen.

Reinhardt, Testamente, S.110f, Nr.78

\begin{tabular}{|ccc}
1410 & Februar 9 & $\begin{array}{c}\text { Hans Melbeck } \\
\text { (mnd.) }\end{array}$
\end{tabular}

TV: Otto Garlop, Bürgermeister; Johann von der Mölen, Nikolaus Sohn, Hartwig von der Mölen, Ratsherren

ANGABEN ZU PERSON UND FAMILIE:

Der Testator war offenbar ehe- und kinderlos ${ }^{11}$. Des Testators Bruder Dietrich ist 1410 in Livland nachgewiesen. Dietrich war Vater zweier Söhne: der eine Sohn Ludolf ist 1418 als Geistlicher belegt, der andere Sohn hieß Dietmar und starb 1430.

VERFÜGUNGEN ÜBER SACHGÜTER:

Für den in Livland weilenden Neffen den Hausrat des Testators. Wenn der Neffe tot sein sollte, dann soll der Hausrat zum Seelenheil des Testators, seiner Eltern und seines Sohnes verwendet werden.

Siegler: Hartwig Beve, Johann Rese, Ratsherren

Papier mit aufgedrückten Siegeln

Reinhardt, Testamente, S.111ff, Nr.79

\begin{tabular}{|ccc|c}
1410 & Juli & 14 & $\begin{array}{c}\text { Ludolf von Hagen } \\
\text { (mnd.) }\end{array}$
\end{tabular}

TV: Metteke, Ehefrau des Testators; Ludolf von Hagen, Vetter des Testators; Johann von Pentze, Prior von Oldenstadt; Godeke von Tzerstede, Ratsherr; Hans Loffhagen, Bürger

ANGABEN ZU PERSON UND FAMILIE:

Der Sülfmeister Ludolf von Hagen war verheiratet mit Metteke. Offensichtlich war er Vater mehrerer Kinder. Genannt werden im Testament Elsebe, Hanseke, Ludolf und Heinrich. Ludolf von Hagen starb im Jahr der Testamentserrichtung. Sein Ohm war der als Testamentsvollstrecker fungierende Ratsherr Godeke von Tzerstede.

VERFÜGUNGEN ÜBER SACHGÜTER:

Man soll ein goldenes Tuch auf des Testators Sarg kaufen, das dann für ein Meßgewand verwendet werden soll. Seinem ersten Sohn Ludolf gibt von Hagen freie Kost und Kleidung solange, wie er unter vierundzwanzig Jahren ist, dafür soll er im Geschäft seiner Frau und der Kinder mitarbeiten, so, wie er es bisher nach Rat der Testamentsvollstrecker getan hat. Nach diesen vierundzwanzig Jahren soll er freie Kost und acht Mark seinen Lebtag erhalten. Will er das nicht, soll er sechs Mark sein Lebtag erhalten. Ebenfalls möchte von Hagen, daß man seinen Testamentsvollstreckern am St. Michaelismarkt ein Paar Hosen schenkt, und zwar die besten, die man kaufen kann. Den Rest seiner immobilen und

\footnotetext{
${ }^{11}$ H.-J. v. WITZENDORFF, Stammtafeln, S.76.
} 
mobilen Güter erhält nach Abzug aller Schulden seine Frau. Im Fall einer Wiederverheiratung seiner Frau soll sie die halbe Herrschaft zurückerhalten, die sie in die Ehe miteingebracht hat; ferner steht ihr ihr Teil des Gutes mit ihren Kleidern und ihrem Geschmeide zu.

Siegler: Ludolf Töbing, Ludolf von Winsen, Ratsherren; Ludolf von Hagen

Reinhardt, Testamente, S.113ff, Nr.80

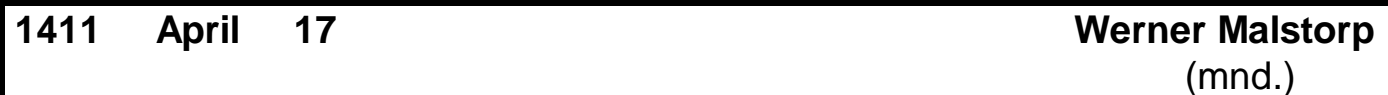

TV: Johann Schermbeck, Heinrik Blanke, Ludolf Bertolomäus, Hermann von Bergen

ANGABEN ZU PERSON UND FAMILIE:

Der Testator war Vater eines Sohnes namens Werner. Offensichtlich war die Ehefrau des Testators zum Zeitpunkt der Testamentserrichtung bereits verstorben.

VERFÜGUNGEN ÜBER SACHGÜTER:

Malstorp stiftet dem Bau von St. Lamberti seinen besten goldenen Ring. Bertold hinterläßt er einen Kessel von einem Zuber Wasser. Arnd erhält seinen besten blauen Rock und Herrmann die beste schwarze Hoike, seine Schwester Metteke bekommt ein Paar Blekeder Laken und die beste Kinderdecke, die St. Jakobsgilde vier Schillinge.

Siegler: Hans von der Mölen, Godeke von Tzerstede, Ratsherren

Papier mit aufgedrückten Siegeln

Reinhardt, Testamente, S.118, Nr.82

1411 April $30 \quad \begin{gathered}\text { Klaus Garlop } \\ \text { (mnd.) }\end{gathered}$

TV: Ludolf von Winsen, Godeke von Tzerstede

ANGABEN ZU PERSON UND FAMILIE:

Klaus Garlop, Bürger zu Lüneburg, war dem Anschein nach zweimal verheiratet, denn er nennt in seinem Testament zwei Ehefrauen, deren eine verstorben ist; er bezeichnet seine Tochter Beate als Waise. Die zweite Ehefrau Aleke lebte noch zum Zeitpunkt der Testamentserrichtung. Über gemeinsame Kinder aus dieser Ehe sagt das Testament nichts aus. Einer weiteren, offenbar nichtehelichen Beziehung mit einer gewissen Tibbeke entstammten die Kinder Ghebeke und Ghereke. Der Testator ging aus der zweiten Ehe des Johann Garlop mit Gebeke Huth hervor ${ }^{12}$. Der Vater und der Bruder des Testators waren Ratsherren.

VERFÜGUNGEN ÜBER SACHGÜTER:

Die Testamentsvollstrecker sollen zunächst die Schulden begleichen. Die erforderlichen Anweisungen dazu hat der Testator innen in einer von ihm besiegelten Schrift gegeben, die auch Auskunft über die Verteilung von Hausrat, Vieh jeglicher Art und Kleidung gibt.

\footnotetext{
${ }^{12}$ H.-J. v. WITZENDORFF, Stammtafeln, S.40.
} 
Seinen gesamten übrigen Nachlaß nebst Hausrat vererbt der Testator seiner Frau Aleke bis auf die Gegenstände des Hausrats, die der Testator Tibbeke, Ghebeke und Ghereke gegeben hat; auch über diesen Vorgang gibt die besondere Urkunde Auskunft.

Wenn gegen diese Regelung mit Erfolg Einspruch erhoben wird, so soll des Testators Hausrat und Fahrhabe, Zimmerholz und Dielen, alles, was in Haus und Hof ist, und der Harnisch, der nicht zum Heergewät gehört, verkauft werden. Vom Erlös soll seine Tochter Ghebeke 30 Mark erhalten. Den Resterlös sollen sich Ghereke und Tibbeke zu gleichen Teilen teilen; den innen zuvor übertragenen Hausrat, die Kleider und das Vieh sollen sie behalten.

Siegler: Ludolf Töbing, Johann Rese, Ratsherren

Reinhardt, Testamente, S.118ff, Nr.83

\section{Juni $6 \quad$ Alard von Pattensen \\ (mnd.)}

TV: Hilke, Ehefrau; Heinrich von Winsen, Priester; Johann Ulczemann, Hans Lüneburg, Vicke Stoffregen, Bürger zu Lüneburg

ANGABEN ZU PERSON UND FAMILIE:

Der Bürger Alard von Pattensen war mit Hilke verheiratet; aus dieser Ehe stammte anscheinend der Sohn Johann. Johann von Pattensen war Vogt; zum Zeitpunkt der Testamentserrichtung des Vaters war er offenbar nicht mehr am Leben ${ }^{13}$.

VERFÜGUNGEN ÜBER SACHGÜTER:

Den mobilen und immobilen Nachlaß erhält die Ehefrau, die über diesen ungehindert entscheiden darf.

Siegler: Klaus Sankenstede, Ludolf von Winsen

Papier mit aufgedrückten Siegeln

Reinhardt, Testamente, S.120, Nr.84

\begin{tabular}{|lcc|c}
\hline 141 & Juli & 13 & $\begin{array}{c}\text { Hermann von Rethem } \\
\text { (mnd.) }\end{array}$
\end{tabular}

TV: Hessenland, der Bäcker; Petrus loghouwe

ANGABEN ZU PERSON UND FAMILIE:

Der Testator, ein Bürger zu Lüneburg, war zweimal verheiratet; aus jeder Verbindung gingen Kinder hervor.

VERFÜGUNGEN ÜBER SACHGÜTER:

Der Testator verfügt mit Zustimmung seiner Frau und seiner Kinder. Seinen Nachlaß|

${ }^{13}$ G. MATTHAEI, Vikariestiftungen, S. 224. 
hinterläßt er seiner Frau Wolborg und seinen zwei Kindern; sie haben freie Verfügungsgewalt über den Nachlaß, denn es ist das Gut Wolborgs.

Papier ohne Siegel

Reinhardt, Testamente, S.121, Nr.85

1412 Februar $29 \quad \begin{gathered}\text { Adelheid Knakerugge } \\ (\mathrm{mnd})\end{gathered}$

TV: Aldich von Penze, Meinecke von Elstere, Bürger zu Lüneburg

ANGABEN ZU PERSON UND FAMILIE:

Adelheid war die Witwe Klaus Knakerugges.

VERFÜGUNGEN ÜBER SACHGÜTER:

Die Testatorin wendet ihre zweitbeste Hoike dem Bau von St. Michaelis zu. Dem Licht im Heiligen Geist auf dem Markt vermacht sie acht Schillinge. Ihre besten Servietten und Tischtücher hinterläßt sie dem Hohen Altar in Scharnebeck.

Siegler: Johann von der Mölen, Ludolf von Winsen

Die Zweitausfertigung auf Papier ist ebenfalls von Johann von der Mölen und Ludolf von Winsen besiegelt.

Reinhardt, Testamente, S.122, Nr.86

1412 März $6 \quad$ Johann Holeborn

(mnd.)

TV: Johann Wokersinn, Heinrich Provest, Bürger

ANGABEN ZU PERSON UND FAMILIE:

Holeborn war Bürger zu Lüneburg. Aus der Ehe mit Beke stammte vermutlich der Sohn Hans.

VERFÜGUNGEN ÜBER SACHGÜTER:

Hans Holeborn hinterläßt der Testator eine neue Jacke und ein Truhe.

Siegler: Hartwig Beve, Johann von der Mölen

Papier mit aufgedrückten Siegeln

Reinhardt, Testamente, S.123, Nr.87

TV: -

ANGABEN ZU PERSON UND FAMILIE:

Dietrich Erbstorf, Bürger zu Lüneburg, war verheiratet mit Abele. 
VERFÜGUNGEN ÜBER SACHGÜTER:

Mit Zustimmung seiner Ehefrau Abele gibt er nach inrer beider Tod inr Wohnhaus, das vor der alten Brücke liegt, mit allem Zubehör und aller Fahrhabe an seine Onkel Ludolf, Johannes und Heinrich, die Söhne des verstorbenen Hans von Haghen. Zu ihren Lebzeiten wollen der Testator und seine Frau das freie Recht an ihren Gütern behalten.

Siegler: Ludolf Töbing, Hans von der Mölen

Reinhardt, Testamente, S.124, Nr.88

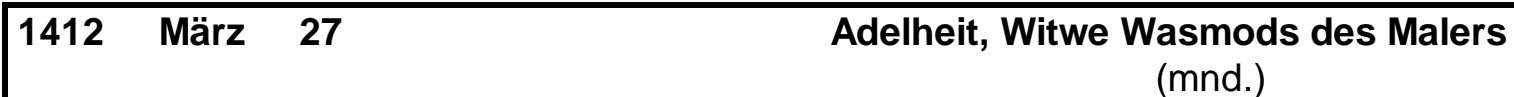

TV: Johann Handorp, Johann Bilne, Priester und Vikare in St. Johannis

ANGABEN ZU PERSON UND FAMILIE:

Wasmod, der verstorbene Mann der Testatorin, war Lüneburger Bürger.

VERFÜGUNGEN ÜBER SACHGÜTER:

Heseke, ihre Magd, erhält eine Mark Pfennige und die Truhe der Testatorin.

Siegler: Johann von der Mölen, Sohn des Nikolaus, Johann von der Mölen, Sohn des Jakob

Reinhardt, Testamente, S.124f, Nr.89

\section{$\begin{array}{llll}1412 & \text { Mai } 15 & \text { Hans von Munster }\end{array}$}

(mnd.)

TV: Klaus Hentesfeld, Ludolf Dryddendel, Bürger zu Lüneburg

ANGABEN ZU PERSON UND FAMILIE: -

VERFÜGUNGEN ÜBER SACHGÜTER:

Den übrigen Nachlaß erhält des Testators Frau Drude und der gemeinsame Sohn Hans zur Nutzung nach Stadtrecht.

Siegler: Heinrich Bere, Godeke Tzerstede

Papier mit aufgedrückten Siegeln

Reinhardt, Testamente, S.125, Nr.90 
ANGABEN ZU PERSON UND FAMILIE:

Johann Heyne war Bürger zu Lüneburg. Er war mit einer gewissen Grete verheiratet, mit deren Zustimmung er das Testament errichtete.

VERFÜGUNGEN ÜBER SACHGÜTER:

Zur Bekleidung Armer zwischen dem St. Michaelis- und dem St. Martinstag sollen jährlich für zwanzig Mark Geldes Tuch und Schuhe gekauft werden. Nach dem Tod seines Bruders Hermann fällt die eine Mark Leibrente an die Rente für die Bekleidung. Den übrigen Nachlaß, Haus, Hof und Zubehör, Mobilien und Immobilien soll seine Ehefrau haben. Nach ihrem Tod soll das gesamte Gut an arme Verwandte fallen und/oder für Gottes Ehre verwendet werden.

Siegler: Hartwig Beve, Ludolf von Winsen

Reinhardt, Testamente, S.125ff, Nr.91

\section{Juni $29 \quad$ Hans Trebbow \\ (mnd.)}

TV: Dietrich Tateren, Priester; Mechthild, Ehefrau; Hermann Snytker und Heinrich Werkmeister, Bürger

ANGABEN ZU PERSON UND FAMILIE:

Trebbow war Kannengießer.

VERFÜGUNGEN ÜBER SACHGÜTER:

Den restlichen mobilen und immobilen Nachlaß erhält seine Fau Mechthild zur freien Verfügung.

Siegler: Hartmut Beve, Johann Rese

Papier mit aufgedrücken Siegeln

Reinhardt, Testamente, S.128f, Nr.92

\section{November 10}

Helmich Rorbag

(mnd.)

TV: Ehefrau Ghese, Hans von Melne, Dietrich Hessenland und Hans Elvers

ANGABEN ZU PERSON UND FAMILIE:

Rorbag war Bürger zu Lüneburg, seine Ehefrau hieß Ghese.

VERFÜGUNGEN ÜBER SACHGÜTER:

Den gesamten Nachlaß gibt er seiner Frau, egal, wo dieser sich befinde, in Erbe, Renten, ob er mobil oder immobil sei. Betont wird die freie Verfügungsgewalt der Ehefrau über den Nachlaß, denn er sei beider wohlgewonnenes Gut, beide hätten ihn erarbeitet.

Siegler: Johann von der Mölen, Sohn des Jakob; Hartwig von der Mölen 
Papier mit aufgedrückten Siegeln

Reinhardt, Testamente, S.129, Nr.93

\begin{tabular}{ccc}
\hline 413 & Januar 21 & Johan Krowel \\
(mnd.)
\end{tabular}

TV: Johann Basedow, Priester; Bernd Basedow, Bürger in Lüneburg

ANGABEN ZU PERSON UND FAMILIE:

Krowel war Bürger in Lüneburg.

VERFÜGUNGEN ÜBER SACHGÜTER:

Die zum Heiratsgut gehörenden Hausgerätschaften erhält seine Ehefrau zur freien Verfügung zurück.

Krowel gibt ihr ferner soviele Grapenkessel, wie sie für sich nötig hat, zum Gebrauch zu ihren Lebzeiten. Nach ihrem Tod sollen sie wieder seinen rechten Erben zukommen. Das übrige mobile und immobile Gut soll die Tochter des Testators erhalten, die Frau des Bernd Basedow.

Siegler: Ludolf Töbing, Ludolf von Winsen

Papier mit aufgedrücken Siegeln

Reinhardt, Testamente, S.130, Nr.94

1413 August $15 \quad \begin{gathered}\text { Johann von der Mölen } \\ \text { (mnd.) }\end{gathered}$

TV: Johann Malstorp, Vikar in der Johanniskirche, Heinrich Viskule, Heinrich Bere, Bürgermeister zu Lüneburg, und Hans Semmelbecker

ANGABEN ZU PERSON UND FAMILIE:

Der Ratsherr und Sülfmeister Johann von der Mölen war der Sohn Jakobs von der Mölen und der Gesche Capellen, der Tochter Dietrich Capellens und der Elisabeth Semmelbecker ${ }^{14}$.

Der Testator wurde im Lauf seiner zwei Ehen Vater von acht Kindern; drei der Töchter werden Nonnen, zwei Söhne studieren in Erfurt, und der im Testament erwähnte Sohn Heinrich ist der einzige, der wie sein Vater die Ratsmitgliedschaft erwirbt.

VERFÜGUNGEN ÜBER SACHGÜTER:

Den Hausrat, das Tafelgeschirr und die Kleinodien, was immer Mölen hinterläßt, vererbt er seinen Kindern. Johann Malstorp erhält die Bibel des Testators für die Dauer seines Lebens, nach seinem Tod soll sie für immer auf dem Chor in St. Lamberti bleiben. Ferner gibt der Testator dem eben genannten Herrn Johann Marderfellfutter und sein wollenes

\footnotetext{
${ }^{14}$ H.-J. v. WITZENDORFF, Stammtafeln, S.79.
} 
Oberkleid, den Rock vererbt er als Meßgewand.

Siegler: Otto Garlop, Bürgermeister, Godeke Tzerstede, Ratsherr

Pergament mit aufgedrückten Siegeln. Die Urkunde ist durch Einschnitte ungültig gemacht.

Reinhardt, Testamente, S.131ff, Nr.95

1413 August 24

Heinrich von Hertber

(mnd.)

TV: Ludolf Töbing, Ratsherr; Hermann Kruse; Reymer, Bäcker

ANGABEN ZU PERSON UND FAMILIE:

Hertber war Bürger zu Lüneburg.

VERFÜGUNGEN ÜBER SACHGÜTER:

Bei Wiederverheiratung bekommt seine Frau 200 Mark Pfennige und ihre Hausgerätschaften.

Siegler: Ludolf von Winsen, Godeke Tzerstede, Ratsherren

Papier mit aufgedrückten Siegeln

Reinhardt, Testamente, S.135f, Nr.96

1413 August 29

Heinrich von dem Dage

(mnd.)

TV: Godeke von Tzerstede, Johann von Oldensen, Klaus von Oedeme und Johann von Luderen

ANGABEN ZU PERSON UND FAMILIE:

Der Testator war Bürger zu Lüneburg.

VERFÜGUNGEN ÜBER SACHGÜTER:

Den übrigen mobilen und immobilen Nachlaß für die Ehefrau Beke zur freien Verfügung.

Siegler: Johann von Embsen, Hartwig von der Mölen

Papier mit aufgedrückten Siegeln

Reinhardt, Testamente, S.136, Nr.97

1413 September $7 \quad$ Johann von Tespe

(mnd.)

TV: Meister Johann Swertfeger, Arnd Cappenberg, Ratsherr, Klaus von Oedeme und Heinrich Schermbeck, Bürger zu Lüneburg

ANGABEN ZU PERSON UND FAMILIE:

Tespe war Bürger zu Lüneburg. 
VERFÜGUNGEN ÜBER SACHGÜTER:

Seine Frau Berte soll das Haus bei der Saline haben und zwanzig Mark Pfennige, acht silberne Löffel und die kleinste silberne Schale sowie mit inren Kindern die Frauengerade. Damit soll sie von seinen anderen Kindern und Besitz abgeteilt sein. Ferner soll seine Tochter Kerstin das Wohnhaus des Testators haben, einen Schrank, eine silberne Schale und einen silbernen Gürtel, aus dem ein Kelch gefertigt werden soll.

Siegler: Ludolf Töbing, Hartwig von der Mölen

Papier mit aufgedrückten Siegeln

Reinhardt, Testamente, S.137, Nr.98

\section{\begin{tabular}{llll}
\hline 413 & September 7 & Beke Godenstorp
\end{tabular} \\ (mnd.)}

TV: Johann Czelk, Priester; Johann Wokersinn, Klaus von Oedeme, Johann von der Heide, Heinrich Crakow

ANGABEN ZU PERSON UND FAMILIE:

Die Testatorin war die Witwe Johann Godenstorps, mit dem sie gemeinsame Kinder hatte.

VERFÜGUNGEN ÜBER SACHGÜTER:

Ihr mobiles und immobiles Gut sollen ihre Kinder erhalten.

Siegler: Ludolf Töbing, Arnd Cappenberg, Ratsherren

Papier mit aufgedrückten Siegeln

Reinhardt, Testamente, S.138f, Nr.100

\section{September $12 \quad$ Heinrich von Gothing \\ (mnd.)}

TV: Heinrich Seygermaker, Curd Dalhausen, Wilhelm von Dassel, Curd Knowel, Bürger zu Lüneburg

ANGABEN ZU PERSON UND FAMILIE:

Der Testator war Bürger zu Lüneburg. Er war verheiratet und Vater zweier Kinder.

VERFÜGUNGEN ÜBER SACHGÜTER:

Gothing vermacht Gheseke, Drudens Tochter, zwanzig Mark Pfennige und ein Paar geziemender Kleider.

Papier mit aufgedrückten Siegeln, die abgefallen sind. Die Urkunde ist durch Einschnitte ungültig gemacht worden.

Reinhardt, Testamente, S.139f, Nr.101 


\section{Februar $4 \quad$ Johannes von Lippinghausen gen. Handorp}

(lat.)

TV: Johannes Synstorp, Lüder Maneke, Johann Tzillik, Johann Varendorp, ständige Benefiziaten an St. Johannis sowie Wykbold Wykboldi, Priester

ANGABEN ZU PERSON UND FAMILIE:

Der Testator war ständiger Vikar in St. Johannis.

VERFÜGUNGEN ÜBER SACHGÜTER:

Der Vikarie in St. Gertrudis, zur Ehre der Jungfrau Maria, des Apostels Mathias der Maria Magdalena und Katharina am Dreikönigsaltar im nördlichen Teil/Flügel stiftet Lippinghausen

ein Meßbuch, ein Brevier, zwei Zinnflaschen, ferner ein besseres Leinentuch für eine Albe und ein Amict unter der Kasel, einen Leinengürtel, vier eherne Töpfe von mittlerer Größe und zwei kleine Töpfe sowie einen Tisch, den inm Herr Johann de Bilne zusammen mit einem Handtuch und einem Tischtuch gab.

Ferner überträgt er der Vikarie des heiligen Willehard in der Kapelle St. Gertrudis das, was er besitzt: zwei mittlere Betten mit zwei paar Laken und zwei Pfühlen sowie zwei Bettdecken und zehn mittelgroße Sitzkissen, dann drei eherne mittelgroße und kleine Töpfe, einen Tisch, der beim Dekan Bardowicks steht, ein Tischtuch und zwei hohe Gefäße. Der Vikarie Aller Apostel überträgt er vier eherne Töpfe, nämlich einen größeren mit drei mittleren; der Testator wünscht, daß all diese Dinge dort bei seinen Nachfolgern immer bleiben. Er schenkt der Vikarie am Heilig-Kreuz-Altar in der St. Ciriacuskirche seinen besseren Schrank. Die genannte Vikarie Aller Apostel und der heiligen Aldegunde in der St. Johanniskirche erhält all sein Backgeschirr, das er in seinem Backhaus hat, mit vier Sitzkissen und zwei hohe Gefäße; Lippinghausen möchte, daß all diese Dinge ewig bei der Vikarie bleiben. Der Vikarie, die er in der Kapelle St. Gertrudis gegründet hat, hinterläßt er sein über der Matraze gestreiftes Bett, das in seiner Kammer steht, mit einem normalen Paar Laken, Pfühl und Kopfkissen sowie einer besseren Decke und einem Bettgestell. Er wünscht, daß von dem nicht gebleichten Leinenstoff, der in einer Truhe in seiner Herberge verwahrt ist, Kleidungsstücke für die Armen gemacht werden. Lippinghausen schenkt dem Magister Eggehard, Archidiakon in Lüneburg, eine größere silberne Spange und eine andere silberne Spange dem Propst in Lüne. Borchard von dem Berge, Prior von St. Michaelis, erhält einen silbernen (Meß-)Becher, Baldewin von Wenden, dem Doktor, das Venezianische Glas mit den silbernen Füßen. Johann Varendorp hinterläßt der Testator seinen Tragaltar mit zwei neuen Flaschen, die er ihm selbst gegeben hat. Er schenkt Johann Synstor eine kleinere silberne Spange/Brosche. Einen kleineren silbernen Krug gibt er Ghereke Wykbold und einen anderen Krug Eggheling Sartor. Ferner besitzt Lippinghausen drei lange silberne Krüge, von diesen schenkt er - mit den jeweiligen Deckeln versehen - einen Nycolaus Grawerok, einen anderen Johannes Elers, jedoch den dritten Herrn Hermann Wykbold. Darüberhinaus schenkt er Hermann Wykbold seinen besseren schwarzen und pelzgefütterten Rock. Johann Tzillik erhält ein Bett, ein Pfühl, ein Paar Laken und ein besseres Kopfkissen mit einem Bettgestell sowie einen Zinnkrug von einen Stübchen Wein. Die Ehefrau Heinrichs von der Heide erhält zwölf silberne Löffel, die ihm Johannes de Bilne gegeben hat. Ferner überträgt er einem jeden seiner genannten Testamentsvollstrecker drei Mark Denare mit einem Paar Hosen. Johann von Pentze hinterläßt er ein mittelhohes Gefäß mit zwei Flaschen von einem halben Stübchen Wein. Heidekinus erhält Lippinghausens neuen Chorrock, der in seiner Truhe ist, Nikolaus Sartor ein Paar Hosen, Hinrik Winsen ein Paar Hosen, Tybbecke, seine Magd, zehn Mark mit einer besseren doppeltgefältelten Hoike sowie das Bett, auf dem sie schläft, sein Kleriker Ludolph vier Mark mit einer doppeltgefältelten schwarzen, grau gefütterten Hoike. 
Siegler: Hartwig Beve, Hartwig von der Mölen

Reinhardt, Testamente, S.146ff, Nr. 105

\begin{tabular}{|ccc}
\hline 1414 & Mai 6 & $\begin{array}{c}\text { Hans Niterd } \\
\text { (mnd.) }\end{array}$
\end{tabular}

TV: -

ANGABEN ZU PERSON UND FAMILIE:

Der Testator hatte eine Beziehung mit seiner Magd namens Grete, die offensichtlich von inm ein Kind erwartete.

VERFÜGUNGEN ÜBER SACHGÜTER:

Seinen gesamten Hausrat soll Grete mit dem Kind erhalten, das sie von Niterd erwartet. Gemeinsam sollen sie darüber verfügen; stirbt einer von ihnen, soll es dem anderen für die Dauer seines Lebens zufallen.

Siegler: Johann von Embsen, Johann Semmelbecker

Reinhardt, Testamente, S.148f, Nr.106

\begin{tabular}{|ccc}
\hline 1414 & Juni 29 & $\begin{array}{c}\text { Heinrich Uplegger } \\
\text { (mnd.) }\end{array}$
\end{tabular}

TV: -

ANGABEN ZU PERSON UND FAMILIE:

Der Testator war Bürger zu Lüneburg. Der Testator war wahrscheinlich der aus Braunschweig eingewanderte, 1382 eingebürgerte Münzmeister, aus dessen Ehe mit Benedicta Thode der Sohn Hans hervorging ${ }^{15}$.

VERFÜGUNGEN ÜBER SACHGÜTER:

Falls sein Sohn heiratet, er oder seine Frau sich nicht mit der Frau des Testators vertragen, dann soll des Testators Frau jedes Jahr dreißig Mark erhalten, dazu soll sie das Besitzrecht haben an seinem Tafelgeschmeide, und sie soll das Bett erhalten, auf dem sie zu schlafen pflegt, mit seinem Zubehör und ihre Truhe(n) sowie ihre Schränke mit ihren Kleinodien und ihren Kleidern; damit mag sie tun und lassen, was sie will. Hiermit sollen der Besitz des Sohn des Testators und seiner Frau vom Gut der Mutter getrennt sein.

Siegler: Heinrich Uplegger, Albert von der Mölen, Johann Schellepeper

Reinhardt, Testamente, S.149f, Nr.107

\begin{tabular}{llll}
\hline 1415 & Juni 28 & Gese Lübberstedt
\end{tabular}

\footnotetext{
${ }^{15}$ H.-J. v. WITZENDORFF, Stammtafeln, S.136.
} 
TV: Johann von Pentze, Priester; Johann Malsdorp; Hans von Elstere

ANGABEN ZU PERSON UND FAMILIE:

Wahrscheinlich war die Testatorin Gesche Drespe, Witwe des 1408 verstorbenen Albert Lübberstedts $^{16}$. Sie war Mutter von vier Kindern und starb 1418.

VERFÜGUNGEN ÜBER SACHGÜTER:

Zu der Vikarie in St. Johannis am Martinsaltar gibt die Testatorin einen angefertigten Kelch, eine Albe und ein Seidenstück. Der Vikarie in St. Nikolai hinterläßt sie eine silberne Schale und Silbergeschmeide, das Alheyd, ihrer Schwester, gehört hatte. Ferner schenkt sie Meynard fünfzehn Mark für seine Priestergewänder. Brun, dem Sohn Jakob Malstorfs, vermacht die Testatorin einen Ring im Wert von drei Mark.

Siegler: Godeke Tzerstede, Johann von Ollensen

Reinhardt, Testamente, S.150f, Nr.108

\begin{tabular}{|cccc}
\hline 145 & Juli 25 & $\begin{array}{c}\text { Klaus Röder } \\
\text { (mnd.) }\end{array}$
\end{tabular}

TV: Helmich Suderburg, Reimer Hoken

ANGABEN ZU PERSON UND FAMILIE:

Der Testator war Bürger zu Lüneburg.

VERFÜGUNGEN ÜBER SACHGÜTER:

Das Wohnhaus des Testators erhält seine Ehefrau Ghese mit allem Hausgerät zur freien Verfügung.

Siegler: Godeke Tzerstede, Johann von Ollensen

Reinhardt, Testamente, S.151f, Nr.109

\begin{tabular}{|ccc|c}
\hline 1415 & Juli & 27 & $\begin{array}{c}\text { Lüder Bardowick } \\
\text { (mnd.) }\end{array}$
\end{tabular}

TV: Hilleke, Ehefrau Bardowicks; Kerstian von Berghen, ihr Bruder; Johann Schellepeper; Hermen Cruse, Ratsherr; Cord Springintgut; Hermen Bardowick, Bruder des Testators

ANGABEN ZU PERSON UND FAMILIE:

Der Testator, Bürger der Stadt Lüneburg, war ein Sohn des Sülfmeisters Dietrich Bardowick aus erster Ehe ${ }^{17}$. Lüder Bardowick heiratete Hille von Bergen, mit der er sechs Söhne und eine Tochter hatte. Der Bruder des Testators, Hermann, war Sülfmeister und Vater von sieben Kindern, die z.T. vom Testator bedacht werden. Lüder Bardowick starb 1420. Sein Cousin Dietrich testierte 1406.

\footnotetext{
${ }^{16}$ H.-J. v. WITZENDORFF, Stammtafeln, S.73.

${ }^{17}$ H.-J. v. WITZENDORFF, Stammtafeln, S.3.
} 
VERFÜGUNGEN ÜBER SACHGÜTER:

Des Testators Hausrat soll an die Ehefrau Hilleke und die Tochter Grete fallen. Man soll zwölf Mark für grauen Stoff geben, mit dem man arme Leute bekleiden soll. Es sollen dreißig Paar Schuhe gekauft werden, die armen Leuten zu geben sind. Ein Seidentuch soll gekauft und dem Sarg des Testators übergelegt werden; wenn sein Begräbnis vorüber ist, soll man das Seidentuch für eine Kapuze eines geistlichen Gewandes der Kirche in Ramelslo geben. Bardowick hinterläßt Grete und Gheseke, den Töchtern seines Bruders, dreißig Mark für ihre Kleidung, wenn sie für die Heirat ausgestattet werden.

Siegler: Hartwig Beve, Dietrich Springintgut

Papier mit aufgedrückten Siegeln

Reinhardt, Testamente, S.152f, Nr.110

$\begin{array}{ccccc}1415 & \text { Juli } & 31 & \begin{array}{c}\text { Johann Hofmann } \\ \text { (mnd.) }\end{array}\end{array}$

TV: Dietrich Springintgut, Ratsherr zu Lüneburg; Cord Springintgut, sein Bruder; Johann Abbenburg

ANGABEN ZU PERSON UND FAMILIE:

Der Testator war Bürger der Stadt Lüneburg.

VERFÜGUNGEN ÜBER SACHGÜTER:

Hofmann vererbt seiner Ehefrau Alheide mit ihrer Tochter Gheseke sein Wohnhaus mit allem Zubehör, allem Hausgerät und Fahrhabe.

Siegler: Godeke Tzerstede, Johann von Ollensen

Reinhardt, Testamente, S.154f, Nr.111

$\begin{array}{ccc}1415 & \text { Dezember } 3 & \begin{array}{c}\text { Abele von Holstele } \\ \text { (mnd.) }\end{array}\end{array}$

TV: Johann Groven, Mann ihrer Tochter; Johan von Hasle; Henning von Bornsen; Hans Vogel

ANGABEN ZU PERSON UND FAMILIE:

Die Testatorin war die Witwe Richard von Holsteles.

VERFÜGUNGEN ÜBER SACHGÜTER:

Ihre Tanten Wobbeke, Gheseke und Aleke, Töchter des verstorbenen Meyneke von Winsen, erhalten jeweils ein Bett und ein Kopfkissen. Die Magd Jürgen Seggers, Metteke, soll eine Stiege Leinen bekommen.

Siegler: Johann von Embsen, Godeke Tzerstede

Papier mit aufgedrückten Siegeln

Reinhardt, Testamente, S.155f, Nr.112 
\begin{tabular}{llll}
\hline 1416 & Mai 2 & Ludolf Woye
\end{tabular}

(mnd.)

TV: Hermann Kruse, Ratsherr zu Lüneburg; Heinrich Blanke; Meine von Elstere; Dietrich von Eschen, Stiefsohn des Testators

ANGABEN ZU PERSON UND FAMILIE:

Der Testator war Bürger der Stadt Lüneburg.

VERFÜGUNGEN ÜBER SACHGÜTER:

Die Ehefrau des Testators erhält die Hälfte des Hausrates. Ferner vererbt Woye ihr sein Wohnhaus mit allem Zubehör. Aus des Testators Fahrhabe soll man seine Nichte Gheseke bekleiden, die die andere Hälfte des Hausrates erhalten soll. Ihrem Bruder Ludwig soll sie ein Bett mit dem entsprechenden Zubehör abgeben.

Siegler: Hartwig Beve, Ludolf von Winsen

Papier mit aufgedrückten Siegeln

Reinhardt, Testamente, S.156f, Nr.113

\begin{tabular}{|lcc|}
\hline 1416 & Juli 19 & $\begin{array}{c}\text { Heinrich Rodenborch } \\
\text { (mnd.) }\end{array}$
\end{tabular}

TV: Johann Blanke, Bernd von Hannover und Hans Saffan, Bürger zu Lüneburg

ANGABEN ZU PERSON UND FAMILIE:

Der Testator war Bürger der Stadt Lüneburg.

VERFÜGUNGEN ÜBER SACHGÜTER:

Grete Mertens erhält den Hausrat Rodenborchs.

Siegler: Hartwig von der Mölen, Hermann Kruse

Papier mit aufgedrückten Siegeln

Reinhardt, Testamente, S.158f, Nr.115

\begin{tabular}{|ccc|c}
\hline 1416 & Juli & 31 & $\begin{array}{c}\text { Dietrich Düsterhop } \\
\text { (mnd.) }\end{array}$
\end{tabular}

TV: Heinrich von Unna, Hermen Cruzen, Ludolf Stöterogge, Andreas Brockhöft

ANGABEN ZU PERSON UND FAMILIE:

Der Sülfmeister Dietrich Düsterhop war mit Alheid von Erpensen verheiratet; der Ehe entstammten fünf Kinder $^{18}$. Der Sohn Dietrich wurde nach dem Studium in Leipzig Sülfmeister.

\footnotetext{
${ }^{18}$ H.-J. v. WITZENDORFF, Stammtafeln, S.29.
} 
VERFÜGUNGEN ÜBER SACHGÜTER:

Die Ehefrau Alheid und der Sohn Dietrich sollen das mobile und immobile Gut erhalten.

Siegel entfernt

Reinhardt, Testamente, S.159f, Nr.116

1417 Februar $8 \quad \begin{gathered}\text { Heinrich Sasse } \\ \text { (mnd.) }\end{gathered}$

TV: Hermann von dem Brake, Priester; Johann, sein Bruder; Peter Sasse, Bruder des Testators

ANGABEN ZU PERSON UND FAMILIE:

Der Testator war Bürger der Stadt Lüneburg.

VERFÜGUNGEN ÜBER SACHGÜTER:

Der Testator hinterläßt sein Haus mit allem Zubehör dem Gotteshaus St. Nikolai zur freien Verfügung. Ein zweites Haus schenkt er mit allen Zugehörigkeiten seinem Bruder Peter.

Siegler: Hartwig Beve, Ludolf Töbing

Papier mit aufgedrückten Siegeln

Reinhardt, Testamente, S.160f, Nr.117

\begin{tabular}{|lcc|}
\hline 147 & August 22 & $\begin{array}{c}\text { Klaus Maler } \\
\text { (mnd.) }\end{array}$
\end{tabular}

TV: Hermann Snitker, Dietrich Glasewert, Bürger zu Lüneburg, Ehefrau Ghese

ANGABEN ZU PERSON UND FAMILIE: -

VERFÜGUNGEN ÜBER SACHGÜTER:

Der Testator vererbt seiner Frau das immobile und mobile Gut.

Siegler: Hartwig Beve, Johann Schellepeper

Reinhardt, Testamente, S.161f, Nr.118

\begin{tabular}{|ccc|}
\hline 1417 & September 22 & $\begin{array}{c}\text { Reineke von Swalen } \\
\text { (mnd.) }\end{array}$
\end{tabular}

TV:Johann von Bodensen, Priester, Dietrich von Swalen, des Testators Bruder, Wobbeke, des Testators Ehefrau

ANGABEN ZU PERSON UND FAMILIE:

Der Testator war Bürger zu Lüneburg. 
VERFÜGUNGEN ÜBER SACHGÜTER:

Das restliche mobile und immobile Gut soll die Ehefrau des Testators erhalten, denn es ist beider selbsterarbeitetes Gut.

Siegler: Hartwig von der Mölen, Hermann Kruse

Papier mit aufgedrückten Siegeln

Reinhardt, Testamente, S.162f, Nr.119

\section{Dezember 9}

Kersten Drespe

(mnd.)

TV: Kersten Drespe, Sohn des Testators; Gerd Gravenstede, Priester; Ghese, Frau des Testators, Hans Elvers, Bürger zu Lüneburg

ANGABEN ZU PERSON UND FAMILIE:

Kersten Drespe war Bürger zu Lüneburg. Der Testator war mit einer Frau namens Ghese verheiratet. Aus dieser Ehe stammten anscheinend die beiden Söhne Kersten und Heinrich, vermutlich auch die mit Namen nicht näher bezeichnete Tochter.

VERFÜGUNGEN ÜBER SACHGÜTER:

Seiner Frau und seinem Sohn Heinrich Drespe hinterläßt er sein Wohnhaus mit dem Hof und mit den sechs alten Buden und alles, was darinnen ist. Im Fall, daß sie sich nicht vertragen können, soll seine Frau die sechs Buden haben und die Buden bei dem Haus bei der Straße, oder Heyne soll ihr zehn Mark Geldes jedes Jahr aus dem Erbe geben.

Siegler: Hartwig von der Mölen, Hermann Kruse

Papier mit aufgedrückten Siegeln

Reinhardt, Testamente,S.163f, Nr.120

1417

\section{Meyne von dem Moyde}

(mnd.)

TV: Metteke, Frau des Testators; Albert von Ekle, Priester; Dietrich und Klaus Remstede, Brüder; Albert Strike

ANGABEN ZU PERSON UND FAMILIE:

Der Testator war Bürger der Stadt Lüneburg. Aus dem Testament ist ersichtlich, daß die Ehefrau des Testators Metteke hie $B^{19}$. Über Kinder werden keine Angaben gemacht.

VERFÜGUNGEN ÜBER SACHGÜTER:

Ein Pilger soll dafür gewonnen werden, nach Aachen zu gehen, ein anderer soll nach Wilsnack pilgern. Man soll innen rechtzeitig Ringe geben, damit sie auf dem Weg nicht betteln müssen.

Siegler: Johann von der Mölen, Hermann Kruses Siegel fehlt

\footnotetext{
${ }^{19}$ WITZENDORFF kennt nicht die Namen der Ehefrau und der Kinder. H.-J. v. WITZENDORFF, Stammtafeln, S.84.
} 
Papier mit aufgedrückten Siegeln, Datum ergibt sich aus dem Rückvermerk

Reinhardt, Testamente, S.164f, Nr.121

\begin{tabular}{llll}
\hline 418 & April & 30 & Werner Volkmer \\
(mnd.)
\end{tabular}

TV: Hermann Kruse, Ratsherr; Johann Wokerzin; Ghereke Wulff; Heinrich Ganderssem

ANGABEN ZU PERSON UND FAMILIE:

Der Testator war Bürger der Stadt Lüneburg.

VERFÜGUNGEN ÜBER SACHGÜTER:

Seine Ehefrau erhält den gesamten Hausrat sowie die Hausgerade zur freien Verfügung. Der Testator wünscht, daß man sechs Ellen von einem Tuch aus Eeclo auf seinen Sarg kaufen soll. Das Tuch soll danach die Magd haben, die ihm und seiner Frau dient.

Siegler: Ludolf Töbing, Johann Semmelbecker

Papier mit aufgedrückten Siegeln

Reinhardt, Testamente, S.165f Nr.122

1418 August $12 \quad \begin{gathered}\text { Tibbeke Remsnyder } \\ \text { (mnd.) }\end{gathered}$

TV: Johann von Pentze, Priester; Hans Vogel; Bernd Stake; Meyne Schnewerding

ANGABEN ZU PERSON UND FAMILIE:

Die Testatorin war die Witwe Hoyer Remsnyders.

VERFÜGUNGEN ÜBER SACHGÜTER:

Ihrer Tochter Beke schenkt die Testatorin ihre Arrasche Hoike. Ihrer Tochter Aleke hinterläßt sie ihren besten weiten Rock. Hans Vogels ältester Tochter gibt sie ihre braune Hoike, ihren schwarzen, engen Rock und ein Bett und einen kleinen Grapen.

Siegler: Ludolf Töbing, Godeke von Tzerstede

Reinhardt, Testamente, S.166f, Nr.123

\begin{tabular}{|llcl}
\hline 1419 & März & 17 & $\begin{array}{c}\text { Immeke Burmester } \\
\text { (mnd.) }\end{array}$
\end{tabular}

TV: Beke von der Mölen; Johann, der Sohn Bekes; Ghereke und Meyne von Elster

ANGABEN ZU PERSON UND FAMILIE:

Die Testatorin war die Witwe Vicke Burmesters. Die die Frauengerade betreffenden Verfügungen deuten auf Kinderlosigkeit der Testatorin hin. Aus dem Geschlecht der Burmester testierten der Schwager der Testatorin, Dietrich (1405), und der in fernerer 
Verwandtschaft stehende Ludolf (1409).

VERFÜGUNGEN ÜBER SACHGÜTER:

Stirbt die Testatorin, so steht ihrer Cousine Beke von der Mölen ihre Frauengerade zu, weil ihre Großmutter und die der Testatorin echte Schwestern von Vater und Mutter her waren, recht und frei geboren, wie es ihr ihre selige Mutter mündlich berichtet hat. Beke von der Mölen hinterläßt sie ihren Kirchstuhl in der Johanniskirche, weil er von ihren Eltern gekommen ist. Immeke Burmester schenkt den Klosterfrauen in Ebstorf eine Tonne Salzwedelsches Bier und jeder Klosterjungfrau eine Semmel, damit sie für sie den goldenen Psalter lesen, während ihr Leichnam über der Erde steht. Ferner hinterläßt sie den Kindern Johanns von der Mölen in demselben Kloster zwei Mark Pfennige und zwei weite Grapen. Heine, ihrem Knecht, vererbt sie einen Kessel nächst dem größten Kessel und einen Grapen nächst dem größten Grapen, die größte Pfanne, ein Paar Laken, ein Pfühl, ein Bett, eine Decke. Metteke Bekerwert erhält einen Grapen. Der Vulenweschen schenkt sie ihren Schrank, der vor der Tür steht. So bleiben noch acht Grapen, zwei Pfannen, zwei Badebecken, vier Kessel, zwei Zinnkannen, fünf Polster und drei Pfühle, ein Bett, ein Paar Bleckeder Laken und zwei Kopfkissen.

Siegler: Johann von der Mölen, Hartwig von der Mölen

Papier mit aufgedrückten Siegeln

Reinhardt, Testamente, S.167ff, Nr.124

\begin{tabular}{|llc|}
\hline 1419 & April 3 & $\begin{array}{c}\text { Borchard Trumper } \\
\text { (mnd.) }\end{array}$
\end{tabular}

TV: -

ANGABEN ZU PERSON UND FAMILIE:

Der Testator war Ratsdiener.

VERFÜGUNGEN ÜBER SACHGÜTER:

Der Sohn Borchard soll den gesamten Nachlaß bis auf 40 Mark erhalten.

Unbesiegeltes Papier, am linken Rand nach der Beschriftung beschnitten.

Reinhardt, Testamente, S.169f, Nr.125

\begin{tabular}{|ccc}
1419 & Juni 11 & $\begin{array}{c}\text { Wibke Saffan } \\
\text { (mnd.) }\end{array}$
\end{tabular}

TV: Johannes Bitenakker, Bartolomeus, Hans Saffan, Sohn der Testatorin

ANGABEN ZU PERSON UND FAMILIE:

Wibke Saffan erwähnt in ihrem Testament ihren Sohn Hans und einen Enkel. Ein Hans Saffan ist als Bäcker überliefert ${ }^{20}$.

\footnotetext{
${ }^{20}$ U. J. DIEDERICHS, Aufruhr, S.207.
} 
VERFÜGUNGEN ÜBER SACHGÜTER:

Die Testatorin hinterläßt ihr restliches Gut Hans Saffan und seinen Erben. Im Gegenzug wünscht die Testatorin bis an ihr Lebensende mit Essen und Trinken und allem Notwendigen versorgt zu werden.

Siegler: Ludolf Töbing, Hartwig von der Mölen

Papier mit aufgedrückten Siegeln

Reinhardt, Testamente, S.170, Nr.126

\begin{tabular}{|ccc}
1419 & Juni 28 & $\begin{array}{c}\text { Klaus Remstede } \\
\text { (mnd.) }\end{array}$
\end{tabular}

TV: Johann Rese; Hermann Kruse, Ratsherr; Dietrich Remstede, Bruder des Testators, Heinrich Lange

ANGABEN ZU PERSON UND FAMILIE:

Klaus Remstede war Bürger in Lüneburg.

VERFÜGUNGEN ÜBER SACHGÜTER:

Das restliche Gut soll seine Frau Hempeke mit den Kindern nach Rat der Testamentsvollstrecker gebrauchen. Im Fall ihrer Wiederverheiratung soll sie 350 Mark erhalten, dazu ihre Kleider und das Heiratsgut, das sie mit in die Ehe brachte.

Siegler: Ludolf Töbing, Johann Schellepeper

Papier mit aufgedrückten Verschlußsiegeln

Reinhardt, Testamente, S.171f, Nr.128

\begin{tabular}{|ccc}
\hline 1420 & November 14 & $\begin{array}{c}\text { Hermann Zierenberg } \\
\text { (mnd.) }\end{array}$
\end{tabular}

TV: Ghese, die Frau des Testators; Johann Andorp, Dekan, Dechant des

Kalands Unserer Lieben Frau und des Heiligen Geistes; Johann Tzillik, ältester und erster Vikar der vier Vikarien des Testators; Nikolaus Grönhagen, Hermann Kruse, Ratsherren zu Lüneburg

ANGABEN ZU PERSON UND FAMILIE:

Zierenberg war Bürger zu Lübeck. In den Urkunden über die Vikariestiftung wird der Testator als aus Lübeck Vertriebener bezeichnet ${ }^{21}$.

VERFÜGUNGEN ÜBER SACHGÜTER:

Für den Bau der Kapelle in St. Nikolai spendet der Testator für einen Zeitraum von zehn Jahren jedes Jahr zehn Mark. Nach Ablauf der zehn Jahre sollen seine Testamentsvollstrecker die zehn Mark Rente für Gottes Ehre ausgeben; damit sollen für fünf Mark Schuhe und für fünf Mark Leinwand oder graues Tuch gekauft werden, mit dem arme Bedürftige jährlich bekleidet werden. Nach dem Tod seiner Frau gibt er von einer Rente dreißig Mark für zwanzig Almosen, die in der Kapelle zu St. Nikolai zu verteilen sind.

${ }^{21}$ G. MATTHAEI, Vikariestiftungen, S. 203. 
Jedes Almosen soll aus zwei Weggen bestehen, einer schonrogge ${ }^{22}$ und einem halben Pfund Butter; in der Fastenzeit sollen Heringe oder Fische im Wert von vier Pfennigen anstelle der Butter verteilt werden. Die Almosenverteilung hat jeden Sonntag zu erfolgen für die Ehre Gottes, zum Trost und Heil für den Testator und seine Frau Geseken, ihre Eltern und Kinder und aller Christen Seelen. Zierenberg möchte, daß sein erster Vikar und seine Nachfahren diese Almosen notdürftigen Hausarmen geben, sich nach denen umsehen, die das am nötigsten haben, und sie sollen es keinem anderen geben. Was von diesen dreißig Mark nach Abzug der Almosen jährlich übrig ist, das soll man zum Schmuck beisteuern, eine Mark soll man davon dem Mann geben, der die Almosen in St.Nikolai unterhält und die Speisung verteilt. Ferner gibt der Testator von zweihundert Mark acht Mark ewiger Rente für Gottes Ehre, mit denen jedes Jahr Schuhe gekauft werden sollen, die bedürftigen Hausarmen gegeben werden sollen.

Die Testamentsvollstrecker sollen nötigenfalls das Geld wieder gewinnbringend anlegen. Geht das nicht, sollen das Almosen und die Schuhverteilung herausfallen.

ZUSÄTZLICHE INFORMATIONEN:

Die Quellen verzeichnen vier am vom Testator errichteten Bartolomäusaltar der Nikolaikirche gestiftete Vikarien ${ }^{23}$.

Siegler: Hartwig Beve, Hartwig von der Mölen

Beide Ausfertigungen des Testaments sind vorhanden

Von diesem Testament gibt es zwei weitere Urkundenausfertigungen: 1420 Nov. 29 und 1423 Nov. 19

Reinhardt, Testamente, S.172ff, Nr.129

1420 November 29

TV: $\quad$ vgl. Testament von 1420 Nov. 14

ANGABEN ZU PERSON UND FAMILIE:

vgl. Testament von 1420 Nov. 14

VERFÜGUNGEN ÜBER SACHGÜTER:

Zierenberg gibt bekannt, daß seine Testamentsvollstrecker verfügungsberechtigt sein sollen über seinen Kirchstuhl bei den Minoriten zu Lüneburg, um inn für ihr Wohlergehen zu benutzen.

Siegler: Hermann Zierenberg, Ludwig Krulle, Johann Beve, Lübecker Ratsherrn

Reinhardt, Testamente, S.176f, Nr.130

\section{Hermann Zierenberg}

(mnd.)

$1420 \quad$ Dezember 32

Aldich von Schneverding

(mnd.)

TV: Aldich, Sohn des Testators; Kersten Witte; Dietrich Bernstede

\footnotetext{
${ }^{22}$ Brot aus feinstem Roggenmehl von dreieckiger Form.

${ }^{23}$ F. KRÜGER, W. REINECKE, Kunstdenkmale, S. 133.
} 
ANGABEN ZU PERSON UND FAMILIE:

Schneverding, Bürger Lüneburgs, war Schmied ${ }^{24}$. Er starb 1428.

VERFÜGUNGEN ÜBER SACHGÜTER:

Schneverding vermacht seinen Söhnen Heinrich und Aldich das Wohnhaus, Hof und Wurd mit allem Zubehör; darauf liegt eine Rente von acht Mark Geldes. Was von seinem Nachlaß übrig ist, mobil oder immobil, Hausgerade, Gerätschaften, das vererbt Schneverding seinem Sohn Heinrich, der dieses mit inm zuerst verdient hat.

Siegler: Johann von Ollensen, Dietmar Duckel

Papier mit aufgedrückten Siegeln. Die Jahresdatierung beruht auf der Amtszeit der als Zeugen fungierenden Ratsherrn

Reinhardt, Testamente, S.177, Nr.131

1421 Februar $12 \quad \begin{gathered}\text { Adelheid Hageman } \\ \text { (mnd.) }\end{gathered}$

TV: Klaus Grönhagen, Ratsherr; Hans Benzen; Lemmeke Bordenow; Bürger

ANGABEN ZU PERSON UND FAMILIE: -

VERFÜGUNGEN ÜBER SACHGÜTER:

Die Testatorin hinterläßt ihren Nachlaß ihrer Tochter Adelheid von der Heiden zur freien Verfügung, denn dieses ist der Testatorin wohlgewonnenes Gut und von niemandem vererbt.

Siegler: Hartwig von der Mölen, Hermann Kruse

Papier mit aufgedrückten Siegeln

Reinhardt, Testamente, S.178, Nr.132

\begin{tabular}{|lcc}
\hline 1421 & April 22 & $\begin{array}{c}\text { Johann Wokersin } \\
\text { (mnd.) }\end{array}$
\end{tabular}

TV: Dietrich Hessenland, Heine von Veling, Heinrich Varendorp, Roder von Meyningholt

ANGABEN ZU PERSON UND FAMILIE:

Der Testator war Bürger der Stadt Lüneburg.

VERFÜGUNGEN ÜBER SACHGÜTER:

Den restlichen Nachlaß gibt der Testator seiner Ehefrau zur freien Verfügung, denn es ist ihrer beider wohlgewonnenes Gut und ist innen von niemandem ererbt.

Siegler: Ludolf Töbing, Heinrich Rubow

Papier mit aufgedrückten Siegeln

\footnotetext{
${ }^{24}$ H.-J. v. WITZENDORFF, Stammtafeln, S.111.
} 


\begin{tabular}{|ccc|c}
\hline 421 & Juni 9 & $\begin{array}{c}\text { Heinrich Salzhausen } \\
\text { (mnd.) }\end{array}$
\end{tabular}

TV: Alheit, Frau des Testators; Dietrich Remstede und Meineke von Lübeck, Bürger

ANGABEN ZU PERSON UND FAMILIE:

Salzhausen war Bürger Lüneburg.

VERFÜGUNGEN ÜBER SACHGÜTER:

Seine Ehefrau soll ihren gesamten Brautschatz, den sie zu ihm brachte, haben. Dazu hinterläßt Salzhausen ihr die Bude bei seinem Wohnhaus mit allem Zubehör. Ihr lebenslanges Wohnrecht ist urkundlich festgelegt. Das nach Abzug der Schulden übrige Gut soll sie zur freien Verfügung haben. Das Gut, über das verfügt wird, haben beide erarbeitet, und es ist von niemandem ererbt.

Siegler: Johann von Ollensen, Dietmar Duckel

Papier mit aufgedrückten Siegeln

Reinhardt, Testamente, S.180, Nr.134

\begin{tabular}{|cccc}
\hline 1421 & Juni 24 & $\begin{array}{c}\text { Meinhard Vischer } \\
\text { (mnd.) }\end{array}$
\end{tabular}

TV: Metteke, Ehefrau des Testators; Klaus von Gothing, Priester; Meyne von Lübeck; Meyne Töbing; Tydeke Remstede; Ludolf von Lyverding

ANGABEN ZU PERSON UND FAMILIE:

Der Testator war Bürger zu Lüneburg.

VERFÜGUNGEN ÜBER SACHGÜTER:

Seiner Frau Mechtild hinterläßt der Testator sein Wohnhaus mit allem Zubehör, mit allem Hausrat und Hausgerade. Alles, was von seinem Nachlaß übrig ist, das gibt er zur freien Verfügung seiner Frau Mechtild, denn es ist ihrer beider wohlgewonnenes Gut und wurde innen von niemandem gegeben oder vererbt.

Siegler: Ludolf Töbing, Hartwig von der Mölen

Gleichzeitige Kopie. Der obere Rand der Urkunde ist nachträglich beschnitten.

Reinhardt, Testamente, S.181, Nr.135 
TV: Heinrich Rubow, Ratsherr; Johann von der Heide; Ludolf von Leverding; Engelke Arborg

ANGABEN ZU PERSON UND FAMILIE:

Der Testator war Bürger zu Lüneburg.

VERFÜGUNGEN ÜBER SACHGÜTER:

Den restlichen mobilen und immobilen Nachlaß sollen die Kinder seiner drei Brüder erhalten.

Siegler: Hartwig von der Mölen, Hermann Kruse

Papier mit aufgedrückten Siegeln

Reinhardt, Testamente, S.183f, Nr.137

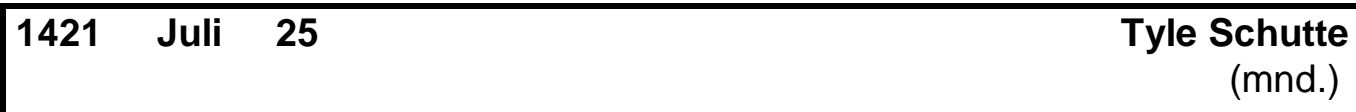

TV: Wilke Basedow, sein Wirt, Bürger zu Lüneburg; Dietrich Densten, Bürger zu Nordhausen; Cord Gramestorf der Jüngere

ANGABEN ZU PERSON UND FAMILIE:

Der Schutte war Bürger zu Nordhausen. Aus seiner Ehe mit Grete gingen mindestens drei Kinder hervor.

VERFÜGUNGEN ÜBER SACHGÜTER:

St. Johannis schenkt der Testator ein blaugefärbtes Laken von den einundzwanzig gefärbten Laken, die er in zwei Ballen in Lüneburg stehen hat. Was nach Abzug aller Schulden von seinem Nachlaß übrig ist, hinterläßt er seiner Frau Grete und den drei Kindern zu gleichen Teilen.

Siegler: Hartwig von der Mölen. Hermann Kruse

Papier mit aufgedrückten Siegeln

Reinhardt, Testamente, S.184f, Nr.138

1421 August 2

Dietrich von Bevensen

(mnd.)

TV: Wilke Basedow, Hans Tespe, Arnold Grybe, Bürger zu Lüneburg

ANGABEN ZU PERSON UND FAMILIE: -

VERFÜGUNGEN ÜBER SACHGÜTER:

Seinen besten Rock gibt er seinem Bruder Henneke. Die anderen Kleider soll man aufteilen und seinen armen Freunden geben.

Siegler: Godeke von Tzerstede, Johann von Ollensen

Papier mit aufgedrückten Siegeln 


\begin{tabular}{|l}
\hline $1421 \quad$ August 23 \\
TV: Johann von Ollensen, Ratsherr, Johann Rickmann, Meyne von Elster, Erik Ghise, \\
Bürger zu Lüneburg \\
ANGABEN ZU PERSON UND FAMILIE: \\
Der Testator war Bürger zu Lüneburg. Eine Schwester ist im Kloster Ebstorf, seine andere \\
Schwester heißt Beke von Esche. \\
VERFÜGUNGEN ÜBER SACHGÜTER: \\
Den übrigen Nachlaß soll nach Abzug der Testamentsverfügungen und des Begräbnisses \\
seine Schwester Beke von Esche erhalten. \\
Siegler: Hermann Kruse, Albert Elver \\
Papier mit aufgedrückten Siegeln \\
Reinhardt, Testamente, S.186f, Nr.140
\end{tabular}

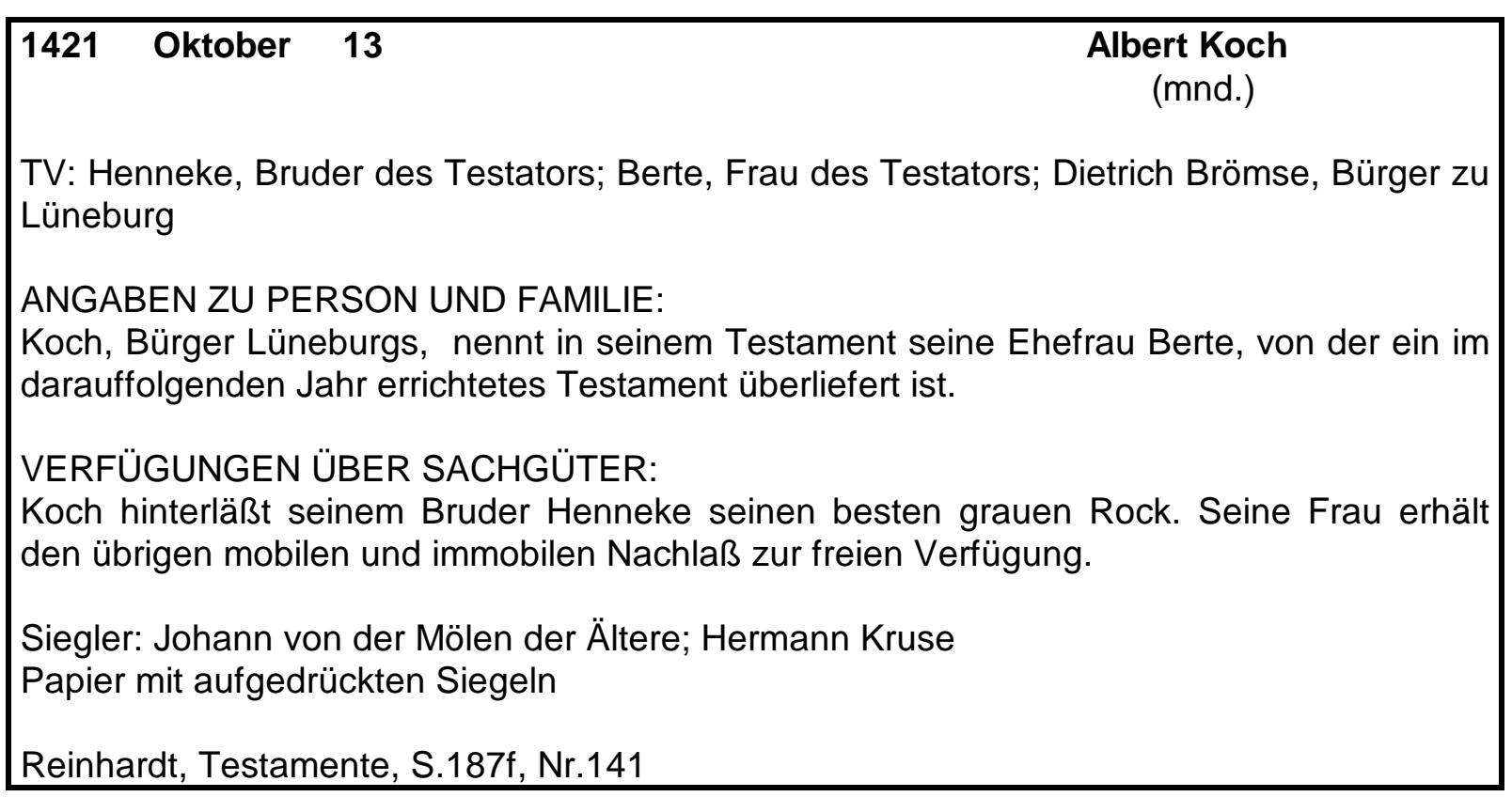

\begin{tabular}{|ccc|c}
\hline 1421 & November 9 & $\begin{array}{c}\text { Dietrich Rogge } \\
\text { (mnd.) }\end{array}$
\end{tabular}

TV: Wulve Witik; Hans Tespe; Ghese, Frau des Testators

ANGABEN ZU PERSON UND FAMILIE:

Der Testator war Bürger Lüneburgs. Er war mit einer gewissen Ghese verheiratet. Aus dieser Ehe stammen der Sohn Werneke und die Tochter Aleke. 
VERFÜGUNGEN ÜBER SACHGÜTER:

Den gesamten mobilen oder immobilen Nachlaß hinterläßt Rogge seiner Ehefrau Ghese und dem gemeinsamen Sohn Werneke; aus dem Wohnhaus mit seinem Zubehör sollen sie jährlich drei Mark Geldes Aleke, der Tochter des Testators, geben.

Siegler: Ludolf Töbing, Johann von der Mölen der Jüngere

Pergament mit aufgedrückten Siegeln

Reinhardt, Testamente, S.188f, Nr.142

\begin{tabular}{|ccc}
1422 & Januar 22 & $\begin{array}{c}\text { Berta Koch } \\
\text { (mnd.) }\end{array}$
\end{tabular}

TV: Cord von Lynden; Priester; Helmeke Lembeke; Johann Werkhagen und Ludolf Dreger

ANGABEN ZU PERSON UND FAMILIE:

Die Testatorin war die Witwe des Bürgers Albert Koch, der im Vorjahr testiert hatte. Offenbar starb das Ehepaar kinderlos.

VERFÜGUNGEN ÜBER SACHGÜTER:

Ihren übrigen mobilen und immobilen Nachlaß gibt sie ihrem Oheim, dem Priester Cord von Lynden, zur freien Verfügung.

Siegler: Johann von der Mölen, Hermann Kruse

Papier mit aufgedrückten Siegeln

Reinhardt, Testamente, S.189f, Nr.143

\begin{abstract}
1422 März 17
Johann Cloke

(mnd.)

TV: Hans Blank, Hans Schermbeck

ANGABEN ZU PERSON UND FAMILIE:

Der Testator war Bürger zu Lüneburg.

VERFÜGUNGEN ÜBER SACHGÜTER:

Seiner Schwester Gheseke Vischer mit ihren Kindern und mit Klaus, seinem Vetter, vererbt Cloke sein Wohnhaus mit allem Zubehör zu gleichem Teil, vorausgesetzt, daß von innen einer noch lebt. Sollten sie gestorben sein, so soll dieser Besitz für das Seelenheil des Testators und seiner Frau genutzt werden. Die einstige Magd Gheseke erhält eine Truhe. Ferner gibt Cloke seinem Vetter ein Bett. Für inn hat der Testator bis jetzt einen großen Kessel und drei Grapen verwahrt, die an den Vetter fallen sollen. Wenn die beschriebenen Gaben vergeben sind, und der ehrsame Rat zu Lüneburg das seinige erhalten hat, dann hinterläßt er das Übrige an Hausrat, Hausgerade, Kleinoden seinem Schwager Hans Schermbeck mit allem Korn, Speck, Fleisch, Holz, Kohlen, Dielen, Brettern zur freien Verfügung.
\end{abstract}

Siegler: Hartwig Beve, Johann von der Mölen 
Papier mit aufgedrückten Siegeln.

Reinhardt, Testamente, S.190f, Nr.144

\section{November 12}

\section{Grete von dem Wede}

(mnd.)

TV: Johann von Ollensen, Ratsherr; Ludolf Ostermann; Ghereke Nygenkerken; Hans Reyegot

ANGABEN ZU PERSON UND FAMILIE:

Die Testatorin war die Witwe des Bürgers Heinrich von dem Wede.

VERFÜGUNGEN ÜBER SACHGÜTER:

Die Testatorin hinterläßt ihrer Magd Mechtild alle Kleider, die der Testatorin auf den Leib geschneidert sind, mit Ausnahme ihrer Frauengerade, dazu das zweitbeste Bett, ein Kopfkissen, zwei Kissen, zwei Paar Laken, eine Decke und eine Truhe, drei Grapen nächst der größten und einen Wandschrank. Hans und Mechtild erhalten Hausgerät, Fässer, Stühle, Bänke, was sie davon nötig haben. Ferner soll die Schwester der Testatorin, die Frau des Johann von Ollesen, Essig erhalten und alles Federbettzeug sowie alle Grapen bis auf die bereits vergebenen.

Siegler: Hartwig von der Mölen, Godeke von Tzerstede

Papier mit aufgedrückten Siegeln.

Reinhardt, Testamente, S.191ff, Nr.145

\begin{tabular}{|cccc}
\hline 423 & März & 30 & $\begin{array}{c}\text { Cord Boltze } \\
\text { (mnd.) }\end{array}$
\end{tabular}

TV: Cord und Hans Boltze, Söhne Cord Boltzes

ANGABEN ZU PERSON UND FAMILIE:

Der Testator war Bürger von Lüneburg; er ist der 1423 verstorbene Cord Boltze, Sohn des Dietrich $^{25}$. Wobbeke Boltze, geborene Semmelbecker, ist des Testators angeheiratete Tante. Das Testament ihres Mannes ist aus dem Jahr 1402 überliefert.

VERFÜGUNGEN ÜBER SACHGÜTER:

Den gesamten mobilen und immobilen Nachlaß hinterläßt Boltze seiner Tante Wobbeke Boltze, Witwe Cord Boltzes, und ihren Söhnen für die Verpflegung, Ehre und Wohltat, die sie inm erwiesen haben. Dies ist das vom Testator wohlgewonnene Gut, das inm von niemandem angeerbt wurde.

Siegler: Albert Elver, Johann von der Mölen der Jüngere

Vorhanden sind beide Ausfertigungen: 1. Pergament mit anhängenden Siegeln, 2. Papier mit aufgedrückten Siegeln

Reinhardt, Testamente, S.193f, Nr.146

\footnotetext{
${ }^{25}$ H.-J. v. WITZENDORFF, Stammtafeln, S.14.
} 
TV: Klaus Trost, Hans Eylebert

ANGABEN ZU PERSON UND FAMILIE:

Der Testator erwähnt in seinem Testament eine Schwester Aleke und ihren Sohn Ludolf.

VERFÜGUNGEN ÜBER SACHGÜTER:

Seiner Schwester gibt Trost vier Mark Pfennige für einen Rock.

Siegler: Ludolf Töbing, Heinrich Rubowe

Die Siegel sind abgeschnitten

Reinhardt, Testamente, S.194f, Nr.147

1423 August $16 \quad \begin{gathered}\text { Johann von Hasle } \\ \text { (mnd.) }\end{gathered}$

TV: Tibbeke, Ehefrau des Testators; Meister Lüder Browel, Sohn der Ehefrau; Hermann Cruse, Ratsherr; Tydeke Remstede

ANGABEN ZU PERSON UND FAMILIE:

Der Testator war Bürger der Stadt Lüneburg.

VERFÜGUNGEN ÜBER SACHGÜTER:

Seine Ehefrau soll graues Lüneburger Laken schneiden und es armen Leuten für die Ehre Gottes geben. Der gesamte Nachlaß soll an die Ehefrau des Testators fallen, denn es ist beider wohlgewonnenes Gut und ihnen von niemandem vererbt.

Siegler: Ludolf Töbing, Johann Schermbeck

Papier mit aufgedrückten Siegen

Reinhardt, Testamente, S.195f, Nr.148

\section{$1423 \quad$ November 19}

Hermann Zierenberg

(mnd.)

TV: Klaus Grönhagen; Johann Andorp, Dekan, Dechant des Kalands Unserer Lieben Frau und des Heiligen Geistes; Johann Tzillik, ältester und erster Vikar der vier Vikarien des Testators; Hermann Kruse, Ratsherr zu Lüneburg

ANGABEN ZU PERSON UND FAMILIE:

Zierenberg war Bürger zu Lübeck.

VERFÜGUNGEN ÜBER SACHGÜTER:

Weitere sechzehn Mark Rente setzt Zierenberg aus, um alle Jahre Schuhe, Tuch und 
Leinwand den Armen zu kaufen.

Siegler: Hermann Zierenberg, Hartwig Beve, Johann Schellepeper

Reinhardt, Testamente, S.196ff, Nr.149

\section{November 23}

Johannes von Lippinghausen

(lat.)

TV: siehe Testamente von 1414 Feb. 4

ANGABEN ZU PERSON UND FAMILIE:

vgl. Testament von 1414 Feb. 4

VERFÜGUNGEN ÜBER SACHGÜTER:

Für die Kapelle St. Gertrudis das von inm bereits gegebene silberne Kleinod; dem Herrn Archidiakon in Modestorpe seine silberne größere Brosche mit einem Bett und einem besseren Pfühl. Die andere Brosche soll Johannes Sinstorp erhalten. Johann Tzillik hinterläßt er einen silbernen Becher mit Deckel, sowohl ein Bett als auch einen Pfühl und zwei Halbstübchenflaschen, einen Mörser mit einem Mörserstößel, gemahlenen Senf und sechs Töpfe. Er gibt Johann de Pentze eine Flasche für ein Stübchen Wein mit zwei hohen Gefäßen. Johann Korffmaker schenkt er zwei Lübecker Florener und ein Bett. Borchard Vledenkarghen vermacht er ein Bett und eine Halbstübchenflasche. Thidericus Betcke gibt der Testator eine Halbstübchenflasche mit zwei hohen Gefäßen, ein Bett und einen silbernen Löffel. Einen langen silbernen Krug erhält der Arzt Johann von Hassia, einen zweiten die Frau Nikolaus Grawerokkes, einen dritten Gertrud, die Frau des Apothekers Laurentius. Lippinghausen besitzt ein silbernes Henkelgefäß, das schenkt er dem Bürgermeister Albert von der Mölen; dessen Frau gibt er sein Venetianisches Glas mit dem Silberfuß. Ferner hat er vier kurze silberne Krüge; Heidekin, Petrus von dem Hope, Johannes Schoenenvlet und Wikbold Wikboldi sollen je einen davon erhalten. Lippinghausen hinterläßt eine kleine silberne Brosche Johannes Basedow. Er gibt seine zwölf silbernen Löffel, die inm Herr Johannes de Bilne gegeben hat, der Frau Heinrichs von der Heide. Johannes Boone bekommt eine Flasche von einem halben Stübchen Wein. Thidericus Schreyen erhält einen Topf aus Keramik und einen Dreifuß. Lippinghausen vererbt Heinrich, dem Pfarrer in Bienenbüttel, den drittbesten Codex, ein Handwaschbecken, zwei Halbstübchenflaschen, eine mit Eisen beschlagene/eiserne niedrige Truhe, die in seiner Kammer steht, zwei silberne Löffel. Wychmann, dem Pfarrer in Hober, gibt er ein Bett, ein hohes Gefäß, zwei Töpfe und einen Kochkessel von einem Krug Wasser. Er hinterläßt Radekinus, dem Pfarrer in Wichmannsburg, zwei Halbstübchenflaschen und einen silbernen Löffel. Ludekinus Grönhagen schenkt Lippinghausen eine Flasche von einem Stübchen und einen silbernen Löffel. Er gibt Herrn Jakob Kannengheter zwei silberne/versilberte Löffel. Der Testator vermacht dem Vikar der Vikarie am Altar St. Willehards in der genannten Kapelle St. Gertrudis, die er selbst besitzt, für die Zeit ihres Bestehens zwei mittelgroße Betten, zwei Paar Laken, zwei Pfühle, zwei Decken und zehn Sitzkissen, drei eherne Töpfe, nämlich einen großen, einen mittelgroßen und einen kleinen, und zwei hohe Gefäße - alle Dinge sollen auf Dauer bei dem Vikar derselben Vikarie bleiben und sollen nicht veräußert werden. Ebenso schenkt er der Vikarie Aller Apostel in der Johanniskirche vier eherne Töpfe, nämlich einen großen und drei mittelgroße, eine Flasche von einem Stübchen Wein, all sein Backgeschirr und vier Stühle mit Kissen und zwei hohe Gefäße zum Verbleiben bei derselben Vikarie. Ferner hinterläßt er der von inm in der Kapelle St. Gertrudis gegründeten Vikarie sein besseres 
gestreiftes Bett, das über dem Speicher in seiner Kammer liegt, ein Paar Laken, ein Pfühl und ein Kopfkissen mit einer etwas besseren Decke und ein Gestell. Er schenkt der Vikarie Heilig Kreuz in der St. Cyriacuskirche seinen Speiseschrank über seiner Kammer und zwei eherne Töpfe. Seiner jetzigen Magd Elyzabeth hinterläßt er ein Bett mit Pfühl und Laken und Decke und das restliche Faden/Tuch und Leinentuch. Seinem jetzigen Schüler Werner gibt er das von inm benutzte Bett mit Pfühl und Decke. Jedoch der Rest seiner Hinterlassenschaften, ob in Geld oder Kleinodien, ob in Büchern, Kleidungsstücken oder Gebrauchsgegenständen soll von seinen Testamentsvollstreckern für die Ehre Gottes und zum Gebrauch der Armen treulich umgewandelt werden. Der Testator bescheinigt, daß er bei seiner Vikarie nur bestimmte Bücher hat, die im Testament eines gewissen Herrn Marquard von Dannenberg, Beneficiat in der Kirche St. Cyriacus, namentlich bezeichnet werden, nämlich ein Winter- und ein Sommerpassionale und die Psalterexegese des Nikolaus von Lyra; diese Bücher sind von Marquard nach seinem Tod für den allgemeinen Gebrauch und Nutzen derer bestimmt worden, die zur Zeit die Almosen für sich in Anspruch nehmen, die von Marquard für den Altar oder die Kapelle der himmlischen Jungfrau Maria unter der Bibliothek des Klosters St. Michaelis in Lüneburg gegründet und zugewiesen worden sind, so wie es deutlich im Testament des Herrn Marquard enthalten ist. Lippinghausen möchte und bittet, daß diese Bücher durch seine Testamentsvollstrecker zum vorgeschriebenen Gebrauch treulich geordnet werden und möglichst schnell dargeboten werden.

Unterschrift und Signet des Notars Heidekinus von Braunschweig

Reinhardt, Testamente, S.201ff, Nr.150

1425 März 21

Geseke Springintgud

(mnd.)

TV: Grete, Frau Alberts von der Mölen; Johann Schellepeper, Hermann Rock

ANGABEN ZU PERSON UND FAMILIE:

Die Testatorin stammte aus dem Geschlecht der Boltzen ${ }^{26}$. Sie war die Witwe des 1423 verstorbenen Ratsherren Dietrich Springintgud. Er war der Vater des Sohnes Johannes. Aus Gesekes erster Ehe mit Nicolaus von Urden stammen die beiden Söhne, die sie in ihrem Testament bedenkt; beide sind Bürger von Lüneburg. Der Rats- und Zirkelherr von Urden starb 1407 in Lübeck. Das Todesdatum der Testatorin ist nicht bekannt; ihr Name ist noch für das Jahr 1435 belegt.

VERFÜGUNGEN ÜBER SACHGÜTER:

Die Testatorin stiftet für ihres Mannes und ihre Seele eine Rente von zehn Mark. Von dieser Rente sollen die Kämmerer des Rates jedes Jahr am St. Michaelstag sechs Mark für graues Tuch den armen Leuten zur Bekleidung geben, von den vier Mark soll man zuvor fünf Paar Schuhe für fünf arme Leute kaufen.

Die Testamentsvollstrecker sollen ihren gesamten Hausrat, Hausgerade und drei goldene Ringe nächst ihres besten Ringes verkaufen und davon eine Rente errichten. Diese Rente soll Albert Semmelbecker haben. Stirbt er ohne rechten Leibeserben, soll die Rente an Springintguts rechtmäßigen Erben fallen. In Lübeck bei Bernd Koninge hat die Testatorin zwei Futter und bei dem Goldschmied Hans Schele ein silbernes Halsband, das sollen ihre Testamentsvollstrecker verkaufen und eine Rente von vier Mark Geldes kaufen. Die Rente fällt als Leibrente zunächst an Ilsebe Gildehusen, Klosterfrau zu Lüne, und nach ihrem Tod

\footnotetext{
${ }^{26}$ H.-J. v. WITZENDORFF, Stammtafeln, S.14, 120 und 137.
} 
an Gheseke Schonewerder, ihre Schwester in Lübeck, wenn diese dann noch lebt; lebt sie aber nicht mehr, so sollen ihre rechten Erben die Rente mit erblichem Recht besitzen. Die Testatorin hinterläßt den beiden Söhnen ihres Ehemannes Nicolaus von Urden sechs silberne Schalen dergleichen Machart, einen silbernen Fuß für eine Schauer oder für ein crudenappe und eyn gefiled vorguldet hovedgad; davon soll man eine Schale für den Fuß anfertigen, die sie um der Liebe der Testatorin willen haben sollen. Dietrich Semmelbecker erhält eine silberne Schale, in der sein Wappen steht; Tyle Doring eine silberne Schale, in der sein Wappen steht, und die Frau Hermen Roders, Gheseke, eine silberne pipkanne; all ihre Kleider und Futter mit Ausnahme der zwei erwähnten Futter, die Kühe und Schweine sollen die Testamentsvollstrecker verkaufen und mit den Pfennigen Ylzebe, ihre Magd, verheiraten und für die Ehe ausstatten. Ylzebe bekommt ein Bett, das zweitbeste Kopfkissen der Testatorin, eine Decke, zwei Kopfkissen und ein Paar Laken. Ferner soll man die silbernen Löffel verkaufen und soll das Geld Metteke geben, der Tochter Dietrich Semmelbeckers. Die Testatorin schenkt drei silberne Becker Johann, dem Sohn ihres Mannes Dietrich.

Siegler: Godeke von Tzerstede, Johann von Ollensen

Gleichzeitige Abschrift der Ausfertigung

Reinhardt, Testamente, S.207ff, Nr.152

1425 März $31 \quad \begin{gathered}\text { Heinrich Müller } \\ \text { (lat.) }\end{gathered}$

TV: Frederik Lyderen, ständiger Vikar in Neumedingen; Hinrich Borcholt, Lüneburger Bürger

ANGABEN ZU PERSON UND FAMILIE:

Heinrich Müller war laycus opidanus in Medingen.

VERFÜGUNGEN ÜBER SACHGÜTER:

Zunächst schenkt er Greteke, seiner Magd, eine graue gefütterte Hoike. Er hinterläßt seinem Bruder Rurus Christian eine rote und schwarze Hoike und seinem Bruder Henning zwei Hoiken, eine von roter und grüner Farbe und eine von grauer Farbe, Handwerksgerät und zwei Truhen.

Unterschrift und Signet des Notars Walter Hössering

Reinhardt, Testamente, S.209ff, Nr.153

\begin{tabular}{|cccc}
\hline 1425 & April & 18 & $\begin{array}{c}\text { Grete von dem Sande } \\
\text { (mnd.) }\end{array}$
\end{tabular}

TV: -

ANGABEN ZU PERSON UND FAMILIE:

Die Testatorin wurde auch Margarete von der Moyde genannt; sie war mit dem Sodmeister Hermann von dem Sande verheiratet ${ }^{27}$. Ihr 1420 bereits verstorbener Mann stammte aus einer Seitenlinie des Adelsgeschlechts der Kind, die sich nicht nur von dem Sande,

\footnotetext{
${ }^{27}$ H.-J. v. WITZENDORFF, Stammtafeln, S.102.
} 
sondern auch Volkmari und Rettmer nannten. Die von dem Sande wanderten 1427 aus Lüneburg $a b$.

VERFÜGUNGEN ÜBER SACHGÜTER:

Der übrige mobile und immobile Nachlaß soll an Albert fallen.

Siegler: Dietmar Duckel, Heinrich Hoyemann

Papier mit aufgedrückten Siegeln. Die Schriftmerkmale lassen eine Auflösung der Minderzahl nur mit 1425, nicht mit $1525 \mathrm{zu}$.

Reinhardt, Testamente, S.211, Nr.154

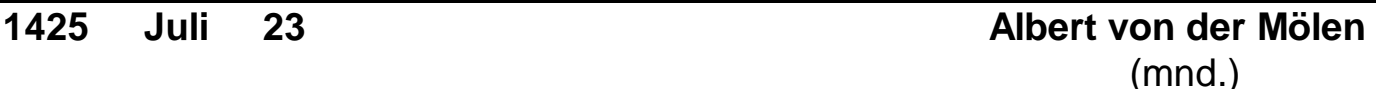

TV: Otto Garlop; Heinrich Bere, Bürgermeister; Johann Schellepeper; Johann von der Mölen, Johanns Sohn; Margarete, Frau des Testators

ANGABEN ZU PERSON UND FAMILIE:

Albert von der Mölen ist 1386 als Ratsherr belegt, 1393 als Bürgermeister ${ }^{28}$. Des Testators Vater war ebenfalls Ratsmitglied. Bereits 1385 war der Testator mit Margarete von Chüden verheiratet. Sie starb 1433.

VERFÜGUNGEN ÜBER SACHGÜTER:

Gesetzt den Fall, daß eine Rente von 320 Mark Kapital in einem Jahr nicht zum Bau der Stadtmauern verwendet wird, so sollen in diesem Jahr graues Tuch und Schuhe armen Leuten zur Bekleidung gekauft werden. Von den Silbersachen des Testators sollen die Testamentsvollstrecker je ein Stück erhalten; die Verteilung obliegt der Frau des Testators gemäß seiner mündlich erteilten Anweisung. Ihr selbst bleibt der unvergabte Hausrat sowie die Fahrhabe des Testators.

Siegler: Albert von der Mölen, Johann von Ollensen, Heinrich Rubow

Papier mit aufgedrückten Siegeln. Die Urkunde ist durch Einschnitte ungültig gemacht und zwischen den Zeilen 68 und 69 zusammengenäht.

Reinhardt, Testamente, S.212ff, Nr.155

\begin{tabular}{|llc|}
\hline 1425 & Oktober 1 & $\begin{array}{c}\text { Dietrich Rosenhop } \\
\text { (mnd.) }\end{array}$
\end{tabular}

TV: Tibbeke, Frau des Testators; Johann Brockhoved; Heinrich Husemann; Cord Dalhusen; Meyneke Meyger

ANGABEN ZU PERSON UND FAMILIE:

Der Testator war Glaser und Bürger der Stadt Lüneburg.

VERFÜGUNGEN ÜBER SACHGÜTER:

Seinen gesamten mobilen und immobilen Nachlaß hinterläßt Rosenhop seiner Ehefrau,

\footnotetext{
${ }^{28}$ H.-J. v. WITZENDORFF, Stammtafeln, S.80.
} 
denn es sei beider wohlgewonnenes und von niemandem angeerbtes Gut.

Siegler: Ludolf Töbing, Heinrich Rubow

Konzept auf Papier

Reinhardt, Testamente, S.215f, Nr.156

$\begin{array}{llll}1426 & \text { April } 2 & \begin{array}{c}\text { Johann von Sprakensen } \\ \text { (mnd.) }\end{array}\end{array}$

TV: Wonneke, Ehefrau des Testators; Johannes, beider Sohn; Albert von Eklo, Priester; Johann Oldenstadt; Ludolf Kerkhove

ANGABEN ZU PERSON UND FAMILIE:

Der Testator war Bürger zu Lüneburg.

VERFÜGUNGEN ÜBER SACHGÜTER:

Seine Ehefrau soll die Bevollmächtigte seines gesamten Nachlasses sein.

Siegler: Hermann Kruse, Johann von der Mölen

Papier mit aufgedrückten Siegeln

Reinhardt, Testamente, S.216f, Nr.157

1427 April 4

Ludolf Bartholomeus

(mnd.)

TV: Johannes Lubberd; Ludolf, Sohn des Testators, Priester und Vikar zu St. Johannis; Hermann Kruse, Ratsherr; Cord Dahlhusen und Eggerd Schnewerding, Bürger zu Lüneburg; Abele, Ehefrau des Testators

ANGABEN ZU PERSON UND FAMILIE:

Batholomäus war Bürger der Stadt Lüneburg. Verheiratet ist der Testator mit Abele. Aus dieser Ehe gingen mehrere Kinder hervor; während die Mädchen nur summarisch als Schwestern erwähnt werden, nennt Bartholomäus in seinem Testament die Söhne Ludolf, Heinrich, Bartholomäus, Cord und Claus.

VERFÜGUNGEN ÜBER SACHGÜTER:

Ludolf, seinem Sohn, hinterläßt der Testator seine größte silberne Schale ohne Fuß, damit daraus ein Kelch für seine neue Vikarie angefertigt werde. Seiner Tochter llsebe schenkt er seine kleinste silberne Schale. Das restliche Gut soll an die Ehefrau und die unabgeteilten Kinder Bartholomäus, Cord, Heinrich und Claus fallen. Seinen besten Rock schenkt der Testator den Franziskanern von St. Marien für ihren Bau, dafür sollen sie seiner und seiner Frau an den Festtagen gedenken. Gesetzt den Fall, Heinrich würde Priester, so soll inm Abele bei seiner Primiz für Kost und Kleidung 40 Mark Pfennige geben.

Siegler: Heinrich Rubow, Johann von der Mölen

Gleichzeitige Abschrift auf Papier.

Reinhardt, Testamente, S.217ff, Nr.158 


\begin{tabular}{|l}
\hline 1428 Mai 22 \\
TV: Curd Dahlhusen, Tideke Ellenberch, Clemens Grael, Ludolf Klentzemann \\
ANGABEN ZU PERSON UND FAMILIE: \\
Der Testator war Bürger der Stadt Lüneburg. Hans von Klentze erwähnt in seinem \\
Testament eine Tochter namens Ilsebe und eine Schwester mit fünf Kindern. \\
VERFÜGUNGEN ÜBER SACHGÜTER: \\
Zum Bau von St. Johannis stiftet der Testator fünf Mark Pfennige und vier Mark Pfennige \\
für die Stilmislichte ${ }^{29}$ überall in der Kirche. Seiner Tochter Ilsebe hinterläßt Klentze dreißig \\
Mark Pfennige sowie seinen gesamten Hausrat und Kleinode, davon sollen seine TV sie \\
ernähren. \\
Siegler: Hermann Kruse, Albert Elver \\
Papier mit aufgedrückten Siegeln \\
Reinhardt, Testamente, S. 219f, Nr.159
\end{tabular}

\begin{tabular}{|ccc}
\hline 1428 & Oktober 27 & $\begin{array}{c}\text { Wobbeke Boltzen } \\
\text { (mnd.) }\end{array}$
\end{tabular}

TV: Hans und Cord, ihre Söhne; Wobbeke und Beke, ihre Töchter

ANGABEN ZU PERSON UND FAMILIE:

Die Testatorin war Witwe Cord Boltzens, eines Ratsherrn zu Lüneburg, dessen Testament aus dem Jahr 1402 überliefert ist. Die Ehe der aus dem Geschlecht Semmelbecker stammenden Testatorin mit Cord Boltzen ist 1383 nachzuweisen ${ }^{30}$. Aus dieser Ehe gingen die fünf Kinder Hans, Beke, Albert, Cord und Wobbeke hervor. Das Testament erwähnt die Schwestern der Testatorin, Beke, die Frau Hans Hoyemanns, und Drude im Kloster Lüne, dessen Priorin sie zumindest ab 1415 war, sowie den Bruder Gherard Semmelbecker, der Priester war ${ }^{31}$. Die Kinder der Testatorin - Albert war vor 1423 gestorben - waren alle verheiratet: Ihr Sohn, der Sülfmeister Hans, war zunächst mit Elisabeth von Hagen die Ehe eingegangen, zum Zeitpunkt der Testamentserrichtung war er mit Herteke Pleskow aus Lübeck verheiratet, und er heiratete nach ihrem Tod Grete Wittinck; die Tochter Beke war die Ehefrau Heinrich Viskules, der Name der Ehefrau Cords ist unbekannt, und die Tochter Wobbeke war mit Nikolaus Schomaker verheiratet.

VERFÜGUNGEN ÜBER SACHGÜTER:

Die Testamentsvollstrecker sollen der Schwester in Medingen die beste Hoike mit dem Futter geben, der Schwester Drude in Lüne die zweitbeste Hoike mit dem Futter, den

\footnotetext{
${ }^{29}$ Lichter, die bei der Konsekration benutzt werden.

${ }^{30}$ H.-J. v. WITZENDORFF, Stammtafeln, S.14.

${ }^{31}$ H.-J. v. WITZENDORFF, Stammtafeln, S. 115.
} 
Kindern der Tochter in Medingen den Rosenkranz aus Korallen, der Tochter Beke Viskule die zwei besten Armreife, de van den festen sy, und dazu die Tafel, in der die Reliquie ist, der Tochter Herdeke, der Frau ihres Sohnes Hans, drei silberne Becher, die sie der Testatorin gab, als sie hierher von Lübeck kam. Ihrer Tochter Wobbeke Schomaker gibt Wobbeke Boltzen ihren Verlobungsring, ihrem Sohn Cord ihren breiten Armreif, Alheid Provest einen silbernen Becher, Cord, dem Kind ihres Sohnes Hans, ihren Ring mit dem blauen Stein und Wobbeke, Hansens Tochter, ihren kleinen Rosenkranz aus Korallen und einen Ring mit dem großen Stein. Gherard Semmelbecker erhält ein Bett und einen Pfühl; diese Dinge hatte die Testatorin von ihrer Schwester Beke bekommen. Für Taleke Boltzen in dem Konvent zu Lübeck ist die schwarze Hoike aus Arras. Im Todesfall der Testatorin soll man ihren zwei Mägden, die bei ihr sind, jeweils einen Rock geben und der Magd ihrer Tochter Beke, die dann bei ihr ist, einen Rock. Hansens Mutter erhält ihre braune Hoike aus Arras, seine Schwester einen Pelz, wenn man sie für die Ehe ausstattet, Hans, der Ohm Wobbeke Boltzens, ein Kleinod im Wert von drei Pfennigen.

Siegler: Johann von Ollensen, Albert Elver

Reinhardt, Testamente, S.220 ff, Nr.160

\begin{tabular}{|ccc}
\hline 429 & Oktober 30 & $\begin{array}{c}\text { Tibbeke Poterow } \\
\text { (mnd.) }\end{array}$
\end{tabular}

TV: Hans Ochtmissen, Heine Amelinghusen

ANGABEN ZU PERSON UND FAMILIE:-

VERFÜGUNGEN ÜBER SACHGÜTER:

Wulmeke, ihrer Magd, hinterläßt die Testatorin das zweitbeste Paar Kleider und ihre grüne Hoike. Weiterhin gibt die Testatorin der Berndeschen ihre blaue Hoike, dafür soll sie nach Wilsnack gehen.

Siegler: Hermann Kruse, Heinrich Rubow

Reinhardt, Testamente, S.222f, Nr.161

$1423 / 1431$

TV: -
Adelheid Seidentopf

(mnd.)

ANGABEN ZU PERSON UND FAMILIE: -

VERFÜGUNGEN ÜBER SACHGÜTER:

St. Johannis soll zum Bau das beste Paar Kleider erhalten. Der Magd Leneke schenkt die Testatorin ihren schwarzen Rock und ihren Pelz. Lippold, ihrem Ohm, hinterläßt sie ein Bett mit zwei Pfühlen, eine Decke und ein Paar Laken sowie sieben Grapen und drei Pfannen, ferner eine blaue Hoike, einen blauen Rock, einen braunen Rock, zwei Schränke, eine Fußtruhe, drei Kessel, vier hölzerne oder metallene Kübel, eine Kanne, zwei Wannen und eine Feuerpfanne für Herrn Johannes Tzillinks Vikarie in St. Nikolai, damit er es warm hat bei dem Altar, den Hermen Zierenberg errichten ließ. 
Siegler: Wulf Witik; Johann Schermbeck

Papier mit aufgedrückten Siegeln. Die Datierung ergibt sich aus Amtszeit der regierenden Ratsherren.

Reinhardt, Testamente, S.223, Nr.162

$\begin{array}{cccc}1430 & \text { Februar } 24 & \begin{array}{c}\text { Hans Junge } \\ \text { (mnd.) }\end{array}\end{array}$

TV: Heinrich Rubow, Ratsherr; Bertold Wilde, Meister Heinrich Werkmester, Heinrich Barum, Bürger zu Lüneburg

ANGABEN ZU PERSON UND FAMILIE:

Hans Junge war ein in den Diensten des Rates Stehender ${ }^{32}$. Vermutlich war er Spielmann. Anzunehmen ist, daß er der Sohn des Lübecker Goldschmieds Stephan Junge war.

VERFÜGUNGEN ÜBER SACHGÜTER:

Den Franziskanern hinterläßt der Testator eine Brosche im Wert von vier Mark Lüneburger Währung, ein silbernes Marienbildnis und eine silberne Kette. Die Brosche ist für eine Chorkappe bestimmt; dafür haben die Franziskaner inm eine Grabstelle in ihrem Kreuzgang gegeben. Die Begräbnisfeiern sollen mit der Kette und dem Marienbildnis beglichen werden. Ein silberne Löffel, der vier Lot wiegt, ist für den Bau von St. Johannis bestimmt. Sein Sohn Yorden erhält den besten weißen Rock und eine rot-schwarze Hoike. Der Testator ist im Besitz eines schwarzen Rockes, den der Sodmeister seinem Sohn Hans, Tydeke Vokelte und Junge gab. Hans hat den Rock durch das Los erhalten und Hans Basimer, Roder und Vredebolt erheben Anspruch auf den Rock; können sie sich nicht einigen, so soll man jedem der drei acht Schillinge und einen Rheinischen Gulden geben, mit denen sie sich eine halbe Tonne Einbecker Bier kaufen können, damit der Rock bei des Testators Sohn Hans bleibt. Dem Rat zu Lüneburg hinterläßt der Testator ein Paar silberner Messer, das um neun Lot Silber liegt, sowie einen goldenen Ring aus drei ineinandergeschlungenen Strängen, der zwei leichte Gulden wiegt. Der Testator bittet den Rat, daß von seinem silbernen Gürtel ein schöner Kelch und eine Patene angefertigt werden sollen: Die vasa sacra sind für die Kapelle des Heiligen Geistes am Markt bestimmt. Heinrich Rubowe erhält einen silbernen Löffel mit einem vergoldeten Knopf, der drei Lot wiegt. Der Testator schenkt der Frau Bertold Wildes einen goldenen Ring mit einer feinen Perle. Der Rosenkranz aus Bernstein, in dem auch Korallen sind, ist für die Marienfigur, bei dem das Licht steht; der Figur soll man den Rosenkranz um den Hals hängen. Die Testamentsvollstrecker sollen zwei Laken Lüneburger Gewandstoff kaufen, von dem je sechs Ellen als Gottesgabe an einen bedürftigen Menschen verschenkt werden soll. Junge besitzt eine silberne Schive, in der das Wappen seiner Herren des Rates zu Lüneburg steht; sie gehört seinem Stiefsohn Hans, der inm vierzehn Rheinische Gulden schuldet. Die Schive gibt Junge inm frei und erläßt die Schulden. Hans bekommt den bislang unvergabten Hausrat. Der Testator besitzt einen Rock, den inm Herr Johann von der Mölen gab; dieser soll den Rock zurückbekommen.

Siegler: Hermann Kruse, Johann Schermbeck

Papier mit aufgedrückten Siegeln

\footnotetext{
${ }^{32}$ M. HASSE, Kleinbildwerke, S. 66.
} 


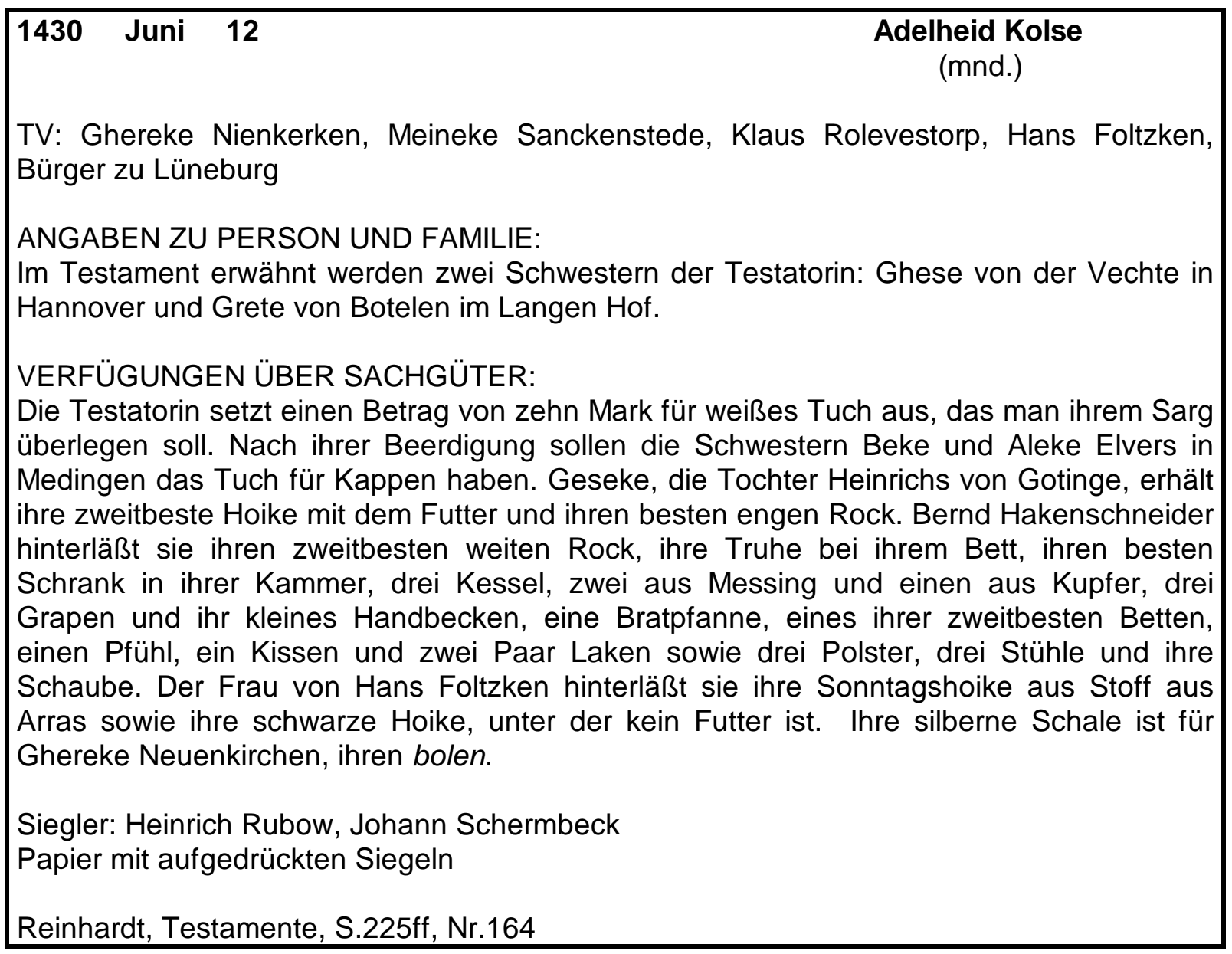

\begin{tabular}{|l|}
\hline $1431 \quad$ Januar 15 \\
$\begin{array}{l}\text { Johann Rese } \\
\text { (mnd.) }\end{array}$ \\
TV: Johann Schellepeper, Klaus Grönhagen, Bürgermeister zu Lüneburg; Ghebeke, Frau \\
des Testators; Heinrich Lange; Hans Rese \\
ANGABEN ZU PERSON UND FAMILIE: \\
Der Testator war Ratsherr zu Lüneburg. Rese war mit Ghebeke verheiratet; ihrer Ehe \\
entstammen drei Kinder. \\
VERFÜGUNGEN ÜBER SACHGÜTER: \\
Rese hinterläßt seinem Ohm, Johann Schellepeper, zwei silberne Becher, die er ihm selbst \\
zuvor gegeben hatte. Klaus Grönhagen erhält seine vergoldete Schauer, Gheverd, sein \\
Bruder, eine silberne Schale, in der ein Einhorn steht, Heinrich Lange sein bestes \\
Marderfutter und Hans Rese sein bestes Iltisfutter. Seiner Frau Ghebeke vererbt er alle \\
Kleinode und ihr Heiratsgut. Dazu soll sie seine anderen Hausgerätschaften und das \\
Silbergeschmeide, das oben nicht erwähnt ist, mit seinen drei Kindern zu gleichem Teile \\
haben.
\end{tabular}


Siegler: Johann Rese, Johann von Ollensen, Johann Schermbeck

Reinhardt, Testamente, S.227ff, Nr.165

1431 Juni $15 \quad \begin{gathered}\text { Margareta von der Mölen } \\ \text { (mnd.) }\end{gathered}$

TV: der jeweils amtierende Ratskämmerer und der oberste Ratsschreiber

ANGABEN ZU PERSON UND FAMILIE:

Die Testatorin war die Witwe Alberts von der Mölen. Sie hatte bereits 1430 ein Testament errichtet, das sie mit dem vorliegenden Testament widerruft. Die von Wittorf sind ihre Ohme. Margareta von Chüden war seit mindestens 1385 mit Albert von der Mölen verheiratet, der Ratsmitglied und Bürgermeister war ${ }^{33}$. Aus dieser Ehe gingen offenbar keine Kinder hervor. Die Testatorin starb 1433.

VERFÜGUNGEN ÜBER SACHGÜTER:

Mit einer Sülzgutrente von zehn Mark sollen die Testamentsvollstrecker den armen Schulkindern der Franziskaner drei Mark geben und soviele Kleider und Schuhe kaufen, wie man dafür kaufen kann.

Jedes Jahr soll eine arme Dienstmagd für ihre Eheausstattung fünf Mark Pfennige von einer Rente erhalten, die für Kleider oder andere Notwendigkeiten verwendet werden sollen. Die anderen fünf Mark der Rente sollen die Testamentsvollstrecker jedes Jahr für weißes und graues Lüneburger Tuch geben, das für die Bekleidung von Hausarmen gedacht ist. Die Testatorin stiftet von einer Rente von achtzehn Mark zwei Mark für die Betten und die Almosen, die sie dem St. Benediktushaus gestiftet hat. Ihr restliches Erbe, seien es Bargeld, Kleinode, Silbergeschmeide oder Hausgerät und ihr Heiratsgut, sei es mobil oder seien es Anlagen, über all dies wird in einer eigenen Urkunde verfügt.

Siegler: Johann von Ollensen, Johann Schermbeck

Abschrift aus dem 17. Jahrhundert StA LG AA P3 c M Nr. 12

Reinhardt, Testamente, S.229ff, Nr.166

Bernd von Erpensen

(mnd.)

TV: -

ANGABEN ZU PERSON UND FAMILIE:

Der Testator, Bürger zu Lüneburg, war der 1432 verstorbene Sülfmeister Bernhard von Erpensen $^{34}$. Mit seiner zweiten Ehefrau Beke Stenhagen hatte er zumindest eine Tochter, die als Begine im Blauen Konvent lebte, und den Sohn Bernd. Aus der ersten Ehe stammten Heinrich und Tibbeke.

VERFÜGUNGEN ÜBER SACHGÜTER:

Beke, seiner ehelichen Frau, hinterläßt der Testator all sein Gut, beweglich und unbeweglich, fahrende Habe, Hausgerade, Ingedome, Silber, Geschmeide, Hausgerade,

Geld und das Gesamte, wo und woran das sei und wo das genannt sei. Seine Tochter

\footnotetext{
${ }^{33}$ H.-J. v. WITZENDORFF, Stammtafeln, S.80.

${ }^{34}$ H.-J. v. WITZENDRFF, Stammtafeln, S. 39.
} 
erhält all ihren Zubehör aus dem Haus, Hof und Wurd.

Siegler: Johann von Ollensen, Albert Elvers

Papier mit aufgedrückten Siegeln

Reinhardt, Testamente, S.233, Nr.167

1432 Januar 31

Hermann Snitker

(mnd.)

TV: Hempeke, seine Frau; Herr Johann Schellepeper, Bürgermeister; Erik Ghise, Ratsherr; Lippold Bodekere, Priester

ANGABEN ZU PERSON UND FAMILIE:

Der Testator war Bürger zu Lüneburg. Nach dem Tod seiner ersten Frau heiratete Snitker erneut. Nicht klar ist, aus welcher der beiden Ehen seine beiden in Lüne lebenden Töchter stammen.

VERFÜGUNGEN ÜBER SACHGÜTER:

Seine Ehefrau soll all ihre Kleider zurückerhalten, Kleinode und die Gerade, die sie mit in die Ehe brachte, aber auch das, was ihr der Testator gab.

Siegler: Johann Schermbeck, Johann Garlop

Überliefert sind zwei Ausfertigungen: 1. Pergament mit Hängesiegeln, 2. Papier mit aufgedrückten Siegeln

Reinhardt, Testamente, S.235f, Nr.169

\begin{tabular}{|ccc}
\hline 1432 & Juni 29 & $\begin{array}{c}\text { Johann Welsrode } \\
\text { (mnd.) }\end{array}$
\end{tabular}

TV: Segeband Amelinghusen, Priester; Klaus Grönhagen, Bürgermeister; Hans Apenborg, Heinrich Grönhagen, Bürger

ANGABEN ZU PERSON UND FAMILIE:

Das Testament nennt eine Schwester des Testators.

VERFÜGUNGEN ÜBER SACHGÜTER:

Seiner Schwester Abele gibt der Testator sieben Ellen von einem Tuch aus Eeclo für einen Rock.

Siegler: Johann von Olensen, Heinrich Hoyer

Papier mit aufgedrückten Siegeln

Reinhardt, Testamente, S.236, Nr.170 
TV: Cord von Hagen, bole des Testators; Johann Pattensen, vadder des Testators; Olrik Dikmann und Johann Crogher, Schwager des Testators

ANGABEN ZU PERSON UND FAMILIE:

Der Testator, Bürger Lüneburgs, war zwei Ehen eingegangen.

VERFÜGUNGEN ÜBER SACHGÜTER:

Der Testator hinterläßt der St Marien zwei Mark Geldes und seinen besten Grapen für Bauarbeiten am Dach. Seinem bolen Conrad von Hagen schenkt er seinen schwarzen, mit dem Iltisfutter gefütterten Rock und Tideke Mauritius seinen Rock mit dem roten Unterfutter sowie seine beste Hoike.

Siegler: Dietrich Heket, Hermann Kruse, Albert Elver

Reinhardt, Testamente, S.239f, Nr.172

\begin{tabular}{|ccc}
1434 & April 12 & $\begin{array}{c}\text { Hans Stute } \\
\text { (mnd.) }\end{array}$
\end{tabular}

TV: Albert Töbing, Bürger; Albert der Kinderen

ANGABEN ZU PERSON UND FAMILIE:

Stute war Mühlenknecht.

VERFÜGUNGEN ÜBER SACHGÜTER:

Den restlichen Nachlaß erhält der Onkel des Testators Meyne von Nordtorp, denn er hat den Testator aufgezogen.

Siegler: Heinrich Hoyemann, Heinrich Lange der Zweite

Papier mit aufgedrückten Siegeln

Reinhardt, Testamente, S.242f, Nr.174

\section{Juni $21 \quad$ Ludolf Töbing \\ (mnd.)}

TV: Johann Garlop, Ratsherr; Meineke Töbing, Bruder des Testators; Meineke Sankenstedt; Hans Töbing, Sohn des Testators

ANGABEN ZU PERSON UND FAMILIE:

1382 ist der Testator in Lüneburg als Bürger nachgewiesen, 1395 als Ratsherr ${ }^{35}$. Als Procurator des Franziskanerklosters ist Töbing 1420 belegt. Aus der Ehe mit Gesche von Abbenburg gingen sieben Kinder hervor. Die Töchter heirateten in die führenden Geschlechter Lüneburgs ein - alsda wären die Sanckenstede, die von der Mölen, Stöterogge, Brömse, Godenstedt und Garlop. Der Sohn Claus wird Vikar in Lüneburg. Der Sohn Hans wird nach dem Studium in Leipzig Ratsherr, 1454 dann Sodmeister.

\footnotetext{
${ }^{35}$ H.-J. v. WITZENDORFF, Stammtafeln, S. 130.
} 
VERFÜGUNGEN ÜBER SACHGÜTER:

Das restliche mobile und immobile Gut soll sein Sohn erhalten.

Siegler: Johann Schermbeck, Heinrich Lange der Zweite

Textverlust durch Löcher im Pergament

Reinhardt, Testamente, S.243f, Nr.175

\section{Juni 1 /mögl. auch Sept. 15}

Friedrich Hogeherte

(mnd.)

TV: Johann von Minden, Ratsschreiber; Hartwig Schomaker; Dietmar Semmelbecker; Heinrich von der Mölen und Heinrich Viskule, der Mann seiner Tochter

ANGABEN ZU PERSON UND FAMILIE:

Der Testator wird 1419 als herzöglicher Vogt in Bleckede geführt, 1423 als Ratsherr in Lüneburg, 1431 als Bürgermeister ${ }^{36}$. In herzöglichem Dienst hatte bereits sein Vater Dietrich gestanden, der Küchenmeister des Herzogs war, und 1372 als Vogt in Lüneburg nachzuweisen ist. Der Testator war verheiratet mit Gertrud von der Mölen, mit der zusammen er eine Tochter Beke hatte. Beke wurde die Ehefrau Heinrich Viskules. Des Testators Bruder Dietrich war Prior von St. Michaelis. Friedrich Hogeherte starb im Jahr der Testamentserrichtung.

VERFÜGUNGEN ÜBER SACHGÜTER:

Die Ehefrau soll weiterhin das Haus bewohnen und ihren Hausrat, Kleider und Kleinodien behalten.

Siegler: Johann Schermbeck, Heinrich Lange der Zweite

Papier mit zwei aufgedrückten Siegeln und zwei Verschlußsiegeln.

Reinhardt, Testamente, S.244ff, Nr.176

\begin{tabular}{|ccc}
1435 & April 2 & $\begin{array}{c}\text { Hartwig Brügge } \\
\text { (mnd.) }\end{array}$
\end{tabular}

TV: Johann von Tespe, Hans Reghagen und Johann Minse

ANGABEN ZU PERSON UND FAMILIE: -

VERFÜGUNGEN ÜBER SACHGÜTER:

Der Bruder des Testators, Dietmar Brügge, erhält eine Hoike und einen Rock von einem Knäul erg - (unleserlich) weiß unterfüttert.

Siegler: Johann Garlop, Ludolf Töbing

\footnotetext{
${ }^{36}$ H.-J. v. WITZENDORFF, Stammtafeln, S. 52.
} 
Papier mit aufgedrückten Siegeln

Reinhardt, Testamente, S.246f, Nr.177

\section{$1436 \quad$ Februar $28 \quad$ Meinecke von Lübeck \\ (mnd.)}

TV: Hermen Kruse, Bürgermeister; Cord Dalhusen; Heinrich Fischer; Hans von Lübeck, Sohn des Testators; Ludolf von Vintlo; Geseke; Hans

ANGABEN ZU PERSON UND FAMILIE:

Die Witwe des Testators Geseke scheint 1438 Johann Brome geheiratet zu haben, bei dessen Einbürgerung im gleichen Jahr Hans von Lübeck als Bürge aufgetreten war ${ }^{37}$. Der Testator, Bürger der Stadt Lüneburg, wird 1422 als Geschworener der Johanniskirche geführt $^{38}$. Er war Vater der Söhne Johann, Heinrich und Meino.

VERFÜGUNGEN ÜBER SACHGÜTER:

Im Fall der Wiederverheiratung der Ehefrau sollen ihr die Testamentsvollstrecker ihre Kleider und den ihr gehörenden Hausrat geben. Das übrige mobile und immobile Gut sollen seine fünf Kinder erhalten.

Siegler: Johann von der Mölen, Heinrich Hoyemann, Ratsherren

Abschrift des 16. Jahrhunderts

Reinhardt, Testamente, S.247f, Nr.178

1436 November $19 \quad \begin{gathered}\text { Ludolf Kirchof } \\ \text { (mnd.) }\end{gathered}$

TV: Hans von Tespe, Gheverd Grönhagen, Hans Stange, Eckerd Wangelo

ANGABEN ZU PERSON UND FAMILIE:

Der Testator war Bürger der Stadt Lüneburg.

VERFÜGUNGEN ÜBER SACHGÜTER:

Kapital im Wert von 300 Mark Pfennigen stellt der Testator für arme Leute zur Verfügung. Die Zuwendungen sollen in Form von Geld, Tuch oder Nahrungsmitteln erfolgen. Jeder seiner Testamentsvollstrecker soll Tafelgeschmeide im Wert von einer Silbermark erhalten.

Siegler: Klaus Grönhagen, Hartwig Schomaker

Überliefert ist eine gleichzeitige Abschrift mit folgendem Rückvermerk: Auschultata est presens copia suprascripta per me Rodolphum Rodolphi, clericum Maguntinensis diocesis publicum imperiali auctoritate notarium. Et concordat cusuo vero originali, quod attestor hac manu mea propria.

Reinhardt, Testamente, S.248f, Nr.179

\footnotetext{
${ }^{37}$ U. J. DIEDERICHS, Aufruhr, S.101f.

${ }^{38}$ H.-J. v. WITZENDORFF, Stammtafeln, S.75.
} 


\begin{tabular}{|ccc}
\hline 437 & Januar 13 & $\begin{array}{c}\text { Metteke Bere } \\
\text { (mnd.) }\end{array}$
\end{tabular}

TV: -

ANGABEN ZU PERSON UND FAMILIE:

Metteke Bere war die Witwe Heinrich Beres, einst Bürgermeister in Lüneburg.

Die Testatorin, die aus dem Geschlecht Hoyemann stammte, war Mutter von fünf Kindern $^{39}$. Der Sohn Heinrich studierte an der Universität von Erfurt, wurde dann Kanoniker in Bardowick. Johann wurde Ratsherr und Bürgermeister, war in Lübeck als Zirkelherr geführt und starb in Lübeck. Dietrich wurde bischöflicher Offizial. Wobbeke heiratete Albert Elver, und Gesche ist als Begine im Blauen Konvent nachgewiesen.

VERFÜGUNGEN ÜBER SACHGÜTER:

Ihrer Tochter Geseke schenkt die Testatorin all ihr Futter, bis auf das unter ihrer besten Hoike. Ferner gibt sie ihr die vier silbernen Löffel. Ihrem Sohn Heinrich gibt sie das große Handbecken; ferner stehen inm der große Grapen und der große Kessel zu. Ihre Kleider und ihren Hausrat soll man verkaufen; mit dem Erlös soll ihr Begräbnis finanziert werden. Das restliche Gut sollen ihr Sohn Heinrich und ihre Tochter Geseke haben.

Siegler: Brand Tzerstede, Dietmar Semmelbecker

Papier mit aufgedrückten Siegeln. Urkunde ist durch Einschnittt ungültig gemacht worden.

Reinhardt, Testamente, S.250ff, Nr.180

\begin{tabular}{|crrr}
\hline 1437 & Juli 11 & Hans Saffan \\
& & (mnd.)
\end{tabular}

TV: Dietrich Nygenborch, Hans Lembeke, Heinrich Ochtmissen

ANGABEN ZU PERSON UND FAMILIE:

Saffan war wahrscheinlich Bäcker ${ }^{40}$.

VERFÜGUNGEN ÜBER SACHGÜTER:

Saffan hinterläßt sein Wohnhaus, Hof, Wurt mit allem Zubehör, dazu alles Hausgerät seiner Ehefrau Geseke. Stirbt sie, dann soll das beschriebene Haus mit seinem Zubehör an seinen Sohn Heinrich fallen, und das Hausgerät soll sie ihren Kindern nach ihrem Willen geben und unter innen aufteilen. Heinrich soll in dem Haus mit der Mutter bleiben. Können sie sich nicht vertragen, so soll sie die Stube vorne am Haus haben, und Heinrich soll ihr Miete für das Haus geben.

Siegler: Ludolf Töbing, Johann Garlop

Papier mit aufgedruckten Siegeln

Reinhardt, Testamente, S.252, Nr.181

\footnotetext{
${ }^{39}$ H.-J. v. WITZENDORFF, Stammtafeln, S. 8 und 53.

${ }^{40}$ H.-J. v. WITZENDORFF, Stammtafeln, S.206f, Nr.65.
} 


\begin{tabular}{|l}
$1438 \quad$ Oktober 10 \\
TV: Baldewin von Wenden, Abt; Ludolf von Hitzacker, Prior des Michaelsklosters; Heinrich \\
$\begin{array}{l}\text { Louwencop; Priester der Heilig Geistkapelle am Neumarkt; Andreas Luder in St. Cyriacus, } \\
\text { Bruno Malstop in St. Nikolai, ständige Vikare der Diözese Verden }\end{array}$ \\
ANGABEN ZU PERSON UND FAMILIE: \\
Der Testator war Almosenverteiler des Benediktinerklosters. \\
VERFÜGUNGEN ÜBER SACHGÜTER: \\
$\begin{array}{l}\text { Der Testator wünscht, daß eine Rente erworben wird für den Ankauf von grauem Tuch, } \\
\text { welches unter den Bedürftigen jährlich aufgrund der drohenden Kälte verteilt werden soll. } \\
\text { Signet und Unterschrift des Notars Ludolf Poppendik } \\
\text { Reinhardt, Testamente, S.252ff, Nr.182 }\end{array}$
\end{tabular}

\begin{tabular}{|ccc}
1439 & Juni 21 & $\begin{array}{c}\text { Soffeke Springintgud } \\
\text { (mnd.) }\end{array}$
\end{tabular}

TV: Die Testamentsvollstrecker ihrer Kinder, eingesetzt von ihrem verstorbenen Ehemann Hans Endewat sowie Heinrich Louwencop

ANGABEN ZU PERSON UND FAMILIE:

Soffeke Springintgud war die Witwe Hans Endewats. Ihre Kinder entstammten der Ehe mit Hans Endewat ${ }^{41}$. Der Lüneburger Bürger Hans Endewat aus einer Seitenlinie der uradligen von Spörcken starb 1432. Die darauf geschlossene Ehe mit dem Barmeister und Ratsherrn Dietrich Springintgud blieb kinderlos ${ }^{42}$. Bei der im Testament genannten Schwester Geseke handelte es sich um ihre mit Dietrich Döring verheiratete Schwägerin Geseke Springintgud. Die aus dem Geschlecht Schomaker stammende Testatorin starb drei Tage nach der Testamentserrichtung ${ }^{43}$.

VERFÜGUNGEN ÜBER SACHGÜTER:

Die Testatorin schenkt ihrer Schwester Geseke den besten Gürtel, den ihr Dietrich Springintgud gab. Will aber die Tochter der Testatorin den Gürtel zurückkaufen, so mag sie es mit zwei Mark Rente tun. Will sie es aber nicht, so kann inn eines von Soffekes anderen Kindern erwerben. Ihrer Muhme hinterläßt die Testatorin die schwarze Hoike und den braunen Rock mit dem Seidenfutter. Die bislang nicht versorgten Kinder erhalten all ihre anderen Kleinode, Ringe, Hausgerätschaften und das Heiratsgut. Der Sohn Curd bekommt den Korallenrosenkranz, Brosche und ihren besten Ring, den ihr ihr Sohn Werner kaufte. Für die anderen Renten und ihre Mitgift gelten die zwischen ihrem Mann, ihren Kindern und ihr ausgehandelten Regelungen.

Konzept oder gleichzeitige Kopie. Rückvermerk: Dit is dat testament, dat ik, Hinrick Schermbeke, af gherurt hebbe in myner scrift.

\footnotetext{
${ }^{41}$ H.-J. v. WITZENDORFF, Stammtafeln, S. 37.

${ }^{42}$ H.-J. v. WITZENDORFF, Stammtafeln, S. 121.

${ }^{43}$ H.-J. v. WITZENDORFF, Stammtafeln, S.115.
} 


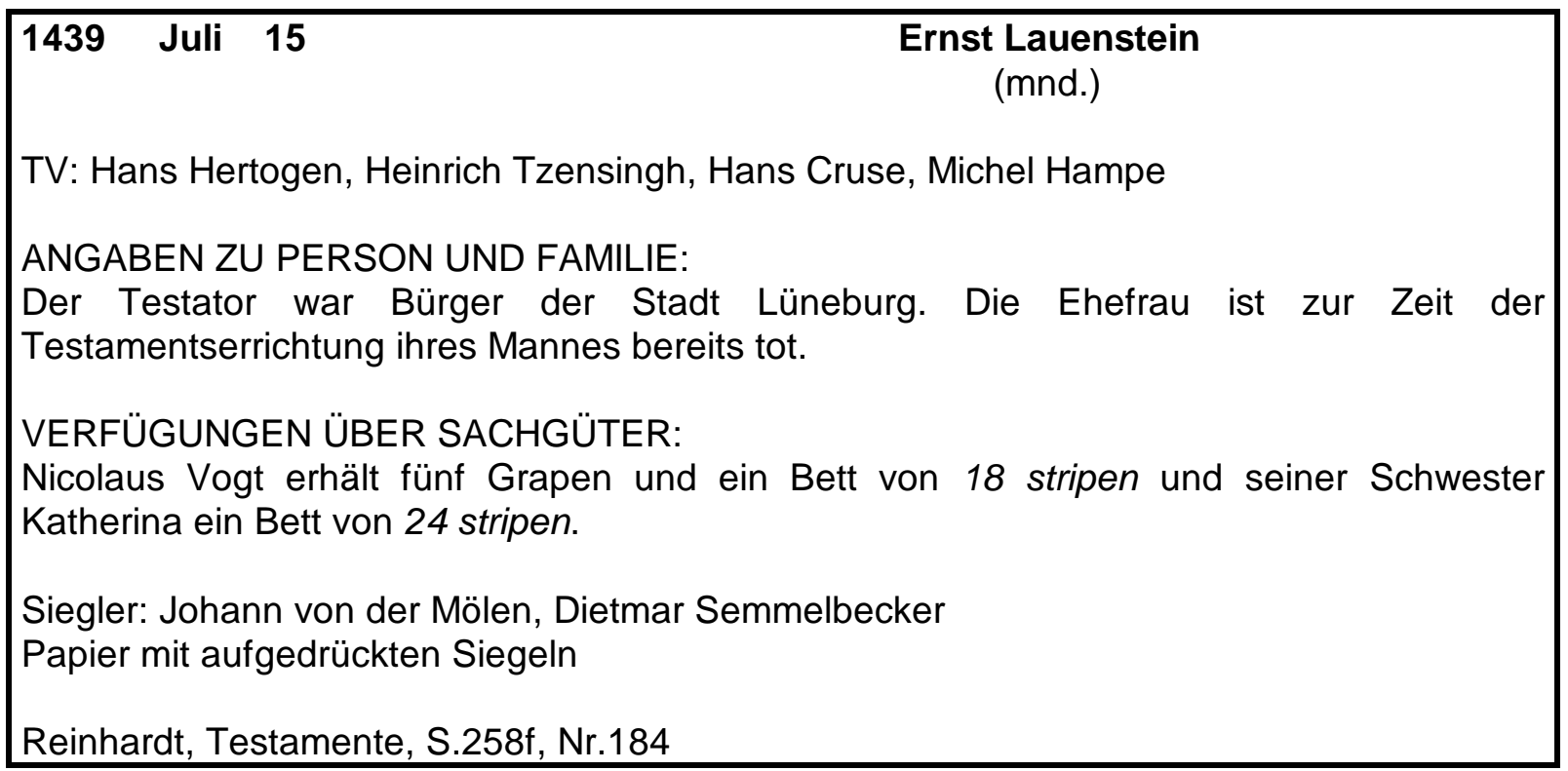

\begin{tabular}{|l|}
\hline 1439 August 9 \\
TV: Bertold Borchard, Hermann Neppen und Jutteke, die Frau des Testators \\
ANGABEN ZU PERSON UND FAMILIE: - \\
(mnd.) \\
VERFÜGUNGEN ÜBER SACHGÜTER: \\
Der Testator hat kein Erbgut erhalten; seinen Besitz hat er zusammen mit seiner Ehefrau \\
erarbeitet. Aus diesem Grund hinterläßt er seiner Frau Jutteke seinen gesamten Nachlaß \\
zur freien Verfügung; sie soll jedoch seine Schulden bezahlen. \\
Siegler: Brand Tzerstede, Dietmar Semmelbecker \\
Papier mit aufgedrückten Siegeln \\
Reinhardt, Testamente, S.259, Nr.185
\end{tabular}

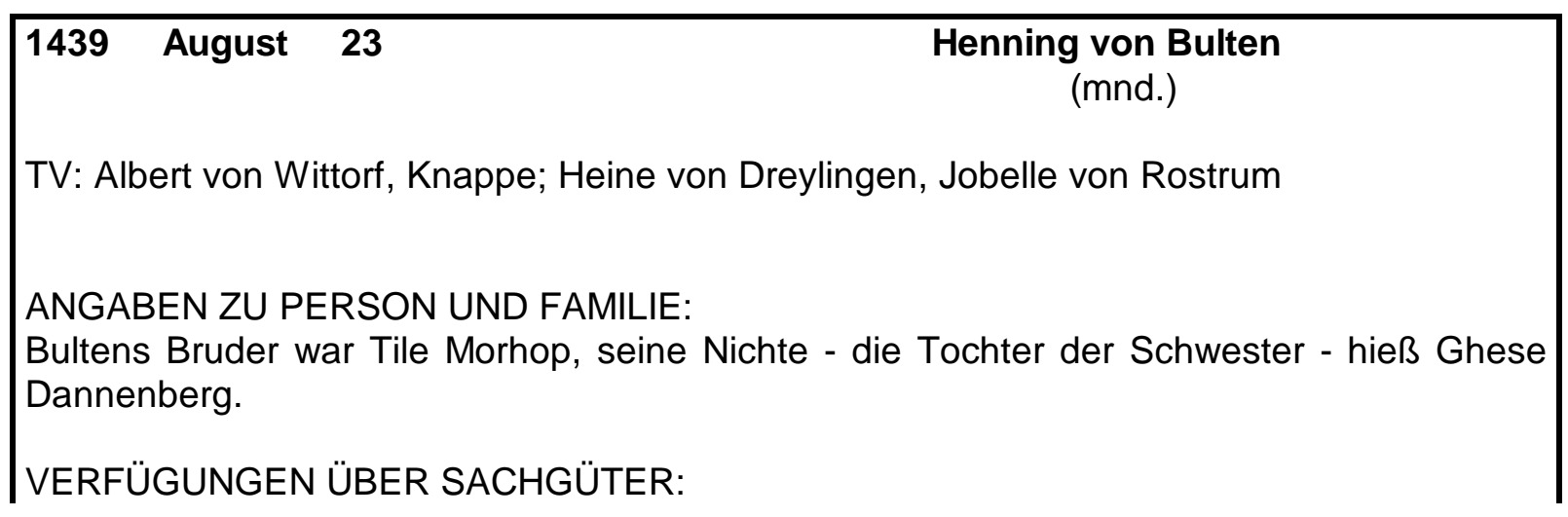


Seine Testamentsvollstrecker sollen von seinem Nachlaß ein gutes goldenes Tuchstück kaufen und davon priesterliche Kleidung mit Alben und Amikten und allem, was dazu nötig ist, anfertigen lassen. Die Gabe sollen sie der Kirche zu Bülten (Kr.Peine) im Ambergau (Landschaft bei Bockenem, Kr. Hildesheim) geben.

Siegler: Brand Tzerstede, Dietmar Semmelbecker

Papier mit aufgedrückten Siegeln

Reinhardt, Testamente, S.260, Nr.186

\section{September $24 \quad$ Christian von Bergen \\ (lat.)}

TV: Heinrich Louwenkop, Priester der Heilig Geistkapelle am Neumarkt, Heinrich Tetendorp, Heinrich Unna, Vikar daselbst, Bruno Malstorp, Vikar in St. Nikolai

ANGABEN ZU PERSON UND FAMILIE:

Der Testator war Vikar in der Johanniskirche und in St. Lamberti. Seine Nichte war die Ehefrau Hermann Kruses des Jüngeren.

VERFÜGUNGEN ÜBER SACHGÜTER:

Sein übriges Gut will der Testator verkaufen und dafür jährliche Einkünfte erstehen, damit in den einzelnen Jahren durch seine Testamentsvollstrecker den Armen Tuch und Schuhe gegeben werden können. Der Testator möchte vor dem Altar der Jungfrau Maria in der Kapelle des heiligen Lambertus beerdigt werden. Seinem Sarg soll ein goldenes Tuch übergelegt werden, aus dem später eine Kasel für die Vikarien in St. Johannis und St. Lamberti gearbeitet werden soll. Für die Vikarien sollen seine Testamentsvollstrecker sollen möglichst schnell ein Buch, einen Kelch und notwendige Altargeräte erwerben.

Gleichzeitige Abschrift, an die folgende Urkunden angeheftet sind: Beglaubigung der Vikariestiftung, Entscheidung des Bischofs Johannes von Verden im Rechtsstreit um das Patronats- und Präsentationsrecht, der zwischen den Testamentsvollsteckern und dem Bürgermeister Schellepeper ausgetragen wurde (Entscheid zugunsten des Bürgermeisters).

Reinhardt, Testamente, S.260ff, Nr.187

\begin{tabular}{|ccc}
1439 & September 25 & $\begin{array}{c}\text { Heinrich Hagen } \\
\text { (mnd.) }\end{array}$
\end{tabular}

TV: Albert Elver, Heinrich Hoyemann, Brand Tzerstede, Dietmar Semmelbecker

ANGABEN ZU PERSON UND FAMILIE:

Der Bürger und Sülfmeister Heinrich von Hagen, 1426 an der Universität zu Rostock nachgewiesen, war verheiratet mit Gheseke Hoyemann ${ }^{44}$. Aus dieser Ehe gingen die Söhne Heinrich und Brand hervor. Heinrich Hagen hatte drei Brüder - zwei studierten in Leipzig - und zwei Schwestern. Der Testator starb 1450. Das Testament seines Vaters ist aus dem Jahr 1410 überliefert.

\footnotetext{
${ }^{44}$ H.-J. v. WITZENDORFF, Stammtafeln, S.50.
} 
VERFÜGUNGEN ÜBER SACHGÜTER:

Seine Frau Gheseke erhält sein Wohnhaus mit allem mobilen und immobilen Zubehör.

Seinem Bruder Heinrich hinterläßt der Testator seinen roten Rock, der mit grauem (Eichhörchen-)Pelz gefüttert ist. Das Tuch, mit dem man ihn zu Grabe trägt, soll seine Schwester in Diesdorp erhalten.

Siegler: Heinrich Lange der Zweite, Ludolf Godenstedt

Papier mit aufgedrückten Siegeln

Reinhardt, Testamente, S.263f, Nr.188

\section{September $28 \quad$ Heinrich Steinhagen}

(lat.)

TV: Beke Töbing, des Testators Schwester; Bernard von Erpensen, Neffe des Testators

ANGABEN ZU PERSON UND FAMILIE:

Der Testator war ständiger Vikar der Johanniskirche und der Gertrudenkirche in Lüneburg. Seine Schwester Beke war in offenbar erster Ehe mit dem Sülfmeister Bernhard von Erpensen verheiratet, der 1432 starb $^{45}$. Sein Testament ist aus dem Jahr 1431 überliefert. Bernhard, einer der beiden aus der Ehe hervorgehenden Söhne, ist 1447 an der Universität in Leipzig nachgewiesen.

VERFÜGUNGEN ÜBER SACHGÜTER:

Seine Schwester Beke Töbing und ihrem Sohn, Bernard von Erpensen, hinterläßt der Testator all sein mobiles und immobiles Gut, sowie Grapen, Kessel, Betten, Pfühle, Kröse, Kannen. Davon soll die Beerdigung bezahlt werden und soviel Tuch gekauft werden, wie es seine Schwester Hempeke für eine Kappe benötigt. Das Tuch soll zunächst als Bahrtuch verwendet werden. Seiner Schwester Wobbeke erhält seinen Arraschen Rock und den mit dem Pelzfutter gefütterten Rock; das Futter soll man herausschneiden und es einem armen Priester geben. Der Rock mit dem blauen Futter und die schwarze Hoike mit dem weißen Futter seinem denst, den seine Schwester wohl kennt. Der Erlös aus dem Verkauf seiner übrigen Kleider sool seinem Seelenheil dienen.

Unterschrift und Signet des Notars Heinrich Brunshausen

Reinhardt, Testamente, S.264f, 189

1439 Oktober 9

TV: Sander Smede, Ludolf Elringdorp

ANGABEN ZU PERSON UND FAMILIE:

Der Testator war Ratsherr zu Uelzen.

\section{Heinrich Blickwedel}

(mnd.)

\footnotetext{
${ }^{45}$ H.-J. v. WITZENDORFF, Stammtafeln, S.39.
} 
VERFÜGUNGEN ÜBER SACHGÜTER:

Seinem Sohn Hans hinterläßt er den gesamten mobilen und immobilen Nachlaß. Stirbt Hans, so sollen die Güter an des Testators Stiefsohn Heinrich Bernsen und seine Kinder fallen.

Siegler: Hans Nyebur, Otto Ortmann

Gleichzeitige Abschrift

Reinhardt, Testamente, S.265f, Nr.190

\section{November $30 / 1440$ Februar $23^{46}$}

Eckhard Stein

(lat.)

TV: Siegfried Hoyemann, Bernhard von Thune, Hermann von Soest

ANGABEN ZU PERSON UND FAMILIE:

Stein war Vikar in St. Johannis.

VERFÜGUNGEN ÜBER SACHGÜTER:

Seiner Vikarie in St. Johannis hat der Testator zum ewigen Verbleib sein Missale gegeben, das er von seinem eigenen Geld schreiben ließ, und ein versilbertes Friedenskreuz. Dem Scholaren Dietmar von Soest überläßt er seine Bücher für die kanonischen Stunden für sich und seine Brüder, wenn er Priester wird. Stein schenkt den Armen und Leprösen in St. Vitus in Uelzen eine Rente von sieben Mark aus einem Kapital von 105 Mark beim Rat von Uelzen, von denen die Provisoren dieser Hospitäler jährlich am Tag der Geburt Johannes des Täufers einem jeden Armen und Leprösen ein Leinentuch für Hemden oder Laken in der Menge geben soll, die diese sieben Mark Einkünfte erlauben.

Unterschrift und Signet des Notars Bertold Engelke

Reinhardt, Testamente, S.266ff, Nr.191

\begin{tabular}{|llcl}
1440 & April 25 & $\begin{array}{c}\text { Gese von Gandersen } \\
\text { (mnd.) }\end{array}$
\end{tabular}

TV: Siverd Gyseke, Mathias der Apotheker, Hans Merren, Ludolf Varendorp

ANGABEN ZU PERSON UND FAMILIE:

Die Testatorin war die Witwe des Bürgers Alberts von Gandersen. Ihre Tochter Gese war die Ehefrau des Apothekers Matthias von der Most verheiratet, der 1474 testierte.

VERFÜGUNGEN ÜBER SACHGÜTER:

Für den Fall, daß Gese kinderlos bleibt, soll der letzte von innen - Gese oder Mathias - es einrichten, daß man von vier Mark Rente, wenn diese noch da sind, graues Gewand und Schuhe um der Ehre Gottes willen für ihres Mannes und ihrer Seele gibt. Was die Testatorin weiterhin an mobilen Frauenutensilien besitzt, an Kleidern und anderem donde, das nicht zu ihrer Frauengerade gehört, das will sie ihrer Tochter und deren Mann

\footnotetext{
${ }^{46} 1439$ wurde das Testament angefertigt, 1440 bei einem Notar eingereicht.
} 
übergeben.

Siegler: Heinrich Lange der Zweite, Dietmar Semmelbecker

Reinhardt, Testamente, S.269f, Nr.192

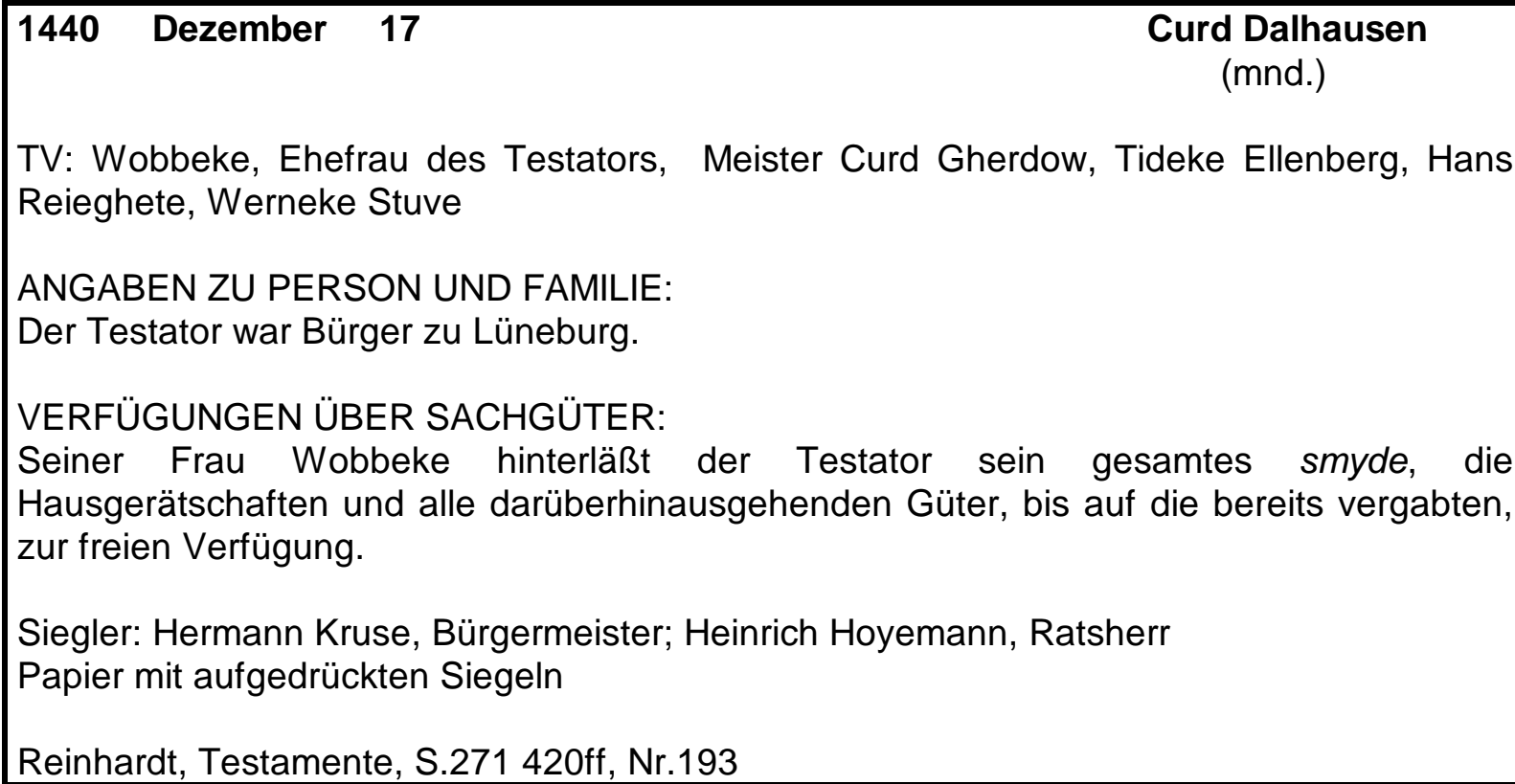

um 1440 Dat. ergibt sich aus Schrift

Alheid Weidelerche

(mnd.)

TV: -

ANGABEN ZU PERSON UND FAMILIE:-

VERFÜGUNGEN ÜBER SACHGÜTER:

Adelheid Weidelerche hat ihr bestes Paar Kleider St. Nikolai gegeben, dort soll man ihrer ewig gedenken. Ihren weißen Rock und die Alltagshoike und ihre Kapuze hinterläßt sie Grete, ihrer Base, ihrer Hausfrau den Pelz.

Siegler: Johann Schermbeck, Ludolf von Godenstedt

Reinhardt, Testamente, S.274 425f, Nr.194

um 1440 Dat. ergibt sich aus Schrift

Johann Tabel

(mnd.)

TV: Johann von Tespe, Johann von Greve, Hans Nakken, Heinrich Nakken

ANGABEN ZU PERSON UND FAMILIE:

Tabel war Bürger zu Lüneburg. Johann Tabel besuchte die Universität in Erfurt, war 
verheiratet und Vater von vier Söhnen ${ }^{47}$.

VERFÜGUNGEN ÜBER SACHGÜTER:

Der Sohn Heinrich Nakken erhält den gesamten Nachlaß, Haus und Hof, was immer der Testator außerhalb und innerhalb besitzt.

Siegler: je zwei Siegel von Johann Schermbeck und Ludolf Godenstedt

Papier mit aufgedrückten Siegeln

Reinhardt, Testamente, S.274f, Nr.195

$1441 \quad$ April 22

Meister Heinrich

(mnd.)

TV: Hans Vluwerk, Tideke Flore, Bernd Sinning, Hans Reiegher

ANGABEN ZU PERSON UND FAMILIE:

Meister Heinrich war werkmester ${ }^{48}$ des Rates zu Lüneburg.

VERFÜGUNGEN ÜBER SACHGÜTER:

Seiner Magd Grete soll man eines seiner beiden besten Federbetten geben und eine Vorkiste. Ferner soll man zwei Laken weißen oder grauen Tuchs für zwölf Mark kaufen, die unter armen Leuten aufgeteilt werden sollen.

Siegler: Heinrich Lange der Zweite, Dietrich Brömse

Reinhardt, Testamente, S.276f, Nr.197

\begin{tabular}{|llcl}
\hline 1441 & Februar & 12 & $\begin{array}{c}\text { Alheid Salzenhausen } \\
\text { (mnd.) }\end{array}$
\end{tabular}

TV: Hans Bulow, Jakob Sars

ANGABEN ZU PERSON UND FAMILIE: -

VERFÜGUNGEN ÜBER SACHGÜTER:

Ihrem Neffen Heinrich Meding schenkt die Testatorin ihren gesamten Nachlaß, wenn der Neffe an Land kommt.

Siegler: Heinrich Hoyemann, Brand Tzerstede, Ratsherren

Gleichzeitige Abschrift

Reinhardt, Testamente, S.275f, Nr.196

$1441 \quad$ August 24

Heinrich Tetendorp

\footnotetext{
${ }^{47}$ H.-J. v. WITZENDORFF, Stammtafeln, S. 152.

${ }^{48}$ Innungs- und Gildenvorsteher; auch Kirchvorsteher.
} 
TV: Bernhard von Lideren, Bruno Malstorp, Johann Dalenborch

ANGABEN ZU PERSON UND FAMILIE:

Tetendorp war ständiger Vikar in der Kapelle St. Lamberti in Lüneburg.

VERFÜGUNGEN ÜBER SACHGÜTER:

Der Kommende in St. Lamberti stiftete der Testator seine neun Bücher und sechs Zinngefäße.

Beke, seine Tante, erhält ein kleineres Bett, Pfühl, Kissen und ein Paar Laken, einen schwarzen, mit dem blauen Stoff gefütterten Rock und einen kleineren Schrank, der in seiner Stube steht. Bruno Malsdorp schenkt der Testator die große Schaufel und zwei kleinere silberne Krather/Becher. Darüberhinaus gibt er Herrn Heinrich Meyger drei Bücher, die sich bei diesem befinden, und ein kleineres Handfaß und Kapuze für Albert. Johann Rumeland hinterläßt er einen besseren schwarzen Rock mit weißem Stoffutter sowie vier bessere Töpfe, den großen Messingkochkessel, ein besseres Bett und eine Decke ((angesichts des Kontextes muß es wohl lodicem und nicht codicem heißen - Anmerkung: S. Mosler-Christoph)) sowie zwei Paaren Laken. Seine Vikarie in St. Lamberti erhält zwei Schränke und die große Truhe. Heinrich von Lideren schenkt er sein altes Stundenbuch, vier (Folgendes nicht leserlich)... seinen besseren Chorrock mit Kapuze sowie seine Albe, die schwarze Toga mit ... gefüttert und ein versilbertes Messer, ein Bett mit einem Paar Laken. Dem Helmold Tetendorp seinen bessseren Wams ..... Zinn von einem Stübchen Wein und ....

Notar: Heinrich Steendorp

Abschrift aus der 2. Hälfte des 15. Jahrhunderts

Reinhardt, Testamente, S.277ff, Nr.198

\section{$1441 \quad$ Oktober 8}

TV: Heinrich Bekker, Heinrich Sengstake, Klaus Wichmanns

ANGABEN ZU PERSON UND FAMILIE:

Johann Pale, Bürger Lüneburgs,war verheiratet mit Wobbeke; mit ihr hatte er die Kinder Vicke und Klaus. Sein Sohn Heineke stammte offenbar aus einer anderen Verbindung.

VERFÜGUNGEN ÜBER SACHGÜTER:

Seinem Sohn Heineke hinterläßt er zwei Fischerkannen. Ferner schenkt er seiner Schwester Ilsebe zweieinhalb Mark Pfennige, die inm Heine Kalyt und Vikke Alberde für zwei Kannen schuldig sind.

Siegler: Johann Schermbeck, Ludolf Godenstedt

Papier mit aufgedrückten Siegeln

Reinhardt, Testamente, S.280, Nr.199 
TV: -

ANGABEN ZU PERSON UND FAMILIE:

Kruse war Bürgermeister. Der neun Tage nach Testamentserrichtung gestorbene Kruse war Ratsherr, Vorsteher der Johanniskirche, ist 1432 als Sülfmeister belegt und wurde 1436 Bürgermeister ${ }^{49}$. Verheiratet war er mit der 1438 verstorbenen Windel Köler. Dieser Ehe entstammten sechs Kinder: Zwei der Söhne studierten in Rostock und Erfurt: Eggert wurde Sechziger, Ratsherr im Neuen Rat und Sodmeister, war dann von 1456 bis 1463 in Gefangenschaft, lebte später in Bardowick ${ }^{50}$; Hans ist als Sülfmeister nachgewiesen ${ }^{51}$. Die drei Töchter heirateten in die Geschlechter der Mölen, Düsterhop und Winsen ein.

VERFÜGUNGEN ÜBER SACHGÜTER:

Vom restlichen Ertrag einer Rente soll man Schuhe und Gewand kaufen und armen Leuten für ewige Zeiten am Allerheiligentag geben. Den drei Töchtern schenkt er die Perlenkrone, die seine verstorbene Frau für seine Töchter machen ließ. Sie sollen sie zusammen mit den Frauen seiner Söhne gebrauchen, aber seine Töchter sollen das Eigentumsrecht daran haben. Ferner gibt er sein Flämisches Tuch oder Decke seiner Tochter Gheseke. Johann, Abt zu Scharnebeck, erhält 60 Lübische Mark für ein Kleinod; Dietrich, Propst zu Lüne, auch 60 Mark für ein Kleinod. Johann von der Mölen, Ratsherr zu Lüneburg, bekommt die zweitbeste silberne Schale, Dietrich Düsterhop die zwei silbernen Becher, Ludolf von Winsen eine silberne Schale. Das Tafelgeschmeide, das er nicht vergeben hat, und die Hausgeräte erhalten seine drei Söhne, also Hans, Hermen und Eggherd.

Siegler: Hermann Kruse, Johann Schermbeck, Ludolf Godenstedt

Reinhardt, Testamente, S.281ff, Nr.200

\begin{tabular}{|llcl}
\hline 442 & Februar 21 & mögl. auch 14 & $\begin{array}{c}\text { Hermann Stekeberg } \\
\text { (mnd.) }\end{array}$
\end{tabular}

TV: Heinrich Veltstede, Vikar im Heiligen Geist auf dem Neumarkt; Heinrich Nymmethopp, Heinrich Dreiling; Thonnies, der Schmied

ANGABEN ZU PERSON UND FAMILIE:

Der Testator war Bürger zu Lüneburg.

VERFÜGUNGEN ÜBER SACHGÜTER:

Der Testator betont, daß er kein Erbgut empfangen habe, weder von seinen Eltern oder von Verwandten. Er habe sein Gut jedoch mit seiner Ehefrau Metteke zusammen in harter Arbeit gewonnen; aus diesem Grund hinterlasse er ihr seinen gesamten Nachlaß, das Guthaben wie auch die Schulden. Normalerweise soll das Erbe erst nach ihrem Tod den Erben, den Kindern der Tochter, zukommen; sie kann ihnen aber auch schon eher etwas geben.

Siegler: Johann von der Mölen, Dietrich Brömse

\footnotetext{
${ }^{49}$ H.-J. v. WITZENDORFF, Stammtafeln, S.65f.

${ }^{50}$ U.J. DIEDERICHS, Aufruhr, S.158f.

${ }^{51}$ H.-J. v. WITZENDORFF, Stammtafeln, S.66.
} 


\begin{tabular}{|l}
\hline $1443 \quad$ Februar 10 \\
TV: Johann Winenbuttel, Priester; Eggherd Wangelo, Hermann von Soest, Ludolf Elebeke, \\
Hermen Gallen, Thomas Smede \\
ANGABEN ZU PERSON UND FAMILIE: \\
Der Testator war Bürger zu Lüneburg. \\
VERFÜGUNGEN ÜBER SACHGÜTER: \\
Mit zwei normalen grauen, in Lüneburg gefertigten Laken soll man arme Leute bekleiden; \\
für 16 Mark soll man armen Leuten Schuhe und Hosen kaufen. Seinen beiden Töchtern \\
Geseke und Cristine hinterläßt der Testator 40 Mark für die Frauengerade. Ferner schenkt \\
er ihnen dazu so viel Leinwand, wie er für die Gerade gekauft hat, und eben so viele \\
Tafellaken, Handtücher, ein Schiffpfund Federn, vier Polster und zehn Federkissenbezüge. \\
Ferner überträgt er sein Heergewät seinen Söhnen, so wie es innen zukommt. Was nach \\
Ausstattung der Kinder übrig ist, das soll seine Ehefrau Geseke erhalten, sowohl das \\
mobile als auch das immobile Gut, Haus, Hof und Hausgerätschaften. \\
Siegler: Johann von der Mölen, Dietrich Brömse \\
Papier mit aufgedrückten Siegeln \\
Reinhardt, Testamente, S.285f, Nr.202
\end{tabular}

\begin{tabular}{|l|}
\hline $1444 \quad$ Mai 8 \\
TV: Richard Pattinenmaker, Dietrich Remstede, Heinrich Saffan \\
(mnd.)
\end{tabular}

\begin{tabular}{|lc|}
\hline 1444 Mai 23 & $\begin{array}{c}\text { Cyeke Witting } \\
\text { (mnd.) }\end{array}$ \\
TV: Werner Witting, Sohn der Testatorin, Priester; Hans & Witting, ihr Sohn; Jakob von \\
Troghel, Bürger zu Lüneburg &
\end{tabular}


ANGABEN ZU PERSON UND FAMILIE:

Das Testament nennt zwei Söhne der Testatorin, Werner und Hans, sowie eine Tochter Grete.

VERFÜGUNGEN ÜBER SACHGÜTER:

Die Testatorin hinterläßt ihrer Schwester Hempeke ihre schwarze Hoike, die sie alle Tage umzuhängen pflegt, ihren besten Pelz und ihre Schaube. Den anderen Pelz gibt sie Metteke Meding. Ihren braunen weiten Rock schenkt sie Vredeke, ihren braunen Alltagesrock Gheseke, der Magd ihrer Tocher Grete. Den braunen Rock, der gemacht wurde aus alter und neuer Kleidung, hinterläßt sie Kyneke Meding im Bardenouwen Hof. Werner, ihrem Sohn, hinterläßt die Testatorin den großen Schrank, der jetzt im Haus Jakob von Trochels steht, und ihr Tragbett, das im Bardenouwen Hof steht. Ferner sei bekannt, daß Grapen, Kruse, Truhen und Kesselhaken ihrem Sohn Werner gehören. Jedoch gehören zwei Kessel in ihrer Bude Hans Varendorp, dem Sohn ihrer Schwester. Eine Hoike der Testatorin soll von Grete, ihrer Tochter Grete, verkauft werden; aus dem Erlös geht je eine Mark an die Bauhütte von St. Johannis, St. Lamberti, St. Marien und Heiligenthal.

Siegler: Johann Schermbeck, Ludolf Godenstedt

Reinhardt, Testamente, S.288f, Nr.204

$\begin{array}{|llc|}1444 & \text { Oktober } 18 & \begin{array}{c}\text { Grete von der Heide } \\ \text { (mnd.) }\end{array}\end{array}$

TV: Brun Malstorp, Heinrich Varendorp, Priester; Hans Elver der Jüngere; Heinrich von der Heide

ANGABEN ZU PERSON UND FAMILIE:

Möglicherweise lebte die Testatorin im Blauen Konvent ${ }^{52}$.

VERFÜGUNGEN ÜBER SACHGÜTER:

Neun Ellen schwarzen Stoff aus Leiden sollen für Aleke Semmelbecker in Lüne gekauft werden. Fünf Mark Pfennige sind Hilfe für einen neuen Mantel ihrer Schwester in Wienhausen oder der Tochter ihres Bruders. Heinrich erhält zwei Betten, zwei Kopfkissen, vier $d u$ (Folgendes unleserlich) kissen und zwölf Polster, ihre Grapen, ihre Kessel und ihr anderes Hausgerät abgesehen von dem, was sie von ihrem Hausrat und Kleinodien anderen gegeben hat.

Siegler: Johann Schermbeck, Dietmar Semmelbecker

Papier mit aufgedrückten Siegeln

Reinhardt, Testamente, S.289ff, Nr.205

$1444 \quad$ November 27

Johannes Weidenknepel

(lat.)

\footnotetext{
${ }^{52}$ Eine Margareta de Heyda ist 1403 und 1422 belegt. H-J. BEHR, Der Convent der blauen Beginen in Lüneburg, in: Lüneburger Blätter 11/12, Lüneburg 1961, S. 191.
} 
TV: -

ANGABEN ZU PERSON UND FAMILIE:

Der Testator war Lübecker Kanoniker.

VERFÜGUNGEN ÜBER SACHGÜTER:

Mit dem Verkauf einiger Mobilien sollen Pilgerreisen nach Rom und ins Heilige Land finanziert werden; die Anzahl der Pilger wird bestimmt durch die Höhe des Erlöses aus dem Verkauf seiner silbernen Kostbarkeiten, der Utensilien, aller Hausratsgegenstände und anderer Dinge, die im Hof zu finden sind. Einen Teil des Erlöses sollen seine Testamentsvollstrecker als Almosen, Kleidungsstücke, Schuhe, Badekleidung unter den Armen und Bedürftigen verteilen. Der Testator hinterläßt dem Propst Johann Walking ein Messer mit einem versilberten Kristallgriff, dem Bischof Nikolaus einen goldenen Ring, Dideric Broun, einem Lübischen Kleriker, für den Fall sein Stundenbuch, daß er die heiligen Weihen empfange, Johann Hagen das Stundenbuch, aus dem er mit inm die Stunden liest, das er für fünfzehn Mark als Pfand erhalten hat. Wenn das Stundenbuch eingelöst wird, soll wenigstens der Wert des Buches eingenommen werden. Von dieser Verfügung ausgenommen sind der Psalter und das Diurnale, die beide unverpfändet sind. Hagen soll einen gefütterten Rock von den einfacheren mit Kapuze haben und einige Bücher; all dieses verbleibt in eigener Benutzung bis zum Tod des Testators. Sein Scholar soll, wenn er innerhalb eines Jahres Priester wird, einen Rock erhalten.

Unterschrift und Signet des Notars Johannes Schilder

Reinhardt, Testamente, S.292ff, Nr.206

1444 Dezember 13

Klaus und Grete von Wening

(mnd.)

TV: Luteke Sprans, Cord Boltzen, Priester und Vikare zu St. Lamberti

ANGABEN ZU PERSON UND FAMILIE:

Klaus von Wening war Bürger von Lüneburg.

VERFÜGUNGEN ÜBER SACHGÜTER:

Die Testamentsvollstrecker sollen der Magd Metteke Ossensen ein Bett geben, einen Pfühl, zwei Paar Laken, eine Decke und zwei Grapen, einen Rock und eine Hoike, von jedem das nächstbeste nach dem Heergewät und der Frauengerade.

Siegler: Albert Elver, Albert Semmelbecker

Gleichzeitige Abschrift

Reinhardt, Testamente, S.297f, Nr.207

1445

Lange Ludolf

(mnd.)

TV: Metteke, seine Ehefrau; Hans von Tespe, Titke Ortburg

ANGABEN ZU PERSON UND FAMILIE: 
VERFÜGUNGEN ÜBER SACHGÜTER:

Unter der letzten Zeile steht von anderer Hand geschrieben: Barum Knieder behält meine mansrade.

Siegler: Johann Schermbeck, Ludolf Godenstedt

Datierung ergibt sich aus der Schrift und der Amtszeit der siegelnden Ratsherren. Papier mit aufgedrückten Siegeln

Reinhardt, Testamente, S.298, Nr.208

\begin{tabular}{|ccc|c}
\hline 447 & Januar 9 & $\begin{array}{c}\text { Peter Schütte } \\
\text { (mnd.) }\end{array}$
\end{tabular}

TV: Albert, Sohn des Testators; Heinrich Grönhagen, Mann der Tochter

ANGABEN ZU PERSON UND FAMILIE:

Der Testator, Bürger Lüneburgs, war Sülfmeister ${ }^{53}$. Seine Tochter Metteke heiratete 1436 den Sülfmeister Heinrich Grönhagen, der nach Festsetzung 1457 aus dem Gefängnis über Uelzen nach Braunschweig floh. Im gleichen Jahr wurde Metteke vermutlich aus Lüneburg ausgewiesen. 1365 wurde sie zusammen mit des Testators Witwe Tibbeke, ihrer Mutter, in Braunschweig erwähnt ${ }^{54}$. Des Testators Sohn Alberd war Sechziger, als Sechzehner erkennbar, Gefängnis und Einlager, aus dem er 1464 entlassen wird. Er war Sülfmeister und Mitglied der Dreifaltigkeitsgilde ${ }^{55}$.

VERFÜGUNGEN ÜBER SACHGÜTER:

Von einer Rente von 20 Mark sollen seine Frau, ihrer beider Kinder und nach innen ihre Erben jährlich Tuch und Schuhe kaufen und unter den Armen aufteilen.

Siegler: Ludolf Godenstedt, Hartwig Schomaker

Reinhardt, Testamente, S.299ff, Nr.209

\begin{tabular}{|ccc|c}
\hline 1447 Mai 29 & $\begin{array}{c}\text { Hans Tespe } \\
\text { (mnd.) }\end{array}$
\end{tabular}

TV: Bernd Weddesen zu Hamburg, Heinrich Louwencop zu Lüneburg, Vikare und Priester; Eghard Wangelow, Ratsherr; Heinrich von der Mölen; Heinrich Rybe

ANGABEN ZU PERSON UND FAMILIE:

Der Testator war Bürger von Lüneburg. Verheiratet war Tespe mit Ilsebe. Gemeinsame Kinder werden in dem Testament nicht erwähnt, lediglich der Stiefsohn Olrik Kruse.

VERFÜGUNGEN ÜBER SACHGÜTER:

Seiner Ehefrau Ilsebe hinterläßt der Testator das Wohnhaus mit seinem Zubehör, beim |

\footnotetext{
${ }^{53}$ H.-J. v. WITZENDORFF, Stammtafeln, S.148.

${ }^{54}$ U. J. DIEDERICHS, Aufruhr, S.140ff..

${ }^{55}$ U. J. DIEDERICHS, Aufruhr, S. 236.
} 
Hof Heinrich Viskules gelegen, zur freien Verfügung für die Dauer ihres Lebens. Sie soll des Testators Bruder Vicke beherbergen und ihm Kost und Trinken geben, und sie soll inm ein Bett mit einem Kopfkissen, mit einer Decke und einem Paar Laken überlassen. Was sie von dem Ingedome und Hausgerade haben soll, will er ihr wohl besonders bestimmen..... Wybeke, der Frau Heinrich Rybens, gibt er seine zwei Gebetsbücher, die ihre Mutter schreiben ließ.

Siegler: Hans Tespe, Bartold Lange, Heinrich Viskule

Papier mit aufgedrückten Verschlußsiegeln. Erhalten sind zwei Abschriften: P3ct7a und ND Manecke 27, fol. 4444ff

Reinhardt, Testamente, S.301ff, Nr.210

\begin{abstract}
1447 August 12
Nickel Lesnis

(mnd.)

TV: Volkmer Klovesteen; Hans Hessen, Kürschner

ANGABEN ZU PERSON UND FAMILIE: -

VERFÜGUNGEN ÜBER SACHGÜTER:

Die beste Hoike ist für die Bauhütte der Barfüßer. Seinem Diener Nickel Becker gibt er sein werktuch, mit dem er alle Tage arbeitet, ausgenommen drei Sägen und eine Zimmeraxt. Aleke, der Magd Volkmer Klovensteins, schenkt er die Stücke Geschmeide, die inm für achtzehn Lübische Schillinge ohne vier Pfennig als Pfand gesetzt worden sind, wenn sie für die Ehe ausgestattet wird. Knöpfe, Spangen, und Silbersachen sind für einen Kelch, dessen Bestimmungsort seine Testamentsvollstrecker je nach Notwendigkeit benennen können.
\end{abstract}

Siegler: Heinrich Hoyemann, Albert von der Mölen

Papier mit aufgedrückten Siegeln

Reinhardt, Testamente, S.304f, Nr.211

\begin{tabular}{|ccc|}
\hline 447 & Dezember 14 & $\begin{array}{c}\text { Hans Kruse } \\
\text { (mnd.) }\end{array}$
\end{tabular}

TV: Johann von der Mölen, Ratsherr, Dietrich Düsterhop, Ludolf von Winsen, Hermen und Eggherd Kruse, Brüder des Testators, Heinrich Braunschweig

ANGABEN ZU PERSON UND FAMILIE:

Der Sülfmeister Hans Kruse ist 1424 an der Universität zu Rostock, 1425 in Erfurt nachgewiesen ${ }^{56}$. Er war zweimal verheiratet, in erster Ehe mit Alheid Döring. Sein Tod wird auf das Jahr 1460 datiert. Sein Bruder Eggherd war am Aufstand 1454/56 beteiligt ${ }^{57}$. |Johann von der Mölen, Dietrich Düsterhop und Ludolf von Winsen waren die Ehemänner|

\footnotetext{
${ }^{56}$ H.-J. v. WITZENDORFF, Stammtafeln, S.66.

${ }^{57}$ U. J. DIEDERICHS, Stammtafeln, Nr.39.
} 
seiner Schwestern. Die 1469 testierende Metteke von Dassel war seine Tochter.

VERFÜGUNGEN ÜBER SACHGÜTER:

Der Testator schenkt Herrn Johann von der Mölen und seiner Frau zwanzig Mark für ein Kleinod, Dietrich Düsterhop und seiner Frau auch zwanzig Mark für ein Kleinod sowie Ludolf von Winsen und seiner Frau zwanzig Mark für ein Kleinod. Ferner sollen seine Testamentsvollstrecker all sein Silbergeschmeide zu Geld machen.

Siegler: Brant von Tzerstede, Johann Töbing

Gleichfalls erhaltene Zweitausfertigung auf Papier mit aufgedrückten Siegeln

Reinhardt, Testamente, S.305f, Nr.212

\section{$1448 \quad$ Mai 17}

Dietrich Ellenberg (mnd.)

TV: Kämmerer des Rates zu Lüneburg, der älteste Kirchgeschworene zu St. Johannis und der Besitzer des Wohnhauses des Testators

ANGABEN ZU PERSON UND FAMILIE:

Der Testator war Bürger zu Lüneburg.

VERFÜGUNGEN ÜBER SACHGÜTER:

Ellenberg spendiert jedem derzeitigen Testamentsvollstrecker jährlich am Martinsabend ein Stübchen Wein, das der jeweilige Hausbesitzer freundlich und ohne Verzug in ihre Häuser senden soll. Und um diesen Wein zu versenden, bestimmt der Testator seine große Zinnkanne, daß sie bei dem Besitzer seines Hauses zu ewigen Zeiten bleiben soll. Das Wohnhaus soll sein Vetter Dietrich haben.

Siegler: Heinrich Lange, Dietmar Semmelbecker

Papier mit aufgedrückten Siegeln

Reinhardt, Testamente, S.306ff, Nr.213

\begin{tabular}{|ccc|c|c}
\hline 1449 & Oktober 9 & $\begin{array}{c}\text { Heinrich Dreyling } \\
\text { (mnd.) }\end{array}$
\end{tabular}

TV: Gobele von Rostern, Dietrich und Hans Werkmester, Brüder

ANGABEN ZU PERSON UND FAMILIE:

Der Testator war Bürger zu Lüneburg.

VERFÜGUNGEN ÜBER SACHGÜTER:

Der Testator beteuert, kein Erbgut empfangen zu haben. Seinen Nachlaß, bestehend aus Häusern, Höfen, Schulden, Bargeld und Hausrat hat er zusammen mit seiner Frau Alheyd durch beider Arbeit erworben.

Siegler: Johann von der Mölen, Johann Töbing

Nachweis: Reinhardt, Testamente, S.310f, Nr.215 
TV: Bernd Redebere, Küster in Oldenstadt; Bernd Sinning, Hans von Ulssen, Heinrich von Laffert, Ludolf Wichtenbeke

ANGABEN ZU PERSON UND FAMILIE:

Der Testator war Bürger zu Lüneburg.

VERFÜGUNGEN ÜBER SACHGÜTER:

Seinem Bruder Heinrich hinterläßt er alle Kleider, die nach Lafferts Leib bemessen sind.

Siegler: Heinrich Viskule

Reinhardt, Testamente, S.311f, Nr.216

\begin{tabular}{|llll}
1451 & März & 12 & $\begin{array}{c}\text { Beke Groning } \\
\text { (mnd.) }\end{array}$
\end{tabular}

TV: Johann Springintgut, Brand Tzerstede, Dietmar Semmelbecker, Johann Rokswale

ANGABEN ZU PERSON UND FAMILIE:

Die Testatorin war die Witwe Hans Gronings. Laut Testament war sie die Mutter Hans Rokswales, Rikele Tzerstedes und einer mit einem Semmelbecker verheirateten Tochter. Ferner verzeichnet das Testament Enkelkinder von einer mit einem Springintgut verheirateten Tochter. Folglich war die Testatorin Elisabeth von dem Lo, die 1405 in erster Ehe Hans Rokswale heiratete, nach 1417 dann Hans Gröning ${ }^{58}$. Gröning hatte in Erfurt studiert, war 1408 herzöglicher Salinenzöllner, zur Zeit seiner Heirat mit Elisabeth Provisor der Nikolaigilde und 1430 Barmeister ${ }^{59}$. Er starb Ende 1432. Als TV hatte Elisabeth von dem Lo engste Familienmitglieder wie Sohn und Schwiegersöhne auserkoren.

Ihr Neffe Johann vame Lo testiert 1464, sein Sohn gleichen Namens 1473.

VERFÜGUNGEN ÜBER SACHGÜTER:

Ihrem Testamentsvollstrecker Johann Springintgut schenkt die Testatorin eine welsche noit. Brand Tzerstede gibt sie eine silberne Schale, in der drei halbe Monde stehen. Ferner schenkt sie Herrn Dietmar Semmelbecker einen silbernen Krug. Ihrem Sohn Hans Rokswale vererbt sie einen silbernen Becher. Ihrer Tochter, der Semmelbeckerschen, hinterläßt sie eine silberne Kette, mit der man sich gürtet, und zwei goldene Ringe; der eine hat einen Smaragd, der andere hat einen braunen Stein. Ihre Tochter Rikele, die Tzerstedesche, bedenkt sie mit einem grünen Seidengürtel mit Silberbeschlag, einem Ring mit einem Saphir, auf dem auf beiden Seiten Malde Wolken steht, und einem schlichten goldenen Ring. Ferner gibt sie jedem Kind ihrer Tochter, der Springintgutschen, und jedem Kind der Tzerstedeschen, einen silbernen Becher. Der Frau Rokswales überträgt sie, wenn er sich verändert, einen roten Gürtel mit Silberbeschlag und einen Ring, in dem ein Saphir steht, den zwei Hände halten, sowie einen Armreif, in dem St. Katherina steht. Stirbt die mit einer Geldrente bedachte Tochter Hans Elbecks, so soll man das Geld sogleich armen

\footnotetext{
${ }^{58}$ H.-J. v. WITZENDORFF, Stammtafeln, S.73.

${ }^{59}$ H.-J. v. WITZENDORFF, Stammtafeln, S. 48.
} 
Jungfrauen zur Hilfe für Gewand, Hemden und Schuhe stiften.

Siegler: Hartwig Schomaker, Johann Elver

Papier mit aufgedrückten Siegeln

Reinhardt, Testamente, S.313ff, Nr.217

\begin{tabular}{|ccc|c}
\hline 1451 & Mai 15 & Ludolf Ossendorf \\
$(\mathrm{mnd})$
\end{tabular}

TV: Titeke Sovenbroder, Hans Koke, Dietrich Penteshorn, Werneke Kulzig

ANGABEN ZU PERSON UND FAMILIE:

Der Testator war Bürger zu Lüneburg. Aus dem Testament geht hervor, daß der Testator mit Beke verheiratet war, dieser Ehe offensichtlich eine Tochter namens llsebe entsprang. Ilsebe war verheiratet mit Hans Koke.

VERFÜGUNGEN ÜBER SACHGÜTER:

Nach dem Tod des Testators und seiner Frau Beke sollen ihr Wohnhaus, Hof und Wurd mit allem Zubehör, Hausgerade und Hausrat frei und unverschuldet an Hans Koke fallen, dem der Testator Ilsebe zur Frau gab.

Siegler: Brand von Tzerstede, Dietmar Semmelbecker

Papier mit aufgedrückten Siegeln

Reinhardt, Testamente, S.314f, Nr.218

1451 Juni 11

Robke van dem Jettebrok

(lat.)

TV: Frederik Viskule, Albert Kloninghusen, Heinrich Raven

ANGABEN ZU PERSON UND FAMILIE:

Aus der Ehe des Testators gingen mindestens sechs Kinder hervor; namentlich sind überliefert: Curd, Heinrich, Olrik, Johann, Rophe sowie eine Tochter namens Metteke, die als Begine in Walsrode lebte.

VERFÜGUNGEN ÜBER SACHGÜTER:

Die restliche Hinterlassenschaft an Fahrhabe, Korn, Saat, Rüstung/Kleidung, Hausgerade, Hausrat und allen mobilen und immobilen Gütern soll zur Tilgung der Schulden und zur Finanzierung des Begräbnisses verwendet werden. Den dann noch verbleibenden Rest soll seine Frau nutzen, wie beide es besprochen haben.

Notar: Meynardus Sars

Gleichzeitige beglaubigte Abschrift

Reinhardt, Testamente, S.316f, Nr.219 
TV: Clement Grale, Dietrich Nyenborg, Pawel Kistenmaker, Bürger zu Lüneburg

ANGABEN ZU PERSON UND FAMILIE:

Der 1485 verstorbene Sülfmeister Ludolf Elebek, Bürger zu Lüneburg, war in erster Ehe mit einer von Wienebüttel verheiratet ${ }^{60}$. Möglicherweise war ihr bevorstehender Tod der Grund für die Anfertigung dieses Testaments. Noch vor 1465 ging der Testator die zweite Ehe, jetzt mit Beke von Grönhagen, ein.

VERFÜGUNGEN ÜBER SACHGÜTER:

Den Barfüßern geben sie einen ihrer großen Eckschränke und den großen Kessel, den sie innen bereits gegeben haben. Ihren großen Schrank aus Tannenholz schenken sie St. Nikolai. Ferner gibt Geseke mit der Zustimmung Ludolfs, ihres Hausherrn, den Kindern ihres Bruders die lantkiste und alles, was darinnen gefunden wird.

Siegler: Heinrich Hoyemann, Heinrich Viskule

Papier mit Oblatensiegel

Reinhardt, Testamente, S.319f, Nr.221

\begin{tabular}{|llc|}
\hline 1451 & August 12 & $\begin{array}{c}\text { Heinrich vom Hove } \\
\text { (mnd.) }\end{array}$
\end{tabular}

TV: Dietrich von Dassel; Hans Witzendorf, Dietrich Ellenberg der Jüngere, Bürger zu Lüneburg

ANGABEN ZU PERSON UND FAMILIE:

Der Testator war Bürger zu Lüneburg. Offensichtlich war vom Hove kinderlos, während sein Bruder zumindest einen Sohn hatte, der vom Testator bedacht wird.

VERFÜGUNGEN ÜBER SACHGÜTER:

Gerd Huxer, Franziskaner in St. Marien, schenkt der Testator elf Mark für eine Kappe und wozu er es nötig hat. Mit einer Rente von dreizehn Mark sollen die Testamentsvollstrecker Gewand und Schuhe kaufen, um arme Leute zu bekleiden. Hermann vom Hove, dem Sohn seines Bruders, schenkt der Testator zwanzig Mark für einen Kelch. Den Resterlös einer Rente soll man jährlich für den Ankauf von Gewand und Schuhen für arme Leute verwenden.

Siegler: Brand von Tzerstede, Dietmar Semmelbecker

Papier mit aufgedrückten Siegeln

Reinhardt, Testamente, S.320ff, Nr.222

$1451 \quad$ September $26 \quad$ Heinrich Hoyer

(mnd.)

TV: Wobbeke, Ehefrau; Johann Springintgud und Albert Semmelbecker, Bürgermeister; 
Marquard Mildehöft, Stadtschreiber; Albert von der Mölen, Ratsherr; Dietrich Schellepeper, Bürger zu Lüneburg

ANGABEN ZU PERSON UND FAMILIE:

Der Testator ist als regierender Ratsherr nachgewiesen in den Jahren 1431, 32, 34, 35, 38 bis 42 sowie 1444, 47 und $1448^{61}$. Vor dem Bekleiden des stadtpolitischen Amts hatte er Karriere an der Saline gemacht, wo er 1428 als Sülfmeister, 1430 als Barmeister geführt wurde $^{62}$. Seine als Testamentsvollstreckerin benannte Frau Wobbeke Stöterogge war seine zweite Ehefrau; in erster Ehe war er mit Gretke von Bardowick verheiratet. Sein vedder Detlev Hoyer ist nach seinem Studium in Erfurt Domherr zu Lübeck geworden, seine Schwester Berteke ist im Kloster Lüne, wo sie Priorin wurde; seine Schwester Bilghe befindet sich in Rane, seine medder Metteke ist mit dem Lüneburger Ratsherrn Erich Ghise verheiratet.

VERFÜGUNGEN ÜBER SACHGÜTER:

Von einem Geldlegat für den Nikolaihof in Bardowick soll die Hälfte für Winterkleidung und Ausbesserung des Bettzeugs verwendet werden. Eine Rente von einer Mark überträgt der Testator dem St. Benedictushof, damit allzeit Betten und Bettuch für die Kranken vorhanden sind und andere Dinge für ihre Bequemlichkeit angeschafft werden können.

Siegler: Heinrich Hoyer, Johann Töbing, Johann Elver

Reinhardt, Testamente, S.322ff , Nr.223

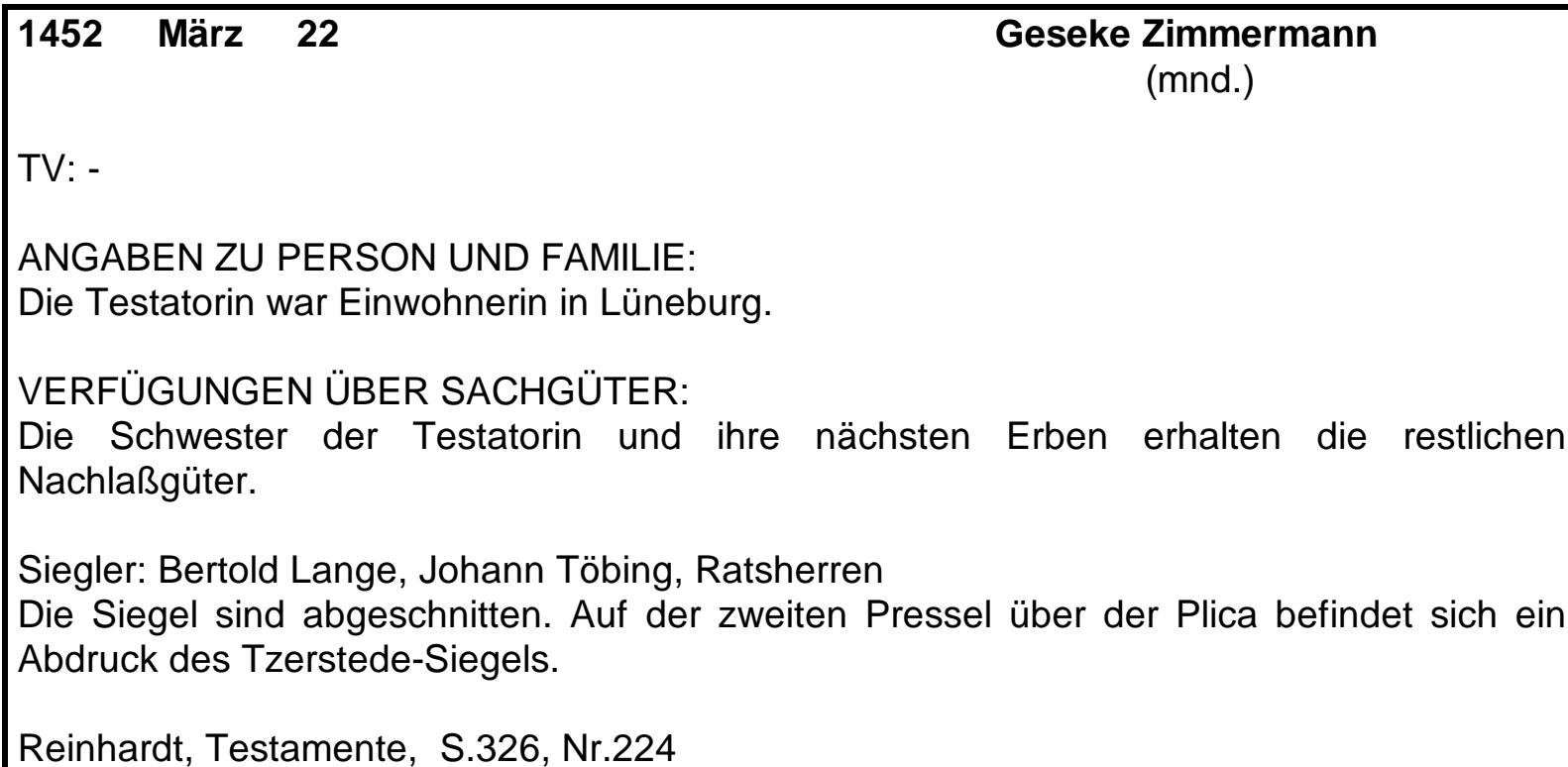

1452 Juli 4

Johannes van Wintem

(mnd.)

TV: Reynste, Frau des Testators; Ludolf Spranse, Priester; Heine Papen und Dietrich von

\footnotetext{
${ }^{61}$ I. STAHL, Ratslinie, Nr. 185, S.167.

${ }^{62}$ H.-J. v. WITZENDORFF, Stammtafeln, S.57.
} 
Hachelde, Bürger zu Lüneburg

ANGABEN ZU PERSON UND FAMILIE:

Der Testator war Bürger zu Lüneburg. Ein 1460 verstorbener Johannes von Winthem ist für die Jahre 1459 und 1460 als regierender Ratsherr nachgewiesen ${ }^{63}$.

VERFÜGUNGEN ÜBER SACHGÜTER:

Da der gesamte Besitz von beiden Eheleuten zusammen erarbeitet wurde, hinterläßt der Testator seiner Ehefrau den gesamten Nachlaß.

Siegler: Dietrich Brömse, Johann Töbing

Papier mit aufgedrückten Siegeln

Reinhardt, Testamente, S.326f, Nr.225

\section{April $10 \quad$ Cord von Rettmer}

(mnd.)

TV: Ludolf Berchdorp, Vicke Bodenstede, Bürger zu Lüneburg

ANGABEN ZU PERSON UND FAMILIE:

Der Testator war Bürger zu Lüneburg. Der Name seiner Frau ist Abele. Seine ältesten Kinder heißen Ludolf und Wibeke.

VERFÜGUNGEN ÜBER SACHGÜTER:

Er vererbt seiner Frau Abele und den beiden Kindern sein Wohnhaus, seinen Hof und die Wurt sowie alles Zubehör.

Siegler: Johann Braunschweig, Heinrich Provest

Reinhardt, Testamente, S.327f, Nr.226

\begin{tabular}{|cccc}
1458 & April & 6 & $\begin{array}{c}\text { Adelheid Kale } \\
\text { (mnd.) }\end{array}$
\end{tabular}

TV: Heinrich Erpensen, Dietrich Ellenberg, Klaus Clentzemann, Ludolf Eimbek

ANGABEN ZU PERSON UND FAMILIE:

Die Testatorin war die Witwe des verstorbenen Meisters Heinrich Kale, Zimmermeister des Ehrsamen Rates zu Lüneburg.

VERFÜGUNGEN ÜBER SACHGÜTER:

Von ihrem Silbergeschmeide soll man einen Kelch anfertigen lassen, eine Patene, ein Meßgewand, ein Amikt und eine Albe; das soll man den Barfüßern zu St. Marien für Gedenkgottesdienste geben.

Siegler: Johann vame Lo, Meine Töbing, Ratsherren

Papier mit aufgedrückten Siegeln, die nur noch bruchstückhaft erhalten sind.

\footnotetext{
${ }^{63}$ I. STAHL, Ratslinie, S.170.
} 


$\begin{array}{llll}1459 & \text { Februar } 10 & \begin{array}{c}\text { Adelheid Miils } \\ \text { (mnd) }\end{array}\end{array}$

TV: -

ANGABEN ZU PERSON UND FAMILIE:

Die Testatorin war die Witwe des Bürgers Ludolf Miils. Laut Testament war sie zweimal verheiratet, von eigenen Kindern ist nicht die Rede.

VERFÜGUNGEN ÜBER SACHGÜTER:

Ihre zweitbeste Hoike schenkt sie ihrer Magd Geseke.

Siegler: Heinrich von der Mölen, Konrad Schellepeper

Reinhardt, Testamente, S.330f, Nr.227 


$\begin{array}{llll}1460 & \text { Mai } 30 & \text { Hilleke von Erpensen } \\ \text { (mnd.) }\end{array}$

TV: Heinrich Stöterogge, Helmeke Masendorp, Bürger zu Lüneburg; Rikele von der Weser, Metteke Elebek und Hillen Stuveken

ANGABEN ZU PERSON UND FAMILIE:

Die Testatorin war Bewohnerin des Blauen Konvents innerhalb Lüneburgs. Sie war die Nichte Mechthild von Erpensens ${ }^{1}$. Gerd, der Bruder der Testatorin, ist zur Zeit der Testamentserrichtung bereits verstorben ${ }^{2}$. Bei dem von der Testatorin bedachten ohm Heinrich von Erpensen wird es sich um den 1461 und 1493 als Vikar in Lüneburg geführten Heinrich aus der zweiten Linie des Geschlechts handeln, der 1483 auch Dechant von Bardowick war.

Metteke Elebeck, Testamentsvollstreckerin und Bedachte, wird 1472 als Vorsteherin des Blauen Konvents genannt ${ }^{3}$.

VERFÜGUNGEN ÜBER SACHGÜTER:

Ferner gibt sie ihrem ohm, Herrn Heinrich Erpensen, ihren langen Schrank, der da unten bei der großen trade steht. Dahinein soll man inm ein Meßgewand legen, das sie ihm selber gemacht hat. Ihre große silberne Schale soll für ewige Zeiten dem Konvent gehören. Solange Beginen in diesem Konvent leben, soll die Schale von ihren Verwandten/Freunden oder denjenigen, die mit ihr versorgt werden, in Verwahrung und gutem Schutz behalten werden. Ihre zwei großen silbernen Becher soll Metteke Elebek behalten und dazu ihr bestes Paar Kleider. Die zweitbeste Hoike soll Geseke Eelbek haben ( Eelbek fehlt in der Abschrift). Ihre meddere Hilleke Stuveke ( Name könnte auch Stuneke lauten) erhält die beste Arrasche Hoike. Ihren Psalter hinterläßt die Testatorin dem Konvent zum ewigen Verbleib. Solange jemand von ihren Verwandten/Freunden oder Mitschwestern in diesem Konvent lebt, soll er den Psalter haben und inn verwahren. Erst nach ihrer aller Tod soll inn der Oberste des Konvents verwahren und inn keiner Mitschwester verweigern, die um inn bittet. Ihren Sonntagsrock soll Rikele von der Weser haben. Was die Testatorin ferner an Hausgerade besitzt, das sollen sich Metteke Elebek und die genannte Hilleke Stuveke (Name könnte auch Stuneke lauten) teilen mit Ausnahme der Grapen, die soll Metteke alleine behalten.

Zwei Ausfertigungen liegen vor: 1. unbesiegeltes Konzept, 2. gleichzeitige unbesiegelte Abschrift

Reinhardt, Testamente, S.331ff, Nr.229

$1461 \quad$ Dezember 14

Heinrich Geismar

(lat.)

TV: Petrus Verchlatz in Boitzenburg, Bruno Malstorp, Vikar in St. Johannis, Dietrich Intwesten, Priester der Diözese Ratzeburg, Johann Raven, Bürger zu Lüneburg

ANGABEN ZU PERSON UND FAMILIE:

Der Testator war Pleban der Pfarrkirche in Böken, Diözese Ratzeburg, sowie Vikar am |

\footnotetext{
'vgl. Testament Metteke Schermbeck 1451 Juli 1.

${ }^{2}$ H.-J. v. WITZENDORFF, Stammtafeln, S.39.

${ }^{3}$ H.-J. v.WITZENDORFF, Stammtafeln, S.156.
} 
Kleineren Heiligen Geist in Lüneburg, Diözese Verden.

VERFÜGUNGEN ÜBER SACHGÜTER:

Der Testator hat Theoderik, seinem Kaplan, ein Missale, einen Kelch, eine Amikt und alle vasa sacra zum Zelebrieren geschenkt. Conrad hinterläßt er seinen schwarzen, mit Ilitispelzen gefütterten Rock. Seine schwarze Hoike und seine Kapuze mit der Cuculla hat er Arnold Meding, einem Verdener Kleriker, seinem Vertrauten, geschenkt. Den besseren Rock und seine Bücher erhält sein Kaplan Theoderic Intwesten mit Ausnahme zweier Bücher, nämlich des Liber Sextus und der Pisana; diese Bücher sind für Bruno Malsdorp bestimmt. Die bessere Hoike, die zu lesenden und zu betrachtenden kanonischen Stundenbücher, aller Hausrat sowie vergoldete und silberne Kleinodien sind bis jetzt in treuer Bewachung bei Alheid, der Witwe des Bürgers Johann Raven. Dies alles soll an seine Magd Grete fallen.

Signet und Unterschrift des Notars Hermann Heren

Von diesem Notariatsinstrument sind zwei Ausfertigungen erhalten. Die Bestätigung des Testaments erfolgte 1470 Dezember 15 durch Bischof Bertold von Verden. Auch diese Urkunde ist erhalten.

Reinhardt, Testamente, S.334ff, Nr.230

\begin{tabular}{|ccc}
\hline 464 & Juli 28 & Johann vame Lo \\
& & (mnd.)
\end{tabular}

TV: Heinrich von der Mölen, Domherr zu Bardowick, Herr Klaus Sankenstedt, Ratsherr, Hans Braunschweig, Heinrich Varendorp, Johann vame Lo, sein Sohn

ANGABEN ZU PERSON UND FAMILIE:

Geboren im Jahr 1411, ist Johann vame Lo 1426 an der Universität Erfurt nachzuweisen, 1433 hatte er das Amt des Sülfmeisters inne, wurde Ratsmitglied -als solcher bezeichnet er sich in der Intitulatio - und 1467 Sodmeister $^{4}$. In erster Ehe war er seit ca. 1436 mit Gesche von Godenstedt verheiratet, in zweiter Ehe seit ca. 1462 mit Elisabeth von Tzerstede. Der Testator war in den Jahren 1452, 53, 58 bis 66 und 68 bis 71 regierender Ratsherr zu Lüneburg $^{5}$. Da aufgrund der nach der Testamentserrichtung weitergehenden Karriere körperliches Gebrechen als Testiergrund wohl ausscheidet, kann man ihn in der zweiten Eheschließung vermuten, die ein Absichern der Kinder aus erster Ehe erforderlich machte. Nach dem Tod des Testators im Jahr 1471 wird Elisabeth erneut heiraten (1476 Heinrich Garlop ${ }^{6}$ ). Des Testators Schwiegermutter Tibbeke Godenstedt testierte 1469.

\section{VERFÜGUNGEN ÜBER SACHGÜTER:}

Der Testator gibt nach seinem Tod nach Bardowick seine silbernen Kannen, die ihm seine verstorbene weseke in ihrem Testament zugewendet hat. Zehn Mark stiftet er zur Unterstützung für eine neue Monstranz in St. Lamberti, die man tagsüber ausstellt. Von den zwanzig Mark, die die Geschworenen in St. Johannis schuldig sind, sollen sie ein Kleinod kaufen für sein Gedächtnis. Vier Dresemesche Laken sind für die Barfüßer in Lüneburg sowie für junge Mönche und arme Jungfrauen im Kloster Isenhagen. Der Testator wünscht er ein vornehmes Begräbnis; so soll man ihm so viel gutes weißes Englisches Tuch über den Sarg legen, wie man für vier Kappen braucht. Das soll man

\footnotetext{
${ }^{4}$ H.-J. v. WITZENDORFF, Stammtafeln, S. 73.

${ }^{5}$ I. STAHL, Ratslinie, Nr. 204, S.170.

${ }^{6}$ H.-J. v. WITZENDORFF, Stammtafeln, S.136. Elisabeth bringt in den acht Ehejahren mit Heinrich Garlop vier Kinder zur Welt. H.-J. v. WITZENDORFF, Stammtafeln, S.41.
} 
sofort nach seiner Beerdigung in das Kloster nach Medingen senden für vier arme Jungfrauen zur Ehre Gottes; dafür sollen sie für ihn beten. Das Geld für die Speisung von 100 armen Leuten an seinem Begräbnis und seiner Jahrfeier sowie das Geld für die Speisung von täglich zwölf Armen während eines Jahres ist in der roten Lade. Gheseke Smede erhält die zweitbeste Hoike. Dem Rat zu Lüneburg hinterläßt er seinen hohen silbernen Becher. Ferner bedenkt er jeden Testamentsvollstrecker mit einem silbernen Becher. Das restliche Gut gibt er seiner Frau Ilsebe mit ihren Kindern, wenn sie die Kinder von inm abteilt. Wenn sie sich nach seinem Tod wiederverheiratet, soll ihr Besitz von dem der Kinder nach Lüneburger Stadtrecht geteilt werden; zuvor gibt vame Lo den Kindern ihr Heergewät. Ist die Ehe mit Ilsebe zum Zeitpunkt des Todes kinderlos, sollen seine Erben in seinem Haus bleiben. In diesem Fall soll man seiner Frau ihre Kleider und Kleinodien folgen lassen, die sie mit zu inm brachte, und ihre Mitgift, die bei ihrem Bruder Godeke Tzerstede ist.

Siegler: Johann Schnewerding

Die beiden anderen Siegel sind abgefallen. Abschrift des Testaments bei ND Manecke 27, S.307ff

Reinhardt, Testamente, S.341ff, Nr.233

\section{November $9 \quad$ Beke von dem Berge \\ (mnd.)}

TV: Vicke Hakensnyder, Hans Richerd, Hans von Wrydel, Hans von Hamelen

ANGABEN ZU PERSON UND FAMILIE:

Die Testatorin war Witwe des Bürgers Hans von dem Berge.

VERFÜGUNGEN ÜBER SACHGÜTER:

Ihren Korallenrosenkranz hat die Testatorin St. Marien ungefähr vor einem halben Jahr gegeben. Hans von Wrydels Tochter schenkt sie ihre braune Hoike. Als Sargtuch soll man ein blaues Laken kaufen, das dann an Grete Witten in dem Blauen Konvent fällt. Ihre beste Arrasche Hoike hinterläßt sie St. Lamberti für Gottesdienste an ewigen Licht.

Siegler: Johann vame Lo, Ludolf Garlop

Am Ende des Testaments: Am linken Rand von Zeile 40 - 44 nachgetragen und gestrichen: Item de Bergeske heft gegeven oren sondaghes hoyken, de is swart, to dem groten Hilgen Geiste, de me er denken scal und ores werdes to den ver tiden etcetera.

Reinhardt, Testamente, S.346ff, Nr.234

$1469 \quad$ Februar 26

Tibbeke Godenstedt

(mnd.)

TV: Hartwig Schomaker, Klaus Sanckenstede, Bürgermeister, Johann vame Lo, Ratsherr, Johann vame Lo, Bürger zu Lüneburg

ANGABEN ZU PERSON UND FAMILIE: 
Die Testatorin war die Witwe Ludolf Godensteds, des Ratsherrn und Sülfmeisters ${ }^{7}$. Sie selbst stammte aus dem Geschlecht von Töbing. Bereits 1450 war ihr Mann gestorben, mit dem sie ca. zwanzig Jahre verheiratet war und mindestens drei Kinder hatte. Zu korrigieren ist die Witzendorffsche Einschätzung des Verwandtschaftsverhältnisses zu den vame Lo. Die bereits verstorbene Gesche, Ehefrau Johann vame Los des Älteren, ist offenkundig nicht die Schwägerin der Testatorin, sondern ihre Tochter ${ }^{8}$. Aus dem Jahr 1464 stammt das Testament ihres Schwiegersohns, aus dem Jahr 1473 das ihres Enkelsohns. Die Schwester der Testatorin, Gebbeke von Töbing, war mit Johann Garlop verheiratet, der nach seinem Studium in Leipzig Lüneburger Ratsherr und Bürgermeister wurde ${ }^{9}$.

VERFÜGUNGEN ÜBER SACHGÜTER:

Die Testatorin stiftet dem Bau von St. Johannis zwanzig Rheinische Gulden wenn die Kirchgeschworenen ihren Kirchenstuhl dem Sohn ihrer verstorbenen Tochter lassen. 200 Rheinischen Gulden und eine Urkunde befinden sich in einer besonderen Lade in ihrer Fußtruhe. Der Testatorin gehört die Frauengerade ihrer Schwester.

Ihr zweitbestes Paar Kleider soll man Soffeke Busse geben, wenn man sie zur Ehe ausstattet. Ferner für die Magd der Testatorin, die am längsten mit ihr zusammen war, die Sonntagshoike ohne Futter. Die nächstbeste Hoike ohne Futter ihrer anderen Magd und jeder einen Rock mit kleinen Ärmeln. Die zwei Arraschen Hoiken sollen verkauft werden, das Geld ist für arme Leute bestimmt. Die übrigen Kleider sind für bedürftige Witwen. Jedem ihrer Testamentsvollstrecker schenkt die Testatorin einen silbernen Löffel mit einem gewundenen Stiel. Den restlichen Nachlaß überläßt sie dem Sohn ihrer Tochter Johann vame Lo.

Siegler: Ludolf Stöterogge, Johann Schnewerding

Papier mit aufgedrückten Siegeln

Reinhardt, Testamente, S.348ff, Nr.235

\begin{tabular}{|ccc|c|c}
\hline 1471 & März & 11 & $\begin{array}{c}\text { Bernd Burmester } \\
\text { (mnd.) }\end{array}$
\end{tabular}

TV: Dietrich Vlodwedel, Hans Henninges, Ludolf Nyenfiend, Bürger zu Lüneburg

ANGABEN ZU PERSON UND FAMILIE:

In der Intitulatio vermerkt der Testator, er werde auch der schwarze Bernd genannt.

VERFÜGUNGEN ÜBER SACHGÜTER:

Nyenfyendes Vater soll man einen neuen Hardewyker Rock geben.

Siegler: Ludolf Stöterogge, Heinrich vom Riepe

Reinhardt, Testamente, S.351ff, Nr.236

\footnotetext{
${ }^{7}$ H.-J. v. WITZENDORFF, Stammtafeln, S.43.

${ }^{8}$ Die Testatorin bezeichnet Johann vame Lo als Sohn ihrer verstorbenen Tochter. Folglich muß ihre Tochter mit einem vame Lo verheiratet gewesen sein, und diese Ehe gibt Witzendorff an als die ca. 1436 geschlossene Ehe zwischen Gesche und Johann vame Lo dem Älteren, die er beim Stammbaum der von dem Loh als Ehe zwischen Gesche von Godenstedt und Johann van dem Lo präzisiert. Die Zuwenung der Frauengerade Tibbeke von Töbings an ihre Schwester Gebbeke Garlop ist Indiz für das ausschließliche Vorhandensein von Söhnen. H.-J. v. WITZENDORFF, Stammtafeln, S. 43 und 73.

${ }^{9}$ H.-J. v. WITZENDORFF, Stammtafeln, S.40 und 130.
} 
TV: Paul Gryp, Stadtvogt; Kersten Engelbrecht, Dietrich Vlotwedel, Bürger zu Lüneburg; die Sovenbrodersche, ihre Schwester

ANGABEN ZU PERSON UND FAMILIE:

Die Testatorin war Bürgerin von Lüneburg.

VERFÜGUNGEN ÜBER SACHGÜTER:

Dem Chor in Walsrode schenkt die Testatorin ihr Teppichbanklaken. Grete Lypers und ihren Kindern hinterläßt sie ihre schwarze Hoike, ihren schwarzen Rock und ihren besten Pelz, ihrer Magd Beke die braune Hoike, den braunen Rock und das Bett, auf dem sie schläft, mit dem Kopfkissen. Lippelde Rosenborg erhält ihren größten Grapen. Metteke, die Vogtin, erhält den blauen Rock und ihre Tochter Barbara den großen silbernen Becher, ferner Geseke, der Vogtin Schwester, die zweitbeste Hoike und den Psalter der Testatorin; dazu soll sie ihre Fußkiste auf dem Boden haben und alles, was darinnen ist. Dem Vogt Paul Gryp hinterläßt sie ihren Schüsselgrapen und den Mörser, ferner dem Gastmeister den zweitbesten silbernen Becher, den anderen nächstbesten soll man Conrad Molleren mit Meister Heinrich Jurgen in Lübeck geben, dazu den silbernen Löffel mit dem Knopf, dann Engelke, dem Sohn Kersten Engelbrechts, das Bett mit dem Flämischen Bettbezug und den Kopfpfühl, das Handfaß, den großen Messingkessel und vier Zinnfässer. Andreas und Cord Sovenbroder bekommen ein Bett und vier Zinnfässer, ihren großen Grapen in dem Bord und ein Handbecken. Nikolaus Netzemann soll das andere große Handbecken und zwei große Zinnfässer erhalten. Die Langesche erbt die Werktagshoike. Für Immeke Haken ist der Pelz bestimmt. Die Schwester der Testatorin, die Sovenbrodersche, soll den Hausrat erhalten, den Geseke Rosemberg nicht vergeben hat. Benötigt die Schwester ihres verstorbenen Mannes den großen Korallenrosenkranz der Testatorin und den großen Kessel nicht, so soll man die Dinge verkaufen und das Geld für die Ehre Gottes vergeben. Die Testatorin schenkt der Thomeschen ihr Gebetbuch, in dem die 70 Namen stehen. Sie hinterläßt Marte, der Schwester des Vogts, zwei Polster, deren Naht mit Kreuzstichen verziert ist. Ferner gibt sie für die Monstranz in St. Nikolai in Lüneburg ihren goldenen Ring, in dem Kasper, Melchior und Balthasar dargestellt sind.

Siegler: Ludolf Stöterogge, Dietrich Döring

Reinhardt, Testamente, S.353f, Nr.237

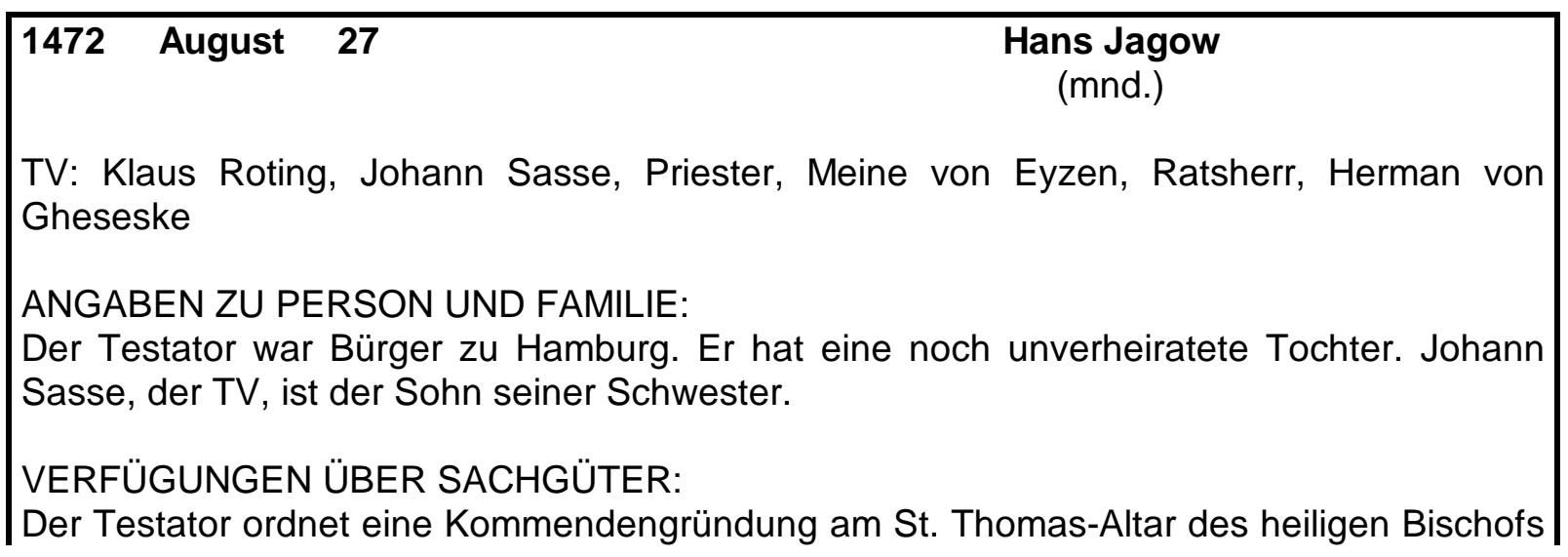


von Canterbury in der St. Katherinenkirche zu Hamburg an. Für die Kommende stiftet er einen Kelch, den man vergolden soll oder einen silbernen Gürtel für ein zu kaufendes Missale; es soll bei inm und seinen Testamentsvollstreckern liegen, wem man den Gürtel von den zwei vorgenannten Zwecken zuwenden will. Zu derselben Kommende gibt er noch ein Goldbrokattuch für 20 Mark, und das Brokattuch und seinen besten Rock soll man auf seinen Sarg legen, wenn er gestorben ist. Diesen Rock stiftet er zum Kirchbau von St. Katharina. Mit dem Brokat soll die Kommende versorgt sein. Die Kommende soll seine Tochter verleihen. Seiner Schwester lutteke und Metteke von Gheseke schenkt er jeweils einen Leidenschen Rock, weiterhin gibt er Hermann von Gheseke seinen roten Rock mit dem llitisfutter. Herrn Johann Sasse gibt er eine neue Leidensche Hoike, von welcherlei Farbe er sie gerne hätte. Ferner schenkt er Hans Woltmann seine beste mit Otterfell gefütterte Hoike. Er gibt Herrn Klaus Rothing seinen zweitbesten silbernen Becher. Ferner schenkt er dem ehrsamen Herrn Pavidus Lutken, Hennike Grote und Meine von Elze, Ratsherren zu Hamburg, jeweils eine silberne Schale. Das übrige Gut fällt an Katharina und ihre Erben.

Beglaubigte Abschrift aus dem 17. Jahrhundert

Reinhardt, Testamente, S.354ff, Nr.238

\section{Juli $23 \quad$ Metteke von Dassel \\ (mnd.)}

TV: Dietrich von Dassel, ihr Ehemann, ihr Sohn Albert, Johann Roer, Vikar in St. Johannis, Dietrich Döring, Ratsherr, Hans Remstede und Cord Stöterogge, Bürger zu Lüneburg

ANGABEN ZU PERSON UND FAMILIE:

Die Testatorin stammte aus dem Geschlecht Kruse ${ }^{10}$. Ihr Vater Hans Kruse testierte 1447. Metteke war in erster Ehe mit Meineke Fischer verheiratet, in zweiter Ehe mit Dietrich von Dasse $^{11}$. Sie starb $1478^{12}$. Dietrich von Dassel war wohl Gewandschneider und war 1458, vermutlich auch 1471, Geschworener der Wandschneider. Aus dem Jahr 1477 ist er als Verkäufer englischen Gewandstoffs belegt. Ferner war er Sülfmeister.

In dem Testament werden sowohl die Enkelkinder aus der ersten Ehe des Sohnes als auch das ungeborene Kind aus der zweiten Ehe ihres Sohnes ${ }^{13}$ bedacht.

\section{VERFÜGUNGEN ÜBER SACHGÜTER:}

Die Testatorin hinterläßt ihrem Sohn Albert ihren silbernen Gürtel, von dem er eine silberne Schale machen lassen soll. Seiner Frau Soffeke gibt Metteke von Dassel eine Taufdecke/Tauftuch und zwei seidene Stücke für die Wiege, beide zum Umsäumen der Wiege mit Bändern; die Testatorin schenkt ihrer Schwiegertochter auch den besten Vorhang. Ihrer Tochter Metteke hinterläßt sie 10 Ellen Engländischen weißen Tuchs. Dietrich und Hanseke erhalten jeweils 3 Rheinische Gulden, damit soll sich jeder einen silbernen Becher kaufen. Mit dem Erlös einer Rente soll man jährlich am St. Michaelistag arme Leute speisen. Wenn man keine Verpflegung kaufen kann, soll man Schuhe und Tuch kaufen und zur Ehre Gottes vergeben. Die Testatorin stiftet dem St. Philippi und Jakobialtar in St. Johannis ein seidenes, rotes Priestergewand, eine Albe und einen

\footnotetext{
${ }^{10}$ H.-J. v. WITZENDORFF, Stammtafeln, S.66.

${ }^{11}$ U. J. DIEDERICHS, Aufruhr, S.111ff.

${ }^{12}$ Dagegen Witzendorff, der ihr Todesjahr 1481 ansetzt. H.-J. v. WITZENDORFF, Stammtafeln, S. 25.

${ }^{13}$ Anders als Witzendorff es mit der Datierung 1481 sieht, muß die zweite Eheschließung Albrechts von Dassels vor oder um 1473 angesetzt werden. Das ungeborene Kind ist wohl Ludolf von Dassel, 1474 geboren, der später seinerseits der Vater von 16 Kindern werden wird. H.-J. v. WITZENDORFF, Stammtafeln, S.25.
} 
Vorhang für den Altar. Ferner wünscht sie den Verkauf ihrer Werktagskleider, nämlich zweier Tuchhoiken und zweier Tuchröcke; das Geld sollen ihre Hausbediensteten erhalten.

Siegler: Heinrich Witting, Godeke Tzerstede, Ratsherren

Rückvermerk: Dyt is myner zeligen husfrouwen Metteken van Dassel testament unde hebbe dat vullenbracht na erem willen unde hebbe dat vorbetert yn anderen dingen also myn testament wol uthwyset.

Reinhardt, Testamente, S.358ff, Nr.239

\begin{tabular}{|lcc}
\hline 473 & September 29 & $\begin{array}{c}\text { Johann vame Lo } \\
(\mathrm{mnd})\end{array}$
\end{tabular}

TV: Heinrich von der Mölen, Domherr und Senior des Kapitels zu Bardowick, Bernd Stake, Vikar zu Lüneburg, Dietrich Brömse, Hans Wolters, Hans Brunswick, Heinrich Varendorp

ANGABEN ZU PERSON UND FAMILIE:

Der Testator war Bürger von Lüneburg. Johann vame Lo der Jüngere lebte von ca. 1437 bis 1482.1455 besuchte er die Universität Leipzig, wurde - zurückgekehrt nach Lüneburg 1468 als Sülfmeister geführt, war 1476 Barmeister, drei Jahre später dann Ratsherr ${ }^{14}$. Im Testament erwähnt er eine Ehefrau namens Greteke ${ }^{15}$. Testiert hatten - wie aus seinem Testament hervorgeht - seine Großmutter Tibbeke Godenstedt und sein Vater Johann vame Lo. Beide Testamente sind für die Jahre 1464 bzw. 1469 überliefert.

\section{VERFÜGUNGEN ÜBER SACHGÜTER:}

Die Testamentsvollstrecker sollen vier Dreszmesche Laken kaufen und unter den jüngsten Brüdern im Barfüßerkloster in Lüneburg verteilen oder unter den ärmsten Jungfrauen im Kloster Isenhagen. Der Testator stiftet er seine Kette und sein Halsband dazu, daß seine Testamentsvollstrecker mit Zutun des Propstes und der Geschworenen der St. Johanniskirche zu Lüneburg ein schönes Kreuz mit dem Leichnam des Gekreuzigten und einem schönen Fuß anfertigen lassen. Unter den Armen des Kreuzes soll das Bild Unserer Lieben Frau und St. Johannis stehen. Das Kreuz soll der Priester, der die Hochmessen singt, zu großen Festen um den Hof tragen. Falls der Testator Gott mit Schmuck oder Verzierungen erzürnt habe, so bitte er inn, dies barmherzig zu vergeben. Für zwei Kommenden in der zu errichtenden Kapelle beim Turm von St. Nikolai stiftet der Testator einen Kelch, ein Buch und ein Meßgewand. Es soll Tuch gekauft werden und unter zwölf armen Leuten auf dem Chor verteilt werden. Seiner Frau überläßt der Testator für ihre Lebenszeit sein Haus am Sande mit allem Zubehör und Hausrat. Wenn aus dieser Ehe den Testator überlebende Kinder hervorgehen sollten, dann sollen Frau und Kinder sein Silbergeschmeide, Kleinode und andere Hausgerade behalten.

Jedem Testamentsvollstrecker schenkt der Testator einen silbernen Becher mit Fuß und vergoldeten Rand. Als Vorlage kann der Becher des Testators dienen. Die Becher sollen von dem Silber, das der Testator liegen hat, angefertigt werden.

\section{ZUSÄTZLICHE INFORMATIONEN:}

Dieses Testament wurde vom Rat nicht als Testament angenommen. Dem auf dem Rückvermerk zu entnehmenden Ablauf zufolge wurde das Testament zunächst vor dem Rat verlesen, woraufhin die Erben Widerspruch einlegten und das Testament nicht anerkannten. Folglich weigerten sich die TV, ihr Amt anzutreten. Jedoch übernahmen die

\footnotetext{
${ }^{14}$ H.-J. v. WITZENDORFF, Stammtafeln, S.73.

${ }^{15}$ Laut Witzendorff war der Testator mit Beata Schomaker, dann mit Alheid von der Mölen verheiratet. H.-J. v. WITZENDORFF, Stammtafeln, S.73.
} 
Erben Schulden und Guthaben des Verstorbenen, beglichen die Schulden, finanzierten die Gaben an Kirchen, Klöster und Arme, worüber Dietrich Brömse eine Urkunde anfertigte. Das übrige Gut haben die Erben unter sich aufgeteilt, und jeder bekam seinen Anteil.

Siegler: Heinrich von der Mölen, Johann Schnewerding. Das Siegel des Testators ist abgeschnitten.

Reinhardt, Testamente, S.360ff, Nr.240

\begin{tabular}{|ccc}
1474 & August 23 & $\begin{array}{c}\text { Beke von Esche } \\
\text { (mnd.) }\end{array}$
\end{tabular}

TV: Bernd Stake, Vikar, Hans Bosemann, Tideke Gade, Hans Braunschweig, Hermann Gudekerl, Bürger zu Lüneburg

ANGABEN ZU PERSON UND FAMILIE:

Die Testatorin war die Witwe Diderichs von Esche, einst Bürger zu Lüneburg.

VERFÜGUNGEN ÜBER SACHGÜTER:

Gheseke Gudekerl, Hermens Tochter, erhält ein Bett nächst dem besten. Ihrer Magd Ilsebe Woyen hinterläßt Beke von Esche eine Truhe, zwei seidene Kissen, vier Federkissen und einen Pfühl. Henneke Rethmer aus Salzhausen schenkt sie jedes Jahr ein neues graues Kleid. Was sie an Silbergeschmeide hinterlassen wird, dafür soll man für die zu errichtende Kommende einen Kelch kaufen; Herr Bernd Stake soll über das Buch verfügen. Den restlichen Nachlaß an Hausrat und Kleinoden sollen die Testamentsvollstrecker verkaufen und den Erlös armen Mägden für die Ausstattung oder armen Priestern für ihre Primiz zukommen lassen.

Siegler: Heinrich von der Mölen, Heinrich Erpensen

Reinhardt, Testamente, S.367ff, Nr.241

\section{$\begin{array}{llll}1474 & \text { September } 10 & \text { Greteke Melbek }\end{array}$ \\ (mnd.)}

TV: Johann Schelen, Ratsherr, Dietrich Moltwedel, Hans Raven, ihr Oheim, Dietrich Buldermann, Bürger zu Lüneburg

ANGABEN ZU PERSON UND FAMILIE:

Die Testatorin war die Witwe des verstorbenen Hans Melbek, sie war Bürgerin in Lüneburg. Das Testament nennt als Namen ihrer Töchter Geseke Buldermann und Alheid Raven ${ }^{16}$. Der Geburtsname der Testatorin lautete Gretke Andersen ${ }^{17}$. Ihr Mann Johann ist Brauer, war Sechziger, ist in den Jahren 1427 bis 1449 als Geschworener der

\footnotetext{
${ }^{16}$ WITZENDORFF verzeichnet nur die Ehe der Aleke von Melbeck, allerdings mit einem Ludeke Raven. H.-J. v. WITZENDORFF, Stammtafeln, S.94.

${ }^{17}$ H.-J. v. WITZENDORFF, Stammtafeln, S. 76.
} 
Johanniskirche geführt ${ }^{18}$.

VERFÜGUNGEN ÜBER SACHGÜTER:

Jedes Jahr soll einem armen Menschen ein Kleid gegeben werden, ein Rock oder eine Hoike. Ihre Tochter Geseke, die Buldermannsche, erhält das Wohnhaus der Testatorin mit seinem Zubehör. Hinzu bekommt sie den unvergebenen Nachlaß.

Siegel abgefallen. Papier mit aufgedrückten Siegeln

Reinhardt, Testamente, S.372f, Nr.243

\section{September 22}

Matthias von der Most

(mnd.)

TV: Johann Ror, Johann Kruse, Vikar in St. Johannis, Mathies Votmann, Kirchherr zu St. Gertrudis, Hans Witzendorff und Hans Gerlages, Bürger zu Lüneburg

ANGABEN ZU PERSON UND FAMILIE:

Der Testator war Apotheker zu Lüneburg. Im Testament wird eine Ehefrau namens Geseke genannt, mit der der Testator offensichtlich keine Kinder hatte, denn er beschreibt Katherina, die Frau Ludolf Wittes, als nächste Verwandte und Erbin seiner Frau. Von der Most war Eigentümer der einzigen Apotheke Lüneburgs, die in der Großen Bäckerstraße lag $^{19}$. Seine Kinderlosigkeit veranlaßte inn, seinen Gehilfen Albert Grönehagen (der im Testament als Apotheker bezeichnet wird) als Nachfolger zu bestimmen. Zu seiner und der Apotheke rechtlichen Sicherheit diente wahrscheinlich der Erbvertrag, den Most und seine 1465 noch lebende Ehefrau mit der anspruchsberechtigten Katherina Witte abschlossen (siehe Testament). Grönehagen und seine Frau Wobbeke starben jedoch an der Pest. So trat von der Most mit dem Rat in Verhandlungen über die Übernahme der Apotheke. 1475 starb er inmitten der Absprachen, die nun von seinen Testamentsvollstreckern fortgesetzt, dann abgeschlossen wurden und mit dem Kauf der Apotheke durch den Rat für 1650 Mark endeten.

Von der Mosts Testament enthält einen Hinweis auf ein von seiner Schwiegermutter angefertigtes Testament.

\section{VERFÜGUNGEN ÜBER SACHGÜTER:}

Von der Most gibt das nach dem Meß-/Gebetbuch größte Buch Unserer Lieben Frauenkirche in Lübeck für die Bücherei. Die Bücherei St. Johannis soll das rote Buch, in dem die Vita Alexanders steht, erhalten. Die Testamentsvollstrecker sollen Ludolf Witten zwei oder drei Kleinode von des Testators Silbergeschmeide geben - sie wissen, wo sie sind; in derselben Lade ist eine kleine silberne Schale, die seine Tochter Katharina, die Begine, haben soll. Ferner ist in derselben Lade ein Kleinod, das Mosts Frau gehört hatte, das soll Metteke, die Tochter Ludolf Wittens haben; dies sollen seine Testamentsvollstrecker verkaufen und ihr das Geld geben, wenn sie für die Ehe ausgestattet wird oder ins Kloster gehen wird und nicht früher. Der Rat zu Lüneburg soll von dem Testator oder seinen Testamentsvollstreckern das Heergewät nicht einfordern, sondern die Schulden bezahlen, die er von der Most schuldig ist; und dann - und nicht vorher - sollen die Testamentsvollstrecker eine große silberne Schale machen lassen, die so ist, wie die zwei auf dem Rathaus; sie sollen sie ins Rathaus geben.

\footnotetext{
${ }^{18}$ DIDERICHS, S. 168ff.

${ }^{19}$ Das nunmehr Ratsapotheke genannte Geschäft besteht noch heute, allerdings in einem anderen Gebäude der Bäckerstraße. D. ARENDS Zur Geschichte der Ratsapotheke Lüneburg, in: Pharmazeutische Rundschau 1960/8, Sonderdruck, ohne Seitenzahl.
} 
Jeder der Testamentsvollstrecker soll eine silberne Schale mit einer vergoldeten Rose darinnen erhalten.

Siegler: Johann Schnewerding, Ludolf Stöterogge

Reinhardt, Testamente, S.373ff, Nr.244

\begin{tabular}{|ccc}
1475 Januar 13 & $\begin{array}{c}\text { Czieke Blank } \\
\text { (mnd.) }\end{array}$
\end{tabular}

TV: Metteke, Witwe Hans Moylekens; Cord Wilde; Beke, seine Ehefrau; Helmeke Moyleken

ANGABEN ZU PERSON UND FAMILIE:

Die Testatorin war die Witwe des verstorbenen Heinrich Blank und Bürgerin von Lüneburg.

VERFÜGUNGEN ÜBER SACHGÜTER:

Die Testatorin hinterläßt Anneke, dem hinterlassenen Kind des verstorbenen Hermen von Hove und seiner Frau Metteke, Tochter der Testatorin, ihr gegenwärtiges Wohnhaus mit allem Zubehör, ferner zwei Betten, auf denen die Testatorin zu schlafen pflegt, und ein kleines Bett mit drei Pfühlen, ferner neun silberne Löffel, eine silberne Gabel, vierzehn Polster, drei Tafellaken, eine rote beneyede Decke, ein Handtuch, eine rote, mit Schnitzerei verzierte Truhe, eine Fußtruhe, einen Falttisch, einen großen schwarzen Kessel, drei Messingkessel, zwölf kleine und große Grapen, vier Pfannen, eine Zinnkanne für ein Stübchen und eine Halbstübchenkanne und drei Zinnflaschen. Wenn aber dieses Kind, bevor es für die Ehe ausgestattet wurde oder später, stirbt und keine eigenen Kinder hinterläßt, so sollen all diese Gaben, die dem Kind hier übertragen wurden, an die nächsten Erben der Testatorin fallen.

Siegler: Heinrich von der Mölen, Heinrich Erpensen

Reinhardt, Testamente, S.378, Nr.245

\begin{tabular}{|ccc}
1475 & April 6 & $\begin{array}{c}\text { Hans Merre } \\
\text { (mnd.) }\end{array}$
\end{tabular}

TV: Johann Schelen, Ratsherr; Matthias von der Most, Apotheker; Hans Witzendorff, Bürger zu Lüneburg

ANGABEN ZU PERSON UND FAMILIE:

Der Testator war Bürger zu Lüneburg. Laut Testament stammte seine Frau Metteke aus dem Geschlecht der von Urden ${ }^{20}$.

VERFÜGUNGEN ÜBER SACHGÜTER:

Den übrigen mobilen wie immobilen Nachlaß soll seine Frau Metteke erhalten. Alles ist für sie, bis auf das Heergewät, das sie dorthin geben soll, wohin es gehört.

\footnotetext{
${ }^{20}$ Witzendorff zufolge war eine Mette von Urden mit Hans von Boltzen verheiratet. Sie starb 1517. H.-J. v. WITZENDORFF, Stammtafeln, S.138.
} 
Siegler: Ludolf Stöterogge, Dietrich Raven

Papier mit aufgedrückten Siegeln

Reinhardt, Testamente, S.379f, Nr.246

1475 April $16 \quad \begin{gathered}\text { Hans Konvelitz } \\ \text { (mnd.) }\end{gathered}$

TV: -

ANGABEN ZU PERSON UND FAMILIE:

Der Testator war Bürger zu Lüneburg. Der Vermerk, das überlieferte Testament sei eine Kopie des Testaments, enthält den Zusatz hanses Konwelitzes des scroders.

VERFÜGUNGEN ÜBER SACHGÜTER:

Die Schwester seiner Frau erhält eine Arrasche Hoike. Einer armen Magd ist eine Hoike zu geben. Den übrigen Nachlaß, Mobilien wie Immobilien, erhält die Frau des Testators.

Siegler: Heinrich vom Riepe, Johann Schnewerding

Papier mit aufgedrückten Siegeln

Reinhardt, Testamente, S.380, Nr.247

\begin{tabular}{|ccc}
\hline 475 & Juni 3 & $\begin{array}{c}\text { Jakob Döring } \\
\text { (mnd.) }\end{array}$
\end{tabular}

TV: Heinrich von Rethem, Heinrich von Embeke, Bürger zu Lüneburg

ANGABEN ZU PERSON UND FAMILIE:

Der Testator war Bürger von Lüneburg. Der Rückvermerk seines Testamentes weist ihn als Meister Jakob den Barbier aus, Jakob Döring genannt. Aus dem Testament geht hervor, daß seine Mutter Agnete in Magdeburg lebte.

VERFÜGUNGEN ÜBER SACHGÜTER:

Seine Frau soll den übrigen Nachlaß erhalten und zu ihrem Besten verwenden, wie es besprochen ist. Herr Reemann in St. Marien erhält einen rheinischen Gulden für eine Kappe.

Siegler: Johann Schele, Dietrich Raven

Papier mit aufgedrückten Oblatensiegeln

Reinhardt, Testamente, S.381f, Nr.248 
|TV: vgl. Testament von 1474 Aug. 31

ANGABEN ZU PERSON UND FAMILIE: vgl. Testament von 1474 Aug. 31

VERFÜGUNGEN ÜBER SACHGÜTER: vgl. Testament von 1474 Aug. 31

SONSTIGE VERFÜGUNGEN: vgl. Testament von 1474 Aug. 31

Siegler: vgl. Testament von 1474 Aug. 31

Papier mit aufgedrückten Siegeln

Reinhardt, Testamente, S.382f, Nr.249

\begin{tabular}{|llc}
1475 & August 17 & $\begin{array}{c}\text { Albert Schulte } \\
\text { (mnd.) }\end{array}$
\end{tabular}

TV: Helmeke Rodendor, Hermann Boysmann

ANGABEN ZU PERSON UND FAMILIE:

Der Testator war Mühlenknecht.

VERFÜGUNGEN ÜBER SACHGÜTER:

Bernd Schulte, Sohn des Bruders, erhält die grünen Kleider des Testators.

Konzept ist unbesiegelt

Reinhardt, Testamente, S.383f, Nr.250

\begin{tabular}{|llc}
\hline 476 & März 4 & Vicke Bottermann \\
(mnd.)
\end{tabular}

TV: Borchard Spring, Vikar zu St. Johannis; Johann Visscher, Kirchherr zu Neetze; Make und Heinrich Bottermann; Henning Hugh; Heinrich Neddermeyer, Dietmar Kocke, Bürger zu Lüneburg

ANGABEN ZU PERSON UND FAMILIE:

Vike Bottermann war Bürger von Lüneburg. Vicke Bottermann lebte offenbar mit seiner Magd Barbara in einem eheähnlichen Verhältnis, aus dem ein gehbehindertes Kind sowie ein zum Zeitpunkt der Testamentserrichtung ungeborenes hervorgingen.

VERFÜGUNGEN ÜBER SACHGÜTER:

Der Rat zu Lüneburg erhält 150 Mark Pfennige, die Herr Ludolf Garlop dem Testator schuldig ist, für ein silbernes Kleinod im Rathaus. Seinen Brüdern hinterläßt der Testator allen Hausrat, den er von seinen verstorbenen Eltern bekommen hat, ausgenommen das, was er hiernach vergabt. Die Kinder erhalten eine silberne Schale mit einem Fuß, acht silberne Löffel, drei silberne Becher und einen Gürtel mit vergoldetem Besatz. Seinem Bruder Make Bottermann gibt der Testator seine schwarze Leidensche Hoike, eine spitze Kapuze, eine braune Kapuze und eine alte braune Hoike. Borchard Spring hinterläßt er einen silbernen Bisamapfel, ferner Johann Visscher einen kurzen silbernen Löffel mit einem vergoldeten Knauf. Seiner Magd Barbara und den Kindern hinterläßt der Testator drei Betten und drei Pfühle, zwei der Betten und Pfühle hat er mit seinem eigenen Geld 
gekauft, und was an Leinwand, Garn, Laken übrig ist, gibt er ihr und ihren Kindern. Ferner für Barbara und die Kinder ein Banklaken und drei Decken, die er gekauft hat, dann sechs mittelgroße Grapen, dabei sind zwei, die der Testator bei Vrigbusch kaufte, zwei Halbstübchen und einen Mesingkessel. Barbara und den Kindern auch 12 silberne Löffel zu gleichen Teilen, die er bei Hans Morse kaufte und dazu die beste braune Hoike und den roten und blauen Rock.

Siegler: Dietrich Brömse, Cord Lange

Reinhardt, Testamente, S.386ff, Nr.252

\section{September 18}

\section{Dietrich Junge}

(lat.)

TV: Johann Roer, Ludolf Mangarten, Bernhard Stake, Vikar in St. Johannis, Dietrich Moltwedel, Johannes Odborn, Bürger zu Lüneburg

ANGABEN ZU PERSON UND FAMILIE:

Dietrich Junge war ständiger Vikar am Allerapostelaltar und der heiligen Jungfrau Aldegundis in der St. Johanniskirche in Lüneburg.

\section{VERFÜGUNGEN ÜBER SACHGÜTER:}

Der Testator möchte in der Johanniskirche vor dem Allerapostelaltar begraben werden bei dem Grab des Johann Handorp; er gibt er den Geschworenen zum Bau der Kirche seinen besseren Rock und die Hoike. Hans Odborn und seiner Frau schenkt er sechs silberne Löffel; die Schwester von Hans Odborn und ihre Tochter erhalten ebenfalls sechs silberne Löffel. Johann Schirwater, Ordensmitglied der Predikanten, schenkt er die Hälfte eines Tuchlakens schwarzen Leidenschen Tuchs für eine Kappe; das Tuch zunächst das Sargtuch des Testators sein. Dem Predigerorden in Lüneburg stiftet er seinen größten Topf und seine größte Zinnamphore, zwei große und zwei kleine Zinngefäße und einen Messingkochkessel,. Ferner gibt er Herrn Bernhard Staken sein größtes kanonisches Stundenbuch, in dem er täglich die kanonischen Stunden zu lesen pflegt, und seinen kleinen Tisch, der in dem heizbaren Raum steht, der zum Hof hinausführt, und vier Zinngefäße und ein Bett. Ferner hat er der Wyrmanschen seinen größten Schrank gegeben, ein kleines ehernes Lavacum und ein Becken. Der Frau Hans Odborns hat er seinen Schrank gegeben, der in der Stube steht. Ludolf Odborn erhält die Zinnamphore von einem Stübchen sowie einen Topf, in dem man ein Huhn kochen kann. Der Magd Metteke, wenn sie bis zum Tag seines Todes bei inm bleibt, schenkt der Testator den Schrank, der vor seiner Kammer steht, und einen kleineren Topf sowie eine Zinnamphore von einem Viertel. Als Testamentsvollstrecker wird Johannes Roer benannt, der einen Silberbecher mit dem Gesicht des Heiligen Johannes erhält, Ludolf Mangarten, der einen Silberbecher bekommt, Bernhard Stake, ständiger Vikar in der genannten St. Johanniskirche, der einen Silberbecher mit dem Gesicht der Heiligen Jungfrau erhält; Dietrich Moltwedel und Johannes Odborn, Laienbürger der genannten Stadt Lüneburg, Diözese Verden, bekommen jeweils einen silbernen Becher. Der Testator ordnet den Verkauf seines großen Bettes an; der Erlös soll der Finanzierung von Seelenmesssen dienen.

VERMERK: Ferner hat der Testator mit der Kraft des Kodizills Herrn Bernhard Staken alle seine Zinngefäße, die über die Geschenkten hinausgehen, gegeben. Ferner zwei Barbierbecken, dies hat derselbe Notar Rodolphus Rodelphi geschrieben. 
Unterschrift und Signet des Notars Rodolphus Rodolphi.

Auf der RÜCKSEITE: Approbation des Testaments durch den Generaloffizial von Verden

von 1478 April 7. Die beiden folgenden Urkunden sind mit der Pressel des

Officialatssiegels unten an dem Testament befestigt.

1477 März 28 Ergänzung des Testaments durch den Testator, Unterschrift und Signet des Notars Rodolphus Rodolphi.

1478 April 6 Inventar des Nachlasses des Theodericus Junge, Unterschrift und Signet des Notars R.R.

Reinhardt, Testamente, S.388ff, Nr.253

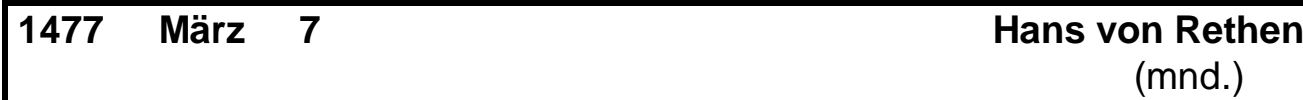

TV: Henning Hughe der Ältere, Heinrich Elvers, Bertold von der Riith, Klaus Rethem, Bürger zu Lüneburg.

ANGABEN ZU PERSON UND FAMILIE:

Der Testator war Bürger zu Lüneburg. Aus dem Testament geht hervor, daß von Rethems Tochter verstorben ist, ihre Töchter aber am Leben sind. Bei diesen Enkelinnen handelt es sich wahrscheinlich um Alheid und Metteke Hunen; ihr Vater, des Testators Schwiegersohn, ist Cord Hunen.

VERFÜGUNGEN ÜBER SACHGÜTER:

Für Dietrich Gribe richtete der Testator eine Kommende ein. Falls der Testator vor der Ausstattung der Kommende mit Ornat und Kleinoden stirbt, sollen seine Testamentsvollstrecker aus seiner unvergabten Hinterlassenschaft die Ausstattung finanzieren. Sterben die Kinder ohne lebende Leibeserben, sollen seine Testamentsvollstrecker diese Rente und Güter, die er den Kindern hinterläßt, jährlich in der Fastenzeit einer Spende zuwenden und gegen Winter den armen Leuten Tuch zum Bekleiden geben; nach dem Tod der Kinder soll nicht deren Vater Cord Hunen erben, weil der Testator Cord mehr zugewendet hat, als er verpflichtet war. Sein übriger Nachlaß ist für die Töchter seiner verstorbenen Tochter.

Siegler: Cord Schellepeper, Heinrich Hoyemann

Weitere Ausfertigung auf Papier mit aufgedrückten Siegeln ist überliefert.

Reinhardt, Testamente, S.393ff, Nr.255

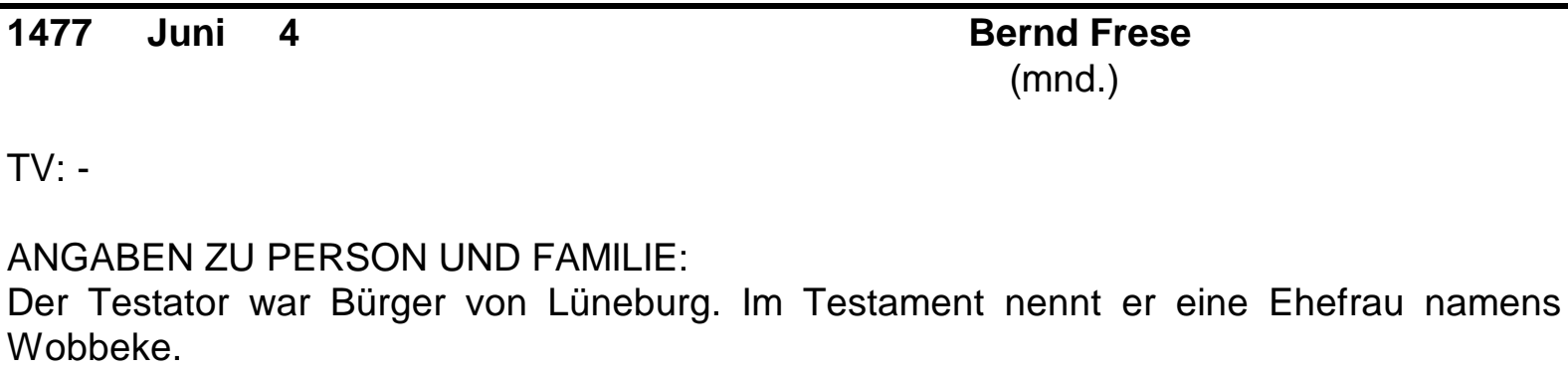

TV: -

ANGABEN ZU PERSON UND FAMILIE:

Der Testator war Bürger von Lüneburg. Im Testament nennt er eine Ehefrau namens Wobbeke.

VERFÜGUNGEN ÜBER SACHGÜTER:

Der Testator erklärt, nichts als Erbteil von seinen Eltern oder anderen Verwandten 
empfangen, sondern seine Güter mit seiner Arbeit erworben zu haben, wobei inm seine Frau Wobbeke geholfen habe; also vermacht der Testator seiner Frau Haus und Hof mit allem Zubehör und Hausgerät. Hinzu gibt er ihr seinen übrigen Nachlaß, in Schulden oder Guthaben, zur freien Verfügung ohne jemandes Einspruchsrecht.

Siegler: Heinrich Erpensen, Heinrich Varendorp

Reinhardt, Testamente, S.396, Nr.256

$\begin{array}{llll}1478 & \text { Mai } & 13 & \text { Ludolf Mangard }\end{array}$

(lat.)

TV: Leonard Lange, Propst; Magister Bertold Bolte, senoir cappellanus; Lippold Goltstede, Rektor der Scholaren; Theodericus Brome und Heinrich Varendorp, Ratsherren; Johannes Garlop, älteste Geschworene von St. Johannis

ANGABEN ZU PERSON UND FAMILIE:

Der Testator war Priester der Verdener Diözese und ständiger Vikar in der St. Johanniskirche in Lüneburg.

VERFÜGUNGEN ÜBER SACHGÜTER:

Der Testator besitzt bestimmte Utensilien, ein Haus und zu seiner Vikarie am Altar der Jungfrau Maria gehörige Kleinodien; der Altar liegt in der Kapelle des heiligen Lamberts in Lüneburg. Weiteres steht in einer bestimmten Urkunde, die man nach seinem Tod in seiner Truhe auffinden wird. Der Testator möchte, daß die Utensilien durch seine Testamentsvollstrecker seinem Nachfolger präsentiert werden. Falls irgendetwas in vasis ligneis veräußert werden sollte, wie er befürchtete, wünscht er den Rückkauf dieser Gefäße. In seinem Haus befinden sich aus Sicherheitsgründen ein Kelch mit Patene und eine bessere Kasel mit ihrem Zubehör, die zu derselben Vikarie gehören. Der Kelch soll mit der Patene und der Kasel seinem Nachfolger übergeben werden.

All seine Bücher stiftet der Testator der Johanniskirche in Lüneburg zum Studium für arme Prediger, Kaplane, Priester, Studenten und Scholaren, wenn die Verwandten des Testators damit einverstanden sind. Die in der Stadt weilenden Kleriker dürfen die Bücher zur Vervollständigung ihrer Studien zu bestimmten Zeiten sowohl in der Stadt Lüneburg als auch außerhalb benutzen; es ist eine Bürgschaft für diese nicht veräußerbaren Bücher anzunehmen $^{21}$. Die Testamentsvollstrecker sollen für die Instandhaltung der Bücher sorgen, damit diese Verfügung über seine Bücher ewig dauert; dafür steht eine Rente bereit. Ferner hat der Testator seiner Tante Wobbeke Abbinghes einen kleinen blauen Rock gegeben. Seine Tante Metteke Nyndorp erhält sein Haus, Gebrauchsgegenstände und Kleinodien. Alle Hausutensilien, die er im Zeitablauf erworben hat, und alle Güter jenseits des vorausgemachten Legats hat er ihr geschenkt.

Unterschrift und Signet des Notars Rodolphus Rodolphi

Eine zweite Ausfertigung des Testaments ist vorhanden.

Nachweis: Reinhardt, Testamente, S. $615 \mathrm{ff}, \mathrm{Nr} .257$

\footnotetext{
${ }^{21}$ In der Regel waren die Bibliotheken Präsenzbibliotheken, doch verliehen z.B. die Franziskanerbibliotheken gegen Leihscheine ihre Bücher auch an Außenstehende. E. SCHLOTHEUBER, Bibliothekswesen und Bibliotheken der Bettelorden, in: 700 Jahre Paulinerkirche, hg. v. E. MITTLER, Göttingen 1994, S. 23.
} 


$\begin{array}{llcc}1480 & \text { August } 13 & \text { Lutke Hilmers } \\ \text { (mnd.) }\end{array}$

TV: Hans Schermbeck, Hans Kerstens, Klaus Pyleken der Jüngere

ANGABEN ZU PERSON UND FAMILIE:

Der Testator war Einwohner zu Lüneburg.

VERFÜGUNGEN ÜBER SACHGÜTER:

Das Gut ist des Testators selbsterarbeitetes Gut, wobei beide Töchter geholfen haben. Der Testator wünscht, daß seine Tochter Metteke aus seinen Gütern oder Kleinodien zuvor die zwei besten und größten Grapen haben soll. Seine Töchter sollen ihrer Schwester Beke aus des Testators hinterlassenen Gütern zwei mittelgroße Grapen und zehn Ellen Tafellaken geben und nicht mehr. Weil sie diese Güter nicht zu erwerben half und sich (folgt gestrichen: dazu nicht als fleißig, sondern als feindselig erwiesen hat/ das Folgende am linken Rand nachgetragen:) auch nicht nach dem Willen ihrer Verwandten/Freunde gerichtet hat (Ende des Nachgetragenen), soll sie damit von allen Gütern gänzlich geteilt und abgeschieden sein.

Siegler: Johann Schnewerding, Heinrich Erpensen

Reinhardt, Testamente, S.400f, Nr.258

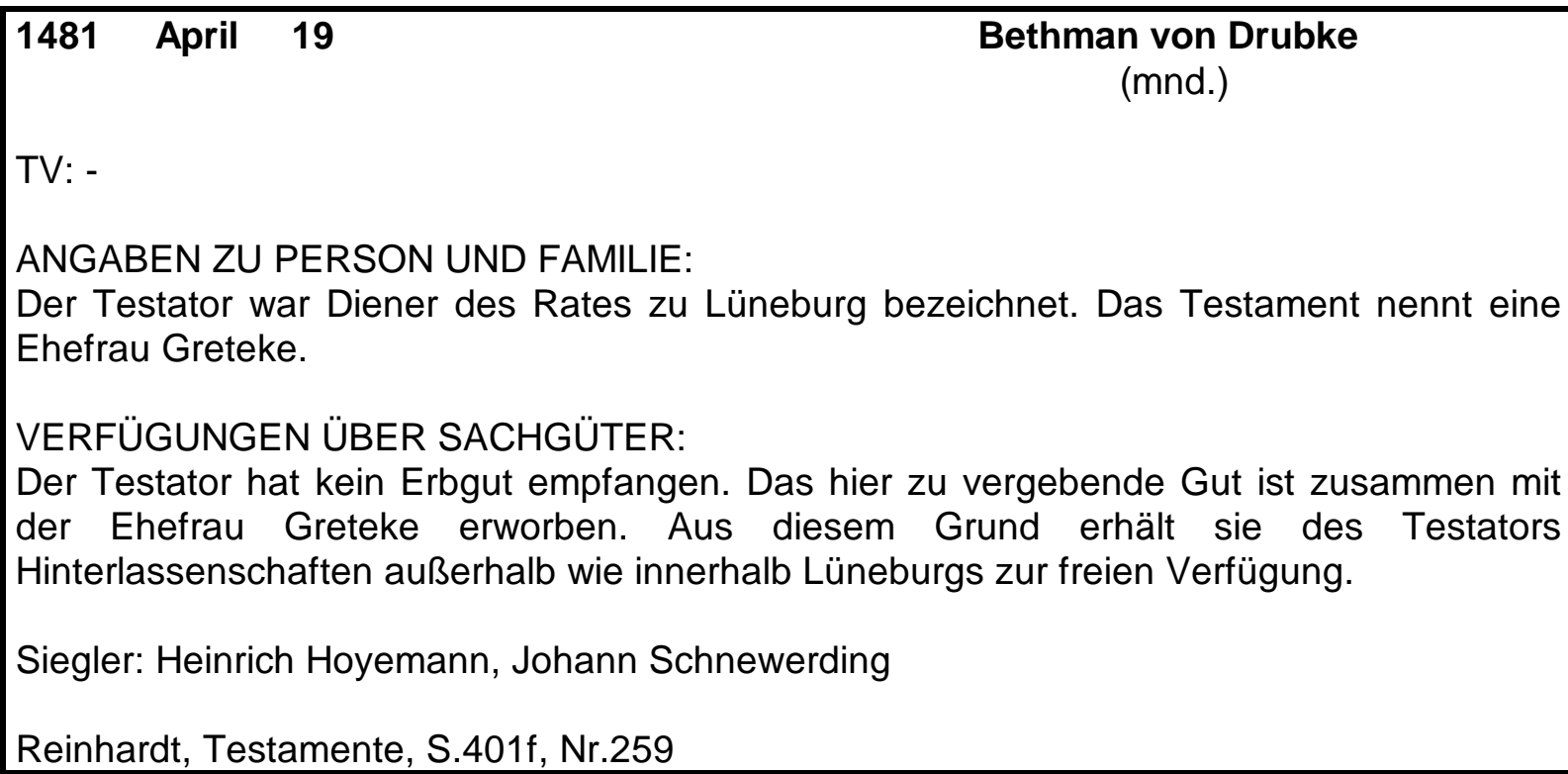

\begin{tabular}{|ccc}
\hline 1481 & Mai 24 & $\begin{array}{c}\text { Luteke Nyebur } \\
\text { (mnd.) }\end{array}$
\end{tabular}

TV: Hans Schermbeck, Bertelde von der Ryth, Klaus Meiger, Make Ottensted, Bürger zu Lüneburg

ANGABEN ZU PERSON UND FAMILIE:

Der Testator war Bürger von Lüneburg.

VERFÜGUNGEN ÜBER SACHGÜTER: 
Den großen Kessel und den größten Grapen soll die Hostienverehrungsfeier am Donnerstagabend in St. Nikolai erhalten. Zu dem neuen silbernen Schrein in St. Johannis gibt der Testator fünf Mark Pfennige. Der Tochter Kersten Kroghers schenkt er die Truhe seiner Mutter, sechs seidene Kissen und die beste Decke. Hans Schermbecks Anneke erhält sechs silberne Löffel. Die Wynhusesche erhält ebenfalls sechs silberne Löffel und ihre Tochter sechs Pfühle. Ferner bekommen die Kinder Bertelds von der Ryth den Korallenrosenkranz seiner Mutter, jede der Töchter einen goldenen Ring und zusammen für sie eins der beiden Silberstücke, die der Testator in seiner Lade liegen hat. Den Töchtern Berteldes von der Ryth schenkt er die sechs besten Pfühle und eine Decke. Der Tochter der Schwester Make Ottenstedens hinterläßt der Testator das andere Stück Silber aus seiner Lade und einen goldenen Ring. Die restlichen Betten sind für die Ausstattung armer Mägde gedacht.

Siegler: Heinrich Erpensen, Johann vame Lo

Papier mit aufgedrückten Siegeln

Reinhardt, Testamente, S.402ff, Nr.260

\section{Juni $5 \quad$ Hans Dobbeler \\ (mnd.)}

TV: Dietrich Moltwedel, Albert Schalen, Engelke Engelbrecht, Heinrich Clentzemann, Hans Reinstorf, Hermann van Hagen

ANGABEN ZU PERSON UND FAMILIE:

Dobbeler, Bürger Lüneburgs, kam aus einem nicht vermögenden Elternhaus, da er kein Erbgut erhalten hatte. Sein Vermögen hatte er gemeinsam mit seiner ersten Ehefrau llsebe erarbeitet. ${ }^{22}$ In zweiter Ehe war er nach dem Tod Ilsebes im Jahr 1468 mit Aleke verheiratet. Das Testament weist Heinrich Clentzemann als den Sohn seiner Frau Aleke aus. Als offenbar eigene Kinder erwähnt der Testator Töchter und den Sohn Peter. Hans Dobbeler wurde zum Sechziger nachgewählt und mußte zeitweise Einlager halten. 1485 ist er als Mitglied der Jürgensgilde erwähnt. Er besaß ein Wohnhaus im Marktviertel mit zwei zugehörigen Buden, in denen zeitweise über sechs Personen leben. Von inm gekaufte Häuser an der Saline und am Sande verkauft er wieder.

\section{VERFÜGUNGEN ÜBER SACHGÜTER:}

Seiner Frau Aleke schenkt er sein Haus, Hof mit allem Zubehör. Ausgenommen sind jene Dinge, über die der Testator in zwei versiegelten Urkunden verfügt, deren eine bei Aleke und ihrem Sohn Heinrich Clentzemann in Verwahrung ist, während sich die andere in den Händen der Testamentsvollstrecker befindet. Den armen Leuten in seinem Gotteshaus stiftet er seinen größten Kupferkessel von zwei Zubern Wasser, wenn sie einen Scheffel Malz sieden wollen. Von seinen drei Messingkesseln stiftet er den größten sowie das größte Handfaß und die größte Zinnkanne ( folgt gestrichen: und sein Schrank und die Senfmühle) und seine Arbeitsschürze. Ferner schenkt er einen seiner Kleiderschränke. Die (über der Zeile nachgetragen) derzeitige Magd Geseke erhält ein Bett, einen Pfühl, in dem sie jetzt zu schlafen pflegt, damit sie sich wohlfühlt (Gesche - zwölf über Gestrichenem: von denen sie zur Zeit sechs hat).

Siegler: Johann vame Lo, Dietrich Wülsche

Das Testament ist im Jahr 1484 revidiert worden, wie das Schlußdatum ausweist.

\footnotetext{
${ }^{22}$ U. J. DIEDRICHS, Aufruhr, S.115ff.
} 


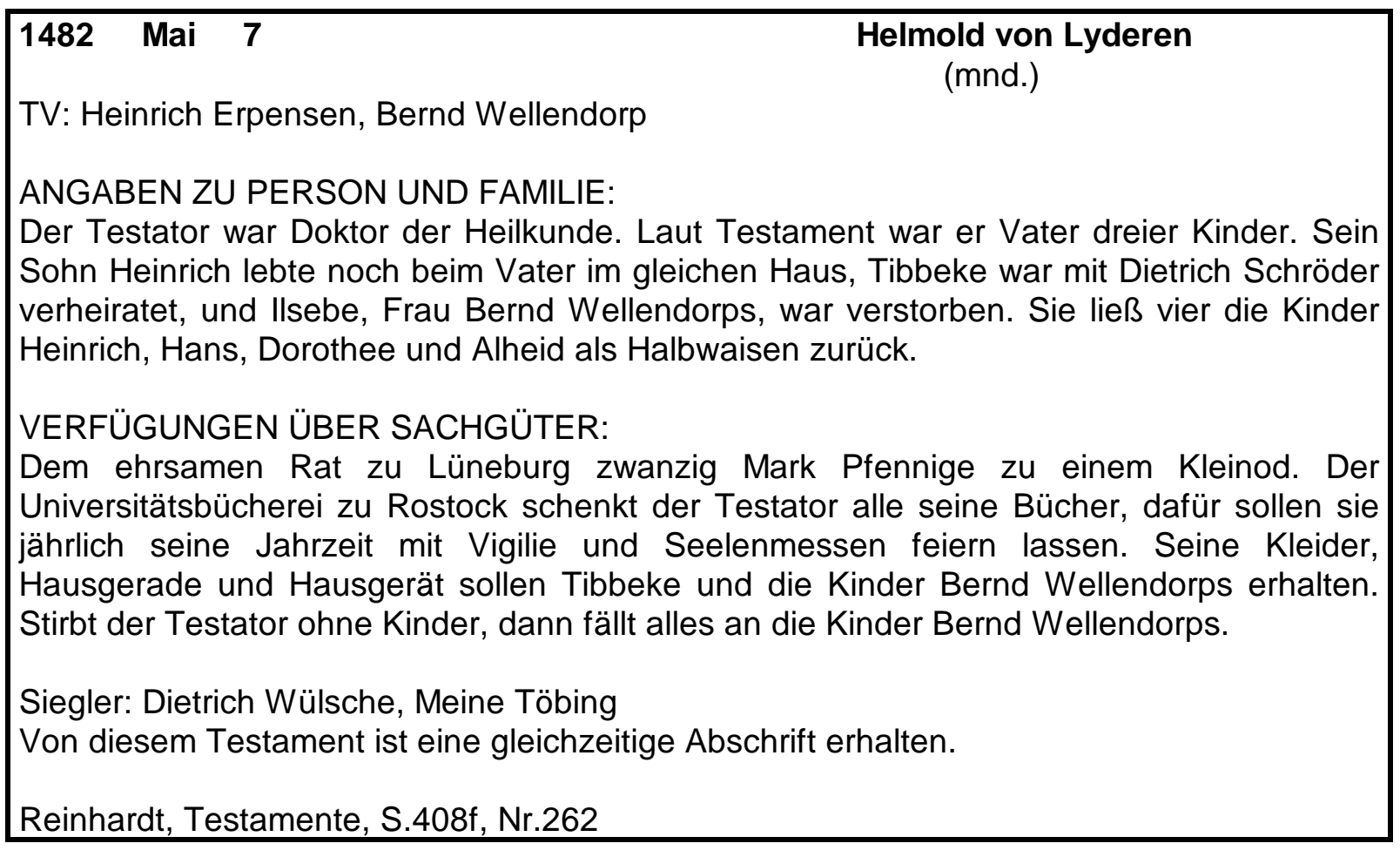

\begin{tabular}{|l}
\hline 1482 Juni 30 \\
TV: Geseke, seine Frau; Henning Hoppensen, weitere Ergänzungen vorbehalten. \\
(mnd.) \\
ANGABEN ZU PERSON UND FAMILIE: \\
Der Testator war Ratsherr zu Lüneburg. Das Amt des regierenden Ratsherrn bekleidete er \\
in den Jahren $1474,78,80,81$ und 1483 bis $86^{23}$. Nachgewiesen ist Heinrich von \\
Erpensen 1440 an der Universität Erfurt, 1458 als Sülfmeister, 1474 als Ratsherr ${ }^{2}$. In \\
erster Ehe war er mit Gretke Lange verheiratet, in zweiter Ehe mit Gesche von Winsen. \\
Aus der ersten Ehe waren Ilsabe und Cord hervorgegangen, mit Gesche von Winsen hatte \\
der Testator die vier Kinder Elisabeth, Mette, Katherina und Gesche. Möglicherweise war \\
er der Ohm der Testatorin Hilleke von Erpensen. Heinrich Erpensen starb 1487. \\
VERFÜGUNGEN ÜBER SACHGÜTER: \\
Seiner Tochter Ilsebe, der Ehefrau Herrn Diderichs Wulsches, gab er 2000 Mark Pfennige \\
als Mitgift, dazu Kleider und Hausrat, wie sich das gebührt. Ferner hat der Testator seiner \\
Tochter Metteke, Johann Schomakers Frau, als Mitgift 2000 Mark Pfennige gegeben, dazu \\
Kleider und Hausrat. Dem ehrsamen Rat zu Lüneburg zwölf Mark feinen Silbers für ein \\
Kleinod auf das Rathaus, dort zu ewigen Zeiten zum Verbleib. \\
ZUSÄTZLICHE INFORMATIONEN:
\end{tabular}

\footnotetext{
${ }^{23}$ I. STAHL, Ratslinie, Nr. 220, S.172.

${ }^{24}$ H.-J. v. WITZENDORFF, Stammtafeln, S. $38 \mathrm{f}$.
} 
Als Stifter der von Gesche Erpensen in St. Nikolai gewünschten Vikarie fungiert der testamentarius Gesche Erpensens, Nikolaus Viskule ${ }^{25}$. Offensichtlich errichtete also auch die Frau des Testators ein eigenes Testament.

Siegler: Heinrich von der Mölen, Johann Schnewerding

Rückvermerk: Original auf der Camerey Nr. CLXXII. Abschrift des 18. Jahrhunderts

Reinhardt, Testamente, S.409ff, Nr.263

1482 Juli 23
TV: Albert Berbom, Greteke, seine Frau, Schwester der Testatorin, Klaus Ulensborg, Klaus
Nyndorpp
ANGABEN ZU PERSON UND FAMILIE:
Die Testatorin war die Witwe des Bürgers Hans Brockhoved.
VERFÜGUNGEN ÜBER SACHGÜTER:
Die Testatorin erklärt, kein Erbgut empfangen zu haben; das hier erwähnte Gut hat sie
zusammen mit ihrem Ehemann erarbeitet.
Die Testatorin hinterläßt sie ihrer Schwester Greteke, der Ehefrau Alberd Berbomes, alle
ihre mobilen und immobilen Güter, Hausgerade und Hausgeräte;was sie über diese
vorgenannte Gabe hinaus hinterlassen wird, soll sie mit ihren Erben gemeinsam nutzen.
Siegler: Dietrich Wülsche, Heinrich Töbing
Reinhardt, Testamente, S.414f, Nr.264

\begin{tabular}{|ccc}
1482 & November 18 & $\begin{array}{c}\text { Dietrich Döring } \\
\text { (mnd.) }\end{array}$
\end{tabular}

TV: -

ANGABEN ZU PERSON UND FAMILIE:

Der Testator war Ratsherr. In den Jahren 1463, 69, 70, 72 bis 82, 84 und 1486 bis 98 ist er als regierender Ratsherr nachgewiesen ${ }^{26}$. Seine Lebensdaten zwischen den Eckpfeilern der Geburt 1430 und des Todes 1498 sind die Erwähnung als Sülfmeister 1456, 1458 als Barmeister und 1463 als Ratsherr ${ }^{27}$. Seit 1453 war er mit Gesche von Töbing verheiratet. Aus ihrer Ehe gingen fünf Kinder hervor. Der einzige Sohn Johann besuchte die Universität in Erfurt, war 1482 Sülfmeister, 1490 Barmeister und wurde seit 1499 als Ratsherr geführt $^{28}$.

In folgendem verwandtschaftlichen Verhältnis stehen weitere im Testament erwähnte Personen zum Testator: Dietrich Döring ist sein Schwiegersohn, Johann Schnewerding der Schwiegervater seines Sohnes ${ }^{29}$.

\footnotetext{
${ }^{25}$ Die Vikarie sollte am Allerheiligenaltar der Nikolaikirche errichtet werden. G. MATTHAEI, Vikariestiftungen, S. 198f.

${ }^{26}$ I. STAHL, Ratslinie, Nr. 213, S. 171.

${ }^{27}$ H.-J. v. WITZENDORFF, Stammtafeln, S. 28.

${ }^{28}$ I. STAHL, Ratslinie, Nr. 242, S. 174.

${ }^{29}$ Für das Geschlecht Schnewerding: H.-J. v. WITZENDORFF, Stammtafeln, S. 109.
} 
VERFÜGUNGEN ÜBER SACHGÜTER:

Jährlich soll die Rente von 31 Mark Geldes eingenommen werden; davon sollen die Testamentsvollstrecker jährlich vier graue Lüneburger und ein weißes Stendelsches Laken kaufen, für das übrige Geld Frauen- und Männerschuhe und es unter den armen Leuten verteilen, den Männern Tuch für ein Kleid und Hosen und Schuhe und den Frauen Tuch und Schuhe. Ferner soll sein Sohn Johann jeden Tag zwei arme Leute zur Speisung benennen, so wie der Testator es getan hat; innen soll man zuvor Kleidung und Schuhe geben. Die Kirchgeschworenen zum kleinen Heiligen Geist sollen Gewand und Schuhe kaufen und den armen Leuten geben.

Siegler: Dietrich Döring, Johann Schnewerding, Heinrich Varendorp

Reinhardt, Testamente, S.415ff, Nr.265

\begin{tabular}{|ccc}
1483 & Mai 28 & $\begin{array}{c}\text { Nickel Wulfferam } \\
\text { (mnd.) }\end{array}$
\end{tabular}

TV: Dietrich Elver, Pawel Wulfferam

ANGABEN ZU PERSON UND FAMILIE:

Der Testator wird im Testamentsformular als verstorbener Bürger, Vater des genannten Klaus, bezeichnet. Der Testator hatte drei Kinder; eine Tochter Greteke und die Söhne Klaus und Hans. Hans bezeichnet der Testator als außer Landes Weilenden.

VERFÜGUNGEN ÜBER SACHGÜTER:

Seinem Sohn Klaus und dessen Kindern schenkt der Testator sein Bett mit dem Deckbett und das Leinentuch, vier Messingkessel, fünf kleine Grapen und den kleinsten Deckel, all seine Zinnkannen, fünf Zinngefäße, das zweitgrößte Handbecken, ein kleines Becken, einen Eisenhut mit dem Brustharnisch und Kragen, einen großen Kessel und sechs Pfühle, das Kontor in der Dornse und zwei Schifftruhen. Ferner hat er seinem Sohn Hans vier Messingkessel gegeben, drei Grapen, einen Deckel, vier Zinngefäße, ein Handbecken und ein kleines Becken, eine große Truhe, vier Seidenkissen, drei silberne Löffel und das Kontor in der Kammer; diese Kessel, Grapen, eine Pfanne, Zinngefäße und das Handbecken sollen größer sein als die, die Klaus zugewendet sind. Das Hausgerät und die Hausgerade, die Hans zukommen, soll man in die große Truhe legen und bitten, daß man die Truhe so lange in der St. Cyriacuskirche aufbewahren darf, bis man in Erfahrung gebracht hat, ob Hans tot oder lebendig ist. Ist er gestorben, so soll der inm zugedachte Teil an die Kinder seines Bruders fallen; das sollen seine Testamentsvollstrecker mit treuer Hand für sie verwalten, damit er als Vater keine Macht hat, es zu veräußern oder zu versetzen. Ferner hat er seiner Tochter Greteke (Folgt gestrichen: Ferner ein Agnus Dei, drei silberne Löffel seines Sohns Klaus Sohn) das rocksmyde, das für drei Mark als Pfand der Elverschen und der Beckerschen stehen, zugedacht. Die Tochter seines Sohnes Ilsebe erhält ein Agnus Dei.

Siegler: Jakob Schomaker, Johann Elver

Papier mit aufgedrückten Siegeln

Reinhardt, Testamente, S.417ff, Nr.266 


\begin{tabular}{|l|}
\hline $1483 \quad$ Juni 10 \\
$\begin{array}{l}\text { TV: Johann Soltwedel, Cord Reder, Priester, Hans } \\
\text { Lüneburg }\end{array}$ \\
$\begin{array}{l}\text { ANGABEN ZU PERSON UND FAMILIE: } \\
\text { Der Testator war Bürger zu Lüneburg. } \\
\text { (mnd.) }\end{array}$ \\
$\begin{array}{l}\text { VERFÜGUNGEN ÜBER SACHGÜTER: } \\
\text { Der Stadtvogt besitzt eine eiserne Winde, die dem Testator gehört; für die Benutzung soll } \\
\text { die Winde behalten. } \\
\text { Siegler: Heinrich Erpensen, Jakob Schomaker } \\
\text { Reinhardt, Testamente, S.419ff, Nr. 267 }\end{array}$ \\
\hline
\end{tabular}

1483 Juli $12 \quad \begin{gathered}\text { Ymmeke Spranse } \\ \text { (mnd.) }\end{gathered}$

TV: Cord Smede, Lutken Graven

ANGABEN ZU PERSON UND FAMILIE:

Ymmeke Spranse war die Witwe Hermann Spranses. Als ihren Ohm bezeichnet die Testatorin Cord Smede.

VERFÜGUNGEN ÜBER SACHGÜTER:

Greteke, der Schwester Heinrich Weydemanns, erhält die blaue Hoike, die andere Schwester, Wunneke, die blaue Arrasche Hoike, und Anneke die Werktagshoike der Testatorin. Der Tochter Hans Weydemanns, Geseke, gibt sie ihre zweitbeste Hoike. Geseke, der Tochter Cord Smeds, schenkt sie ihren silbernen Becher. Die Testatorin betont, kein Erbgut empfangen zu haben. Das hier Vergabte hat sie selbst erarbeitet und erspart.

Siegler: Jakob Schomaker, Johann Elver

Papier mit aufgedrückten Oblatensiegeln

Reinhardt, Testamente, S.421f, Nr.267a

\section{Januar $9 \quad$ Hartwig Hannover \\ (lat.)}

TV: Johannes Bars, Vikar von St. Johannis; Gerbert Overwyn, Vikar an St. Lamberti; Bertold Engelke, Kommendist an St. Michaelis; Johannes Amelinghausen, Vikar an ST. Cyriacus

ANGABEN ZU PERSON UND FAMILIE:

Der Testator, Mitglied des Ordens des heiligen Benedikts, war Priester und Pfründner in der Krypta des Klosters St. Michaelis. 
VERFÜGUNGEN ÜBER SACHGÜTER:

Der Vikarie am St. Katherinenaltar in der Kapelle der Lambertikirche schenkt der Testator zwei Becher, eine silberne Schale, zwei Gürtel mit Schließen sowie sechs silberne Löffel für einen anzufertigenden Kelch; diese Vikarie hat er gegründet, auf die Einkünfte bezieht sich der Inhalt einer Urkunde in einem kleinen Schrein in seiner Klausur. Ferner soll Herr Heinrich (folgt gestrichen: Mynden), Begine in Winsen, ein Buch mit rotem Ledereinband über die Theologie erhalten. Seinem Scholaren schenkt er ein Buch über speram matinalem. Dem Priester Johann Minden hinterläßt er ein Diurnale mit Ledereinband. Dem Priester Bertold Enghelke schenkt er seinen größeren Zinnkrug. Enghelke soll sich ein Kleid von des Testators Kleidern aussuchen für seine inm verschiedentlich erwiesenen Dienstbarkeiten. Seine Testamentsvollstrecker sollen die anderen Einkünfte, die er in Winsen und anderswo hat, nach dem Inhalt darüber angefertigter Urkunden einfordern; sie sollen davon Stoffe und Schuhe zur Bekleidung der Armen in den einzelnen Jahren geben; nach deren Tod sollen die Verwalter der Kalandsbruderschaft in der erwähnten Johanniskirche zu Lüneburg die Einkünfte einfordern und, wie dargelegt, zu ewigen Zeiten den Armen in Tuch und Schuhen geben.

Mit der Pressel des Offizialatssiegels des Bistums Verden sind zwei weitere Urkunden angeheftet:

1. 1484 April 24: Bestätigung des Testaments und der Testamentsvollstrecker durch den

Vikar und Offizial des Bistums Verden, Hermann Brietling

2. 1484 Dezember 9: Entpflichtung der Testamentsvollstrecker durch den Vikar und

Offizial Hermann Brietling

Die zweite Urkunde befindet sich auf der Rückseite der ersten. Beide sind ausgefertigt von dem Notar Hermann Telemann.

Reinhardt, Testamente, S.423ff, Nr. 269

1485 Januar 31

Geseke Leyferd

(mnd.)

TV: Alheitf von Kalle, Johann Hogestern, Priester, Hans Rodenborch, Hans Hennynes, Cord von der Heide

ANGABEN ZU PERSON UND FAMILIE:

Die Testatorin war die Witwe des verstorbenen Henning Leyferd.

VERFÜGUNGEN ÜBER SACHGÜTER:

Den Mönchen in Winsen stiftet die Testatorin ihr Agnus Dei für ein Kußtäfelchen, ihre zwei größten Grapen, einen Mörser, einen Leuchter mit vier Hälsen für einen Altar, eine wrachte Decke für die Sakristei, ihr größtes Handfaß und einen Leuchter mit vier Schilden; sie wünscht, daß die Jahrzeit des Ehepaares Leyferd jedes Jahr begangen wird. Ihr ewangelium boeck gibt sie nach Isenhagen, eine wrachte Decke in die Sakristei und ferner einen ihrer Schränke. Der Wenkeschen schenkt sie ihr zweitbestes Paar Laken und die nächstbesten sechs Stuhlkissen. Der Frau Klaus Pepers hinterläßt sie eine schwarze Arrasche Hoike, ihre beste schwarze Sube, den besten Armreif und ihr kleinstes Handfaß. Ferner gibt sie der Frau Cord von der Heides ihr größtes Bett, einen großen Pfühl und ihre rote Arrasche Hoike. Roleff von Kalle hinterläßt sie die beste Badekappe mit dem glänzenden Beutel und seiner Schwester Geseke den brauenen Rock, der so lange der beste der Testatorin war, das längste Tafeltuch, das längste Handtuch, vier lakendoke, ein Paar Laken, zwei Rollbetten, eine Badekappe und das größte Paar Wangenkissen. Ihrer Magd Geseken schenkt sie ihre schwarze Tuchhoike, den silbernen Ring mit dem blauen 
Stein und das kleinste Paar Wangenkissen, dem der rote Arrasche Stoff vorgesetzt ist, sowie eine Zinnschüssel. Ferner gibt sie ihrer Magd Wobbeke, die am St. Michaelstag zu ihr kam, ihr größtes Bett, über dem der Leinwandbezug ist, und den kleinsten Pfühl, der das billigste Tuch ist. Wobbeke, der Tochter Aleke Standorpps, hinterläßt sie ein Bett mit 24 Streifen und den Pfühl, der längsgestreift ist, sowie ein Paar Wangenkissen, die grün eingefaßt sind, den silbernen Ring, der vergoldet ist, zwei lakendoke und eine Zinnschüssel. Ihre einstige Magd Aleke Reinstorf bekommt einen Pfühl, da kein wollenes Tuch übrig ist für einen Hoikenkragen, fünf vergoldete Knöpfe, eine Lade, ein Tafellaken und zwei Rollbetten, ein lakendok und die Zinnschüssel mit der Rose.

Siegler: Dietmar Sankenstedt, Heinrich Töbing

Papier mit aufgedrückten Siegeln

Reinhardt, Testamente, S.426ff, Nr.270

1486 Mai 1

Gevehard Gronehagen

(lat.)

TV: -

ANGABEN ZU PERSON UND FAMILIE:

Der Testator war Priester der Diözese Verden. Gevehard Grönhagen war eines der sechs Kinder Gevert Grönhagens, des herzöglichen Vogts in Bardowick, und der Tibbeke von der Mölen ${ }^{30}$. Familienmitglieder, darunter auch der Vater des Testators und seine zwei Brüder, studierten in Erfurt oder Rostock. Die drei Schwestern des Testators blieben unverheiratet; zwei wurden Nonnen in Ebstorf bzw. Lüne, die dritte ist als Vorsteherin des Blauen Konvents nachgewiesen. Ein Bruder des Testators, Nikolaus, wurde Bürgermeister in Lübeck.

VERFÜGUNGEN ÜBER SACHGÜTER:

Den Restbestand an mobilen Gütern sollen des Testators Onkel, Dietrich und Nikolaus Wulsche, unter den Familienangehörigen und den Armen verteilen; dazu erteilt Grönhagen innen die Vollmacht.

Siegler: Offizial von Verden

Gleichzeitige beglaubigte Kopie

Reinhardt, Testamente, S.428ff, Nr.271

1487 Dezember 6

Geseke Wangelow

(mnd.)

TV: Tochter Grete, der je älteste Diffinitor des Kalands, der älteste Kirchgeschworene von

${ }^{30}$ H.-J. v. WITZENDORFF, Stammtafeln, S.48. 
St. Johannis, Heinrich Drespe, Johann Schnewerding, Ratsherr, Klaus Holstenland

ANGABEN ZU PERSON UND FAMILIE:

Die Testatorin war die Witwe des verstorbenen Ratsherrn Eggherd Wangelow. Als regierender Ratsherr ist Wangelow 1446, 47 und 1459 bis 53 nachgewiesen ${ }^{31}$. Er starb 1455. Im Testament wird die gemeinsame Tochter Grete erwähnt, nun eine verheiratete Grawerock. Als Vater der Testatorin wird Johann Wynckelmann genannt.

VERFÜGUNGEN ÜBER SACHGÜTER:

Die Testatorin bekennt, daß sie von niemandem Erbgut empfangen hat. Von ihrem verstorbenen Vater Johann Wynckelmann bekam sie 300 Mark als Mitgift. Nach seinem Tod erhielt sie 900 Mark an Gut und Geld, damit sie seinem Willen folgend zwei Kinder für das Kloster ausstatten konnte.Das hat die Testatorin 500 Mark und mehr gekostet. Ferner soll man dem Rat zu Lüneburg ein Kleinod von 30 Mark Pfennigen geben.

Siegler: Heinrich Varendorp, Dietrich Wülsche

Reinhardt, Testamente, S.430ff, Nr.272

\begin{tabular}{|ccc}
\hline 489 & April 1 & $\begin{array}{c}\text { Christofel Rekel } \\
\text { (mnd.) }\end{array}$
\end{tabular}

TV: Dietrich Nyebur,Cord Tostede, Bürger zu Lüneburg

ANGABEN ZU PERSON UND FAMILIE:

Rekel war Bürger zu Lüneburg. Das Testament nennt eine Ehefrau Beke sowie eine Tochter.

VERFÜGUNGEN ÜBER SACHGÜTER:

Das Gut hat der Testator selbsterarbeitet. Seiner Ehefrau Beke hinterläßt er dieses Gut, das er in Renten hinterlassen wird, in Bargeld, als Hausgerät, als Kleider und andere Sachen. Sie soll es ohne jemandes Mitsprache behalten, damit tun und lassen, was sie will.

Siegler: Godeke Tzerstede, Johann Garlop

Papier mit aufgedrückten Siegeln

Reinhardt, Testamente, S.433f, Nr. 273

1489 Dezember 12

Hans Reinstorp

(mnd.)

TV: Ludolf Reinstorp, Dietrich Buldermann, Hans Kruse, Bürger zu Lüneburg

ANGABEN ZU PERSON UND FAMILIE:

Der Testator war Bürger zu Lüneburg.

\footnotetext{
${ }^{31}$ I. STAHL, Ratslinie, Nr. 194, S. 168.
} 
VERFÜGUNGEN ÜBER SACHGÜTER:

Das restliche mobile und immobile Gut soll an die Frau und die Tochter fallen.

Siegler: Johann Garlop, Ludolf Tzerstede

Papier mit aufgedrückten Siegeln. Erhalten ist auch eine notariell beglaubigte Abschrift

Reinhardt, Testamente, S.435f, Nr.274

\begin{tabular}{|l|l|}
\hline $1490 \quad$ Januar 15 & \multicolumn{1}{c}{$\begin{array}{c}\text { Heinrich Elver } \\
\text { (mnd.) }\end{array}$} \\
TV: Henning Hugh der Ältere, Hans Holstenland und Bernd von Rede, Bürger zu Lüneburg \\
ANGABEN ZU PERSON UND FAMILIE: \\
Elver war Bürger Zu Lüneburg. \\
$\begin{array}{l}\text { VERFÜGUNGEN ÜBER SACHGÜTER: } \\
\text { Das Gut, über das er verfügt, ist selbsterarbeitetes Gut. Den Restbestand an Gütern erhält } \\
\text { die Ehefrau. }\end{array}$ \\
$\begin{array}{l}\text { Siegler: Johann Schnewerding } \\
\text { Das zweite Siegel ist abgefallen, die Pressel ist noch vorhanden. } \\
\text { Reinhardt, Testamente, S.436ff, Nr. } 275\end{array}$
\end{tabular}

\begin{tabular}{|ccc}
1490 & Mai 11 & $\begin{array}{c}\text { Heinrich Winthe } \\
\text { (mnd.) }\end{array}$
\end{tabular}

TV: Cord Hagen, Drewes Dietmar, Arndt Blomen, Hermen Spur, Bürger zu Lüneburg

ANGABEN ZU PERSON UND FAMILIE:

Der Testator war Bürger zu Lüneburg.

VERFÜGUNGEN ÜBER SACHGÜTER:

Mit dem Verkauf des gesamten Nachlasses sollen die testamentarischen Verfügungen finanziert werden. Für den Bau der Johanniskirche stiftet der Testator die Hoike seiner Frau, das zweitbeste Geschmeide und seinen Ehering; dem Kirchherrn des großen Heiligen Geists eine Albe, ein Amikt, zum Bau von St. Marien die grüne Sube seiner Frau und das Geschmeide, das des Testators verstorbene Mutter gegeben hat. Für den kleinen Heiligen Geist sind die beste Hoike seiner Frau und Geschmeide bestimmt. Fünf Mark für die Kapelle St. Marien, damit soll man das Bild verzieren. Tibbeke schenkt der Testator fünf Mark, dazu die beste Decke seiner Frau. Ferner der Schutteschen die zweitbeste Hoike seiner Frau ohne das Geschmeide. Den Schwestern hinterläßt er die Hausgeräte, die er von deren Vater bekommen hat. Nach dem Gutdünken der Testamentsvollstrecker soll Brand ein Kleinod übergeben werden. Sechs graue und weiße Laken soll man armen Leuten zur Ehre Gottes stiften. Seiner Base Geseke Soltouwe hinterläßt der Testator die beste Hoike seiner Frau ohne das Geschmeide, wenn sie sich rechtschaffen verhält. Tut sie das nicht, so soll man dieses anderweitig für die Ehre Gottes verwenden. Der Arndschen Magd schenkt er eine schwarze Hoike und ein Paar Laken, 
damit sie für seine Seele bittet. Aleke Wolsche soll man einen weißen Pelz und einen Rock von schwarzem Hardwiker Tuch machen lassen. Ferner soll man seinem Vetter Albert Soltouw ein Kleinod aus des Testators Haus geben für ungefähr fünf Mark. Das älteste Kind von Smets Tochter erhält den grünen Rock seiner Frau. Sein Vater und das Kind erhalten je eine silberne handtruwe gegeben werden, die in seiner Truhe liegen. Ferner soll man seiner Base in Arnstorf von den besten Polstern geben, wenn sie für die Ehe ausgestattet wird wird. Seiner Base, der Arbergschen, hinterläßt er einen Schleier. Ferner schenkt der Testator Aleke Helmold die beste rote Bettdecke seiner Frau und ein Paar roter weiter Ärmel mit dem Geschmeide.

Konzept auf Papier

Reinhardt, Testamente, S.438ff, Nr.276

\begin{tabular}{|ccc|c}
\hline 1491 & Februar & 8 & $\begin{array}{c}\text { Heinrich Töbing der Ältere } \\
\text { (mnd.) }\end{array}$
\end{tabular}

TV: Heinrich Töbing, Sohn des Testators, Dietmar Töbing, Bürger zu Lüneburg

ANGABEN ZU PERSON UND FAMILIE:

Der Testator, Bürger Lüneburgs, entstammte dem Geschlecht der Töbing ${ }^{32}$. Sein Studium hatte er in Rostock und Leipzig absolviert. Töbing war zweimal verheiratet. Aus der ersten Ehe mit Barbara Viskule stammmten die Kinder Meino (er verstarb jung), Beate, Barbara, Gesche und Heinrich; Heinrich der Jüngere wurde Sülf-, dann Barmeister, und später dann Ratsherr. Aus der zweiten Ehe mit der Goldschmiedstochter Mette Sommer ging die Tochter Agnete hervor ${ }^{33}$. In seinem Testament gibt der Testator an, Mette sei zum Zeitpunkt der Heirat bereits verwitwet gewesen.

VERFÜGUNGEN ÜBER SACHGÜTER:

Mit seiner Frau hat Töbing als Mitgift 600 Mark Vermögen empfangen, dazu sollte er fünf Mark Geldes jährlicher Rente bekommen und dazu die Hälfte von ihren Kleinodien, Hausrat und Roggen, auch die Hälfte der ausgegebenen Schuld, die ihr ihr verstorbener Ehemann hinterlassen hat.

Siegler: Johann Elver, Ludolf Tzerstede

Papier mit aufgedrückten Siegeln. Erhalten ist auch eine notariell beglaubigte Kopie

Reinhardt, Testamente, S.441ff, Nr.277

TV: Cord Smith, Hans Moller, Hans Eeckholt, Bürger zu Lüneburg

ANGABEN ZU PERSON UND FAMILIE:

Der Bürger war Bürger zu Lüneburg.

VERFÜGUNGEN ÜBER SACHGÜTER:

Ludtke Helmede im Heiligen Geist und seiner Schwester Metteke in Telmer (Kreis)

\footnotetext{
${ }^{32}$ H.-J. v. WITZENDORFF, Stammtafeln, S.132f.

${ }^{33}$ Angaben über den Stammbaum der Sommers bei H.-J. v. WITZENDORFF, Stammtafeln, S. 119.
} 
Lüneburg) schenkt der Testator jeweils ein Viertel vom Hardewiker Laken. Seinem Sohn Hans gibt er den Nachlaß, Haus, Hof, mobil und immobil, mit dem aufgelisteten Hausrat und die Schulden. Ferner zwölf Zinngefäße und acht Kannen, sieben Grapen und ein Handbecken, ein dorslach und ein Handfaß, vier große und kleine Betten und einen Pfühl, einen großen Kessel von drei Zubern Wasser mit einem Dreifuß, vier Messingkessel und zwei große Kupferkessel. Der Testator gibt bekannt, mit Balemann sieben kleine Lüneburger Laken zu haben, die bezahlt sind, das Stück für sieben Mark. Er hat in seiner Dornse vier Walsroder Laken und zwei Lüneburger Laken - das größere gehört inm. Das restliche Gut soll der Sohn Hans mit dem Hausrat und den Schulden erhalten.

Siegler: Godtke Tzerstede, Meine Töbing

Papier mit Oblatensiegel

Reinhardt, Testamente, S.443ff, Nr.278

\begin{tabular}{|ccc}
1492 & Februar 20 & $\begin{array}{c}\text { Hans Meyger } \\
\text { (mnd.) }\end{array}$
\end{tabular}

TV: Heinrich Elbek, Schwiegersohn des Testators, Hans Rikemann, Bürger zu Lüneburg

ANGABEN ZU PERSON UND FAMILIE:

Der Testator, Bürger Lüneburgs, erwähnt seine Tochter Metteke, die mit Heinrich Elebek verheiratet ist sowie aus dieser Verbindung hervorgegangene Enkelkinder. Jener Schwiegersohn ist der 1517 verstorbene Vorsteher der Annen- und der Gertrudgilde, dessen Ehe mit einer Mette, die 1540 starb, bezeugt ist ${ }^{34}$. Aus dieser Ehe gingen vier Söhne hervor; Johann wurde Magister, und Heinrich ist an der Universität Erfurt nachgewiesen - über den Werdegang der beiden anderen Söhne ist nichts bekannt.

VERFÜGUNGEN ÜBER SACHGÜTER:

Die Tochter des Testators soll alle mobilen und immobilen Hinterlassenschaften erhalten.

Siegler: Dietrich Brömse, Heinrich Garlop

Reinhardt, Testamente, S.447f, Nr.280

\section{Juli $8 \quad$ Dietmar Daldorppe \\ (mnd.)}

TV: Lambert, Apotheker, Schwiegersohn des Testators, Cord Hagen, Heinrich Hamermann, Bürger

ANGABEN ZU PERSON UND FAMILIE:

Dietmar Daldorp, Bürger Lüneburgs, hatte eine Tochter Anneke, die mit dem Apotheker Lambert verheiratet war. Dieser Lambert Ratbrock war der erste vom Rat angestellte Apotheker, denn nach dem Tod des kinderlos verstorbenen Apothekers Matthias von der Most (Testament 1474 Sept.22 ), dem die Apotheke gehört hatte, kaufte der Rat die Apotheke ${ }^{35}$.

\footnotetext{
${ }^{34}$ H.-J. v. WITZENDORFF, Stammtafeln, S. 33.

${ }^{35}$ D. ARENDS, Geschichte der Ratsapotheke, in: Pharm. Rundschau Nr. 8, 1960.
} 
VERFÜGUNGEN ÜBER SACHGÜTER:

Der Testator gibt bekannt, daß ihm zusammen mit seiner Frau Hilleke Erbgüter zugefallen sind; so vererbt er der gemeinsamen Tochter Anneke Haus, Hof und alle seine hinterlassenen Güter; nichts wird außerdem vererbt.

Siegler: Ludolf Tzerstede, Hartwig Stöterogge

Reinhardt, Testamente, S.448ff, Nr.281

\begin{tabular}{|ccc}
\hline 1493 & Oktober 26 & Hans Tetendorp \\
(mnd.)
\end{tabular}

ANGABEN ZU PERSON UND FAMILIE:

Der Testator, Bürger Lüneburgs, bezeichnet sich als Sohn des verstorbenen Mathäus. Das Testament seines Vaters stammte aus dem Jahr 1491. Die Testamente von Vater und Sohn deuten aufgrund etlicher Verfügungen über Tuch auf ein mögliches Berufsfeld hin. Eine Konkretisierung könnte in der Identifizierung der Bedachten Hebele von der Mölen als der Frau eines Tuchhändlers, des sogenannten Flandernfahrers Woldemars von der Mölen, liegen ${ }^{36}$.

VERFÜGUNGEN ÜBER SACHGÜTER:

Alheyd, der Tochter Bernd Kieffinges, schenkt der Testator den brauen Rock seines Vaters. Der Frau Cord Jordans hinterläßt er das Leinentuch, das sie verwahrt. Sie und ihr Ehemann verwahren fünf Ellen gemustertes Tuch; diese fünf Ellen Tuch stiftet der Testator den Kirchherren von St. Nikolai für Gott. Hebele von der Mölen erhält sein Leinentuch Laken, Hemden, Hauben, Kragen, jeweils zwei Paar. Meynhard Molsinck hat zehn silberne Löffel, die soll er behalten. Der Tochter seiner Schwester schenkt der Testator seiner Mutter smyde, ver par und einen Korallenrosenkranz, und alle Kleinode, so wie sie das Testament seines Vaters ausweist, wenn sie volljährig wird.

Papier mit aufgedrücktem Siegellack, jedoch ohne Abdruck

Reinhardt, Testamente, S.450ff, Nr.282

$\begin{array}{|llc|}1494 & \text { September } 10 & \begin{array}{c}\text { Gesche Henning } \\ \text { (mnd.) }\end{array}\end{array}$

TV: Ludolf Reynstorp, Bruder der Testatorin; der jeweilige Vorsteher der Almosen und Kirchgeschworenen zu St. Nikolai, die ihr Mann gestiftet hat - zur Zeit sind das Hans Holstenland, Bernd von Rode, Heinrich Krumstro und Hermann Barum

ANGABEN ZU PERSON UND FAMILIE:

Die Testatorin war die Witwe des verstorbenen Hans Hennig, einst Bürger zu Lüneburg.

VERFÜGUNGEN ÜBER SACHGÜTER:

Ihrer Schwester, der Krumstroschen, schenkt die Testatorin ein Bett, einen Pfühl, eine

\footnotetext{
${ }^{36}$ H.-J. v. WITZENDORFF, Stammtafeln, S. 82.
} 
Decke, zwei Paar Wangenkissen und sechs Paar Laken, dazu soll man sie Zeit ihres Lebens frei wohnen lassen in der Eckbude des Wohnhauses der Testatorin, welches gelegen ist bei St. Nikolai, neben dem Haus der Lüner. Wenn ihre Schwester verstorben ist, so soll die Bude bei dem Haus bleiben. Dazu soll sie so viel von den Hausgerätschaften der Testatorin haben, wie sie zur Not mit einer Magd nötig hat. Ferner soll man ihr ein Deckbett geben. Die Testatorin hinterläßt ihr den schwarzen gefütterten Unterrock und ihre beste Arrasche Hoike. Metteke von Rode soll die nächstbeste Schaube der Testatorin erhalten sowie die kurze blaue Hoike und einen silbernen Becher mit einem goldenen Rand. Ferner soll man aus den Gütern der Testatorin eine silberne Kanne für 100 Mark Pfennige anfertigen lassen, die ihr Bruder Ludolf Reinstorp haben soll; sie schenkt inm einen silbernen Becher mit goldenem Rand. Wenn ihr Bruder gestorben ist, soll die Kanne bei seinen Kindern bleiben, damit sie der Testatorin gedenken. Ihrer weseke Wobbeke Wichtenberten schenkt die Testatorin ihre beste gefütterte Schaube und ihre schwere kurze Hoike sowie einen silbernen Becher mit einem goldenen Rand. Metteke und Cylie Wichtenbeke, Jungfrauen zu Diesdorf, soll man jeweils so viel Tuch geben, wie jede für eine Haube nötig hat. Heinrich Krumstro all den Harnisch, Kragen, eisernen Hut und alles, was der Bewaffnung dient, bekommen, dazu erhält er den größten hängenden Leuchter der Testatorin und ihr größtes Handfaß, damit er ihrer gedenkt. Für ihn ist weiterhin ein silberner Becher mit einem goldenem Rand bestimmt. Ludolf Krumstro erhält ein Bett von achtzehn Streifen, einen Pfühl, zwei Wangenkissen, eine Decke, vier Paar Laken, die kleinsten zwei Handbecken, sechs mittelgroße Grapen, zwei große Messingkessel, zwei kleine Messingkessel und einen großen Kessel von einem Zuber Wasser, einen silbernen Löffel mit einem kurzen Stiel, einen silbernen Becher und ein Deckbett. Den Observantenbrüdern im Kloster St. Marien in Lüneburg soll man ein Laken Tuch für ihre Bekleidung kaufen. Dem Knecht Cord schenkt die Testatorin ein Bett, einen Pfühl, zwei Paar Laken, ein Wangenkissen, eine Decke. Ihre Magd Abel erhält ein Bett und Tuch, so wie die Testatorin es ihr versprochen hat; das Tuch liegt in einer Truhe auf dem Boden über der Kammer ihrer Schwester. Ihren Testamentsvollstreckern schenkt die Testatorin einen silbernen Becher von vier Mark Pfennigen, die ihr Bruder Ludolf nach ihrem Tod aus ihren Gütern anfertigen lassen soll und ihnen zuschicken soll, damit sie der Testatorin gedenken.

\section{ZUSÄTZLICHE INFORMATIONEN:}

In der Nikolaikirche sind zwei Vikarien von der Testatorin gestiftet worden, eine von ihrem Mann ${ }^{37}$. Als Inhaber des Patronatsrechts werden in den Quellen z.T. die testamentarii des Ehemannes genannt, so daß ein Testament Hans Hennings wohl vorhanden gewesen sein muß.

Siegler: Dietrich Döring, Meine Töbing

Reinhardt, Testamente, S.452ff, Nr.283

\begin{tabular}{|lc|}
\hline 1494 & $\begin{array}{c}\text { Lorenz König } \\
\text { (mnd.) }\end{array}$ \\
& \\
TV: Johann Schnewerding, Hartwig Stöterogge, & Ratsherr, Hans Schnewerding, Bartold \\
Wackenhagen, Ilsebe, seine Frau &
\end{tabular}

\footnotetext{
${ }^{37}$ Am Allerheiligenaltar Vic. II, III und IV. Die Vikarien III und IV werden beschrieben als Gade almechtich, Marien der hemmelschen koniginnen, der hilgen moder sunte Annen und allen Gades hilgen ... to dem altare $s$. Anne in dercapellen, dar inne men der Henningesschen ... almissen plecht to ghevende. G. MATTHAEI, Vikariestiftungen, S. 199ff.
} 
ANGABEN ZU PERSON UND FAMILIE:

Der Testator war Bürger zu Lüneburg.

VERFÜGUNGEN ÜBER SACHGÜTER:

Bis auf eine Bude im Wert von 100 Mark hat König kein Erbgut empfangen. Der Testator hat 800 Mark Rentenbesitz. Wenn eine der Renten ausgelöst wird, soll man dafür armen Leuten Tuch und Schuhe kaufen. Der Testator schenkt dem ehrsamen Rat zu Lüneburg 40 Mark Pfennige für (folgt gestrichen: ihrem Stadtbau) ein Kleinod in ihrer Schenkschive im Rathaus. Den weiteren Nachlaß, namentlich sein Haus und Hof und alles, was darinnen ist an Silbergeschmeide, an Hausrat, oder was er an Renten oder an Geld besitzt, schenkt der Testator Dietrich Basedow in Lübeck. Jeder der Testamentsvollstrecker soll einen silbernen Becher von fünf Mark Pfennigen für ein Kleinod erhalten, damit sie des Testators gedenken; diese soll die Frau Königs anfertigen lassen und jedem vorkec (Lücke durch Beschädigung des Pergaments) in die Hand schicken soll.

Gleichzeitige Abschrift

Reinhardt, Testamente, S.457ff, Nr.285

\section{März $12 \quad$ Ludolf Brodermann \\ (mnd.)}

TV: Alheit, Frau des Testators, Hermann von dem Hagen, Hans Moring, Hans und Peter Elebek, Brüder, Bürger zu Lüneburg

ANGABEN ZU PERSON UND FAMILIE:

Der verheiratete Testator hatte einen Neffen Ludolf in Melbeck.

VERFÜGUNGEN ÜBER SACHGÜTER:

Bis auf 100 Lübische Mark hat der Testator alles Gut zusammen mit seiner Frau erarbeitet. Die restlichen Hinterlassenschaften, seien es Haus, Hof oder draußen oder drinnen, Kleinode, Silberschmuck, Geräte, Schulden - all dies gibt der Testator seiner gegenwärtigen Frau.

Siegler: Johann Garlop, Ludolf Tzerstede

Reinhardt, Testamente, S.460f, Nr.286

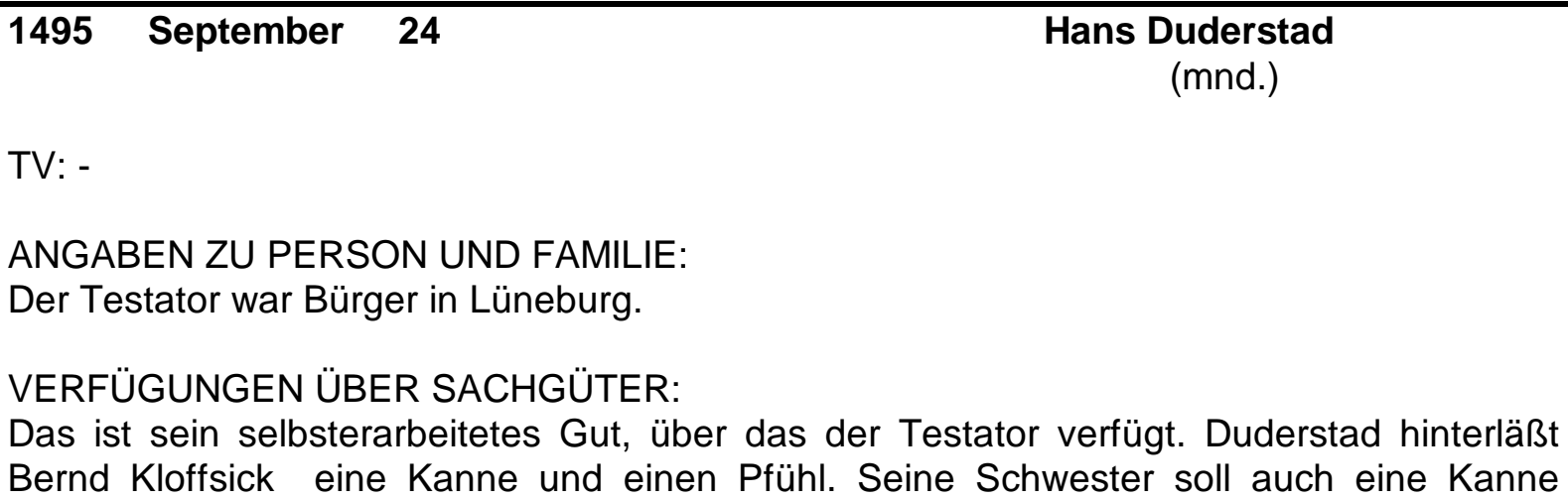

TV: -

ANGABEN ZU PERSON UND FAMILIE:

Der Testator war Bürger in Lüneburg.

VERFÜGUNGEN ÜBER SACHGÜTER:

Das ist sein selbsterarbeitetes Gut, über das der Testator verfügt. Duderstad hinterläßt Bernd Kloffsick eine Kanne und einen Pfühl. Seine Schwester soll auch eine Kanne haben. Meinhart im Kloster Heiligenthal erhält ein Paar Leinenlaken und einen Pfühl. Der 
Frau seines Bruders, Geseke, hinterläßt der Testator Holz und Späne, wie sie zur Feuerung dienen, und dazu eine Kanne und einen Pfühl. Das restliche Heergewät soll für Legate ad pias causas verwendet werden. Der restliche Nachlaß soll an Geseke Duderstadt fallen.

Siegler: Dietrich Wülsche, Meine Töbing

Papier mit aufgedrückten Siegeln

Reinhardt, Testamente, S.461f, Nr.287

\begin{tabular}{|ccc|c}
\hline 497 & Dezember 28 & $\begin{array}{c}\text { Dietrich Vloetwedel } \\
\text { (mnd.) }\end{array}$
\end{tabular}

TV: Lambert Radtbrock, der Abt; Hans Molre, der Wandschneider

ANGABEN ZU PERSON UND FAMILIE:

Der Testator, Bürger Lüneburgs, erwähnt seine Ehefrau.

VERFÜGUNGEN ÜBER SACHGÜTER:

Seiner Ehefrau Geseke hinterläßt der Testator sein jetziges Wohnhaus zu mit allem, was darinnen ist, und allem, was er besitzt.

Siegler: Heinrich Hoyemann

Das zweite Siegel ist abgefallen

Reinhardt, Testamente, S.463f, Nr.289

\section{\begin{tabular}{llll}
\hline 1497 & Juli 21 & Hans Rodenborg
\end{tabular} \\ (mnd.)}

TV: Roleff von Kalve, Priester, Jakob Schomaker, Bürgermeister, Meister Caspar, Stadtschreiber, Dietrich Moller, Luteke Reinstorp, Dietrich Mauricius

ANGABEN ZU PERSON UND FAMILIE:

Der Testator war Bürger Lüneburgs. Er erwähnt seine Frau Wypke, gemeinsame Kinder und einen Bruder sowie eine Schwester.

VERFÜGUNGEN ÜBER SACHGÜTER:

Der Testator wünscht, daß man seinen Bruder Gerd nach dem Tod des Testators mit Verpflegung und geziemender Kleidung und anderen Notwendigkeiten versorgt, wenn er den Testator überlebt.

Siegler: Dietrich Wülsche, Meine Töbing

Papier mit aufgedrückten Siegeln

Reinhardt, Testamente, S.462f, Nr.288 
TV: Laurenz König

ANGABEN ZU PERSON UND FAMILIE:

Die Testatorin war die Witwe Werneke Harendorps.

VERFÜGUNGEN ÜBER SACHGÜTER:

Die Nyenborgesche schuldet der Testatorin für Leinwand 6 Mark, die die Testamentsvollstrecker für die Ehre Gottes geben sollen.

Siegler: Johann Schellepeper. Das erste Siegel ist abgefallen.

Reinhardt, Testamente, S.464ff, Nr.290

\begin{tabular}{|ccc}
\hline 1499 & August 28 & $\begin{array}{c}\text { Hilleke Blickershusen } \\
\text { (mnd.) }\end{array}$
\end{tabular}

TV: Hans Croger der Ältere, der Ohm der Testatorin, Dirick Buldermanne, Hermen Krusen und Henning Hoppenhove, Bürger zu Lüneburg

Stirbt Hans Croger der Ältere, dann soll Hans Croger der Jüngere inm in das Amt folgen, danach der älteste Ältermann der St. Jakobsgilde. Stirbt Dirick Buldermann, soll ihm der älteste Kirchgeschworene von St. Johannis folgen. Stirbt Hans Kruse, dann soll ihm der älteste Ältermann der St. Jürgensgilde der Ackerleute folgen. Stirbt Henning Hoppenhove, dann soll ihm der älteste Kirchgeschworene von St. Gertrud folgen. Es sollen immer vier Testamentsvollstrecker sein.

ANGABEN ZU PERSON UND FAMILIE:

Die Testatorin war die Witwe Hans Blickershausens.

VERFÜGUNGEN ÜBER SACHGÜTER:

Ihre Testamentsvollstrecker sollen ein upstent von 30 Mark Pfennigen für den Kelch haben und drei Ornate, die die Testatorin für Messen im Großen Heiligen Geist gestiftet hat, so daß diese Stiftung nicht vergeht. Ihrem Ohm, Hans Croger dem Älteren, schenkt die Testatorin ein Deckbett und ihren besten silbernen Becher, einen Dreifuß und dazu alle Kannen und alle Geräte, die dazu gehören. Hans Croger der Alte erhält die Stühle und Bänke. Hans Croger dem Jüngeren hinterläßt die Testatorin ein Bett mit einem Pfühl, ein Tragbett, zehn Zinngefäße, ihre zwei größten Grapen, eine Senfmühle. Ihrer Magd Metteke schenkt die Testatorin zwei Betten und einen Pfühl, den die Magd bereits hat, die grüne Londoner Hoike der Testatorin, ihren grünen Leidenschen Rock und den braunen Unterrock. Die Testatorin hinterläßt ihrer Muhme Beke in Lasren die schwarze Weghoike und die beste lange Hoike, ferner gibt sie die Alltagsschaube der Gronebergeschen. Hans Blickershusen in Lübeck wird mit dem großen Grapen, vier Zinngefäßen und der neuen Stübchenzinnkanne bedacht, mit dem großen Handbecken, dem großen Handfaß und der silbernen Schale von fünf Mark Pfennigen oder ungefähr 7 1/2 Lot Gewicht eines halben Quentchens. Was die Testatorin hierüberhinaus an Hausgerade und Hausgerät hinterlassen wird, sollen sich Hans Croger der Jüngere, Hermen Burmester, seine Schwester Beke und Grete Westvale mit ihrem Bruder und ihren Schwestern und Cordt Focke teilen und sich darüber gütlich ausgleichen, der Testatorin dabei gedenken, und diese Aufteilung soll in Gegenwart der Testamentsvollstrecker geschehen. Eine u.a. aus diesem Haus gehende Rente in Höhe einer Mark stiftet die Testatorin dem Großen Heiligen Geist für Kohle für die Feuerschapen für die armen Leute im langen Haus; das 
vorvergabte Geld, zusammen zehn Mark Rente, ist unauslöslich. Eine Mark Rente für Kohlen für den Feuerschapen in St. Michaelis, den die Testatorin dorthin gegeben hat. Die Testamentsvollstrecker sollen weiterhin jährlich aus den rechten Einkünften des Testaments eine Mark Geldes dem Heiligen Geist auf dem Markt für Kohlen für den Feuerschapen stiften.

Siegler: Die Ratsherren Johann Schnewerdinge und Bartold Wittig Abschrift aus der 1. Hälfte des 16. Jahrhunderts

Reinhardt, Testamente, S.468ff, Nr.292

\begin{tabular}{|ccc}
1500 & Februar 1 & $\begin{array}{c}\text { Hans Holstenland } \\
\text { (mnd.) }\end{array}$
\end{tabular}

TV: Ludolf Reinstorf, Hermann Barum, Heinrich Krumstro und Hermann von dem Berge

ANGABEN ZU PERSON UND FAMILIE:

Der Testator bezeichnet sich als Bürger zu Lüneburg. In dem Testament ist die Rede von des Testators Ehefrau Geseke, seinem Bruder Andreas und dem Neffen Heinrich.

VERFÜGUNGEN ÜBER SACHGÜTER:

Was der Testator über das Vergabte hinaus an Gütern besitzt, nämlich an Rentenbriefen, an Hausgerade, an Hausrat, Kleinodien und Silberschmuck, das hinterläßt er seiner jetzigen Frau Geseke, damit sie es zeit ihres Lebens benutzen kann; sie soll diese Güter von des Testators Testamentsvollstreckern alle beschreiben lassen. Wenn sie stirbt, dann sollen die Güter sämtlich wieder an das Testament fallen; davon sollen die Testamentsvollstrecker, wo es ihnen am passendsten erscheint, eine Kommende von 60 Marken Rente stiften. Das Restliche sollen sie für die Ehre Gottes verwenden. Wenn des Testators Frau Kinder bekommt, die den Tod des Vaters überleben, dann soll dieses Testament machtlos sein und der gesamte Nachlaß soll an die Frau und beider Kinder fallen.

Siegler: Johann Döring, Hans Kruse, Ratsherren

Reinhardt, Testamente, S.472ff, Nr.293 



\section{Lüneburger Bildmaterial}

\section{Zum Thema:Schmuckstücke}

1. Agnus-Dei-Ostensorium, Mitte 15. Jahrhundert, Silber, graviert und teils vergoldet, $17,5 \mathrm{~cm} \times 8,4 \mathrm{~cm}$ (Fuß) $\times 5,8 \mathrm{~cm}$. Herkunft möglicherweise aus dem Hospital zum Heiligen Geist (E. MICHAEL, Führer Museum, S. 176f, H 47)

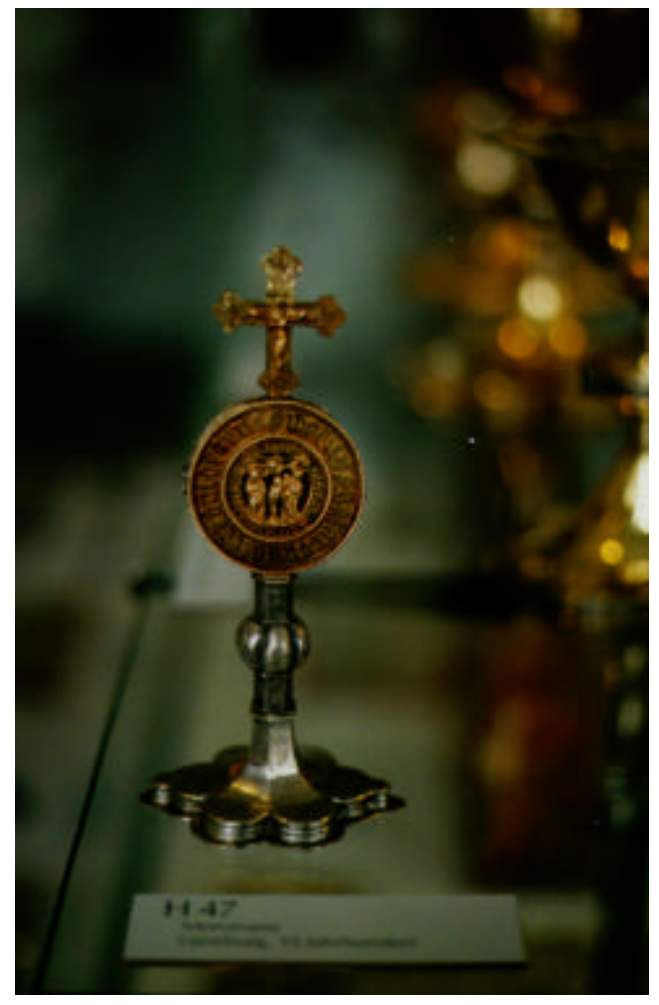

2. Anhänger, letztes Viertel des 15. Jahrhunderts, Silber, teilvergoldet, Durchmesser $6,1 \mathrm{~cm}$. Möglicherweise im Kontext der Agnus-Dei-Kapseln zu sehen (E. MICHAEL, Führer Museum, S. 167, H 35.1) Darstellung im Text S. $282 f$

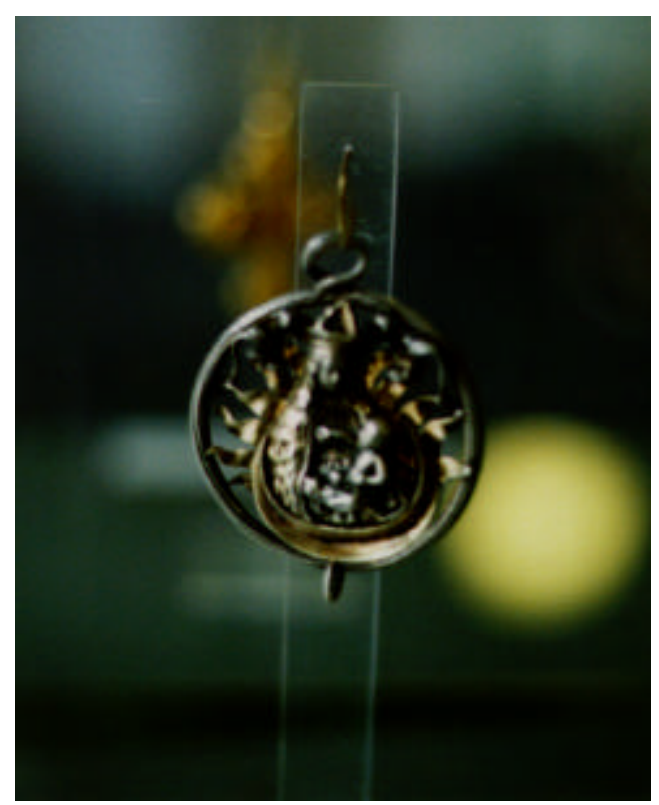


3. Agnus-Dei-Kapsel, letztes Drittel des 15. Jahrhunderts, Silber, teilvergoldet, Bergkristall, Höhe $1,7 \mathrm{~cm}$, Durchmesser $5,1 \mathrm{~cm}$ Herkunft möglicherweise aus einem Hospital oder der Ratskapelle (E. MICHAEL, Führer Museum, S. 167, H 35)

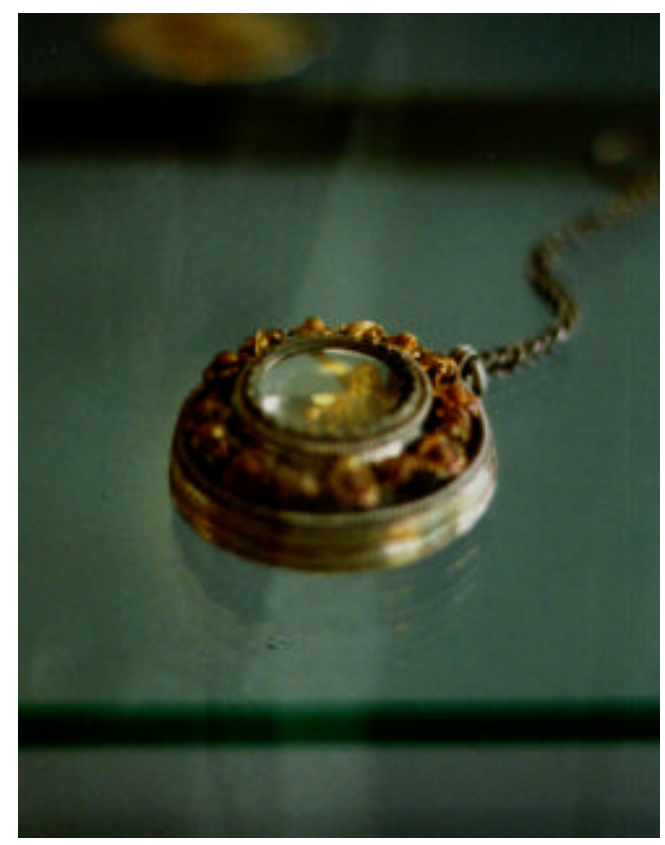

Zum Thema: (Privates) Andachtsbild

1. Andachtsbild, Westfalen, um 1530 , Pfeifenton, $70 \times 54 \mathrm{~cm}$. Als Herkunft wird die Kapelle des Hauses Am Sande 16 angegeben. (E. MICHAEL, Führer Museum, S. 90ff, E 54)

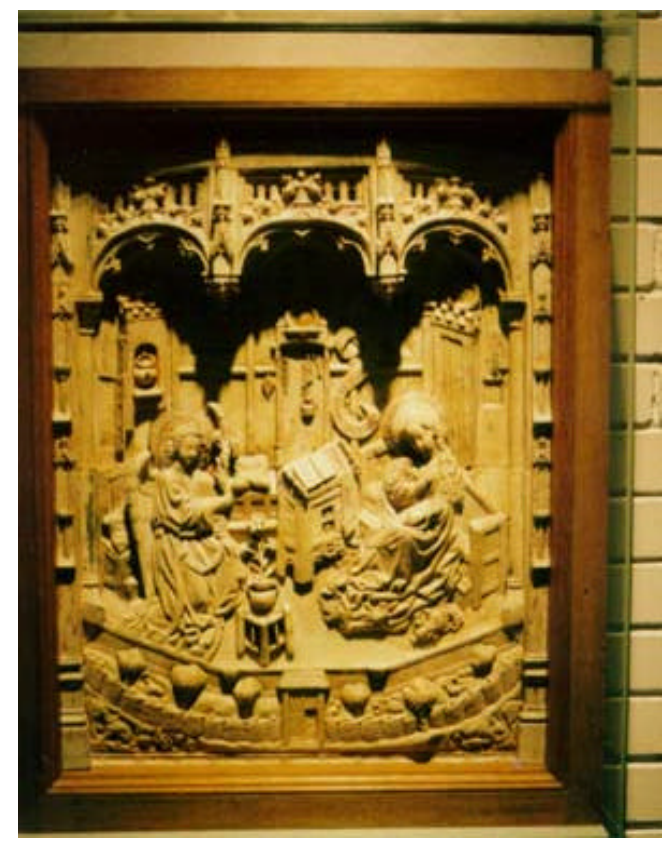


2. Pacificale, 1471, Bronze, Vergoldungsreste, $17,8 \times 8,3 \times 5,1 \mathrm{~cm}$. Der Goslarer Stiftsgeistliche Dietrich von dem Berge schenkt

1471 das ursprünglich mit Reliquien versehene Kußtäfelchen der Kirche zu Hittfeld, das zu den Besitzungen der Familie von dem Berge gehörte. (E. MICHAEL, Führer Museum, S. 35, A 27) Darstellung im Text S. $283 f$
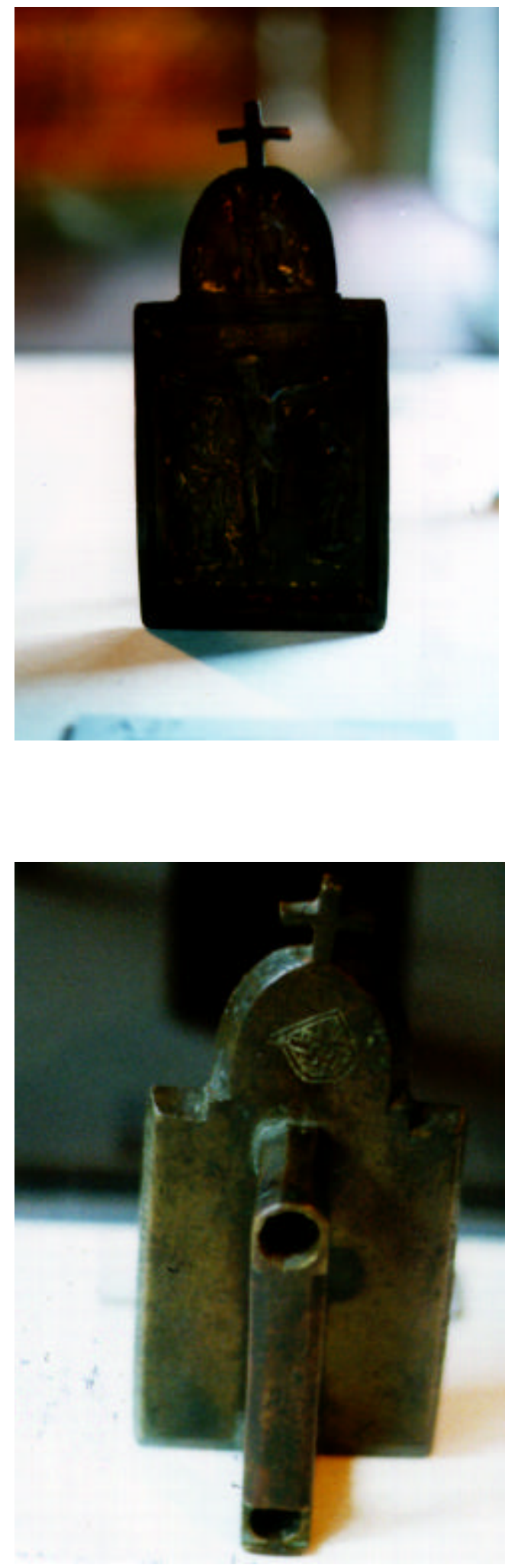


\section{Zum Thema: Bettzubehör und goldenes Sargtuch}

Die Darstellungen stammen aus der Lüneburger Bilderchronik aus den Jahren um 1595. Trotz der fast einhundertjährigen Zeitdifferenz zwischen Untersuchungszeitraum und Anfertigung des Aquarells darf die Bildquelle als Beleg dienen, denn die hier exemplarisch vorgeführten Realien waren im Lauf dieser einhundert Jahre keinen gravierenden Veränderungen ausgesetzt.

Darstellung des Todes und des Begräbnisses des Welfenherzogs Wilhelms, Papier, $32,5 \times 41,0 \mathrm{~cm}$. Die Todesdarstellung zeigt die verschieden großen Polster, das Bespannen der Matratze mit einem weißen Laken und das Einhüllen der kostbaren Überdecke mit einem Laken. Der Leichenzug zeigt den mit einem goldenen Sargtuch versehenen Sarg (möglicherweise Goldbrokat?). (E. MICHAEL, Führer Museum, S. 17, A 1; Darstellung „goldenes Sargtuch“ im Text S. 303)
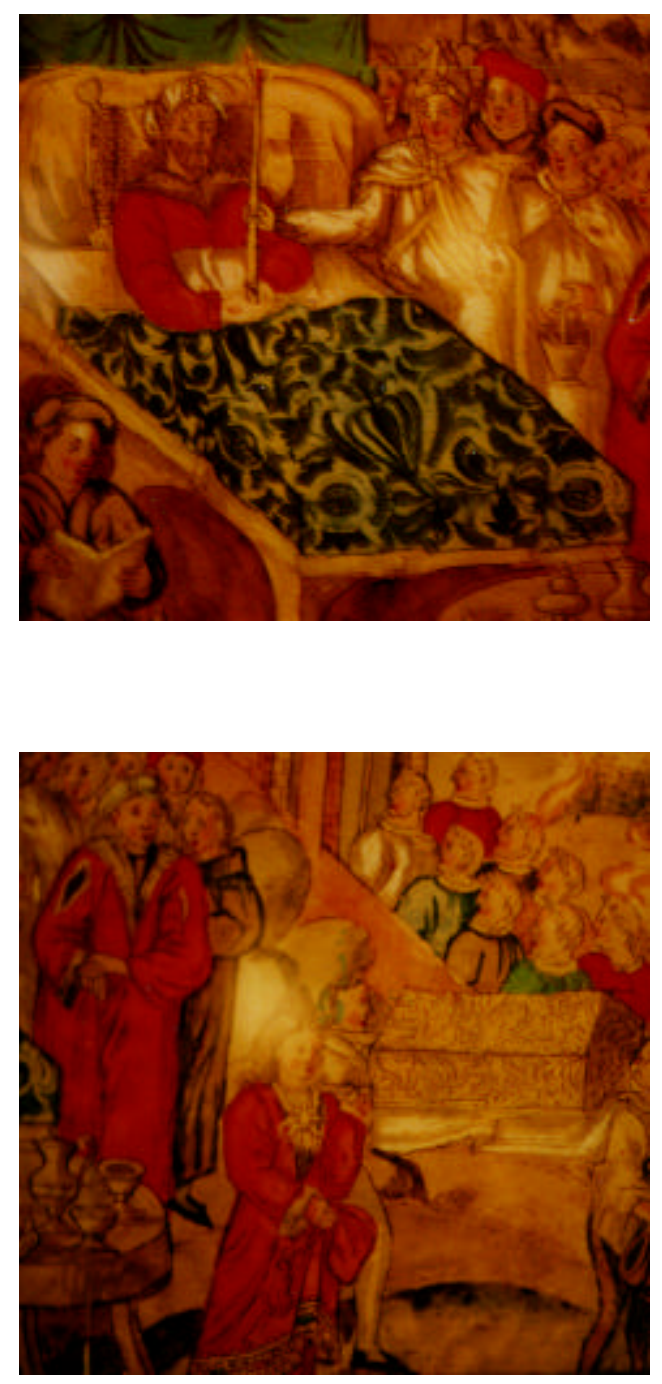
Zum Thema: Truhen

Vorderwand einer Truhe, um 1500, Eiche, rot bemalt, $87 \times 176 \mathrm{~cm}$. (E. MICHAEL, Führer Museum, S. 85, A 43)
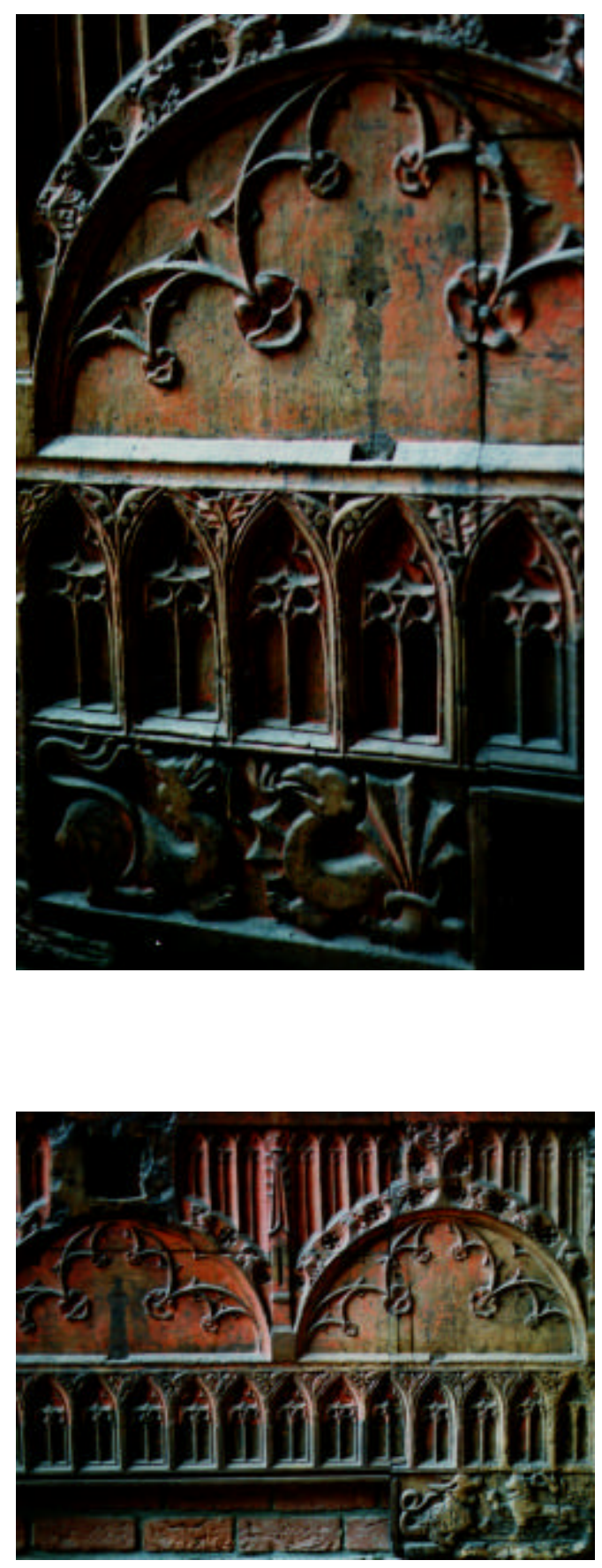


\section{Zum Thema: Schrankmobiliar und Beutelbuch}

1. Schrank, 15. Jahrhundert, Eiche, $203 \times 156 \times 63 \mathrm{~cm}$. Herkunft wohl aus dem Heilig Geist-Hospital (E. MICHAEL, Führer Museum, S. 85, E 44)

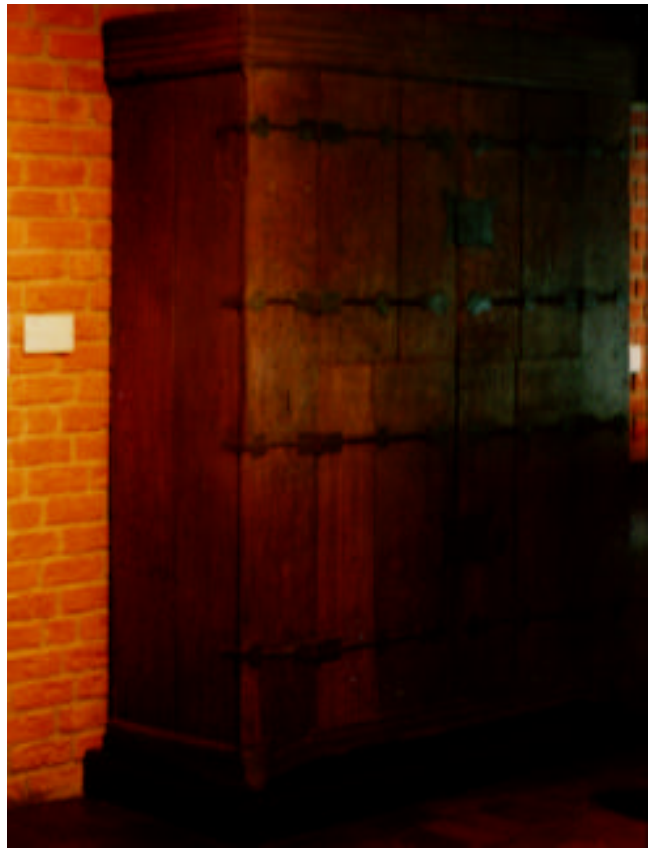

2. Hostienschrank, um 1510 , Eiche, bemalt, $245 \times 98 \times 36 \mathrm{~cm}$. Herkunft wohl aus dem Heilig-GeistHospital. Der unter dem Kreuz stehende Johannis hält in seiner rechten Hand ein Beutelbuch. (E. MICHAEL, Führer Museum, S. 178, H 53)

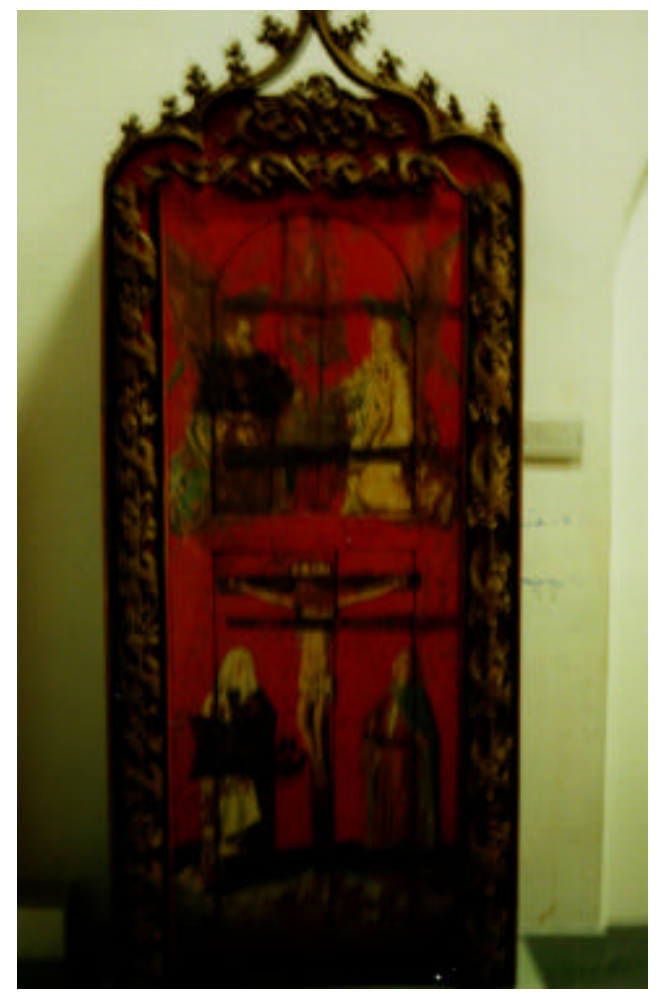




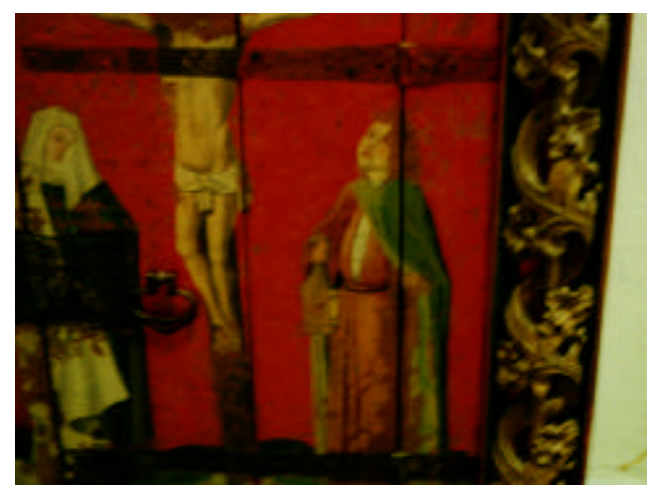

\section{Zum Thema: Tisch}

Falttisch, um 1330, Eiche, bemalt, eiserne Beschläge, $73 \times 658 \times 78 \mathrm{~cm}$. Herkunft wohl aus der Burg auf dem Kalkberg. (E. MICHAEL, Führer Museum, S. 21, A 4) Darstellung im Text S. 394f
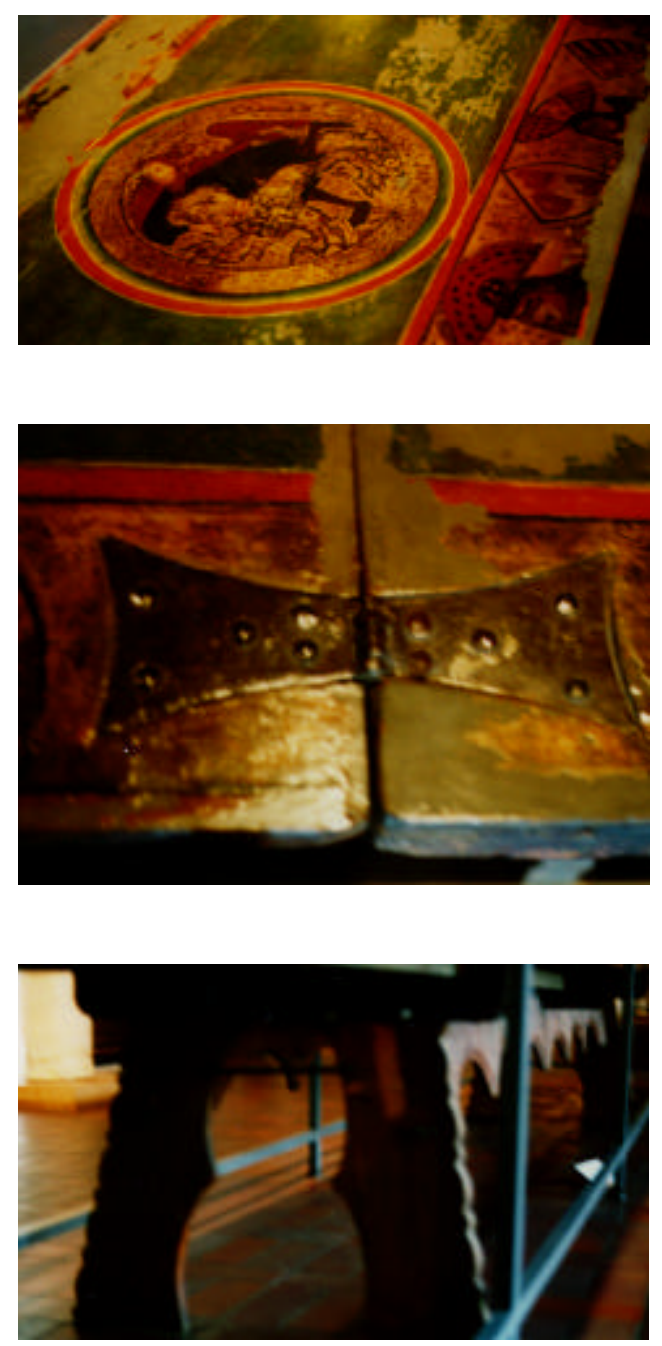
Verzeichnis der Abkürzungen:

$\begin{array}{ll}\text { AFGK } & \text { Archiv für Frankfurts Geschichte und Kunst } \\ \text { LSAK } & \text { Lübecker Schriften zur Archäologie und Kulturgeschichte } \\ \text { RDK } & \text { Reallexikon zur deutschen Kunstgeschichte } \\ \text { UB LG } & \text { Urkundenbuch der Stadt Lüneburg } \\ \text { ZAM } & \text { Zeitschrift für Archäologie des Mittelalters } \\ \text { ZRG GA } & \begin{array}{l}\text { Zeitschrift der Savigny-Stiftung für Rechtsgeschichte, } \\ \text { Germanistische Abteilung }\end{array} \\ \text { ZVhG } & \text { Zeitschrift des Vereins für hamburgische Geschichte } \\ \text { ZVLGA } & \text { Zeitschrift des Vereins für Lübeckische Geschichte und } \\ & \text { Altertumskunde }\end{array}$

\section{QUELLEN}

Stadtarchiv Lüneburg (StA LG)

- Urkunden; die Urkunden werden nach Formatgruppen (a, b, c) und Datum zitiert

- Registrum primum (R1), Signatur AB 15

U. REINHARDT, Testamente

Lüneburger Testamente des Mittelalters 1323-1500,

bearbeitet von Uta Reinhardt, (Manuskript)

\section{GEDRUCKTE QUELLEN UND REGESTEN:}

BRANDT, Ahasver von, Regesten der Lübecker Bürgertestamente des Mittelalters, Bd.I: 1278-1350, Bd.II: 1351-1363 (=Veröffentlichungen zur Geschichte der Hansestadt Lübeck, Bde. 18 und 24), Lübeck 1964, 1973.

LOOSE, Hans-Dieter, Hamburger Testamente 1351 bis 1400 (=Veröffentlichungen aus dem Staatsarchiv der Freien und Hansestadt Hamburg, Bd. XI), Hamburg 1970.

MACK, Dietrich, Testamente der Stadt Braunschweig. Teil I: Altstadt 1314-1411 Adenstede bis Holtnicker (=Beiträge zu Genealogien Braunschweiger Familien. Forschungsberichte zur Personen- und Sozialgeschichte der Stadt Braunschweig 3/I), Göttingen 1988.

MACK, Dietrich, Testamente der Stadt Braunschweig. Teil II: Altstadt 1314-1411 Dungelbeck bis Rike (=Beiträge zu Genealogien Braunschweiger Familien. Forschungsberichte zur Personen- und Sozialgeschichte der Stadt Braunschweig 3/II), Göttingen 1989.

REINHARDT, Uta, Lüneburger Testamente des Mittelalters 1323 bis 1500 (=Veröffentlichungen der Historischen Kommission für Niedersachsen und Bremen, Bd.37: Quellen und Untersuchungen zur Geschichte Niedersachsens im Mittelalter; Bd.22), Hannover 1996. 


\section{LITERATURVERZEICHNIS:}

ADERS, Günter, Das Testamentsrecht der Stadt Köln im Mittelalter (=Veröffentlichungen des Kölnischen Geschichtsvereins 8), Köln 1932.

ALLIK, Kadri-Rutt, Die Revaler Testamente aus dem 15. Jahrhundert (=unveröffentlichte Hausarbeit zur Erlangung des Magistergrades am Fachbereich Historisch-Philologische Wissenschaften der Universität Göttingen), Göttingen 1995.

AMMANN, Hektor, Deutschland und die Tuchindustrie Nordwesteuropas im Mittelalter, in: Wirtschaft und Gesellschaft (=Die Stadt des Mittelalters, Bd. 3), hg. v. Carl HAASE, Darmstadt 1973, S. 55-136; Erstveröffentl. in: Hansische Geschichtsblätter 72, S. 1-63.

APPUHN, Horst, Der Buchkasten aus dem Rathaus zu Lüneburg, in: Lüneburger Blätter, Heft 14, Lüneburg 1963, S. 5-21.

APPUHN, Horst, Das private Andachtsbild im Mittelalter an Hand der Funde des Klosters Wienhausen, in: Das Leben in der Stadt des Spätmittelalters (=Österreichische Akademie der Wissenschaften. Philosophisch-Historische Klasse, Sitzungsberichte Bd. 325; Veröffentlichungen des Instituts für mittelalterliche Realienkunde Österreichs, Bd.2), Wien 1977, S. 97-109.

APPUHN, Horst, Möbel des hohen und späten Mittelalters in den ehemaligen Frauenklöstern um Lüneburg, in: Klösterliche Sachkultur des Spätmittelalters (=Österreichische Akademie der Wissenschaften, Philosophisch-Historische Klasse, Sitzungsberichte Bd. 367, Veröffentlichungen des Instituts für mittelalterliche Realienkunde Österreichs, Bd. 3), Wien 1980 , S. 343-352.

APPUHN, Horst, Der Psalter. Eine Bilderhandschrift, Dortmund 1980.

APPUHN, Horst und Jürgen Wittstock, Mittelalterliche Hausmöbel in Norddeutschland, in: Kat. „Aus dem Alltag der mittelalterlichen Stadt“, Bremen 1982, S. 43-54.

APPUHN, Horst, Realienkunde und Kunstgewerbe des späten Mittelalters, in: Die Erforschung von Alltag und Sachkultur des Mittelalters. Methode-Ziel-Verwirklichung (=Österreichische Akademie der Wissenschaften, Philosophisch-Historische Klasse, Sitzungsberichte $\mathrm{Bd}$. 6, Veröffentlichungen des Instituts für mittelalterliche Realienkunde Österreichs Bd. 6 ), Wien 1984, S. 193-199.

APPUHN, Horst, Bildstickereien des Mittelalters in Kloster Lüne, Dortmund 1990/3.

APPUHN, Horst, Einführung in die Ikonographie der mittelalterlichen Kunst in Deutschland, Darmstadt 1991/4.

ARENDS, Dietrich, Zur Geschichte der Ratsapotheke Lüneburg, in: Pharmazeutische Rundschau, 2. Jahrgang, Nr. 8, 1960, Sonderdruck.

ARIES, Phillipe, Bilder zur Geschichte des Todes, München/Wien 1984.

ARIES, Phillipe, Geschichte des Todes, München 1987.

ARNOLD, Klaus, Frauen in den mittelalterlichen Hansestädten - Eine Annäherung an die Realität, in: Hansische Geschichtsblätter 108, 1990, S. 13-29.

AURENHAMMER, Hans und Adolf WEIS, „Andachtsbild“ , in: LThK, Bd. 1, Sp. $504 f$. 
BACHMANN, Karl, Die Rentner der Lüneburger Saline 1200-1370 (=Veröffentlichungen des Instituts für Historische Landesforschung der Universität Göttingen, Bd. 21), Göttingen 1983.

BÄNSCH, Birgit, Der Schatz der Goldenen Tafel zu Lüneburg bis 1235, in: Kat. „Heinrich der Löwe und seine Zeit“, München 1995, S. 313-328.

BAUR, Paul, Testament und Bürgerschaft. Alltagsleben und Sachkultur im spätmittelalterlichen Konstanz (=Konstanzer Geschichts- und Rechtsquellen XXXI), Sigmaringen 1989.

BEISSEL, Stephan, Die Verehrung der Heiligen und ihrer Reliquien in Deutschland im Mittelalter (unveränderter reprographischer Nachdruck der Originalausgabe von 1890 und 1892), Darmstadt 1991.

BEHR, Hans-Joachim, Der Convent der blauen Beginen in Lüneburg, in: Lüneburger Blätter, Heft 11/12, Lüneburg 1961, S. 181-193.

BENKER, Gertrud, Bürgerliches Wohnen. Städtische Wohnkultur, München 1984.

BETHE, Hellmuth, „Edelsteine“, in: RDK, Bd. 2, Sp. 714-742.

BINDING, G., „Armarium“, in: Lexikon des Mittelalters, Bd. I, Sp. 964.

BLASCKE, Rainer, Die Meister der Flügelmalereien der Lüneburger Goldenen Tafel, in: Niederdeutsche Beiträge zur Kunstgeschichte, Bd. 17, 1978, S. 61-86.

BODEMANN, Eduard, Die älteren Zunfturkunden der Stadt Lüneburg (=Quellen und Darstellungen zur Geschichte Niedersachsens, Bd. 1), Hannover 1883.

BOEHN, Otto von, Der Lederkasten im Lüneburger Rathausmuseum, in: Lüneburger Blätter, Heft 2, Lüneburg 1951, S.59-64.

BOOCKMANN, Hartmut, Leben und Sterben in einer mittelalterlichen Stadt. Über ein Göttinger Testament des 15. Jahrhunderts, Göttingen 1984.

BOOCKMANN, Hartmut, Dreimal Kulturgeschichte, Alltagsgeschichte, Geschichte der materiellen Kultur, in: Zeitschrift für historische Forschung 3, 1986, S. 201-215.

BOOCKMANN Hartmut, Die Stadt im späten Mittelalter, München 1986.

BOOCKMANN, Hartmut, Die Lebenswelt eines spätmittelalterlichen Juristen. Das Testament des doctor legum Johannes Seelberg, in: Philologie als Kulturwissenschaft, Festschrift für Karl Stackmann, hg. v. Ludger GRENZMANN, Hubert HERKAMMER und Dieter WUTTKE, Göttingen 1987, S. 287-305.

BOOCKMANN, Hartmut, Das Leben in städtischen Häusern um 1500, in: Mensch und Umwelt im Mittelalter, hg. v. B. HERRMANN, Wiebaden 1996 (zuerst Stuttgart 1986), S. 194206.

BORSCHEID, Peter, Alltagsgeschichte - Modetorheit oder neues Tor zur Vergangenheit, in: Wolfgang SCHIEDER, Volker SELLIN, Soziales Verhalten und soziale Aktionsformen in der Geschichte (=Sozialgeschichte in Deutschland, Bd.III), Göttingen 1987, S. 78-100.

BRANDT, Ahasver von, Mittelalterliche Bürgertestamente. Neuerschlossene Quellen zur Geschichte der materiellen und geistigen Kultur (=Sitzungsberichte der Heidelberger Akademie der Wissenschaften, Phil.-Hist. Klasse), Heidelberg 1973, 3, S. 5-32; erneuter 
Druck in: Lübeck, Hanse, Nordeuropa. Gedächtnisschrift für Ahasver von Brandt, hg. im Auftrag des Hansischen Geschichtsvereins von Klaus FRIEDLAND und Rolf Sprandel, Köln 1979, S.336-358.

BRAUDEL, Fernand, Der Alltag (=Sozialgeschichte des 15. - 18. Jahrhunderts, Bd.1), München 1990.

BRAUN, Joseph, „Agnus Dei“, in: RDK, Bd. I, Sp. 212-214.

BRAUN, Joseph, „Altardecke“, in: RDK, Bd. I, Sp. 489.

BRAUN, Joseph, „Altargerät“, in: RDK, Bd. I, Sp. 489-492.

BRINKMANN, Bodo, Zur Rolle der Stundenbücher in der Jenseitsfürsorge, in: Kat. „HimmelHölle-Fegefeuer“, München 1994, S. 91-100.

BRÜBACH, Nils, Kauffschlag und Herrenmesse - Messen und Jahrmärkte und ihre Funktion für den Raum zwischen Weser und Elbe, in: Kat. „Hanse•Städte•Bünde“, Magdeburg 1996, S. 375-395.

BÜTTNER, J. H., Genealogie- oder Stamm- und Geschlechter-Register der vornehmsten adligen Patriziergeschlechter, Lüneburg 1704.

BUNGENSTOCK, W., „Gerade“, in: Handwörterbuch zur Rechtsgeschichte, hg. v. A. ERLER und E. KAUFMANN, Bd. 1, Berlin 1964, Sp. 1527-1530.

BURSCHE, Stefan, Das Lüneburger Ratssilber (=Kunstgewerbemuseum Berlin, Bestandskatalog XVI), Berlin 1990.

CRAMER, Thomas, Geschichte der deutschen Literatur im späten Mittelalter (=Geschichte der deutschen Literatur im Mittelalter, Bd.3), München 1990.

DAXELMÜLLER, Christoph, Heil- und Volksglaube, in: Kat. „Aus dem Alltag der mittelalterlichen Stadt“", S. 181-192.

DELORT, ROBERT, Geschichte des mittelalterlichen Alltags. Theorie-Methoden-Bilanz der Forschung, in: Mensch und Objekt im Mittelalter und in der frühen Neuzeit. Leben-AlltagKultur (=Österreichische Akademie der Wissenschaften, Philosophisch-Historische Klasse, Sitzungsberichte, Bd.568, Veröffentlichungen des Instituts für mittelalterliche Realienkunde Österreichs Bd. 13 ), Wien 1990, S. 53-66.

DELORT, Robert, „Pelze“, in: Lexikon des Mittelalters, Bd. VI, Sp. 1866-1868.

DENEKE, Bernward, „Möbel“, in: Lexikon des Mittelalters, Bd. VI, Sp. 699-703.

DEXEL, Walter, Das Hausgerät Mitteleuropas. Wesen und Wandel der Formen in zwei Jahrtausenden, Berlin 1962.

DIEDERICHS, Urs Justus, Der Aufruhr von 1454-1456 in der Stadt Lüneburg. Eine prosophographische Untersuchung, Kiel 1981.

DIMT, Günter, Haus und Wohnung zwischen Mittelalter und Neuzeit am Beispiel Oberösterreichs, in: Haus und Familie in der spätmittelalterlichen Stadt, hg. v. Alfred HAVERKAMP, Köln/Wien 1984, S. 66-98. 
K. DINGELSTEDT, „Betnuß“, in: RDK, Bd. II, Sp. 371-377.

DIRLMEIER, Ulf, Untersuchungen zu Einkommensverhältnissen und Lebenshaltungskosten in oberdeutschen Städten des Spätmittelalters (=Abhandlungen der Heidelberger Akademie der Wissenschaften, Philosophisch-Historische Klasse 1978, 1); Heidelberg 1978.

DIRLMEIER, Ulf, Realienkunde und mittelalterliche Wirtschaftsgeschichte Deutschlands, in: Die Erforschung von Alltag und Sachkultur des Mittelalters. Methode-Ziel-Verwirklichung (=Österreichische Akademie der Wissenschaften, Philosophisch-Historische Klasse, Sitzungsberichte $\mathrm{Bd}$. 6, Veröffentlichungen des Instituts für mittelalterliche Realienkunde Österreichs Bd. 6), Wien 1984, S. 122-128.

DIRLMEIER, Ulf, Alltag, materielle Kultur, Lebensgewohnheiten im Spiegel spätmittelalterlicher und frühneuzeitlicher Abrechnungen, in: Mensch und Objekt im Mittelalter und in der frühen Neuzeit. Leben-Alltag-Kultur (=Österreichische Akademie der Wissenschaften, Philosophisch-Historische Klasse, Sitzungsberichte Bd. 568 Veröffentlichungen des Instituts für mittelalterliche Realienkunde Österreichs Bd. 13), Wien 1990, S. 157-180.

DRESCHER, Hans, Zu den bronzenen Grapen des 12. und 16. Jahrhunderts aus Nordwestdeutschland, in: Kat. „Aus dem Alltag der mittelalterlichen Stadt“, Bremen 1982, S. 157-174.

DUBY, Georges, Geschichte des privaten Lebens. Vom Feudalzeitalter zur Renaissance (=Geschichte des privaten Lebens, Bd. 2), Frankfurt a. M. 1990.

DÜRIG, Walter, „Agnus Dei“ - Absatz III: A.D. als Sakramentale, in: LThK, Bd. 1, Sp. $303 f$.

EBEL, Wilhelm, Über die rechtsschöpferische Leistung des mittelalterlichen deutschen Bürgertums, in: Untersuchungen zur gesellschaftlichen Struktur der mittelalterlichen Städte in Europa, Sigmaringen 1974, S. 241-258.

EBENBAUER, Alfred, Antike Stoffe, in: Epische Stoffe des Mittelalters (=Kröners Taschenausgabe, Bd. 483), hg. v. Volker MERTENS und Ulrich MÜLLER, Stuttgart 1984, S. 247-289.

EISENBARTH, Liselotte Constanze, Kleiderordnungen der deutschen städte zwischen 1350 und 1700 (=Göttinger Bausteine zur Geschichtswissenschaft 32), Göttingen/Berlin/Frankfurt a.M. 1962.

ELBERN, Viktor H., „Kelch“, in: LThK, Bd. 6, Sp. 104-106.

ELLERMEYER, Jürgen, „Schichtung“ und „Sozialstruktur“ in spätmittelalterlichen Städten. Zur Verwendbarbeit sozialwissenschaftlicher Kategorien in historischer Forschung, in: Gechichte und Gesellschaft, 6/1980, S. 125-149.

ENNEN, Edith, Stadt und Schule in ihrem wechselseitigen Verhältnis vornehmlich im Mittelalter, in: Die Stadt des Mittelalters, hg. v. Carl HAASE, Bd. 3, Darmstadt 1976, S. 455479.

ENNEN, Edith, Die europäische Stadt im Spätmittelalter, München 1994, 5. erweiterte und überarb. 4. Auflage.

ENNEN, Edith, Frauen im Mittelalter, München 1985, 2. Auflage. 
ERDMANN, Wolfgang und Horst NITSCH, Spätmittelalterliche und frühneuzeitliche Perlen aus einer Kloake der Fronerei auf dem Schragen zu Lübeck, in. LSAK, Bd. 12, Bonn 1986, S. 137-165.

ERSKINE CLEMENT, Clara, Legendary and Mythological Art (Erstveröffentlichung als A Handbook of Legendary and Mythological Art, New York 1876), London 1994.

EULER, L. H., Geschichte der Testamente in Frankfurt, in: AFGK, Heft 5, 1853, S.1-48.

FALK, Alfred, Haus, Wohnen und Hausrat - Pött un Pann, in: Kat. „Die Hanse“, Bd. 1, Hamburg 1989, S. 400f.

FISCHER, Irene, Die theologischen Handschriften (=Handschriften der Ratsbücherei Lüneburg, Bd.II), Wiesbaden 1972.

FRESSEL, Hans, Do was tho Luneborch grote Pestilente. Medizin und Seuchenbekämpfung im Mittelalter, in: Beilage der Landeszeitung, 19./20. August 1989, 44. Jahrgang, Nr. 192, S. 10.

GEHRKE, Dietmar und Eckhard MICHEAL, Museum für das Fürstentum Lüneburg (=museum, Ausgabe 9/1991), Braunschweig 1991.

GELDNER, Ferdinand, Inkunabelkunde (=Elemente des Buch- und Bibliothekswesens, Bd.5), Wiesbaden 1978.

GIERATHS, G., „Peregrinus“, in: LThK, Bd. 8, Sp. 270.

GLADEN, Jutta, Testamente - Spiegel spätmittelalterlichen Lebens und Wirkens, in: Kat. „Hanse•Städte•Bünde“, Magdeburg 1996, S. 518-524.

GMELIN, Hans Georg, Spätgotische Tafelmalerei in Niedersachsen und Bremen, Hannover 1974.

GOETZ, Hans-Werner, Geschichte des mittelalterlichen Alltags. Theorie-Methoden-Bilanz der Forschung, in: Mensch und Objekt im Mittelalter und in der frühen Neuzeit. Leben-AlltagKultur (=Österreichische Akademie der Wissenschaften, Philosophisch-Historische Klasse, Sitzungsberichte Bd.568, Veröffentlichungen des Instituts für mittelalterliche Realienkunde Österreichs Bd. 13), Wien 1990, S. 67-102.

GRAMS-THIEME, M., „Koralle“, in: Lexikon des Mittelalters, Bd. V, Sp. $1441 f$.

GROEBNER, Valentin, Ökonomie ohne Haus. Zum Wirtschaften armer Leute in Nürnberg am Ende des 15. Jahrhunderts (=Veröffentlichungen des Max-Planck-Instituts für Geschichte 108), Göttingen 1993.

HAMMEL-KIESOW, Rolf, Michael NORTH und Stuart JENKS, Außenbeziehungen der sächsischen Städte. Lübeck-Hamburg-Übersee, in: Kat. „Hanse•Städte•Bünde“, Magdeburg 1996, S. 338-374.

M. HASSE, Neues Hausgerät, neue Häuser, neue Kleider - eine Betrachtung der städtischen Kultur im 13. und 14. Jahrhundert sowie ein Katalog der metallenen Hausgeräte, in: ZAM 7/1979, S. 7-83.

HASSE, Max, Die Bedeutung des metallenen Hausgeräts für die Bürger des 13. und 14. Jahrhunderts, in: LSAK, Bd.4, Bonn 1980, S. 133-138. 
HASSE, Max, Kleinbildwerke in deutschen und skandinavischen Testamenten des 13., 14. und frühen 15. Jahrhunderts, in: Niederdeutsche Beiträge zur Kunstgeschichte, Bd.20, 1981, S. 60-72.

HAVERKAMP, Alfred, Haus und Familie in der spätmittelalterlichen Stadt (=Städteforschung: Reihe A, Darst. 18), Köln/Wien 1984.

HEERS, Jacques, Vom Mummenschanz zum Machttheater. Europäische Festkultur im Mittelalter, Frankfurt a. M. 1986.

HEIMPEL, Hermann, Auf neuen Wegen der Wirtschaftsgeschichte, in: Wirtschaft und Gesellschaft (=Die Stadt des Mittelalters, Bd. 3), hg. v. Carl HAASE, Darmstadt 1973, S. 9ff; Erstveröffentl. in: Vergangenheit und Gegenwart 23, 1933, S. 495-515.

HEYNE, Moritz, Das deutsche Wohnungswesen von den ältesten geschichtlichen Zeiten bis zum 16. Jahrhundert (=Fünf Bücher deutscher Hausaltertümer Wohnungswesen von den ältesten geschichtlichen Zeiten bis zum 16. Jahrhundert, Bd. 1), Leipzig 1889.

HEYNE, Moritz, Das deutsche Nahrungswesen von den ältesten geschichtlichen Zeiten bis zum 16. Jahrhundert (=Fünf Bücher deutscher Hausaltertümer Wohnungswesen von den ältesten geschichtlichen Zeiten bis zum 16. Jahrhundert, Bd. 2), Leipzig 1901.

HEYNE, Moritz, Körperpflege und Kleidung bei den Deutschen von den ältesten geschichtlichen Zeiten bis zum 16. Jahrhundert (=Fünf Bücher deutscher Hausaltertümer Wohnungswesen von den ältesten geschichtlichen Zeiten bis zum 16. Jahrhundert, Bd. 3), Leipzig 1902.

HÖMBERG, Wolfgang, Spätmittelalterliche Bronzemörser aus Norddeutschland, in: Kat. „Aus dem Alltag der mittelalterlichen Stadt", S. 147-155.

HOFSTÄTTER, Hans, Spätes Mittelalter (=Kunst im Bild, Bd. 18), München o.J..

HOLBACH, Rudolf, Inventar und Testament des Scholaster Arnold von Hohenecken (†1422). Mobilbesitz und materielle Kultur, Mentalität und persönliche Bindung eines Trierer Prälaten im Spätmittelalter, in: Kurtrierisches Jahrbuch 19, 1979, S. 111-150.

HUIZINGA, Johan, Herbst des Mittelalters. Studien über Lebens- und Geistesformen des 14. und 15. Jahrhunderts in Frankreich und in den Niederlanden (=Kröners Taschenausgabe Bd. 204), Stuttgart 1975.

HUNDSBICHLER, Helmut, Kleidung, in: Alltag im Spätmittelalter, hg. v. Harry KÜHNEL, Graz/Wien/Köln 1984, S. 232-253.

HUNDSBICHLER, Helmut, Wohnen, in: Alltag im Spätmittelalter, hg. v. Harry KÜHNEL, Graz/Wien/Köln 1984, S. 254-270.

ISENMANN, Eberhard, Die deutsche Stadt im Spätmittelalter 1250-1500. Stadtgestalt, Recht, Stadtregiment, Kirche, Gesellschaft, Wirtschaft, Stuttgart 1988.

JAACKS, Gisela, Städtische Kleidung im Mittelalter, in: Kat. „Aus dem Alltag der mittelalterlichen Stadt“, Bremen 1982, S. 219-232.

JAACKS, Gisela, Bekleidung in den Hansestädten, in: Kat. „Die Hanse“, Bd. 1, Hamburg 1989, S. 402-405. 
JAACKS, Gisela, Seidenes Bekleidungsbeiwerk aus den Lübecker Altstadtgrabungen, in: LSAK 23, 1993, S. 295-301.

JAACKS, Gisela, Kleidung und Textil im Oldenburger Sachsenspiegel, in: Kat. „der sassen speyghel. Sachsenspiegel - Recht - Alltag“, Bd. 2, Oldenburg 1995, S. 399-410.

JARITZ, Gerhard, Die realienkundliche Aussage der sogenannten „Wiener Testamentsbücher", in: Das Leben in der Stadt des Spätmittelalters (=Österreichische Akademie der Wissenschaften. Philosophisch-Historische Klasse, Sitzungsberichte 325; Veröffentlichungen des Instituts für mittelalterliche Realienkunde Österreichs, Bd.2), Wien 1977, S. 171-190.

JARITZ, Gerhard, Zur Lebenshaltung in niederösterreichischen Kleinstädten während des späten Mittelalters, in: Festschrift für Friedrich Hausmann, hg. v. Herwig EBNER, Graz 1977, S. 249-264.

JARITZ, Gerhard, Seelenheil und Sachkultur. Gedanken zur Beziehung Mensch-Objekt im späten Mittelalter, in: Europäische Sachkultur. Gedenkschrift aus Anlaß des 10jährigen Bestehens des Instituts für mittelalterliche Realienkunde, hg. v. Harry KÜHNEL (=Österreichische Akademie der Wissenschaften. Philosophisch-Historische Klasse, Sitzungsberichte 374; Veröffentlichungen des Instituts für mittelalterliche Realienkunde Österreichs, Bd.4), Wien 1980, S. 57-81.

JARITZ, Gerhard, Österreichische Bürgertestamente als Quelle zur Erforschung städtischer Lebensformen des Spätmittelalters, in: Jahrbuch für Geschichte des Feudalismus, Bd.8, 1984 , S. 249-264.

JARITZ, Gerhard, Mittelalterliche Realienkunde: Quellenbefund und Quelleninterpretation, in: Die Erforschung von Alltag und Sachkultur des Mittelalters. Methode-Ziel-Verwirklichung. (=Österreichische Akademie der Wissenschaften, Philosophisch-Historische Klasse, Sitzungsberichte 433; Veröffentlichungen des Instituts für mittelalterliche Realienkunde Österreichs Bd. 6), Wien 1984, S. 33-44.

JARITZ, Gerhard, Mittelalterliche Realienkunde und Fragen von Terminologie und Typologie. Probleme, Bemerkungen und Vorschläge am Beispiel der Kleidung, in: Terminologie und Typologie mittelalterlicher Sachgüter: Das Beispiel der Kleidung (=Österreichische Akademie der Wissenschaften, Philosophisch-Historische Klasse, Sitzungsberichte 511, Veröffentlichungen des Instituts für mittelalterliche Realienkunde Österreichs Bd. 10), Wien 1988, S. 7-19.

JARITZ, Gerhard, Zwischen Augenblick und Ewigkeit. Einführung in die Alltagsgeschichte des Mittelalters, Wien 1989.

JARITZ, Gerhard, Religiöse Stiftungen als Indikator der Entwicklung materieller Kultur im Mittelalter, in: Materielle Kultur und religiöse Stiftung im Spätmittelalter, hg. v. H. APPELT (=Österreichische Akademie der Wissenschaften. Philosophisch-Historische Klasse, Sitzungsberichte 554; Veröffentlichungen des Instituts für mittelalterliche Realienkunde Österreichs, Bd. 12), Wien 1990, S. 13-35.

JELZER, Peter, Jenseitsmodelle und Jenseitsvorsorge, in: Kat. „Himmel-Hölle-Fegefeuer, S. 13-26.

KASHSNITZ, Rainer, Formen mittelalterlicher Gläser, in: Kat. „Aus dem Wirtshaus zum Wilden Mann“, Nürnberg 1984, S. 33-56. 
KALKMANN, Ludolf, Zur Geschichte der hamburgischen Testamente, in: ZVhG 7, 1883, S.193-202.

Katalog „Das Lüneburger Ratssilber“, bearb. v. Horst APPUHN, Lüneburg 1954.

Kat. „Das Schnütgen-Museum. Eine Auswahl“, Köln 1964/3.

Katalog „Gotik in Österreich“, hg. v. Harry KÜHNEL, Krems an der Donau 1967.

Katalog „Aus dem Alltag der mittelalterlichen Stadt“ Handbuch zur Sonderausstellung im Bremer Landesmuseum für Kunst und Kulturgeschichte (Focke-Museum) (=Hefte des FockeMuseums 62), Bremen 1982.

Katalog „Weiße Westen - Rote Roben. Von den Farbordnungen des Mittelalters zum individuellen Farbgeschmack" (=Katalog zur Sonderausstellung der Staatlichen Museen Preußischer Kulturbesitz Berlin. Museum für Völkerkunde und Museum für Deutsche Volkskunde), hg. v. Heide MÜLLER und Heide NIXDORF, Berlin 1983.

Katalog „Aus dem Wirtshaus zum Wilden Mann. Funde aus dem mittelalterlichen Nürnberg“, hg. v. Rainer BRANDL und Rainer KAHSNITZ, Nürnberg 1984.

Katalog „STADT IM WANDEL“, Kunst und Kultur des Bürgertums in Norddeutschland 11501650, hg. v. Cord MECKSEPER, 4. Bde., Stuttgart-Bad Cannstadt 1985.

Katalog „Das ritterliche Basel. Zum 700. Todestag Konrads von Würzburg“, hg. v. Christian Schmid-Cadalbert, Basel 1987.

Katalog „Die Hanse. Lebenswirklichkeit und Mythos“, hg. v. Jörgen BRACKER, 2. Bde., Hamburg 1989.

Katalog "Geschichte des Alters in ihren Zeugnissen von der Antike bis zur Gegenwart" (=Veröffentlichungen des Braunschweigischen Landesmuseums 72), hg. v. Gerd BIEGEL, Braunschweig 1993.

Katalog „700 Jahre Paulinerkirche“, hg. v. Elmar MITTELER, Göttingen 1994.

Katalog „Himmel-Hölle-Fegefeuer. Das Jenseits im Mittelalter“, hg. v. Peter JELZER, München 1994.

Kat. „Eines Fürsten Traum. Meinhard II.-Das Werden Tirols“, Dorf Tirol.Innsbruck 1995.

Katalog „Heinrich der Löwe und seine Zeit. Herrschaft und Repräsentation der Welfen 11251235“, hg. v. Jochen LUCKHARDT und Franz NIEHOFF, 3. Bde., München 1995.

Katalog „der sassen speyghel. Sachsenspiegel - Recht - Alltag“, hg. v. E. KOOLMAN, E. GÄSSLER, F. SCHEELE und M. FANSA, 2. Bde., Oldenburg 1995.

Katalog „Hanse•Städte•Bünde. Die sächsischen Städte zwischen Elbe und Weser um 1500“, hg. v. Matthias PUHLE, 2. Bde., Magdeburg 1996.

KEMPERDICK, Stefan, Zum Werk des Johannes Bornemann. Überlegungen zu Chronologie und Vorbildern, in: Niederdeutsche Beiträge zur Kunstgeschichte, Bd. 33, 1994, S. 57-86.

KLEINHANS, A., „Nikolaus von Lyra“, in: LThK, Bd.7, 1986, S. $992 f$. 
KLONDER, Andrej, Geschichte der materiellen Kultur. Theorie und Praxis der Forschungen, in: Die Erforschung von Alltag und Sachkultur des Mittelalters. Methode-Ziel-Verwirklichung (=Österreichische Akademie der Wissenschaften, Philosophisch-Historische Klasse, Sitzungsberichte, Bd. 6), hg. v. H. APPELT, Wien 1984, S. 14-16.

KLONDER, Andrej, Geschichte der materiellen Kultur des Mittelalters und der Frühneuzeit. Theorie-Methoden-Forschungsbilanz, in: Mensch und Objekt im Mittelalter und in der frühen Neuzeit. Leben-Alltag-Kultur (=Österreichische Akademie der Wissenschaften, Philosophisch-Historische Klasse, Sitzungsberichte, Bd.568), hg. v. H. APPELT, Wien 1990, S.23-36.

KLOSTERBERG, Brigitte, Zur Ehre Gottes und zum Wohl der Familie: Kölner Testamente von Laien und Klerikern im Spätmittelalter (=Kölner Schriften zu Geschichte und Kultur, Bd.22), Köln 1995.

KOCHER, Gernot, Rechtsgeschichte und mittelalterliche Realienkunde, in: Die Erforschung von Alltag und Sachkultur des Mittelalters. Methode-Ziel-Verwirklichung (=Österreichische Akademie der Wissenschaften, Philosophisch-Historische Klasse, Sitzungsberichte, Bd. 6), hg. v. H. APPELT, Wien 1984, S. 99-121.

KÖBLER, Gerhard, Das Familienrecht in der spätmittelalterlichen Stadt, in: Haus und Familie in der spätmittelalterlichen Stadt, hg. v. Alfred HAVERKAMP, Köln/Wien 1984, S. 136-160.

KOLMER, Lothar, Spätmittelalterliche Testamente. Forschungsergebnisse und Forschungsziele. Regensburger Testamente im Vergleich, in: Zeitschrift für bayerische Landesgeschichte 52, 1990, S. 475-500.

KRAUT, Wilhelm Theodor, Das alte Stadtrecht von Lüneburg, Göttingen 1846.

KRONSHAGE, Walter, Hausinventare Göttinger Bürger im ausgehenden Mittelalter, in: Göttinger Jahrbuch, Nr. 4, 1955/56, Göttingen 1956, S. 76-85.

KRÜGER, Franz, Skulpturen und Formsteine (=Führer durch die Sammlungen des Museumsvereins für das Fürstentum Lüneburg, Bd. V, 1), Lüneburg 1908.

KRÜGER, Franz und Wilhelm Reinecke (Barb.), Die Kunstdenkmale der Stadt Lüneburg (=Neudruck des gesamten Werkes 1889-1976, hg. in Zusammenarbeit mit dem Niedersächsischen Landesverwaltungsamt-Institut für Denkmalpflege-Hannover, Bd. 34), Osnabrück 1980.

KUBINYI, Andras, Die Rolle interdisziplinärer Forschung für die mittelalterliche Realienkunde, in: Die Erforschung von Alltag und Sachkultur des Mittelalters. Methode-ZielVerwirklichung. (=Österreichische Akademie der Wissenschaften, Philosophisch-Historische Klasse, Sitzungsberichte 433; Veröffentlichungen des Instituts für mittelalterliche Realienkunde Österreichs Bd. 6), Wien 1984, S. 45-52.

KÜHNEL, Harry, Die materielle Kultur des Spätmittelalters im Spiegel der zeitgenössischen Ikonographie, in: Kat. „Gotik in Österreich“, Krems a. d. Donau 1967, S. 7-36.

KÜHNEL, Harry, Beträge der Orden zur materiellen Kultur des Mittelalters und weltliche Einflüsse auf die klösterliche Sachkultur, in: Klösterliche Sachkultur des Spätmittelalters (=Österreichische Akademie der Wissenschaften, Philosophisch-Historische Klasse, Sitzungsberichte, Bd. 367), hg. v. H. APPELT, Wien 1980, S. 9-29.

KÜHNEL, Harry (Hg.), Alltag im Spätmittelalter, Graz/Wien/Köln 1984. 
KÜHNEL, Harry, Bilderwörterbuch der Kleidung und Rüstung. Vom Alten Orient bis zum ausgehenden Mittelalter (=Kröners Taschenausgabe Bd. 453), Stuttgart 1991.

KÜHLBORN, Marc, Keramik und Glasfunde „Auf der Altstadt 29“, in: Kat. „Ton Steine Scherben“, Lüneburg 1996, S. 41-70.

KUNZE, Konrad, Das Märtyrerbuch. Grundlagen einer Interpretation, in: Zeitschrift für deutsche Philologie, Nr. 90, 1971, S. 429-449.

LEGNER, Anton, Das Andachtsbild im späten Mittelalter. Eine Betrachtung vor dem Elendchristus im Braunschweiger Dom, in: Kat. „Stadt im Wandel“, Bd. IV, S. 449-465.

LEHNER, Julia, Die Mode im alten Nürnberg (=Schriftenreihe des Stadtarchivs Nürnberg, Bd.36), Nürnberg 1984.

LEITHE-JASPER, Manfred, DISTELBERGER, Rudolf, Schatzkammer und Sammlung für Plastik und Kunstgewerbe (=Kunsthistorisches Museum Wien, Bd.1), London.München 1982.

LENGELING, Emil, „Kuß“ Abschnitt II - Friedenskuß, in: LThK, Bd. 6, S. 696.

LENTZE, Hans, Das Wiener Testamentsrecht des Mittelalters, in: ZRG/GA 69, 1952, S.98154 und ZRG/GA 70, 1953, S.158-229.

LESNIKOW, Michail P., Der Hansische Pelzhandel zu Beginn des 15. Jahrhunderts, in: Hansische Studien. Heinrich Sproemberg zum 70. Geburtstag, Berlin 1961, S. 219-273.

LEXER, Matthias, Mittelhochdeutsches Taschenwörterbuch, Stuttgard 1983, 37. Auflage.

LOENING, Otto, Das Testament im Gebiet des Magdburger Stadtrechts (=Untersuchungen zur deutschen Stadt- und Rechtsgeschichte, Heft 82), Breslau 1906.

LOOSE, Hans-Dieter, Erwerbstätigkeit der Frau im Spiegel Lübecker und Hamburger Testamente des 14. Jahrhunderts, in: Zeitschrift des Vereins für Lübeckische Geschichte und Altertumskunde, 60/1980, S. 9-20.

LOOSE, Hans-Dieter, Leben und Kultur der Bürger mittelalterlicher Hansestädte (=Magdeburger Gesprächsreihe, Heft 3), Magdeburg 1992.

LÜBBEN, August, Mittelniederdeutsches Handwörterbuch (=reprographierter Nachdruck der Ausgabe von 1888), Darmstadt 1989.

MASCHKE, Erich, Soziale Gruppen in der deutschen Stadt des späten Mittelalters, in: Über Bürger, Stadt und städtische Literatur im Spätmittelalter. Bericht über Kolloquien zur Erforschung der Kultur des Spätmittelalters 1975-1977 (=Abhandlungen der Akademie der Wissenschaften in Göttingen, Historisch-Philologische Klasse, 3. Folge, Nr. 121), hg. v. J. FLECKENSTEIN und K. STACKMANN, Göttingen 1980, S. 127-145.

MATTHAEI, Georg, Die Vikariestiftungen der Lüneburger Stadtkirchen im Mittelalter und im Zeitalter der Reformation (=Studien zur Kirchengeschichte Niedersachsens, Bd.4), Göttingen 1928.

MATTHAEI, Georg, Lüneburgs Kirchen und Schulen, in: Aus Lüneburgs tausendjähriger Vergangenheit. Festschrift, hg. im Auftrag der Stadt Lüneburg von Ulrich WENDLAND, Lüneburg 1956, S. 30-65. 
MECKSEPER, Cord, Kleine Kunstgeschichte der Stadt im Mittelalter, 1982.

MEYER, Erich, „Besteck“, in: RDK, Bd. II, Sp. 356-366.

MEYER, Theodor, Ein Reliquiar vom Jahr 1471 aus der Kirche Sancti Mauritii zu Hittfeld, in: 5. und 6. Jahresbericht des Museumsvereins für das Fürstentum Lüneburg 1882-1883, Lüneburg 1884, S. 87-88.

MEYER, Theodor, Inventar des Nachlasses des weiland Propstes zu St. Johann in Lüneburg M. Joh. Koller 1536, in: 5. und 6. Jahresbericht des Museumsvereins für das Fürstentum Lüneburg 1882-1883, Lüneburg 1884, S. 73-86.

MEYER, Werner, Der Beitag der Archäologie zur mittelalterlichen Realienkunde, in: Die Erforschung von Altag und Sachkultur des Mittelalters. Methode-Ziel-Verwirklichung (=Österreichische Akademie der Wissenschaften, Philosophisch-Historische Klasse, Sitzungsberichte, Bd. 6), hg. v. H. APPELT, Wien 1984, S.88-98.

MICHAEL, Eckhard, Die Inschriften des Lüneburger St. Michaelisklosters und des Klosters Lüne (=Die Deutschen Inschriften, Bd.24), Wiesbaden 1984.

MICHAEL, Eckhard (Bearb.), Museum für das Fürstentum Lüneburg. Führer durch die Sammlungen, Lüneburg 1991.

MILITZER, Klaus, Ratsverfassungen und soziale Schichtungen, in: Kat. „Hanse•Städte• Bünde, Magdeburg 1996, S. 152-162.

MITTERAUER, Michael, Probleme der Stratifikation in mittelalterlichen Gesellschaftssystemen, in: Geschichte und Gesellschaft, Sonderheft 3/1977, S. 13-43.

MITTHOFF, Hektor Wilhelm Heinrich, Kunstdenkmale und Alterthümer im Hannoverschen, 4. Bd. (=Fürstentum Lüneburg), Hannover 1877.

MÖRKE, Olaf, Der gewollte Weg in Richtung <Untertan>. Ökonomische und politische Eliten in Braunschweig, Lüneburg und Göttingen vom 15. bis in das 17. Jahrhundert, in: $H$. SCHILLING, H. DIEDERICHS, Bürgerliche Eliten in den Niederlanden und in Nordwestdeutschland (=Städteforschung.Veröffentlichungen des Instituts für vergleichende Städtegeschichte Münster, Reihe A, Bd. 23), Köln-Wien 1985, S. 119-133.

MOHRMANN, Ruth-E., Wohnen und Wohnkultur in nordwestdeutschen Städten, in. Kat. „Stadt im Wandel“, Bd.3, S. 513-530.

MOSLER, Susanne, Das Sülzgut in den frühen Lüneburger Testamenten (=unveröffentlichte Staatsexamensarbeit am Fachbereich Historisch-Philologische Wissenschaften der Universität Göttingen), Göttingen 1989.

H. MÜLLER, H. NIXDORF, Weiße Westen - Rote Roben. Von den Farbordnungen des Mittelalters zum individuellen Farbgeschmack $(=$ Katalog zur Sonderausstellung der Staatlichen Museen Preußischer Kulturbesitz Berlin. Museum für Völkerkunde und Museum für Deutsche Volkskunde), Berlin 1983.

MUSSNER, Franz, „Wasser“, in: LThK, Bd. 10, Sp. 694.

NEUENSCHWANDER, E., „Leonardo Fibonacci“, in: Lexikon des Mittelalters, Bd. VI, Sp. $1893 f$. 
NOLTE, Ernst, Quellen und Studien zur Geschichte des Nonnenklosters Lüne bei Lüneburg (=Studien zur Kirchengeschichte Niedersachsens, Bd.6), Göttingen 1932.

OHLER, Norbert, Sterben und Tod im Mittelalter, München/Zürich 1990.

OHLER, Norbert, Reisen im Mittelalter, München 1993/3.

OHLER, Norbert, Zur Seligkeit und zum Troste meiner Seele. Lübecker unterwegs zu mittelalterlichen Wallfahrtsstätten, in: ZVLGA 63, 1983, S. 83-103.

OTTENJANN, Helmut, Das Sondervermögen "Gerade" sowie Kiste und Lade im Oldenburger Sachsenspiegel und im bäuerlichen Erbrecht des Ammerlandes, in: Kat. „der sassen speyghel. Sachsenspiegel - Recht - Altag“, Bd. 2, S. 379-397.

PAULI, C. W., Abhandlungen aus dem lübischen Rechte. III. Teil: Das Erbrecht der Blutsfreunde und die Testamente, Lübeck 1841.

PENNERS, Theodor, Der Umfang der altdeutschen Nachwanderung des 14. Jahrhunderts in die Städte des Ostseegebiets, in: Lüneburger Blätter, Heft 2, 1951, S.27-58.

PIPER, Henning, Testament und Vergabung von Todes wegen im braunschweigischen Stadtrecht des 13. bis 17. Jahrhunderts (=Braunschweiger Werkstücke 24), Braunschweig 1960.

RAMACKERS, Johannes, „Aachenfahrt“, in: LThK, Bd.1, Sp.1.

REINECKE, Helmut, Holz - Arbeiten (Bauschreinermöbel) (=Führer durch die Sammlungen des Museumsvereins für das Fürstentum Lüneburg, Bd. III, 2), Lüneburg 1932.

REINECKE, Helmut, Zwei bemalte Falttische der Gotik, in: Lüneburger Blätter, Heft 1, 1950, S. 7-14.

REINECKE, Wilhelm, Die kirchliche Abteilung (=Führer durch die Sammlungen des Museumsvereins für das Fürstentum Lüneburg, Bd. II), Lüneburg 1911.

REINECKE, Wilhelm, Lüneburgs ältestes Stadtbuch und Verfestungsregister (=Quellen und Darstellungen zur Geschichte Niedersachsens, Bd. VIII), Hannover/Leipzig 1903.

REINECKE, Wilhelm, Geschichte der Stadt Lüneburg, 2. Bde. (=Nachdruck der Ausgabe Lüneburg 1933 durch die Heinrich-Heine-Buchhandlung Lüneburg), Lüneburg 1977.

REINECKE, Wilhelm, Lüneburger Zinn. Das Amt der Lüneburger Zinngießer, Lüneburg 1947.

REINHARDT, Uta, Saline Lüneburg 956-1980, in: Der Anschnitt, Zeitschrift für Kunst und Kultur im Bergbau 2, 1981, S. 46-61.

REINHARDT, Uta, Stiftersorgen - Das Testament der Elisabeth Stöterogge (1385), in: Recht und Alltag im Hanseraum, Festschrift für Gerhard Theuerkauf (=,De Sulte“. Nr.4), hg. v. Silke URBANSKI, Christian LAMSCHUS, Jürgen ELLERMEYER, Lüneburg 1993, S. 359-384.

REINLE, Adolf, Die Ausstattung deutscher Kirchen im Mittelalter. Eine Einführung, Darmstadt 1988. 
RIETHMÜLLER, Marianne, to troste miner sele. Aspekte spätmittelalterlicher Frömmigkeit im Spiegel Hamburger Testamente (1310-1400) (=Beiträge zur Geschichte Hamburgs, Bd.47), Hamburg 1994.

RING, Edgar, Das Töpferhaus. Ausgrabungen und bauarchäologische Untersuchungen des Töpferhauses in Lüneburg, in: Kat. „Ton Steine Scherben“, Lüneburg 1996, S. 34-39.

RÖSENER, Werner, Sozialgeschichte und mittelalterliche Realienkunde, in: Die Erforschung von Alltag und Sachkultur des Mittelalters. Methode-Ziel-Verwirklichung in: Die Erforschung von Alltag und Sachkultur des Mittelalters. Methode-Ziel-Verwirklichung. (=Österreichische Akademie der Wissenschaften, Philosophisch-Historische Klasse, Sitzungsberichte 433; Veröffentlichungen des Instituts für mittelalterliche Realienkunde Österreichs Bd. 6), Wien 1984, S. 53-59.

RUH, Kurt, „Nikolaus von Lyra“, in: Verfasserlexikon, Bd.6, 1987, Sp. 1117-1122.

RUH, Kurt, Geistliche Prosa, in: Neues Handbuch der Literaturwissenschaft, Bd. 8 (=Europäisches Spätmittelalter), hg. v. Willi ERZGRÄBER, Wiesbaden 1978, S. 565-605.

SCHAUERTE, Heinrich, „Agnus Dei“ Abschnitt IV - A.D. volkskundlich, in: LThK, Bd. I, Sp. 204.

SCHILDHAUER, Johannes, Hansestädtischer Alltag auf der Grundlage der Stralsunder Bürgertestamente des 14. bis zum Ausgang des 16. Jahrhunderts (=Abhandlungen zur Handels- und Sozialgeschichte 28), Weimar 1992.

SCHLOTHEUBER, Eva, Bibliothekswesen und Bibliotheken der Bettelorden, in: Kat. „700 Jahre Paulinerkirche“, Göttingen 1994, S. 21-24.

SCHMIDT-WIEGAND, Ruth, Kleidung, Tracht und Ornat nach den Bilderhandschriften des „Sachsenspiegels“, in: Terminologie und Typologie mittelalterlicher Sachgüter: Das Beispiel der Kleidung (=Österreichische Akademie der Wissenschaften, Philosophisch-Historische Klasse 511, Sitzungsberichte Bd. 10), Wien 1988, S. 143-175.

SCHMITT, Otto, Reallexikon zur deutschen Kunstgeschichte, Stuttgart $1937 \mathrm{ff}$.

SCHREINER, Klaus, Bücher, Bibliotheken und „Gemeiner Nutzen“ im Spätmittelalter und in der Frühneuzeit, in: Bibliothek und Wissenschaft, Bd. 9, hg. v. Udo HÖGY und Hellmut VOGELER, Wiesbaden 1975, S. 202-249.

SCHRÖDER, Hans, Gotische Truhen, in: Festblätter des Museumsvereins für das Fürstentum Lüneburg, Nr. 4, Lüneburg 1932.

SCHÜPPERT, Helga, Der Beitrag der Literaturwissenschaft für die mittelalterliche Realienkunde, in: Die Erforschung von Alltag und Sachkultur des Mittelalters. Methode-ZielVerwirklichung (=Österreichische Akademie der Wissenschaften, Philosophisch-Historische Klasse, Sitzungsberichte, Bd. 6), hg. v. H. APPELT, Wien 1984, S. 158-167.

SCHÜTTE, Sven, Bürgerliches Hausgerät des Hoch- und Spätmittelalters in Nordwestdeutschland, in: „Kat. „Stadt im Wandel“, Bd. 3, S. 545-568.

SCHÜTTE, Sven, Glas in der mittelalterlichen Stadt, in: Kat. „Aus dem Alltag der mittelalterlichen Stadt“, Bremen 1982, S. 133-144.

SCHURR, V., „Predigt“, in: LThK, Bd. 8, Sp. 705-718. 
SCHWARZ, Dietrich W. H., Sachgüter und Lebensformen (=Grundlagen der Germanistik, Bd. 11), Berlin 1970.

SHAHAR, Shulamith, Kindheit im Mittelalter, Reinbek bei Hamburg, 1993.

STAHL, Irene, Lüneburger Ratslinie, in: Niedersächsisches Jahrbuch für Landesgeschichte 59, 1987, S. 139-183.

STÄHLI, Marlis, Die theologischen Handschriften.Quartreihe. Die juristischen Handschriften (=Handschriften der Ratsbücherei Lüneburg, Bd. III), Wiesbaden 1981.

STUTTMANN, Ferdinand, Meisterwerke der Niedersächsischen Landesgalerie, Köln o. J. .

TERLAU - FRIEMANN, Karoline, Lüneburger Wohnkultur des 16. Jahrhunderts, in: RolfJürgen GROTE und Peter KÖNIGFELD, Raumkunst in Niedersachsen, München 1991, S. 81-97.

TERLAU - FRIEMANN, Karoline, Lüneburger Patrizierarchitektur des 14 . bis 16. Jahrhunderts. Ein Beitrag zur Bautradition einer städtischen Oberschicht, Lüneburg 1994.

THIEL, Erich Joseph, Die liturgischen Bücher des Mittelalters. Ein kleines Lexikon zur Handschriftenkunde, in: Börsenblatt für den Deutschen Buchhandel. Frankfurter Ausgabe 83, 23. Jahrgang, 17. Oktober 1967, S. 2379-2395.

THURICH, Erich, Die Geschichte des Lüneburger Stadtrechts im Mittelalter, Lüneburg 1960.

TSCHIPKE, Ina, Lebensformen in der spätmittelalterlichen Stadt. Untersuchungen anhand von Quellen aus Braunschweig, Hildesheim, Göttingen, Hameln und Duderstadt (=Schriftenreihe des Landschaftsverbandes Südniedersachsen, Bd.3), Hannover 1993.

UHDE-STAHL, Brigitte, Figürliche Buchmalereien in den spätmittelalterlichen Handschriften der Lüneburger Frauenklöster, in: Niederdeutsche Beiträge zur Kunstgeschichte, Bd.17, 1978, S. 25-60.

UHDE, Jörn-Wolfgang, Die Lüneburger Stadtschreiber von den Anfängen bis zum Jahr 1378, Hamburg 1977.

UITZ, Erika, Die Frau in der mittelalterlichen Stadt, Freiburg i. Br. 1992.

VAVRA, Elisabeth, Kunstwerke als Quellenmaterial, in: Europäische Sachkultur. Gedenkschrift aus Anlaß des 10jährigen Bestehens des Instituts für mittelalterliche Realienkunde, hg. v. Harry KÜHNEL (=Österreichische Akademie der Wissenschaften. Philosophisch-Historische Klasse, Sitzungsberichte 374; Veröffentlichungen des Instituts für mittelalterliche Realienkunde Österreichs, Bd.4), Wien 1980, S. 229-232.

VAVRA, Elisabeth, Kunstgeschichte und Realienkunde, in: Die Erforschung von Alltag und Sachkultur des Mittelalters. Methode-Ziel-Verwirklichung (=Österreichische Akademie der Wissenschaften, Philosophisch-Historische Klasse, Sitzungsberichte, Bd. 6), hg. v. H. APPELT, Wien 1984, S. 193-199.

VAVRA, Elisabeth, Kritische Bemerkungen zur Kostümliteratur, in: Terminologie und Typologie mittelalterlicher Sachgüter: Das Beispiel der Kleidung (=Österreichische Akademie der Wissenschaften, Philosophisch-Historische Klasse 511, Sitzungsberichte Bd. 10), Wien 1988 , S. 21-45.

VAVRA, Elisabeth, „Schmuck“, in: Lexikon des Mittelalters, Bd. VII, Sp. 1508-1510. 
VAVRA, Elisabeth, „Bisamapfel“, in: Lexikon des Mittelalters, Bd. II, Sp. 227.

VAVRA, Elisabeth, „Kleidung“, in: Lexikon des Mittelalters, Bd. V, Sp. 1198-1201.

VAVRA, Elisabeth, „Gürtel“, in: Lexikon des Mittelalters, Bd. IV, Sp. $1796 f$.

VIERHAUS, Rudolf, Die Rekonstruktion historischer Lebenswelten. Probleme moderner Kulturgeschichtsschreibung, in: H. LEHMANN, Wege zu einer neuen Kulturgeschichte (=Göttinger Gespräche zur Geschichtswissenschaft, Bd. 1), Göttingen 1995, S. 5-28.

VOLGER, Wilhelm Friedrich, Urkundenbuch der Stadt Lüneburg, 3 Bde., Hannover 1872, 1875 (= I.+II. Bd.), Lüneburg 1877 (=III. Bd).

VOLGER, Wilhelm Friedrich, Lüneburger Geschichte in Einzeldarstellungen (=Nachdruck der „Lüneburger Blätter" von 1855 bis 1866 im Verlag der Heinrich-Heine-Buchhandlung), Lüneburg 1986.

WALZ, Angelus, „Rosenkranz“, in: LThK, Bd. 9, Sp. $46 f$.

WAGNER, Johannes, „Amikt“, in: LThK, Bd. 1, Sp. 438.

WAGNER, Johannes, „Cappa“, in: LThK, Bd. 2, Sp. 928.

WAGNER, Johannes, „cingulum“, in: LThK, Bd. 2, Sp. 1205.

WENTZEL, Hans, „Bisamapfel“, in: RDK, Bd. II, Sp. 770-774.

WENTZEL, Hans, „Becher“, in: RDK, Bd. II, Sp. 135-147.

WENTZEL, Hans, „Becken“, in: RDK, Bd. II, Sp. 151-163.

WENTZEL, Hans, „Bekleiden von Bildwerken“, in: RDK, Bd. II, Sp. 219-225.

WENTZEL, Hans, „Bett“, in: RDK, Bd. II, Sp. 383-393.

WIERSCHIN, Martin (Bearb.), Handschriften der Ratsbücherei Lüneburg. Miscellanea und Historica, Wiesbaden 1969.

WILCKENS, Leonie von, Terminologie und Typologie spätmittelalterlicher Kleidung , in: Terminologie und Typologie mittelalterlicher Sachgüter: Das Beispiel der Kleidung (=Österreichische Akademie der Wissenschaften, Philosophisch-Historische Klasse 511, Sitzungsberichte Bd. 10), Wien 1988.

WILLIAMS-KRAPP, Werner, Studien zu „Der Heiligen Leben“, in: Zeitschrift für das deutsche Altertum, Nr. 105, 1976, S. 274-303.

WINTER, Georg, Die ältesten Lüneburger Kämmereirechnungen, in: Lüneburger Blätter, Heft 2, 1951, S. 5-26.

WINZER, Fritz, Kulturgeschichte Europas, Köln o. J.

WISWE, Mechtild, Hausrat aus Kupfer und Messing, München 1979.

WISWE, Mechthild, Anmerkungen zur Frage nach den Herstellungsorten von Messingbecken, in: Kat. „Stadt im Wandel“, Bd. 3, S. 323-326. 
WITTHÖFT, Harald, Das Kaufhaus in Lüneburg als Zentrum von Handel und Faktorei, Landfracht, Schiffahrt und Warenumschlag bis zum Jahr 1637, Lüneburg 1962.

WITTHÖFT, Harald, Struktur und Kapazität der Lüneburger Saline seit dem 12. Jahrhundert, in: Vierteljahresschrift für Sozial- und Wirtschaftsgeschichte, Bd. 63, 1.Heft, Wiesbaden 1976, S. 11-117.

WITTHÖFT, Harald, Umrisse einer Historischen Metrologie zum Nutzen der wirtschafts- und sozialgeschichtlichen Forschung. Maße und Gewicht in Stadt und Land Lüneburg, im Hanseraum und im Kurfürstentum/Königreich Hannover vom 13. bis zum 19. Jahrhundert (=Veröffentlichungen des Max-Planck-Instituts für Geschichte 60/1), Göttingen 1979.

WITTHÖFT, Harald, Über die normative Wirkung von Produktionsbedingungen der Lüneburger Saline und ihren Einfluss auf Wirtschaft und Gesellschaft Norddeutschlands, in: Stadt und Salz (=Beiträge zur Geschichte der Städte Mitteleuropas, Bd. X), hg. v. Wilhelm RAUSCH, Linz 1988, S. 181-194.

WITTSTOCK, Jürgen, Pilgerzeichen und andere Wallfahrtsdevotionalien in Norddeutschland, in: Kat. „Aus dem Alltag der mittelalterlihcen Stadt“, S. 193-200.

WITZENDORFF, Hans-Jürgen von, Stammtafeln Lüneburger Patriziergeschlechter (=Veröffentlichungen der „Familienkundlichen Kommission für Niedersachsen und Bremen sowie angrenzende ostfälische Gebiete“ 2), Göttingen 1952.

WUNDER, Heide, Probleme der Stratifikation in mittelalterlichen Gesellschaftssystemen. Ein Diskussionsbeitrag zu Thesen von M. Mitterauer, in: Geschichte und Gesellschaft, 4/1978, S. 542-550.

WURM, Helmut, Körpergröße und Ernährung der Deutschen im Mittelalter, in: Mensch und Umwelt im Mittelalter, hg. v. B. HERRMANN, Wiebaden 1996 (zuerst Stuttgart 1986),S. 101108.

WURMBACH, Edith, Das Wohnungs- und Kleidungswesen des Kölner Bürgertums um die Wende des Mittelalters, Bonn 1930.

ZAHND, Urs Martin, Spätmittelalterliche Bürgertestamente als Quellen zu Realienkunde und Sozialgeschichte, in: Mitteilungen des Institus für österreichische Geschichtsforschung, Bd. 96/1-2, 1988, S. 55-78.

ZECHLIN, Erich, Lüneburgs Hospitäler im Mittelalter (=Forschungen zur Geschichte Niedersachsens I. 6), Hannover 1907.

ZIMMERMANN, Gerd, Ein Bamberger Klosterinventar von 1483/86 als Quelle zur Sachkultur des Spätmittelalters, in: Klösterliche Sachkultur des Spätmittelalters (=Österreichische Akademie der Wissenschaften, Philosophisch-Historische Klasse, Sitzungsberichte, Bd. 367), hg. v. H. APPELT, Wien 1980, S.225-246. 